Jürn Gottschalk

\title{
Eigennamen und Lyrik
}

Studien zur Verwendung von Eigennamen in Gedichten

Dissertation zur Erlangung des philosophischen Doktorgrades an der Philosophischen Fakultät der Georg-August-Universität Göttingen

Göttingen 2008 


\section{Vorbemerkung}

Der vorliegende Text ist eine überarbeitete Version meiner Dissertation, die von mir 2004 an der philosophischen Fakultät der Universität Göttingen eingereicht wurde. Der Tag der mündlichen Prüfung war der 14.07.2005. Berufliche Verpflichtungen haben mich längere Zeit davon abgehalten, die Veröffentlichung voranzutreiben.

Ich danke für die geduldige Betreuung dieser Arbeit Herrn Prof. Dr. Werner Frick und Herrn PD Dr. Burkhard Moennighoff.

Weiterhin danke ich besonders Herrn Prof. i. R. Dr. Christian Wagenknecht und Herrn Prof. Dr. Dr. h.c. Karl Stackmann für die menschliche Ermutigung und für die institutionelle Förderung der Arbeit in ihrer Anfangsphase.

Der Studienstiftung des Deutschen Volkes habe ich sehr zu danken für die großzügige Förderung durch ein Promotionsstipendium.

Für die stets undankbare Aufgabe des Korrekturlesens danke ich vor allem meiner Frau Susanne Ahrens.

Schließlich darf nicht vergessen werden: Jede Minute bei der Arbeit war der Familie geraubt. Dafür, dass sie mir diesen Raub gelassen und gegönnt hat, sei ihr gedankt!

Göttingen, Dezember 2008 


\section{How to interpret names when you see them - Einleitung}

Stanley Fish beginnt seine Schrift How to recognize a poem when you see one ${ }^{1}$ mit der Anekdote, wie seine Studenten eine Reihe von Eigennamen an der Tafel als Gedicht interpretierten:

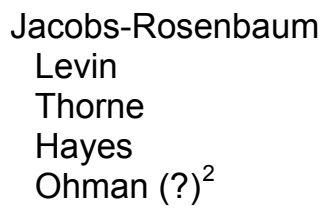

Fish zufolge handelt es sich um die Auflistung einiger Namen von Linguisten, die er in der vorangegangenen Unterrichtsveranstaltung an die Tafel geschrieben hatte. Das Fragezeichen habe seine Unsicherheit in bezug auf die Schreibweise des letzten Namens angedeutet. Er habe seinen Studenten vorgespiegelt, daß es sich um ein Gedicht der ihnen aus dem Seminar bereits bekannten Sorte handele. Die in der Interpretation religiöser Gedichte des 17. Jahrhunderts geschulten Studenten hätten die Eigennamenliste daraufhin so interpretiert, daß eine dichte und einigermaßen kohärente religiöse Aussage mit Bezügen auf Jakobs Himmelsleiter und die Heilserwartung des Menschen durch Christus entstanden sei. ${ }^{3}$

Fish entwickelt an diesem Beispiel seine These, daß die Norm zur Behandlung von Texten nicht vom Text, sondern in Interpretationsgemeinschaften gesetzt werde. ${ }^{4} \mathrm{Es}$ ist sicherlich kein Zufall, daß Fish für seine Argumentation ausgerechnet eine Aufzählung von Eigennamen verwendet. Eigennamen können den ,Unwissenden’ offenbar zu besonders abwegigen Deutungen verleiten. Bei keiner anderen Zeichenkategorie wäre eine so große Diskrepanz zwischen der Bedeutung des ursprünglichen Gebrauchstextes und dem von den Studenten konstruierten ,poetischen' Text ${ }^{5}$ möglich gewesen.

Gleichzeitig sind Eigennamen ein wichtiger Bestandteil der Sprache. Sprachliche Vorgänge wie die Identifizierung mit Hilfe von Namen, die Zuschreibung von Eigenschaften mit Namen und die Deutung von Namen werden von Dichtern vielfältig zur poetischen

\footnotetext{
${ }^{1}$ Vgl. Fish 1980.

${ }^{2}$ Fish 1980, S. 323

${ }^{3}$ Vgl. Fish 1980, S. 323-325

${ }^{4}$ Vgl. Fish 1980, S. 327. Es lassen sich Zweifel anmelden, ob der Text wirklich adäquat als religiöses Gedicht des 17. Jahrhunderts gelesen werden kann. Wenn die Namen als solche erkannt werden, sind sie recht modern - besonders der Doppelname. Weiter müssen Fishs Schüler doch einige Verrenkungen unternehmen, um aus den Namen Appellative zu machen: besonders im Falle von „Ohman(?)“ - „Amen“. Ohne den deutlichen und irreführenden Hinweis ihres Lehrers, der ihnen sagte, dies sei ein RenaissanceGedicht, wären die Schüler wohl kaum auf die Idee gekommen, es entsprechend zu interpretieren. Die gesamte Interpretation beruht also auf einer falschen Prämisse, die, da sie nicht in Frage gestellt wird, zur ad hoc-Hypothesenbildung führt, um alle auftretenden Unstimmigkeiten zu beseitigen.

${ }^{5}$ Daß sie die Namen als Namen erkannt hatten, folgt aus Fishs Beschreibung; vgl. Fish 1980, S. 325.
} 
Gestaltung mit Sprache genutzt. Fishs Namenreihe könnte daher tatsächlich ein manieristisches Gedicht gewesen sein.

In der literaturwissenschaftlichen Onomastik werden Funktion und Bedeutung von Namen in Lyrik $^{6}$ vergleichsweise selten behandelt. Dies mag damit zusammenhängen, daß sich unter Onomasten hartnäckig das Vorurteil hält, in lyrischen Texten herrsche in bezug auf Eigennamen eher Enthaltsamkeit. ${ }^{7}$ Außerdem verstehen Eigennamenforscher und Literaturwissenschaftler unter ,poetischen Namen' zumeist Namen fiktiver Figuren und Orte. ${ }^{8}$ Diese werden in Texten der Gattung ,Lyrik' seltener gestaltet als in Epik und Dramatik. Dennoch sind Texte der Gattung ,Lyrik' nicht unergiebig für die Eigennamenanalyse. Wie sich im Laufe der Arbeit herausstellen wird, finden sich in Texten der Gattung ,Lyrik' zahlreiche reale und fiktionale Eigennamen, die in unterschiedlichsten Funktionen die Gestaltung des Gesamttextes beeinflussen. Die Untersuchung von Eigennamen unter den spezifischen Textbedingungen einer noch genauer zu definierenden Gattung ,Lyrik' liefert eine notwendige Ergänzung zu den zahlreichen Analysen zu Eigennamen in Erzähltexten und Dramen.

An der Onomastik sind viele wissenschaftliche Disziplinen beteiligt. Die Vorgehensweise von Arbeiten der literaturwissenschaftlichen Onomastik bei der Bestimmung der Bedeutung und Funktionen von Eigennamen ist dementsprechend vielfältig. Arbeiten der literaturwissenschaftlichen Onomastik mögen literarhistorisch, rhetorisch oder linguistisch-sprachphilosophisch ausgerichtet sein. ${ }^{9}$ Sie können sich in jedem Fall selten einer ausführlichen allgemeinen und systematischen Analyse des Eigennamenzeichens entziehen. Immer nimmt die allgemeine Untersuchung des literarischen Namenszeichens einen breiten Raum ein, weil bei dem Leser Kenntnisse der Onomastik nicht vorausgesetzt werden können. Vor allem aber muß der literaturwissenschaftlich Interpretierende sich des sprachlich Möglichen bewußt werden, um den Umgang eines Autors mit Eigennamen zu verstehen. Hierzu bedarf es einer sprachsystematischen Untersuchung, die sich nicht darauf beschränkt, die faktische Namenverwendung des Autors zu referieren.

Da die Herangehensweise der vorliegenden Arbeit sprachphilosophisch ist, bilden die Intuitionen der Sprachphilosophie den Ausgangspunkt der Analyse der literarischen Ei-

\footnotetext{
${ }^{6}$ Ashley 1980, S. 10; Eine Ausnahme ist die Arbeit von Wittstruck 1989 über den dichterischen Namengebrauch in spätmittelalterlicher Lyrik.

${ }^{7}$ Vgl. Kalverkämper 1994, S. 232.

${ }^{8}$ Fricke 1996, S. 1536.

${ }^{9}$ Vgl. z.B. Birus 1978; Wittstruck 1989; Kopelke 1990.
} 
gennamenverwendung. Aus diesem Grund behandeln wir in der Tradition der literaturwissenschaftlichen Onomastik zu Beginn der Arbeit sprachphilosophische Entwürfe zu Eigennamen. Während aber die sprachphilosophische Eigennamenanalyse in den meisten Arbeiten der literaturwissenschaftlichen Onomastik zur Pflichtübung geworden ist, die auf den eigentlichen Verlauf der Arbeit wenig Einfluß hat, werden die Intuitionen der Sprachphilosophie zu Eigennamen hier für die Beschäftigung mit literarischen Eigennamen fruchtbar gemacht. Dazu berücksichtigen wir nicht nur die üblicherweise genannten Theoretiker Mill, Frege und Kripke. Eingang in diese Arbeit finden auch jene Intuitionen, die aus eher unbekannten Modellen der jüngsten Debatte um reale und auch fiktionale Eigennamen erwachsen. ${ }^{10}$

Diese Ansätze liefern ein differenziertes Modell der Eigennamenbedeutung, auf dessen Grundlage Eigennamen in Gedichten systematisch interpretiert werden können. Die theoretischen Abschnitte sind daher nicht bloß Ouvertüre der anschließenden Untersuchungen einzelner Autoren. Vielmehr nähern wir uns dem Phänomen des Eigennamens in Gedichten auf drei verschiedenen Wegen: zunächst sprachphilosophisch durch die Analyse der Bedeutungsstruktur realer und fiktionaler Namen, dann systematisch durch die Analyse einzelner Funktionen von Eigennamen speziell in Gedichten und schließlich durch die Untersuchung des autorspezifischen Namengebrauchs bei Theodor Fontane und Edwin Arlington Robinson. Dem Anliegen dieser drei Abschnitte entsprechend wandelt sich der Stellenwert des einzelnen Gedichts in dieser Arbeit: Im ersten, theoretischen Abschnitt liefern einzelne Gedichte Namenbeispiele, anhand derer die Struktur von Eigennamen analysiert wird. Wir stellen hier die sprachphilosophische Frage ,Was für eine Bedeutungsstruktur haben Instanzen eines Zeichentyps (Eigennamen) in Gedichten?'

Im zweiten, systematischen Abschnitt geht es um die spezifischen Funktionen von Eigennamen im Gedicht. Hier sollen beispielhaft genannte Gedichte die Möglichkeiten illustrieren, Eigennamen im Gedicht zu verwenden. Wir stellen die Frage ,Wie werden Instanzen der Zeichenkategorie ,Eigenname' unter den spezifischen Textbedingungen der Gattung ,Lyrik' integriert?' Nicht der einzelne Autor mit seinen besonderen Namenverwendungen, wohl aber die Textbedingungen und ihr Einfluß auf die Namenverwendung stehen hier im Vordergrund.

Schließlich untersuchen wir im dritten Teil der Arbeit die Namenverwendung zweier Autoren: Theodor Fontane und Edwin Arlington Robinson. Hier finden aspektorientierte Gedichtanalysen vor dem Hintergrund der Sprach- und Eigennamenverwendung in dem

${ }^{10}$ Damit tragen wir der Einschätzung Wimmers Rechnung, daß die Sprachphilosophie unter den onomastischen Disziplinen das Eigennamenpotential am stärksten berücksichtige, vgl. Wimmer 1993, S. 49. 
gesamten CEuvre der Autoren statt. Fontane und Robinson haben wir unter systematischen Gesichtspunkten ausgewählt. Beide Autoren verwenden viele Eigennamen in ihren Gedichten. Beide benutzen Eigennamen nicht naiv, sondern vor einem sprachskeptischen Hintergrund. Insofern treten Mechanismen der Eigennamenverwendung hier besonders deutlich zutage. Schließlich ergänzen Fontane und Robinson sich sprachsystematisch: erstens in der Grundlage ihrer Sprachskepsis, weil Fontane vorwiegend den gesellschaftlichen und kommunikativen, Robinson vorwiegend den metaphysisch-epistemologischen Wert der Namen berücksichtigt; zweitens, weil sich bei Fontane vorwiegend reale Eigennamen, bei Robinson vorwiegend fiktionale Eigennamen finden; drittens, weil Fontane Eigennamen vorwiegend zur indirekten Evokation des Sprechers verwendet während Robinson die direkte Evokation des Namenträgers durch Eigennamen gestaltet.

Die zu diesem Abschnitt gestellte Frage lautet, Wie werden Eigennamen von diesen beiden Autoren verwendet und implizit oder explizit bewertet?'

Die drei Herangehensweisen ergeben ein Gesamtbild des Umgangs mit realen und fiktionalen Eigennamen in Gedichten. Sie verdeutlichen damit den Beitrag der Eigennamenanalyse zur Gedichtinterpretation. 


\section{Theoretische Überlegungen}

\subsection{Der Eigenname: ein unsicheres Zeichen?}

\subsubsection{Namen in isolierten Äußerungen}

Hier ligt Poot,

Hej is dood. ${ }^{1}$

Wird ein Leser mit diesem Gedicht konfrontiert, bietet inm das Verständnis der meisten darin enthaltenen Wörter keine Schwierigkeiten, sofern er ein kompetenter Sprecher ist. Schwierig wird es lediglich mit der Bedeutung des Zeichens ,Poot'. Der Leser mag erkennen, daß es sich um ein Zeichen in der Funktion eines Eigennamens handelt. ${ }^{2}$ Dann weiß er immerhin, daß ein Individuum gemeint ist. Mehr kann der Leser dem Namenzeichen zunächst nicht entnehmen. Es könnte sich um einen Mann handeln (,hej“ = ,er'), aber auch um ein Tier, denn ,poot' ist auch ein Appellativ und heißt ,Pfote'. Der Satz ,Poot is dood.' hat andererseits nicht die sparsame Bedeutung von ,er ist tot'. Vielmehr enthält er sehr viele Informationen, wenn der Leser weiß, daß mit ,Poot' der niederländische Dichter Hubert Korneliszoon Poot gemeint ist, der aufgrund seines Namens Objekt unzähliger Epitaphe wurde. ${ }^{3}$ Die Frage nach der Bedeutung eines isolierten Satzes ist in dem Moment, in dem dieser einen Eigennamen enthält, nicht mehr so einfach zu beantworten. Der Leser muß sich zwei Fragen stellen, will er die genaue Bedeutung des Epitaphs erfassen: Worauf bezieht sich der Name? Welchen semantischen Inhalt muß ein Botschaftsempfänger mit dem Namen verbinden?

\subsubsection{Der Name als singulärer Terminus}

In der Sprachphilosophie und Linguistik gelten geäußerte Eigennamen als singulär definite Termini, die auf genau ein Objekt des universe of discourse referieren und dieses identifizieren. Sie werden unterschieden von allgemeinen Termini (,Menschen ...'), das sind Nominalphrasen, die distributiv oder kollektiv auf eine Klasse von Objekten referieren, und von singulär indefiniten Termini (,irgendein Mensch ...'), das sind Nominalphrasen, die auf ein nicht als einzelnes bestimmtes Objekt als Mitglied einer Klasse re-

\footnotetext{
1 „Hier liegt Poot, / Er ist tot“; Komrij 1979, S. 104; der Autor ist Gerrit van de Linde ljzn.

2 "Die Kategorie ,Eigenname' wird im Folgenden als sprachliche Funktion begriffen. Das heißt: jedes Zeichen und jede erfundene Phonem- oder Graphemkombination kann als Eigenname verwendet werden; vgl. Blanár 2001, S. 15. Dem Zeichen selbst ist also zunächst nur aufgrund der grammatischen Integration einschließlich der Großschreibung anzusehen, ob es sich um einen Eigennamen handelt - zu Erkennensweisen unbekannter Zeichenkombinationen; vgl. auch Christmann/Schreier 2003, S. 248 f. Höchstens kann man von einem gewissen ,Eigennamenschatz' ausgehen. Das heißt von einem Kernbestand an Zeichen, die typischerweise als Eigenname benutzt werden und deren Zeichenkörper kompetenten Sprechern bekannt sind; vgl. Kalverkämper 1994, S. 210-215; Napoli 1997, S. 187; Wimmer 1993.

${ }^{3}$ Vgl. Heesen/Jansen/Schilders 1997.
} 
ferieren. Zu den singulär definiten Termini gehören neben Eigennamen (,Poot ...') $)^{4}$ Nominalphrasen bzw. definite descriptions ${ }^{5}$, die auf genau ein Objekt referieren (,der (genau bestimmte) Mensch ...') und indexikalische Zeichen (,du ...' $)^{6}$. Diese einzelnen Untergruppen singulär definiter Termini unterscheiden sich in der Art, ihr Referenzobjekt sprachlich zu präsentieren. Definite descriptions präsentieren es begrifflich, indexikalische Zeichen präsentieren es als Element einer kommunikativen Situation. Auf welche Art sich geäußerte Eigennamen auf ein Referenzobjekt beziehen und wie Eigennamen zu einem semantischen Inhalt kommen ist strittig: indirekt über verborgene singulär definite Nominalphrasen, wie indexikalische Zeichen durch einen situationsbezogenen character, der die spezifische sprachliche Präsentation des Referenzobjekts beschreibt (etwa: ,ich = der Sprecher dieser Äußerung'), oder direkt und ganz ohne einen „mode of presentation"? ${ }^{7}$ Wir vertreten im Folgenden die Position, daß der Inhalt von Eigennamen vor allem von der kommunikativen Gewohnheit einer Sprechergemeinschaft abhängt. Die Stellung des Eigennamens im semantischen System der Sprache liegt zwischen den Kategorien definite description und indexical. ${ }^{8}$ Weder sind geäußerte Namen semantisch leer, noch haben sie eine eindeutig festgelegte Bedeutung. Dies führt dazu, daß die Bedeutung - der „cash value of reference“9 - von Eigennamen unsicher ist. ${ }^{10}$ Der Eigenname ist, so also unser Ausgangspunkt, ein unsicheres Zeichen.

Diese semantische Unsicherheit von Eigennamen wirft vier Fragen auf: 1) Welche Informationen müssen mit einem Eigennamenzeichen verbunden werden, um es zu verstehen? 2) Wie ist der Name mit dem Namenträger verbunden? 3) Was trägt das Namenzeichen selbst zur Bedeutung des Namens bei? 4) Welchen kommunikativen Wert im Sinne emotionaler und normativer Assoziationen hat ein Name?

\footnotetext{
${ }^{4}$ Vgl. Lyons 1977, Bd. 1, S. 174-215. Zu den Begriffen ,definite' und ,ambiguous description', die Lyons' Kategorie der singulär indefiniten Termini nicht berücksichtigt, vgl. Russell 1980, S. 28f. Lyons' Modell ist sehr präzise, hat sich aber in der Sprachphilosophie nicht durchgesetzt.

${ }^{5}$ In der terminologie Tugendhats heißen sie ,Kennzeichnungen'. Diese beschreiben den Gegenstand, auf den sie referieren, durch die Angabe bestimmter Charakteristika und durch den bestimmten Artikel eindeutig (vgl. Tugendhat 1990, S. 147, S. 348; Lyons 1977, Bd. 1, S. 179).

${ }^{6}$ Deiktische Ausdrücke zeichnen sich durch ihre Situations- und Verwendungsabhängigkeit aus; Lyons 1977, Bd. 2, S. 636 f.

${ }^{7}$ Vgl. etwa Recanati 1997, S. 135; McKinsey 1995, S. 366.

${ }^{8}$ Wir stehen damit der Position Kaplans nahe; vgl. David Kaplan 1989, S. 562 f.; vgl. auch die Kritik Ackermanns 1989.

${ }^{9}$ Diesen Begriff prägt Yagisawa 1995, S. 215.

${ }^{10}$ Vgl. etwa Evans 1982, S. 385; Lyons 1977, Bd.1, S. 178 f.
} 


\subsubsection{Die erste Unsicherheit des Namens: die definite description des $\mathrm{Na}$ -} menträgers

Das nomen proprium ,Poot' steht für ein Individuum, das auch beschrieben werden kann. Insofern könnte ein Name für eine Kennzeichnung ${ }^{11}$ stehen, mit der wir den Namenträger identifizieren können. Der ,Ahnvater' des Deskriptivismus, Gottlob Frege, ${ }^{12}$ geht davon aus, daß Eigennamen wie alle anderen Zeichensorten einen "Sinn“ und eine „Bedeutung“ haben. Der "Sinn“ ist die „Art des Gegebenseins“, die dem bezeichneten Gegenstand zugeschrieben wird: die Art, wie man Zugang zu dem Gegenstand findet. Die „Bedeutung“ ist bei Frege der durch das Zeichen „bestimmte Gegenstand“, auf den das geäußerte Zeichen referiert. ${ }^{13}$ Die Erfassung des Sinns garantiert bei singulär definiten Termini zwar den Zugang zum Referenzobjekt, nicht jedoch die vollständige Erfassung dieses Objekts. ${ }^{14}$ Diese Unklarheit macht Frege an einem Eigennamen deutlich:

Aber mit der Kenntnis der deutschen Sprache ist es eine eigene Sache, wenn es sich um Eigennamen handelt. Es kann leicht sein, daß nur wenige mit dem Satze „Dr. Lauben ist verwundet worden" einen bestimmten Gedanken verbinden. Zum vollen Verständnis gehört in diesem Falle die Kenntnis der Vokabel „Dr. Gustav Lauben“. Dann [wenn zwei Sprecher verschiedene Charakteristika des gleichen Namenträgers mit dem Eigennamen verbinden, dabei aber die dem jeweils anderen Sprecher bekannten Charakteristika nicht kennen] sprechen Herbert Gerner und Leo Peter, soweit der Eigenname „Dr. Lauben“ in Betracht kommt, nicht dieselbe Sprache, obwohl sie in der Tat denselben Mann mit diesem Namen bezeichnen; denn daß sie das tun, wissen sie nicht. ${ }^{15}$

In seiner berühmten Passage aus Über Sinn und Bedeutung hatte Frege zum Beweis, daß Eigennamen Sinn haben, zwei verschiedene Eigennamen mit gleicher Referenz aber unterschiedlicher "Art des Gegebenseins“ (also einem jeweils eigenen ,Sinn') analysiert - „Morgenstern“ und „Abendstern“. ${ }^{16}$ Hier dagegen betrachtet er zwei Äußerungen des gleichen Eigennamens mit der gleichen Referenz. Diese Äußerungen des gleichen Namens können trotz der Identität der Zeichen mit den verschiedenen möglichen

\footnotetext{
${ }^{11}$ Manchmal werden diese auch „co-notions“ genannt; vgl. Everett 2000, S. $46 \mathrm{f}$.

12 Vgl. etwa Wolf 1985, S. 16 f.; Birus 1978, S. 26 f.; Debus 1985, S. 313.

${ }^{13}$ Frege verwendet den Begriff ,Eigenname' bekanntlich für die Kategorie ,singulär definiter Terminus'; Frege 1994, S. 41 f. Bei uns heißt Eigenname dagegen nach wie vor nomen proprium. Freges Begriffe ,Sinn' und ,Bedeutung' werden meist den Termini ,Intension' und ,Extension' ähnlich gebraucht, auch wenn sie nicht gänzlich übereinstimmen; vgl. Nute 1995, 379; Frege 1994, S. 41; Tugendhat 1990 , S. 148. Frege scheint schließlich Substantive wie ,Morgenstern', die später von Tugendhat als Kennzeichnungen verstanden werden, als Eigennamen auch im engeren Sinne zu beschreiben; vgl. Frege 1994, S. 41; Tugendhat 1990, S. 146; Birus 1978, S. 23 f.

${ }_{14}$ Vgl. Frege 1994, S. 41 f.; Tugendhat 1990, S. 148.

15 Vgl. Frege 1993, S. 38 f. Castañeda meint, daß zum Verständnis eines Satzes mit einem Namen die Identität der Sprecher und Hörerreferenz ausreiche und Sinnidentität nicht notwendig sei; vgl. Castañeda 1979 , S. 37.

${ }^{16}$ Vgl. Frege 1994, S. $46 \mathrm{f}$.
} 
,Sinnen' (Intensionen) des Eigennamens verschiedene „Gedanken“17 ausdrücken. In diesem Fall gibt es also bei objektiv gleicher Referenz des Eigennamens mehrere subjektive „Arten des Gegebenseins“ (mehrere ,Sinne’) des gleichen Zeichens, die verhindern, daß die Sprecher sich der Identität ihrer beiden Referenzobjekte bewußt werden. Diese Situation kann, nach den Beispielen Freges zu urteilen, auch bei indexikalischen Ausdrücken eintreten, nicht aber bei den Kennzeichnungen einer definite description. ${ }^{18}$ Frege geht sogar so weit, zu vermuten, daß viele Sprecher mit einem Satz, der einen Namen („Dr. Lauben“) enthält, gar keinen bestimmten Gedanken verbinden. Er zieht daraus den normativen Schluß, für eine wissenschaftliche Sprache müsse „eigentlich gefordert werden, daß mit jedem Eigennamen eine einzige Weise verknüpft sei, wie der, die oder das durch inn Bezeichnete gegeben sei“. ${ }^{19}$ Die eindeutige Kenntnis der „Vokabel Dr. Lauben“ meint vermutlich mindestens die Kenntnis einer eindeutigen und verbindlichen Definition mit genus proximum und differentia specifica. ${ }^{20}$

Ein Interpret des Epitaphs würde also mit Frege sagen: Es sollte eine eindeutige Kennzeichnung ,Poots' geben, auf die ein Name wie jede eindeutige definite description den Sprecher festlegt und die jeder Sprecher mit dem Namen verbindet. Dann könnte auch jeder Leser das fragliche Gedicht verstehen. Nur ist dies in einer natürlichen Sprache meist nicht der Fall.

Bertrand Russell bestimmt zunächst, daß Eigennamen abgekürzte Beschreibungen seien. ${ }^{21}$,Poot' würde inm zufolge also eine vollständige Beschreibung des niederländischen Dichters abkürzen und damit der Ökonomie der Sprache dienen. Jedoch können Eigennamen bei Russell wie bei Frege in verschiedenen Äußerungen variabel für verschiedene Kennzeichnungen stehen, solange das Referenzobjekt gleich bleibt. ${ }^{22}$ Der Benutzer fremder Namen stütze sich ohnehin nur deswegen auf definite descriptions

\footnotetext{
${ }^{17}$ Die ,Sinne' von Sätzen; vgl. Frege 1993, S. 33.

${ }^{18}$ Vgl. Frege, 1993, S. 38 f.; Perry 1997, S. 6-8.

${ }^{19}$ Frege 1993, S. 39.

${ }^{20}$ Frege 1993, S. 39. Eine solche ,Einsinnigkeit' hatte Frege schon in Über Sinn und Bedeutung angemahnt. Die auf verschiedene Sprecher einer Sprache verteilte ,Mehrsinnigkeit' von Eigennamen sei eine Schwäche der „Volkssprache“; vgl. Frege 1994, S. 42 und S. 44; Wolf 1985, S.14. Ebenso ist die Objektivität der Eigennamen für die Objektivität der Satzintension notwendig; vgl. Frege 1993, S. 49-53. Eine nahe Alternative zu Freges ,Eigennamendefinition' bietet das Modell W.V.O. Quines, das sich sehr nahe an Freges und Russells Aussagen hält; vgl. Quine 1980a, S. 167; Quine 1980b, S. 317; Lerner/Zimmermann 1991, S. $350 \mathrm{f}$.

21 "That is to say, the thought in the mind of a person using a proper name correctly can generally only be expressed explicitly if we replace the proper name by a description."; Russell 1980, S. 29. Russell merkt bekanntermaßen an, daß die eigentlichen ,logischen Eigennamen' indexikalische Ausdrücke wie ,this' seien; vgl. dazu auch Wolf 1985, S. 13; Birus 1978, S. 25.

${ }^{22}$ Russell plädiert also keineswegs uneingeschränkt für eine hinter dem Namen verborgene Konjunktion der Kennzeichnungen des Namenträgers. Dies behauptet dagegen noch Wolf 1985, S. 13; vgl. für unsere These Russell 1980, S. 29 f.
} 
des Namenträgers, weil er nur über diese Zugang zu dem Namenträger habe („knowledge by description“). Dies gelte, obwohl der Sprecher mit einem Namen durchaus gerne direkt auf den Namenträger referiere. ${ }^{23}$ Russell konstatiert also eine Differenz zwischen einer vom Sprecher intendierten, einer situationsabhängigen tatsächlichen und einer allgemeinen Namenbedeutung. Nur der Namenträger selbst könne den eigenen Namen mit „knowledge by acquaintance“ des Namenträgers direkt referierend benutzen. ${ }^{24}$ Auf diese Weise kann Russell verschieden große Mengen von Kennzeichnungen unterscheiden, die der Namenbenutzer je nach seiner Kenntnis vom Namenträger mit dem Eigennamen verbinden kann:

It will be seen that there are various stages in the removal from acquaintance with particulars: there is Bismarck to people who knew him; Bismarck to those who only know of him through history; [...]." 25

Der Namenbenutzer muß zur adäquaten Namenverwendung lediglich wissen, daß alle ihm und anderen jeweils unabhängig voneinander zu einem Namen einfallenden Kennzeichnungen zu einer konstanten Entität gehören. ${ }^{26}$

Russell würde demnach hinter ,Poot' eine vollständige Beschreibung des Schriftstellers Hubert Korneliszoon Poot vermuten. Nach seiner Theorie konnte nur Hubert Poot selbst diese vollständige Beschreibung mittels Kennzeichnungen mit dem Namen verbinden. Russell als Leser verbände sie zwar auch gerne mit dem Namen, aber er hätte nur ein begrenztes Wissen über Poot, mit dem er sich aber zufrieden gäbe, solange dieses Wissen auf den Namenträger auch zutrifft.

Aus den Unsicherheiten der Verbindung zwischen den Kennzeichnungen des Namenträgers und dem Namen kann die radikale Konsequenz gezogen werden, daß Eigennamen mit gar keinem semantischen Inhalt verbunden sind. Vor allem John Stuart Mill hat bekanntlich diese Ansicht vertreten. Ihm zufolge unterscheiden Eigennamen ein Individuum von anderen, ohne es näher zu qualifizieren: „[...] these [proper] names are simply marks used to enable those individuals to be made subjects of discourse." ${ }^{27}$ Der Eigenname ist daher bei Mill anders als eine Kennzeichnung ein reines Merkzeichen, das die Idee des Objektes in der Erinnerung markiert und hilft, sie aufzurufen. ${ }^{28}$ Eigennamen haben nach der Millschen Theorie nur Bezug auf das Referenzobjekt („denotati-

\footnotetext{
${ }^{23}$ Vgl. Russell 1980, S. 31; Russell skizziert damit nicht nur einen sprachlichen, sondern auch einen epistemischen Wunsch des Menschen.

${ }^{24}$ Vgl. Russell 1980, S. 29-32; Frege 1993, S. 39 f., sagt Ähnliches für das indexikalische Personalpronomen ,ich'.

${ }^{25}$ Russell 1980, S. 31.

${ }^{26}$ Russell 1980, S. 30.

27 Vgl. Mill 1900, S. 36 f.

28 Vgl. Mill 1900, S. 38.
} 
on“), nicht aber wie Kennzeichnungen einen Bezug auf bestimmte Eigenschaften („connotation“). ${ }^{29}$ Sie tragen demnach nichts zum semantischen Inhalt eines Satzes bei, sondern bestimmen lediglich ein Referenzobjekt. Für Mill können sie höchstens (zufällig) vorhandenes enzyklopädisches Vorwissen aktivieren. ${ }^{30}$ Die Verbindung der Kennzeichnungen des Namenträgers mit dem Eigennamen ist bei Mill eine Folge der Verbindung zwischen dem Eigennamenzeichen und dem Referenzobjekt. Demnach haben Eigennamen anders als Kennzeichnungen nicht nur keinen eindeutigen Sinn. Sie setzen vielmehr als Bedingung für die Zuordnung einer Bedeutung zum Namen die Kenntnis der Eigenschaften des Referenzobjekts voraus, statt sie zu liefern. ${ }^{31}$

Mill würde zu unserem Epitaph also sagen: Es wird das denotierte Objekt Hubert Poot aufgerufen. Über diesen wird mit dem Namen aber nichts ausgesagt. Es mag immerhin Leser geben, die den Namenträger kennen. Deren Vorwissen über den Autor Poot kann durch den Namen dann aktiviert werden.

Mills radikale Argumentation zieht zwar die Konsequenz aus der Unsicherheit der Kopplung von Kennzeichnung und Namen, sie stimmt aber nicht mit der Intuition zusammen, daß man einen Namen nicht benutzt, ohne damit wenigstens ein Minimum an Information über den Namenträger zu meinen oder zu wissen. Wer gar nichts über Poot weiß nicht einmal, ob es sich um Mensch, Tier oder Sache handelt -, kann ihn nicht identifizieren und sich auch schlecht mit einem Namen auf ihn beziehen.

Edmund Husserl versucht, dieses Problem im Rahmen einer reinen Referenztheorie zu Iösen. ${ }^{32}$ Er bestimmt den Namen zunächst als singulären Terminus. Dabei unterscheidet er wie Frege zwischen semantischem Inhalt und der Referenz referierender Ausdrücke ${ }^{33}$ sowie zwischen objektivem und subjektivem Inhalt eines Ausdrucks. ${ }^{34}$ Wie Frege geht auch Husserl davon aus, daß ein Referenzobjekt durch die Intension des verwendeten Ausdrucks ermittelt wird. ${ }^{35}$

Interessant sind für uns vor allem Husserls Ausführungen zu den semantischen Besonderheiten des Namens, die die Intuitionen Freges präzisieren. Husserl kritisiert an Mills Theorie zwar, daß dieser die Eigennamen zu reinen Anzeichen (im Sinne von Sympto-

\footnotetext{
29 Vgl. etwa Wettstein 1995, S. 109; Birus 1978, S. 21 f.; Lerner/Zimmermann 1991, S. 367.

${ }^{30}$ Vgl. Mill 1900, S. 38.

31 So später auch Strawson 1993, S. 192 f.

${ }^{32}$ Für unser Thema ist eine ,phänomenologische' Namenanalyse auch insofern interessant, als sie unsere „Erfahrung mit Rede“ in den Mittelpunkt des Interesses stellt; vgl. Smith 1996, S. 650.

${ }^{33}$ Vgl. Husserl 1987, S. 28; Welton 1983, S. 58 f. Husserl differenziert „bedeutungsgebende“ und „bedeutungserfüllende“ intentionale Akte als die „Bedeutung“ eines Zeichens (das ist bei Frege der ,Sinn') von der "gegenständlichen Beziehung“ (das ist bei Frege die ,Bedeutung'); Husserl 1984, S. 53.

${ }^{34}$ Husserl 1984, S. 57.

${ }^{35}$ Husserl 1984, S. 54 f.; Husserl unterscheidet weiterhin zwischen dem mentalen (intentionalen), bedeutungsverleihenden Akt und dem physischen Akt der menschlichen Rede; vgl. Smith 1996, S. 653.
} 
men) der Vorstellungen ,im Kopf des Sprechers' mache. Doch im Gegensatz zu Frege folgt er Mill trotzdem darin, daß Eigennamen nicht attributiv seien. Eigennamen geben Husserl zufolge anders als definite descriptions keine Attribute an, die das Referenzobjekt klassifizieren. ${ }^{36}$ Bei einer Äußerung mit Eigennamen liege der Gedanke der Äußerung eher bei dem Referenzobjekt des Namens ${ }^{37}$ als bei "gedachten Bestimmungen“ Husserls Äquivalent zu Freges „Sinn“ bzw. der „Art des Gegebenseins“. 38

Husserl bildet in diesem Zusammenhang den Begriff der „Eigenvorstellung“. Mit dieser beziehe sich ein Subjekt auf eine Erscheinung unabhängig von allen möglichen Kennzeichnungen. ${ }^{39}$ Sie unterscheide sich von der „Bestimmungsvorstellung“, die sich auf die Kennzeichnungen eines Gegenstands beziehe. Eigennamen stehen Husserl zufolge für eine solche Eigenvorstellung des Namenträgers. Sie können wie bei Mill als Erinnerungszeichen von definite descriptions fungieren und legen den Sprecher nicht auf eine bestimmte Kennzeichnung fest. ${ }^{40}$ Man kann daraus folgern, daß ein Unterschied besteht zwischen einem „idealen“ Inhalt eines Satzes (der Proposition) und dem „realen“ Inhalt (dem intendierten Inhalt) der einzelnen Äußerung mit einem Eigennamen. ${ }^{41}$ Der ideale Inhalt umfaßt den ganzen Namenträger, der reale nur den jeweils ,gemeinten' Ausschnitt aus dessen definite description. Daher hängt auch bei Husserl die Referenz von Äußerungen mit Eigennamen von der Intention ab, die der Äußerung zugrunde liegt. ${ }^{42}$ Da der Namenträger zu verschiedenen Zeiten unter verschiedenen Perspektiven betrachtet werden kann, ist in verschiedenen Äußerungen (die „intentionale Akte“ darstellen) mit dem gleichen Namen oft Unterschiedliches gemeint. Dies gilt, obwohl der Eigenname immer auf den gleichen Gegenstand referiert. ${ }^{43}$

Die Bedeutung eines Namens besteht daher für Husserl auch nicht aus der Summe der Kennzeichnungen, die mit dem Namenträger verbunden werden können (also der vollständigen definite description):

Die Eigenbedeutung ist nicht aus den B e d e u t u n g e $\mathrm{n}$ zusammengesetzt, die auf die gegenständlichen Bestimmtheiten als gesonderte Intentionen gerichtet sind. ${ }^{44}$

\footnotetext{
${ }^{36}$ Husserl 1984, S. 64 f.; vgl. Welton 1983, S. 66.

${ }^{37}$ Das ist der "gegen mancherlei Unterschiede äquivalenter Kategorialien unempfindliche[n] Sachverhalt"; Husserl 1987, S. 98.

${ }^{38}$ Husserl 1987, S. 100.

39 Husserl bildet das Beispiel mit einem indexikalischen Ausdruck „Dies ist ein Haus“, in dem "Dies“ für eine solche undifferenziertes ,Meinen' des Referenzobjekts steht; vgl. Husserl 1987, S. 174.

${ }^{40}$ Husserl 1984, S. 53 und S. 59; Welton (1983, S. 58 f.) beschreibt Husserls umgekehrtes Theorem der „Logischen Untersuchungen“, daß trotz verschiedener Wahrnehmungen mit einem Eigennamen stets der gleiche Gegenstand gemeint sei.

${ }^{41}$ Zur realen und idealen Bedeutung von intentionalen Akten vgl. Smith 1996, S. 654.

${ }^{42}$ Vgl. Smith 1996, S. $653 \mathrm{f}$.

${ }^{43}$ Vgl. Husserl 1987, S. 175.

44 Husserl 1984, S. 308; vgl. Welton 1983, S. 58 f.
} 
Vielmehr nennt ein Sprecher nach Husserl mit einem Namen den Namenträger als Ganzes (,in einem Pulse“), ohne sich explizit auf eine oder mehrere Kennzeichnungen zu beziehen. ${ }^{45}$ Diese undifferenzierte Gesamtbedeutung des Namens wird als offener und weder Sprecher noch Hörer notwendigerweise bekannter ,semantischer Pool' vorausgesetzt. Bei Bedarf wird der für die Situation relevante Ausschnitt der definite description eines Namenträgers explizit genannt. ${ }^{46}$ Denn ohne diese könne

die aktuelle Bedeutung die Richtung auf die bedeutete Gegenständlichkeit nicht gewinnen [...]. Wie unanschaulich, dürftig, vage, unbestimmt sie [die Person Schultze] auch vorgestellt sein mag, gänzlich fehlen kann der Vorstellungsinhalt nicht. ${ }^{47}$

Die von Husserl gegebenen Hinweise basieren auf einer Unterscheidung, die Soames jüngst mit „the simplest and most fundamental question to be answered by a semantic theory“ verbunden hat: „What do sentences say or express (relative to various contexts of utterance)?" Diese Frage ist Soames zufolge eng verbunden mit einer weiteren Frage: „What do speakers say, and what beliefs do they express, when they assertively utter sentences of their language?" ${ }^{48}$ Diese Ergänzung weist darauf hin, daß in literarischen wie nichtliterarischen Äußerungen von dem semantischen Inhalt einer Äußerung ein intendierter Inhalt unterschieden werden muß. ${ }^{49}$ Der semantische Inhalt ist die gleichbleibende Information (die Proposition), die die Äußerung enthält. ${ }^{50}$ Neben diesem

\footnotetext{
${ }^{45}$ Vgl. Husserl 1984, S. 308 f.; Deutsch 1989, S. 183 f., nennt dies das Fehlen einer komplexen syntaktischen Struktur von Eigennamen.

${ }^{46}$ Vgl. Husserl 1984, S. 306; vgl. so auch Strawson 1993, S. 20. Auch Strawson wendet sich gegen die Vorstellung, daß Eigennamen keinerlei Verbindung zu Kennzeichnungen haben. Er spricht aber ausdrücklich und in scharfer Abgrenzung von Bertrand Russell davon, daß Namen nicht durch die mit innen verbundenen Kennzeichnungen auf ihr Referenzobjekt verwiesen; Strawson 1968, S. 81 f.; vgl. auch Aschenberg 1991, S. 16. „Ad hoc conventions“ können für Strawson den Namengebrauch in unterschiedlichem Grade normieren. Daher geht er davon aus, daß Eigennamen auf gewisse Eigenschaften des Namenträgers nur dann hindeuten, wenn und soweit starke Namengebungskonventionen bestehen etwa in dem Sinne, in dem ,Peter' im Deutschen ein männlicher Name ist; vgl. Strawson 1968, S. 82. Doch gleichzeitig sind Eigennamen Strawson zufolge wertlos, wenn sie nicht durch eine Beschreibung des Namenträgers gestützt werden (,worthless without a backing“); Strawson 1993, S. 20; vgl. Donnellan 1972, S. 356 f. Die mit einem Eigennamen zusammenhängende „composite description“ des Namenträgers soll nach Strawson zu den Präsuppositionen einer Äußerung mit Eigennamen gehören. Dieses „presupposition-set" ist variabel und entspricht den in einer Kommunikationsgemeinschaft verbreiteten Kennzeichnungen des Namenträgers; Strawson 1993, S. 193; vgl. auch Evans 1985, S. 311.

47 Husserl 1984, S. 306 f. Diese Theorie nimmt zu einem guten Teil die ,Bündeltheorie' John Searles vorweg. Searle versucht, der von Frege postulierten Unsicherheit der Namenbedeutung dadurch entgegenzukommen, daß er Eigennamen (vgl. Wennerberg 1998, S. 41-69) ein ,Merkmalsbündel' zuordnet; Searle 1958, S. 171. Ein Eigenname steht demnach für einen hinreichend großen Ausschnitt aus einem Bündel disjunktiv verbundener Charakteristika, die von den Sprechern ,an den Namen gehängt' werden; vgl. Searle 1994, S. 253; Cobb-Stevens 1990, S. 118. Diese ermöglichen in den Grenzen der betreffenden Disjunktion einen Bezug mit variierendem Sinn (Frege) auf Entitäten, die dennoch eindeutig identifiziert werden; vgl. Searle 1994, S. 171 f. Searle sieht hier eine besondere Eigenschaft der Eigennamen. Wittgenstein dagegen nimmt Namen nur als Stellvertreter für alle singulären Termini; vgl. Wittgenstein 1984, S. 267 (§ 79).

${ }^{48}$ Soames 2002, S. 3.

${ }^{49}$ Vgl. Evans 1985, S. 309; Soames 2002, S. 55; Ashley 1979, S. 8, S. 11.

${ }^{50}$ In der Sprachphilosophie wird ,Proposition' unterschiedlich definiert. Eine Möglichkeit, der wir uns anschließen, ist folgende: [eine Proposition ist] ,the shared meaning of this sentence and all its synonyms, in English or elsewhere"; vgl. Wagner 1995, S. 658.
} 
semantischen Inhalt haben geäußerte Worte und geäußerte Sätze einen weiteren Inhalt, der je nach Kontext variiert:

This extra, nonsemantic information [of an enunciation] comes in a variety of types from a variety of sources; some of it is asserted, some is implied or suggested, and some is merely intended to be imparted to those hearers who happen to have the requisite background knowledge to extract it. ${ }^{51}$

Beide Formen des Inhalts beziehen sich sowohl auf den gesamten Satz als auch auf die einzelnen Zeichen, bzw. deren Beitrag zum Inhalt.

Bei Äußerungen mit Eigennamen scheint Husserl zufolge eine besonders enge Verbindung zwischen dem von der Sprecherintention bestimmten intendierten Inhalt und dem semantischen Inhalt zu bestehen. Während die „Sache, genommen in der Weise, wie sie hierbei besagt ist“52, durch definite descriptions zumindest auf alle Elemente des semantischen Inhalts der verwendeten Zeichen festgelegt ist, besteht eine solche Festlegung bei Eigennamen nicht. Einerseits bezieht sich der Eigenname auf den benannten Gegenstand, ohne dabei einzelne Eigenschaften des Gegenstandes zu unterscheiden. ${ }^{53}$ Dies ist die „Eigenbedeutung“ des Eigennamens. ${ }^{54}$ Andererseits beruht eben dieser Bezug auf der Kenntnis wenigstens einiger Eigenschaften des Gegenstandes.

Das Besondere dieser Unterscheidung für unseren Namengebrauch liegt darin, daß der semantische Inhalt des (vergebenen) Eigennamens immer größer ist, als die situationsabhängig variable Information, die der Sprecher mit dem Namen transportieren will also der intendierte Inhalt: ,Poot' heißt: ,der Dichter' und ,der Niederländer'. Der von mir geäußerte Satz ,Der große Poot!' meint unter Umständen nur den Dichter, weil ich nicht weiß, daß er Niederländer ist. Ganz gleich aber, was ich mit dem auf Poot referierenden Namen meine, der Name schließt diese Informationen immer ein, weil er den Namenträger ,in jeder Hinsicht' meint. Bei den Appellativen einer Äußerung ist dies genau umgekehrt: ,Hund' bedeutet: ,ein vierbeiniges Säugetier mit Fell und Fängen'. Der von mir geäußerte Satz ,Ein Hund!' meint unter Umständen ,das große schwarze, zähnefletschende, vierbeinige Säugetier mit Fell und Fängen, das auf dich zukommt' - also mehr als die Definition des Begriffs. ${ }^{55}$

Husserl zufolge bezeichnet unser Gedicht mit dem Namen ,Poot' demnach die ganze Person Hubert Korneliszoons, ohne ausdrücklich zu sagen, welcher Aspekt von ihm mit

\footnotetext{
51 Soames 2002, S. 109.

52 Vgl. Husserl 1987, S. 28.

53 „In einem Strahl“; Husserl 1984, S. 308; vgl. auch Coseriu 1975, S. 251, in Anschluß an Leibniz, Lotze und Husserl.

${ }^{54}$ Vgl. Husserl 1984, S. 684, S. 305 f.; Smith 1996, S. 659.

55 Vgl. Searle 1994, S. 254. Nach Hansack beziehen sich Eigennamen auf eine potentiell unendliche Menge von Informationsbestandteilen, auf eine offene Menge. Er betont, daß der bisherige Fehler der Sprachphilosophie die Zuordnung des Namens zu einem Referenzobjekt sei; vgl. Hansack 1990, S. 41.
} 
dem Namen gemeint ist. Eine Frage an den Sprecher würde erst klären, an welche Eigenschaften Poots er mit der Namenäußerung gedacht hat.

\subsubsection{Die zweite Unsicherheit des Namens: Namen als Teil einer kommu- nikativen Situation}

Die Entwicklung der vorgestellten description theories zeigt, daß die sprachphilosophischen Theorien der Eigennamenbedeutung den mit einem Namen verbundenen Kennzeichnungen zunehmend Variabilität zuschreiben. Alle neueren Theorien sowohl des descriptivism als auch der indexical-reference- und historical-chain- oder auch causalchain-theories setzen diese Entwicklung fort. Sie vermuten, der semantische Inhalt des Eigennamens hänge deutlich von der kommunikativen Situation ${ }^{56} a b$, in der er verwendet wird.

Den entscheidenden Schritt in diese Richtung machen zunächst die Theorien Donnellans, Kripkes und Kaplans, die gemeinhin als (historical, causal oder communicative) chain theories bezeichnet werden. Diese orientieren sich an John Stuart Mill. Für sie ist der Name eng an einen kommunikativen Kontext gebunden, wie etwa eine Bemerkung David Kaplans zeigt:

But among the criteria [für die richtige Anwendung eines Wortes] there must be some that touch on the utterer's intention to use a word in conformity with the conventions of a particular linguistic community. For proper name words, in part because they are so easily introduced, this aspect of the presemantic determination is especially important. ${ }^{57}$

Die „präsemantische“ Festlegung für die richtige Anwendung eines Namens ist für Donnellan, Kaplan und Kripke der Namengebungsakt. ${ }^{58}$ Die Namengebung kreiert bei Kaplan ein Wort, das ,direkt', ohne die Vermittlung durch eine Kennzeichnung referiert ${ }^{59}$ :

In the case of proper names, the reference can be fixed in various ways. In an initial baptism it is typically fixed by an ostension or a description. Otherwise, the reference is usually determined by a chain, passing the name from link to link. ${ }^{60}$

Demnach ist ein Eigenname auch hier nicht äquivalent zu einer Beschreibung. Ein Gegenstand muß auch keinerlei Eigenschaften aufweisen, um als Träger eines Eigennamens zu gelten. Der Eigenname wird vielmehr in einem Namengebungsakt an den Namenträger vergeben. In dieser und nur in dieser Situation können dann je nach Konvention auch deskriptive oder andere charakterisierende Eigenschaften des Namens das

\footnotetext{
${ }^{56}$ Unter einer ,kommunikativen Situation' verstehen wir den engeren und weiteren Kontext einer Eigennamenäußerung.

${ }^{57}$ Kaplan 1989, S. 559.

${ }^{58}$ Vgl. Donnellan 1972; Kaplan 1989, S. 560; Kripke 1972.

${ }^{59}$ Vgl. Kaplan 1989, S. 483, S. 560 f.; Ackermann 1989, S. 5.

${ }^{60}$ Kripke 1972, S. 328; vgl. Martinich 1984, S. 186 f.
} 
Zeichen mit dem Namenträger verbinden. ${ }^{61}$ Die Namengebung kann von der institutionellen Taufe einer Person bis hin zur gelegentlichen Spitznamengebung unterschiedlich stark konventionell geregelt sein. Von einer solchen ,Taufe' muß eine referenzbewahrende Kette von Namenverwendungen bis zur jeweiligen aktuellen Namenverwendung reichen. ${ }^{62}$ Diese Kette bewirkt eine Art ,verlängerter Deixis' des verwendeten Namens, die bis zum materiellen Namenträger zurückreicht. Der Sprecher, der einen Namen verwendet, möchte mit diesem Namen auf dasselbe Objekt referieren wie diejenigen Sprecher, von denen er den Namen gelernt hat. Die Verwendung und der semantische Inhalt eines Namens beruht daher bei jedem Sprecher auf einer eigenen durch die kommunikative Kette verlängerten direkten Referenz auf einen bestimmten Gegenstand. ${ }^{63}$ Die Kette ist dem Sprecher und dem Hörer nicht immer bewußt, aber theoretisch rekonstruierbar. ${ }^{64}$

Die Vertreter der chain theories berücksichtigen auf der Grundlage der ,direkten Referenz' mittels kommunikativer Ketten auch die Rolle der definite descriptions beim Gebrauch und Verständnis von Eigennamen. So räumt Kripke ein, daß das Referenzobjekt eines Namens häufig mit Hilfe einer Beschreibung ermittelt wird. Er bestreite lediglich, daß diese definite description die Bedeutung des Namens konstituiere. ${ }^{65}$ Kaplan zufolge fallen bei Eigennamen die semantische Referenz und die vom Sprecher intendierte Referenz zusammen. Das Namenszeichen erhält seinen Inhalt („semantic content“) aufgrund der durch den Sprecher intendierten Referenz. ${ }^{66}$ Daher hätten gleiche Namen verschiedener Objekte (der Dichter ,Poot' oder die Katze ,Poot') verschiedene semantische Inhalte. Sie seien anders als indexikalische Zeichen nicht in der Weise kontextabhängig („context-sensitive“67), daß sie bei jeder Verwendung mit dem wechselnden Kontext auch die Referenz wechseln würden. Die drei Möglichkeiten eines Zeichens, Bedeutung zu tragen: Referenz, appellativer Inhalt und indexikalischer Charakter, fielen im Eigennamen zusammen.

\footnotetext{
${ }^{61}$ Vgl. Wimmer 1995, S. 378.

62 Vgl. auch Evans 1985, S. 315; die beste konzentrierte Darstellung der Thesen Kripkes bietet Soames 2002, S. 4f.

${ }^{63}$ Vgl. Kripke 1972, 298 f.; Donnellan 1972, S. 373 f.; Wettstein 1995, S. 110; Soames 2002, S. 4 f.

${ }^{64}$ Vgl. etwa Donnellan 1972, S. 373 f.

${ }^{65}$ Vgl. Kripke 1972, S. 270 und S. 328; vgl. auch Kuzminski 1979, S. 456; Martinich 1984, S. 188 f.; Bach 1987, S. 135.

${ }^{66}$ Es ist also keine falsche Anwendung eines Namens möglich wie in dem Fall, daß ein Hund als, die Katze da' bezeichnet wird.

${ }^{67}$ Vgl. Kaplan 1989, S. 561 f.; vgl. auch den Begriff der „relativity“ bei Deutsch 1989, S. 180 f., der ausführt, daß der Charakter von indexicals den Rahmen der Referenz transzendierten (sich auf diesen selbst bezögen), während Eigennamen diesem Rahmen, der durch den Namengebungsakt („dubbing“) bestimmt wird, immanent blieben; vgl. Deutsch 1989, S. 186.
} 
Wenn Kaplan daher sagt, er betrachte das Referenzobjekt als Bedeutung des Eigennamens, meint er damit, daß die durch die Namengebung hergestellte Referenz als primäre Beziehung des Namenzeichens sowohl einen semantischen Inhalt des Namens als auch eine stabile Zuordnungsfunktion im Sinne eines indexikalischen ,Charakters' bewirke und bestimme. ${ }^{68}$ Eigennamen sind bei Kripke und Kaplan aufgrund ihrer ,verlängerten Deixis' „rigid designators“. ${ }^{69}$ Alle Eigenschaften des Referenzobjektes - das heißt, alle Kennzeichnungen, die mit dem Eigennamen verbunden werden - können sich beliebig ändern, ohne daß sich die Referenz des Eigennamens ändert. Zudem kann ein Sprecher mit einem Namen auf den Namenträger referieren, obwohl er eine völlig falsche definite description mit dem Eigennamen verbindet. Folglich referiert der Eigenname in allen möglichen Welten, in denen er verwendet wird, auf dasselbe Objekt jener Welt, in der dieses getauft worden ist. ${ }^{70}$ Dies hat zur Folge, daß mit Eigennamen die „transworld identification“ eines Objekts möglich ist. Ein Sprecher referiert mit einem Namenszeichen unabhängig von einem Kontext über mehrere mögliche Welten hinweg auf die Ursprungswelt des Namens. ${ }^{71}$ Dies fällt besonders dann auf, wenn ein Sprecher kontrafaktische Aussagen über reale Entitäten macht:

It is only relative to the frame of reference consisting of the first [real] world that the sentence ,Hitler does not exist' is true in the second [fictitious] world. ${ }^{72}$

In einer solchen Aussage über eine mögliche oder fiktive Welt, in der der Dichter Poot nicht existiert, referiert der Eigenname 'Poot' nicht auf die fiktive Welt, sondern auf die aktuelle reale Welt, in der Poot existiert(e). Mit dem Gedicht kann also unter Umständen auch etwas über Poot behauptet werden, was nicht stimmt. Dennoch handelt es sich um ein Gedicht über Poot. Auf der Ebene der Referenz scheint die Bedeutung des Namens also nicht unsicher, sondern im Gegenteil ganz besonders sicher zu sein.

Die zentrale Intuition der Theorien einer kommunikativen Eigennamenreferenz liegt also zunächst darin, daß die Bedeutung von Eigennamen von einem Kontext abhängt, zu dem ein vor der ,allgemeinen' Namenverwendung stattfindender Namengebungsakt gehört. Wenn wir also wissen wollen, was der Name ,Poot' in unserem Gedicht bedeutet, müssen wir nach den direct reference theories vor allem herausfinden, wer auf den Namen ,Poot' getauft wurde. ${ }^{73}$ Dies klingt einfach genug, zeigt aber die zweite große

\footnotetext{
${ }^{68}$ Vgl. Kaplan 1989, S. 562.

${ }^{69}$ Vgl. Kripke 1972, S. 269 f.; Kaplan 1973, S. 501-503; in bezug auf die Namensemantik zu den geringen Unterscheidungen zwischen den Theorien vgl. etwa Martinich 1984, S. 181-187.

${ }^{70}$ Vgl. Kripke 1972, S. 270f.; Lerner/Zimmermann 1991, S. 368.

${ }^{71}$ Vgl. Kripke 1972, S. 271.

72 Deutsch 1989, S. 182.

73 Dies führt in jedem Fall dazu, daß die Namenbedeutung „object-dependent“ ist. Verändert sich das benannte Objekt, verändert sich auch die Bedeutung des Eigennamens; vgl. auch Davidson 2000, S. 287.
} 
Unsicherheit der Namenbedeutung: Zumeist ist es sehr schwierig herauszubekommen, wer wann vom wem auf welchen Namen getauft wurde.

Zudem ist damit auch nicht geklärt, ob ein aktueller Sprecher mit der Äußerung eines Namens auch diesen Namenträger meint. Dies führt einige Autoren zu der Annahme, Eigennamen seien indexikalische Zeichen, die sich durch ihren ,Charakter' auf ein Objekt bezögen. Unter ,Charakter' verstehen sie dabei eine auf den Äußerungskontext bezogene Funktion, die dem Zeichen kontextabhängig einen Referenten zuordnet: „Very briefly, a character is a function from contexts of utterance to contents“. ${ }^{74}$,Ich' steht danach für ,der Sprecher dieser Äußerung', ,dies' für ,das vor Augen liegende Objekt' oder ,das Objekt, auf das gestisch gewiesen wird' usw. Von einem mehrdeutigen Zeichen soll sich ein indexikalisches Zeichen dadurch unterscheiden, daß eine gleichbleibende Regel angewendet wird, die die jeweiligen verschiedenen Referenten abhängig von einer Situation bestimmt ${ }^{75}$ - von einem „extra-semantic feature of its context of utterance“. ${ }^{76}$ So geht z.B. François Recanati davon aus, der indexikalische ,Charakter' eines Namens laute: ,referiert auf den Träger von ,N.N." Dieser Charakter verbinde den Namen nicht mit einem festen semantischen Inhalt im Sinne einer definite description des Namenträgers, sondern mit dem Namenträger selbst. ${ }^{77}$ Doch werden Eigennamen Recanati zufolge als Kennzeichnung des enzyklopädischen Eintrags einer Entität verwendet. Insofern stehe der Eigenname ,für' eine definite description, wenn er als Etikett („label“) eines mentalen Ordners („file“) diene, der die Kennzeichnungen des Namenträgers enthalte. Eigennamen sind für Recanati ein Mittel dazu, die Kommunikation zu vereinfachen. Sie hängen ihm zufolge davon ab, daß die Teilnehmer der Kommunikation trotz unterschiedlicher Kenntnis der Eigenschaften des Namenträgers zumindest alle wissen: Poot ist in ihrer Sprechergemeinschaft der ,Träger des Namens ,Poot”. ${ }^{78}$

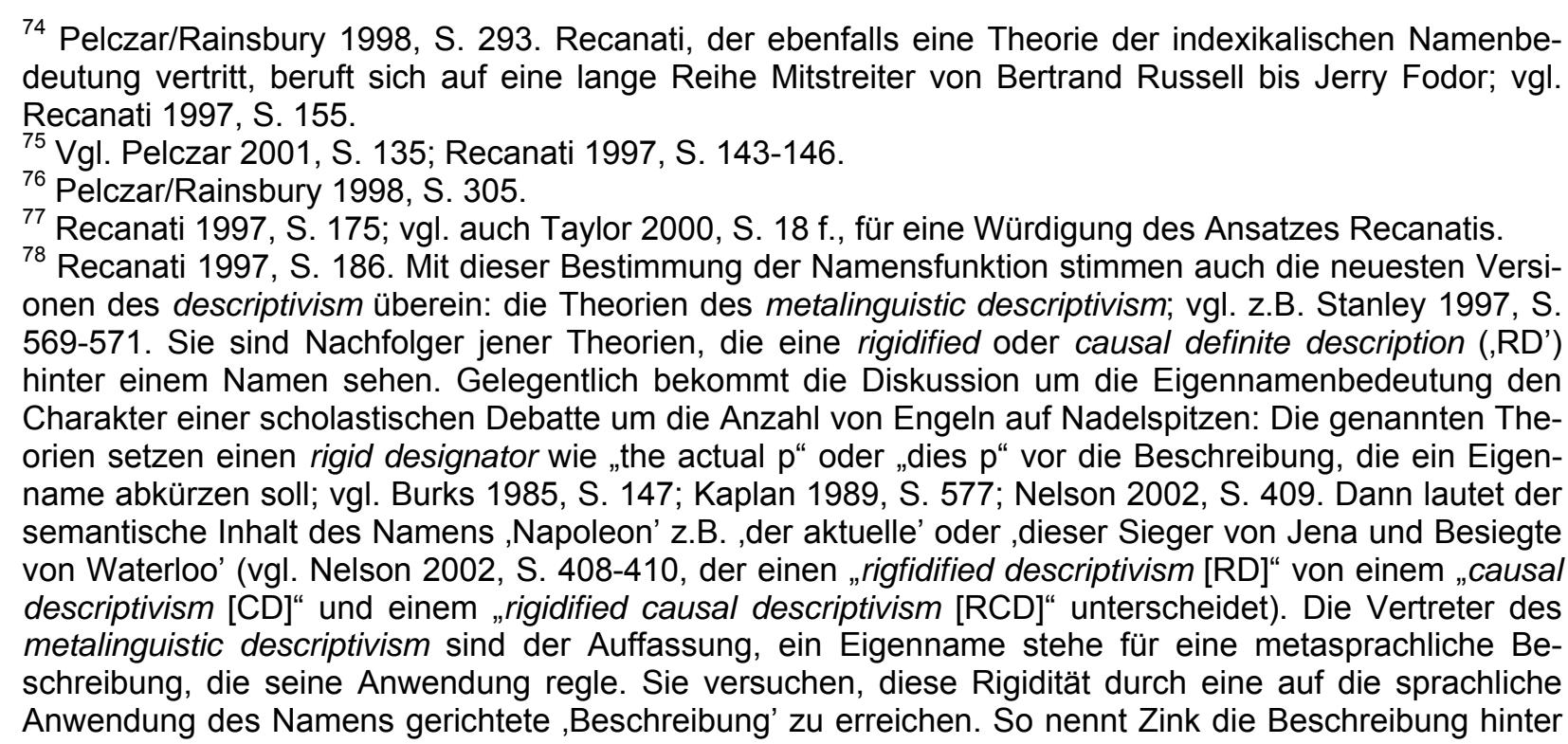


Die Bedeutung des Namens ,Poot' hängt auch hier von Kommunikationsgewohnheiten

ab, die sehr oft äußerst schwer zu bestimmen sind und die vor allem nur einer begrenzten Sprecherzahl bekannt sind. ${ }^{79}$ Neuere Theorien der Eigennamenbedeutung betonen so auch die verschiedenen kommunikative Einschränkungen, denen Eigennamen unterliegen. So komme Eigennamen eine genuine „localness“ zu, weil sie von einer räumlich und zeitlich unter Umständen stark beschränkten Subgemeinschaft abhingen. ${ }^{80}$ Auch die Verwendung des semantisch nicht transparenten Namens sei nur mit Bezug auf die dazugehörige ,Kommunikationsgewohnheit' der Sprechergemeinschaft zu erfassen. ${ }^{81}$

Pelczar und Rainsbury betonen, geäußerte Eigennamen bezögen sich als „doubly conventional signs" auf die jeweils in einer kommunikativen Situation gültige Namengebung

einem Eigennamen: „Diejenige Person, welche wirklich ,EN' genannt wird und zum Zeitpunkt $Z$ am Ort $O$ geboren wurde."; Zink 1985, S. 166; ähnlich macht es die von Nelson 2002, S. 409 f., beschriebene Theorie des "causal descriptivism" (CD): "the entity standing in relation R to my current use of the name n". Bach postuliert in seiner "nominal description theory" (,NDT'), daß "the bearer of ,N" als Beschreibung den Inhalt des Namens liefere; vgl. Bach 1987, S. 135; Bach 2002; zu einer ähnlichen Theorie vgl. auch Orilia 2000. Nelson vertritt einen "rigidified causal descriptivism" (,RCD'): "All names n are such that there is some definite description [the actual entity standing in the appropriate causal-historical chain to my use of ,n'] that gives the content of n"; Nelson 2002, S. 408 und S. 410. Hier bildet die Kennzeichnung nur in Abhängigkeit von der direkten Referenz über kommunikative Ketten den semantischen Inhalt des Namens. Nelson konstruiert also eine Namenbedeutung, die eine Kombination aus einer vorrangigen kommunikativen Kette und einer nachrangigen definite description ist. Wie in der Theorie Kaplans ist es das Referenzobjekt, das den Inhalt des Zeichens bestimmt.

Alle diese Theorieentwürfe zeigen, daß eine definite description in irgendeiner Form mit dem Eigennamen verbunden wird, auch wenn in jedem Fall die direkte Referenz Vorrang bei der Feststellung des Referenzobjekts hat. Ein naheliegender Einwand gegen eine naive Theorie dieser Form ist, daß die Eigenschaft, den Eigennamen zu tragen, nur in Ausnahmefällen und eindeutig gekennzeichnet aktualisiert wird: „Ein ,Dietrich' hat angerufen“ statt „Dietrich hat angerufen“; vgl. dazu etwa Lyons 1977, Bd. 1, S. 217 f.

${ }^{79}$ Wenn aber die Namenbedeutung nur in der direkten Referenz bestünde - wie es die chain theories zu behaupten scheinen -, kann nicht erklärt werden, wie jemand bei Kenntnis der Namen trotzdem nicht wissen kann, daß, Hesperus $=$ Phosphorus'. Dies liegt daran, daß die kommunikative Kette den Sprecher zu dem gleichen Referenzobjekt führt; vgl. etwa die Darstellung in Pelzcar/Rainsbury 1998, S. 308-310. Ein ähnliches Argument gegen die causal chain theories besteht darin, daß sie den Wandel der Referenz nicht erklären können, den ein Name im Verlauf seiner Verwendung erfahren kann; vgl. Evans 1985; Martinich 1984, S. 188 f. Der Eigenname ,Madagaskar' - so das bekannteste Beispiel Gareth Evans' wurde zunächst für einen Teil des afrikanischen Festlandes verwendet. Europäische Afrikareisende irrten sich über die Referenz des Namens. Sie glaubten, es sei der Name der heute so benannten Insel und verwendeten inn bei ihrer Rückkehr in Europa entsprechend - mit dem Ergebnis, daß heute die Insel tatsächlich ,Träger' des Namens ist. Die europäischen Afrikaforscher hatten dabei nicht die Intention, den Namen anders als die Eingeborenen zu verwenden. In diesem Beispiel sind alle Bedingungen für den Aufbau einer kommunikativen Kette erfüllt. Dennoch referierten die Forscher und alle auf sie hörenden Europäer auf die Insel - der definite description entsprechend, die sie dem Namen zuordneten. Der von innen benutzte Name referierte nicht auf den Kontinent, obwohl sie die Referenz in einer kommunikativen Kette von Namenbenutzern übernommen hatten, die auf den Kontinent referierten. In diesem Fall hat also eine begleitende Kennzeichnung die kommunikative Kette ausgeschaltet; vgl. Evans 1985, S. 321 f. Diese Beispiele zeigen auch, daß die historical chain theories in hohem Grade von den Intentionen des Sprechers ausgehen. Ein Sprecher, der einen Namen ,übernimmt', muß die Intention haben, auf das gleiche Objekt zu referieren wie derjenige, von dem er den Eigennamen hat. Gleichzeitig muß diese Intention ausreichen, um eben auf den Namenträger zu referieren. Zu einer Kritik der Beispiele vgl. Schröder 1994; Soames 2002, S. 71, führt eine Erklärung der direct reference theories für ,Freges puzzles' an; vgl. Soames 2002, S. 63-72, S. 76 f. Martinich 1984, S. 189-191, postuliert zum gleichen Zwecke eine „Olympian Description Theory of Reference“, die von nicht perfekten ,Sterblichen' („mortals“) ausgeht, die als Namenbenutzer zwar von einer vollständigen Deskription des Namenträgers wissen, selbst aber in ihren Beschreibungen des Namenträgers fehlbar sind.

${ }^{80}$ Vgl. Recanati 1997, S. 146-149; vgl. auch Kalverkämper 1978, S. 32; Schwarz 2000, S. 36.

${ }^{81}$ Vgl. Recanati 1997, S. 401. 
(„a dubbing in force“). ${ }^{82}$ Insofern müßten die Sprecher wissen, daß der Eigenname ,N.N.' dazu diene, auf das Objekt zu referieren, das in der kommunikativen Situation als Träger des Namens ,N.N.' gelte. ${ }^{83}$ Innerhalb des Namensystems seien Namen mit unterschiedlich großer Variabilität („synchronic variability“) zu finden. Nach Pelczar und Rainsbury bedarf der verbreitete Rufname „Hubert“ daher eher einer Referenzspezifikation als eine Kombination aus Ruf- und Familienname, etwa ,Hubert Korneliszoon Poot'. ${ }^{84}$

Perry schließlich hebt hervor, daß definite descriptions inr Referenzobjekt durch ihren semantischen Inhalt auch für denjenigen klassifizierten, der das Referenzobjekt selbst nicht kennt. ${ }^{85}$ Bei Eigennamen dagegen werde das Zeichen direkt mit dem Referenzobjekt assoziiert. ${ }^{86} \mathrm{Da}$ die Namengebungskonvention, die diese ,direkte Assoziation' von Name und Namenträger bewirke, ,freizügig’ sei („a permissive convention“) und viele verschiedene Objekte den gleichen Namen tragen könnten, müsse durch Kontextelemente festgelegt werden, welcher Namenträger vom Namenbenutzer gemeint sei - besonders durch gemeinsames Wissen über den gemeinten Namenträger bei Sender und Empfänger der Botschaft. ${ }^{87}$ Allerdings habe der Kontext, der bei indexikalischen Ausdrücken direkt das Referenzobjekt bestimme, bei Eigennamen lediglich die Hilfsaufgabe, die richtige Konvention herauszufinden, durch die der Inhalt der Äußerung festgelegt werde. Dies führe dazu, daß die ,Reflexivität' bei Eigennamen verschwinde, wenn der Name erst einmal mit einer bestimmten Referenz eingeführt worden sei. Bei indexikalischen Zeichen bleibe sie dagegen bestehen. ,Ich' bedeute inhaltlich ,der Sprecher dieser Äußerung', während ein Name inhaltlich die definite description des Namenträgers bedeute, nachdem den situationsabhängigen Wahrheitsbedingungen gemäß eindeutig sei, von welchem Namenträger die Rede ist. ${ }^{88}$

,From a semantical point of view' bieten alle diese Theorien unterschiedliche Modelle dafür, daß der individuelle Namengebrauch von einer Sprechergemeinschaft abhängt. Klärungsbedürftig ist darüber hinaus die umgekehrte Frage, wie in der Sprechergemeinschaft die Eigennamenreferenz aufrechterhalten wird. ${ }^{89}$ Eine Erklärung dieser

\footnotetext{
${ }^{82}$ Pelczar/Rainsbury 1998, S. 294, S. 298.

83 Pelczar/Rainsbury 1998, S. 297; vgl. auch Aschenberg 2002, S. 108.

${ }^{84}$ Pelczar/Rainsbury konstruieren eine Skala von ,high frequency indexicals', die ihren Inhalt in jeder Äußerung relativ zum Kontext bestimmen, hin zu ,low frequency indexicals', die sich auf einen größeren Kommunikationszusammenhang stützen; vgl. Pelczar/Rainsbury 1998, S. 296.

85 „A certain specific contextual relationship“; Perry 1997, S. 10.

86 "Direct association“; Perry 1997, S. 9 f.

87 "Perry 1997, S. 10.

${ }^{88}$ Perry nennt diese Wahrheitsbedingungen die „relative truth conditions“; vgl. Perry 1997, S. 14-18.

${ }^{89}$ Vgl. Recanati 1997, S. 160.
} 
,zweiten Stufe' der Eigennamenbedeutung bietet die Theorie Gareth Evans'. ${ }^{90}$ Evans macht einen weiteren Schritt hin zu einer kommunikativen Theorie der Eigennamenbedeutung. ${ }^{91}$ Er geht davon aus, daß eine kausale Verbindung zwischen den Eigenschaften (Verhaltensweisen etc.) des Referenzobjekts und dem semantischen Inhalt des Eigennamens besteht. ${ }^{92}$ Der Name wird nach Evans in einem „umgebenden Kontext“ verwendet. In diesem Kontext soll der Namenträger mit seinen Eigenschaften der Ursprung der Kennzeichnungen sein, die mit seinem Namen verbunden werden. ${ }^{93}$ Ein Eigenname ist nach Evans erst dann der Name, den ein Objekt ,trägt', wenn er als Bezeichnung für dieses Objekt eine gewisse Verbreitung hat. ${ }^{94}$ Doch kann ein Eigenname für ein Objekt (etwa als Spitzname) auch beliebig kurzzeitig und kleinräumig eingeführt werden. In Evans Modell existiert eine Gruppe von Produzenten (,producers“) des semantischen Hintergrunds eines Eigennamens - bestehend aus Sprechern, die mit dem Referenzobjekt selbst in Kontakt stehen. Diese Gruppe besitzt die Kompetenz, einem Eigennamen einen semantischen Inhalt zu geben und die Referenz festzustellen bzw. festzulegen. ,Produzenten' können ständig neue Eigenschaften des Referenzobjektes angeben („co-notions“95) und die sich bereits im Umlauf befindende definite description stützen, indem sie sich auf ihre knowledge by acquaintance des Namenträgers berufen. ${ }^{96}$

Dagegen sind Konsumenten („consumers“) nach Evans’ Modell Sprecher, die den Eigennamen über Dritte erfahren haben und auf diese verweisen müssen, wenn sie die Benutzung rechtfertigen wollen. Sie kennen lediglich jene Charakteristika genau, die ihnen zusammen mit dem Eigennamen mitgeteilt wurden. ${ }^{97}$ Eigennamen haben bei E-

${ }^{90}$ Eine ähnliche Theorie vertritt Loar 1975 und besonders 1980 . Wir beziehen uns hier hauptsächlich auf die weiter ausgeführte Theorie Evans'.

${ }^{91}$ Vgl. seine ,Absichtserklärung' in Evans 1985, S. 335; Loar 1980, S. 85 f. beschreibt seine Theorie als "(metalinguistic) descriptivism“ und betont, daß der deskriptive Inhalt des Namens „is called N“ ist. Nach Loar berücksichtigt eine solche Theorie, daß die Referenz des aktuellen Namenbenutzers auf der Referenz vorheriger Namenbenutzer bzw, Namenbenutzungen beruht. Insofern sei sein descriptivism „the causal theory made self-conscious“.

${ }^{92}$ Vgl. Evans 1985, S. 323.

${ }^{93}$ Vgl. Evans 1985, S. 317, S. 326 f.

94 Der Name muß „a certain currency“ haben; Evans 1982, S. 376; vgl. Loar 1976, S. 368, S. 371 f.; Taylor 2000, S. $25 \mathrm{f}$.

${ }^{95} \mathrm{Vgl}$. Everett 2000, S. $46 \mathrm{f}$.

96 Vgl. Evans 1982, 376 f.; Loar 1980, S. 87 beschreibt diese Gruppe etwas erweiternd und ohne Bezug zum knowledge by acquaintance folgendermaßen: „there is a class of potential users of that name whose use sustains the general use and whose reference determines the general reference [...the sources...]."

97 Vgl. Evans 1982, S. 377; dabei unterscheidet Evans zwischen attributiv verwendeten (,Jeder $\Phi$ ist N.N.') und ,normalen', referentiell gebrauchten Eigennamen (,N.N. ist $\Phi^{\prime}$ ); Evans 1982, S. 378; vgl. auch die „competence conditions“ für den Namengebrauch, wie sie Soames 2002, S. 65, anführt: „In order to be a competent user of a name $n$ of an object $o$, two things are required. i) One must have acquired a referential intention that determines $o$ as the referent of $n$. Two ways in which this may be done are by picking up $\mathrm{n}$ from others who used it as a name of $\mathrm{o}$, and intending use $\mathrm{n}$ to refer to the same thing they did, or by being independently acquainted with o and introducing $n$ as a name for 0 . ii) One must realize that to assertively utter $\mathrm{n}$ is $\mathrm{F}$ is to say of the referent, o, of $\mathrm{n}$ that it ,is $\mathrm{F}$."' 
vans eine Verbreitungsgeschichte relativ zu diesen beiden Gruppen. Zunächst gibt es eine Zeit, in der die Namenträger ,zuhanden' sind und Produzenten des Namens existieren, zu denen auch der Namenträger selbst gehört (wenn es sich um eine Person handelt). Bei Namen zeitlich (und räumlich) weit entfernter Referenzobjekte sind alle Namenbenutzer nur noch ,Konsumenten'. Doch gehen auch sie davon aus, daß es Produzenten gegeben hat, die den deskriptiven Hintergrund des Namens durch persönliche Bekanntschaft mit dem Namenträger gelernt haben. ${ }^{98}$

Sprecher intendieren nach Evans, mit einem Eigennamen auf jenes Objekt zu referieren, auf das in einer Sprechergemeinschaft mit diesem Namen üblicherweise referiert wird. Der Namenbenutzer beziehe sich auf eine bestimmte Praxis der Namenbenutzung („a name-using practice“) und gehe davon aus, daß es ein von der Sprechergemeinschaft geteiltes Wissen über das Referenzobjekt gibt. ${ }^{99}$ So könne der Eigenname auch dann weiter verwendet werden, wenn dem Namenträger kontrafaktisch Eigenschaften zugeschrieben würden. ${ }^{100}$ Das geteilte Wissen bilde eine mit dem Namen verbundene definite description - „the standard story“. 101 Je dichter das kommunikative Netzwerk sei, um so fester seien bestimmte Eigenschaftszuschreibungen an den Eigennamen gebunden. ${ }^{102}$

Der Hörer einer Äußerung mit einem Eigennamen müsse es zunächst anerkennen, wenn der Sprecher mittels einer Formel, bestimmter Kontextfaktoren oder durch den entsprechenden Gebrauch des Namens „wie selbstverständlich“ eine bestimmte Referenz des Namens postuliere. Gehöre er allerdings selbst zu den Produzenten des bereits etablierten Eigennamens, so könne er den Sprecher auch korrigieren. Denn um einen verwendeten Eigennamen zu verstehen, muß der Hörer einer Äußerung Evans zufolge über die Tatsache hinausgehen, daß der Name referiert. Sei der Hörer mit dem Referenzobjekt bekannt, so könne er alle ihm über dieses Objekt bekannten Tatsachen in seine Vorstellung einbeziehen: „[...] the single main requirement for a use of a proper name is that one think of the referent". ${ }^{103}$

Der Name ,Poot' erhält seinen Inhalt dieser Theorie zufolge daher, daß er in einer Sprechergemeinschaft für eine bestimmte Person verwendet wird. Der Leser geht davon aus, daß der Autor des Epitaphs als Produzent oder Konsument zu dieser Sprechergemeinschaft gehört. Er bezieht sich durch sein Epitaph auf den Namengebrauch dieser

\footnotetext{
${ }^{98}$ Vgl. Evans 1982, S. 391-398; zu einer von Husserl ausgehenden ähnlichen Idee vgl. Welton 1983 , S. 74.

${ }^{99}$ Vgl. Evans 1985, S. 329; Evans 1982, S. 384.

100 Vgl. Evans 1982, S. 377, S. 384.

${ }^{101}$ Vgl. Evans 1982, S. 401.

102 Vgl. Evans 1982, S. 379, S. 383, S. 385.

${ }^{103}$ Evans 1982, S. 400 und S. 403.
} 
Gemeinschaft. Das ist im Falle unseres Epitaphs besonders aufschlußreich, denn der Name ,Poot' hatte - wie anfangs erwähnt - vor allem eine literarische Verbreitung als idealer ,Epitaphreim'. Daher ist zu vermuten, daß Gerrit van de Linde ljzn in seinem in dieser Tradition späten Epitaph vor allem die durch zahlreiche andere Epitaphe entstandene ,halbreale’ Figur ,Poot' gemeint hat. Er benutzt den Namen für: ,jene Person, auf deren Namen so viele Epitaphe gemacht wurden, weil dieser sich so gut auf ,dood' reimt.' Sein Epitaph kann demnach als ,metapoetisches' Gedicht gelesen werden: Nachdem so viele Epitaphe auf Poot gemacht wurden, kann jetzt nur noch die lapidare Mitteilung seines Todes in ein neues Epitaph geformt werden. Alle weitergehenden Äußerungen wurden schon gemacht.

Eigennamen haben nach allen vorgestellten semantischen Modellen einen unsicheren semantischen Inhalt. Die Bedeutungsstruktur des Eigennamens besteht in der Verbindung zwischen der definite description des Namenträgers, dem Namenzeichen und dem Namenträger selbst. Da die Referenz eines Namens durch die Namengebung unabhängig von einer Beschreibung des Namenträgers (,direkt') hergestellt wird, sind die Verbindungen zwischen Namenzeichen und definite description sowie zwischen Zeicheneigenschaften des Namens sekundär. Die Verbindung einer definite description des Namenträgers mit dem Namenzeichen in einer Äußerung ist daher vom Wissen und den Intentionen des Namenbenutzers abhängig. ${ }^{104} \mathrm{Ob}$ der Horizont des Sprechers mit dem des Hörers übereinstimmt, hängt zunächst vom allgemeinen Wissen, das in einer Sprechergemeinschaft über den Namenträger vorhanden ist, zusammen. ${ }^{105}$ Verfügen Gesprächsteilnehmer in einer konkreten Gesprächssituation nicht sicher über einen gemeinsamen Kenntnisstand, so ist eine kommunikative Spezifikation des semantischen Hintergrunds nötig. Gesprächsteilnehmer müssen sich der „relevant presuppositions“ des jeweiligen Namengebrauchs versichern. ${ }^{106}$ Tritt der Eigenname dagegen ohne einen spezifizierenden Kontext auf, geht der Sprecher entweder von einer in der kommunikativen Gemeinschaft verbreiteten Bedeutung aus oder meint das Referenzobjekt ohne nähere Qualifizierung in seiner Gesamtheit. Dies heißt auch, daß Eigennamen eine Tendenz zur Privatheit aufweisen. Während die Bedeutung von anderen Sprachzeichen an ein mit anderen Sprachteilhabern geteiltes Sprachsystem gebun-

\footnotetext{
${ }^{104}$ Diese Einschätzung geht über die populäre Position hinaus, Eigennamen hätten bei minimaler Extension eine maximale Intension; vgl. Kalverkämper 1978, S. 63 f.; Schwarz 2000, S. 37.

${ }^{105}$ Vgl. Blanár 2001, S. 14.

${ }^{106}$ García-Carpintero 2000, S. 138. In diesen Bereich gehören auch die in der analytischen Philosophie der Sprache beliebten Diskussionen um die Bedeutungsunterschiede mehrerer referenzgleicher Namen; vgl. jüngst dazu Pierce 2003.
} 
den ist, kann der einzelne Sprecher einen Eigennamen im Extremfall nur für einzelne Fälle und nur für sich selbst verwenden.

\subsubsection{Die dritte Unsicherheit des Namens: das Eigennamenzeichen}

Auch wenn Eigennamen eigentlich ,semantisch leer' sind, gibt es Mechanismen, die es dem Teilnehmer einer Kommunikationsgemeinschaft erleichtern, vom Namenszeichen auf den Namenträger zu schließen. Die Namenreferenz wird im Namengebungsakt konstituiert, indem durch sprachliche und nichtsprachliche Konventionen ein Namenzeichen mit einem Namenträger verbunden wird. Ein als Name verwendetes Appellativ (z.B. ,Cielo') wird daher zwar durch den Namengebungsakt von Intensionen (,Himmel') entleert, es erhält aber durch die Regeln der Namengebung Bedeutung (z.B. ,Kind italienbegeisterter Eltern'). ${ }^{107}$ Ein Eigennamenzeichen kann daher Zeicheneigenschaften haben, die es für eine bestimmte Namengebung prädestinieren - seine SORTALEN PRÄDIKATE. ${ }^{108}$ Sortale Prädikate sind dem kompetenten Sprecher als gewöhnlich mit dem Eigennamen verbunden bekannt, wenn sie auch nicht notwendig auf den Namenträger zutreffen. Durch die einer Sprechergemeinschaft bekannten sortalen Prädikate können aus dem Eigennamenzeichen Vermutungen über den Namenträger, vor allem aber über die Einstellungen des Namengebers zum Namenträger abgeleitet werden. Namen können also als abstrakte Zeichen komplexe Bedeutungskomponenten haben: ,Kerstin' z.B. als \{typisch weiblicher Name\} oder ,Hektor' als \{heutzutage in Deutschland eher für Hunde gebräuchlich\} oder ,Hedwig' als \{etwas altertümlich\}. ${ }^{109}$ Sortale Prädikate sind für den Namenkonsumenten auch dadurch bedeutungstragend, daß ein bestimmter Eigenname jeweils vergleichsweise aktuell vergeben wird und deswegen im Gegensatz zu Appellativen keine langfristige Wandlung der Zeichengestalt die Motivation der Zeichenvergabe verwischt. ${ }^{110}$ Der enzyklopädisch wie sprachlich kompetente Sprecher kann also aus der Namengestalt auf Motivationen beim Namengebungsakt und von diesen wiederum auf den Zeichenträger schließen.

Sortale Prädikate können auf der PHONETISCHEN STRUKTUR der Sprache basieren: wodurch etwa ,Dreda' als potentieller Frauenname gelten kann. Sie können weiter durch den aktualisierten semantischen Gehalt einzelner Wortbestandteile - im Folgenden: die

\footnotetext{
107 Vgl. Birus 1978, S. 28 f.; Austin 1972, S. 37; Debus 1985, S. 306, S. 309, S. 315; Debus 2002, S. 21, S. 24; Blanár 2001, S. 22-28.

${ }^{108}$ Vgl. Wolf 1985, S. 32 f. Sortale Prädikate eines Namens werden im Folgenden durch geschweifte Klammern gekennzeichnet: \{sortales Prädikat\}; vgl. zu ,Sortalen' auch Recanati 1997, S. 169-172; die Termini ,Markierung' und ,Konnotation' (Sandig 1995, S. 544) sollten wegen ihrer anderweitigen Verwendung hier nicht benutzt werden. ,Verwendungsrestriktion' (Sandig 1995, S. 544) wiederum benennt den Grund der Ausbildung sortaler Prädikate.

${ }^{109}$ Vgl. dazu von sprachphilosophischer Seite Strawson 1968, S. 79 f.

110 Vgl. Šrámek 1995, S. 381; Bertills 2002, S. 74.
} 
URSPRUNGSSEMANTIK - entstehen: z.B. ,Gottlob' für ein Kind aus frommer Familie. Ebenso kann die Sprachgeographie sich auswirken: bei ,Jan' die Herkunft aus Norddeutschland oder bei den Namen der verschiedenen natürlichen Sprachen die Herkunft aus dem jeweiligen Sprachraum. Eine etablierte Praxis - „dynastische Vornamen“111 —, bestimmte gesellschaftliche Strukturen (Familiennamen) oder Rechtsgewohnheiten (in Deutschland z.B. das Verbot beliebiger Eigennamenbildung für Personen) bewirken ebenfalls bestimmte sortale Prädikate. ${ }^{112}$ Insgesamt lassen sich nur schwer Eigennamen ganz ohne sortale Prädikate denken.

Der Namengeber kann durch die Namengebung Verschiedenes ausdrücken wollen: sein Verhältnis zum getauften Objekt (z.B. freudige Annahme durch ,Felicitas' oder den enttäuschten Wunsch eines Sohnes durch ,Wilhelmine') oder Wünsche, Erwartungen und Hoffnungen an den Getauften (z.B. durch pietistische Eigennamen wie ,Leberecht'). Der Taufende kann das getaufte Objekt weihen: einem Heiligen, einer Gottheit oder im Falle der Patennamen einer Person. Er stellt so über die Äquivozität des Namens eine Verbindung zu einer anderen Person her. Er kann aber auch - im Rahmen des gesetzlich Erlaubten - sich selbst im semantischen Potential des Namens ausdrücken, indem er eigene Vorlieben oder Idole einfließen läßt ${ }^{113}$, bestimmte Lautkombinationen bevorzugt oder eine fremde Herkunftssprache wählt. ${ }^{114}$ Da der Namengeber wortschöpfend tätig sein kann, drücken sich im Eigennamen semantische und pragmatische Regeln z.B. juristischer Provenienz, Regeln wie die Lautsemantik einer Sprache und womöglich sogar Sprachuniversalien aus, die den Namengeber beeinflussen. Aber auch private Dispositionen des Namengebers spielen eine Rolle, die auf intersubjektiv nur unvollkommen zugänglichen Mechanismen ,in den Köpfen' der Namengeber beruhen. ${ }^{115}$

Die durch sortale Prädikate erlangten Erkenntnisse eines Namenrezipienten sind äußerst vage. Die Regeln der Namenvergabe sind einem Wandel ausgesetzt. Sie sind weder immer Teil der allgemeinen Sprachkompetenz, noch so fest an die Eigennamen gebunden wie definitorische Eigenschaften an ein Appellativ. ${ }^{116}$ Zweitens sind sie als ,geregelte Assoziationen' zwar durch eine Regel bestimmt, die eine bestimmte Assoziation bewirkt. Die Wahrscheinlichkeit, daß die Assoziation durch das benannte Objekt bestätigt wird, hängt aber von der Etabliertheit und Eindeutigkeit der Konvention oder

\footnotetext{
${ }^{111}$ Vgl. Bach 1953, S. 209.

112 Vgl. Seibicke 1982, S. 25-28; Debus 1985, S. 316.

113 In diesem Fall ist der Eigenname präfiguriert; vgl. Lamping 1983, S. 46-48.

${ }^{114}$ Vgl. Debus 1985, S. 319 f.

115 Die sortalen Prädikate eines Namenszeichens können bei starker Normierung zu den „Glückensbedingungen“ der Namenvergabe gehören. Ein unpassender Name wird dann nicht zum Eigennamen der Person; vgl. Seibicke 1982, S. 25-27. Meist aber beeinträchtigt ein unpassender oder ungehöriger Name zwar die Psyche des Namenträgers, nicht aber die Gültigkeit des Taufaktes; vgl. Debus 1985, S. 316.

${ }^{116}$ Vgl. Debus 1985, S. 315, S. 325.
} 
Regel ab. ${ }^{117}$ Schließlich drücken sich im Eigennamen die Intentionen und Erwartungen des Namengebers aus. Aus diesen kann indirekt auf den Namenträger geschlossen werden. Zuerst aber muß auf den Namengeber geschlossen werden. Allgemein spricht der Name um so eindeutiger, je stärker die Konvention ist, die die Namengebung bestimmt. ${ }^{118}$ Besonders intensiv ist der Bezug des Eigennamenzeichens zum Namenträger bei den spontan und informell vergebenen und auf bestimmte Eigenschaften oder Situationen bezogenen Spitz- und Kosenamen (Übernamen). Der Namengeber kann sich nach den hier geltenden Konventionen mit dem gesamten semantischen Potential des Eigennamens auf das ganze Objekt beziehen.

Für die isolierte Instanz des Namens ,Poot' heißt das: über die Unsicherheit der sortalen Prädikate hinaus ist der Status des Namens oft aus dem Namenszeichen nicht zu ersehen. Handelt es sich z.B. um einen Rufnamen, einen Familiennamen oder einen Übernamen? Welche Konventionen der Namengebung regulierten die Vergabe dieses $\mathrm{Na}-$ mens? Welche Intentionen der Namengeber spielten eine Rolle?

Der Name ,Poot' ist für den Leser des Epitaphs auch in dieser Hinsicht ein äußerst unsicheres Zeichen.

Alle semantischen Verbindungen zwischen Eigennamen und Namenträger - die definite description des Namenträgers, die Referenz des Namens und die sortalen Prädikate sind für den Rezipienten einer Äußerung mit Eigennamen instabil. Unsicherheit des Namenrezipienten kann in bezug auf die gültige Namengebung bestehen, in bezug auf die Korrektheit der mit dem Namen verbundenen Kennzeichnung oder auf die Angemessenheit der sortalen Prädikate. ${ }^{119}$ Man kann schon an dieser Stelle annehmen, daß in der Kommunikationssituation eines Gedichts, in dem Eigennamen in sehr schmalen Kontexten auftreten, sich diese Unsicherheiten stark bemerkbar machen. Das Verstehen eines Gedichts und seiner kommunikativen Strategien verlangt eine Auseinandersetzung mit diesen Unsicherheiten.

\subsubsection{Die vierte Unsicherheit des Namens: der Kommunikationswert}

Wie unsere sprachphilosophischen Betrachtungen gezeigt haben, ist die Semantik eines Namens äußerst unsicher. Eigennamen sind zudem überaus wichtig für das Funktionieren vieler komplexer kommunikativer Handlungen. ${ }^{120}$ Sie haben neben dem „Intentionswert", der die Namengebung bei einem bestimmten Namen motiviert, und neben

\footnotetext{
${ }^{117}$ Vgl. Debus 1985, S. 316.

${ }^{118}$ Vgl. Debus 1985, S. 316; Strawson 1968, S. 78 f.

${ }^{119}$ Vgl. zur Unsicherheit sortaler Prädikate auch Gutschmidt 1984, S. 141.

${ }^{120}$ Vgl. Schwitalla 1995, S. 498.
} 
ihrem semantischen Inhalt, den sie von ihrem Referenzobjekt erhalten, einen „Kommunikationswert“. Das ist eine mit dem Namen verbundene Einschätzung und Bewertung des Namenträgers, die durch die Verwendung des Namens im kommunikativen Netz bestimmt wird. ${ }^{121}$

T.S. Eliots berühmte Gedichtsammlung Old Possum's Book of Practical Cats beginnt mit einem Einleitungsgedicht über The Naming of Cats. Eliot behauptet humoristisch, jede Katze hätte drei Namen: einen für den alltäglichen Gebrauch, etwa „Peter“ oder auch „Electra“, einen besonderen, aus dem sie ihr Selbstbewußtsein zögen, wie etwa „Munkustrap“ oder „Quaxo“ und einen geheimnisvollen, den die Katze nie preisgäbe:
But above and beyond there's still one name left over,
And that is the name that you never will guess;
The name that no human research can discover-
But THE CAT HIMSELF KNOWS, and will never confess.
When you notice a cat in profound meditation,
The reason, I tell you, is always the same:
His mind is engaged in a rapt contemplation
Of the thought, of the thought, of the thought of his name:
His ineffable effable
Effanineffable
Deep and inscrutable singular name. ${ }^{122}$

Dies ist zunächst nur eine humoristische lyrische Darstellung der von Katzennarren behaupteten geheimnisvollen Aura der Katze. Daß die Katzen Eliots in den nachfolgenden Gedichten und Balladen alle Namen des Typs zwei tragen, überrascht nicht weiter. ${ }^{123}$ Für die Frage nach dem Verhältnis von Eigennamen und Identität versteckt sich dagegen wesentlich mehr hinter Eliots Dreiteilung der Katzennamen. Die Namenkategorien, die Eliot konstruiert, zeigen die unterschiedlichen Verbindungen des Namens mit der personalen Identität. „Everyday names“ haben einen rein pragmatischen Charakter. Sie sind leicht zu merken, möglichst kurz und inhaltlich völlig bedeutungslos für den Namenträger. Diese Namen charakterisieren den Namenträger nicht, allenfalls die Vorlieben des Namengebers: „There are fancier names if you think they sound sweeter, [...].“124 Die ,besonderen Namen' dagegen geben durch ihre Zeichenstruktur dunkle Hinweise auf Assoziationen zum Namenträger. Sie enthalten bedeutsame Bestandteile wie „trap“ oder „pat“ und scheinen einer gewissen Lautsymbolik zu gehorchen. ${ }^{125}$ Diese Namen wirken nicht nur auf den Namenbenutzer, sondern auch auf den Namenträger selbst: „[...] / Else how can he keep up his tail perpendicular, / Or spread out his

\footnotetext{
${ }^{121}$ Seibicke 1982, S. 22 f.; Debus 2002, S. 33, beziehen den Begriff „Kommunikationswert“ auf sekundäre Motivationen bei der Namengebung. Wir verwenden diesen Begriff weitergehend im Sinne einer Geltung, die der Name in einer Sprechergemeinschaft hat.

122 Eliot 1982, S. 1.

${ }^{123}$ Vgl. zu dieser Erkenntnis Lambert 1990, S. 39.

124 Eliot 1982, S. 1 [Hervorhebung: JG].

${ }^{125}$ Vgl. dazu Lambert 1990.
} 
whisker, or cherish his pride?“"126 Dieser Name ist ein ,Aushängeschild’ des Namenträgers, das dieser sich auch selbst anschaut. Dennoch erfaßt auch dieser Name nicht die Essenz der Person. Der dritte und ewig geheime Name zeigt, daß es stets noch etwas gibt, das durch keines der Sprachzeichen, die inn im universe of discourse identifizieren, erfaßt wird. Die Essenz der Person bleibt für den Eigennamen unerreichbar. Der geheime Name tritt nicht als Sprachzeichen in den Diskurs ein. ${ }^{127}$

Eliot gestaltet in seinem Einleitungsgedicht die Problematik des Namens: Der Name ist für die Persönlichkeitsentwicklung auf pragmatischer und psychologischer Ebene äußerst wichtig, hat aber - nach modernem Verständnis - mit dem inneren Wesen des Menschen nichts zu tun. Dabei gibt es zwei kommunikative Wirkungsbereiche des Eigennamens, die zumeist mit einer modernen oder archaischen Form der Namenmagie in Verbindung gebracht werden können - die Identität und Integrität des Namenträgers, wenn es sich um eine Person handelt, sowie die Memorialfunktion des Namens. ${ }^{128}$

\subsubsection{Eigennamen und die personale Identität}

Es steht außer Zweifel, daß die Persönlichkeit eines Namenträgers nicht auf eine physiologische Beschreibung reduziert werden kann. ${ }^{129} \mathrm{D}$. Dennett gibt als entscheidendes Kriterium für „personhood“ eines Individuums vielmehr eine „besondere Art des Bewußtseins“ an: „sometimes this is identified as self-consciousness of one sort or another." 130 Dieses Selbstbewußtsein bewirkt, daß eine Person in der Lage ist, auf Metaebenen gegenüber den intentionalen Einstellungen anderer und seiner selbst Stellung zu beziehen. ${ }^{131}$ Diese Möglichkeit - zu der nach Dennett der Sprachbesitz eine notwendige Bedingung ist ${ }^{132}$ - konstituiert das (moralische) Handeln einer Person, die Zuschreibung dieser Eigenschaft die Anerkennung der Person als Person. ${ }^{133}$ Da der epistemische Zugriff auf die Personenhaftigkeit sowohl für die Person selbst, vor allen Dingen aber für den Außenstehenden sich äußerst schwierig gestaltet, ist entsprechend auch die Frage nach der Identität von Personen nicht leicht zu beantworten. Mit dem Selbstbewußtsein tritt ein zeitgebundenes Element in den Identitätsbegriff ein, da sowohl Verhalten als auch Gedanken nur in einem Zeitraum stattfinden können und Bewußtsein sich zudem vorwiegend in Gedanken und sprachlichem Verhalten ausdrückt.

\footnotetext{
${ }^{126}$ Eliot 1982, S. 1.

127 Vgl. zur jüdischen Tradition des speziellen religiös-geheimen Namens z.B. Frank 1987, S. 38; zum magischen Namenverständnis Hutter 2003, Sp. 33.

${ }_{128}$ Vgl. zur Magie der Eigennamen auch Debus 2002, S. 13-20.

${ }^{129}$ Vgl. Williams 1978, S. $37 \mathrm{ff}$.

${ }^{130}$ Vgl. Dennett 1976, S. 178.

${ }^{131}$ Vgl. Dennett 1976, S. 193.

132 Vgl. Dennett 1976, S. 178 f.

${ }^{133}$ Vgl. Dennett 1976, S. 175.
} 
Die Anerkennung durch andere, denen der privilegierte Zugang zum Bewußtsein einer Person fehlt, spielt bei der Identifizierung der Identität eine große Rolle.

Im Anschluß an Mead entwirft Habermas dazu drei Identitätsstufen: „numerische Identität" (Gegenstandsidentität), „generische Identität" (der Personenbegriff wie bei Dennett) und "qualitative Identität“. ${ }^{134}$ Auf der Stufe der ,qualitativen Identität' verbindet Habermas eine ethische Komponente mit dem Identitätsbegriff, in den er Verantwortlichkeit für die eigene „Biographie“ einschließt. ${ }^{135}$ Identität muß in diesem Fall kognitiv erworben werden und kann auch wieder verloren gehen. ${ }^{136}$ Durch den ,Erwerb einer Identität' wird die Person zu jener ,moralischen Person', die autonom handeln kann und sich selbst auf ein Ziel hin oder nach eigenen Vorstellungen entwirft. Diese Person muß sich nach Habermas zu ihrer ,Biographie' und damit zur Kontinuität der eigenen Person in Zeit und Raum bekennen. Das Bekenntnis zu ihrer Lebensgeschichte - die „historische Rekonstruktion“ - soll Habermas zufolge ein öffentliches Bekenntnis sein, also eines, über das man seiner Gesellschaft Rechenschaft ablegen kann. ${ }^{137}$

Eigennamen spielen bei dieser öffentlichen Konstituierung einer personalen Identität eine wichtige Rolle. Der mentale Teil der komplexen, weil aus Leib und Seele bestehenden Person braucht den Namen als Zeichen der Kontinuität und damit der Identität, weil der Bezug mit dem situationsabhängigen und instabilen indexikalischen Zeichen ,ich' nicht ausreicht. ${ }^{138}$ Personennamen sind daher eng an den Namenträger gebunden, weil sie den Namenträger identifizieren, weil sie durch die institutionelle Namengebung als eine Eigenschaft mit dem Namenträger assoziiert werden und weil der Eigennamenträger selbst ex post den semantischen Hintergrund eines Namens bildet, also für diesen verantwortlich ist. ${ }^{139}$ Zudem ist das Wissen um den eigenen Eigennamen eine der nicht ohne weite Konsequenzen für die personale Identität anzuzweifelnden Gewißheiten der sich ihrer selbst bewußten Person. ${ }^{140}$

Die Identifikation der Sprechenden und anderer im Gespräch, die Anrede und Veränderungen am Namen wie Koseformen oder Verunstaltungen des Namens als Indikatoren sozialer Relationen, Namenverweigerung oder die interne Namengebung zur sozialen Gruppenbildung geben zusammen mit der hohen Informationsdichte bei gleichzeitiger Kürze dem Namen zusätzlich eine hohe kommunikative Wichtigkeit. ${ }^{141}$

\footnotetext{
${ }^{134}$ Vgl. Habermas 1988, S. 155 und S.162.

${ }^{135}$ Vgl. Habermas 1988, S. 151.

${ }^{136}$ Vgl. Habermas 1988, S. 154.

137 Vgl. Habermas 1988, S. $162 \mathrm{f}$.

${ }^{138}$ Vgl. Strawson 1993, S. 87-117; dagegen: Ryle 1990, S. 13-25.

${ }^{139}$ Vgl. Debus 2002, S. 18; vgl. auch Schwarz 2000, S. 37, zu Firmen- und Produktnamen.

${ }^{140}$ Vgl. Wittgenstein 1992, § 470.

${ }^{141}$ Vgl. Schwitalla 1995, S. 498-504; Debus 1995, S. 393-397; Thies 1978, S. 42-50.
} 
Eigennamen können daher das Identitätsgefühl und die Identität des Namenträgers stark beeinflussen. So konstatiert z.B. Norbert Elias eine „Wir-Ich-Balance“ des Individuums, die vom Eigennamen garantiert wird. ${ }^{142}$ Der Eigenname in seiner "Doppelform“ als Vor- und Familienname konstituiere sowohl das von allen anderen verschiedene Individuum, als auch seine Zugehörigkeit zu einer Gesellschaft, die den "Mutterboden“ bilde, aus dem die „persönlichen Merkmale herauswachsen“. ${ }^{143}$

Die hohe Bedeutung des Eigennamens für die Ausbildung einer ,öffentlichen' personalen Identität steht im Kontrast zur unsicheren kommunikationsabhängigen Referenz des Namens. Ein Eigenname wird um so sicherer korrekt angewendet, je stärker er ,kommunikativ' aufrechterhalten wird. Z.B. wird bei der kontextarmen Verwendung des Eigennamens ,Angela Merkel' jeder Sprecher des Deutschen schnell an die entsprechende Person des öffentlichen Lebens denken und nicht an meine weithin unbekannte Nachbarin. Personen aus meiner Nachbarschaft werden dagegen in ihrer ,kommunikativen Subassoziation' eher die Nachbarin meinen. Die Struktur der durch den Namen ,veröffentlichten' Identität hängt von der kommunikativen Aktivität ab, die in Bezug auf diesen Namen entfaltet wird.

Wenn die Aufrechterhaltung einer bestimmten Namenbedeutung ständig gestört wird, so kann dies zu Identitätsproblemen führen. Die Kontinuität der Person, wie sie - gerade in einer medienbestimmten Gesellschaft - im Namen intersubjektiv zugänglich ist, wird durch die Dichte und Weite des kommunikativen Netzwerkes, das eine bestimmte Namengebung gültig macht (,a dubbing in force') in ihrer Anfälligkeit bestimmt. Dies kann so weit gehen, daß der deskriptive Hintergrund eines Namens in den Vordergrund treten und zur semantischen Form der Präsentation des Namens werden kann: ,Er ist ein wahrer "Napoleon" ist ein möglicher und nicht ungewöhnlicher Satz, ,Er ist ein wahrer ,Peter" hingegen kann nur sehr begrenzt verwendet werden.

Dem Namenträger selbst sind dabei große Teile der Entwicklung des semantischen Namenhintergrunds entzogen. Dies gilt zum einen für den Intentionswert des Namens, der von dem Namengeber bestimmt wird. Die Probleme von Menschen, denen ihre Eltern Namen von falschen Idolen (,Adolf') oder üblen Vorlieben (,Whiskey') gegeben haben, liegen auf der Hand. Zum anderen kann die Verwendung des eigenen Namens durch andere Sprecher nie vollständig kontrolliert werden. Daher ist auch keine Beherrschung der mit dem Namen verbundenen, oft wertenden Kennzeichnungen möglich. Die öffentliche ,Objektivierung' der Person kann in schweren Konflikt mit dem eigenen

\footnotetext{
${ }^{142}$ Vgl. Elias 1994, S. 246.

143 Elias 1994, S. 244, S. 246.
} 
Selbstbild geraten. Durch die Weigerung, einen Namen zu kommunizieren, kann schließlich eine Identität angezweifelt und auch zerstört werden.

Dabei unterscheiden sich poetische wie alltägliche ,Namenspiele' sprachtheoretisch von anderen Wortspielen. Der Name hängt eng mit der Person zusammen. Dadurch bezieht sich ein Spiel mit dem Namen direkt auf die Persönlichkeit des Namenträgers. Im polemischen wie im verehrenden Umgang mit Namen wird das Namenszeichen so eng mit dem Namenträger verbunden, daß die Behandlung des Namens als Behandlung des Namenträgers gelten kann. ${ }^{144}$ Dies liegt zum einen daran, daß der Eigenname als eindeutiges Mittel der individuellen Repräsentation und Identifikation im universe of disourse zu gelten hat. Zum anderen ergibt es sich daraus, daß ein Eigenname dem Namenträger ,gehört'. Er ist ein für ihn individuell gewähltes oder zusammengestelltes Zeichen, für dessen kommunikativen Wert er verantwortlich ist und das durch die Kennzeichnung ,Träger des Namens N.N.' als Zeichen zu seiner definite description gehört. Während z.B. in einer Polemik der Angegriffene mit pejorativen Appellativen verunglimpft werden kann, wobei die Wörter selbst aber lediglich als ,Werkzeuge' dienen, ist der Name ein Teil der Person. Der Name hat in gewissem Sinn den Status einer symbolischen bildlichen Darstellung des Namenträgers:

Auch das Bild stellt die Sache nicht nur für die subjektive Reflexion eines Dritten, eines Zuschauers dar, sondern es ist ein Teil ihrer eigenen Wirklichkeit und Wirksamkeit. Wie der Eigenname eines Menschen, so ist auch sein Bild ein Alter ego: Was inm widerfährt, widerfährt dem Menschen selbst. ${ }^{145}$

\subsubsection{Gedächtnis und Nameninhalt}

Eigennamen haben zumindest für den Namenträger einen hohen Kommunikationswert.

Dieser beruht darauf, daß der Name den Namenträger individuell repräsentiert. Gleichzeitig bedingt gerade diese Individualität, daß Eigennamen kommunikativ nur in gewissen Grenzen Geltung haben können:

If it be looked on as an instance of a prodigious memory, that some generals have been able to call every soldier in their army by his proper name, we may easily find a reason, why men have never attempted to give names to each sheep in their flock [...] much less to call every leaf of plants, or grain of sand that came in their way, by a peculiar name. ${ }^{146}$

Der kommunikative Nutzen von Eigennamen ist nach John Lockes Worten beschränkt, weil sie sich stets auf Einzelnes beziehen. Da Namen zudem eigene, von einer einzelnen ,natürlichen' Sprache losgelöste Systeme bilden, werden sie leicht vergessen.

\footnotetext{
${ }^{144}$ Dies zeigt etwa die immer wieder zitierte Äußerung Goethes zu einem Namenspiel Herders mit seinem Namen: „denn der Eigenname eines Menschen ist nicht etwa wie ein Mantel, der bloß um ihn her hängt und an dem man allenfalls noch zupfen und zerren kann, sondern ein vollkommen passendes Kleid, ja wie die Haut selbst ihm über und über angewachsen, an der man nicht schaben und schinden darf, ohne ihn selbst zu verletzen"; Goethe 1989, S. 407.

${ }_{145}$ Cassirer 2003, Bd. 12, S. 52.

${ }^{146}$ Vgl. Locke 1997, S. 435; vgl. auch und im Anschluß daran Leibniz 1961, S. 36-39.
} 
Freud führt eigens das Erinnern und Vergessen von Namen zusammen mit dem Vergessen fremdsprachiger Wörter als Paradebeispiel für Mechanismen des Vergessens vor:

In einer großen Reihe von Fällen wird ein Name vergessen, nicht weil er selbst solche Motive [psychische Gründe, aus denen man etwas ,gerne' vergißt] wachruft, sondern weil er durch Gleichklang und Lautähnlichkeit an einen anderen streift, gegen den sich diese Motive richten. ${ }^{147}$

Die Schwierigkeit, Eigennamen zu erinnern, hängt mit der schieren Menge an Eigennamen und ihrer Abhängigkeit von der Sprechergemeinschaft zusammen. Während Namen mit hoher Verbreitung - etwa ,Napoleon' - auch fest in das Gedächtnis eingeprägt sind, werden wenig benutzte Eigennamen schnell vergessen. Jede Verwendung eines Eigennamens trägt daher - absichtlich oder unabsichtlich - zur Verbreitung dieses Eigennamens bei.

Wie wir gesehen haben, sind Eigennamen dabei nur sehr lose mit einer Beschreibung des Gegenstandes verbunden. Das Erinnern an den Gegenstand zieht deshalb nicht unbedingt das Erinnern an den Namen nach sich. Die Erinnerung sowie die Störung der Erinnerung scheinen sich vielmehr für Freud über die Zeicheneigenschaften des Namens zu vollziehen.

Der Eigenname ist zusätzlich ein Mittel zur Identifikation des Namenträgers weit über dessen Existenz hinaus. ${ }^{148}$ In der ,späten Namengeschichte' gibt es keine unmittelbaren Produzenten des Namens mehr, die den semantischen Inhalt am benannten Objekt belegen könnten. ${ }^{149}$ Daher entwickelt sich die Bedeutung des Namens ohne eine nichtsprachliche Korrekturinstanz - die knowledge by acquaintance des Namenträgers weiter. Der semantische Inhalt eines Namens kann sich weit von der definite description entfernen, er kann die mit ihm verbundenen Kennzeichnungen auch verlieren, wie es z.B. Percy Bisshe Shelley in seinem berühmten Gedicht auf Ramses II. darstellt:

\footnotetext{
OZYMANDIAS

I met a traveller from an antique land

Who said- "Two vast and trunkless legs of stone

Stand in the desert.... Near them, on the sand,

Half sunk, a shattered visage lies, whose frown,

And wrinkled lip, and sneer of cold command,

Tell that its sculptor well those passions read

Which yet survive, stamped on these lifeless things,

The hand that mocked them, and the heart that fed;

And on the pedestal, these words appear:

My name is Ozymandias, King of Kings,

Look on my works, ye Mighty, and despair!

Nothing beside remains. Round the decay

Of that colossal wreck, boundless and bare
}

\footnotetext{
${ }^{147}$ Freud 2000, S. 95; vgl. auch Napoli 1997, S. 187, zu Sprachkompetenz und Namenkompetenz.

${ }^{148}$ Vgl. Moraru 2000, S. 54.

${ }^{149}$ Vgl. Evans 1982, S. 391.
} 
The lone and level sands stretch far away." ${ }^{150}$

Gleichzeitig werden die Namen berühmter realer und fiktiver Entitäten von vielen Institutionen einer Kultur bewahrt und verwendet. Die sind ein wichtiger Bestandteil nicht nur eines individuellen, sondern auch des kollektiven Gedächtnisses. ${ }^{151}$

Auf diese Weise dienen Eigennamen dazu, eine aus vielen individuellen Elementen bestehende Wirklichkeit zu organisieren. Dabei hebt ein im kollektiven Gedächtnis hochfrequenter Eigenname die Wichtigkeit des benannten Gegenstandes hervor. ${ }^{152}$ Er kann für eine definierte Menge von Informationen stehen und wie ein Apellativ verwendet werden. ${ }^{153}$ Der Name bietet dann die Möglichkeit, viele Informationen zu bündeln und zu materiell zu repräsentieren. Insofern sind Eigennamen besonders wichtig, um Erinnerungen aufrechtzuerhalten. Sie sind ,Knotenpunkte' der Diskurse, die der Sprechergemeinschaft Orientierung bieten. Das shared knowledge über Eigennamen wird daher für eine Kommunikationsgemeinschaft sehr wichtig. Das gemeinsame Wissen bezieht sich nicht nur auf die Auswahl von Eigennamen, deren Kenntnis von einem kulturell kompetenten Sprecher vorausgesetzt wird, sondern auch auf die relevanten Inhalte, die mit den jeweiligen Namen verbunden werden und zu denen auch normative Einschätzungen des Namenträgers gehören.

Da sowohl das Eigennamensystem als auch der Inhalt einzelner Eigennamen unsicher sind (s.o.), muß das geteilte Wissen über und zu Eigennamen ständig kommunikativ aufrechterhalten werden. Dazu tragen auch und vor allem literarische Texte bei, die umgekehrt selbst von dem Funktionieren eines Eigennamensystems abhängig sind.

Wenn die Erinnerung an einen Eigennamen in einer Kommunikationsgemeinschaft intensiv aufrechterhalten wird, wird dieser zu einem in dieser Gemeinschaft berühmten Namen. Goethe inszeniert am Beginn des Buches der Liebe seines West-Östlicher Divan einen Aufbau neuer exemplarischer Namen mit einem Hinweis auf die Funktion der Namen berühmter exempla:

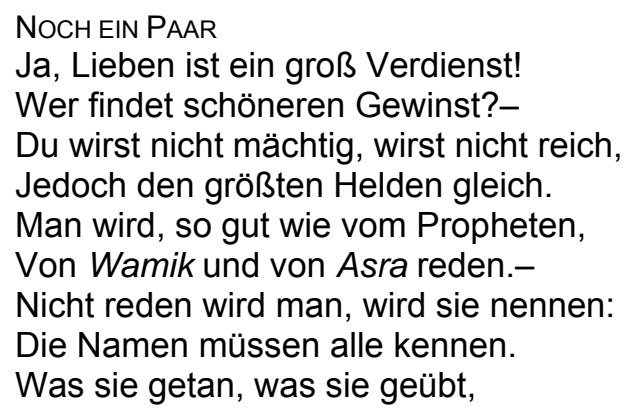

\footnotetext{
${ }^{150}$ Vgl. Shelley 1977, S. 103.

${ }^{151}$ Vgl. die etwas emphatische Darstellung Mainberger 2003, S. 154.

152 Vgl. Blanár 2001, S. 16 f.; vgl. Locke 1997, S. 436; Leibniz 1961, S. 39.

153 Vgl. Wimmer 1995, S. 373; Aschenberg 2002, S. 105.
} 
Berühmte Eigennamen - wie Goethe sie hier einführen möchte - bezeichnen Entitäten, die nicht nur in einem Text oder in der Äußerung einer eng beschränkten Gruppe auftauchen. Diese Namen sind Teil dessen, was von einem kompetenten Sprecher einer Sprache als bekannt vorausgesetzt werden kann. Die mit einem Namen verbundene Bedeutung wird zu diesem Zweck allerdings modifiziert, damit der individuelle Gegenstand wie ein ,Quasi-Appellativum' funktionieren kann. Der Gegenstand wird dazu - wie von Goethe in seinem Gedicht vorgeführt - auf eine begrenzte und homogene kennzeichnende Eigenschaftsmenge reduziert. ${ }^{155}$ Die mitgedachten Kennzeichnungen können so zu einer definitorischen Komponente werden. Dies ermöglicht z.B. die Verwendung des Eigennamens als Antonomasie: ,Er ist ein Napoleon. ${ }^{156}$ Die Erwähnung solcher ,Quasi-Appellative' dient der Verknappung, Bündelung und Lokalisierung von Informationen, sowie zur Verbindung verschiedener Diskurse.

Allerdings sind auch die ,Quasi-Konnotationen' solcher ,Quasi-Appellative' nicht eindeutig und von geringerer kommunikativer Reichweite als die Intensionen richtiger Appellativa. Wenn etwa jemand sagt ,ein echter Itzenplitz', wirkt der Name auf den heutigen Hörer ohne eine Kontextangabe nicht als Appellativ. ,Quasi-Konnotationen' können überdies sehr verschiedener Natur sein. Mit Eigennamen verbinden sich Anekdoten oder Ereignisse, typische Eigenschaften, berühmte Werke, Taten oder Fähigkeiten, berühmte Äußerungen oder Ansichten und verbreitete Wertungen. ${ }^{157}$ Elemente der ursprünglichen definite description werden also stillschweigend vorausgesetzt oder auch eliminiert, ,Leerstellen' teilweise durch dienliche Elemente aufgefüllt. Die Bedeutung des Namens wird auf diese Weise reduziert und entfernt sich oft weit von der definite description des ursprünglich denotierten Objektes. ${ }^{158}$

Der Wissensstand des Sprechers wie der zu erwartende Wissenstand des Empfängers und die Kontextinformationen entscheiden über den mitgeteilten Inhalt des Namenszeichens in einer Äußerung. Bei überschaubaren Wissenskontexten können bekannte Namen als Chiffre fungieren. Je unüberschaubarer dagegen Kontexte werden desto unsicherer und im Zweifelsfalle kleiner ist die Information, die tatsächlich mit den Eigennamen verbunden wird. Dies gilt insbesondere, wenn der Sprecher ausgiebig von der

\footnotetext{
${ }^{154}$ Vgl. Goethe 1994, S. 27 f.

${ }^{155}$ Vgl. Schwarz 2000, S. 39, zu einem ähnlichen Vorgang bei der Imagebildung zu Firmen- und Produktnamen.

${ }^{156}$ Vgl. etwa Thurmair 2002. Diesen Vorgang der ,Appellativierung' und ,Monosemierung' von Eigennamen ignoriert Braun 2002.

${ }_{157}^{15 g l . ~ E v a n s ~ 1982, ~ S . ~} 385$

${ }^{158}$ Vgl. aus dem Blickwinkel der Mythentheorie Wülfing/Bruns/Parr 1991, S. 7 f.
} 
Technik des name-dropping Gebrauch macht: Wie die folgende Definition des Begriffs name dropping zeigt, kann man sich die Unsicherheit des Namenzeichens zunutze machen:

name-dropping: practice of casually mentioning the names of famous people one knows or pretends one knows in order to impress others. ${ }^{159}$

Appellativierte Eigennamen bieten dem Autor die Gelegenheit, einen semantisch offenen Text zu gestalten. Er kann darauf spekulieren, daß der Leser sich mehr bei einem Namen denkt als der Autor weiß. ${ }^{160}$

Bei berühmten Eigennamen kann man davon ausgehen, daß eine allgemein anerkannte und meist weitgehend kohärente ,normale' Beschreibung des Namenträgers in einer Gesellschaft oder einer Gruppe verbreitet ist. Eine Darstellung kann dieser Normalbeschreibung entsprechen oder von ihr abweichen. Die Abweichung hat dann wiederum Signifikanz. Die mit dem Namen verbundene aktuelle definite description motiviert die Verwendung als Chiffre und setzt gleichzeitig Grenzen für die augenblickliche Abweichung. Da sich bei zunehmender räumlicher und örtlicher Distanz vom benannten Objekt die Bedeutung verselbständigen kann, ist bei der unkommentierten Verwendung von Eigennamen ein Verweis auf die jeweilige aktuelle definite description eher zu vermuten als das Aufrufen einer detaillierten und originalgetreuen Beschreibung.

Zusammenfassend können wir feststellen, daß Eigennamen neben einem unsicheren semantischen Inhalt auch einen unsicheren kommunikativen Status haben. Anders als z.B. Appellative wie ,Köter', deren pejorativer Sinn Teil der Intension ist, bedarf die Erklärung des kommunikativen Status von Namen wie ,Adolf' eines ausführlichen Bezugs auf eine Gesellschaft und deren Geschichte. Bei der Namenverwendung in Äußerungen, bzw. Texten, die an eine anonyme und nicht eindeutig vorherzubestimmende Menge von Adressaten gerichtet sind - wie bei veröffentlichten literarischen Texten wird der Namenverwender besonders auf den kommunikativen Wert des jeweiligen Namens achten müssen. Gleichzeitig ist der Name wegen seiner besonderen Anbindung an den Namenträger in zur Veröffentlichung bestimmten Texten äußerst sensibel zu handhaben. Auch hier stellen sich einem Autor oder dessen Sprecher besondere Aufgaben.

\footnotetext{
159 So heißt es im Oxford Advanced Learners Dictionary, Cowie 1989, S. 822 [Unterstreichung: J.G]. Mit dem Vokabular der Rhetorik beschrieben handelt es sich zum großen Teil um Namen, die exempla als ornatus oder argumentum ab auctoritate benennen sowie um die Figur der Personifikation und der ,Vossianischen Antonomasie'; vgl. Lausberg 1963, S. 74 (§ 207).

${ }^{160}$ Vgl. Eco 1995, S. 160-163.
} 


\subsection{Unsichere literarische Eigennamen: Wahrheit und Fiktion}

\subsubsection{Fiktion und Realität - die Rolle wahrer Sätze in fiktionalen Texten}

OP РОOT

Hier ligt Poot, hij is dood. ${ }^{161}$
ELMER KARR

\author{
What but the love of God could have softened \\ And made forgiving the people of Spoon River \\ Toward me who wronged the bed of Thomas Merritt \\ And murdered him beside? \\ Oh, loving hearts that took me in again \\ When I returned from fourteen years in prison! \\ Oh, helping hands that in the church received me, \\ And heard with tears my penitent confession, \\ Who took the sacrament of bread and wine! \\ Repent, ye living ones, and rest with Jesus. ${ }^{162}$
}

Wie aus unseren theoretischen Überlegungen deutlich wurde, ist die Namenbedeutung unsicher. Die Intension eines in einer Äußerung verwendeten Eigennamens hängt zu einem wesentlichen Teil von der Intention des Namenverwenders und der Referenz des Namens ab.

Die Grabschrift des ,Schoolmeesters' Gerrit van de Linde ljzn ${ }^{163}$ wurde dabei stillschweigend als faktuale Äußerung behandelt. Sie steht aber nicht auf dem realen Grab des Dichters Hubert Korneliszoon Poot ${ }^{164}$, wie man erwarten könnte. Zumindest das indexikalische Zeichen ,hier' referiert also nicht korrekt. Beim ebenfalls oben zitierten Gedicht aus Masters' Spoon-River-Anthologie existieren Personen mit den Namen ,Elmer Karr' und ,Thomas Merritt' ebensowenig wie der Ort ,Spoon River'. Auch diese ÄuBerung entspricht also nicht der Wahrheit. Beide Texte werfen für den Leser die Frage auf, ob bzw. in welcher Weise die in ihnen vorkommenden Namen auf die Realität referieren und was für eine Bedeutungsstruktur sie haben.

Setzt man dabei als engste Beschreibung einer geglückten Referenz voraus, daß

"the standard case of reference is that where the full set of intentions characteristic of reference is present, the relevant beliefs of speaker and hearer about each other and about the object, context, and relevant facts of language are true, and the speaker does indeed succeed in identifying the intended object through using an appropriate referring expression", ${ }^{165}$

hängen die Bedeutung eines Satzes und die Referenz der in ihm enthaltenen Eigennamen eng mit den Wahrheitsansprüchen des Sprechers bzw. des Autors zusammen. Die Wahrheitsansprüche des Autors oder die Wahrheit des Textes - mithin die Frage nach

\footnotetext{
161 Gerrit van de Linde ljzn in: Komrij 1979, S. 104.

162 Masters 1992, S. 270.

163 Komrij 1979, S. 104.

164 Vgl. Heesen/Jansen/Schilders 1997, S. 194. Dort wird auch bezweifelt, daß das Epitaph tatsächlich von Gerrit van de Linde ljzn stamme. Der Einfachheit halber gehe ich von dieser Zuschreibung aber auch im Folgenden weiter aus.

${ }^{165}$ Crittenden 1991, S. 54; vgl. auch Martinich 1984, S. 163-167.
} 
der Fiktionalität oder ,Faktualität' des literarischen Textes - bilden daher einen wichtigen Aspekt der Namenbedeutung. ${ }^{166}$

Aus diesem Grund wird im Folgenden geklärt, inwieweit in fiktionalen und literarischen Texten mit wahren Sätzen Wahrheitsansprüche erhoben werden können. Wir gehen zunächst von Gabriels Begriff der Fiktion aus: Demnach ist ein „erfundener (,fingierter') einzelner Sachverhalt oder eine Zusammenfügung solcher Sachverhalte zu einer erfundenen Geschichte“ eine Fiktion. ${ }^{167}$ Dementsprechend definieren wir 'fiktionale Texte' zunächst im Anschluß an Gabriel und Hoops als Äußerungen, die eine Lizenz beanspruchen, erfundene Objekte und/oder Sachverhalte zu gestalten, und die zumindest partiell auch von dieser beanspruchten Lizenz Gebrauch machen. ${ }^{168}$ Diese Definition impliziert, daß fiktionale (literarische) Texte durchaus auch wahre Sätze enthalten können. Das Verhältnis dieser faktualen Sätze zu den fiktionalen Sätzen in einem literarischen Werk soll im Folgenden geklärt werden.

Die mit Bezug auf die Wahrheit fiktionaler Texte eingenommenen Positionen werden von Lamarque/Olsen grob in no truth theories und pro truth theories aufgeteilt. ${ }^{169}$ In der neueren Diskussion dominieren unter den Pro-Truth-Modellen jene Theorien, die man pro general truth theories nennen kann. Ihnen zufolge stellen Autoren in (fiktionalen) literarischen Texten Wahrheitsansprüche höchstens in bezug auf generelle, thematische Wahrheiten, die im Text gestaltet werden. Die in einem (fiktionalen) literarischen Werk verborgen oder offen geäußerten ,Wahrheiten' sind demnach meist moralischer Natur ${ }^{170}$, etwa in der Form generischer Aussagen (,die Revolution frißt ihre Kinder'), typologischer Aussagen (,Menschen mit den Eigenschaften w in der Situation x vollziehen Handlung y mit der Konsequenz z') oder einfacher Allaussagen (,alle Menschen sind gut / schlecht / beides'). Auch die metaphorische Wahrheit eines literarischen Textes das heißt deren Bezug zur Realität als Metapher für die Realität - kann als solche allgemeine Wahrheit gewertet werden. ${ }^{171}$

Unter den no truth theories dominieren seit längerer Zeit Theorien, die man truth is irrelevant theories nennen mag. Sie bestreiten die Relevanz von Wahrheit oder Falschheit

\footnotetext{
${ }^{166}$ Die Diskussion um die Referenz literarischer Texte wird größtenteils außerhalb der Disziplinengrenzen der Literaturwissenschaft als Debatte um die „metaphysics of fictional objects“ (Crittenden 1991) geführt. Ausführlich nimmt allerdings Rühling 1996 darauf Bezug.

167 Gabriel 1997, S. 594.

168 Vgl. Hoops 1979, S. 301.

169 Vgl. Lamarque/Olsen 1994, S. 1-25

170 Vgl. New 1999, S. 120-123.

${ }^{171}$ Vgl. Lamarque/Olsen 1994, S. 339-367; New 1999, S. 118. Zu den Modellen metaphorischer Wahrheit zählen wir auch Paul Ricœurs Entwurf; vgl. Ricœur 1989-1991, bes. Bd. I, S. 122-129, Bd. II, S. 10. Ricœur lehnt einen direkten referierenden Bezug literarischer Rede auf die reale Welt mit Wahrheitsanspruch und in berichtender Funktion ab.
} 
(fiktionaler) literarischer Texte für die Frage nach deren fiktionalem Status. In diesem Fall spielt unabhängig von dem Wahrheitsstatus der Sätze die Wahrheit in (fiktionalen) literarischen Texten keine Rolle, aufgrund des Zusammenspiels der Textelemente ${ }^{172}$ bzw. der poetischen Funktion ${ }^{173}$, aufgrund der Imagination oder Visualisierung eines Inhaltes im game of make-believe ${ }^{174}$ oder aufgrund der Art, in der ein Inhalt entwickelt wird. ${ }^{175}$ Diese Ansätze gehen einher mit dem Übergang von semantischen und pragmatischen Fiktionstheorien, die sich mit der Wahrheit literarischer Rede beschäftigen, zu Theorien der sozialen Praxis oder der ,Institution literarischer Fiktion', die konstatieren, $\mathrm{da}$ in einem game of pretence ${ }^{176}$, einem game of make-believe oder dem vom Leser eingenommenen fictive bzw. aesthetic stance ${ }^{177}$ von Wahrheitsansprüchen und deren Erfüllung abgesehen wird. Fragen nach dem ,Dasein' oder ,Sosein' (fiktiver) Objekte literarischer Rede oder Sachverhalte werden abgelöst von Fragen nach der Präsentation von Objekten in (fiktionaler) literarischer Rede:

„[...]jemand kann so sprechen, als ob er einen Sachverhalt in bestimmter Weise präsentiert

(z.B.: BEHAUPTET), obwohl er dies gar nicht tut“. ${ }^{178}$

Solche Theorien gestehen fiktionalen literarischen Werken durchaus zu, daß sie Wahrheiten enthalten. Sie gehen dennoch davon aus, daß in fiktionaler Literatur diese Äußerungen ohne Wahrheitsanspruch gemacht werden, bzw. daß die faktische Wahrheit einzelner Sätze in literarischen Werken für deren fiktionalen Status keine Rolle spiele.

\footnotetext{
${ }^{172}$ Vgl. z.B. Olsen 1987, S. 171, der für eine ästhetische Intention beim Autor plädiert, die den literarischen Text dominiere. Die Bedeutung (meaning) eines Werkes werde durch die Verbindung (interrelation) der unterschiedlichen Elemente vom Leser konstituiert. Dabei spielten truth und reference keine Rolle.

${ }^{173}$ Vgl. Jakobson 1989.

${ }^{174}$ Vgl. Evans 1982, S. 353-363.Vom Leser eines literarischen Werkes werde die Einstellung verlangt, am make-believe teilzunehmen: „We are intended by the author to make-believe that the story as uttered is true“, Currie 1990, S. 18; vgl. auch Walton 1990, bes. S. 67-69.

${ }_{176}^{175}$ Vgl. Lamarque/Olsen 1994, S. 437.

${ }^{176}$ Mit der Theorie der pretended reference ist die Idee, fiktionale Literatur tue so als ob..., auf die Referenz literarischer Rede angewendet worden. Searle schlägt vor, besondere pragmatische Konventionen (horizontal conventions) anzunehmen. Diese machten fiction zu einem Sprachspiel ohne jene pragmatischen Regeln (vertical rules), die Sprache sonst mit der Wirklichkeit verbänden; vgl. Searle 1975, S. 46; Crittenden 1991, S. 46. Der Autor eines literarischen Werkes vollziehe eine „nondeceptive pseudoperformance."; Searle 1975, S. 65; vgl. Currie 1990, S. 13. Literarische Rede ist gewissermaßen von der Realität losgekoppelt. Auch Evans 1982, S. 353-368, geht davon aus, daß mit fiktionaler Rede nur vorgeblich (pretended) referiert und die Wirklichkeit beschrieben werde. Als Beispiel beschreibt Evans Kinder, die mit Sand spielen und vorgeben (to pretend), Kuchen zu backen. In diesem Fall ist etwas vorhanden (geformter Sand, mud-pies), auf das mit eigentlich unzutreffenden Begriffen (,Kuchen') referiert würde. Im Falle des literarischen Textes würde dagegen auf nichts referiert, da eine Sprachhandlung vorgetäuscht würde, nämlich das Informieren über reale Ereignisse; vgl. Evans 1982, S. 359 Fn. 32. Der Autor gibt nach Evans und Searle nur vor, illokutionäre Akte zu vollziehen; vgl. Searle 1975, S. 66; Evans 1982, S. 359 Fn. 31; vgl. auch Gabriel 1979, S. 246. Er kann also auch vorgetäuschte Aufrufe, Befehle oder Wünsche aussprechen.

${ }_{177}^{177}$ Vgl. Lamarque/OIsen 1994, S.43-46; Davies 1997, S. 12.

${ }^{178}$ Die Begriffe "Dasein“ und „Sosein“ verwendet Gabriel 1997, S. 595. In die Fiktionstheorie eingeführt wurden sie von Alexius Meinong. Im Folgenden verwenden wir wie Gabriel ,fiktional' für die Klassifizierung von Texten, ,fiktiv' für die von Objekten bzw. Entitäten; vgl. hierzu und zum Zitat Gabriel 1997, S. 596 und S. 595.
} 
Im Rahmen dieser Debatten scheint dabei weitestgehend und stillschweigend Einigkeit über die Kategorie der ,auf Einzelnes bezogenen Sachaussagen' ${ }^{179}$ und ihrer Wahrheit $\mathrm{zu}$ bestehen. Den pro general truth theories und den truth is irrelevant theories ist gemeinsam, daß sie für literarische Texte die Relevanz der Wahrheitsansprüche von Berichtsätzen ablehnen. ${ }^{180}$ Auch für Sätze, die (aufgrund referierender Ausdrücke wie z.B. realer Eigennamen) auf die reale Welt referieren, soll daher gelten, daß sie dies nicht mit Wahrheitsanspruch tun ${ }^{181}$ oder daß der vorhandene wahre und richtige Bezug auf Außertextliches für den Leser keine oder nur eine untergeordnete Rolle spielt. ${ }^{182}$

Des ,Schoolmeesters' Äußerung erhöbe demnach nicht den Anspruch, die Behauptung ,Poot ist tot' sei wahr. Hubert Korneliszoon Poot könnte tot oder lebendig sein, dies spielte keine Rolle für den fiktionalen literarischen Text. Ebenso wäre die Frage nach der Existenz und über das Gesagte hinausgehende Eigenschaften Elmar Karrs und Spoon Rivers für die literarische Schätzung des Textes unwichtig. Die genaue Überprüfung von (scheinbar) unbedeutenden Fakten der realen Welt, die in den literarischen Text eingeflossen sein könnten, führt nach dieser Ansicht vielmehr zum „paranoiden Lesen“. 183

Die meisten Theorien literarischer Referenz gehen daher davon aus, daß die Rede in einem (fiktiven) literarischen Text in bezug auf ihre Wahrheit und besonders auf ihre Wahrheitsansprüche homogen bewertet werden muß. ${ }^{184}$ Nur so meint man die ontologische und rezeptionstheoretische „untidiness“ vermeiden zu können, daß reale und fiktive Entitäten zusammentreffen oder daß der Leser ständig zwischen Äußerungen mit und solchen ohne Wahrheitsanspruch wechseln muß. ${ }^{185}$ Ausdruck dieses ausschließlichen Bezugs auf den Gesamttext ist z.B. die Verwendung eines Operators (etwa eines „sayso-operator"), der vor jeden fiktionalen Text und vor die relevanten Teile der Rede über fiktive Welten zu stellen sei. Dieser drückt die nicht behauptende und nicht referen-

\footnotetext{
179 Etwa: „Am 15. August 2002 erschoß Edmund in einer abgelegenen Straße Berlins seinen Rivalen.“ als Subkategorie der „propositional truth“; Pettersson 2000, S. $117 \mathrm{f}$.

${ }^{180}$ Vgl. etwa auch Gabriel 1979, S. 254 f.; in diesem Sinne jüngst auch Weimar 2003, S. 240-245. Ausnahmen bilden Hoops 1979, bes. S. 289, S. 300-304, und Martinich 2001. Der umgekehrte Ansatz der poststrukturalistischen Ansätze, generell Referenz und Wahrheit auch faktualer Texte in Frage zu stellen (vgl. dazu aus analytischer Sicht z.B. Zipfel 2001, S. 50-56), scheint uns irrelevant zu sein, da es uns um die Ansprüche von Texten (bzw. Sprechern) innerhalb eines Begriffssystems geht.

${ }^{181}$ Vgl. Gabriel 1975, S. 28; vgl. den Überblick Lamarque/Olsens 1994, S. 1 f.; Gabriel 1982, S. 543: „Fictional discourse' was then explicated via negationis as discourse for which the rules for assertions and the rules of reference and denotation are not to be followed."

${ }^{182}$ Vgl. Lamarque/Olsen 1994, S. 52 pass. und S. 120; vgl. auch Davies 1997, S. 7; New 1997; New 1999, S. 116; Dilworth 2002, S. 269 f.

${ }^{183} \mathrm{Vgl}$. Eco 1999, S. 143, dort erscheint in der Übersetzung der „paranoische Leser“.

${ }^{184}$ Vgl. Gabriel 1975, S. 32; Crittenden 1982, S. 335; Crittenden 1991, S. 135; Lamarque/OIsen 1994, S. 28; Zipfel 2001, S. 76.

${ }^{185}$ Vgl. Gabriel 1979, S. 249; Olsen 1987, S. 171; Lamarque/Olsen 1994, S. 285. Anderegg 1977, S. 117, spricht sogar von der "gestörten Geschlossenheit” des Werkes.
} 
tialisierbare Rede für den gesamten Text aus, auch wenn de facto einzelne Sätze durch Zufall oder weil Bereiche der Realität in den Text integriert werden - auf die reale Welt referieren. ${ }^{186}$

Gegen eine solche Homogenität der Unwahrheit fiktionaler Texte wurde schon von John Searle eingewandt, daß

most fictional stories contain nonfictional elements: along with the pretended references [...] there are $[\ldots]$ real references $[\ldots]$.

Searle bemerkt weiter, die meisten fiktionalen Werke enthielten auch nichtfiktionale Rede. ${ }^{187}$ Nelson Goodman stellt ebenfalls die These auf, daß

the difference among literary works between fiction and nonfiction thus seems to become less a matter of overall literary truth or falsity than of percentage of true and false component sentences. [...] Pure fiction and pure nonfiction are rare. ${ }^{188}$

Doch auch wenn in diesem Sinne nur Teile eines Textes ,unwahr' sind, wird dem gesamten Werk meist der Erkenntniswert (cognitive value) auf der Berichtsebene abgesprochen. Die geäußerten Wahrheiten seien trivial oder nur eine Aufbauhilfe für die imaginierte Situation. ${ }^{189}$

Unter den Vorgaben aller genannten Theorien haben Masters und des ,Schoolmeesters' Texte vom Wahrheitsanspruch her den gleichen Status. Dies ist aus mehreren Gründen unbefriedigend: Erstens kann für die Rezeption keine grundsätzliche Unterscheidung zwischen der Verwendung des realen und vergleichsweise leicht erschließbaren Namens ,Poot' und der Verwendung der fiktionalen Namen ,Elmar Karr' und ,Spoon River' gemacht werden. ${ }^{190}$

Zweitens bleibt eine Besonderheit der Namen in Masters Gedicht Elmer Karr unberücksichtigt: Masters benutzt sowohl fiktionale Namen für fiktive Personen, als auch reale Namen und fiktive Namen für reale Personen. Der Name ,Elmar Karr' könnte also durchaus ein realer Name einer realen Person oder ein fiktiver Name einer realen Person sein. Darüber besteht bei dem Leser Ungewißheit, weil es sich um einen unbekannten Namen handelt. Während ,Poot' für eine signifikante Gruppe von Sprechern einen semantischen Inhalt hat, ist ,Elmar Karr' selbst als realer Name für die meisten Sprecher des Englischen semantisch leer. ${ }^{191}$

\footnotetext{
${ }^{186}$ Vgl. zu lyrischen Texten Levin 1976; vgl. auch Davies 1997.

187 Searle 1975, S. 72; vgl. auch Crittenden 1991, S. 140; Martin 1982, S. 224 f.; Warner 1999, S. 38-41; Olsen 1987, S. 164; Gabriel 1982, S. 542.

${ }_{188}$ Goodman 1982, S. 164; vgl. auch Martinich 2001, bes. S. 98 und S. 104.

189 Vgl. etwa Gabriel 1982, S. 542-544.

190 Da der Name als Teil eines fiktionalen Textes begriffen wird, sprechen wir hier stets von einem ,fiktionalen Namen'. Als ,fiktiven Namen' bezeichnen wir einen ,falschen Namen' einer realen Person.

${ }_{191}$ Vgl. den Kommentar zu Elmar Karr in Masters 1992, S. 414; allgemein zur Namengebung vgl. exemplarisch die Kommentare in Masters 1992, S. 411, S. 396.
} 
Schließlich kann drittens in eine Analyse mittels der vorgestellten Modelle nicht aufgenommen werden, daß des ,Schoolmeesters' Epitaph das für eine Untergruppe dieser Textsorte typische Zusammenspiel einer wahren Behauptung (der Dichter Poot sei tot) und einer falschen Behauptung (er liege am Ort der Äußerung) enthält. Die Entfaltung der Textsorte ,Epitaph' wird zum Teil gerade darin deutlich, daß Grabschriften literarisiert und fiktionalisiert werden, d.h., daß viele nicht auf dem Grabstein einer gestorbenen Person angebrachte Epitaphe auf diese Person verfaßt wurden. ${ }^{192}$

wie diese Beispiele zeigen, ist die Analyse des Zusammenspiels wahrer und falscher Aussagenbestandteile und der mit den Texten erhobenen Wahrheitsansprüche für die Interpretation durchaus relevant.

Im Folgenden wollen wir daher entgegen dieser stillschweigend verbreiteten Ansicht der Fiktionstheorien - mit Blick auf die Verwendung von Eigennamen in Lyrik und unter Berufung auf John Searle und Nelson Goodman - davon ausgehen, daß Autoren fiktionaler und literarischer Texte unter bestimmten Bedingungen und in unterschiedlichem Grade Anspruch auf die Wahrheit eines Teils ihrer Sätze erheben können. ${ }^{193}$ Daraus folgt, daß im Bereich der Literatur daher ein gradueller Übergang von fiktionalen zu nicht-fiktionalen Texten besteht.

Dies gilt nun nicht nur in bezug auf die Wahrheit der Sätze, sondern vor allem auch in bezug auf die Wahrheitsansprüche und mithin die Wahrheitsverpflichtungen des Autors. ${ }^{194}$ Um solche Ansprüche und Verpflichtungen zu erklären, bedienen wir uns eines jüngst vorgeschlagenen Modells Martinichs auf der Grundlage des Griceschen cooperative principle of conversation. ${ }^{195}$ Nach Martinich besteht die Fiktionalität eines Textes in der ,Suspendierung' der Griceschen konversationellen Maxime der Qualität, die Martinich so reformuliert: „Do not participate in a speech act unless you satisfy all the condi-

\footnotetext{
${ }^{192} \mathrm{Vgl}$. Wiegand 1997, S. 475.

${ }^{193} \mathrm{Vgl}$. eine Randbemerkung bei Künne 1995, S. 143.

194 Zur vollen Referenz realer Namen in fiktionalen Werken vgl. Currie 1990, S. 128 f.

${ }^{195}$ Vgl. Martinich 2001, S. 97 passim. Grice kümmert sich als intentionalistischer Semantiker um die kontextabhängigen Inhalte von Gesprächsbeiträgen - also um das, was mitgemeint, vorausgesetzt oder impliziert wird, aber nicht ausdrücklich durch die Wort- und Satzsemantik gesagt wird. Grundlage seines Modells zur Erfassung dieser zusätzlichen Bedeutungsbestandteile ist das bekannte „cooperative principle of conversation": "Make your conversational contribution such as is required, at the stage at which it occurs, by the accepted purpose or direction of the talk exchange in which you are engaged"; Grice 1989, S. 26. Um dieses recht allgemeine Prinzip anwendbar zu machen, nennt Grice einige Maximen, in denen es spezifiziert wird: „Quantität“: Mache deinen Beitrag weder zu informationsarm noch zu informationsreich!; „Qualität“: Versuche einen wahren Beitrag zu machen!; „Relation“: Sei relevant!; „Art und Weise“: Sei verständlich, klar, eindeutig, kurz und ordentlich! Die Einhaltung dieser Maximen kann von den Gesprächspartnern vorausgesetzt werden. Aus innen schließen sie auf Nichtgesagtes, das aber mitgemeint ist („conversational implicatures“). Gegen die Maximen kann man auf teils reglementierte Weise verstoßen, und Maximen können sich gegenseitig hemmen. Dann oder aus anderen Gründen kann man eine Maxime heimlich nicht erfüllen. Man kann von einer Maxime ,offiziell' zurücktreten, oder man kann sie grob mißachten.
} 
tions for it's nondefective performance." ${ }^{196}$,Suspendierung' heißt für Martinich, daß eine Maxime für einen Sprechakt nicht erfüllt wird. Dies geschieht in Rahmenbedingungen, in denen festgelegt ist, daß die Maxime nicht immer gelten muß. Die Suspendierung erlaubt es also, in einzelnen Sprechakten von einer Maxime zurückzutreten. ${ }^{197}$ Dieses Modell läßt ganz in unserem Sinne wahre Aussagen mit Wahrheitsansprüchen und Referenz auf die reale Welt in fiktionalen Texten zu. ${ }^{198}$ Allerdings zeigt es nicht, welches die „Bedingungen für eine fehlerfreie Ausführung“ sind. Dies kann nur mit Bezug auf das intendierte Ziel der Handlung bestimmt werden. Die Suspendierung der Maxime „Qualität“ bietet letztlich gar keinen Anhaltspunkt, fiktionale Texte von faktualen Texten zu unterscheiden, denn sie kann in beiden ,Genres' gültig bleiben. Daher ist es vorzuziehen, im Falle der fiktionalen literarischen Rede diese Maxime nicht zu suspendieren, sondern die besonderen Rahmenbedingungen der jeweiligen fiktionalen Rede zu formulieren. Statt der ,Suspendierung' findet also vielmehr eine grundsätzliche ,zielabhängige Relativierung' der Maxime der ,Qualität' statt, die alltagssprachlich lediglich durch die epistemische Unzulänglichkeit des Sprechers relativiert wird: Try to make your contribution one that is true. ${ }^{199}$

Bei fiktionalen Texten geschieht es nun, daß genau diese Maxime für die gesamte Rede relativiert ist. Daher kann von der Wahrheit und Wahrhaftigkeit abgewichen werden, sei es für das Ziel der Rede, sei es für eine andere Maxime. Das Ziel zugunsten dessen die Maxime der Qualität relativiert wird, läßt sich im Falle fiktionaler literarischer Texte etwa in folgender Definition von Literatur ausdrücken: Ein Text wird dann als, literarisch' betrachtet, wenn er in seiner Gestaltung auf einer oder allen sprachlichen Ebenen (der formalen Gestaltung, der Grammatik, Semantik, Pragmatik oder der Kommunikationsfunktionen) primär von ästhetischem Interesse ist. ${ }^{200}$

\footnotetext{
${ }^{196}$ Martinich 2001, S. 96 passim.

197 Martinich 2001, S. 100: „Suspending: Not fulfilling one or more maxims in set circumstances in which the maxim does not always apply."

${ }^{198}$ Vgl. Martinich 2001, S. 97.

199 Martinich 1984, S. 24 f. Diese Maxime ist gegenüber den Zielen der Konversation anscheinend immun - es darf keine bewußte Falschaussage gemacht werden, aus welchem Grunde auch immer. Auch im Falle der Maximenkonkurrenz ist sie unantastbar. Während man zugeben darf, daß man um der Kürze willen zu wenig informativ war, darf man wohl kaum sagen, daß man gelogen habe, um kurz zu bleiben.

200 ,Primär von ästhetischem Interesse' meint, daß der jeweilige Text unter den Kriterien von ,schön' und ,häßlich' bewertet wird. Diese Bewertung ist in einem weiten Sinne zu verstehen, der auch die Umwertung etwa des Häßlichen, des Ergreifenden, ,Fordernden' oder ,die innere Welt Verändernden' etc. als ,schön' abdeckt. ,Schön' kann an einem Text sowohl die formale Gestaltung (etwa im Vers), als auch eine elegante Argumentation, der Umgang mit den dargestellten wahren oder fiktiven Sachverhalten oder eine (vielleicht moralisch) schöne Reaktion in einer kommunikativen Situation sein. Jeder Text kann unter ästhetischen Gesichtspunkten betrachtet werden. Aber erst, wenn dieses Interesse dominiert, wird ein Text gemeinhin als ,literarischer Text' bezeichnet. Dies zeigt sich deutlich an wissenschaftlichen oder gesellschaftsbezogenen Texten, die zumeist erst, wenn sie ,Klassiker', also wissenschaftlich oder gesellschaftlich überholt sind, zur Literatur werden. Für nicht-literarische Fiktionen können ähnliche Maximen -
} 
Das Entscheidende an der Relativierung einer Maxime ist, daß diese Maxime nicht für die gesamten Rede und damit für die wahren wie die unwahren Sätze außer Kraft gesetzt wird, wie es sowohl die Suspendierung als auch das offizielle Zurücktreten von einer Maxime bewirken würden. Die Maxime wird vielmehr zugunsten eines zu erreichenden Ziels ,öffentlich' hintangesetzt. Das Erreichen des Ziels der Rede ist dann der Maßstab, an dem die einzelne Hintansetzung dieser oder anderer Maximen gemessen wird. Man ,spürt' die Verletzung der Maxime noch.

Die Abweichung von der Wahrheit bedarf daher auch in fiktionalen literarischen Texten letztlich einer Rechtfertigung durch die anderen Maximen oder das Ziel der Rede. Auf diese Weise ist sowohl eine Kritik an Falschaussagen in einem Werk als auch eine Kritik an Verstößen gegen andere Maximen möglich. Nur so wird z.B. Kritik an ,sinnlosen Spielereien der Phantasie' ebenso wie an ,Faktenhuberei', erklärbar, wie sie Vertreter verschiedener ästhetischer Richtungen gegen ihre jeweiligen Gegner vorbringen.

Der Anspruch des Autors auf Wahrheit der in seinen Texten geäußerten Behauptungen wird schließlich durch die Position der Äußerung in der Erzählstruktur des Textes (gemeint sind: Äußerungen auf der Erzählerebene, auf der Figurenebene etc.) nachhaltig beeinflußt. Insofern sollte zwischen einem direkten Anspruch des Autors und der Verantwortlichkeit des Autors für indirekt auf inn zurückweisende Ansprüche unterschieden werden. Der Fall, daß der Autor in seinem Werk tatsächlich selbst spricht, ist eher selten. Man muß also einen Großteil der literarischen Texte, die einen wie auch immer vom Autor getrennten Erzähler oder Sprecher aufweisen, als fiktionale Texte in unserem Sinne ansehen. Denn sie beginnen mit der impliziten oder expliziten und unwahren Aussage: ,Der Erzähler existiert und berichtet, daß... ${ }^{201}$ Die komplexe Situation des Wahrheitsanspruches ist in diesem Fall, daß der Autor wahre Sätze in seinem Werk benutzt, die er auch für wahr hält und mit Wahrheitsanspruch schreibt, die aber in der Fiktion des Textes von der fiktiven Erzählerfigur ausgesprochen werden. Somit ist der Autor verantwortlich für Äußerungen, die er nicht selbst macht, bzw. die nicht real, sondern nur fiktiv gemacht werden. Diese Situation verkompliziert sich weiter, wenn auf der Ebene der Figurenrede wahre Sätze ausgesprochen werden.

Jedoch läßt sich diese scheinbar komplizierte Situation relativ leicht lösen: Auch wenn Sätze von einem Erzähler bzw. einer Figur gesprochen werden, weiß der Leser, daß ,im wirklichen Leben' nun einmal der Autor die Sätze geschrieben hat. Deshalb ist dieser für alles, was in seinem Werk steht, letztendlich verantwortlich. Bei der Auslegung des

etwa die ,Anschaulichkeit' für Gedankenexperimente in der philosophischen Ethik etc. - gefunden werden.

${ }^{201}$ Explizite Herausgeberfiktionen spezifizieren genau diese Situation. 
Werkes muß daher ein Kontext für einzelne Äußerungen rekonstruiert werden, der eine Beurteilung ermöglicht, inwieweit ein Autor eine Aussage seiner (Erzähler-)Figur gutheißt oder verurteilt. Als Beispiel diene uns eine Romanfigur, die den Holocaust leugnet. Dieses Leugnen ist zunächst nicht dem Autor anzulasten. Er wird dafür nicht moralisch oder strafrechtlich belangt. Es hängt aber von der weiteren Gestaltung des Romans ab, ob man inm diese Äußerung nicht doch anlastet: Ist die fragliche Figur uneingeschränkt positiv dargestellt? Ist sie eine Identifikationsfigur? Kann aus dem Roman auf die Wirkungsabsicht des Autors geschlossen werden? Je nach dem Status der Äußerung und der äußernden Figur wird dem Autor die in der Äußerung gefundene Meinung durchaus zugeschrieben werden können. Damit treffen inn dann auch die entsprechenden Vorwürfe.

Ein Beispiel für Wahrheitsansprüche, die Wahrheitsverpflichtungen unterschiedlichen Grades nach sich ziehen, bietet Agha Shahid Alis Gedicht The Dacca Gauzes von 1987. Es beginnt wie folgt

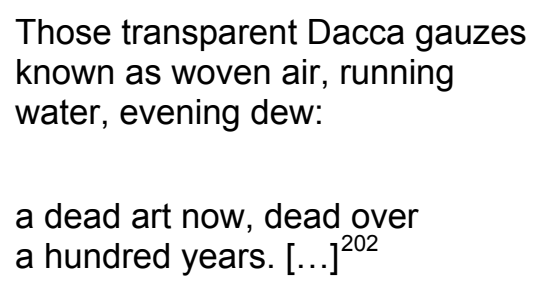

Diese Verse referieren auf eine nachprüfbare historische Situation - die Zerrüttung des indischen Weberhandwerks durch englische Manufakturprodukte Ende des 19. Jahrhunderts. Es wäre dem Dichter Unwahrheit durchaus vorzuwerfen, wenn diese Ereignisse zu seiner Zeit nur 10 Jahre zurücklägen, der Satz also offensichtlich falsch wäre. Denn es gibt kein Anzeichen dafür, daß der Autor sich von der ,Stimme' des Gedichts distanzierte. ${ }^{203}$ Das im Text gestaltete poetische Bild unterstützt durch seine Wahrheit und historische Belegbarkeit den ,antikolonialistischen' und sozialkritischen Impetus des Gedichts. Die Wirkung des Textes hängt von der Wahrheit des Satzes ab. Sie hängt auch davon ab, daß der Leser diesen Satz als wahren Satz erkennt. Dem Leser kann außerdem eine zwar bruchstückhafte, aber dennoch wichtige Information über den Zu-

\footnotetext{
202 Ferguson/Salter/Stallworthy 1996, S. 1835.

203 Diese Forderung an den Autor darf nicht mit der Forderung nach Präzision verwechselt werden. Ob die Zerschlagung des Weberhandwerks in Indien 130 oder 103 Jahre zurückliegt, spielte auch dann keine Rolle, wenn Aga Shahid Khan seine Äußerung nicht als Gedicht, sondern als Zeitungsbericht geschrieben hätte. Läge sie nur 99 1/2 Jahre zurück, würde der Fehler weit weniger negativ bewertet, als wenn sie nur 3 Jahre zurückläge - ebenso im Zeitungsbericht, negativer wohl in einer geschichtswissenschaftlichen Arbeit.
} 
stand der Welt gegeben werden. ${ }^{204}$ Der Sprechakt BERICHTEN gehört hier zur pragmatischen Struktur des Gedichts.

Die letzte Strophe des Gedichts hingegen - sie handelt wie ein Großteil des Textes von der Großmutter des Sprechers - erhebt nicht notwendig einen Wahrheitsanspruch:

One morning, she says, the air was dew-starched: she pulled it absently through her ring. ${ }^{205}$

Der Wahrheitsgehalt dieses, ,lyrischen Bildes' ist kaum nachprüfbar, denn es handelt sich um ein ,privates Ereignis'. Eine solche Äußerung glaubt ,man' bei entsprechendem Vertrauen auf den Sprecher ungeprüft, wenn sie wahrscheinlich ist. Wahrheit spielt infolgedessen nur eine untergeordnete Rolle, selbst wenn die Aussage wahr sein sollte. Das Verlangen nach Beweisen würde in diesem Fall den Leser tatsächlich zu einem 'paranoiden Leser' machen. Aber auch bei einer entsprechenden Alltagsäußerung dem „natürlichen Erzählen“ im Gegensatz zum „künstlichen Erzählen“206 - wäre ein Nachforschen zumindest ungewöhnlich.

Insofern enthält das Gedicht sowohl Behauptungen, deren Wahrheit praktisch nachprüfbar ist, als auch solche, deren Wahrheit nur theoretisch überprüft werden könnte. Den pro general truth theories (s.o.) kann in dieser Hinsicht zwar zugestanden werden, daß es Literatur um die Entwicklung eines „menschlich interessanten Inhalts“207 oder auch um das Zusammenspiel der Elemente des Textes geht und daß die Berichtswahrheit selbst nicht das einzige Ziel eines literarischen Gesamttexts ist. Daher gehen wir wie alle neueren Ansätze ${ }^{208}$ davon aus, daß der competent reader zumindest fiktionaler literarischer Texte nicht grundsätzlich die Berichtswahrheit der Texte voraussetzt. Der Autor solcher Texte ist allerdings dann zur Wahrheit verpflichtet, wenn er den Leser im Text oder Kontext darauf hinweist, daß er Wahrheitsansprüche erhebt. Die Erfüllung eingegangener Wahrheitsverpflichtungen durch angezeigte bzw. geäußerte Wahrheitsansprüche unterschiedlicher Tragweite gehört in diesen Fällen ebenso zu den ästhetischen Bestandteilen des Textes wie alle anderen Bestandteile. ${ }^{209}$ Dies gilt unbeschadet der Tatsache, daß der Leser zunächst mühevoll und möglicherweise ohne endgültigen Erfolg die Wahrheitsansprüche des Autors herausfinden muß, wie etwa im Falle der

\footnotetext{
${ }^{204}$ Daß der Leser sich genauer informieren muß, um den Kontext zu verstehen, spricht nicht dagegen, daß hier Wahrheitsansprüche an einen Berichtsatz gestellt werden.

${ }^{205}$ Ferguson/Salter/Stallworthy 1996, S. 1835; „,she” ist die Großmutter, „it” sind die Tücher.

${ }^{206}$ Vgl. Eco 1999, S. 160.

207 Lamarque/Olsen 1994, S. 437.

${ }^{208}$ Vgl. Lamarque/Olsen 1994; Walton 1990; Evans 1982.

209 So schlägt es dagegen New 1999, S. 117, vor.
} 
Herausgeberfiktion. Man kann auch mit Eco sagen, die erkennbaren Wahrheitsansprüche seien Teil eines jeweils zwischen Autor und Publikum geschlossenen ,Vertrages' ${ }^{210}$ Eine solche ,Selbstverpflichtung' des Autors im fiktionalen literarischen Bereich führt dazu, daß der Autor sich eine zusätzliche Möglichkeit oder auch Gefahr semantischpragmatischer Abweichungen schafft. Der in der Literatur mögliche Einsatz fiktiver wie realer Eigennamen spielt für die Feststellung und Bewertung, ob der Text die Maxime des ästhetischen Gelingens erfüllt, eine besondere Rolle. ${ }^{211}$ Denn mit Sätzen über eine fiktive Stadt (etwa Spoon River) oder gar eines fiktiven Landes kann ein Autor außer mit der generell falschen - aber durch die Gesetze der Fiktionalität erlaubten - präsupponierten Existenzaussage nicht von der Wahrheit abweichen. Mit Sätzen über London dagegen hat der Autor die Möglichkeit, zahlreiche signifikante Abweichungen zu konstruieren. Über den Text hinausweisende Eigennamen dienen unter Umständen der besonders intensiven Illusionierung, da der Leser sich ein sehr konkretes und ihm detailliert bekanntes Objekt vorstellen kann. Gerade wegen dieser Teilnahme des Lesers am Aufbau der visualisierten Welt setzt sich aber der Autor auch der Kritik des Lesers an unmotivierten Abweichungen von der vorab bestehenden gestalteten Welt aus. Indem der Autor in einer realen Stadt eine fiktive Straße oder fiktive Personen einführt, kann er sich wiederum bei der Beschreibung von Details dieser Straße und der Personen im Rahmen der durch den realen Ortsnamen gegebenen Grenzen Freiräume für nicht signifikant abweichende Erfindungen schaffen. Diese Freiräume werden um so kleiner, je mehr reale Objekte in das literarische Werk integriert werden. Sätze über reale bzw. fiktive Objekte - auf die zumeist durch reale bzw. fiktive Eigennamen referiert wird - schaffen somit Begrenzungen oder Freiräume, mit denen der Autor umgehen kann und muß. Dadurch wird generell eine weitere Form der künstlerischen Abweichung, nämlich die Abweichung von spezifischen bekannten Wahrheiten, in den fiktionalen literarischen Text eingeführt: „We recognize that the poet has accepted truth as an additional norm. ${ }^{212}$ Umgekehrt kann ein Dichter - gerade in Lyrik - minutiös ein reales Erlebnis, ein reales Objekt schildern, dabei aber durch die Vermeidung aller für einen zeit- und ortsfernen Leser dienlichen Hinweise auf diese Faktizität deutlich machen, daß die Faktizität für diesen literarischen Text keine Rolle spielt. So läßt sich die partielle Eigennamenarmut der Gedichte einzelner Dichter, Strömungen oder Epochen erklären.

\footnotetext{
${ }^{210}$ Vgl. Eco 1999, S. 141.

${ }^{211}$ Vgl. etwa die beiläufige Bemerkung bei Martinich 2001, S. 105

212 Elliott 1966/67, S. 80; Elliott bezieht sich allerdings nur auf generische und allgemeine Wahrheiten, die dem Trivialitätsverdacht ausgesetzt sind (vgl. das Beispiel Ecos 1999, S. 127 f.; Gutschmidt 1984, S. 145).
} 
Die Wahrheit spielt damit eine ähnliche Rolle wie die sprachliche Norm für stilistische Abweichungen. ${ }^{213}$ Der Beitrag einzelner Sätze zum Ganzen kann oft nicht gewürdigt werden, wenn man nicht den Wahrheitsstatus des Satzes beachtet. Auch die Gesamtaussage eines Textes und seine Ästhetik bzw. seine ästhetische Würdigung können durchaus damit zusammenhängen, ob einzelne Sätze absichtlich oder unabsichtlich wahr oder falsch sind.

Allgemein scheinen reale Eigennamen in fiktionalen literarischen Texten von den ausdrücklichen wie unausgesprochenen Vertretern der truth is irrelevant theories und der pro general truth theories mit Unbehagen betrachtet zu werden. Dieses Unbehagen wurzelt darin, daß die Bedeutung von Eigennamen oft nicht ohne Rekurs auf den realen Autor und sein Umfeld geklärt werden kann. Eigennamen gehören in hohem Maße zu jenen Zeichen von denen z.B. Wimsatt trotz seines Plädoyers für eine nichtintentionalistische Leseweise von Lyrik zugeben muß, daß es „private or semiprivate meanings attached to words and topics by an author or by a coterie of which he is a member" gebe. ${ }^{214}$

Reale Eigennamen sind ,unsichere Kandidaten' in angeblich nicht referierenden Texten, die in einer noch zu klärenden Weise über den Text hinausweisen. Auch fiktionalen Eigennamen (Namen rein innertextlich konstituierter fiktiver Namenträger) ist aus dieser Sicht nicht ganz zu trauen, denn ihre Ähnlichkeit mit realen Eigennamen verleitet dazu, ,nichtexistierende Objekte' oder mentale Entitäten ,im Kopf des Autors' anzunehmen, auf die er mit dem Namen referiert.

Da auch Lyrik ein unsicherer Kantonist ist, sobald es um die Wahrheitsansprüche und die Fiktionalität literarischer Rede geht, und die neueste Lyriktheorie zumeist davon ausgeht, daß Lyrik sowohl fiktional als auch nichtfiktional sein kann, ist die Frage nach den Referenzqualitäten (realer) literarischer Eigennamen von erhöhtem Interesse für die Lyrikanalyse.

\subsubsection{Wer einmal lügt, dem glaubt man nicht?}

Wenn aus dem Text oder Kontext die besprochenen Wahrheitsansprüche und Verpflichtungen des Autors deutlich werden, umfaßt das Interesse an einem literarischen Werk ,als solchem' auch das Interesse an der Wahrheit und der Referenz einzelner Aussagen. ${ }^{215}$ Verpflichtungen geht der Autor schon dann ein, wenn er reale Eigennamen verwendet. Überdeutlich werden die Ansprüche, wenn sie im Kontext explizit ge-

\footnotetext{
${ }^{213}$ Vgl. Davies 1997, S. 4.

214 Wimsatt 1967, S. 10; vgl. auch Levin 1976, S. 156.

215 Vgl. Pettersson 2000, S. 122, S. 129 f., S. 134.
} 
stellt werden. So veröffentlicht z.B. das Politische Journal 1793 eine Ode gegen die Franzosen mit einer entschuldigenden Einleitung:

Obgleich Gedichte, nach dem Plane unseres Journals, von demselben ausgeschlossen sind, und nicht mitgeteilt werden können, so giebt es doch Fälle, welche eine Ausnahme erfodern. Wir haben daher schon ein paar mal unsern Lesern Gedichte vorgelegt. Die Gründe, die uns zur Mitteilung des Nachstehenden bewegen, sind einleuchtend. Es enthält selbst Facta unsrer Zeit, es ist ein politisches Gedicht, und es klärt, auf eine verdienstvolle Weise, eine jetzt durch die Franzosen verbreitete lasterhafte Idee auf [...]. ${ }^{216}$

Es wird explizit auf die Berichtsqualität des nachfolgenden Textes hingewiesen. Der poetische Text wird in das politische Journal aufgenommen, weil er einen direkten Bezug auf die Wirklichkeit beanspruchen kann. Das nachfolgende Gedicht Brutus und die Franzosen enthält allerdings mehr Polemik als „Facta“, wenn auch die auftretenden Eigennamen den Bezug auf die Realität aufrechterhalten:
Ihr stellt des Brutus Bildniß in den Tempel ${ }^{217}$
Der neuen Gleichheit und Ochlokratie,
Des Raubrechts und der Blutphilosophie!
[...]
Ihr raubt dem redlichsten im Reiche Leben, Erbe,
Ludwig, dem Guten; nie von ihm betrübt,
Habt ihr einst selbst sein sanftes Herz geliebt;
Wie ihr im bittren Wahnsinn rieft: Er sterbe!
Rieft ihr im sonst ein freudig: Lebe! zu;
So wend't sich Wind und Franken-Sinn im Nu. ${ }^{218}$

Eine literaturkritische Wertung wie auch eine Interpretation würde richtige und (strategisch) falsche Beschreibungen der Lage in Frankreich vor dem Hintergrund der vorher im Kontext eingegangenen Ansprüche zu berücksichtigen haben - wobei in diesem Fall zu klären wäre, ob des Autors Ansprüche mit denen der Herausgeber übereinstimmen. ${ }^{219}$

$\mathrm{Zu}$ den Anhaltspunkten, die die Wahrheitsansprüche eines literarischen Textes ${ }^{220}$ erkennbar werden lassen, gehören neben der Textsorte bzw. dem Genre die erschließbaren Intentionen des Autors. ${ }^{221}$ Der Autor geht durch seine Art und Weise der Beschrei-

\footnotetext{
${ }^{216}$ Anonym erschienen in: Politisches Journal nebst Anzeige von gelehrten und andern Sachen, 1793, erster Band, drittes Stück, S. 239.

${ }^{217}$ Die faktische Neuigkeit, welche in dem Text beschrieben wird, ist wohl der ,staatliche Atheismus' im revolutionären Frankreich.

${ }_{218}$ Politisches Journal 1793, S. 239-242.

${ }^{219}$ Für ein ähnliches Beispiel vgl. Martinich 2001, S. 97. Diese Erfüllung selbstgestellter Normen hat wenig zu tun mit dem „vulgar and philistine error", an einem literarischen Text zu kritteln, weil er Unwahrheiten oder Halbwahrheiten enthält (Elliott 1966/67, S. 82). Letzteres verkennt die Dominanz ästhetischer Bewertung über die Bewertung der Korrektheit des Textes. Nach unserer Überzeugung können aber unter entsprechenden Vorgaben Wahrheitsansprüche in die ästhetische Bewertung einfließen.

${ }^{220}$ Vgl. Deutsch 2000, S. 155.

${ }^{221}$ "What is true in fiction can vary with genre and no general principle of content holds"; Crittenden 1991,

S. 133; vgl. auch die Einschätzung Uwe Johnsons in Pettersson 2000, S. 134 f.
} 
bung, durch die von inm beschriebenen Sachverhalte ${ }^{222}$, durch die Verwendung von Eigennamen sowie durch explizite Bindungen Verpflichtungen ein, an deren Erfüllung sein Werk gemessen werden kann. Die (Werk-)Kontexte, in denen Texte veröffentlicht werden, zeigen, inwieweit Berichtswahrheit beansprucht wird. Wenn ein Autor gewohnheitsmäßig die Orte der Handlung richtig beschreibt, wird eine Falschbeschreibung auffallen. Ebenso kann ein Autor explizit Wert darauf legen, daß gewisse Episoden in seinen Romanen oder Gedichten wirklich geschehen sind. ${ }^{223}$ Die Verpflichtung des Autors besteht darin, daß er eine zusätzliche Sphäre möglicher Abweichungsphänomene eröffnet. Zum ,hermeneutischen Zirkel' der Interpretation gehört es auch, daß die (offensichtliche) faktische Wahrheit oder Falschheit der geäußerten Sätze in einem (fiktionalen) literarischen Werk selbst die Ansprüche der Sätze andeutet und konstituiert.

Man könnte zwar mit Lamarque/OIsen erstens einwenden, daß die Berichtswahrheit eines literarischen Textes den Leser einfach nicht interessiere und es deswegen nur auf den allgemeinen Wahrheitsanspruch oder die Präsentation eines menschlich interessanten (erfundenen oder realen) Inhalts ankomme. Dieser Einwand ist dem Versuch verwandt, die Wahrheit literarischer Rede zugunsten der ästhetischen Autonomie in Form der Autoreferenz literarischer Werke zurückzustellen. Wenn der Leser sich über die 'vertikale' Verbindung zwischen Welt und Satz oder Text niemals sicher ist, wird die Aufmerksamkeit auf die Sprache selbst gelenkt. Man muß allerdings nur annehmen, daß auch und gerade Mechanismen wie die Referenz eines Eigennamens auf reale Objekte in einem Satz mit Wahrheitsanspruch exemplifiziert werden können, um die Frage nach Referenz und Wahrheit in literarischen Texten auch in diesem Modell zu rechtfertigen. Ein solcher Fall ist etwa die Aussage ,er (Poot) ist tot' im Poot-Epitaph vom ,Schoolmeester'. Zwar ist die ursprüngliche Referenz eines literarischen Textes (etwa eines 'Gelegenheitsgedichtes') für den Rezipienten vielfach tatsächlich bedeutungslos, weil er den Text unter anderen Gesichtspunkten liest. ${ }^{224}$ Dann wird der Text dereferentialisiert oder autoreferentialisiert. Dies ist aber ein Vorgang, der den ursprünglichen Anspruch auf Referenz als Teil des Werkes nicht ungeschehen macht. ${ }^{225}$

\footnotetext{
${ }^{222}$ Diese beiden Punkte beziehen sich z.B. darauf, daß ein Autor dadurch, daß er eine in der Realität unmögliche Allwissenheit beansprucht oder deutlich irreale Ereignisse beschreibt, den Anspruch auf Wahrheitsähnlichkeit für den Leser erkennbar aufgeben kann; vgl. auch Sutrop 2002, S. 337-339.

${ }^{223}$ Vgl. Crittenden 1991, S. $131 \mathrm{f}$.

${ }_{224}^{224}$ Vgl. Warner 1999, S. 48 f.

${ }^{225}$ Möglich ist auch die nachträgliche Entdeckung der Referenz eines Textes. Würde aufgedeckt, daß Arthur Conan Doyle mit Sherlock Holmes minutiös das Leben eines historischen Detektivs beschrieb, den er persönlich kannte, wandelte sich der Charakter des Romans etwa zum ,dokumentarischen Roman', der Behauptungen enthielte. Crittenden 1982, S. 344, irrt, wenn er davon ausgeht, daß 'Sherlock Holmes' immer eine fiktive Figur bleiben müsse. Entscheidend wäre aber vor allem die Erschließbarkeit der Wahrheit des Textes. Wenn der Text so geschrieben ist, daß eine Entdeckung des Wahrheitsbezugs so gut wie unmöglich ist, würde der Fiktionalitätsanspruch wohl gewahrt.
} 
Zweitens kann versucht werden, die Funktion der Wahrheit durch reine Wahrheitsähnlichkeit (verisimilitude) ${ }^{226}$ zu ersetzen. Doch auch in diesem Fall kann die Beachtung der Wahrheit einzelner Sätze gefordert werden. Nach dem Schluß ab esse ad posse ist das wirklich Geschehene am ehesten wahrscheinlich und wahrheitsähnlich, weil es eben wahr ist. Auf die 'Einzelfall-Berichtswahrheit' kann der Autor daher gerade im Rahmen einer Rechtfertigung allgemeingültiger Äußerungen im Text zurückgreifen. ${ }^{227}$ Erklärbar ist dieser Effekt mit dem Kinderspiel des Sandkuchenbackens ${ }^{228}$ oder der Funktion literarischer Texte als real oder materiell vorhandene Grundlage, die eine Imagination anregt (sogenannte „prompters“ oder „props“) in einem game of make-believe, wie Evans oder Walton es zur Erklärung von ,Fiktion' gestalten. ${ }^{229}$ Je ähnlicher die als Grundlage einer Fiktion verwendeten realen Objekte dem sind, was sie im Spiel darstellen sollen, desto einfacher ist die Imagination. Der Spieler und Benutzer eines realen props kann verpflichtet sein, gewisse reale Eigenschaften zu berücksichtigen. Wenn daher zum ,Sandkuchenbacken' ein wirkliches, wenn auch stumpfes Messer benutzt wird, dann wird der Spieler kaum ohne besonderen Grund das Messer an der Schneide fassen und mit dem Griff den fiktiven Kuchen schneiden wollen. Tut er es doch, gerät er gegenüber seinen Mitspielern unter Umständen in Begründungsnot. Entsprechend kann eine vorgebliche (pretended) Erzählung realer Tatsachen durch den teilweisen richtigen Bezug und Anspruch auf bekannte wahre Tatsachen an Glaubhaftigkeit gewinnen und dem Leser das Eintreten in die institutionalisierte literarische Konvention erleichtern. Volle Wahrheitsansprüche können in diesem Spiel auch nicht durch die Trennung zwischen Wahrheit in der ,fiktionalen Welt' (, "wahr*') und Wahrheit in der ,aktuellen Welt' (,wahr') entkräftet werden. ${ }^{230}$ Erkennbare Ansprüche auf Wahrheitsparallelität würden in diesem Fall einen Schluß von der *Wahrheit* in der möglichen Welt ${ }^{231}$ auf die Wahrheit in der aktuellen Welt erlauben. Wenn der Autor reale props einsetzt, erwartet man ten-

\footnotetext{
${ }^{226}$ Vgl. Fricke 1981, S. 49 f.; Pavel 1986, S. 47; Olsen 1987, S. 175; Crittenden 1991, S. 135; Warner 1999, S. 40; New 1999, S. 119.

${ }^{227}$ So vermutet es schon Aristoteles in seiner Poetik (Aristoteles 1982 1451b).

${ }^{228}$ Siehe dazu auch Fußnote 176.

${ }^{229}$ Vgl. Evans 1982, S. 353-363, und Walton 1990, S. 21-25; Walton 2000, S. 72 f.; bei Lamarque/Olsen 1994, S. 127, wird die Möglichkeit erwähnt, reale Eigennamen als props eines game of make-believe zu betrachten.

${ }^{230}$ So versuchen es etwa Currie 1990, S. 128; Eco 1999, S. 121 f., Davies 1997, S. 4 passim.

${ }^{231}$ Wir betrachten ,fiktive Welten' als den ,möglichen Welten' verwandt. Für eine ,fiktive Welt' können im Gegensatz zur möglichen Welt auch logische Gesetze und Naturgesetze umgeformt werden. Insofern sind fiktive Welten wesentlich unabhängiger von der realen Welt als mögliche Welten. Dennoch haben sie die Gemeinsamkeit, daß die reale Welt der Ausgangspunkt ist. Die meisten fiktiven Welten haben somit den größten Teil ihrer Elemente mit der realen Welt gemeinsam (vgl. Zipfel 2001, S. 84-90).
} 
denziell auch die Berücksichtigung allgemein bekannter Wahrheiten, da sonst ein Verfremdungseffekt eintritt, der der (ästhetischen) Motivation bedarf. ${ }^{232}$

Die kontextabhängige ,Fiktionslizenz' bewirkt, daß zwar wie auch immer ästhetisch motivierte Abweichungen von der Wahrheit nicht kritisiert werden. Anders sieht es aber im Falle von nicht motivierten Irrtümern des Autors aus. Diese können durchaus kritisiert werden, wobei als Maßstab die bekannten Intentionen des Autors oder der Bekanntheitsgrad der betroffenen 'Wahrheiten' genommen werden kann. ${ }^{233}$ So kann etwa Robert Gernhardt in seinen Gedanken zum Gedicht an Günther Kunerts Gedicht Verlangen nach Bomarzo, das einen Gang durch den Parco dei Mostri schildert, kritisieren, daß die dortigen Tuffsteinfiguren als Granitfiguren beschrieben werden. Denn durch die Eigennamen im Titel und am Gedichtanfang wird ein reales setting identifiziert. ${ }^{234}$ Der ästhetische Genuß des Lesers Gernhardt, der die beschriebene Örtlichkeit kennt, ist durch diese inm nicht ausreichend motivierte Abweichung ${ }^{235}$ gestört.

Wir stellen zusammenfassend fest, daß ein fiktionaler literarischer Text in bezug auf Wahrheitsansprüche und -verpflichtungen drei Arten von Aussagen enthalten kann:

Erstens kann der Autor über Sinngebilde sprechen, die nicht existieren, also die falsche Behauptung 'Das Erzählte geschah...' oder 'Der erwähnte ... existiert' präsupponieren. ${ }^{236}$ Mit einem verwendeten Eigennamen referiert der Sprecher (Autor) in diesem Fall nur scheinbar auf ein Objekt außerhalb des Textes. In Wirklichkeit konstituiert der Name ein von Autor und Lesern gemeinsam nach den Maßgaben des Textes imaginiertes evtl. visualisiertes - Gebilde. Diese Abweichung von der Wahrheit ist durch die ästhetischen Qualitäten des fiktionalen Werkes generell gerechtfertigt (wenn das Werk denn solche Qualitäten besitzt).

Zweitens kann der Autor über reale Entitäten ,Falsches' aussagen. Die Abweichung von der Wahrheit hat nicht unbedingt die Dereferentialisierung etwa eines verwendeten Eigennamens zur Folge. Abweichungen von der Realität müssen motiviert sein. ${ }^{237}$

\footnotetext{
${ }^{232}$ Vgl. auch Martinich 2001, S. 105: ,[...] he [eine reale Person, die auch als fiktive Figur gestaltet wird] is not only a fictional character and did not exist only in fiction. If a friend is a mental object because she is in another person's mind, it is also true that she is not only a mental object."

${ }^{233} \mathrm{Vgl}$. Eco 1999, S. $143 \mathrm{f}$.

234 Vgl. Gernhardt 1990, S. 57 f.

${ }^{235}$ Vgl. auch Hoops 1979, S. 312, bes. Fn. 132; die Erklärung, „daß es halt auf diese Weise besser paßt“ oder "klingt“, reicht zur Motivation nicht aus, da dann der durch die realen Eigennamen erhobene Anspruch gerade konterkariert wird. Eine tiefere Bedeutungsschicht, die etwa die Vergänglichkeit des Tuffsteins im Unterschied zum dauerhaften Granit ausspielte, ist nicht zu sehen. Gernhardts Kritik zielt also berechtigterweise auf die Unachtsamkeit des Autors Kunert.

${ }_{236} \mathrm{Vgl}$. Lamarque/Olsen 1994, S. 57.

${ }^{237}$ Vgl. Currie 1990, S. 164.
} 
Drittens schließlich kann ein Autor ebenso gut Wahres über reale Entitäten behaupten bzw. behaupten wollen. Verwendete Eigennamen referieren in diesem Fall uneingeschränkt ${ }^{238}$, Abweichungen werden als Fehler und unter Umständen als Schwäche des Werkes gesehen.

Als weiterer Aspekt müssen für die Feststellung der genannten Wahrheitsansprüche zwischen verschiedenen Satztypen unterschieden werden: So muß die Wahrheit präsupponierter oder im Sinne Grice' implizierter Sätze von der Wahrheit explizit geäußerter Sätze unterschieden werden. ${ }^{239}$ Ebenso muß unterschieden werden zwischen nur privat und auch öffentlich bekannten Wahrheiten, wie etwa: ,Den 23.11.1979 stand ich früh auf' gegenüber 'J.K. Rowling ist reich'. ${ }^{240}$ Geäußerte private Wahrheiten sind im Nachhinein nicht oder kaum überprüfbar. Dementsprechend geht ein Autor - wie im übrigen jeder Sprecher - beim Bericht über private Wahrheiten auch kaum eine Verpflichtung ein, das Gesagte tatsächlich zu beweisen. Ein solches Verlangen nach einem Beweis über die Wahrscheinlichkeit hinaus wäre in diesen Fällen unangemessen. ${ }^{241}$ Auch zwischen ,auch subjektiv' und ,nur objektiv' trivialen Wahrheiten besteht ein Unterschied. Lamarque und Olsen kritisieren die pro general truth theories mit Hinweis auf die Trivialität vieler präsupponierter Wahrheiten, wie etwa, „that people walk on the ground and do not fly" in Eliots Roman Middlemarch. ${ }^{242}$ Dies ist aber nur ein Typ meist stillschweigend präsupponierter Wahrheiten eines literarischen Werkes. Empirische Wahrheiten, wie sie der Satz ,London liegt an der Themse' ausdrückt, sind dagegen zwar weithin bekannt. Dennoch sind sie subjektiv nicht trivial. In ihrem Fall kann sich der Autor irren, oder er kann vermuten, daß sein Leser diesen Sachverhalt nicht kennt oder daß der Leser nicht sicher ist, ob der Autor den Sachverhalt berücksichtigt. Man kann im Anschluß an New sagen, Wahrheiten werden auch durch fiktionale literarische Werke vermittelt. ${ }^{243}$ Die Äußerung oder Präsupposition einer solchen Wahrheit muß weder trivial noch redundant sein.

\footnotetext{
${ }^{238}$ Vgl. Kroon 1994, S. 207.

${ }^{239}$ Vgl. auch New 1999, S. 110.

240 Charakteristischerweise lehnen Lamarque/Olsen ihre Ablehnung wahrer singulärer Berichtssätze in fiktionalen literarischen Texten mit dem Hinweis auf schwer überprüfbare Berichtssätze („John worked in the fields.“) und allgemeinen Aussagen („Working in the fields is tiring.“) ab und lassen gerade die überprüfbaren Berichtssätze aus (etwa: „Napoleon verlor die Schlacht bei Waterloo.“); vgl. Lamarque/Olsen 1994, S. 54.

${ }^{241}$ Umberto Eco verweist in dieser Hinsicht auf den jeweiligen Modell-Leser und den Modell-Autor, die sich aus dem Werk und den von dem Werk gestellten Ansprüchen rekonstruieren ließen (vgl. Eco 1999, S. 143-151).

${ }_{242}$ Vgl. Lamarque/Olsen 1994, S. 326.

${ }^{243}$ Vgl. New 1999, S. 114 f.
} 


\subsubsection{Namenreferenz, Fiktion, Wahrheit und Gedichtinterpretation}

Sätze mit Eigennamen geben Aufschluß darüber, ob und welche Wahrheitsansprüche ein literarischer Text erhebt. Besonders an realen Namen mit ihrer Möglichkeit zur transworld identification zeigt sich der Status literarischer Äußerungen. Wie sich die Vernachlässigung der möglichen Referenz eines realen Namens und sich daran anschließender Wahrheitsansprüche auf Gedichtinterpretationen auswirkt, soll hier an drei Beispielen gezeigt werden, in denen Gedichte zum beleg literaturtheoretischer Thesen herangezogen wurden:

Samuel R. Levin fragt in seinem Aufsatz "Concerning what kind of speech act a poem is" nach dem Sprechakt, der in der realen Welt mit einem Gedicht vollzogen wird. ${ }^{244} \mathrm{Er}$ kommt zu dem Ergebnis, daß Lyrik generell die Einladung des Autors an den Leser darstelle, sich eine Welt vorzustellen, in die sich auch der Autor imaginativ hineinversetze. Levin schlägt vor, vor jedes Gedicht eine implizite performative Formel zu setzen, die lautet: „I imagine myself in and invite you to conceive a world in which.... ${ }^{245}$ Damit bestimmt er den Sprechakt von Gedichten als Kombination eines expressiven Aktes (,ich stelle mir vor...") und einer Selbstverpflichtung (,ich lade dich ein, zu..."). Die Textfunktion von Gedichten und die durch ein Gedicht realisierten Sprechakte seien mimetisch. Gedichte erfültten die Bedingungen zum Gelingen von Sprechakten nicht. ${ }^{246}$ Als Beispielgedicht führt Levin William Blakes Holy Thursday an. ${ }^{247}$

'Twas on a Holy Thursday, their innocent faces clean, The children walking two \& two, in red \& blue \& green, Grey-headed beadles walkd before with wands as white as snow, Till into the high dome of Paul's they like Thames' waters flow.

O what a multitude they seemd, these flowers of London town!

Seated in companies they sit with radiance all their own.

The hum of multitudes was there, but multitudes of lambs,

Thousands of little boys \& girls raising their innocent hands.

Now like a mighty wind they raise to heaven the voice of song,

Or like harmonious thunderings the seats of heaven among.

Beneath them sit the aged men, wise guardians of the poor;

Then cherish pity, lest you drive an angel from your door. ${ }^{248}$

Die dort auftretenden realen Ortsnamen erklärt er so, daß sie "features of the real world" in die Fiktion des Textes einbrächten. Weder die realen Eigennamen, noch der

\footnotetext{
${ }^{244}$ Levin 1976.

${ }^{245}$ Levin 1976, S. 150; vgl. den ähnlichen Ansatz von Sutrop 2002, S. 337.

${ }^{246}$ Vgl. Levin 1976, S. 147.

${ }^{247}$ Alle folgenden Zitate befinden sich in Levin 1976 auf den Seiten 156-159.

${ }^{248}$ Ferguson/Salter/Stallworthy 1996, S. $672 f$.
} 
gesamte Text referierten aber auf die reale Welt oder stellten Wahrheitsansprüche. Selbst wenn die Aussagen wahr wären, käme es uns, den Lesern, nicht darauf an: „A poem is like a report by a traveller from outer space or time.“249

Levin bedenkt dabei nicht, daß reale Namen nicht nur einzelne Objekte in das Gedicht integrieren. Blakes Text wird umgekehrt auch in die reale Welt eingeordnet, die der potentiell unendliche Kontext der referierenden realen Namen evoziert. ${ }^{250}$ Der konkrete reale Hintergrund ist der Anknüpfungspunkt der subjektiven und poetischen Imaginationen und Reflexionen des Sprechers. Der Autor verpflichtet sich - unter anderem mit der Verwendung realer Eigennamen - zur Berücksichtigung gewisser präsupponierter Wahrheiten als Konzession an das enzyklopädische Wissen seiner Leser. Offensichtliche Fehler und ästhetisch unmotivierte Abweichungen von der Realität (etwa wenn London an der Elbe läge oder Waisenkinder nicht in die Kirche dürften etc.) würden eine Schieflage oder eine starke Änderung des Bildes bewirken. ${ }^{251}$ Dadurch, daß Blake einen realen Anlaß für seine Reflexion benutzt, wird erstens die poetische Hinwendung von der konkreten und realen Beobachtung zur religiös-allegorischen Überhöhung erst möglich. Zweitens wird der zeitgenössische und ortskundige Leser durch das gemeinsam erfahrbare reale Bild wesentlich stärker in den Text einbezogen als durch eine abstrakte Beschreibung der Orte. Der Leser kann sagen: ,Stimmt, genauso ist es!' Wenn in der letzten Zeile aus dem poetischen Bild eine moralisch-appellierende Schlußfolgerung gezogen wird, unterstützen die Anknüpfung an die Realität und die Einbindung des Lesers die Appellfunktion ${ }^{252}$ des Gedichts. Die Fragen Levins: „Does it matter [...] whether the church being entered is or is not St. Paul's?" und „[...] could not other names have been substituted for Thames and London?" müssen entgegen seiner eigenen Antworten in dieser Reihenfolge mit ,ja' und ,nein' beantwortet werden, denn die Textfunktion hängt entscheidend von der wahrheitsgemäßen Beschreibung ab.

Wolfgang G. Müller versucht, ,Subjektivität' als Gattungskennzeichen für ,Lyrik' zu rehabilitieren und führt dies am Beispiel von Edward Thomas' Adlestrop aus:

\footnotetext{
Yes, I remember Adlestrop-

The name, because one afternoon

Of heat the express-train drew up there

Unwontedly. It was late June.
}

The steam hissed. Someone cleared his throat.

No one left and no one came

On the bare platform. What I saw

\footnotetext{
249 Levin 1976, S. 157, S. 159.

250 Vgl. New 1999, S. 115.

251 Vgl. zu einem ähnlichen Fall Elliott 1966/67, S. 79.

252 Hier scheint Blake sein poetisches Bild nach dem mittelalterlichen vierfachen Schriftsinn auszulegen.
} 
Was Adlestrop—only the name

And willows, willow-herb, and grass,

And meadowsweet, and haycocks dry,

No whit less still and lonely fair

Than the high cloudlets in the sky.

And for that minute a blackbird sang

Close by, and round him, mistier,

Farther and Farther, all the birds

Of Oxfordshire and Gloucestershire. ${ }^{253}$

Hierzu bemerkt er, Ortsbewußtsein konstituiere sich in diesem Gedicht in „einem Akt [subjektiver] poetischer Wahrnehmung“. „Durch einen Namen wird die Erinnerung an eine Eisenbahnfahrt wachgerufen [...]. Der Name wird optisch perzipiert [...]. Daran schließt sich [...] eine Reihe von wahrgenommenen Naturdetails an. ${ }^{\text {"254 }}$ Müller beachtet dabei nicht, daß das Gedicht Thomas' die Dereferentialisierung eines referierenden realen Ortsnamens inszeniert. Durch die Überschrift des Gedichts und die erste Zeile werden Erwartungen nach Sinnfüllung des weithin unbekannten Eigennamens ,Adlestrop' geweckt. ${ }^{255}$ Doch der Sprecher nimmt im Folgenden nur den Namen auf dem Bahnhofsschild wahr, er sieht lediglich das ,Etikett' des Ortes, zu dem er keinen Inhalt findet. In der dritten Strophe verliert sich erst der Blick im Himmel, dann ebenso das Gehör in der vierten Strophe in den Weiten zweier Regionen. Der reale Ortsname wird in beiden Fällen nicht mit einem zur Identifikation des Ortes führenden semantischen Inhalt gefüllt. Die Andeutung zu Beginn der ersten Strophe „Yes, I remember Adlestrop - The name [...]" zeigt bereits die alles Gegenständliche in subjektiven Eindrücken auflösende Wahrnehmung im Rest des Gedichts.

Während das wichtigste Kennzeichen des Ortsnamens ,Adlestrop' seine relative Unbekanntheit ist, dienen die zwei Regionennamen am Ende des Gedichts der eher allgemeinverständlichen Einordnung der Reflexion. Erst im letzten Vers wird durch die Ausweitung der Eindrücke des Sprechers auf die Regionen „Oxfordshire and Gloucestershire" der fragliche Ort auch für ein größeres Publikum greifbar. Denn Regionen und ihre Landschaften sind meist überregional bekannt und mit bestimmten grundlegenden Kennzeichnungen (,lieblich', ,rauh' etc.) behaftet. An diesem producer- oder consumerEigennamenwissen zu Regionennamen kann nun auch die mit Adlestrop selbst nicht vertraute Leserschaft den Eindruck des Gedichts messen. Eigennamen bestimmen in diesem Fall wie auch bei William Blake unter anderem die Rezeptionsstrategie eines Autors. Während der Sprecher beim konkreten, aber nicht faßbaren Einzelfall (dem Ort

\footnotetext{
${ }^{253}$ Ferguson/Salter/Stallworthy 1996, S. 1148.

${ }^{254}$ Müller 1998, S. 102.

${ }^{255}$ Es handelt sich um einen Ort in Oxfordshire. Allerdings ist Adlestrop auf den wenigsten Karten zu finden. Insofern handelt es sich um einen zumindest überregional unbekannten Ort.
} 
Adlestrop) beginnt und anschließend den Blick weitet und auf den Horizont der Region ausrichtet, wird der Leser umgekehrt nach der Präsentation eines inm unbekannten Ortes durch die Erwähnung der Regionen mit seinem eigenen Erfahrungswissen in das Erlebnis des Sprechers einbezogen.

Lamarque und Olsen schließlich benutzen zur Darstellung ihrer Version einer no truth theory unter anderem William Wordsworth' Lines composed a Few Miles above Tintern Abbey, on Revisiting the Banks of the Wye during a Tour. July 13, 1798. ${ }^{256}$

Sie geben durchaus zu, daß es einen realen Anlaß zu dem Gedicht gab und daß dieser Anlaß durch die Daten im Titel identifiziert wird. Dennoch halten sie das Gedicht für fiktional: „to be considered as presented in the fictive mode“. ${ }^{257}$ Sie schließen dies daraus, daß der Haupttext keine Aussagen enthält, die der Zustimmung oder Ablehnung durch den Leser bedürften: „What is important is the theme that grows out of the presentation of subject in the poem. "258 Einzelne Sätze mit Wahrheitsanspruch in einem Gedicht anzusiedeln, führe zu der unbefriedigenden Situation, daß der Leser ständig zwischen verschiedenen Einstellungen dem Geäußerten gegenüber wechseln müsse. ${ }^{259}$ Daher sei der „propositional content“ nur dazu da, fiktive „states of affairs“ zu charakterisieren. $^{260}$

Bei genauerer Betrachtung erkennt man tatsächlich, daß Wordsworth einen ,typisch lyrischen' Haupttext ohne explizite Realitätsanbindung komponiert hat. Der wegen seiner Länge recht unhandliche, aber für Wordsworth nicht untypische Titel ist aber dann notwendig, um die deiktischen Ausdrücke des Textes zu konkretisieren und mit einem semantischen Inhalt zu füllen. Der Haupttext enthält entgegen Lamarques und Olsens Postulat zahlreiche Aussagen, deren Wahrheitsansprüche aufgrund des ungewöhnlich konkreten Titels der Zustimmung des Lesers bedürfen. Denn es werden konkrete Einzelheiten des realen Ortes angesprochen. ${ }^{261}$ Wären die beschreibenden Sätze alle auf offensichtliche Weise falsch, so wäre der ausführliche Titel lächerlich. Mit dem konkreten Titel verpflichtet sich der Autor zu einer wahrheitsgetreuen Darstellung. Würde er diese Verpflichtung nicht einlösen, änderten sich entweder Funktion und Bedeutung des Textes $^{262}$ - wenn hinter der Abweichung eine Absicht vermutet werden könnte -, oder

\footnotetext{
${ }^{256}$ Vgl. Ferguson/Salter/Stallworthy 1996, S. 699-703; wir drucken das Gedicht wegen seiner Länge hier nicht ab.

${ }^{257}$ Vgl. Lamarque/Olsen 1994, S. 283 f.

${ }^{258}$ Vgl. Lamarque/Olsen 1994, S. 284.

${ }^{259}$ Vgl. Lamarque/Olsen 1994, S. 285.

${ }^{260}$ Vgl. Lamarque/Olsen 1994, S. 284.

${ }^{261}$ Vgl. dazu auch Hühn/Schönert 2002, S. 298.

${ }^{262}$ Vgl. New 1999, S. 117.
} 
es änderte sich der literarische Wert des Textes - wenn die Abweichung auf einer Ungeschicklichkeit beruhte.

Die drei hier vorgeführten Fälle zeigen, daß die Anbindung an reale Kontexte und die Einbeziehung der Wahrheitsansprüche und der Referenz der Gedichte die Interpretation des jeweiligen literarischen Textes stark beeinflussen. Legt der Autor die Referentialisierung des Textes nahe, sind Wahrheit und Referenz in Gedichten für die Beurteilung der Textstrategien und für die Beurteilung des literarischen Wertes wichtig. Eigennamen spielen dabei eine bedeutende Rolle.

Texte mit unterschiedlichen Wahrheitsansprüchen werden von den sprachanalytischen Theorien der Fiktion leicht übersehen, weil sie sich bei der Beurteilung des referentiellen Status von Literatur gerne von vornherein auf "clear cases of standard fiction“ beschränken. ${ }^{263}$ Besonders Gedichte mit Eigennamen sind kein ,clear case'. Wie wir gesehen haben, sind Eigennamen in bezug auf ihre Referenz wie ihren semantischen Inhalt unsichere Zeichen. In Texten der Altagskommunikation regelt der unmittelbare Kontext den (intendierten) semantischen Nameninhalt bzw. die intendierte Referenz des Namens. Mehrdeutige oder unbekannte Namen führen zu metakommunikativen Sequenzen oder zum Abbruch der Kommunikation. Geht man davon aus, daß durch einen literarischen Text eine Textwelt aufgebaut wird ${ }^{264}$, bilden Eigennamen komplexe Verbindungsstellen zwischen der textinternen Situation und der textexternen Welt (zwischen Text und Kontext). Als rigid designators können sie über die Textgrenzen hinaus referieren und eine unbestimmt große Menge an Informationen in die textinterne Situation einbringen. Dadurch vermitteln sie unter Umständen ein Weltwissen, dessen Verbindung mit den übrigen Textelementen unsicher ist. Alle Eigennamen referieren daher zunächst auf innertextliche Objekte: auf Objekte, die Teil der im Text gestalteten Situation sind. Doch kann unterschieden werden zwischen Eigennamen, deren Namenträger auch außerhalb der textinternen Situation existiert, und Eigennamen, deren Namenträger nur in der textinternen Situation existiert. Aus welchen unterschiedlichen Gründen die Bedeutungsstruktur beider Namentypen unsicher ist, werden wir im Folgenden untersuchen.

\footnotetext{
${ }^{263}$ Crittenden 1982, S. 335 f.

${ }^{264}$ Vgl. zu einer genaueren Bestimmung des Begriffs ,Textwelt': Beckmann 1991, bes. S. 7-9; vgl. auch den Hinweis in Weimar 2003, S. 232.
} 


\subsubsection{Namen außertextlicher Objekte}

\subsubsection{Formen des referentiellen Bezugs auf den Kontext eines literarischen Werkes}

Wie die drei Gedichtbeispiele des vorhergehenden Kapitels schon andeuten, können Gedichte prima facie als die Domäne von Namen, die über den Text hinausweisen, bezeichnet werden, weil die einzelnen Namenzeichen weitgehend kontextisoliert sind. Dabei muß es sich nicht um Namen realer Objekte handeln. ${ }^{265}$ Vielmehr ist die Lyrik anzusehen als Bereich der dem impliziten Leser bekannten oder der berühmten über den Text hinaus weisenden Eigennamen, mögen diese nun real (,Napoleon') oder fiktional (,Zeus') sein. Dennoch werden wir im Folgenden der Kürze halber von ,realen Eigennamen' sprechen, wenn wir Namen meinen, die über den Text hinaus weisen, denn aus der Perspektive eines fiktionalen Textes sind alle außertextlichen Entitäten ,realer' als die rein innertextlich konstituierten Entitäten.

Im Folgenden sollen die Möglichkeiten des referierenden Bezuges über Textgrenzen hinaus genauer untersucht werden. Die Grundlage dieser Untersuchung wurde mit der sprachanalytischen Betrachtung der Eigennamenreferenz gelegt. Sie wird hier um eine Theorie der Bezugnahme literarischer Werke auf eine außertextliche Welt durch Eigennamen erweitert. Nach einer allgemeinen Festlegung möglicher Formen von Referenz im Anschluß an Nelson Goodman werden die verbreiteten Positionen zur Referenz realer Namen in fiktionalen Texten analysiert. Anschließend wird eine eigene Position dargelegt.

Als ,Bezug eines Zeichens auf etwas anderes' kann der Begriff der Referenz vielfältig benutzt werden. ${ }^{266}$ Bei einer ungenauen Verwendung des Referenzbegriffs entstehen allerdings scheinbare Konkurrenzen und ,Paradoxien' z.B. zwischen dem Realitätsbezug politischer Lyrik und deren Autoreferenz oder zwischen dem individuellen Bezug eines Gelegenheitsgedichts und dessen generalisierter Bedeutung. Deswegen sollte zwischen der Referenz im engeren Sinne (verbal und pictorial denotation ${ }^{267}$ ) und anderen Möglichkeiten der referierenden Bezugnahme unterschieden werden, wie sie Goodman als forms of reference beschrieben hat: exemplification, expression und representation. ${ }^{268}$ Die Referenz im engeren Sinne (denotation) eines Ausdrucks ist der

\footnotetext{
${ }^{265}$ Dies behauptet Burdorf 1995, S. 167, S. 169 f., zu unrecht; Gutschmidt 1984, S. 139 f., benennt ebenso irrtümlich den Roman als eigentliche Sphäre der über den Text hinausweisenden Namen.

${ }^{266}$ Vgl. Goodman 1984, S. 55.

${ }^{267}$ Vgl. Goodmann 1984, S. 55 f. und S. 57 f.

${ }^{268}$ Vgl. Goodman 1976; Scholz 1984, S. 80-85.
} 
Gegenstand, die Situation, die Gruppe oder die Klasse, die der Ausdruck in der Rede vertritt. $^{269}$

Goodman zufolge kann es zwischen Zeichen und Objekten weitere Formen der Bezugnahme geben: Beschreibungen, bildliche Darstellungen und auch Eigennamen klassifizieren ein denotiertes Objekt als ein „Soundso“ (representation-as). ${ }^{270}$ Representationas bildet unter anderem die Grundlage dafür, daß eine Eigenschaft am denotierten Objekt ausgezeichnet wird und daß das Objekt diese exemplifiziert.

„Exemplification is possession plus reference“271: Etwas exemplifiziert eine Eigenschaft, wenn es diese Eigenschaft hat und der Kontext erkennen läßt, daß auf diese verwiesen werden soll. Wichtig für die Exemplifikation ist die Komponente ,possession'. Sie trennt bei sprachlichen Kunstwerken die Sphäre der fiktiven oder realen erzählten (evozierten) Welt von dem Vorgang des Erzählens bzw. der sprachlichen Gestaltung.

Der Name in unserem Epitaph

Hier ligt Poot,

hij is dood. ${ }^{272}$

ermöglicht zwei kategorisch voneinander zu trennende Arten der exemplification. Erstens referiert der Eigenname auf eine konkrete Person oder Figur. Dieser Namenträger kann durch seine Eigenschaften, die den semantischen Hintergrund des Namens bilden, etwas exemplifizieren - Eigenschaften, Handlungsweisen, Schicksale, weitere Personen, die durch den Namenträger ,symbolisiert' werden usw. Ein Eigenname in einem literarischen Text baut so eine kettenartige complex reference aus denotation und exemplification auf. ${ }^{273}$ Dieses Potential nutzen etwa Grabinschriften, die aus dem Leben des Toten ein exemplum machen, z.B. für die Nichtigkeit des Lebens als vanitasTopos:

Hier legt begraven Poot,

Die leeft, al is hy doot. ${ }^{274}$

Zum anderen kann das Zeichen selbst seine Eigenschaften exemplifizieren, ein Name zu sein, bestimmte Klangeigenschaften oder eine bestimmte Semantik zu haben usw.

Die Exemplifikation des Zeichens macht Wortspiele mit Namen möglich:

Hier leggen begraven Poots poten,

Dees Poot heeft ieders poot verstoten. ${ }^{275}$

\footnotetext{
${ }^{269}$ Eigennamen in Kunstwerken stehen dabei durchaus zwischen verbal und pictorial reference, weil sie den Namenträger in einem „dichten System“ (dense system) als nicht qualifiziertes Ganzes darbieten.

${ }_{270}^{270}$ Vgl. Goodman 1976, S. 30 Fn. 25.

${ }^{271}$ Goodman 1976, S. 53; in der Klassifikation Goodmans finden sich häufiger solche versteckten intentionalen Elemente.

${ }^{272}$ Gerrit van de Linde ljzn in: Komrij 1979, S. 104.

${ }^{273}$ Vgl. Goodman 1984, S. 61.

274 „Hier liegt begraben Poot, / Er lebte, schon ist er tot"; Komrij 1986, S. 974.
} 
Sie kann darüber hinaus auch ,Klangspiele' anregen, die kaum noch ,Sinnspiel' enthal$\operatorname{ten}^{276}$ :

Hier slaapt den grooten digter Poot

Nog grooter niet door poot o doot

Poot gepoot poeet poot ook

Maar door poto wiert al rook. ${ }^{277}$

Weiter drückt Zeichen a nach Goodman dann eine Stimmung $b$ aus (expression), wenn "(1) a possesses or is denoted by $b$; (2) this possession or denotation is metaphorical; and (3) a refers to $b .{ }^{278}$ Auf referierende wortsprachliche Ausdrücke angewendet bedeutet dies, daß ein Ausdruck eine Stimmung ausdrücken kann, wenn auf seine Zeicheneigenschaften metaphorisch der Stimmungsbegriff angewendet werden kann: Der Name ,Roquiarol' klingt (das heißt, ,ist im übertragenen Sinne') schauriger als „Falterle', ohne daß eine genauere Bestimmung möglich wäre. Darüber hinaus kann in einer Kette der complex denotation ${ }^{279}$ wieder auch auf den denotierten Gegenstand ein Stimmungsbegriff angewendet werden, den dieser dann ausdrückt. Der Namenträger Napoleon - nicht nur der Name ,Napoleon' - steht so z.B. auch für ,das Heroische'.

Festzuhalten ist, daß ein referierender Ausdruck in einem literarischen Text ein Objekt denotiert und es dabei klassifiziert (representation-as). ${ }^{280}$ Der Ausdruck selbst kann als token seinen type bzw. dessen Zeicheneigenschaften exemplifizieren. Das denotierte Objekt seinerseits kann seine Eigenschaften oder weitere Objekte exemplifizieren. Die Eigenschaften der Zeichen wie der genannten Objekte können Stimmungen ausdrücken.

Die Kategorien exemplification und expression stellen Potentiale referierender Äußerungen dar, die des Nachweises der Sprecherintention bedürfen. Durch Kontext- und Kotextfaktoren müssen bestimmte Eigenschaften des Zeichens oder des Referenzobjekts aktualisiert werden, um vom Zeichen oder dem Referenzobjekt ausgedrückt oder exemplifiziert zu werden. Kontextfaktoren bestimmen zudem in hohem Maße, ob und worauf ein Ausdruck referiert - ob ,Apoll' die mythische Figur meint, einen Fürsten oder

\footnotetext{
275 „Hier liegen Poots Pfoten begraben, / Dieser Poot hat jedermanns Pfote abgelehnt“; Komrij 1986, S. 974.

${ }_{276}^{27}$ Zu dieser Unterscheidung vgl. Wagenknecht 1975, S. 17.

277 „Hier schläft der große Dichter Poot / Noch größer nicht durch Knochen oder Tod / Poot, ein Poet mit Pfoten pflanzte auch / Aber durch Poto [?] wurde es alles Rauch“; Komrij 1986, S. 974; vgl. Goodmans Ausführungen zu autoreferentiellen Zeichen in Goodman 1976, S. 59.

278 Vgl. Goodman 1976, S. 95

${ }^{279}$ Vgl. Goodman 1982, S. 162 f.: „[...] for the literary work, forms and feelings and other features exemplified or expressed or signified through varied short or long referential chains usually count for more."

${ }^{280}$ Festzuhalten ist, daß gerade bei Eigennamen die Klassifizierung auf besondere Weise über sortale Prädikate etc. vor sich geht (s.o.).
} 
einen Hund. $\mathrm{Zu}$ beachten ist dabei, daß die Ausrichtung auf einen Kontext nicht ohne jeglichen Bezug auf vorkommende referierende Ausdrücke geklärt werden kann. Die verlangte Referentialisierung von Namen bewegt sich in einem Zirkel. ${ }^{281}$

Das Zusammenspiel der verschiedenen forms of reference in einem Text ermöglichen schließlich die allgemeine Anwendung oder Generalisierbarkeit des konkret Gesagten. $^{282}$

\subsubsection{Außertextliche Objekte und die Textwelt: Positionen}

Goodmans forms of reference zeigen das Potential der Referenz literarischer Eigennamen. Dennoch tun sich sprachphilosophische Entwürfe zur Fiktionalität schwer damit, diese möglichen Formen der Referenz und die Rolle der Eigennamen in diesem Zusammenhang in ihre Modelle fiktionaler literarischer Sprachverwendung zu integrieren.

Die Befürworter einer generellen Bedeutungslosigkeit der Referenz fiktionaler literarischer Texte auf eine, reale Welt' integrieren über die Textwelt hinausweisende Eigennamen in ein rein innertextliches System. Realen Eigennamen sprechen sie in fiktionalen literarischen Texten die direkte Referenz über den Text hinaus ab. Diese stünden lediglich für eine umfangreiche definite description, die sich aus den expliziten Prädikationen im Text und zusätzlich aus enzyklopädischen Informationen anderer Quellen zusammensetzten. Auf dieser Grundlage wird innerhalb eines Textes ontologisch nicht unterschieden zwischen Eigennamen, die fiktive Personen beschreiben, Eigennamen, die auf reale Personen anspielen, Eigennamen, die reale oder aus anderen Texten übernommene Personen oder Figuren neu gestalten und schließlich Eigennamen, die tatsächlich auf reale Personen referieren. Eigennamen außertextlicher Entitäten unterschieden sich lediglich in ihrem Inhalt, weil sie anders als nur auf innertextliche Entitäten referierende Namen einen umfangreichen Sinn in den literarischen Text einbrächten. ${ }^{283}$ Demnach referiert für Lamarque und Olsen der Name ,London' in einem fiktionalen literarischen Text nicht auf „London per se“ sondern auf "London under certain aspects“. Sie sprechen daher realen Eigennamen in fiktionalen literarischen Texten die uneingeschränkte (,pure“) Referenz ab. ${ }^{284}$

\footnotetext{
281 Auch Autoreferentialität ist in vielen Fällen eigentlich eine Form der exemplification und zu unterscheiden von Selbstreferenz im Sinne selbstbezüglicher Schreibweisen. Zeichen bzw. Eigennamen in einem Text können daher polyfunktional sein, also etwas denotieren und gleichzeitig etwas anderes exemplifizieren, vgl. Scholz 1984, S. 81.

282 Etwa im Sinne der Griceschen Konversationsmaxime „Be relevant.“ (vgl. Grice 1989, S. 27); Scholz 1984, S. 80-85, bezeichnet dies als „sekundäre Extensionen“; vgl. Gabriel 1975, 60 f.; Gabriel 1982, S. 543.

${ }^{283}$ Vgl. Birus 1978, S. 31-34; jüngst z.B. auch Koß 2002, S. 169; kritisch: Schillemeit 1982.

${ }^{284}$ Vgl. Lamarque/Olsen 1994, S. 81.
} 
Der Vorgang der Integration eines realen Eigennamens in einen fiktionalen Text ist jedoch komplizierter. Es besteht sowohl ein Bezug des Namens zum außertextlichen Namenträger, als auch ein Bezug zum innertextlich gestalteten Objekt. Der Rezipient muß auf der einen Seite den Eigennamen als Zeichen verstehen, das auf ein reales Objekt referiert, um die sich dahinter verbergende definite description zu suchen und zu erschließen. Auf der anderen Seite muß er den Eigennamen als dereferentialisierten bzw. rein innertextlich referierenden Namen erkennen, ohne die über das reale Objekt erschlossenen Informationen zu verlieren. ${ }^{285}$ Nur so kann er begreifen, daß Shakespeares Wittenberg, in dem Hamlet wohnte, dem realen Wittenberg zwar nicht vollständig entsprechen soll, daß im Text aber von einem Wittenberg die Rede ist, das vieles mit dem realen Wittenberg gemein haben soll.

Einige Theorien versuchen dieses Problem dadurch zu lösen, daß sie zwei Namenträger des gleichen Namens postulieren: neben dem realen noch einen von diesem abgeleiteten fiktiven. So schreibt Rodiek zu kontrafaktischen Gestaltungen Napoleons in fiktionalen Texten:

Der Name ,Napoleon' referiert prinzipiell auf die reale Person Napoleon [...]. Dort, wo der kontrafaktische Napoleon $\left(\mathrm{N}_{\mathrm{k}}\right)$ hinsichtlich bestimmter Eigenschaften mit dem realen Napoleon $\left(N_{r}\right)$ nicht vereinbar erscheint, werden bei der Lektüre die entsprechenden $\mathrm{N}_{r}$-Merkmale dergestalt neutralisiert, daß ein homogener $N_{k}$ als fiktionale Gestalt zustande kommt. Einerseits ist die Verschmelzung von $\mathrm{N}_{\mathrm{k}}$ und $\mathrm{N}_{\mathrm{r}}$ nur eine Als-Ob-Verschmelzung, andererseits gilt sie nur für die Dauer der Lektüre. Tatsächlich koexistieren im Bewußtsein des Lesers der reale und der kontrafaktische Napoleon als deutlich unterscheidbare Größen. ${ }^{286}$

Anders geht Parsons vor, der von der kausalen Referenz der Eigennamen in fiktionalen Texten auf nichtexistierende und existierende Objekte ausgeht und daher die vom Eigennamen denotierten realen Objekte in die Textwelt zu integrieren sucht. Es handelt sich für ihn um verschiedene Gruppen von Objekten. Die Objekte können rein fiktiv sein (,native objects') oder aus einer anderen möglichen oder der realen Welt 'importiert' werden (,immigrant objects'). ${ }^{287}$ Zusätzlich unterscheidet Parsons noch ,surrogate objects': Diese sind mit Hilfe „of our common understanding“ bekannter realer Objekte erschaffene fiktive, bzw. nichtexistierende Objekte. Ein Sprecher in einem fiktionalen Text könne zwar auf das reale London (the object 'N') und ebenso auf das Surrogat-London (the object , $N$ of the story $s$ ') referieren, nicht aber auf beide gleichzeitig. ${ }^{288}$

Zipfel präzisiert Parsons' Modell dahingehend, es handle sich bei ,immigrant objects' um Objekte, die für die Fiktion nicht signifikant verändert, bei ,surrogate objects' dage-

\footnotetext{
${ }^{285}$ Whiteside 1987, S. 178 f., spricht in diesem Fall von einer primären Referenz auf den außertextlichen Namenträger und einer sekundären Referenz auf ein Autor-Leser-Artefakt.

${ }^{286}$ Rodiek 1993, S. 273.

${ }^{287}$ Vgl. auch Zipfel 2001, S. $91 \mathrm{f}$.

${ }^{288}$ Vgl. Parsons 1980, S. 58.
} 
gen um Objekte, die signifikant verändert würden. Zu diesen Fällen tritt noch ein dritter Fall hinzu, in dem ,Napoleon' nur der präfigurierte Name einer Gestalt der Fiktion ist. Es findet dabei eine Taufe auf einen berühmten Namen statt, die eine Verbindung zwischen dem Getauften und dem ursprünglichen Namenträger herstellt.

Rodieks und Zipfels Erklärungen bleiben allerdings so lange unbefriedigend, wie der Begriff der ,Signifikanz' nicht geklärt wird. Rodiek stellt Behauptungen über die Leserpsyche unbewiesen gegen die von inm selbst beschriebene sprachliche Tatsache, daß der Eigenname immer auf einen aktuell intendierten Namenträger referiere. Sein Postulat widerspricht der Intuition, daß der ,Napoleon $_{k}$-Text' unter Umständen von Napoleon und dessen kontrafaktischen, aber möglichen Handlungsweisen handelt, nicht aber von

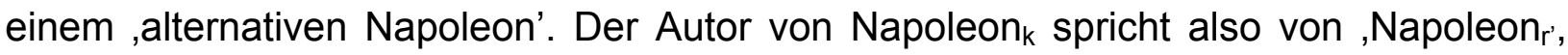
auch wenn er diesem eine andere Handlungsweise etc. zuschreibt. Deutlich wird dies, wenn man sich die notwendigen Schritte in einem game of make believe zu diesem Text vor Augen führt. In dem Satz eines fiktionalen Textes ,Napoleon stirbt auf Korsika' wird etwas über Napoleon gesagt. Die Aussage ist falsch. Zur Konstitution des game of make believe gehört es nun, daß der Leser annimmt, Napoleon sei auf Korsika gestorben. Er muß nicht annehmen, daß ein kontrafaktischer Napoleon auf Korsika starb. Es existier(t)en nicht zwei Napoleons, derjenige des Textes und derjenige der Realität. Vielmehr wird im Text etwas Fiktives über den realen Napoleon behauptet. Nach Parsons, Rodiek und Zipfel muß der Satz ,Napoleon stirbt auf Korsika' metasprachlich paraphrasiert werden als ,des Autors N.N. Napoleon stirbt auf Korsika'. Plausibler scheint uns die Paraphrase der ,Autor N.N. läßt Napoleon auf Korsika sterben' oder ,Napoleon stirbt in N.N.'s Werk auf Korsika (...und nicht auf St. Helena)'. ${ }^{289}$ Die erste Paraphrase referiert im Gegensatz zur zweiten und dritten nicht auf den realen Napoleon. Das game of make believe einer solchen Fiktion verlangt nicht, daß man sich eine andere Figur vorstellt. Vielmehr muß der Leser sich vorstellen, der reale Napoleon $\left(\mathrm{N}_{\mathrm{r}}\right)$ hätte anders gehandelt oder wäre anders gewesen als in der Realität. Die extreme Gegenposition zu Rodiek und Parsons wird jüngst von Friend vertreten. Sie geht davon aus, daß der reale Namenträger in jedem Fall das Referenzobjekt eines Namens („connected name“) bleibt. ${ }^{290}$ Weiche eine fiktionale Beschreibung deutlich von der Realität ab, werde die Referenz auf den realen Namenträger trotzdem nicht unterbrochen. ${ }^{291}$ Friend ihrerseits beachtet dabei nicht, daß ab einem bestimmten Grad der Abweichung einer fiktionalen Beschreibung von der definite description eines realen Namenträgers, die Referenz auf

\footnotetext{
${ }^{289}$ Vgl. Friend 2000, S. 190 f.; Brock 2002, S. 1.

${ }^{290}$ Friend 2000, S. $186 \mathrm{f}$.

291 Friend 2000, S. 195.
} 
diesen Namenträger grundsätzlich in Frage gestellt wird. Es ist immer ein Minimum an zutreffenden Kennzeichnungen vonnöten, das die Referenz des Namens sicherstellt, sonst wird eine Sprechergemeinschaft von einem neuen gültigen Namengebungsakt ausgehen.

Sowohl Parsons als auch Zipfel und Rodiek gehen aus einer fiktionstheoretischen Sicht davon aus, daß bei Abweichungen von der Realität aus den außertextlichen immigrant objects innertextliche surrogate objects („pseudo-reale Objekte“ ${ }^{292}$ ) werden. Vom Standpunkt der Eigennamentheorie ist dies dann unbefriedigend, wenn man sich vor Augen führt, worüber der Autor spricht, wenn er einen Satz mit einem realen Eigennamen benutzt.

Modelle, die auf der kausalen Eigennamentheorie und einer Mögliche-Welten-Semantik aufbauen, können auf andere Weise mit Entitäten verschiedener Provenienz umgehen, die in einem Text auftauchen. Ein Mögliche-Welten-Operator, der vor metasprachliche und objektsprachliche Sätze oder Texte gestellt wird, schließt nicht aus, daß mittels eines rigid designators - z.B. dem Namen eines realen Objektes - über mehrere mögliche Welten hinweg referiert wird (transworld identification). Im literarischen Text wird ein set von möglichen Welten zusammengebunden, zu dem auch die reale Welt gehört. ${ }^{293}$ Als rigid designators referieren Eigennamen realer Personen nun auch in fiktionalen literarischen Texten so lange auf ihre realen Namenträger, wie durch den literarischen Text nicht eine neue ,Tradition' begründet wird, ${ }^{294}$ also so lange, wie keine neuer Namengebungsakt (implizit) postuliert wird.

Die Beschränkung der kausalen Referenz auf die Autorvorstellungen würde die Referenz auf reale Gegenstände ('Immigranten') in fiktionalen Texten als Referenz auf Vorstellungen des Autors von der Realität erklären. Kontrafaktische Aussagen über reale Objekte können durch die subjektive Vorstellung, die ein Autor sich von dem Gegenstand macht, zustandekommen. Die Idee des make-believe ist gegenüber einer möglichen Referenz über den literarischen Text hinaus ebenso flexibel. ${ }^{295}$ Currie geht z.B. davon aus, daß in einem literarischen Werk sowohl „fictional names“ als auch „proper names“ vorkommen. ${ }^{296}$ Fiktionale Namen referierten als „descriptive names“ auf Rollen

\footnotetext{
292 Zipfel 2001, S. 97-102.

${ }^{293}$ Vgl. Pavel 1986, S. 42, S. 46; Wolterstorff 1979, S. 107.

294 Zu einem Beispiel für die „transworld identification“, vgl. z.B. Kripke 1972, S. 282.

295 Vgl. Currie 1990, S. 35, S. 128.

296 Vgl. Currie 1990, S. 128-131; Gutschmidt 1979, S. 111; Gutschmidt 1984, S. 139 f., unterscheidet irreführend zwischen „literarischen Namen“ und „Namen von Objekten außerhalb der Fiktion“. Uns gelten dagegen alle Namen in einem literarischen Werk als Teil der literarischen Rede und damit als ,literarische Namen'.
} 
(roles) im Sinne der Beschreibungstheorie Wolterstorffs. ${ }^{297}$ Sätze, in denen fiktionale Namen vorkämen, seien nur in der Fiktion wahr. Personennamen dagegen referierten über den Text hinaus, wenn der Autor die reale Person meine. ${ }^{298}$ Sätze eines fiktionalen Textes mit realen Eigennamen seien sowohl in der Fiktion als auch in der Wirklichkeit wahr. Sie könnten deshalb die Funktion haben, Elemente und Situationen der Wirklichkeit in das make-believe einzubringen, die dieses wahrheitsähnlicher machten. ${ }^{299}$ Es hängt innerhalb eines literarischen Werkes zu einem guten Teil von den Intentionen des Autors ab, ob eine einzelne Aussage, die Eigennamen enthält, mit Wahrheitsanspruch gemacht wird und ob sie über den Text hinaus referieren soll. Reale Eigennamen können entweder ein Ebenbild (counterpart) der realen Entität oder diese selbst meinen. ${ }^{300}$ Da Fiktionalität eher eine Frage der intentionalen illocutionary force als der Bedeutung (meaning) ist und die Intentionen des Autors nicht immer klar zu bestimmen sind, ${ }^{301}$ ist auch nicht immer eindeutig, in welchem Maße und mit welchem Anspruch literarische Eigennamen referieren. Wir werden im Folgenden auf der Grundlage einer moderaten Position zur Eigennamenreferenz über den Text hinaus die verschiedenen Möglichkeiten der Eigennamenreferenz über die Textwelt hinaus beschreiben, wie sie für die Gedichtanalyse von Bedeutung sind.

\subsubsection{Formen der Namenreferenz über die Textwelt hinaus: eine moderate literatur-} wissenschaftliche Position

Im Gegensatz zu den vorgestellten philosophisch orientierten Modellen, vertreten wir in der Diskussion um die Referenz realer Namen in literarischen Texten eine moderate Position. Sie ist dadurch gekennzeichnet, daß sechs verschiedene Formen der Namenreferenz über die Grenzen der Textwelt hinaus angenommen werden.

Eine außertextliche Entität (eine Person oder ein Ort) kann erstens durch die unkommentierte und nicht weiter gestaltete Erwähnung des Eigennamens in ein Gedicht integriert werden. In diesem einfachsten Fall der Referenz über den Text hinaus beziehen sich die referierenden Ausdrücke und die aus dem Satz folgende definite description wahrheitsgemäß und mit Behauptungsanspruch auf außertextliche existierende Objekte. Dies gilt allemal auch, wenn der Eigenname als Zitat, ohne eine gestaltete Figur zu bezeichnen, verwendet wird. ${ }^{302}$

\footnotetext{
${ }^{297}$ Vgl. auch Currie 1990, S. 171-180.

298 "To have in mind“; Currie 1990, S. 128-135.

299 "Vgl. Currie 1990, S.128 f.

${ }^{300}$ Vgl. Crittenden 1991, S. 135.

${ }^{301}$ Vgl. Crittenden 1991, 135; Currie 1990, S. 13.

302 Vgl. Thies 1998, S. 407; Müller 1991a, S. 150.
} 
Präsupponierte oder geäußerte Sätze haben in diesem Fall die Funktion, die fiktiven Ereignisse in der realen Welt zu lokalisieren, indem reale Objekte unverändert in die fiktive Welt integriert werden. ${ }^{303}$ Sie geben keine Information zu Handlungen des Namenträgers in der fiktiven Welt. Informationen über Eigenschaften des Namenträgers sind vollkommen wahrheitsgemäß und oft allgemein bekannt. Streng genommen wird in die definite description immer das relationale Prädikat, existierte in einer Welt mit der fiktiven Handlung' aufgenommen. Doch bedeutet dieses eher, daß die fiktive Welt an die reale Welt angenähert wird, als daß Falsches über das reale Objekt behauptet würde. ${ }^{304}$ In dieser Form der Eigennamenverwendung wird der Eigenname als Bestandteil des Diskurses (in Figuren- oder Erzählerrede) erwähnt. Die ,unwahre' Aussage wird über die Welt des realen Objekts, nicht über das Objekt selbst gemacht. Die wahre Aussage über das Objekt ist zumeist allgemein bekannt und kann an außerliterarischen Kriterien gemessen werden. Ein Beispiel dafür ist der Beginn von Edgar Lee Masters Gedicht Jacob Goodpasture, in dem der Sprecher dieses Namens eine fiktive Figur ist, der Ortsname ,Fort Sumter' hingegen ein berühmter realer Name, der den Ort denotiert, an dem der amerikanische Bürgerkrieg begann:

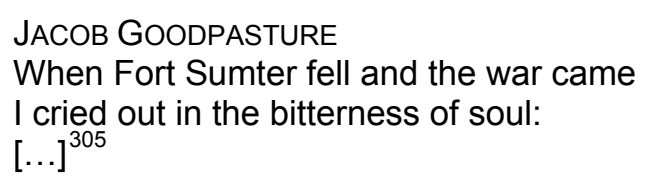

Im Rahmen des make-believe können Referenzen auf reale Objekte die Funktion haben, dem Leser die Anreicherung der expliziten Zeichenbedeutung durch eigene Kenntnisse zu ermöglichen. ${ }^{306}$ Während Sätze mit den Eigennamen fiktiver Entitäten semantisch nicht unabhängig vom Gesamttext verstanden werden können, ${ }^{307}$ sind Sätze mit Namen realer Personen in einem gewissen Maße autonom. Der Leser ist als consumer anderer Informationsquellen oder als mit der Person bekannter producer berechtigt, über die vom Autor gegebenen Informationen hinaus Wissen über die dargestellte Person oder Figur zu akkumulieren. Dies gilt für alle Entitäten in einem literarischen Text, für die der Autor nicht das producer-Monopol hat, also auch für fiktive Entitäten anderer Texte.

Zweitens können reale Entitäten als gestaltete Entitäten in die fiktive Welt integriert werden:

\footnotetext{
${ }^{303}$ Vgl. Seibicke 1982, S. 89 f.; Viljoen 2002, S. 311.

${ }^{304}$ Vgl. Zipfel 2001, S. 100.

${ }^{305}$ Vgl. Masters 1992, S. 132, und den Kommentar auf S. 380.

${ }^{306}$ Vgl. Crittenden 1991, S. 48 f.

${ }^{307}$ Vgl. Currie 1990, S. 155.
} 
In fiction we do sometimes use genuine proper names to pick out particular individuals and say something about them that is part of the make-believe. ${ }^{308}$

Ein auf diese Weise verwendeter realer Eigenname referiert auf die reale Welt, während die definite description, die sich aus dem Satz ergibt (also die im Satz erfolgende Eigenschaftszuschreibung, etwa „der Mann, der mit dem fiktiven Romanhelden sprach“) nicht auf das entsprechende reale Objekt zutrifft, sondern nur auf die mögliche Welt des Romans. ${ }^{309}$ Damit erfolgt eine kontrafaktische Zuschreibung, denn der gesamte Satz referiert durch den Eigennamen, der im Gegensatz zu der definite description eines Objekts ein rigid designator ist - also über mehrere mögliche Welten hinweg.

Der Struktur nach sind solche ,nicht erfüllten Prädikationen' als Aussagen der normalsprachlichen Lüge am nächsten. Daß Rechtsstreitigkeiten um Behauptungen über reale Personen in Romanen ausgetragen werden, beruht auf dieser strukturellen Ähnlichkeit. Tritt in einem als literarisch verstandenen Werk eine solche ,Falschaussage' auf, wird sie gemeinhin nicht als Lüge oder Irrtum angesehen. Vielmehr wird nach ihrem Sinn oder ihrer Funktion gefragt. Sinn und Funktion erschließen sich erst, wenn die einzelnen ,Falschaussagen' in ihrer Differenz zur Wahrheit und die Art und Größe dieser Differenz erfaßt werden. Da jede Integration einer realen Entität das bereits erwähnte fiktionale relationale Prädikat ,existierte und handelte in einer Welt mit der fiktiven Figur' enthält, wird die Unterscheidung von immigrant object und surrogate object hinfällig, da streng genommen jedes immigrant object zum surrogate object wird. ${ }^{310}$

Dennoch unterscheidet sich die Referenz des Eigennamens über den Text hinaus deutlich nach der Schwere der Verstöße gegen die Wahrheit: Es kann auf sanfte Weise gegen die Wahrheit verstoßen werden, indem fiktive Ereignisse in einen bekannten realen Rahmen eingebaut werden: etwa, wenn eine historische Person des öffentlichen Lebens auf einer im literarischen Text beschriebenen historisch-realen Großkundgebung einen Blick mit einer Figur des Textes wechselt oder wenn eine private Meditation der ,pseudo-realen Figur' dargestellt wird. Aus der Kenntnis literarischer Praxis kann der Leser relativ sicher sein, daß dies nicht möglich war (die Figur existierte nie), den Beweis kann er aber anhand von Biographien der genannten realen Person nicht führen. ${ }^{311}$ Die reale Person ist in diesem Fall die Basis der gestalteten Figur. ${ }^{312}$ Reale Eigennamen dienen auch in diesem Fall zumeist der Einordnung einer fiktiven Handlung in einen realen Hintergrund.

\footnotetext{
${ }^{308}$ Vgl. Currie 1990, S. 148.

${ }^{309}$ Vgl. Wolterstorff 1979, S. 107

${ }^{310}$ Vgl. anders: Zipfel 2001, S. 97 f., S. 100.

${ }^{311}$ Vgl. Currie 1990, S. 156.

312 Vgl. Crittenden 1991, S. 135-137; Crittenden 1982, S. 335; Currie 1990, S. 136 f.
} 
Drittens kann mit einem Eigennamen zwar der reale Namenträger gemeint sein. Dieser wird aber in einen Kontext gestellt, der zeitlich und/oder räumlich vollkommen von dem realen Kontext getrennt wird. Der fiktive Kontext und das Handeln der realen Person in diesem Kontext werden gestaltet. Der reale Kontext und der bekannte semantische Hintergrund des realen Eigennamens werden hingegen nicht verändert, sondern als Zusatzinformation vorausgesetzt oder interpretierend herangezogen. Da der neue Kontext des Namenträgers mit dessen realem Kontext keine Berührungspunkte hat, wird die gesamte außertextliche Entität in den Text integriert. Ein Beispiel dafür ist das Sonett „Werther a su sepultura“ des Conde de Noroña. ${ }^{313}$ Es spricht der tote Werther über den süßen Genuß (joy of grief), den ihm die regelmäßig an seinem Grab weinende Lotte bereitet. Die ,Fortschreibung' des Goetheschen Briefromans hat die Freiheit, ohne allzu enge Grenzen durch die Vorgeschichte eine neue Situation zu gestalten. Gleichzeitig wird eine neue Note gesetzt, indem das dem Sturm und Drang verpflichtete verzweifelte Ende des Romans durch eine weiche und eher empfindsame Fortsetzung post mortem abgemildert wird. Da die Vorgeschichte als bekannt vorausgesetzt wird, findet keine Erläuterung des Namenhintergrunds durch eine definite description statt. Weder das genaue Verhältnis Werthers und Lottes noch der Grund für Werthers Tod werden beschrieben. ${ }^{314}$

Viertens: Wenn deutlich gegen bekannte Wahrheiten über den realen Namenträger verstoßen wird, kann wie im vorherigen Beispiel eine intakte Referenz mit abweichenden Beschreibungen angenommen werden. Eine andere Möglichkeit ist, daß sich die Referenz wandelt und der Eigenname äquivok wird. In diesem Fall wird ein fiktiver Namenträger gestaltet und mit dem Namen ,getauft', der durch den Namen den Vergleich mit dem realen Namenträger nahelegt. Je mehr diese Figur eines literarischen Werkes kontrafaktisch gestaltet wird, desto eher ist man geneigt, den Namen lediglich als präfigurierten Namen zu sehen. Der Verweis auf den präfigurierenden Namenträger ist dann nur noch ein Teil der sortalen Prädikate des Namens, der einen generellen Hinweis auf die Eigenschaften der Figur gibt. ${ }^{315}$ So gestaltet Edgar Lee Masters in Percy Bisshe Shelley einen untalentierten und lernunwilligen Kleinstadtbewohner dieses Namens, der bei einem Jagdunfall ums Leben kommt. Es ist kaum ein Zweifel möglich, daß es sich

\footnotetext{
${ }^{313}$ Vgl. Ruiz Casanova 1998, S. 406.

${ }^{314} \mathrm{Vgl}$ zu einem ähnlichen Beispiel Lamping 1993, S. 106.

315 Debus 2002, S. 35 f., spricht von ,Graden der Fiktionalisierung' realer Eigennamen in fiktionalen Texten.
} 
hier nicht um eine Umgestaltung des realen Namenträgers handelt. Der Sprecher zieht dann am Ende selbst einen Vergleich zu seinem Namensvetter. ${ }^{316}$

In diesem Fall kann die extreme Mehrdeutigkeit von Eigennamen und gleichzeitige Implikation der Einzigartigkeit des benannten Objektes neben der Charakterisierung der Figur auch zu intertextuellen Verbindungen verwendet werden. Der alludierende Name ${ }^{317}$ weist dann auf eine Figur hin, die auch außerhalb des Textes existiert, und stellt neben der eventuellen Charakterisierungsfunktion eine Verbindung zwischen der Figur und dem anderen Namenträger her, die auch auf die außertextliche Figur oder Person zielen kann. Wie wir schon bei der Untersuchung der Rolle von Berichtswahrheit in fiktionalen literarischen Texten gesehen haben, eignen Eigennamen sich besonders zum Aufbau von Verbindungen über die Textwelt hinaus, weil sie auch ohne kontextuelle Hinweise Anspielungen auf Außertextliches enthalten können. ${ }^{318}$ Die Bedingungen für eine sinnvolle Konstatierung intertextueller Bezüge durch Eigennamen - Kohärenz mit dem Kontext, kommunikative Verfügbarkeit des enzyklopädischen Wissens und Erhöhung der ,semantischen Funktionalität' des Textes ${ }^{319}$ - werden oft von vielfältigen Auslegungen von Eigennamenzeichen scheinbar leicht erfüllt. Durch die scheinbare Eindeutigkeit der Eigennamen bei gleichzeitiger potentiell unendlicher Vieldeutigkeit ${ }^{320}$ können in einem Text in unterschiedlichem Grade Verbindungen zwischen fiktiven und realen Individuen hergestellt werden. ${ }^{321}$ Wegen der Namenwahl- und Namengestaltungsfreiheit sind dabei alle Eigenschaften des gegebenen Namenzeichens potentielle Kandidaten für intertextuelle Hinweise. Eigennamen sind damit die deutlichsten allusion-markers. ${ }^{322}$ Verweist der Eigenname auf ein außertextlich existierendes Individuum, kann er dazu dienen, das Gedicht mit anderen Texten zu korrelieren. ${ }^{323}$

Unerwünschte intertextuelle Bezüge von Eigennamen zu vermeiden, ist dabei unter Umständen schwieriger, als Verbindungen herzustellen. Umberto Eco wählt für die Beschreibung seines Versuchs, in einem seiner Romane die „unendliche Semiose“ zu verhindern, bezeichnenderweise Eigennamen als Beispiel für nicht vom Autor intendierte intertextuelle Hinweise. ${ }^{324}$ Sein Problem als Romanautor gilt in noch stärkerem Maße für Texte der Gattung Lyrik, da Intertextualität hier nicht durch einen ausführlichen Ko-

\footnotetext{
${ }^{316}$ Vgl. Masters 1992, S. 121.

${ }^{317}$ Vgl. Müller 1991a, S. 150.

${ }^{318}$ Vgl. Hebel 1991, S. 142.

${ }^{319}$ Vgl. Stocker 2002, S. 304 f.; vgl. auch Eberhardt 2002, S. 34-36.

${ }^{320}$ Vgl. Lausberg 1963, S. 54 (§ 135 f.).

${ }^{321}$ Vgl. Müller 1991b, S. 103 f.

322 Vgl. Nicolaisen 1995, S. 566; Stocker 2002.

${ }^{323}$ Vgl. Hebel 1991, S. 138.

${ }^{324}$ Vgl. Eco 1995, S. 160-163.
} 
text eingeschränkt werden kann. ${ }^{325}$ Das intertextuelle 'Geflecht', in das ein Gedicht im Laufe seiner Rezeption spekulativ gestellt wird, kann - gerade aufgrund von Eigennamen - weit über das hinausgehen, was der Autor intendiert hat.

Schließlich ist noch der fünfte Fall zu berücksichtigen, daß ein fiktionaler Eigenname auch ein fiktiver Eigenname ist und die unter diesem Namen gestaltete Figur auf eine reale Entität bzw. Person verweisen soll. Anakreontische Stereotypennamen sind der Standardfall einer solchen Namenverwendung. Der Eigenname und sein Kontext bezeichnen eine Rolle, die auf eine reale Person projiziert wird. Dadurch referiert der $\mathrm{Na}-$ me auf die reale Person und repräsentiert sie gleichzeitig kontrafaktisch als ein "Soundso“. ${ }^{326}$ Der Text spricht dann zwar über die reale Person. Es wird aber nicht die Person beschrieben, sondern im Sinne van Inwagens werden der realen Person Eigenschaften zugeschrieben (to be ascribed to), die sich aus dem gewählten Eigennamen und expliziten Beschreibungen ergeben. Die Eigenschaften der realen Person spielen nur insoweit eine Rolle für die Figur, als sie explizit erwähnt werden, um eine Identifizierung zu ermöglichen. Auch wenn die Person nicht identifizierbar ist, hat der Rezipient unter Umständen das Bewußtsein, daß irgendeine reale Person gemeint ist. Symptomatisch für diesen Fall der Referenz über den Text hinaus sind die vielfältigen Erkundigungen nach möglichen realen Namenträgern. So fragt etwa Hölty bei Friedrich Leopold Graf zu Stolberg nach verschiedenen weiblichen Bekanntschaften: „Es würde mir auch Lieb sein, wenn Sie mir den Namen der Doris schrieben, auf welche Sie das schöne Odarion gemacht haben [...].“327

\subsubsection{Berühmte Eigennamen}

Der sechste Fall, der für literaturwissenschaftliche Untersuchungen von Bedeutung ist, verdient eine ausführlichere Würdigung: berühmte Eigennamen. ${ }^{328}$ Diese sind dafür prädestiniert, eine große Menge außertextlicher Informationen auf dem meist engen Raum des Gedichts zu konzentrieren. Solche berühmten Eigennamen eignen sich dabei sowohl dazu, komplexe Sachverhalte zu präsentieren und zu exemplifizieren, als auch dazu, die dargestellten Ereignisse auf eine allgemeine Ebene bzw. auf einen 'öffentlichen Nenner' zu bringen. ${ }^{329}$ Auf diese Weise können berühmte Eigennamen in

\footnotetext{
${ }^{325}$ Vgl. z.B. die intertextuellen Spekulationen bei Paul de Man 1985, S. 66 f.

${ }^{326}$ Anders Currie 1990, S. 129.

327 Brief Höltys an den Grafen zu Stolberg vom 19. Januar 1774, Hölty 1998, S. 338.

${ }^{328}$ Vgl. z.B. auch Hebel 1991, S. 142 f.

${ }^{329}$ Vgl. Killy 1972, S. 87 f.
} 
einem Gedicht umfassende Kontexte außerhalb des Textes aufrufen, die ein ganzes Netz an „cotextualizations“ bilden. ${ }^{330}$

Zu den berühmten Namen zählen besonders die Namen mythischer Figuren ${ }^{331}$, Namen aus berühmten literarischen Werken oder Namen berühmter realer Personen und Orte aus vergangenen Zeiten (etwa: ,Zeus', ,Don Quijote', ,Cäsar' oder ,Atlantis'). In literarischen Texten - besonders in Gedichten -haben solche berühmten Namen sich oft bis auf einige Bedeutungsbestandteile von ihren ursprünglichen Namenträgern oder ihrer ursprünglichen Bedeutung getrennt. Sie haben auf eine gewisse Weise „das Bürgerrecht in der realen Welt erworben“. 332 Castañeda spricht zudem Schriftstellern die Fähigkeit zu, Charaktere zu gestalten, die eine gewisse Unabhängigkeit von ihrem Ursprungstext erlangen können. ${ }^{333}$ Es ist schwierig, in diesen Fällen eine Referenz des Eigennamens zu bestimmen, denn dies erforderte, Objekte mit zweifelhaftem ontologischen Status zu berücksichtigen, die unabhängig von einzelnen Geschichten existieren und dennoch fiktiv sind.

Wolterstorff versucht zur Erfassung dieser Referenzverhältnisse zwischen dem „Faustcharacter simpliciter“ und dem „Faust-in-Goethe's-Faust-character“ zu unterscheiden, in dem der Faust simpliciter enthalten sei. Faust simpliciter sei der kleinste gemeinsame Nenner, dessen definite description jene Eigenschaften enthalte, die alle einzelnen Gestaltungen der ,Rolle' gemeinsam haben. ${ }^{334}$ Diese Dichotomie reicht allerdings nicht aus, um vorhandene Möglichkeiten zur weiterführenden Figurengestaltung und Namenverwendung zu erklären, die im Folgenden erläutert werden.

Zunächst kann man zu bekannten Eigennamen Figurengestaltungen finden, die eine kausale oder historische Namenkette (im Sinne Kripkes) aufrechterhalten. Deren Eigennamen referieren auf den ursprünglichen Namenträger. Everett etwa geht dazu von einem „shared initial segment of referential framework“ und einem (fiktionalen oder realen) ,Urnamen' aus, auf die sich spätere Namenverwendungen beziehen. ${ }^{335}$ Auch besteht die Möglichkeit, eine Figur auf der Basis einer außertextlichen Entität zu gestalten, wodurch die kommunikative Namenkette aufrechterhalten werden kann. Da aber sowohl reale Objekte als auch nonexistent objects immer nur unvollständig bekannt sind, bieten sich dem Autor vielfältige Gestaltungsmöglichkeiten unter Rückgriff auf vorhan-

\footnotetext{
${ }^{330}$ Vgl. Müller 1991b, S. 103; Hebel 1991, S. 136-139, S. 152, S. 155.

${ }^{331}$ Vgl. Faderman 2000.

332 Eco 1999, S. 167; Taylor beschreibt die Zuordnung einer definite description zu Namen fiktiver Objekte als "conception“, die nicht mit einer objektiven Wirklichkeit verbunden sei (vgl. Taylor 2000, S. 28 f., S. $31 \mathrm{f}$.$) .$

${ }^{333}$ Vgl. Castañeda 1979, S. 44 f.

${ }^{334}$ Vgl. Wolterstorff 1979, S. 116.

335 Everett 2000, S. 59.
} 
dene bekannte Eigennamen und deren Namenträger. Objekte, die keinem producer (mehr) zugänglich sind, sind also eigentlich nicht unvollständig, wie Castañeda, van Inwagen u.a. annehmen (s.o.), sondern eher ,übervollständig'. Eigenschaften, für die sie nicht determiniert sind, können innen nachträglich - und von verschiedenen Autoren auch widersprüchlich - zugeschrieben werden. Es ist dann eine Frage des kollektiven Gedächtnisses, welche Zuschreibungen langfristig in die simpliciter-Bedeutung aufgenommen werden. ${ }^{336}$

Des Weiteren können mit vorhandenen Eigennamen neue Traditionen bzw. kausale Ketten begonnen werden, die von dem ursprünglichen Namenträger schwach beeinflußt sind. Die Namen referieren in diesem Fall nicht mehr auf den ursprünglichen Namenträger. Die Namengleichheit stellt aber eine Verbindung mit der Tradition der Darstellungen des ursprünglichen Namenträgers her. Insbesondere deutliche Inkohärenzen bei der Gestaltung von Entitäten in mehreren Texten führen zu solcher Äquivozität des Namens. Weiterentwicklungen und Gegenentwürfe unter einem berühmten Eigennamen bilden dann ein Netz von Gestaltungen. Wenn ein solches Netz besteht, ruft der Eigenname - in einem Einzeltext simpliciter gebraucht - unspezifisch die Bedeutungen des gesamten Netzes auf, bezeichnet aber nicht mehr ein bestimmtes Objekt. Die Verbindungen des Netzes werden durch den gemeinsamen Eigennamen und durch Ähnlichkeits- und Äquivalenzrelationen aufrechterhalten.

Für eine Kultur wichtige Eigennamen bzw. deren Objekte oder Rollen verursachen mit der Zeit viele und komplexe Verbindungen verschiedenster Traditionen. Dies führt zu einer minimierten simpliciter-Bedeutung, da der 'gemeinsame Nenner' aller Gestaltungen immer kleiner wird. Gleichzeitig wird die maximale mit einem Eigennamen zu verbindende definite description immer komplexer und inkohärenter. Von Evans' Referenzmodell für Eigennamen ausgehend muß man solchen Eigennamen zunächst die Referenz absprechen: Wenn in der kommunikativen Praxis einer Produzentengruppe die Kennzeichnungen, die auf den einen Träger verweisen, und diejenigen, die auf den anderen deuten, als Bedeutung eines Eigenamens vermischt werden, hat der Eigenname für Evans im strengen Sinne keine Referenz mehr. ${ }^{337} \mathrm{Er}$ wird also nicht als äquivokes Zeichen verstanden, da der Sender wie der Empfänger nicht mehr verschiedene Gestalten unterscheiden. Vielmehr werden einer nicht-existierenden Entität als semantischer Hintergrund des Namens Merkmale der verschiedenen in der Realität oder im kollektiven Gedächtnis existierenden Entitäten zugesprochen.

\footnotetext{
${ }^{336}$ Vgl. Wülfing/Bruns/Parr 1991, bes. S. 5-9.

${ }^{337}$ Vgl. Evans 1982, S. 386-390.
} 
Mit Evans ist darauf hinzuweisen, daß bei Objekten, die nicht mehr existieren, nach kurzer Zeit alle Eigennamenbenutzer Konsumenten sind. Da die mit einem Eigennamen verbundenen Kennzeichnungen nun nicht mehr anhand des Referenten und beglaubigt durch einen Produzenten überprüft werden können, kann mit Sicherheit davon ausgegangen werden, daß sie sich nach dem ,Stille-Post-Verfahren' mit der Zeit verselbständigen. Demnach kann eine kausale oder historische Kette zwar die intendierte Referenz aufrechterhalten, sie kann aber nicht garantieren, daß die Eigenschaftszuschreibungen stimmen.

Bekannte Namen wirken deshalb, wenn sie simpliciter gebraucht werden, auch nicht mehr als gezielter intertextueller Hinweis auf einen anderen Text oder eine reale Gestalt. Der Name ,Zeus' - in einem Text des Jahres 2004 simpliciter und ohne Spezifizierung erwähnt - vermag allenfalls generell auf die in der westlichen Kultur vorherrschende Vorstellung von ,Zeus' oder auf die griechische Kultur zu verweisen. Für einen genaueren Bezug etwa zu einer bestimmten Tradition ist eine Spezifizierung durch Kound Kontext nötig.

Die Namen berühmter Orte und berühmter Personen sind dementsprechend eher selten Stellvertreter eines realen Gegenstandes. Sie haben vielmehr einen ,Sinn' (Frege), der dem ,Diskurs' zu entnehmen ist, in dem die Namen verwendet werden. ${ }^{338}$ Anhand des Äußerungskontexts kann entschieden werden, ob oder in welchem Maße eine Referenz vom Autor intendiert ist: Der Name kann tatsächlich auf den Namenträger referieren, er kann sich aber auch auf gewisse aktuelle, mit dem Namenträger verbundene Stereotypen oder Assoziationen beziehen oder auch letztlich dazu dienen, durch seinen kulturellen Kontext, seine Zeichenstruktur und seine standardisierte Bedeutung Stimmungen hervorzurufen.

\footnotetext{
${ }^{338}$ Wird ein wichtiger und bekannter Ort simpliciter genannt, so handelt es sich oft um eine „kulturell vermittelte ,reale' Örtlichkeit“ (Niefanger 1993, S. 71). „Assoziative und semiotische Hinweise verweisen auf allgemeines kulturelles Wissen [...], auf spezifische Diskurse und Diskursformationen [...] oder auf nur vage bestimmbare ,Stimmungskontexte', letztlich auf eine gewisse Lösung der Signifikanten von den Signifikaten und ihren ursprünglichen Kontexten" (Niefanger 1993, S. 70 f.). Darüber hinaus ist zu betonen, daß sich Assoziationen auf einer anderen Ebene bewegen als semiotische Hinweise. Ein Eigenname kann gerade durch seine Referenz und deren Kontext Assoziationen anregen. Eigennamen in literarischen Texten sollten also auf keinen Fall auf Bedeutungen aus dem ,kulturellen Wissen' und dem kollektiven Gedächtnis reduziert werden. Das in einem Gedicht Ausgedrückte ist oft an einen realen Ort und ein reales Erlebnis gebunden. Niefanger selbst bringt z.B. mit dem Restaurant ,Sacher' ein Beispiel dafür, daß das Wissen über die reale Situation an einem realen Ort die Assoziationen zu einem Namen erst möglich macht (vgl. Niefanger 1993, S. 77 [Fn. 58]).
} 


\subsubsection{Namen rein innertextlicher Objekte}

\subsubsection{Die Referenz fiktionaler Namen}

COUSIN NANCY

Miss Nancy Ellicott

Strode across the hills and broke them,

Rode across the hills and broke them-

The barren New England hills-

Riding to hounds

Over the cow-pasture.

Miss Nancy Ellicott smoked

And danced all the modern dances;

And her aunts were not quite sure how they felt about it,

But they knew that it was modern.

Upon the glazen shelves kept watch

Matthew and Waldo, guardians of faith,

The army of unalterable law. ${ }^{339}$

Wie wir in unseren bisherigen Ausführungen gezeigt haben, sind reale Eigennamen in faktualen Texten ,unsichere Zeichen', weil das Zeichen selbst nicht festlegt, welcher semantische Inhalt mit inm in einer Äußerung vermittelt werden soll. Des Weiteren sind Eigennamen in fiktionalen Texten mit zusätzlicher Vorsicht zu behandeln, da ihr referentieller Status außerordentlich unsicher ist. Dies gilt für reale Eigennamen, wie das vorherige Kapitel zeigte. Es gilt aber auch für fiktionale Eigennamen. Dies wird dieses Kapitel erweisen.

T.S. Eliot gestaltet in seinem Gedicht nicht eine reale, sondern eine fiktive Person, die er mit dem Eigennamen ,Nancy Ellicott' benennt. Bei einem solchen fiktionalen Namen ist der Status des Referenzobjekts selbst unklar. Die Bedeutungsstruktur fiktionaler Eigennamen unterscheidet sich daher von der Bedeutungsstruktur realer Eigennamen grundsätzlich. Ein - auch literaturwissenschaftlich relevantes - Problem aller Bestimmungen literarischer Figuren, das die Frage nach der Referenz literarischer fiktionaler Eigennamen zu Tage fördert, ist die Zuordnung von Prädikaten zu Eigennamen. Betroffen sind davon vor allem die Zuschreibungen jener Prädikate, die dem Objekt in der fiktiven Welt zukommen. Für Gedichte spielt diese Frage eine besonders wichtige Rolle, da die sparsamen Kontexte auch bei fiktionalen Eigennamen das eigenständige Ergänzen von Prädikaten seitens des Lesers erfordern. Welche Prädikate darf der Leser der benannten Figur zusprechen? Nach einer Darstellung der sprachanalytischen Diskussion wird im Folgenden auch hier eine moderate literaturwissenschaftliche Position vorgeschlagen.

${ }^{339}$ Eliot 1998, S. 23; vgl. Langenbach 1994, S. 179 f. 
Ansätzen zur Analyse fiktionaler Eigennamen, die von einer description theory der Eigennamenbedeutung ausgehen, fällt es relativ leicht, fiktionale von realen Eigennamen zu unterscheiden. Sie gehen davon aus, daß fiktionale Eigennamen nicht referentialisierbar seien. Eigennamen werden im Rahmen von non-assertion theories generell auf Kennzeichnungen zurückgeführt, auch wenn sie kein Referenzobjekt haben. Fiktionale Eigennamen sind demnach abgekürzte Beschreibungen ohne beschriebenen Gegenstand. Sie sind leere Scheineigennamen, die auf der Ebene des semantischen Inhalts aber den realen Eigennamen gleichen. ${ }^{340}$ In der Fregeschen Terminologie haben Eigennamen keine Bedeutung, die durch die „Art des Gegebenseins" bestimmt würde. Auch wenn Frege Sätzen in literarischen Texten durchaus zugesteht, Gedanken auszudrücken, interessieren den Leser von Literatur inm zufolge nur die Bilder und Gefühle, die durch das Werk ausgelöst werden, nicht die Referenz der Rede. ${ }^{341}$

Theorien, die von der kausalen Theorie der Referenz ausgehen, müssen für fiktionale Eigennamen entweder das Referenzobjekt erklären oder proper names und fictional names funktional voneinander trennen. Die ,erste Generation' der Vertreter kausaler Referenztheorien ${ }^{342}$ neigt dazu, Eigennamen fiktiver Entitäten die Referenz abzusprechen. Da eine kausale Verbindung zwischen einem nichtexistierenden fiktiven Gegenstand und der Verwendung eines Eigennamens ihrer Ansicht nach nicht möglich ist, könne der Eigenname einer literarischen Figur auch nicht echt referieren. Der Name erwecke höchstens die Illusion einer Referenz. Donnellan geht von Blockaden aus („blocks of the referential history"), die bei fiktionalen Eigennamen systematisch verhinderten,

\footnotetext{
${ }^{340}$ Vgl. Frege 1993, S. 104. Schiffer vertrat jüngst diese Position als „pleonastic Fregeanism“ (Schiffer 2000, bes. S. 15 f.). Vgl. auch Klemm 1984, S. 223 f. und Künne 1995. Die Prädikate des semantischen Hintergrundes können als Verbindung zur realen Welt betrachtet werden: Martin 1982 bringt die Idee, daß fiktionale Eigennamen nur abgekürzte Beschreibungen seien, mit der Intuition zusammen, daß fiktionale literarische Texte zumindest generisch auf die Wirklichkeit referieren. Er spricht den Konnotationen (im Millschen Sinne) von Beschreibungen fiktiver (mythischer) Objekte Referenz zu: „For a fictional concept refers by virtue of the referential validity of its constituent connotations. It is always a hybrid construct formed from actual features of the world that we know" (Martin 1982, S. 229). Fiktion ist nach Martin nie ganz fiktiv: "There will indeed always be things that correspond to its very detail, somewhere, in some way" (Martin 1982, S. 229, S. 233); vgl. auch Olsen 1987, S. 165-167. Martin nutzt dabei nur die Vieldeutigkeit des Referenzbegriffs zu einer Scheinlösung. Die einzelnen Komponenten einer Beschreibung referieren ebensowenig wie die Definition eines Objektes. Nach der Idee Martins würde die Beschreibung „Der pfeiferauchende Detektiv, dessen Assistent ,Watson' heißt“ durch Konnotationen auf alles Pfeiferauchende und auf alle Detektive der Welt, aber nicht auf Sherlock Holmes referieren. Interessant an der Frage nach der Referenz in literarischen Texten ist aber nicht, ob mehr oder weniger zufällig irgendwo irgend etwas den Beschreibungen literarischer Rede entspricht, und ebensowenig, ob fiktive Figuren aus Wirklichkeitskomponenten zusammengesetzt sein können oder müssen, sondern ob singuläre Referenz in fiktionaler Rede möglich ist.

${ }^{341}$ Vgl. Frege 1994, S. 48; Warner 1999, S. 29. In angelsächsischen Ländern hat dies bei nonkognitivistischen Theorien literarischer Rede zu der Überzeugung geführt, Literatur hätte nur emotive Funktion (vgl. dazu z.B. Martin 1999, S. 30).

${ }^{342}$ Vgl. z.B. Donnellan 1974; Kaplan 1989, S. 607-610; Crittenden 1991, S. 70; Parsons 1982, S. 316, weist auf „talks“ mit Kripke hin.
} 
daß eine kommunikative Kette von einem getauften Gegenstand zur aktuellen Namenverwendung führe. ${ }^{343}$ Die kausale Kette endet in diesem Fall bei einer Instanz, die den Namenträger dann nur noch beschreiben kann, ohne kausalen Kontakt mit inm zu haben. Van Inwagen formuliert für kausal referierende Eigennamen entsprechend: „But no one ever dubbed or baptized the main satiric villainess of Martin Chuzzlewit Mrs. Gamp. “344 Fiktionale Eigennamen funktionierten hier in der letzten Instanz eher wie Appellative in fiktionaler Rede. ${ }^{345}$

Eine Alternative dazu besteht darin, eine Referenz fiktionaler Eigennamen auf abstrakte Entitäten anzunehmen. Wolterstorff z.B. geht davon aus, daß Eigennamen kausal nicht auf ein individuelles Objekt, sondern auf ein bestimmtes „person-kind“ referierten. Ein Autor definiere den ,Personentyp' mit einer definite description, die unter dem Eigennamen zusammengefaßt werde und die weder Vorstellung noch Objekt sei. ${ }^{346}$ Auch hier wird der Eigenname letztlich als Stellvertreter einer definite description gesehen.

Gottfried Gabriel konstatiert, fiktionale Eigennamen bezögen sich in fiktionaler Rede auf durch „literarische Texte konstituierte Sinngebilde (des Individuentyps)“. ${ }^{347}$ In seinem "(nicht-psychologistischen) Konzeptualismus" wird "fiktionale Rede" dementsprechend als „nicht-behauptende Rede“ definiert, „die keinen Anspruch auf Referentialisierbarkeit [der definite descriptions, Eigennamen und deiktischen Ausdrücke] oder auf Erfülltheit [der Prädikate] macht“. ${ }^{348}$ Die Eigennamen würden dabei so verwendet, als ob sie referierten. ${ }^{349}$ Allerdings bleibt Gabriel eine genaue Bestimmung dessen, was ein 'Sinngebilde' zu einer Einheit macht, schuldig. Im Anschluß an sein Modell versucht er, die semantische Tiefenstruktur von metafiktionalen Sätzen, die scheinbar auf fiktive Objekte referieren, durch eine nominalistische Paraphrase offenzulegen. Aus der Äußerung: 'Der fiktive Erzähler in Thomas Manns Roman...' wird dann etwa: 'Die fiktionale Erzählerbeschreibung in Thomas Manns Roman...' ${ }^{350}$ Solche Paraphrasen wurden schon von Ryle vorgeschlagen. ${ }^{351}$ Sie führen dazu, daß metafiktionale Äußerungen mit Eigennamen literarischer Figuren auf andere Äußerungen referieren, während fiktionale Sätze mit Eigennamen gar nicht referieren. ${ }^{352}$

\footnotetext{
${ }^{343}$ Vgl. Donnellan 1974, S. 22-25.

${ }^{344}$ Van Inwagen 1977, S. 307.

${ }^{345}$ Vgl. Crittenden 1991, S. 37.

${ }^{346}$ Vgl. Wolterstorff 1979, S. 109, S. 114.

${ }^{347}$ Gabriel 1975, S. 28; vgl. Currie 1988, bes. S. 488.

${ }^{348}$ Gabriel 1975, S. 28.

${ }^{349}$ Vgl. Gabriel 1987, S. 75, S. 73; Gabriel 1982, S. 542; Martin 1982, S. 213 f.

${ }^{350}$ Vgl. Gabriel 1987, S. 74.

${ }^{351}$ Vgl. Ryle 1933.

${ }^{352}$ Vgl. Crittenden 1991, S. 26 f.
} 
Parsons' Modell der nonexistent objects beruft sich dagegen auf die Intuitionen und Intentionen des Sprachbenutzers. Parson fordert, „fictional objects at face value“ zu nehmen, so daß fiktionale Eigennamen auf nichtexistierende Objekte referieren können. ${ }^{353}$ Da man von literarischen Gegenständen genauso wie von existierenden Gegenständen spreche, intendiere man auch, wahre Tatsachen von Objekten auszusprechen, wenn man von literarischen Figuren etwas prädiziere. Literarische Ausdrücke hätten die Funktion, auf vom Autor erschaffene (created) Objekte zu referieren. ${ }^{354}$ Diese Objekte seien aber nicht existierende und nicht vollständige Objekte, die nicht unabhängig von den Intentionen eines Sprechers seien. Parsons nimmt daher auch an, daß Namen ,Sinn' (Frege) haben, obwohl sie nicht synonym sein sollen mit einer bestimmten definite description. ${ }^{355}$ Er berücksichtigt zwar die kausale Theorie der Eigennamenreferenz. Seine Verwendung dieser Theorie deutet aber auch auf ein verstecktes nicht-referentielles Bild fiktionaler Eigennamen hin. In der kausalen Referenzkette soll bei fiktionalen Eigennamen ein non-causal link oder non-causal step enthalten sein, der „something like exemplification or tokening“ darstelle. ${ }^{356}$ Dieser nicht-kausale Schritt verweise entweder auf den Text oder auf eine Proposition. Der Unterschied dieses Modells zu Gabriels „Sinngebilden“ ist zu vernachlässigen. ${ }^{357}$

Wiederum einen anderen Weg beschreitet Pavel. ${ }^{358}$ Er unterscheidet zwischen einem strukturellen und einem historischen Aspekt der Kripkeschen Eigennamen. Strukturell funktionierten fiktive Eigennamen so wie reale Eigennamen. Eine impositio nominis (eine Taufe) identifiziere ein Objekt. Die Eigennameneinführung fiktiver Personen bewirke keinen block im Sinne Donnellans, sondern einen Schritt in eine andere Domäne: etwa jene der Götter oder der Literatur. Dies impliziere, daß eine ganze fiktive Welt - also ein Kontext - zu einzelnen fiktiven Entitäten bestehen müsse, damit die Namen der fiktiven Entitäten referieren könnten. In historischer Hinsicht gebe es analog zur Arbeitsteilung in der alltäglichen Begriffsbestimmung ${ }^{359}$ auch für fiktive Eigennamen anerkannte Experten, die nach anerkannten Prinzipien die richtige Referenz festlegten. ,Hamlet' wäre demnach „a well-individuated fictional object who has a rigid designation“. ${ }^{360}$

\footnotetext{
353 Vgl. Parsons 1982, S. 315; Parsons 1987, S. 51; Crittenden 1991, S. 7.

354 Vgl. Parsons 1980, S. 58.

355 Vgl. Parsons 1980, S. 122.

356 Vgl. Parsons 1980, S. 121.

357 Dies konstatiert auch Gabriel selbst (Gabriel 1987, S. 75). Zu einer logisch differenzierten Analyse dieser Gemeinsamkeit vgl. Zalta 2000.

${ }^{358}$ Vgl. Pavel 1986, S. 31-42.

${ }^{359}$ Vgl. Putnam 1975.

${ }^{360}$ Pavel 1979, S. 189.
} 
Dennoch läßt Pavel den Status des Namenträgers eines fiktionalen Namens, der auf dem ontologischen Status fiktiver Welten beruht, im Unklaren. Denn der move in eine andere Domäne erklärt nicht, worauf der Name letztendlich referiert.

\subsubsection{Kohärenz und Inhalt fiktionaler Eigennamen}

Die bisher vorgestellten Modelle deuten darauf hin, daß fiktionale Eigennamen zwar eine Referenz suggerieren, die Referenzfunktion aber offensichtlich nicht auf konventionelle Weise erfüllen. Dennoch werden den Namenträgern und damit ihren Eigennamen bestimmte Eigenschaften zugeordnet.

Für van Inwagen sind fiktionale Objekte eine nicht reduzierbare Subkategorie der „theoretical entities of literary criticism“. ${ }^{361}$ Die Literaturwissenschaft nehme diese Einheiten an, um über Literatur reden zu können, ohne daß sie dadurch im starken ontologischen Sinne existierten. Der literarische Text mache keine Behauptungen (assertions) und referiere nicht auf literarische Figuren. Fiktiven Namenträgern würden im literaturkritischen Diskurs Eigenschaften realer Objekte ('ein dänischer Prinz sein') nur zugeschrieben (ascription). Sie würden nicht über sie ausgesagt (to predicate). Die Existenz literarischer Figuren als theoretische Einheiten mit bestimmten Eigenschaften - etwa: 'vortrefflich gestaltet sein' - sei so trotzdem möglich. ${ }^{362}$

Fiktive Entitäten sind nach dieser Theorie hinsichtlich der ihnen zugeschriebenen 'gewöhnlichen' Eigenschaften systematisch unvollständig. Die Zuschreibung von Prädikaten ist nur insoweit möglich, als sie der Paraphrase entsprechen 'Der Figur N.N. werden im Roman die Prädikate $\mathrm{F}(\mathrm{x})$... zugeschrieben' (to be ascribed to). ${ }^{363}$ Fiktive Entitäten haben daher eine spezielle Form der Existenz, die ein beschränktes ,Sein' (subsisten$c e)^{364}$ ist. Sie sind nach diesen Modellen nur auf die explizit genannten Eigenschaften festgelegt. ${ }^{365}$ Eigenschaften über das explizit Genannte hinaus können einfach negiert werden.

Insofern wäre Cousin Nancy aus dem obigen Gedicht Eliots eine unvollständige Figur, die zwar raucht und tanzt, nicht aber Fahrrad oder Auto fährt oder boxt. Eine namentlich genannte literarische Figur läßt sich jedoch kaum auf die explizit genannten Eigenschaften reduzieren, da der Name die Vorstellung vollständiger Entitäten evoziert und auch

\footnotetext{
${ }^{361}$ Vgl. van Inwagen 1977, S. 302 f.

362 Im gleichen Sinne haben fiktive Objekte bei Parsons im Vergleich zu realen Objekten ,außerordentliche' Eigenschaften (extranuclear oder extraordinary): etwa ,eine gestaltete Figur des fiktionalen Textes XY zu sein'. Diese seien den gewöhnlichen Eigenschaften (nuclear oder ordinary) - etwa ,groß zu sein' vorgeordnet. Die gewöhnlichen Eigenschaften könnten den Namenträgern nur in Abhängigkeit von den außergewöhnlichen Eigenschaften zugesprochen werden (vgl. Parsons 1987, S. 63; Parsons 1982 , S. 319, S. 323).

${ }^{363}$ Vgl. van Inwagen 1977, S. 308.

${ }^{364}$ Vgl. Crittenden 1991, S. 8 f., S. 64 f.

${ }^{365}$ Vgl. Parsons 1980, S. 56.
} 
nichtdefinitorische und nicht explizit genannte Stereotypen die Vorstellung bestimmen. Zu klären ist daher auch, wie die Vorstellung von und der Umgang mit einer Figur sich zu den explizit genannten descriptions der Figur in einem fiktionalen Text verhalten. Denn über die in einem Text genannten Attribute hinaus mögen einer Figur bzw. einem fiktionalen Eigennamen mit guten Gründen weitere Attribute zugeordnet werden, ohne daß damit unendlich viele beliebige Eigenschaften in die Fiktion eintreten müssen. ${ }^{366}$ Einschlägige Fragen wären in unserem Fall: Hat Nancy zwei Beine oder nur eins? Hat sie langes oder kurzes Haar? Hat sie Sommersprossen? Hat oder hatte sie Vater und Mutter?

Der deskriptiven Evokationskraft literarischer fiktionaler Eigennamen tragen jene Modelle Rechnung, die Ergänzungen durch Präsuppositionen bzw. Implikaturen vorsehen. Sie gestehen zu, daß man gewisse wahre Sätze über literarische Figuren oder Entitäten äußern kann, die auf supponierten allgemeinen und öffentlichen Wahrheiten aus dem Umfeld des Autors beruhen. ${ }^{367}$ Intentional objects sind dann vollständig in einem intentionalen Sinne. Denn der Leser weiß, daß die Objekte in der Erzählung (,from the standpoint inside the story') vollständig sein sollen. ${ }^{368}$ Vom Standpunkt ,outside the story' muß unterschieden werden zwischen „overt contents“ und einer Stereotype, den „unattributed features being filled in from the background“. ${ }^{369}$ Der Leser nimmt in einem solchen Modell an, daß die Charaktere einer fiktiven Welt einen Zugang zu anderen Charakteren dieser Welt haben, der uns logisch verbaut ist, und daß die Figuren einander vollständig zugänglich sind. Nur vom metaphysischen, nicht vom logischen Standpunkt aus sind literarische Figuren nach diesen Modellen unvollständig. ${ }^{370}$

Dabei bleibt allerdings unbeantwortet, inwieweit man überhaupt davon sprechen kann, daß Figuren ,einen Zugang zueinander haben', und ob auch der Autor eines fiktionalen Werkes den Zugang zu seinen Figuren hat, den diese selbst haben sollen. Tauchen in einem fiktionalen literarischen Text die Namen realer Entitäten in Sätzen mit oder ohne Wahrheitsanspruch auf (etwa ,Nancy Ellicott' oder ,Waldo' für Ralph Waldo Emerson in Eliots Gedicht), stellt sich weiter die Frage, wie und in welchem Maße sich der Standpunkt ,outside the story' von jenem, inside the story' unterscheidet.

Die Annahme von Ergänzungen des explizit über eine Figur oder fiktive Entität Gesagten birgt zudem massive Konsistenzprobleme. Zwar stellen sich im Anschluß an Rus-

\footnotetext{
${ }^{366}$ Vgl. New 1999, S. 112 f.

${ }^{367}$ Vgl. Lewis 1978, S. 45; Crittenden 1991, $132 \mathrm{f.}$

${ }^{368}$ Vgl. Crittenden 1982, S. 339.

${ }^{369}$ Vgl. Crittenden 1982, S. 336 f., S. 338; Crittenden 1982, S. 339.

${ }^{370}$ Vgl. Crittenden 1982, S. 344.
} 
sells Eigennamentheorie (s.o.) reale wie fiktive Objekte dem Subjekt epistemisch auf ähnliche Weise dar, da sie beide dem Subjekt nie vollständig zugänglich und deshalb nur als individuelle Masken („individual guises“) bekannt sind. ${ }^{371}$ Bei realen Objekten müssen aber die Prädikatzusammenstellungen konsistent sein und auf eine potentielle Vollständigkeit verweisen („consubstantiation“). Bei fiktiven Objekten wird die Prädikatmenge dagegen nicht unbedingt durch diese Forderungen begrenzt („consociation“). ${ }^{372}$ Derartige Objektbeschreibungen können also inkonsistent sein und zahlreiche nicht determinierte Stellen in bezug auf mögliche Kennzeichnungen aufweisen, ohne daß der Name mehrdeutig wird. ${ }^{373}$

Gegen Theorien der nonexistent objects wird daher eingewendet, daß systematisch kontradiktorische Einheiten angenommen werden müssen. ${ }^{374}$ Diese Kritik betrifft allerdings auch die Kritiker, die zumeist nonassertive-Modelle vertreten. Da literarische Figuren nicht vollständig und widerspruchsfrei gestaltet sein müssen, kann der Autor im Laufe der Romangestaltung verschiedene, auch kontradiktorische Eigenschaften (er-) finden. Darüber hinaus können verschiedene Rezipienten kontradiktorische Eigenschaften imaginativ ergänzen, zumal wenn sie selbst als Autoren an der Figur weiterarbeiten. Solche Vorgänge stellen die Einheit der Figur als nonexistent object wie als Sinngebilde in Frage.

Daß fiktionale Eigennamen ,ungerade' referieren, also auf ihren ,Sinn' (Frege), meint in der ursprünglichen Fregeschen Lesart: literarische Sätze mit Eigennamen fiktiver Personen beziehen sich auf objektive Gedanken, bedeuten aber nicht ,das Wahre' oder ,das Falsche'. ${ }^{375}$ Dementsprechend können auch nichtreferierende Sätze einen Gedanken ausdrücken oder auch nicht. In einem Fregeschen Modell drückt „Miss Nancy Ellicott / Strode across the hills“ einen Gedanken aus, der in diesem Fall nicht wahrheitsfähig ist, weil es Cousin Nancy nicht gibt oder gab. ,Grün sind deine gelben Haare' dagegen drückt keinen Gedanken aus, weil es sich um eine nicht sinnvolle Zusammenstellung von Prädikaten handelt. ${ }^{376}$

Für die Imagination beim Lesen literarischer Texte muß daher konstatiert werden, daß eine kohärente definite description die Vorstellung einer Entität/Person evozieren kann. Wenn dagegen semantisch kontradiktorische definite descriptions unter einem Eigen-

\footnotetext{
${ }^{371}$ Vgl. Castañeda 1979, bes. S. 54.

372 Vgl. Castañeda 1979, bes. S. 55 f.

${ }^{373}$ Vgl. etwa New 1997, S. 423, S. 425.

374 Vgl. Woods 1982, S. 558; Crittenden 1991, S. 6.

${ }^{375}$ Vgl. Frege 1993; Frege 1994, S. 48.

${ }^{376}$ Vgl. dazu Ferber 1998, S. 153-156.
} 
namen zusammengestellt werden, verliert der Text einen Teil seiner bildlichen Evokationskraft zugunsten der Autoreferenz.

\subsubsection{Imaginäre Taufsituationen?}

Fiktionale Eigennamen suggerieren wie reale Namen, es habe eine - allerdings imaginäre - Situation bestanden, in der der Name an ein Objekt vergeben worden sei. Andernfalls stellen sie kein genuines Eigennamenzeichen dar. Es bietet sich daher an, auch für innertextliche fiktionale Eigennamen von einer Taufsituation auszugehen, bei der lediglich die Bedingungen der Taufe gegenüber der ,realen' Taufsituation verändert sind.

Es ist naheliegend anzunehmen, daß, rein innertextlich referierende Eigennamen' über kommunikative Ketten auf die Vorstellungen des Autors referieren. Schon Castañedas (nicht kausales) Modell impliziert, daß Eigennamen auf die Vorstellungen des Autors verweisen: Er billigt fiktiven Entitäten einen shadow of reality zu, der darauf beruhe, daß referierende literarische Ausdrücke auf ,Gedachtes' als Unterkategorie des ,Denkbaren' referierten. ${ }^{377}$

Deutlicher vertritt Howell die Ansicht, daß sich fiktionale Eigennamen auf Autorvorstellungen bezögen. Wenn der Autor seinen literarischen Gegenstand taufe, dann halte er ihn vor sein inneres Auge. Der Autor wende seine Aufmerksamkeit einem individuellen Bereich zu, der nicht nur von darauf angewendeten Prädikaten bestimmt werde. Diesem gebe er einen Namen, der dann als rigid designator fungiere. Auf dieser Grundlage ließen sich fiktive Welten evozieren, die in einem nicht-metaphysischen Sinne mögliche Welten seien. Diese Welten ermöglichten es einem Rezipienten, die Referenz von literarischer Rede zu erschließen. ${ }^{378}$

Das Problem dieses quasi-millschen Ansatzes ist, daß mit ihm von einer unendlich großen Menge subjektiver Informationen ausgegangen werden muß, die eine literarische Figur als Produkt der Imagination des Autors zwar potentiell besitzt, die aber aus dem Text auf keinerlei Weise erschließbar sind. Der Leser hätte danach kaum je die Möglichkeit, einen literarischen Text adäquat zu verstehen, da seine Vorstellungen in potentiell unendlich vielen Punkten von der des Autors abwichen. ${ }^{379}$ Gegen die Theorie spricht außerdem, daß eine literarische Figur auch ohne die konkrete Vorstellung des Autors von einem mentalen Objekt entstehen kann. Die Vorstellungen des Autors können sich auch bei der Werkschöpfung verändern, etwa wenn einzelne Abschnitte eines Textes veröffentlicht werden, bevor der gesamte Text fertiggestellt ist. Schließlich ist

\footnotetext{
${ }^{377}$ Vgl. Castañeda 1979, S. 49; zur Kritik vgl. Currie 1997, S. 425.

${ }^{378}$ Howell 1979, S. 172.

${ }^{379}$ Vgl. Nicolaisen 1995, S. 561 f.
} 
zweifelhaft, ob Leser mit ihren Äußerungen über ein literarisches Werk und dessen Figuren tatsächlich auf Vorgänge im 'Hirn des Autors' referieren wollen. Der Versuch, auf Vorstellungen eines supponierten idealen Autors auszuweichen, die nicht mit denen des realen Autors übereinstimmen müssen ${ }^{380}$, bietet dabei ebensowenig eine Lösung. Sie führt in einen infiniten Regreß, da immer weiter gefragt werden kann, wer die Vorstellung von der Vorstellung von der Vorstellung usw. hat.

Einig kann man sich darüber werden, daß literarische Namen dazu dienen, individuelle Zusammenstellungen von Beschreibungen von Namenträgern zu organisieren, seien deren Referenzobjekte nun fiktiv oder real. ${ }^{381}$

\subsubsection{Die Evokation fiktiver Namenträger durch Eigennamen - eine moderate Positi-} on

Eine philosophische Ontologie tut gut daran, nicht von Existenzen zu sprechen, die nicht existieren. Dagegen bedarf die literaturwissenschaftliche Untersuchung eines ontologisch und psychologisch moderaten Modells, das der Produktion und Rezeption literarischer Werke angemessen ist. ${ }^{382}$ Es bietet sich daher an, dem Gabrielschen Modell zu folgen und von Sinngebilden zu sprechen, die keine Objekte im ontologischen Sinne sind. Dies hat den Vorteil, daß die letztbegründende Basis aller Erkenntnis über literarische Entitäten - der Text mit seinen expliziten Aussagen - nicht aus dem Blick verschwindet. Mit Lamarque und Olsen gesprochen: bei fiktionalen Eigennamen findet die Namengebung im Text statt. ${ }^{383}$

Auch wenn die Textinterpretation nicht imaginierend oder visualisierend an der vom Text evozierten Welt teilnimmt, ${ }^{384}$ sollte für die literaturwissenschaftliche Interpretation ein Modell angenommen werden, das der Möglichkeit der bildlichen Imagination Rechnung trägt. Nur so kann berücksichtigt werden, daß mit Sätzen über literarische Figuren nicht über Sätze in Texten geredet wird: ${ }^{385}$

A fictional character [...] is a character depicted in a fiction under the conventions of storytelling whereby a reader is invited to make-believe that there is some actual particular who possesses the defining characteristics. The properties that constitute a character are normally those designated by the descriptive sense of the proper name assigned to the charac$\operatorname{ter}[\ldots]{ }^{386}$

\footnotetext{
${ }^{380}$ Vgl. Currie 1990, S. 156.

${ }^{381}$ Vgl. Taylor 2000, S. $30 \mathrm{f}$.

${ }^{382} \mathrm{Vgl}$. Thomasson 2003, S. 156.

${ }^{383}$ Vgl. Lamarque/Olsen 1994, S. 83; Salmon 1998, S. 300.

384 Vgl. Gabriel 1975, S. 81.

${ }^{385}$ Vgl. Crittenden 1991, S. 26 f.

${ }^{386}$ Lamarque/Olsen 1994, S. 99.
} 
Der Begriff der ,Imagination' umfaßt neben den explizit genannten Eigenschaften des Sinngebildes auch ,motivierte' Assoziationen. ${ }^{387}$,Motiviert' sind Assoziationen, wenn sie sich mit dem Text sowie mit textexternen Hinweisen auf Autorintentionen argumentativ begründen lassen. Es sind sowohl auf Autorseite als auch auf Rezipientenseite eine Vielzahl nicht in diesem Sinne motivierter Assoziationen anzunehmen. Diese beeinflussen unter Umständen die teilnehmende Imagination, werden aber nicht als Teil der Textbedeutung wahrgenommen. ${ }^{388}$

Motivierte Assoziationen sind zu unterscheiden vom allgemeinen shared framework ${ }^{389}$, das argumentativ begründet werden kann. Dieses umfaßt gewisse Standardbedingungen, Stereotypen und Universalien, die solange gelten, wie sie nicht explizit oder implizit widerrufen werden. Das shared framework ermöglicht es, eine Geschichte zu erzählen, ohne jedes Detail des realen Objekts explizit einführen oder berücksichtigen zu müssen. ${ }^{390}$ Darüber hinaus ergeben sich aus dem explizit Mitgeteilten und den allgemeinen Umständen Wahrscheinlichkeiten für einzelne Ergänzungen. ${ }^{391}$ Ergänzungen durch den Autor werden nicht etwa durch die Referenz auf Autorvorstellungen ermöglicht, sondern durch Präsuppositionen und Implikaturen, die es erlauben, von der Abwesenheit einer Korrektur auf Standardbedingungen zu schließen. ${ }^{392}$

In der phänomenologischen Schule - also mit Berufung auf Husserls ,Einstrahligkeit' des Eigennamens in bezug zu den Kennzeichnungen des Namenträgers - wird nun weitergehend behauptet, der Eigenname ermögliche die "Illusionierung“ durch das „punktuelle Verleihen“ des „äußeren Habitus der Realität“. ${ }^{393}$ Dies ist allerdings eine Funktion, die Eigennamen und definite descriptions in literarischen Texten gemeinsam ist. Die description wird genau wie der Name von einer ,Eigenvorstellung' begleitet. ${ }^{394}$ Der Unterschied zwischen der Verwendung eines Eigennamens und der Verwendung einer definite description besteht vielmehr darin, daß der Eigenname suggeriert, der benannte Gegenstand sei Teil einer kommunikativen Praxis. Dies beruht auf dem auf die geltende Namengebung verweisenden Charakter des Namenszeichens Dieser lautet: ,wird N.N. genannt' (Recanati) oder ,trägt bei uns den Namen N.N.' (Evans). Poetisch hebt etwa T.S. Eliot dies durch die vertraute Vornamenverwendung und die Ver-

\footnotetext{
${ }^{387}$ Vgl. Frege 1994, S. 43 f.

${ }^{388}$ Etwa: 'Für mich wird Hamlet immer die Gesichtszüge David Garricks haben'.

${ }^{389}$ Vgl. Crittenden 1991, S. 58 f.

390 Vgl. Crittenden 1991, S. 130.

${ }^{391}$ Vgl. Currie 1997, S. 426.

392 Everett 2000, S. 56, spricht von einer „thin aboutness“ von Eigennamen und Beschreibungen, die auf den Sprechern gemeinsamen Quellen der Referenzfestlegung beruht. Für den Fall, daß die Namenverwendung auf der gemeinsamen Kenntnis der benannten Objekte beruht, redet er von „thick aboutness“. ${ }^{393}$ Vgl. Ingarden 1965, S. 261; Lamping 1983, S. 30.

${ }^{394}$ Vgl. Husserl 1987, S. 173.
} 
wandtschaftsbezeichnung im Titel "Cousin Nancy" hervor. In einem literarischen Werk steht hinter einer solchen unkommentierten Verwendung eines Eigennamens die Suggestion, der Verwender des Eigennamens habe über das Objekt, von dem er spricht, noch weitere Informationen als die mitgeteilten, bzw. er habe als Namenproduzent sogar ,Umgang' (knowledge by acquaintance) mit dem Objekt. ${ }^{395}$ Der Autor als Schöpfer der ,nonexistent objects' ist dabei der notwendig einzige producer (Evans) der Eigennamenbedeutung, denn seine Charaktere sind „man-made abstract artifacts, born of [...his...] fertile imagination. “396 Der Autor kann daher auf seine eigene Vorstellung referieren, die er als einziger by acquaintance (Russell) kennt. Er benutzt also den Namen nicht nur als vorgeblich (pretended) referierendes Zeichen. ${ }^{397}$ Alle anderen Namenbenutzer sind notwendig Konsumenten und müssen sich dementsprechend auf die Aussagen und erschließbaren Intentionen des Autors verlassen. Sie benutzen den Eigennamen deskriptiv und bilden sich ihre eigene Vorstellung; dies alles aber in dem Bewußtsein, daß der Autor sich etwas vorgestellt hat, als er die Figur (und nicht nur den Eigennamen) erschuf. Sie referieren daher auf die Autorvorstellung der Figur insoweit, als diese ein „man made-artifact“ ist. ${ }^{398}$ Kann der Autor nicht mehr befragt werden, funktioniert der literarische Eigenname wie Eigennamen, deren Träger nicht mehr existieren, so daß alle Sprecher Konsumenten sind. Es bleibt auch in diesen Fällen zumindest die Suggestion oder Vermutung bestehen, daß jemand (der Autor) irgendwann einen direkten Zugang zum Namenträger besaß. ${ }^{399}$

Während eine Kennzeichnung mit Demonstrativpronomina zwar eine Begegnung mit dem Referenzobjekt suggerieren kann, suggeriert die Verwendung eines Eigennamens, daß es mindestens ein Wesen gibt, das mit dem benannten Objekt in einem länger dauernden Verhältnis steht. Aus diesem ,Verhältnis' ist die Namengebung hervorgegangen und der Eigenname verweist auf die Namengebungssituation. In diesem Sinne ruft der Name eher als eine Beschreibung ein ,lebendiges Bild' einer Person hervor.

Die Referenz auf scheinbare Objekte kann von der Verweigerung aller Referentialisierbarkeit unterschieden werden. Die „Grenzen des Denkbaren“400 spielen eine besondere Rolle in bezug auf die Referenz, da ihre Überschreitung die ,vertical rules' der Referenz

\footnotetext{
${ }^{395}$ Vgl. auch Martinich 2001, S. 109.

396 Salmon 1998, S. 300.

397 Dies behauptet etwa Salmon 1998, S. 301.

${ }^{398}$ Vgl. Salmon 1998, S. 304. Darauf beruht auch der zuerst von Josef Schächter, später von Carl, Crittenden und anderen postulierte ,Sphärenwechsel' für die Verifikation von Aussagen über fiktive Entitäten (vgl. Schächter 1978, S. 141-144; Carl 1974, S. 205; Crittenden 1991, S. 62 f., S. 71).

${ }^{399}$ Vgl. Evans 1982, S. 391-398.

${ }^{400}$ Fricke 1981, S. 54-62.
} 
über den Text hinaus deutlich abkoppeln und zur horizontalen Referenz bzw. zur Autoreferenz führen. Offensichtlicher nonsense ist demnach ein Indiz für die Intention des Autors, kein make-believe initiieren zu wollen. Trotzdem behält auch der Eigenname einer inkohärent gestalteten Figur immer noch eine gewisse Evokationskraft. Man könnte auch sagen, daß mit Eigennamen benannte ,unmögliche Entitäten' zwar keine semantischen bzw. intentionalen Objekte (objects of thought), aber immer noch ,grammatische Objekte' (objects of [pretended] reference) sind. ${ }^{401}$ Semantisch unmögliche definite descriptions („Colourless green ideas...“) dagegen geben gar keine Referenz vor.

\subsection{Zusammenfassung: Eigennamen als unsichere Zeichen in literarischen Texten}

Unsere sprachanalytischen und literaturtheoretischen Untersuchungen ergeben folgendes Bild: Eigennamen sind unsichere Zeichen, weil sie janusköpfig sind. Auf der einen Seite nehmen sie auf eindeutige Weise Bezug auf ein Individuum und repräsentieren ihren Namenträger sprachlich als individuell ausgesuchtes oder gebildetes label. Ein Namenverwender scheint daher mit einem bestimmten Eigennamen einen Namenträger eineindeutig und umfassend zu ,meinen'. Auf der anderen Seite ist sprachsystematisch und kommunikativ in keiner Weise eindeutig, was ein Sprecher mit einem Eigennamen wirklich ,meint'. Ein verwendeter Eigenname gibt weder die Kennzeichnungen preis, an die ein Sprecher bei der Namenverwendung denkt, noch den kommunikativen Wert, den er dem Namen beimißt. Die Vieldeutigkeit von Eigennamen und das komplizierte sprecherabhängige Gefüge der kennzeichenunabhängigen Referenz durch Eigennamen läßt es für den Empfänger darüber hinaus auch unklar bleiben, auf welche Entität sich der Name überhaupt beziehen soll. Eigennamen bedürfen also umfassender kommunikativer Ergänzungen in einem Kontext oder einem Kotext, um eindeutig zu sein.

In literarischen Texten tritt als weitere Unsicherheit hinzu, daß der Namenträger aus mehreren fiktionalen oder realen Welten stammen kann. Auch hier wird durch Eigennamen nicht explizit festgelegt, welchen Status der Namenträger hat. Eigennamen dienen der Evokation literarischer Figuren, da sie eine vollständige und kommunikativ eingebundene Entität suggerieren. Sie spezifizieren aber diese Entität auch im literarischen Text nicht und geben deren Kennzeichnungen und deren Status nicht preis. Die Möglichkeit der transworld identification durch Eigennamen ermöglicht schließlich auch in fiktionalen Texten den Bezug auf reale Entitäten und auch in faktualen Texten den Bezug auf fiktionale Welten. Eigennamen können so deutliche Hinweise darauf geben, welchen Wahrheitsanspruch literarische Texte haben. Aber auch hier sind weitgehende

${ }^{401}$ Vgl. Crittenden 1991, S. 66 Fn 11. 
Ko- und Kontextergänzungen nötig, um ein Namenszeichen verständlich zu machen. Bei bekannten und berühmten Namen mag dies enzyklopädisches Wissen sein, bei unbekannten Namen knowledge by acquaintance.

Wenn wir nun im Folgenden zur Betrachtung von Eigennamen in Gedichttexten kommen, wird sich zeigen, wie mit diesem äußerst unsicheren und äußerst kontextabhängigen Zeichen in Gedichttexten umgegangen wird, die dem Rezipienten eines verwendeten Namenzeichens prima facie nur sehr spärliche Kotexte liefern können. 


\section{Systematische Überlegungen}

\subsection{Texte der Gattung Lyrik}

\subsubsection{Eigennamen und der ,entstofflichte Charakter' des Gedichts}

Bisher haben wir Gedichte als Beispiele herangezogen, ohne die alles andere als klaren Begriffe ,Gedicht' oder ,Lyrik' zu hinterfragen. Eine Untersuchung des Eigennamengebrauchs bedarf aber der genauen Bestimmung der Textbedingungen, unter denen Eigennamen verwendet werden. Nur werfen schon seit der poetologischen Konstitution der Gattung die Definitionsversuche des Begriffs Lyrik zahlreiche Probleme auf - vor allem aufgrund der Begriffe der ,Unmittelbarkeit' und des ,Subjektiven', die immer wieder zur Definition der Gattung herangezogen werden:

[Der] Charakter des Unmittelbaren, Entstofflichten, den wir zu Recht oder Unrecht uns gewöhnt haben, als Kriterium von Lyrik anzusehen, und über den nur die angestrengte Bildung uns hinausführt, ${ }^{1}$

prägt immer noch vielfach den Umgang mit Gedichten. Daß diese von Adorno beschriebene Tendenz bei weitem nicht für jedes Gedicht gilt, ist festgestellt worden. ${ }^{2}$ Dennoch prägt sie das common-sense-Bild von Lyrik. ${ }^{3}$ Eine bestimmte Textgestaltung wird damit in den Vordergrund gerückt. Dargestellt wird weder eine fiktive oder reale äußere noch eine zeitlich und räumlich gebundene Welt. Statt dessen bildet das überzeitlich gültige Innere des Subjekts, das Allgemeine, dargestellt mit Hilfe der äußeren Welt, den Stoff des Gedichts. In neueren Versionen dieser Beschränkung wird angenommen, Lyrik entstehe, wenn man im normalen Handlungsablauf innehalte. ${ }^{4}$ Die Reflexion im Gedicht wird dann als ,Übersprungshandlung' oder als Meditation verstanden. ${ }^{5}$ Lyrik bleibt demnach aus den Begrenzungen eines alltäglichen Handelns herausgelöst. ${ }^{6}$ Lyrik zu interpretieren, hieße dann, ein movement of consciousness zu beschreiben, das sich auf fundamentale Aspekte menschlichen Daseins bezieht. ${ }^{7}$ Mit die-

\footnotetext{
${ }^{1}$ Adorno 1991, S. 53.

${ }^{2}$ Vgl. Müller-Zettelmann 2000, S. 35.

${ }^{3}$ Für die im Folgenden genannten angelsächsischen Ansätze sei darauf hingewiesen, daß der Sprachgebrauch ,poetry' und ,lyrics' in mancher Hinsicht stärker voneinander trennt als das Deutsche. Dennoch läßt sich auch für den englischen Sprachraum eine gewisse Tendenz feststellen, in der Kategorie 'Gedicht' noch die Subkategorie 'lyrisches Gedicht' zu unterscheiden. Während Gedichte von den anderen Großgattungen dann durch formale Eigenschaften getrennt sind, ist das lyrische Gedicht wiederum durch eine besondere Haltung des Sprechersubjekts gekennzeichnet; vgl. z.B. die Einteilung in Fairer/Gerrard 1999 , S. xvi.

${ }^{4}$ Vgl. Frye 1985, S. 32.

${ }^{5}$ Vgl. Frye 1985, S. 32 und S. 33.

${ }^{6}$ Vgl. Frye 1985, S. 34.

${ }^{7}$ Vgl. Culler 1988, S. 292.
} 
sem Modell geht einher, daß die Subjektivität der Lyrik als private Erfahrung verstanden wird, die durch künstlerische Gestaltung intersubjektiv zugänglich gemacht wird. ${ }^{8}$

Die Abwendung vom Alltäglichen und von den Alltagsfunktionen der Sprache bewirkt nach dieser Vorstellung eine Sinnintensität:

Lyric turns away, not only from ordinary space and time, but from the kind of language we use in coping with ordinary experience. ${ }^{9}$

Das lyrische Gedicht beschäftigt sich Frye zufolge nicht mit ,Äußerlichkeiten':

Personality or selfhood triumphs in the drama; the divine and all that is not Me triumphs in the lyric [gemeint ist nicht das gesellschaftlich bestimmte Äußere, sondern das kreativ auf die Gesellschaft reagierende Innere im Sinne Meads]. ${ }^{10}$

Diese Doktrin der besonderen Subjektivität von Lyrik interessiert uns insofern, als sie zeigt, daß Eigennamen in der Gattung Lyrik grundsätzlich nicht unproblematisch sind. Die Verwendung von Eigennamen scheint auf den ersten Blick nicht in dieses commonsense-Konzept von Lyrik zu passen. Denn Namen sind im Gegensatz zum ,Ich' prima facie eine gesellschaftlich bestimmte Äußerlichkeit, eine feste Bestimmung in Raum und Zeit, Ausdruck einer gewissen Distanz und Objektivität gegenüber dem Namenträger. Die historischen Wurzeln dieser Lyrikbestimmung sind z.B. bei G.W.F. Hegel zu finden. Er zeigt, welche Position Eigennamen unter diesen Voraussetzungen haben. Für Hegel spielt die Referenz von Eigennamen in Gedichten keine Rolle. Eigennamen sind inm höchstens Platzhalter ihrer sortalen Prädikate. Der Lyrikdichter - so Hegel - feiert in seinen Gedichten sich selbst, nicht den dort genannten Helden:

Pindars Helden [...] sind uns leere Namen geblieben, er selbst aber [...] steht unvergeßlich als Dichter da [...]. ${ }^{11}$

Es gibt aber eine Form, in der auch Eigennamen in dieses Bild der Lyrik integriert werden können. Sie treten auf als „an invoking of names of specific and trusted power“. ${ }^{12}$ In diesem Fall werden die Namen nicht im alltagssprachlichen Sinne gebraucht, sondern angerufen. Dabei kommen neben dem referentiellen Alltagswert des Namens dessen nichtreferentielle Qualitäten zum Tragen. Gleichzeitig wird der kommunikative Wert des Namens in die Gedichtgestaltung einbezogen. Namen werden also sowohl nach der am Formalen orientierten, als auch nach der an Subjektivität ausgerichteten Lyrikdefinition polyvalent und sinnintensiv durch die Berücksichtigung aller Zeicheneigenschaften mit ihrer Einbindung in die Gesamtstruktur des Textes.

\footnotetext{
${ }^{8}$ Vgl. Hühn 1995, S. 10 f.

${ }^{9}$ Frye 1985, S. 34.

10 Tucker 1985, S. 230; vgl. auch Hühn/Schönert 2002, S. 300.

${ }_{11}^{11}$ Hegel 1973, III, S. 440.

12 Frye 1985, S. 35.
} 
Eine am Formalen orientierte Definition kann allerdings im Gegensatz zum subjektivistischen common sense-Bild der Lyrik auch die Referenz des Namenzeichens in den Text integrieren.

Die mit den Begriffen des ,Subjektiven' und der ,Unmittelbarkeit' verbundenen Unschärfen verleiten Literaturwissenschaftler dazu, dieser Kategorie die Relevanz für die Textproduktion und Textinterpretation abzusprechen und statt dessen entweder den einzelnen Text als individuelles Phänomen zu betrachten oder auf historisch und normativ wirksame Subkategorisierungen wie ,Ballade' oder ,Sonett' zurückzugreifen. ${ }^{13}$ Dennoch wird ein Gattungsbegriff ,Lyrik', der die für die Eigennamenverwendung relevanten Texteigenschaften einer Textgruppe abgrenzt ${ }^{14}$, für diese Untersuchung von Nutzen sein, wie hier zu zeigen ist.

Gattungsvorgaben sind zunächst bei der Produktion und der Rezeption von Texten in einer Sprechergemeinschaft bewußt oder unbewußt präsent. So wie der bildende Künstler sich mit den Grenzen und Möglichkeiten seines Materials kreativ auseinandersetzt, entsteht das Kunstwerk ,Gedicht' auch dadurch, daß der Autor mit den inhaltlichen und formalen Vorgaben seines sprachlichen Materials arbeitet, zu dem eben auch die Gattungsbegriffe als Ordnungskategorien von Textgruppen gehören. ${ }^{15}$ Dies ist bei der Interpretation von Gedichten zu berücksichtigen. Das Postulat, nur die Einzeltexte seien relevant, wäre insoweit naiv gegenüber den Rezeptions- und Produktionsbedingungen von Texten in Sprechergemeinschaften.

\footnotetext{
${ }^{13}$ Vgl. z.B. Fricke 1981, S. 133; Conrady 1994, S. 50; Helmstetter 1995, S. 27-29; Hühn 1998, S. 216, S. 237; Müller-Zettelmann 2000, S. 12-14 und 16. Die Schwierigkeit, die vielfältigen Formen zu erfassen, die vorwissenschaftlich und literarhistorisch als ,Lyrik' bezeichnet werden, hat in der Lyriktheorie Definitionsversuche mit unterschiedlichem ,Flexibilitätsgrad' hervorgebracht. ,Starre' Definitionen nennen ein oder wenige Kriterien, die notwendig und hinreichend sein sollen, um einen lyrischen Text zu konstituieren. Sie sind einfach zu kritisieren, da sich immer ein Beispiel finden läßt, das intuitiv als Lyrik bezeichnet werden kann und doch gerade über das jeweilige definiens nicht verfügt; vgl. die Strategie Müller-Zettelmanns 2000, S. 18f., S. 28. ,Flexible' Definitionen nehmen entweder zentrale und periphere Komponenten an oder gehen von einer Menge Eigenschaften aus, von denen ein hinreichender Anteil erfüllt werden muß; vgl. Burdorf 1995, 20f. Zusätzlich werden ,weiche' Modelle angeboten, die von ,Tendenzen' und ,graduellen Unterschieden' ausgehen; vgl. Müller-Zettelmann 2000, S. 139-156. Diese Modelle berücksichtigen, daß es bei jedem Begriff Randbereichsunschärfen und Übergangsformen gibt. Dabei kann in Abhängigkeit vom jeweils gewählten Genre oder Gattungsbegriff zwischen stärker und schwächer normierenden Kontexten mit jeweils kleineren oder größeren Randbereichsunschärfen unterschieden werden. Bex 1992, S. 6-10, unterscheidet graduell zwischen open und closed contexts. Auch die Rede von ,Tendenzen' kann in den meisten Fällen kritisiert werden, da sie auf der einen Seite keine klare Begriffsabgrenzung ermöglicht, auf der anderen implizit das durch starre Definitionen geprägte Lyrikbild stützt, indem jene Lyrik, die die Tendenzen voll erfüllt, die ,eigentlichere' Lyrik wird; vgl. Knörrich 1992, S. XV; Pierce 2003, S. 154.

${ }^{14}$ Vgl. Hühn/Schönert 2002, S. 289.

${ }^{15}$ Vgl. Schmidt 1968, S. 291; Gombrich 1961, S. 36-39; Wollheim 1980, S. 42f.; Culler 1988, S. 292; Bex 1992, S. 12.
} 
Nun scheint es gerade unter dem Aspekt der Wirkung in einer Sprechergemeinschaft sinnvoll, die Gattung 'Lyrik' durch historisch und normativ wirksame Untergattungen (etwa ,Sonett', ,Ode' etc.) zu ersetzen. ${ }^{16}$ Denn einer Sprechergemeinschaft sind aller Wahrscheinlichkeit nach historisch abgegrenzte Genres präsent und nicht literaturwissenschaftliche Gattungsbegriffe. Ein Begriff der Großgattung ,Lyrik' ist jedoch dann gerechtfertigt und sinnvoll, wenn er auf eine nominale Definition zielt. Diese versucht, eine Gruppe von Texten vor dem Hintergrund jener gemeinsamen Eigenschaften zu interpretieren, die für sie kennzeichnend sind. ${ }^{17}$ Insofern ist ein Gattungsmodell dienlich, wenn es eine Beschreibung der für die Rezeption und Produktion der Texte relevanten Gemeinsamkeiten liefert. ${ }^{18}$ Die Integration einzelner Zeichen - Eigennamen - in einen Text ist vor dem Hintergrund derartiger beschränkender oder etwas ermöglichender Texteigenschaften zu verstehen. Diese stellen freiwillig gewählte Bedingungen dar, mit denen der Autor sich auseinanderzusetzen hat, wenn er seinen Text gestaltet. Formale Vorgaben sind dadurch eng in den kreativen Prozeß eingebunden und lassen sich keinesfalls als "ganz äußerliche Kriterien“19 abtun.

Uns interessieren im Folgenden jene Texteigenschaften, die den Eigennamengebrauch besonders betreffen. Das sind zunächst die formalen Textbedingungen, nach denen ein Eigenname in den Text integriert wird. Weiterhin ist der referentielle Status des Textes von Bedeutung, das heißt die Fiktionalität von Gedichten. Damit hängt schließlich die Frage nach dem Verhältnis von Gedichten zu ihrem Kontext für die Vertextung des Eigenamengebrauchs zusammen. Am Ende soll eine Arbeitsdefinition der Textgattung ,Lyrik' oder ,Gedicht' stehen, auf die sich diese Arbeit beziehen kann.

\subsubsection{Das Gedicht als formal überstrukturierter Text}

Als zentrales Kennzeichen der Gattung Lyrik ${ }^{20}$ als Teil der Trias Epik - Dramatik - Lyrik sehen wir die formale Überstrukturierung des Textes an. Diese verstehen wir als „Textbildungsverfahren“21, das etwa die Versrede, die Zeilenrede oder auch ein Figurengedicht konstituieren kann. Prototyp solcher sich auf die sprachliche Form beziehenden Definitionsversuche ist die Trivialdefinition, ein Gedicht sei „ein Text mit viel Platz drum herum“. ${ }^{22}$ Diese Definition drückt aus, daß das Seitenformat nicht den Textumriß be-

\footnotetext{
${ }^{16}$ Vgl. Fricke 1981, S. 133.

${ }^{17}$ Vgl. dazu aus textlinguistischer Sicht Heinemann/Viehweger 1991, S. 129-133.

${ }^{18}$ Vgl. Köhler 1989, S. 13.

${ }^{19}$ Müller 1998, S. 94.

20 Es sollen im Folgenden mit Burdorf die Begriffe Lyrik und Gedicht systematisch als extensions- und intensionsgleich betrachtet werden.

${ }^{21}$ Knörrich 1992, S. XXXXIII.

${ }^{22}$ Vgl. Burdorf 1995, S. 12 im Anschluß an Wolfgang Kayser.
} 
stimmt. Im engsten Sinne sind darin die Kriterien ,Kürze' und ,Versbindung' enthalten. ${ }^{23}$ Im weiteren Sinne ist der ,Platz links und rechts' des Gedichttextes ein Symptom der zusätzlichen Bindung des Textes durch „Superstrukturen“24 - d.h. über die grammatischen Vorgaben hinausgehende und mit der Grammatik konkurrierende, das Sprachmaterial auswählende und anordnende Einflüsse. So versteht etwa Conrady Gedichte als sprachliche Äußerungen in einer „speziellen Schreibweise“, d.h. mit einer besonderen Anordnung der Schriftzeichen. ${ }^{25}$ Fricke faßt einen Vorläufer seines später als „dominierende grammatische Abweichung“26 einflußreichen Lyrikkriteriums folgendermaßen:

Mir scheint, daß man für alle diese Arten von Lyrik kein anderes gemeinsames Merkmal wird finden können als eine dominierende Tendenz zur strukturellen Systembildung unter den formalen Ordnungsbeziehungen (z.B. Regelung von Akzentverteilungen, Silbenzahlen oder Zeilenlängen; Textgliederung durch wiederkehrende Klangäquivalenzen wie Reim, Assonanz oder Alliteration; graphische Makrostruktur im konkreten Gedicht usw.). ${ }^{27}$

Superstrukturen, die den Text systematisch gestalten, führen zu motivierten und damit bedeutungstragenden formalen Abweichungen von der Gemeinsprache. ${ }^{28}$

Aus der „strukturellen Systembildung“ erwächst eine unterschiedlich stark ausgeprägte strukturelle Dominanz der Form über den dargestellten Inhalt des Textes. Dies ist ein betont ,weiches' Kriterium, das fließende Übergänge zu anderen formal überstrukturierten epischen bzw. dramatischen Textsorten beinhaltet. ${ }^{29}$

${ }^{23}$ Vgl. Burdorf 1995, S. 58; zum Problem des Druckbildes bei Gedichten bis zur frühen Neuzeit vgl. etwa Burdorf 1995, S. 12.

${ }^{24}$ Vgl. Link 1981, S. 92-97.

${ }^{25}$ Conrady 2000, S. 13.

${ }^{26}$ Fricke 1981, S. $116 \mathrm{f}$

${ }^{27}$ Fricke 1977, S. 136.

${ }^{28}$ Vgl. Lamping 1993, S. 44 ff.; kritisch: Lamping 2000, S. 238. Nach dieser Einschätzung ist auch die ,Unordnung' des beau désordre (vgl. Knörrich 1992, S. XXV) eine bedeutungstragende Abweichung von der Alltagsgrammatik oder von systematisch vorgegebenen Schemata. Die einzelnen, unsystematischen Formelemente sind ihrerseits wieder strukturierende bedeutungstragende Elemente des Gedichts.

${ }^{29}$ Die Zuordnung neuer Texte zu einer Gattung wird am ehesten deutlich, wenn man die Herausbildung einer Gattung durch das Verhältnis der Vertreter der Gattung zueinander erklärt. Der Begriff 'Familienähnlichkeit' erfreut sich in diesem Zusammenhang in der Gattungstheorie und besonders in der Lyriktheorie einer gewissen Beliebtheit, vgl. Fishelow 1991. Er wird gern dazu genutzt, der Gattung Lyrik eine besondere ,lyriktypische Offenheit' zuzusprechen und den Lyrikbegriff letztendlich aufzulösen. (MüllerZettelmann 2000, S. 61: „[...] es sind diese heterogenen, weder gattungsdistinktiven, noch notwendig vorhandenen, noch historisch invarianten, noch zwingenderweise kausal verbundenen Charakteristika die in ihrer polymorphen Gesamtheit die [...] lyrische Gattung konstituieren.") Nach Wittgenstein sind allerdings alle Begriffsextensionen - also auch diejenigen der Gattungsbegriffe Epik und Dramatik - durch Familienähnlichkeiten bestimmt. Aus dieser Sicht sind also sowohl Lyriktheorien, die eine unflexible Definition propagieren, verfehlt, als auch solche, die versuchen, Heterogenität als besonderes Kennzeichen nur der Lyrik zu konstatieren. Dagegen hilft der Begriff der Ähnlichkeit, einen offenen, aber nicht beliebigen Lyrikbegriff zu erlangen. Ähnlichkeit ist logisch intransitiv. Das heißt für einen von Wittgensteins Begriff ausgehenden Lyrikbegriff, daß jeder Text, der als Lyrik gesehen werden soll, mit mindestens einem weiteren Gedicht, das seinerseits anerkanntermaßen Lyrik ist, in einer Ähnlichkeitsrelation stehen muß, keineswegs aber zu allen Gedichten. Die Ähnlichkeit mit einem anerkannten Text ist notwendiges und hinreichendes Kriterium der Gattungszugehörigkeit; vgl. Wittgenstein 1984, S. 279 (§ 69); vgl. dazu Wennerberg 1998, S. 41-69. Etablierte oder kanonische Texte spielen eine wichtige Rolle bei der Bestimmung subjektiv neuer Texte als Lyrik. Da alle subjektiv neuen Texte durch Ähnlichkeitsrelationen mit an- 
Das Dominanzkriterium kann auf zwei Arten interpretiert werden, die die berühmten zwei Seiten der einen Medaille bilden. Einerseits meint es, daß vorgegebene Gedichtoder Strophenformen den Verlauf des Textes bzw. dessen Produktion dominieren. In dieser Hinsicht ist die formale Dominanz am deutlichsten in stark normierten Gedichtformen, etwa der strengen Sonettform. Von der anderen Seite betrachtet, bedeutet eine Dominanz der Form, daß die gesamte formale Mikrostruktur des Textes bedeutungstragend ist. ${ }^{30}$ Dies gilt besonders für Gedichte, die keine vorgegebene Gedicht-, Strophenoder Versform, dafür aber eine semantisch bedeutsam variierende Struktur (etwa den Zeilenumbruch) aufweisen. Das „einzelne sprachliche Zeichen“ ist in derart überstrukturierten Texten „aus seinen grammatischen und syntaktischen Zusammenhängen“ gelöst, „um ihm ein Maximum an Aufmerksamkeit zu sichern“. ${ }^{31}$ Da so das einzelne Zeichen unter vielfältigen Vorgaben Teil einer komplexen Struktur ist, können alle seine Eigenschaften bedeutungstragend werden. Die Mikrostrukturen werden „polyfunktional“ und „sinnintensiv“32, die klanglichen und graphischen Zeichenqualitäten werden betont. ${ }^{33}$ Dies führt dazu, daß auch intertextuelle Bezüge und ansonsten unterschwellig

erkannten Texten in Verbindung stehen, ist der Begriff nicht beliebig anwendbar. Über intransitive Ähnlichkeitsrelationen stehen die Texte der Gattung Lyrik miteinander indirekt in Verbindung, ohne durch direkte Ähnlichkeit verbunden zu sein. Der Gattungsbegriff hat daher eine Geschichte, die dazu führt, daß durch die - bei genügend langer Entwicklung zahlreichen und langen - Ketten von nichttransitiven Ähnlichkeitsrelationen Texte unter einen Begriff fallen können, die untereinander überhaupt nicht ähnlich sind. Die Bedeutung des nicht weiter spezifizierten Begriffs 'Lyrik' hängt von dem jeweiligen 'Ist-Zustand' ab, weil vorhandene als Lyrik eingestufte Texte den Spielraum bzw. die Grenzen für die Einstufung weiterer neuer Texte setzen. Dabei wird die Grenze nicht theoretisch, sondern durch neue Texte verschoben. Die sich wandelnde Definition des Begriffs wirkt sich rückwirkend auf die Kategorisierung älterer Texte aus. Die Tatsache, daß 'Lyrik' erst spät als eigene Gattung definiert wurde, erklärt, daß sehr unterschiedliche Texte mit sehr unterschiedlichen Traditionen und Eigenschaften von Beginn an eine heterogene Extension des Begriffs ergeben haben. Durch explizite Signale kann die Zugehörigkeit zu einer Gattung eingefordert werden, wenn die Eigenschaften des Textes nicht mit den Vorbildeigenschaften übereinstimmen. Die explizite, aber kontrafaktische Bezeichnung als 'Ode' oder 'Gedicht' kann dazu dienen, den Rezipienten aufzufordern, nach nicht offensichtlichen Ähnlichkeiten zu suchen oder nicht an der Oberfläche vorhandene Ähnlichkeiten zu konstruieren, vgl. Fricke 1981, S. 135 f. Ähnlichkeitsrelationen erklären auch die Verbindung von Textsorten und historischen Genres (vgl. Fricke 1981, S. 132 f.) zu einer historisch kontinuierlichen Gattung. Dem wittgensteinsch verstandenen Gattungsbegriff verwandt ist der Ansatz, statt einer positiven Definition nur den permanenten Verstoß gegen formale Vorgaben als Unterscheidungskriterium anzugeben. Die lyrikspezifische „Transgression“ sprachlicher Schemata (Stierle 1979a, S. 514 passim) soll darin bestehen, daß die Diskursüberschreitungen - also der Bruch mit alltäglichen oder etablierten Kommunikationsgewohnheiten - 'diskontinuierlich' sind und außerdem durch eine „translinguistische Organisation“ der "multiplizierten“ Kontexte begleitet werden. Entkleidet man Stierles Modell seines diskurstheoretischen Vokabulars, ergibt sich, daß die Besonderheit der Lyrik darin bestehe, daß sie durch die Form der in ihr verwendeten sprachlichen Elemente ein zusätzliches, evtl. nicht harmonisierendes Bedeutungssystem aufbaue; vgl. Stierle 1979a, S. 517 ff. und 1979b, S. 746; Burdorf 1995, S. 21.

${ }^{30} \mathrm{Vgl}$. z.B. Bierwisch 1965.

${ }^{31}$ Lamping 1993, S. 43.

32 Bierwisch 1965; Schmidt 1968, S. 294; Austermühl 1981, S. 148. Auch ready-mades enthalten durch Superstrukturen eine neue Bedeutung. Der Künstler kann ein Bedeutungspotential an einem vorgegebenen Material bzw. Objekt erkennen und durch die Präsentation in neuem Kontext vorhandene Bedeutungen hervorheben oder neue Bedeutungen schaffen.

${ }^{33}$ Vgl. Schmidt 1968, S. 291: „Die Sprachmittel können im Gedicht bis an die Grenzen ihrer in der Alltagssprache üblichen Funktionsweisen aktiviert werden und darüber hinaus neue, für die Alltagssprache 
mitschwingende oder abgelegene Bedeutungsnuancen der verwendeten Zeichen (besonders der Eigennamen) stärker beachtet werden. Auf diese Weise werden die Arbitrarität und die Linearität des sprachlichen Zeichens in Gedichten aufgehoben. ${ }^{34}$ Sprachliche Zeichen erfahren eine „iconic transmutation“. ${ }^{35}$ Die ,Dominanz des Formalen' und die erhöhte Aufmerksamkeit auf den Text selbst erklären die oftmals postulierte verstärkte Autoreferenz im Gedicht: ,Lyrik' gilt vielen Lesern und Forschern als Manifestation des nicht referentiellen, automimetischen ,Innersten der Sprache'. ${ }^{36}$

Dies hat besonders für die intuitive Einschätzung von Eigennamen Folgen. An den nomina propria wird besonders eine „Aura“ bzw. der reiche semantische Hintergrund zum „stimmungsorientierten, suggestiven, konnotationsreichen Sprechen“ in Gedichten hervorgehoben ${ }^{37}$ : „In der Dichtung lebt die innere Form eines Namens, das heißt der semantische Wert seiner Konstituenten, wieder auf. "38 Zwar ist die damit verbundene naive Position, dem Gedicht jeden direkten Außenweltbezug abzusprechen, durchaus verbreitet. ${ }^{39}$ Dennoch gestehen zumindest die meisten semiotischen Modelle lyrischer Autoreferenz dem Gedicht neben dem Bezug auf sich selbst zumindest auch einen - allerdings zweitrangigen - Bezug auf die Welt zu. So postuliert z.B. Mukařovsky die Dominanz der Autoreferenz, ohne die Referenz gänzlich zu negieren:

Poetic reference is primarily determined, then, not by its relationship to the reality indicated, but by the way it is set into the verbal context. ${ }^{40}$

Durch Superstrukturen bewirkte „Autoreflexivität“41 bedeutet dann lediglich einen Rückbezug auf die nicht selbstverständliche Aussage des Gedichts. Eine solche tendenzielle Autoreferenz besteht, wenn man so will, in einem „emphatic foregrounding of the materiality of the sign and the communicative act“. ${ }^{42}$ Sie kann sich - aus theoretischer Sicht

untypische Wirkungsweisen entfalten, die potentiell alle als bedeutungswirksam gesehen werden müssen, solange sie als Muster, Form oder Struktur erkennbar bleiben."

${ }^{34}$ Vgl. Widdowson 1984, S. 145.

35 Warning 1997, S. 23; Culler 1985, S. 40f.; Bex 1995, S. 163; aus kognitionswissenschaftlicher Perspektive: Christmann/Schreier 2003, S. 369.

${ }^{36}$ Vgl. Tucker 1985, S. 235; Culler 1975, S. 162. Es muß dabei unterschieden werden zwischen der 'allgemeinen' Autoreferenz, die allen literarischen Texten zugeschrieben wird, und einer besonders starken Autoreferenz, die speziell der Lyrik zukommen soll; vgl. Tucker 1985, S. 229; Müller-Zettelmann 2000, S. 112.

${ }^{37}$ Vgl. Bernhart 1993, $372 \mathrm{f}$.

38 Jakobson 1989, S. 118 f; unter Bezug auf Wallace Stevens führt Roman Jakobson in einer kurzen Passage vor, wie Eigennamen in Gedichten „redend“ werden. Er unterscheidet nicht zwischen nomen proprium und nomen appellativum. Die Aktivierung der Ursprungssemantik („new“ von „New Haven“) steht neben der assoziierenden Abwandlung von Eigennamen („Haven“ - „Heaven“) und der Pseudoetymologie von Appellativen („Cocktail“ - „Cock“). Die Referenz des Eigennamens behandelt Jakobson nicht. ${ }^{39}$ Vgl. Müller-Zettelmann 2000, S. 51; Austermühl 1981, S. 182 f.

${ }^{40}$ Mukařovsky 1976, S. 156; Wienold 1994, S. 223 f.; vgl. auch die falsche Zuschreibung von absoluter Autoreferenz durch Müller 1998, S. 97.

${ }^{41}$ Vgl. Knörrich 1992, S. XXXIII.

${ }^{42}$ Vgl. Hühn 1998, S. 217; Hühn 1995, S. 11. So betont Lamping 1993, S. 111: „Deshalb ist wohl eine Rede denkbar, die keine poetische Funktion [i.S. Jakobsons] erfüllt, aber nicht eine, die nur eine poetische Funktion erfüllte." Er teilt dementsprechend die Lyrik in 'referentielle, emotive, konative, phatische 
- daher auch auf das emphatic foregrounding gerade der Referenzfunktionen des Zeichens erstrecken, die daher auch in einem poetischen Werk relevant bleiben. ${ }^{43}$

In diesem Sinne kann ein auf die Realität referierendes Zeichen gleichzeitig autoreferentiell sein. ${ }^{44}$ Eigennamen im Gedicht werden daher nicht lediglich „erwähnt“, wie verschiedentlich behauptet wurde. ${ }^{45} \mathrm{Im}$ Gedicht "feiert" vielmehr die Sprache und diese „Feier" schließt gerade das Verhältnis der Sprache zur Welt ein. ${ }^{46}$

Die Dominanz des Formalen erklärt auch die von der Trivialdefinition postulierten künstlichen Begrenzungen des Gedichtes, links und rechts'. ${ }^{47}$ Anders sieht es allerdings bei der Frage nach der typischen Länge bzw. Kürze eines Gedichtes aus. ,Kürze' als Gattungskriterium wird zu Recht bestritten. ${ }^{48}$ Infolgedessen wird sie nur noch mit Vorbehalt genannt oder auf eine verdichtete "Sageweise" und einen "lyriktypischen Lakonismus" reduziert. ${ }^{49}$ Wenn man anerkennt, daß nichtlineare und analog wahrzunehmende Strukturen nicht allzu lang werden dürfen, da sie sonst kognitiv nur schwer zu erfassen sind, so läßt sich allenfalls von einer daraus folgenden Tendenz zur Kürze bei Texten sprechen. Dies gilt nur insoweit, als längere Gedichte zu stärkerer linearer Regulierung neigen, während kürzere von komplexen formalen Ordnungsstrukturen bestimmt sein können, die alle Elemente des Gedichts nichtlinear miteinander verbinden. ${ }^{50}$ Bei zunehmender linearer Regulierung der Textstruktur liegt die inhaltliche Strukturierung immer näher. Die formalen Ordnungsbeziehungen werden immer lockerer und damit weniger

und metapoetische' „lyrische Gedichte" ein. Die Literaturtheorie vergißt allzu oft diese notwendige Einbeziehung der semantischen Zeicheneigenschaften in den poetischen Gebrauch der Sprache (vgl. etwa Lawn 2001, S. 117). Es gibt einen weiteren Unterschied, der bei einem naiven Gebrauch des Begriffs ,Autoreferenz' mißachtet wird, nämlich denjenigen zwischen der Referenz des Textes auf sich selbst und metapoetischen Gedichten, die sich auf dichterische oder auch nichtdichterische Sprachverwendung beziehen. Es ist ein Unterschied zu machen zwischen einem Gedicht, dessen sprachliche Zeichen primär ihre eigenen types exemplifizieren und einem Gedicht, das explizit poetologische Prinzipien oder das Funktionieren von Sprache allgemein behandelt; vgl. die Nichtbeachtung dieses Unterschieds z.B. bei Hühn 1993, S. 122; Hühn 1995, S. 12.

${ }^{43}$ Die Referenz ist also Teil der Sprache in poetischer Funktion und nicht ein grundsätzlicher Bezug der Altagssprache, der in Gedichten relativiert wird; anders z.B. Helmstetter 1995, S. 30.

${ }^{44} \mathrm{Vgl}$. auch Hühn/Schönert 2002, S. $289 f$.

${ }^{45}$ Vgl. Bex 1995, S. 165; Widdowson 1984, S. 153, S. 156 f.

46 „Und so eine seltsame Verbindung [des Wortes mit dem Gegenstand] hat wirklich statt, wenn nämlich der Philosoph, um herauszubringen, was die Beziehung zwischen Namen und Benanntem ist, auf einen Gegenstand vor sich hin starrt und dabei unzählige Male einen Namen [d.i. ein Appellativ] wiederholt [...]. Denn die philosophischen Probleme entstehen, wenn die Sprache feiert." Wittgenstein 1984, § 38. Eine Verbindung von Wittgensteins Sprachphilosophie mit Gadamers Theorien vom Spiel der Sprache in poetischen Texten zieht Lawn 2001.

${ }^{47}$ Vgl. z.B. Strachan/Terry 2000, S. 11.

${ }^{48}$ Vgl. Fricke 1981, S. 117.

${ }^{49}$ Austermühl 1981, S.189; Knörrich 1992, S. XXXVII f.; vgl. auch Bernhart 1993, S. 374 f.

${ }^{50} \mathrm{Vgl}$. Müller-Zettelmann 2000, S. 73-76; Hühn/Schönert 2002, S. 290. Allerdings gibt es auch in diesem Fall Gegenbeispiele; vgl. Fricke 1981, S. 117. 
dominierend. ${ }^{51}$ Unter diesem Vorbehalt kann Kürze als ,Gattungssymptom' anerkannt werden. Die strukturelle Dominanz der Form ist ein minimales Kriterium, das zumindest als ein Kennzeichen des Gedichts alle wichtigen neueren Entwürfe zur Lyriktheorie anerkennen. ${ }^{52}$

\subsubsection{Das Gedicht als fiktionaler oder nichtfiktionaler Text}

Die in den vorherigen Abschnitten herangezogenen Gedichtbeispiele deuten schon darauf hin, daß der fiktionale Status von Gedichten unklar ist. Dementsprechend besteht keine Einigkeit darüber, ob Texte der Gattung Lyrik generell als fiktional einzustufen sind. ${ }^{53}$ Geht man davon aus, daß Autor und Sprecher von Gedicht zu Gedicht in unterschiedlich starkem Maße getrennt sind, bleiben grundsätzlich drei Verhältnisse zwischen dem Sprecher des Gedichts und dem realen Autor vorstellbar: Das Sprechersubjekt ist explizit gestaltet und mit dem realen Autor ganz oder teilweise zu identifizieren; das Sprechersubjekt ist explizit gestaltet und als Fiktion vom historischen Autor völlig zu trennen; das Sprechersubjekt ist nicht explizit gestaltet. Darüber hinaus wandeln sich die Kommunikationsstrukturen, in die ein Gedicht eingebettet ist, und die im Gedicht gestalteten Rollen mit der Veröffentlichung des Gedichts; z.B. indem ein ursprünglich handgeschriebenes Liebesgedicht aus einem privaten Brief an einen genau bestimmten Adressaten in einer Gedichtanthologie gedruckt und so einem breiten und anonymen Publikum präsentiert wird.

Diejenigen Gedichte, an denen sich die Debatte um die Authentizität des Sprechersubjekts entzündet, gehören der dritten Kategorie an und zeichnen sich dadurch aus, daß „the speaking presence“ vom Text zwar konstituiert, aber nicht gestaltet wird. ${ }^{54}$ Dies hängt auch mit der Kürze vieler Gedichtformen zusammen, die eine eingeschränkte explizite Darstellung von fiktiven oder realen Welten nur eingeschränkt zulassen. Im Unterschied zu Texten, die eine fiktive Welt aufbauen oder die reale Welt gestalten, müssen das sprechende Subjekt und die Sprechsituation aus dem Gesagten mehr oder weniger indirekt erschlossen werden. Der Charakter wird ,zwischen den Zeilen' kreiert. ${ }^{55}$

${ }^{51}$ Ein Beispiel ist das Versepos Canto General Pablo Nerudas, das sich dem Leser aufgrund der aufwendigen formalen Strukturierung der einzelnen in ihm enthaltenen Texte eher eine lange Folge von lyrischen Gedichten darstellt, denn als ein Epos.

52 Definitionen, die eine bestimmte strukturelle Eigenschaft als Gattungsmerkmal des lyrischen Gedichts anführen, dominieren unter den neueren Versuchen, Lyrik zu definieren; vgl. Fricke 1977, S. 136; Fricke 1981, S.115; Culler 1985, S. 43 f.; Tucker 1985; Lamping 1993, bes. S. 23-38 und 39; Lamping 2000, S. 237; Strachan/Terry 2000, S. 9 f.

${ }^{53}$ Vgl. Burdorf 1995, S. $166 \mathrm{f}$.

${ }^{54}$ Vgl. Tucker 1985, S. 232.

${ }^{55}$ Vgl. Tucker 1985, S. 232. Backus spricht in diesem Zusammenhang von "no-names“, Sprechern oder Figuren, die existieren und gleichzeitig nicht existieren, vgl. Backus 1967, S. 6. 
Solche Gedichte werden oft als Äußerungen des realen Autors behandelt. Der in einem Gedicht dargestellte Hintergrund ist dann die engere oder weitere Situation des realen Autors. Wäre das Sprechersubjekt grundsätzlich mit dem realen Autor identisch, enthielte das Gedicht eine authentische Aussage, die wie jede Aussage den pragmatischen Glückensbedingungen genügen müßte. Das heißt, bei assertorischen Sprechakten müßten die Aussagen wahr und wahrhaftig sein, bei appellativen Sprechakten der wirklichen Intention des Sprechers entsprechen etc. Diese Position der „älteren, ,naiveren' Literaturgeschichte“ ${ }^{56}$ ist sicherlich unzureichend. Im Gedichttext können sich aber immerhin Hinweise darauf befinden, daß der Autor Wahrheits- und Wahrhaftigkeitsansprüche erhebt. Dies sind vor allem Daten, die die Einbindung in einen konkreten pragmatischen Kontext signalisieren: Eigennamen, Datumsangaben, Publikationsformen etc. Es sind dies unter Umständen Signale dafür, daß eine Einbettung in einen realen Kontext intendiert ist.

In Käte Hamburgers differenziertem Modell der Lyrik als nichtfiktionaler Gattung ist das „Aussagesubjekt“ der lyrischen Aussage tatsächlich der reale Dichter, auch wenn daraus nicht zu schließen ist, daß der Dichter reale Erlebnisse gestaltet. Vielmehr wird die Gestaltung des Gedichts durch den realen Autor zur Aussage des Gedichts. ${ }^{57}$ Das „Erlebnisgestaltungserlebnis“ läßt das Gedicht in Hamburgers Modell ganz am „Subjektpol“ angesiedelt sein. Damit sei das „Iyrische Aussagesubjekt“ unterschieden von „historischen“ und „pragmatischen Aussagesubjekten“, deren reale historische Eigenschaften und Kontexte für die „Wirklichkeitsaussage“ des Textes bedeutsam seien. Ebenso sei das „Iyrische Aussagesubjekt“ vom „theoretischen Aussagesubjekt“ (etwa wissenschaftlicher Texte) zu unterscheiden, das selbst als ,Sprecherfigur' für die Bedeutung des Textes nicht relevant sei. ${ }^{58}$

In einem zweiten Modell werden die Gedichte mit unklarem Status generell als fiktional eingestuft. ${ }^{59}$ So betont Culler, der Unterschied zwischen der Lektüre eines Briefs und der Lektüre eines Gedichts liege darin, daß das Gedicht nicht in realer Zeit und realem Raum situiert sei und Rekonstruktionsversuche des Lesers einen fiktiven Kontext schüfen. Insofern sei Lyrik „impersonal“, deiktische Ausdrücke referierten auf eine fiktive Situation und nicht auf den „ordinary circuit of communication"60:

The deictics do not refer us to an external context but force us to construct a fictional situation of utterance, to bring into being a voice and a force addressed, and this requires us to consider the relationship from which the qualities of the voice and the force could be drawn

\footnotetext{
${ }^{56}$ Hamburger 1977, S. 217.

${ }^{57}$ Vgl. Hamburger 1977, S. 220 f.

${ }^{58}$ Vgl. Hamburger 1977, S. 38 f.

${ }^{59}$ Vgl. die ,Lehrbuchposition' Burdorfs in Burdorf 1995, S. $188 \mathrm{f.}$

${ }^{60}$ Vgl. Culler 1975, S. 166, S. 165.
} 
and to give it a central place within the poem. ${ }^{61}$

Die Gattung Lyrik ist grundsätzlich fiktional, wenn man Sprecher und realen Autor in diesem Sinne stets trennt. Dann wird die Struktur des Rollengedichts auf alle Gedichte angewendet, indem diese im Sinne eines dramatischen Monologs „as representations of possible historical utterances“ verstanden werden. ${ }^{62}$ Das Gedicht ist nach solchen Modellen eine öffentliche Angelegenheit. Es ist durch die Regeln der Sprache bestimmt und nicht durch die Intentionen des Autors. ${ }^{63}$ Dies gilt selbst dann, wenn der Autor über sich selbst schreibt. Denn auch biographische Wahrheiten; z.B. Ortsangaben etc., sollen im poetischen Akt in die imaginierende Darstellung überführt werden. ${ }^{64}$

Eine letzte Möglichkeit, Gedichte mit unsicherem Fiktionalitätsstatus zu behandeln, ist, von einer „Offenheit“ von Lyrik auszugehen. Äußerstenfalls bleibt dann eine „von einer sprechenden Person weitgehend losgelöste Sinnkonstellation“ von der potentiellen kommunikativen Situation des Gedichts übrig: ${ }^{65}$

The rhetoric of [...the poem...] suggests that there is no such thing as cultural construction, no social class, race, or gender. [...The...] universal 'l' simply addresses other such abstract selves. The assumption made is that such voice-and-address is a form of poetic license. ${ }^{66}$

Die Verborgenheit des Sprechers führe dazu, daß die Referenz der Ausdrücke des Gedichts offen bleibe. „Das Relevante“ des Gedichts sei „die Artikuliertheit" des Sprechers, nicht dessen reale oder fiktionale Herkunft. ${ }^{67}$ „Faktische Beglaubigung“ soll keine Rolle spielen angesichts der „artikulierten Möglichkeit problematischer Identität des Subjekts“. ${ }^{68}$ Der problematische lyrische Diskurs ist für diese Theorien reflexiv und hat seinen „Fluchtpunkt“ im „lyrischen Subjekt“. ${ }^{9}$ Verweise auf den Sprecher bildeten eine „Leerdeixis“, ${ }^{70}$ bzw. bezögen sich auf ein Strukturprinzip des Gedichts. Das heißt, daß alle Pronomina eine kommunikative Position kennzeichnen, die abhängig ist von der nicht explizit dargestellten Position des Sprechers. So sagt auch Fricke: Zumindest diejenigen Gedichte, die keine Rollenangaben und keine dramatischen Fiktionsangaben enthielten, seien nur deshalb nicht fiktional, weil keine Fiktion über einen Sprecher aufgebaut werde. ${ }^{71}$ Andere Gedichte seien fiktional oder faktual. Ausgeschlossen aus die-

\footnotetext{
${ }^{61}$ Vgl. Culler 1975, S. 166.

62 Culler 1985, S. 41.

${ }^{63}$ Vgl. Wimsatt 1967, S. 3-18.

${ }^{64}$ Vgl. Culler 1975, S. 167. Hühn etwa wendet das Meadsche Modell von „I“ und „Me“ auf diesen Fall an: Das „I“ kann sich nicht selbst beobachten, ohne sich zu einem früheren „Me“ zu machen, sich also zu veräußerlichen und verdinglichen und sich damit auch zu fiktionalisieren, vgl. Hühn 1998, S. 223f.

${ }^{65}$ Vgl. Austermühl 1981, S. 189-197, S. 192.

${ }^{66}$ Vgl. Perloff 1998, S. 252.

${ }^{67}$ Vgl. Stierle 1979a, S. 520.

68 Stierle 1979a, S. 521.

69 Stierle 1979a, S. 521.

${ }^{70}$ Vgl. Spinner 1975, S. 17.

${ }^{71}$ Vgl. Fricke 1981, S. 124; Burdorf 1995, S. 168. Allerdings setzt Fricke offenbar Fiktion mit Illusionierung gleich. Gegen Illusionierung spricht die Abwesenheit eines realen Bezugsfeldes, aus der eine fiktive Per-
} 
sem Lyrikbegriff wird zumeist - etwa in Stierles Modell - wiederum alle „pragmatische Lyrik" mit konkreter Realitätsanbindung. ${ }^{72}$

Eine endgültige Entscheidung zwischen den drei Extremen, Lyrik zu lesen - als rein fiktionalen dramatischen Monolog eines fiktionalen Sprechers, als Mitteilung eines realen wertvollen Erlebnisses des Autors ${ }^{73}$ oder als Äußerung einer nicht gestalteten abstrakten Leerstelle, die vom Leser eigenständig gefüllt wird - muß keineswegs gefällt werden. ${ }^{74}$ Vielmehr besteht ein Kontinuum zwischen diesen Möglichkeiten, das durch innertextliche und außertextliche Faktoren beeinflußt wird. Es scheint, als wäre die Gattung Lyrik in dieser Hinsicht flexibel. ${ }^{75}$ Sprecher oder Erzählinstanz und realer Autor können eng beieinander liegen oder weit auseinandertreten. ${ }^{76}$ Die Unmittelbarkeit oder Mittelbarkeit des sprechenden Subjekts kann aus der Textoberfläche erschlossen werden, z.B. wenn kein Bezug auf die Sprecherfigur, camera eye-Techniken oder eine „verweigerte Konkretheit des lebensweltlichen Bezugs“ zu finden sind. ${ }^{77}$

Der Lyrikbegriff ist also in bezug auf seine Fiktionalität variabel. ${ }^{78}$ Mit einem Gedicht kann sowohl ein Sprechakt mimetisch dargestellt als auch dieser dargestellte Sprechakt tatsächlich vollzogen werden. ${ }^{79}$ Letzteres geschieht etwa im politischen Gedicht, das aus aktuellem Anlaß geschrieben und zu einem bestimmten Zeitpunkt auf Flugblättern verteilt wird. ${ }^{80}$ Die Besonderheit ist hier, daß der dargestellte Sprechakt auch mit dem Gedicht (zumindest bei seiner ersten Veröffentlichung) tatsächlich vollzogen werden

son konstruiert werden könnte, so daß das ,lyrische Ich' eine "Leerdeixis“ bzw. eine „abstrakte Aussageinstanz" bildet; vgl. Spinner 1975, S. 15; Bernhart 1993, S. 365. In solch einem Fall wird die lyrische Rede zur „monologischen, strukturell einfachen und absoluten Rede“; Lamping 1993, S. 63; Bernhart 1993, S. 371; vgl. kritisch Schönert 1999, S. 292 f. Auch Lamping verweist auf das Fehlen einer gestalteten „Redevermittlung“ und einer Sprechsituation; vgl. Lamping 1993, S. 93 f.; Bernhart 1993, S. 363.

${ }^{72}$ Stierle 1979a, S. $521 \mathrm{f}$.

${ }^{73}$ Vgl. Culler 1988, S. 293.

${ }^{74}$ Burdorf 1995, S. 197, verkennt die Notwendigkeit, biographische Recherchen dort anzustellen, wo der Text Hinweise auf einen Kontext gibt. Auch Burdorf meint, sich zwischen Modellen entscheiden zu müssen; vgl. aber auch Burdorf, S. 198.

${ }^{75}$ Diese Flexibilität teilt Lyrik mit den allgemeinen Selbstdarstellungen von Individuen: Das gesellschaftliche Rollenspiel etc. als soziologisches Phänomen macht einen guten Teil der Debatte um die Authentizität des lyrischen Ichs (vgl. Schönert 1999, S. 289) überflüssig. Auch im nicht literarischen Bereich stellen Personen sich unter flexiblem Bezug auf 'die Wahrheit' dar.

${ }^{76}$ Vgl. Hühn 1995, S. 13; Hühn 1998, S. 222 f. und S. 238 f.

${ }^{77}$ Bernhart 1993, 367, 370.

78 Vgl. etwa die Integration der Fiktionalität in eine Typologie der Textfunktionen bei Heinemann/Viehweger 1991, S. 150-153.

${ }^{79} \mathrm{Vgl}$. Levin 1976, S. 146. Gedichte können demnach wie Erzähltexte über eine story-line verfügen. Das Vorhandensein einer erzählten story-line ist auch das eigentliche Kriterium, das "Gedichte fiktionaler Ausgestaltung" von anderen Gedichten intuitiv unterscheiden läßt.

${ }^{80}$ Stierles Urteil über die „Gelegenheits- und Zwecklyrik“: sie erfülle nur ein „Diskursschema“ und „überschreite" es nicht, ignoriert dabei, daß der Text in allen Fällen einen Sprechakt bzw. eine Textfunktion ,literarisch' exemplifiziert (im Sinne Goodmans); vgl. Stierle 1979a, S. 521 f. Auch pragmatisch eingebundene Lyrik ist damit außerhalb des konkreten Handlungszusammenhangs von ,literarischem' Interesse und kann zur ,Problematisierung eines Diskurses' dienen. 
soll. Eine 20 Jahre später stattfindende Veröffentlichung dieses Gedichts in einer Gedichtanthologie der politischen Lyrik vollzieht diesen Sprechakt dann nicht mehr. Er wird nur noch mimetisch dargestellt. Darüber hinaus kann auch ein Interesse an der kollektiven oder individuellen Aussageinstanz und an deren Bewußtseinshaltung bestehen, seien diese nun real oder fiktiv. ${ }^{81}$

Ebenso variabel ist der Lyrikbegriff schließlich in bezug auf die „Situationstypen“. ${ }^{82}$ Die Gattungszugehörigkeit wird nicht dadurch beeinflußt, ob ein Text als Gelegenheitsgedicht nur zum privaten Gebrauch, als panegyrisches Gedicht zum öffentlichen Vortrag oder als Teil einer Anthologie zur situationsabhängigen Veröffentlichung bestimmt ist. Dementsprechend sind die Parameter der Kommunikationssituationen vielfältig, auf die sich ein Gedicht beziehen kann.

Gedichte verweisen auf Kontexte, in die sie eingeordnet werden müssen. Die im Text gestaltete Situation gibt unterschiedlich deutliche Hinweise auf eine jeweils unterschiedlich konkrete Kontextwelt. ${ }^{83}$ Je nachdem, ob der dargestellte Sprechakt nach diesen Hinweisen in der realen oder in einer fiktiven Welt oder in mehreren möglichen Welten angeordnet ist, ist der Text faktual oder fiktional oder in bezug auf den Realitätsgehalt nicht bestimmt. ${ }^{84}$ Der Leser eines Gedichts muß daher aus dem Text selbst und seinem unmittelbaren Kontext erschließen, ob es sich um einen fiktionalen oder faktualen Text handelt. Er hat mit allen Möglichkeiten von Wahrheitsansprüchen und der Eigennamenreferenz zu rechnen. Prima facie deuten reale Eigennamen in Gedichten den nicht fiktionalen Status des Textes an. Sie verweisen auf die Referentialisierbarkeit des Gedichts, sei es zur Imagination, sei es zur Überprüfung der Aussagen, sei es zur Allusion auf einen weiten Kontext. ${ }^{85}$ Fiktionale Eigennamen dienen dagegen der impliziten Aufforderung, sich ein fiktives Objekt vorzustellen und stellen die Referentialisierbarkeit des Textes in Frage. ${ }^{86}$

\footnotetext{
${ }^{81}$ Vgl. Bernhart 1993, S. 369, S. 373: „Lyrische Sprache ist fiktionalisierende Sprache als Evidenz eines aussagenden Bewußtseins; hingegen ist epische Sprache fiktionalisierende Sprache als Medium einer Wirklichkeitsaussage“.

${ }_{82}$ Heinemann/Viehweger 1991, S. 153-158.

${ }^{83}$ Die Frage nach der Unterscheidung zwischen Sprecher und Autor wird an dieser Stelle nicht entschieden. Die Kontextwelten, auf die der Text verweist können in höcht komplexer Weise mit der Welt des Autors zusammenhängen oder auch nicht zusammenhängen.

${ }^{84}$ Man beachte, daß schon ein Verstoß gegen die Wahrheit den Text zum fiktionalen Text über eine mögliche Welt macht. Ein Text, der also eine falsche Behauptung in einen realen Kontext stellt, gestaltet eine fiktive Welt. Die einwandfreie Wahrhaftigkeit eines expressiven Gedichts beinhaltet, daß der Sprecher sein „Erlebnisgestaltungserlebnis“ in den expressiven Sprechakt integriert, so wie Käte Hamburger es als definiens konstatiert. Ansonsten sind auch faktual erscheinende Gedichte „fictional representations of a nonfictional utterance“; Culler 1985, S. 39.

${ }^{85}$ Vgl. Lamping 1993, S. 129. Lamping verwechselt die referentielle Funktion eines Textes im Sinne der Textfunktion BEHAUPTEN mit der Referentialisierbarkeit eines Textes. So können referentialisierbare Eigennamen durchaus in Texten auftreten, die emotive, phatische oder konative Textfunktionen haben.

${ }^{86} \mathrm{Vgl}$. etwa Debus 2002, S. 76 f.
} 


\subsubsection{Das Gedicht als isolierter Gesprächsbeitrag}

Der Abgrenzung von den für alle formalen Lyrikdefinitionen problematischen Versepen und Versdramen soll der kommunikative Status eines Textes der Gattung Lyrik dienen. Gedichte gestalten eine innertextliche Kommunikationssituation. Bei der Lektüre eines veröffentlichten Textes muß der Leser zunächst von dieser innertextlich gestalteten Situation ausgehen. Analog zur pragmatischen Textanalyse der Textlinguistik ${ }^{87}$ muß auch bei literarischen Texten zwischen einer Textillokution - als mit dem gesamten Text fingierter oder vollzogener Sprachhandlung, im Sinne der ,Textfunktion' der Textlinguistik - und der Textperlokution - als Wirkungsabsicht, bezogen auf den gesamten Text unterschieden werden. ${ }^{88}$ Die Textillokution bezeichnet den Sprechakt bzw. die Sprachhandlung, die mit einer Äußerung vollzogen oder mimetisch nachgeahmt wird. Die Textperlokution bettet dagegen den Text in einen historischen Kontext ein, der Intentionen des Autors und die Erwartungen des anvisierten Publikums einschließt. So kann ein literarischer Text als ein Beitrag zu einer Kommunikationssituation behandelt werden, der eine bestimmte Handlung darstellt und damit auf eine bestimmte Wirkung gerichtet ist. Zu der Kommunikationssituation, in die ein Text eingebettet ist, gehört auch die ,Institution Literatur', die bestimmte Publikationsformen und bestimmte Rezeptionsweisen umfaßt. ${ }^{89}$

Schlaffer führt in diesem Sinne zur Gattung Lyrik aus, daß Gedichte eine Handlung nicht beschrieben, sondern vielmehr eine Handlung seien. Dies, so Schlaffer, unterscheide sie von Erzähltexten. ${ }^{90}$ Präzisierend sollte man allerdings sagen, daß mit einem Erzähltext die Textfunktion als sprachliche Handlung des Berichtens oder Erzählens

\footnotetext{
${ }^{87}$ Vgl. etwa Rolf 2000 , bes. S. $422 \mathrm{f}$.

${ }^{88}$ Vgl. Brinker 1992, S. 93; verschiedene Sprechhandlungen können sich hierarchisch gegliedert zu einer Textfunktion zusammensetzen. Zur Textfunktion literarischer Texte vgl. den dezidiert sprachwissenschaftlichen Beitrag von Kühn 1989; vgl. auch auch Zipfel 2001, S. 32-34, der allerdings den Fehler macht, die Textillokution (Textfunktion) mit dem „Ziel“ des Textes gleichzusetzen, und damit die Textperlokution unterschlägt. „[Die Textfunktion] ist vielmehr, die in einem Text encodierte, sich in einem Text als Kommunikationsinstrument ausprägende Intention'“; Heinemann/Viehweger 1991, S. 139. Es kann durchaus eine Mitteilung gemacht werden, um einen Wunsch erfüllt zu bekommen. Ebenso kann etwas erzählt werden, um Menschen zu einer Haltung oder Handlung zu bringen. Den Menschen kann mit dem gleichen Ziel auch etwas befohlen werden.

${ }^{89}$ Vgl. auch Zipfel 2001, S. 39-49, der den Begriff der Kommunikation unnötigerweise problematisiert. Der Sprechaktbegriff kann nicht ohne weiteres auf relativ situationsunabhängig existierende literarische Texte übertragen werden. Vor allem erfaßt er nicht den ,Wert' literarischer Texte. Er bildet aber die Grundlage dafür, einen Text qualifiziert verstehen zu können. Weitere allgemeine und abstrakte Bedeutungsschichten bauen auf dieser Grundsätzlichen Bedeutung im kommunikativen Kontext auf. Es soll hier angenommen werden, daß auch die Produktion literarischer Texte intentional und auf eine Wirkung ausgerichtet ist. Die Wirkung entspricht der Perlokution bei Sprechakten, die fiktiv oder real mit dem Text durchgeführte Handlung der Illokution. Dies wird mit Bezug auf Schrifttexte auch als „zerdehnte Sprechsituation“ bezeichnet; vgl. Zipfel 2001, S. 34-38.

${ }_{90}$ Vgl. Schlaffer 1995, S. 54; vgl. auch Wolf 1998, S. 263. Etwas Ähnliches berücksichtigt schon Stierle 1979a, S. 515, wenn er im Falle der Lyrik von der „Transgression des narrativen Schemas“ spricht.
} 
vollzogen oder fingiert wird. ${ }^{91}$ Auch wenn Erzähltexte nicht nur simple ,Berichte oder Erzählungen über etwas Gewußtes' sind und verschiedene Textperlokutionen haben mögen ${ }^{92}$, ist zumindest ihre Textillokution auf die berichtende oder erzählende Funktion beschränkt. ${ }^{93}$ Mit Gedichten kann dagegen die gesamte Breite möglicher Sprechaktkategorien als Textfunktion vollzogen werden. „The language of statement" ist in Gedichten nur eine einzelne Subkategorie der möglichen „language[s] of performance“94, die durch den Text realisiert werden können. Gedichte verlangen vom Leser daher primär die imaginierte oder tatsächliche Teilnahme an einer Äußerungssituation. Dies haben sie mit Erzähltexten gemeinsam, die eine gestaltete Erzählsituation haben. Der Teilnehmer des ,Spiels' kann dabei grundsätzlich die Position des Sprechers, des Adressaten oder eines zuhörenden Dritten einnehmen. Nicht die Wahrheit des Gesagten, sondern die Wahrhaftigkeit des Sprechers steht im Vordergrund der Imagination - wobei die Wahrheit in der Wahrhaftigkeit oft eingeschlossen ist. ${ }^{95}$

Lyrischer Rede wird gerne eine einheitliche Textfunktion zugeordnet. ${ }^{96}$ Die triviale und oft auch auf die gesamte Literatur ausgeweitete Version dieser Vereinheitlichung ist die generelle Zuschreibung einer emotiven Funktion oder einer expressiven Funktion. ${ }^{97}$ Lyrik solle nur Gefühle und Einstellungen des Sprechers ausdrücken, um Gefühle hervorzurufen. ${ }^{98}$ Doch hat die neuere Forschung begonnen, Texten der Gattung Lyrik eine Vielfalt von Sprechaktmöglichkeiten - meist die gesamten sprachlich zur Verfügung stehenden Kategorien - als Textfunktion zuzuordnen. ${ }^{99}$ Mit einem Gedicht kann der gestaltete Sprecher (s.o. unter 2.1.2) diesen Überlegungen zufolge z. B. etwas befehlen, fragen, anordnen oder ausdrücken. ${ }^{100}$ Es gibt dabei keinen theoretischen Grund, die Textfunktionen des Berichtens, Beschreibens, Darstellens oder Erzählens für Gedichte nicht zuzulassen. ${ }^{101}$

\footnotetext{
${ }^{91}$ Vgl. Lamarque/Olsen 1994, S. 71. Erzähltexte beschreiben dann auch (Sprach-)Handlungen.

${ }^{92}$ Dies behauptet etwa Bex 1992, S. 5.

${ }^{93}$ Zum komplexen Sprechakt ERZÄHLEN vgl. Zipfel 2001, S. 58-61.

94 Schlaffer 1995, S. 54; vgl. auch Hühn/Schönert 2002, S. 299 (ohne expliziten Bezug auf Schlaffer).

${ }^{95} \mathrm{Vgl}$. dazu auch Zipfel 2001, S. 79.

${ }^{96}$ Unter den jüngsten Beiträgen zur literaturwissenschaftlichen Onomastik scheint diesen Fehler Horstmann 2001, S. 40, zu machen.

${ }_{97}$ Vgl. dazu Frye 1985, S. 32; Stierle 1979a, S. 505 f.; Wollheim 1980, S. 137; Heinemann/Viehweger 1991, S. 153.

${ }^{98}$ Vgl. Schlaffer 1995, S. 50; Lamping 1993, S. 63.

${ }^{99} \mathrm{Vgl}$. Lamping 1993, S. 110 f. Bernhart erweitert die emotive (sprecherbezogene) Funktion auf die „Mitteilung“ „kognitiver, sozialer, politischer und anderer Haltungen“, womit er die Funktion des Textes stillschweigend auf assertorische Akte reduziert, vgl. Bernhart 1993, S. 365.

${ }^{100}$ Allerdings ist die Tatsache, daß Gedichte sich nicht verkürzt referieren lassen, nicht auf deren sprechaktliche Gestaltung (Schlaffer 1995, S. 54), sondern auf deren formale Abweichung zurückzuführen. Auch Sprechakte lassen sich verkürzt beschreiben.

${ }^{101}$ Vgl. Culler 1985, S. 50f.; implizit auch Hühn/Schönert 2002, S. 287 f.
} 
Einen besonderen Status haben sprachspielerische und manieristische Gedichte. Nur schwer kann man sich etwa Ernst Jandls „oskar zu pastior" als Beitrag zu einem alltäglichen Gespräch vorstellen. ${ }^{102}$ Das Lyriktypische an solchen Gedichten ist, daß sie keinen expliziten Kontext zu der jeweiligen sprachspielerischen oder manieristischen ÄuBerung anbieten. Es handelt sich um Beiträge, die direkt an den Zuhörer gerichtet sind. Insofern gehört auch die Funktion „ÄSTHETISCH WIRKEN“103 zu den möglichen Textfunktionen eines Gedichts.

Mit einem Gedicht kann also jeder Sprechakt vollzogen werden. Daher verstehen wir Gedichte im Folgenden als einen Ausschnitt aus einem zu rekonstruierenden Gespräch. Das heißt, in der im Gedicht dargestellten Kommunikationssituation wendet sich ein Sender an einen Empfänger, um etwas mitzuteilen. Sowohl der Kontext der Äußerung, als auch das übrige Gespräch (etwa die Reaktion des Empfängers oder vorhergehende Schritte des Gesprächs) stehen außerhalb des Textes. Der Text ist aber unmittelbar auf sie bezogen. Gedichte stellen so einen von ihrem zu supponierenden Kontext ISOLIERTEN GESPRÄCHSBEITRAG eines Sprechers in einem imaginierten oder realen ,Austausch von Äußerungen'104 dar. (Im Gegensatz dazu sind Erzähltexte zwar auch in eine Situation eingebettet: in die reale Situation des Autors und möglicherweise in eine erkennbare fiktive Situation des Erzählers. Aber das Erzählen einer Geschichte von Romanlänge bedeutet doch immer ein Heraustreten aus der unmittelbaren Gesprächssituation.)

Der Sprecher eines Gedichts kann im Gedichttext konkretisiert werden, oder es kommen durch Kontextisolation viele verschiedene und möglicherweise auch nicht miteinander harmonische Kontexte in Frage. ${ }^{105} \mathrm{Zu}$ den Glückensbedingungen eines Sprechaktes gehört, daß der Empfänger zumindest alle für das Verständnis des exemplifizierten Sprechaktes relevanten Informationen über die Gesprächssituation besitzt. ${ }^{106}$

\subsubsection{Zusammenfassung: eine Arbeitsdefinition}

Die Einschätzung des Gedichts als isolierter Gesprächsbeitrag gesteht Gedichten strukturelle Komplexität (etwa einen Erzähler oder zitierte Figurenrede) zu und schließt so-

\footnotetext{
102 Jandl 1992, S. 164.

${ }^{103}$ Vgl. Heinemann/Viehweger 1991, S. 150.

${ }^{104}$ Heinemann/Viehweger 1991, S. $181 \mathrm{f}$.

${ }^{105}$ Das ist die „nichtlineare“ „Multiplikation der simultanen Kontexte“ (Stierle 1979a, S. 515-517, S. 523 f.).

${ }^{106}$ Vgl. etwa den Fall, daß es drei offene Türen zu einem Raum gibt und jemand sagt: „Mach' doch mal die Tür zu!“ Je mehr Gewicht die Erzählerperspektive in der Erzählung bekommt (etwa im Falle des inneren Monologs), desto ähnlicher wird die Erzählsituation der Situation eines Gedichts. Die Kenntnis der Erzählsituation ist nicht unbedingt notwendig für das Verstehen der erzählten Ereignisse. Zu den Glückensbedingungen des Erzählens und Berichtens gehört, daß alle für das Verständnis des Erzählten relevanten Kontextfaktoren genannt werden. Im Zweifelsfall können Kontextfaktoren des Erzählens so starken Einfluß auf die Darstellung haben, daß sie das eigentliche Zentrum des Textes bilden. In diesen Fällen nähern sich Erzähltexte der Lyrik.
} 
wohl ,dialogische Gedichte' als auch Figurengedichte ein. Sie ist insofern umfassender als Dieter Lampings ,derzeit klärendste Lyrikdefinition' ${ }^{\prime 07}$ des „Iyrischen Gedichts“ als „strukturell einfache, monologische Rede in Versen“. ${ }^{108}$ An sprachspielerischen Gedichten wird allerdings deutlich, daß das formale Kriterium Lyrik vorrangig definiert. ${ }^{109}$ Im Falle eines ,clash of criterias' gibt die strukturelle Dominanz der formalen Ordnungen den Ausschlag bei der Gattungszuordnung.

Wir haben nach einer Gedichtdefinition gesucht, die die für die Eigennamenverwendung relevanten Faktoren der Form, des Kontextbezugs und der Fiktionalität berücksichtigt. Folgende Definition wird deshalb unsere Textauswahl im Folgenden leiten: Als Gedicht wird ein Text dann bezeichnet, wenn er strukturell dominant nach formalen Ordnungsmustern organisiert ist und als ein isolierter Gesprächsbeitrag verstanden werden kann, der einen unmittelbaren Äußerungskontext evoziert. Der fiktionale oder faktuale Status des Textes, der Kontext der Textproduktion, der Textpräsentation und Textrezeption sowie die Textfunktion von Gedichten sind variabel.

\subsection{Funktionen von Eigennamen in überstrukturierten Texten - Einleitung}

\subsubsection{Namen, Namenträger und Text: Typologien zur Namenfunktion}

Eine Deutung und Interpretation der Namenverwendung in einem Gedicht muß berücksichtigen, daß ein Eigenname eine bestimmte Funktion (bzw. mehrere Funktionen) in einem „Gesamtgefüge“ hat. ${ }^{110}$ Welche Rolle Eigennamen in Gedichten spielen können, wird an einem Ausschnitt aus einer Gedichtinterpretation der berühmten „Grundbegriffe der Poetik“ Emil Staigers erkennbar. Auch wenn diese Interpretation nicht auf Eigennamen ausgerichtet ist, veranschaulicht Staiger in ihr die Qualitäten seines Begriffs des „Lyrischen“"111 an Eigennamen aus Clemens Brentanos Ballade von der Lore Ley ${ }^{112 .}$

Alle Momente des Lyrischen: Musik, Verflüssigung, Ineinander, hat Brentano im Mythos von der Loreley zusammengefaßt [....]. Ihr Name schon, bestehend aus Vokalen und Liquiden, tönenden und flüssigen Lauten, ist Musik und als solche eingegeben durch den Namen des Felsens bei Bacharach. Ihr Name ist schmelzend wie ihre Augen, und wie ihre Augen schmelzt ihr Gesang. ${ }^{113}$

\footnotetext{
107 Fricke 2000, S. 499.

108 Lamping 1993, S. 66-68.

${ }^{109}$ Vgl. auch Burdorf 2000, S. 504.

110 Vgl. Kopelke 1990, S. 48.

111 Staigers Begriff des „Lyrischen“ weicht sehr von der hier skizzierten nominalen Definition ab. Dennoch bezieht er sich wie alle Lyriktheorien auf ein annähernd gleiches Korpus von Texten, da der explizite Ausschluß von Texten, die intuitiv der Gattung zugeordnet werden, selten ist. Daher lassen sich seine Ausführungen auch für unser Modell fruchtbar machen.

${ }^{112}$ Um des Arguments Willen sei an dieser Stelle von dem vieldiskutierten Problem einer Gattungszuordnung der Textsorte ,Ballade' abgesehen.

${ }^{113}$ Staiger 1961, S. 70 f. Staiger behandelt Brentanos Ballade nach den Kriterien zur Bestimmung von Lyrik. Differenzierter ist Lyrik bei ihm in seiner bekannten Bestimmung durch den „lyrischen Stil: Erinne-
} 
Staiger berücksichtigt hier intuitiv zunächst zwei verschiedene Funktionsbereiche des Eigennamens. Dominierend ist der Schluß vom Namen auf den Namenträger. Der Name läßt den Namenträger vor den Augen des Lesers erscheinen. Mit dem Namen und seinen Zeicheneigenschaften wird die mythische Figur über das explizit im Text Gesagte hinaus ${ }^{114}$ charakterisiert. Der Name ist ein möglicher erster Zugang zur Figur („Der Name schon..."). Er hat evokative Funktion. Daneben berücksichtigt Staiger aber auch textbezogene Funktionen. So faßt der Name für inn den ganzen Mythos zusammen. Der Name „Lore Ley“ und der ebenso erwähnte Ortsname „Bacharach“ verbinden außerdem die Welt des Mythos mit der realen Welt, denn der Felsen bei Bacharach ist ein - dem Balladentext zu entnehmendes - motivierendes Element der mythischen bzw. literarischen Taufe. ,Lore Ley' verbindet schließlich auch die fiktive Welt des Dargestellten mit dem darstellenden Text. Denn der Name ist ein poetisch vom Dichter eingesetztes sprachliches Element des Textes, und er stellt gleichzeitig als Eigenname der Protagonistin eine Entität der dargestellten fiktiven oder realen Welt dar. ${ }^{115}$ Dies erlaubt Staiger in seiner Interpretation, die gemeinsamen musikalischen und ,Iyrischen' Qualitäten der Darstellung und des Dargestellten mit Hilfe der Namen zu beschwören.

Eigennamen spielen also zum einen eine wichtige Rolle bei der Evokation der benannten Entitäten aus der im Text gestalteten Welt - dies sind die ,namenträgerbezogenen Funktionen' von Eigennamen. Zum anderen haben sie Bedeutung für den thematischen und formalen Aufbau des Textes, die Kontexteinbindung und für die Textstrategien des gesamten Textes - dies sind die ,textbezogenen Funktionen' von Eigennamen. ${ }^{116}$

In den letzten 30 Jahren hat die literaturwissenschaftliche Onomastik auf dem Gebiet der Funktionstypologie zahlreiche Entwürfe vorgelegt. ${ }^{117}$ Die Zusammenstellungen dieser Entwürfe sind jedoch zumeist intuitiv zusammengestellte ,offene Reihen'. ${ }^{118}$ Darin unterscheiden sich die Namenfunktionstypologien von den sprachtheoretisch fundierten

rung" gekennzeichnet, der in Anlehnung an Heidegger das Vergegenwärtigen von Stimmungen und nicht die raum-zeitliche Bestimmung von Vergangenem meint (vgl. Staiger 1961, S. 13-82). Weitere und weitergehende Bestimmungen der Lyrik in diesem Sinne finden sich z.B. bei Petersen 1996, S. 120-142, oder Horn 1998, S. 19; vgl. auch Burdorf 1995, S. 4 f.

${ }_{114}$ Der verführerische Gesang der Loreley gehört zum Mythos, er wird aber in Brentanos Ballade nicht erwähnt.

${ }^{115}$ Nomina appellativa haben dagegen nicht an der dargestellten Welt teil, es sei denn als Zitat oder Figurenrede; vgl. auch Coseriu 1975, S. 242.

${ }_{116}$ Erwähnt, aber nicht ausgeführt wird diese Kategorie von Debus 2002, S. 90, Fn. 161.

117 Daher erstaunt es, daß auch von neuesten Beiträgern zur literaturwissenschaftlichen Onomastik behauptet wird, es gebe wenig oder keine Funktionstypologien. So ist es etwa bei Bertills 2003 oder Horstmann 2001, S.16-18 und S. 263, zu lesen, unter Nichtbeachtung der funktionstypologischen Beiträge Thies' 1978 und Lampings 1983.

${ }^{118}$ Dies gilt auch noch für die systematischere Darstellung bei Debus 2002, S. 90. 
Typologien zur Namenbedeutung. ${ }^{119}$ Eine Schwäche dieser Entwürfe - bezogen auf unsere Untersuchung - liegt in ihrer Orientierung an fiktionalen Erzähltexten. Diese Ausrichtung bewirkt bestimmte Beschränkungen: auf die isolierte Untersuchung des Namenszeichens, auf fiktionale Namen, auf figurencharakterisierende Funktionen der Namen. Besonders auf den Textaufbau bezogene Funktionen von Namen werden zumeist vernachlässigt. Gerade sie erhalten aber in Gedichten eine besondere Bedeutung.

Die ausführlicheren typologischen Untersuchungen der literaturwissenschaftlichen Onomastik - etwa Lamping, Thies oder Kopelke ${ }^{120}$ - beschäftigen sich vorwiegend mit rein innertextlich referierenden Figurennamen und daher auch hauptsächlich mit Funktionen, die sich direkt auf den Namenträger beziehen. Lampings wirkungsmächtige Typologisierung berücksichtigt Funktionen zum Verhältnis von Namenträger und Namenbenutzer: Eigennamen dienten auf ökonomische Weise der „Identifizierung“ einer Figur im Verlauf der Erzählung. Namen ermöglichten weiterhin in stärkerem Maße als Appellative die „Illusionierung“, weil sie „punktuell“ den „äußeren Habitus der Realität“ verliehen. ${ }^{121}$ Der Gebrauch von Eigennamen diene ferner der „Akzentuierung“ einer Figur aus der Sicht des Erzählers, der „Perspektivierung“ ${ }^{122}$ eines Objekts aus dem Blickwinkel des Erzählers und anderer Figuren und schließlich der „Konstellierung“ der Figuren untereinander.

Die genannten Funktionen werden von Namenbenutzern einschließlich des Namengebers wahrgenommen. Lamping nennt aber auch eine Funktion, die nur das Verhältnis von Namenträger und Namengeber betrifft: Figuren werden durch die Zeichenkomponenten und Präfigurationen ihrer Namen charakterisiert („Charakterisierung“). Dazu gehören bei Lamping auch Funktionen der lokalen und zeitlichen Einordnung der Figuren. Dies ist diejenige zentrale Funktion, die traditionell von der literaturwissenschaftlichen Onomastik untersucht wird ${ }^{123}$ : Der Namengeber kann dem Eigennamen eine „Färbung geben“, indem er die „Eigenschaften“ des intensionslosen Namens mit „Merkmalen“ des benannten Objekts in Verbindung bringt. ${ }^{124}$ Mit „klassifizierenden Namen“ nutzt er sortale Prädikate aus der Alltagsnamengebung oder aus literarischen Konventionen. ${ }^{125}$

\footnotetext{
${ }^{119}$ Vgl. Debus 2002, S. 57.

120 Vgl. Thies 1978, S. 39-96; Lamping 1983; Kopelke 1990, S. 47-138. Kopelke nennt zwar stilistische Funktionen (vgl. Kopelke 1990, S. 53), konzentriert sich in ihrer Untersuchung dann aber doch auf die figurenbezogenen Namenfunktionen.

${ }_{121}$ Vgl. Ingarden 1965, S. 261; Lamping 1983, S. 30

122 Vgl. Burelbach 1986; Combrink 1983, S. 88 f.

${ }^{123}$ Vgl. etwa Berend 1942; Malone 1957.

${ }^{124}$ Vgl. Birus 1978, S. 31-33; Birus 1987, S. 41 f.; Fricke 1996, S. 1536; alle mit Bezug auf Frege 1987, S. 86.

${ }^{125} \mathrm{Vgl}$. Birus 1987, S. 41
} 
Durch ihre Ursprungs- und Lautsemantik haben literarische Namen als „redende“ und „klangsymbolische Namen““26 eine auf den Namenträger bezogene Bedeutung. „Redende Namen“ können durch die Assoziationen, die die Ursprungssemantik erweckt, sprechen oder als „deskriptive“ Eigennamen ${ }^{127}$ durch ihre Etymologie mit Appellativa verbunden sein und eine Eigenschaft des Objektes direkt ansprechen. Sie fallen im zweiten Fall ins ,Appellativische’ zurück. ${ }^{128}$ „Verkörperte Namen“129 schließlich charakterisieren den Namenträger durch den Bezug auf einen bekannten früheren Träger des gleichen Namens.

Das Verhältnis von Namenträger und Namen bildet einen dritten Bereich. In der „Mythisierung" findet eine enge Bindung zwischen Namen und Namenträger statt, bei der die Einflußnahme (auf der Handlungs- oder Erzählebene) auf den Namen auch einen Einfluß auf den Namenträger bewirkt. ${ }^{130}$

Einige literaturwissenschaftlichen Typologisierungsentwürfe enthalten neben den direkt figurenbezogenen Funktionen auch wenige Beispiele textbezogener Funktionen.

Das sind zunächst Funktionen, die auf der Referenz der Namen über die Textwelt hinaus beruhen: Dazu gehört schon die Funktion, nicht nur dem Namenträger, sondern auch der fiktiven Welt und dem Text „couleur locale“ und „couleur historique“ ${ }^{131}$ durch reale oder real präfigurierte Eigennamen zu verleihen. Gutschmidt nennt unter den „Funktionen, die den Text als Ganzes betreffen“ die Anbindung an die Realiät sowie die „zyklisierender Funktion“, bei der mehrere Texte durch Eigennamen miteinander verbunden werden. ${ }^{132}$ Bei Thies betreffen „stilistische Komponenten“ zwar primär das Verhältnis zwischen Namenträger und Namenbenutzer. Doch faßt er unter den „Darstellungsfunktionen“ auch die „Namen als Zitate“ (gemeint sind intertextuelle Verbindungen durch Namen). ${ }^{133}$ Wittstrucks Arbeit zu Namen in spätmittelalterlicher Lyrik erwähnt ebenso die Anbindung an die Realität in der politischen Lyrik bzw. die Integration reichhaltiger außertextueller Informationen durch Eigennamen, allerdings ohne sie in eine Typologie einzubinden. ${ }^{134}$ In seine Funktionstypologie der Eigennamen, nimmt er aber

\footnotetext{
${ }^{126}$ Vgl. Birus 1987, S. 45.

${ }^{127}$ Vgl. Lamping 1983, S. 42.

128 Vgl. Debus 1985, S. 307.

${ }^{129}$ Vgl. Birus 1987, S. 45.

130 Vgl. Lamping 1983, S. 105-122.

131 Gerus-Tarnawecky 1968, S. 313.

132 Gutschmidt 1984, S. 139-142.

133 Thies 1978, S. $66 \mathrm{f}$.

${ }^{134}$ Vgl. Wittstruck 1987, S. 251, S. 306-316.
} 
die „Testimonialfunktion“ und die „Ausrichtung der Namensnennung auf ein [bestimmtes] Publikum" auf. ${ }^{135}$

Eine zweite Gruppe der textbezogenen Funktionen betrifft die inhaltliche Organisation des Textes: Durch die „differenzierende Funktion“ unterschiedlicher oder kontrastierender Namen werden nach Gutschmidt Textpassagen (in Prosatexten) ,innertextuell' geordnet und voneinander getrennt. ${ }^{136}$ Thies erwähnt unter den „Identifizierungsfunktionen“ die „Namendramaturgie“ und meint damit die Organisation des Textverlaufs durch Namennennungen. Weiterhin nennt er als „thematische Symbolfunktion“ die Anspielung auf ein Textthema durch den oder die Namen und ihre Bedeutung. Auch Kopelke erwähnt diesen Aspekt der „Namen als [thematische] Leitmotive“. ${ }^{137}$ Aschenberg unterscheidet unter dem Titel „Diskursfunktionen von Eigennamen“ die „Themafixierung“ und „Themaentwicklung“ durch Eigennamen, die „Intertextualität“, sowie die „Mehrsprachigkeit“ eines Textes durch Namen und die Etablierung einer Kommunikationssituation, das heißt die Festlegung der „Gesprächsrollen“ und die Herstellung von „Sozialkontakten“. 138

Eine dritte Gruppe schließlich bilden jene Funktionen, die die ästhetische Gestaltung des Textes betreffen. So nennt Gutschmidt die Möglichkeit, mit Eigennamen ein Genre anzuzeigen. ${ }^{139}$ Weiterhin gehört in die Kategorie der textbezogenen Funktionen die von Gerus-Tarnawecky erwähnte „Relevance to form“, ${ }^{140}$ die in "relevance to rhyme“ und „relevance to rhythm“ des Eigennamens auftritt. ${ }^{141}$ Gerus-Tarnawecky ordnet allerdings der „relevance to rhyme“ alle klanglich-rhetorischen Figuren, aber auch die namenträgerbezogene bedeutsame Lautsymbolik unter und versteht unter „relevance to rhythm“ vor allem Veränderungen am Namen aus rhythmischen Gründen. Ihre Typologie beschreibt daher keine besonderen Eigenarten von Eigennamen in Gedichten, da die Techniken der Elision und der formabhängigen Ergänzung auch bei anderen Zeichenkategorien angewendet werden können. Gerus-Tarnawecky weist im Grunde lediglich darauf hin, daß auch Eigennamen in die formale Gestaltung eines Textes eingebunden sind. Die Besonderheiten der Integration von Eigennamen berücksichtigt sie nicht. Wittstruck berücksichtigt unter der Kategorie des „formal-ästhetischen Aspekts“ die „Reim/Metrum-/Rhythmusbindung“ des Namens, Alliteration und Assonanz sowie die syntak-

\footnotetext{
${ }^{135}$ Wittstruck 1987, S. 474.

${ }^{136}$ Vgl. Gutschmidt 1984, S. 139-142.

137 Kopelke 1990, S. 83-86.

138 Aschenberg 2002, bes. S. 114-122.

139 Vgl. Gutschmidt 1984, S.142.

140 Gerus-Tarnawecky 1968, S. 313, im Anschluß an Rudnyckyj 1959, S. 382.

${ }^{141}$ Vgl. Gerus-Tarnawecky 1968, S. 313 und S.
} 
tische Einbettung des Namens in den Vers. ${ }^{142}$ Die Funktionen der „Namenkomik“ und der „Ästhetisierung“ bei Kopelke und Lamping betreffen zumindest zum Teil ebenfalls den Gesamttext:

Der Name kann darüber hinaus, wie andere Elemente des Textes auch, an der Konstituierung der Erzählung als eines ästhetischen Gebildes beteiligt sein. ${ }^{143}$

Der Umgang mit literarischen und nicht-literarischen Konventionen und die Gestaltbarkeit des Eigennamens ermöglichen dem Autor einen „selbstzweckhaften“ und von der Bezeichnungsfunktion losgelösten Umgang mit Eigennamen unter ästhetischen Aspekten, oft mit humoristischem Ziel. ${ }^{144}$ Dabei ist allerdings zu beachten, daß die Ästhetisierung im Falle der fiktionalen Figurennamen selten wirklich nur ,selbstzweckhaft' sein wird. Die Einschätzung eines Namens unter ästhetischen Gesichtspunkten wirkt sich vielmehr fast immer auf die Einschätzung der benannten Figur aus. Sie ist gleichzeitig "Charakterisierung“ und gehört in das Dreiecksverhältnis von Namenträger, Namen und Namengeber.

\subsubsection{Name, Text und Namenbenutzer: eine Typologie}

Wie wir gesehen haben, werden in den bisherigen Typologien vorwiegend figurenbezogene, und weniger die textbezogenen Funktionen berücksichtigt. Eine Analyse des Eigennamengebrauchs in Gedichten sollte aufgrund des Gattungscharakters verstärkt auf die textbezogenen und die sprecherbezogenen Funktionen Bezug nehmen. Eine systematische Funktionstypologie literarischer Eigennamen sollte zudem der Bedeutungsstruktur des Eigennamens Rechnung tragen. Grundlage einer Typologie muß daher der Status von Referenz, semantischem Inhalt und der besonderen Zeichengestalt des Namens sein. In bezug auf den Kommunikationswert des Namens sind neben der Unterscheidung von figuren- und textbezogenen Funktionen weitere Differenzierungen des Namengebrauchs in Texten zu berücksichtigen:

Eigennamen kommen bei der Organisation der in einem Gedicht mimetisch oder real vollzogenen Sprechakte drei grundsätzlich verschiedene Funktionen zu: Namen können dazu dienen, den Namenträger als Objekt in die Rede zu integrieren (,Namennennung'). Weiterhin können sie einen Sprechakt auf einen Adressaten ausrichten (,Anrede'). Schließlich können sie das Namenzeichen selbst repräsentieren (,Erwähnung').

Bei der Namennennung bezieht sich der Name auf eine Entität der fiktiven oder realen Texthintergrundwelt. Der Namenträger ist kein Teilnehmer der aktuellen engeren Kom-

\footnotetext{
142 Wittstruck 1987, s. 474.

143 Lamping 1983, S. 83.

${ }^{144}$ Vgl. Lamping 1983, S. 90; Kopelke 1990, S. 75-86.
} 
munikationssituation. ${ }^{145}$ Der Name wird vielmehr gegenüber Dritten genannt: dem oder den Adressaten des Gedichts. Dabei kann der Name genannt werden, um eine Figur zu gestalten (,figurgestaltende Namennennung'). Im Text wird in diesem Fall etwas über den Namenträger mitgeteilt. ${ }^{146} \mathrm{Im}$ anderen Fall wird der Namenträger nicht als Figur des Textes gestaltet bzw. als Figur evoziert (,diskursive Namennennung'). Es kommt auf die durch den Namen vermittelte diskursive Bedeutung an. ${ }^{147}$ Diskursive Nennungen von Eigennamen sind vor allem metaphorisch oder als Etikett eines exemplum gebrauchte Namen. Die diskursive Namennennung legt nicht fest, welche Existenz der Namenträger in der gestalteten Welt hat. Die figurgestaltende Namennennung geht dagegen von der Existenz des Namenträgers als Figur der Welt des Textes aus und ordnet damit die gestaltete Welt zeitlich und räumlich ein.

Im Falle der Anrede beim Namen ${ }^{148}$ ist der Namenträger auf der Kommunikationsebene des Sprechers angesiedelt. Der Sprecher richtet in diesem Fall die gesamte Äußerung oder Teile der Äußerung auf einen bestimmten Adressaten aus. Der Status des Textes und die Textfunktion werden durch die Referenz und den semantischen Hintergrund des Namens beeinflußt.

Unterschieden werden muß schließlich noch die ,Erwähnung des Namenzeichens'. In diesem Fall wird der Name nichtreferierend gebraucht. Objekt der Rede ist der als Eigenname verwendbare Zeichenkörper selbst. Die Erwähnung des Namenszeichens ist bis auf die Zeicheneigenschaften leer.

Ein Bereich, den die genannten Typologien vollständig aussparen, ist die Charakterisierung des Namenbenutzers und des Namengebers durch die verwendeten Namen, bzW. durch die Art der Namenverwendung. Texten der Gattung Lyrik wird aufgrund ihres Charakters als isoliertem Beitrag zu einem Gespräch ein mimetisches Darstellungs- und Illusionierungspotential meist in bezug auf das Sprechersubjekt und die Textfunktion

\footnotetext{
145 Im Falle einer Kommunikationssituation, an der mehrere Personen teilnehmen, wird auch alltagssprachlich das Problem der adäquaten Namenverwendung deutlich. Mit einem Adressaten über einen dritten Anwesenden zu reden (und dabei dessen Namen rein benennend zu verwenden), gilt als unhöflich und wird zumeist durch bestimmte verbale und nonverbale Mittel gemildert. So versucht man etwa durch eine halbe Wendung zu dem Namenträger hin diesen als halb Angeredeten zu integrieren. Verbal wird diese Wendung oft durch ein dem Namen folgendes „hier..." ausgedrückt: ,Peter hier hat das auch einmal erlebt.'

${ }^{146}$ Anders definiert Lamping 1983, S. 15, dem Modell Bühlers folgend die Benennung als „Teil einer Rede, die darstellenden Charakter hat" und unterscheidet von ihr den (expressiven) „Ausruf“ des Namens. Die Sprechaktkategorie des Satzes, in dem ein Name verwendet wird, oder gar diejenige einer gesamten Rede ist aber von der Funktion des Namens zumindest partiell unabhängig. So kann eine Benennung auch in einem expressiven Sprechakt stattfinden. Insoweit ist die Grundlage der Kategorisierung Lampings nicht geeignet.

${ }_{147}^{14}$ Vgl. Horstmann 2001, S. 105.

${ }^{148}$ Die Trennung von ,Anrede' und ,Namennennung' entspricht der Unterscheidung von vocative funktion und referential function (vgl. Lyons 1977, S. 217).
} 
zugesprochen. ${ }^{149}$ Dies legt es nahe, auch Eigennamen auf den Sprecher und seine Äußerung zu beziehen. Die Anrede und die Benennung sagen nicht nur etwas über den Namenträger, sondern vor allem über das Verhältnis von Namenbenutzer, Namengeber und Namenträger aus. Der Name gibt das Verhältnis von Namenbenutzer und Namengeber zum Namenträger preis. Anhand von Namen läßt sich außerdem etwas über die Intentionen des Namenbenutzers oder Namengebers erfahren, sich selbst zu charakterisieren.

Auf der Basis vorhandener Typologien, aber mit dem Schwerpunkt auf der sprachphilosophischen Systematik und den besonderen Textbedingungen der Gattung Lyrik kategorisieren wir die Funktionen der Namenverwendung im Gedicht folgendermaßen:

Zunächst unterscheiden wir textbezogene Funktionen von figurenbezogenen Funktionen. TeXtBeZOgene FUNKTIONEN beziehen sich auf die Rolle des Namens im Gesamtgefüge des Textes. Diese Funktionen spielen in Gedichten aufgrund der dominierenden formalen Ordnungsbeziehungen eine besonders wichtige Rolle.

Eigennamen dienen dabei auf der Grundlage der besonderen Eigennamenreferenz zunächst der KONTEXTBINDUNG DES TEXTES. Kontextbindung meint die ANBINDUNG des Textes an einen fiktionalen oder realen Kontext und die Verbindung verschiedener Textebenen. Der Namenträger kann dabei figurengestaltend genannt werden. ${ }^{150}$ Wenn der Namenträger beim Namen angeredet wird, dient der Eigenname der AUSRICHTUNG des Textes auf einen Kontext. Eine Kontextbindung stellt schließlich auch die TRANSPOSITION dargestellter Sachverhalte in einen anderen Kontext dar. Diese Funktionen beruhen auf der Eigenschaft von Eigennamen, als rigid designators über die im Text dargestellte Welt (ob fiktional oder nicht) auf die reale Umwelt des Lesers oder auf außer- oder innertextliche fiktionale Welten referieren zu können und so durch die transworld identification auch Objekte außerhalb des Textes zu identifizieren. ${ }^{151}$

In einem überstrukturierten Text kommt der Position einer Namennennung oder Anrede beim Namen eine erhöhte Bedeutung für die formale und inhaltliche Struktur bzw. den Verlauf des Textes zu: die TeXtSTRUKTURIERUNG. Diese Funktion beruht auf der komplexen Struktur des semantischen Inhalts eines Eigennamens. Eigennamen bestimmten

\footnotetext{
${ }^{149}$ Vgl. Bernhart 1993; Wolf 1998.

150 Diese Transposition findet auch bei der Anwendung von Stereotypennamen auf reale oder fiktive Objekte statt. Sie dienen der Typisierung dieser Objekte und können damit auch namenträgerbezogene Funktion haben (vgl. auch Wittstruck 1987, S. 327-335).

${ }^{151}$ Vgl. auch Gutschmidt 1984, S. 140. Zu dieser Funktion gehört auch die 'klassische' Testimonialfunktion (vgl. Wittstruck 1987, S. 336-347).
} 
den Verlauf des Textes in besonderer Weise dadurch, daß ihr weiter semantischer Inhalt im Text entfaltet wird und daß sie Informationen zusammenfassen und verdichten. In überstrukturierten Texten hat schließlich besonders die ÄSTHETISCHE FUNKTION der Formerfüllung durch Eigennamen ein großes Gewicht. Die Isolierung des Eigennamens läßt dessen Zeicheneigenschaften besonders hervortreten.

In FIGURENBEZOGENER FUNKTION dienen Eigennamen, die auf im Text gestaltete Figuren referieren, der DIREKTEN EVOKATION eines Namenträgers (sei es eine auch außertextlich existierende oder eine rein innertextliche fiktionale Entität). Diese Namen können das Wissen über die benannten bzw. angeredeten Entitäten und deren Verhältnis zum Autor, zu anderen Objekten bereichern. Hier finden die figurenbezogenen Namenfunktionen Lampings vorwiegend ihren Ort. Darüber hinaus charakterisieren die von einem Sprecher ausgewählten Namen und ihre Verwendungsweise dessen Idiolekt. Namen aus dem Namenrepertoire eines Sprechers evozieren diesen indirekt (das ist die Funktion der INDIREKTEN EVOKATION des Namenbenutzers).

Es ergibt sich folgendes System der Eigennamenfunktionen in Gedichten:

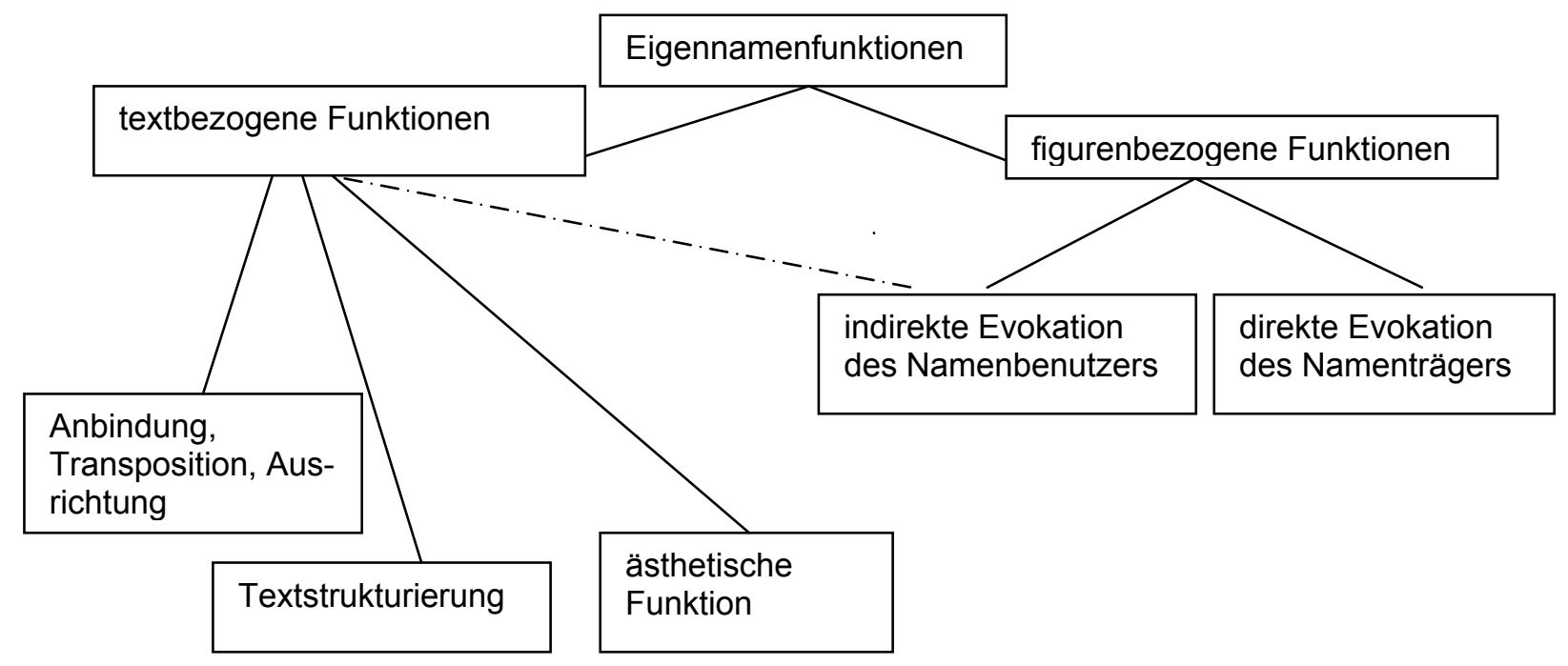

\subsection{Textbezogene Funktionen}

\subsubsection{Textstrukturierende Funktionen - der semantische Hintergrund des Namens und der Textverlauf}

\subsubsection{Namen und Textstrukturierung}

Namen spielen aufgrund ihres weiten, aber unsicheren Bedeutungspotentials sowie aufgrund ihrer formalen Auffälligkeit eine wichtige Rolle für die Strukturierung von Texten. In den Blick textlinguistischer Analysen der Namenposition geraten vor allem Nameninitiationen und Namenersetzungen durch indexikalische Zeichen oder Appellati- 
ve. ${ }^{152}$ Der ,janusköpfige“ Charakter, der Eigennamen zugeschrieben wird, wirkt sich auf die Informationsverteilung in einem Gedichttext entscheidend aus. ${ }^{153}$ Eigennamen sind zunächst semantisch leer. Sie benötigen daher eine semantische Ergänzung, die entweder durch enzyklopädisches Wissen um den semantischen Hintergrund eines über den Text hinaus referierenden Namens oder durch den Kotext vom Sprecher geliefert werden kann. Dem intendierten Leser bekannte Namen können auf vorhergehende Texte oder Textabschnitte verweisen, während Namen, die dem intendierten Leser unbekannt sind, im nachfolgenden Text mit Sinn gefüllt werden müssen. ${ }^{154}$ Seine textstrukturierende Funktion hängt dabei von dem recht unwägbaren enzyklopädischen Wissen des Lesers und des Autors ab. ${ }^{155}$

Eine Differenz zur Alltagssprache ${ }^{156}$ bei der Eigennamenverwendung erwächst literarischen (fiktionalen) Texten auf der pragmatischen Ebene. Die Verwendung nicht eingeführter und unbekannter Eigennamen ohne identifizierende Kotexte führt in der Alltagssprache zu metakommunikativen Exkursen der Sprecher. Bei den in einem literarischen Text verwendeten Eigennamen umfaßt die nach dem principle of benevolence geforderte „produktive Rezeption des Lesers“"157 die Bereitschaft, aus dem reichen Arsenal der Bedeutungsmöglichkeiten eines Namens die für den Gesamttext relevanten Bedeutungen zu erkennen oder nach einer formalen Motivation für die Namenverwendung zu suchen. ${ }^{158}$ Dabei ist der Autor der ,Souverän' über die Dosierung der Information in seinen Texten. ${ }^{159}$ Dennoch wird auch an einen literarischen Text (an ein Gedicht) unter Umständen die Erwartung herangetragen, den für den Text relevanten Hintergrund des Namens zu nennen. ${ }^{160}$

Das Besondere der Einbindung von Eigennamen in einen Gedichttext ist, daß Namen in die verschiedenen (formalen) Ordnungsstrukturen eingebunden sind, die den Gedichtverlauf steuern. ${ }^{161}$ Geht man davon aus, daß "the description of a poem's structure, then, becomes the answer to the question, 'What keeps it going?' [...and...] 'What stops

\footnotetext{
${ }^{152}$ Vgl. Kalverkämper 1978, S. 392-396; Tschauder 1989, bes. S. 13-19.

${ }^{153}$ Vgl. Kalverkämper 1994, S. 214.

154 Vgl. Tschauder 1989, S. 15; Kalverkämper 1978, S. 390; Kalverkämper 1994, S. 225; Schwarz 2000 , S. 36; Aschenberg 2002, S. 115. Eigennamen haben textlinguistsich eine doppelte Extremposition inne. Als Wort sind sie einerseits ein weitreichender und starker Textdeterminator, andererseits sind sie auch selbst stark vom Text abhängig, d.h. determiniert; vgl. Fix 2003, S. 82.

${ }^{155}$ Vgl. zur Unsicherheit der Namen bei Trakl: Perels 1979, S. 318 f.; vgl. zum Leserwissen aus kognitionstheoretischer Sicht Christmann/Schreier 2003, S. 252-254.

${ }^{156}$ Vgl. Schmidt 1968.

${ }^{157}$ Vgl. Schmidt 1968, S. 302.

${ }^{158}$ Vgl. Kalverkämper 1978, S. 32; Schwarz 2000, S. 36, zu nichtliterarischen Prosatexten.

${ }^{159}$ Vgl. Kalverkämper 1994, S. 226.

${ }^{160}$ Vgl. z.B. Gernhardt 2000, S. 74.

${ }^{161}$ Insofern hat Horstmann unrecht, wenn sie konstatiert, daß sich die Namenfunktionen in allen Gattungen sehr ähnelten; vgl. Horstmann 2001, S. 39 Fn. 48; vgl. auch Wittstruck 1987, S. 474.
} 
it from going?'“, stehen der mehrdimensionale dynamische Ablauf des Textes und die Einbindung von Namen in diesen Ablauf im Vordergrund. ${ }^{162}$ Im Gedicht beeinflußt besonders die gewählte Gedichtform die dynamische Struktur insofern, als eingegangene Bindungen nach Erfüllung verlangen. Eine bestimmte metrische Struktur, ein eröffneter Reim, eröffnende Abschnitte, die eine Gedichtform erkennen lassen, oder Wiederholungen und Variationen (etwa ein Refrain etc.), schließlich auch der Beginn bekannter Phrasen wecken Lesererwartungen. Die diese Erwartungen an die Form erfüllenden oder nicht erfüllenden Elemente erhalten ein besonderes Gewicht. ${ }^{163}$ Das Sonett Das Wort Hoffnung von Ludwig Harig führt dies für Eigennamen vor:

\title{
DAS WORT HOFFNUNG \\ Für Ernst Bloch
}

Schau hin, vor deinem Fuß bricht auf und gähnt ein Loch.

Auf einmal klafft ein Riß, der lang geschlossen blieb.

Es öffnet sich die Welt und ist ein weites Sieb.

Ein Wort nur hält dich fest für eine Weile noch.

\begin{abstract}
Zwar ist es nur ein Wort. Mit einem Hauch jedoch verwandelt es sich jäh in einen starken Trieb.

Das Wort, das Hoffnung heißt, beschreibt ein Lustprinzip, und ders gesprochen hat, ein Philosoph, heißt Bloch.
\end{abstract}

Nun ist ein schönes Wort, selbst wenn es ein Prinzip ist, nichts als ein leerer Schall, auch wenn's dir noch so lieb ist, und nicht einmal der Trieb verstopft das Loch der Welt.

Das Wort muß Feder sein, der Treib die feste Zwinge: ikarisches Gerät, das dich auf leichter Schwinge, bevor du abwärts stürzt, ein Weilchen oben hält. ${ }^{164}$

Hier wird in den Paratexten zunächst der Eigenname ,Ernst Bloch' durch die Anspielung auf den berühmten Werktitel Das Prinzip Hoffnung und durch die Widmung „Für Ernst Bloch“ aktualisiert. Die Erwartung des Wiederauftretens dieses Namens wird mit den Blockreimen ,Loch : noch : jedoch' bis zum Ende der Quartette des Sonetts mit formalen Mitteln geschürt. Der Name 'Bloch' dient dazu, die Reimerwartung aufzulösen. Indem er den Inhalt und die Form abschließt, bildet er die von der strengen Sonettform geforderte Zäsur nach den Quartetten. Der Eigenname ist hier deutlich in die durch die Form vorgegeben Textstrategie eingebunden.

In jedem Text mit Eigennamen lassen sich solche Strategien der Namenverwendung und -positionierung (eine „Namendramaturgie“ oder „Namenstrategie“) ausmachen, die

\footnotetext{
162 Vgl. Herrnstein-Smith 1968, S. 4. Die dynamische Entwicklung eines Gedichtes kann auf dargestellten oder im Leser hervorgerufenen Stimmungen, auf kommunikativen Strategien oder auf dem Umgang mit formalen Sprach- und Formelementen beruhen. Bestimmend für den Ablauf in diesem Sinne ist daher die unterschiedliche Dichte der Textabschnitte auf allen Sprachebenen.

${ }_{163}$ Vgl. Herrnstein-Smith 1968, S. 36. Vgl. Killy 1972, S. 57.

${ }^{164}$ Harig 1988, S. 40.
} 
auf die allgemeine Textstrategie abgestimmt sind. ${ }^{165}$ Ein besonderes Gewicht erhalten Eigennamen dabei, wenn sie thematisch im Zentrum des Textes stehen. ${ }^{166}$

Eigennamen wechseln in Wiederaufnahmestrukturen mit anderen koreferierenden Elementen aus stilistischen und inhaltlichen Gründen ab. ${ }^{167}$ Bei mehrfacher Namennennung lassen sich auch in Gedichten die durch die Norm der stilistischen Variation bewirkten variierenden Wiederaufnahmerelationen finden. ${ }^{168}$ So besteht die Nameninitiation zu Beginn des Textes typischerweise aus einem vollen Namen. Dieser wird im Verlauf des Gedichts von dem vertraulicheren Vornamen abgelöst, bevor am Ende des Gedichts summierend wieder der volle Name verwendet wird: etwa in den jeweiligen ersten Versen der acht Strophen von E.A. Robinsons Miniver Cheevy: „Miniver Cheevy, child of scorn, [...] // Miniver loved the days of old [...] // Miniver sighed for what was not, [...] // Miniver mourned the ripe renown [...] // Miniver loved the Medici, [...] // Miniver cursed the commonplace [...] // Miniver scourned the gold he sought, [...] // Miniver Cheevy, born too late [...]." 169 Die Nennung des vollständigen Ruf- und Familiennamens garantiert oder suggeriert hier die eindeutige Identifikation des Namenträgers. Er erfaßt die Person (scheinbar) ,objektiv'. Die vertrauliche Anrede des bereits Identifizierten beim Vornamen dient dagegen vornehmlich der Perspektivierung. ${ }^{170}$ Die Wiederholung des vollständigen Namens zum Abschluß der Äußerung deutet dann wiederum eine Distanzierung des Sprechers an. Nach den vertraulichen Nennungen über den Gedichtverlauf hinweg wird nun resümiert und der Namenträger noch einmal abschließend, vollständig und ,objektiv' vor Augen geführt.

Eine Möglichkeit der poetischen Abweichung von den Kommunikationsgewohnheiten der Alltagssprache besteht darin, auf dem Namen zu insistieren. Wird der Name auf engem Raum häufig wiederholt, prägt er sich besonders ein. In Edgar Allen Poes Eldorado etwa stellt der Autor den refrainartig wiederholten Namen in jeweils neue semantische Kontexte und kombiniert auf diese Weise Wiederholung und Variation. ${ }^{171}$ Das mythische Eldorado bleibt das konstante Ziel eines Ritters, dessen scheiternde Suche geschildert wird. Dabei bleibt der Name ,Eldorado' semantisch leer. Lediglich im Ratschlag eines ,Pilgerschattens' wird der Hauch einer Bedeutung des Ortes gegeben: Eldorado

\footnotetext{
${ }^{165}$ Wittstruck 1987, S. 28, S. 469; Gutschmidt 1979, S. 114; vgl. auch Sandig 1995, S. 542 f.; Fleischer 1995, S. 558 f.; zu Substitutionsabläufen vgl. Kalverkämper 1994, S. 230.

${ }^{166}$ Vgl. auch Filips 1967, S. 71-76.

${ }^{167}$ Vgl. Heinemann/Viehweger 1991, S. 38f.; Killy 1972, S. 35-56.

${ }^{168} \mathrm{Vgl}$. Fleischer 1995, S. $557 \mathrm{f}$.

169 Vgl. Ferguson/Salter/Stallworthy 1996, S. 1108.

${ }^{170}$ Vgl. z.B. Ferguson/Salter/Stallworthy 1996, S. 688, S. 884, S. 1108; Pickerodt 2001, S. 72. Eine häufig anzutreffende Variante ist auch der Wechsel zwischen verschiedenen Namen der gleichen Entität - etwa zwischen ,Phöbus' und ,Apoll'. Ein solcher Wechsel dient der Abwechslung, da beide Namen weder semantisch noch pragmatisch unterschieden sind; vgl. z.B. Komrij 1986, S. 933.

${ }^{171} \mathrm{Vgl}$. Ferguson/Salter/Stallworthy 1996, S. 884.
} 
steht für ein unerreichbares, aber konstant bestehendes Ziel. Durch die insistierende Wiederholung des Ortsnamens führt Poe wiederholt dem Leser den Mythos vor Augen. Die Aura des Namens wirkt auf den Leser, ohne daß Poe dabei in seinem Gedicht einen Beitrag zum semantischen Inhalt des Namens machte. Es handelt sich um ein Gedicht nicht über Eldorado, sondern über die Suche nach dem Unerreichbaren. ${ }^{172}$

Die textstrukturierenden Funktionen von Eigennamen lassen sich am besten an zwei Gedichtsorten am Rande der Gattung deutlich machen. Daher werden in den folgenden drei Abschnitten zunächst die Namenverteilungen in inhaltlich dominierten Balladen sowie in makrostrukturell deutlich formal dominierten Figurengedichten als Beispiele für deutlich inhaltlich bzw. deutlich formal orientierte Strategien im Mittelpunkt stehen. Anschließend zeigen wir anhand der weniger auffälligen Strategien in ,konventionellen' Gedichten, wie sich die Verwendung von Eigennamen auf den Verlauf eines Gedichts auswirken kann.

\subsubsection{Eigennamen und story line - Eigennamen und Textumriß}

\subsection{Charakterisierung und Handlungsverlauf}

Balladen sind durch eine den Textaufbau dominierende story line ${ }^{173}$ gekennzeichnet. Sie sind in dieser Hinsicht Erzähltexte, die sich durch die Versbindung von Erzähltexten in Prosa unterscheiden. Im Gegensatz zu Versepen findet in Balladen die Verteilung der Eigennamen auf einem Raum statt, der vergleichsweise stark begrenzt ist. ,Erzählende Textverteilungsstrategien' lassen sich daher in Balladen ,komprimiert' beobachten. Dies soll im Folgenden im Hinblick auf die Namenverwendung in zwei Beispielen des Erzählens in der Ballade betrachtet werden.

The Ballad of East and West aus dem zweiten Teil der Barrack-Room Ballads Rudyard Kiplings, den Other Verses, ist ein Beispiel für eine an einen Erzählvorgang gebundene, stark wirkungsorientierte Namengebung und -dramaturgie. ${ }^{174}$ Ein einleitender Abschnitt gibt das Thema der Ballade an: das urtypische Zusammentreffen zweier „starker Männer“, deren Heldenhaftigkeit die scheinbar unüberwindlichen kulturellen Differenzen zwischen „Ost und West“ überwiegt. ${ }^{175}$ Eine typische Abenteuerromanszene - der krie-

\footnotetext{
172 Zu einem ähnlichen Gebrauch von Eigennamen in Prosatexten vgl. Aschenberg 2002, S. 115.

173 'Gedichte fiktionaler Ausgestaltung' sollen hier diejenigen Gedichte genannt werden, die über eine story line verfügen und hauptsächlich Inhaltlich strukturiert sind; vgl. Lampings Begriff der 'erzählenden Rede', Lamping 1993, S. 96; Schönert 1999, S. 292; oder Links Begriff der ,narrativen Lyrik', Link 1979, 192. Das Vorhandensein einer story line und nicht das Auftreten von Figuren bestimmt die dem Epos ähnliche Namenverwendung; vgl. anders Horstmann 2001, S. 39 Fn. 48.

${ }_{174}$ Vgl. Kipling 1989, S. 75-83; vgl. allgemein auch Bertills 2003, S. 48.

175 Vgl. Kipling 1989, S. 75.
} 
gerische Pferderaub beim militärischen Gegner und das Wiedererlangen der Beute im heroischen Zweikampf - bildet die Handlung der Ballade.

Den Text eröffnet der Name eines Raubritters: „Kamal' wird nicht näher erläutert, doch weist der arabische Klang als sortales Prädikat den Namenträger als (südwestasiatischen) Moslem aus. ,Kamal' wird als Anführer einer Gruppe von 20 Kriegern als einziger Einheimischer namentlich genannt. Seine Gegenspieler, "the Colonel“ und „the Colonel's son that led a troop of the Guides“ werden dagegen nur mit dieser definite description identifiziert und nicht namentlich genannt. ${ }^{176}$ Von Bedeutung ist ihr militärischer Rang. Dieser ruft den Kontext des englischen Kolonialheeres auf und steckt den Handlungsraum der Soldaten (als Befehlshaber) in Analogie zum einheimischen warlord ab. Durch die Gegenüberstellung von Rang und Eigenname wird der Gegensatz zwischen den anonymen Repräsentanten der Nation und ihres heldenhaften Heeres und den individuellen Repräsentanten einer ungeordneten - exotisch wilden - Welt betont. Es stehen sich nicht zwei Staaten gegenüber, sondern wildernde Räuber treffen auf das geordnete Gefüge des Kolonialheeres.

Die definite descriptions der Handelnden stellen nicht nur die Differenzen von ,Ost' und ,West' dar, sondern darüber hinaus auch die gemeinsame Ebene, auf der das schicksalhafte Ereignis stattfindet. Die Benennung des eigentlichen Helden der Ballade, „the Colonel's son" weist voraus auf die ,urtümlichen' kulturübergreifenden Kräfte, die hier aufeinander treffen. Der Held erfüllt seine Sohnespflicht und nicht nur einen militärischen Auftrag als besoldeter Angestellter eines Staates. Im ,show-down' der Ballade findet ein archaischer Kampf zwischen urtypischen Helden statt. Der Räuber wird durch den Sohn beeindruckt, der aus den Handlungsweisen des angestellten Soldaten - der gedankenlosen Pflichterfüllung - heraustritt und ausdrücklich ohne Unterstützung des Heeres (erwähnt werden Männer und Proviant) den Pferdedieb jagt. ${ }^{177}$ Daher kann Kamal am Ende auch den Mut des Soldaten ,von Mann zu Mann' anerkennen. „The Colonel's son“ droht inm zwar mit der geballten Macht des Kolonialheeres. Er betont aber auch, daß er „my fathers mare“ um jeden Preis wiedererlangen will und schenkt sie Kamal schließlich, autorisiert „by the blood of my clan“. ${ }^{178}$ Die Motivation der Handlungen bewegt sich auf einem mythisch-archaischen Gebiet, das sogar „Ost und West“ vereinigt.

Die Betonung der Eingeborenennamen und der Verzicht auf die Namen der britischen Soldaten haben aber noch weitere Gründe. In Kiplings Barrack-Room Ballads and O-

\footnotetext{
${ }^{176}$ Kipling 1989, S. 75 f.

177 Vgl. Kipling 1989, S. 77.

178 Kipling 1989, S. 79 f.
} 
ther Verses wird die exotische Atmosphäre der englischen Kolonien vor allem durch den soldatischen Soziolekt und Eigennamen aufgebaut. Eigennamen haben hier die Funktion, eine Welt zu imaginieren und die weiteren Referenzen der indexikalischen oder appellativischen Ausdrücke festzulegen. Sie wirken weltkonstituierend. Das gilt für Ortsnamen, die den Handlungsort festlegen ${ }^{179}$, aber auch für mit topographischen sortalen Prädikaten versehene Personennamen. Symptomatisch für diese Funktion der Namen ist die Präsentation eines mohammedanischen Soldaten, der den Fluchtweg Kamals beschreibt. Dieser wird (im Gegensatz zu anderen Nebenfiguren) mit seinem Namen und einer begleitenden namenartigen und klassifizierenden Kennzeichnung eingeführt: „Mahommed Khan, the son of the Ressaldar“. ${ }^{180}$ Der Name selbst hebt die Exotik des stimmungsbeladenen Handlungsortes hervor. Er ist eine überdeutliche Kombination aus einem Stereotypennnamen für $\{$ Muslim\} und \{Asiat\}, aus dem Namen des Religionsgründers des Islam und dem asiatischen ,Adelsprädikat'. Die beigefügte Stammesherkunft betont, daß trotz seiner militärischen Einbindung "Mahommed Khan", der scout, hier auch als einheimischer Mann und Krieger spricht, der an der überkulturellen heroischen Handlung teilnimmt. So wie "the Colonel's son" eben vordringlich Sohn und nicht etwa ,Soldat Miller' ist, ist "the son of the Ressaldar" in diesem Moment zuförderst Stammeskrieger.

Kipling nimmt sich immerhin neun Verse Zeit für die Darstellung des Fluchtweges Kamals durch die Worte Mahommed Khans, wobei die teilweise wiederholten Ortsnamen besonders wichtig werden. Der Bericht nennt exotische reale Ortsnamen aus dem südostasiatischen Raum: „Abazai“, „Bonair“ und „Fort Bukloh“. Weiterhin benutzt er die so exotische wie archaische Beschreibung und Ortsbezeichnung nach Naturphänomenen (,if je know the track of the morning mist“ und „the Tongue of Jagai“). ${ }^{181}$ Diese Beispiele der Mikrotoponymie ${ }^{182}$ eignen sich, besonders zur Benennung exotischer, archaischer und schicksalhafter Orte, da sie als redende Namen ,urtümlich' wirken und den bezeichneten Ort metaphorisch oder konkret beschreiben.

Durch die ausführliche Nennung der Ortsnamen vor Beginn der eigentlichen Handlung wird ein Raum eröffnet, in dem sich die dann folgende Handlung abspielen wird. Der Klang der Namen und die vage topographische Zuordnung spielen dabei die Hauptrolle für die Namenwirkung. Die Namen werden unkommentiert verwendet. Dies zeigt besonders das Ende der Ballade, an dem Kamal seinem von inm selbst als Soldat zu den

\footnotetext{
${ }^{179}$ Vgl. zu Ortsnamen in der Literatur auch Laur 1996, S. $121 \mathrm{f}$.

180 Vgl. Kipling 1989, S. 76.

${ }^{181}$ Vgl. Kipling 1989, S. 76.

182 Vgl. zu dem Begriff Koß 2002, S. 147.
} 
Briten geschickten Sohn ankündigt: „Belike they will raise thee to Ressaldar when I am hanged in Peshawur“. ${ }^{183}$ Einander gegenübergestellt werden hier ein Ort in der Hand eines befriedeten Stammes, der offensichtlich auf Seiten der Kolonialherren focht - wie die Benennung des scout „Mahommed Khan, son of the Ressaldar" textintern deutlich macht - und der wichtige Standort der britischen Kolonialverwaltung.

Der Verzicht auf die namentliche Benennung just der Identifikationsfigur „the Colonel's son" läßt sich schließlich auch noch aus der Perlokution der Balladen in Kiplings Barrack-Room Ballads and Other Verses erklären. Kipling vermeidet die namentliche Individualisierung der Vertreter britischer Kolonialmacht in seinen Balladen. Der Sprecher der im Tingeltangel gesungenen Barrack-Room Ballads heißt „Thomas Atkins“, ein Name der als Mustername für ,der Soldat' steht. Die Balladen zielen auf eine starke Identifikation mit der Sprecherfigur, die daher immer als ,Stereotyp' angesprochen werden muß und nicht als wirkliches Individuum. Der zweite Teil - Other Verses - zeichnet ein exotisch-heroisches Bild, durch das sich der Leser mit dem britischen Kolonialheer identifizieren bzw. solidarisieren kann. Dazu liefert der Verzicht auf die namentliche Identifikation die Grundlage.

Die Eigennamen in Kiplings Ballade dienen zwar auch der Charakterisierung der Figuren. Sie haben aber darüber hinaus die Aufgabe, den Handlungskontext und das Thema hervorzuheben und dienen der Leserlenkung. Diese Verlagerung der Eigennamenfunktion von figurenorientierten Funktionen hin zu Textorganisationsfunktionen wird in Gedichten als formal überstrukturierten Texten besonders deutlich.

\subsection{Standardisierte Textverläufe}

Die Namendramaturgie von Erzähltexten ist je nach Textsorte in unterschiedlichem Maße durch die Form vorherbestimmt. In stärker regulierten bzw. standardisierten Gattungen ist auch die Eigennamenverwendung stärker standardisiert. Dadurch werden Eigennamen zum Textsortensignal, das den Text den Erwartungen des Lesers gemäß strukturiert. Als Beispiel für solche Erzähltextstrategien dient uns Die Söhne Haruns von Conrad Ferdinand Meyer. ${ }^{184}$ Diese scheinbare Märchenballade exemplifiziert eine Textsorte mit besonders klaren Handlungsabläufen und Eigennamenstrategien:

Meyers Ballade folgt in der Namenverteilung den Prinzipien des Märchens. Sie beginnt mit einer Namentrias aus zwei sehr ähnlichen und alliterierenden Namen und einem dritten, deutlich abweichenden Namen: „Assur, Assad, Scheherban“. In diesen Eigennamen spiegelt sich schon der Ablauf der Handlung. Nach der Einleitung durch die Fra-

\footnotetext{
183 Kipling 1989, S. 82.

${ }^{184}$ Vgl. Meyer 1963, S. 270; vgl. auch die nicht vollendete Fortsetzung: Meyer 1975, S. 400-403.
} 
ge des alten Herrschers Harun geben zwei Söhne unzureichende und konventionelle Antworten. Textlinguistisch ausgedrückt gehören sie mit ihren Aussagen zum ,thematischen' Teil des Textes. Die beiden älteren Söhne sind die Staffage, die den eigentlichen Plot vorbereitet. Der dritte Bruder ist derjenige, welchem die eigentliche Aufmerksamkeit gewidmet ist und der den wichtigen Teil der Handlung und das Thema des Märchens ausspricht. Sie lautet etwas vereinfacht: Aus wahrer Liebe opfert man sich in aller Stille, Heimlichkeit und Bescheidenheit, statt mit großem Prunk.

Jeweils ein Balladenabschnitt wird einem der Brüder zugeordnet, wobei die Länge der Abschnitte zunimmt. Assurs Vorschlag nimmt eine Strophe ein, Assads zwei, Scheherbans Vorschlag vier Strophen. Die Namen der älteren Brüder stehen jeweils am Beginn der Strophen und gliedern damit den Text. Scheherbans Rede, in der er im Unterschied zu den konventionellen und unzureichenden Antworten der Brüder die ideale Antwort auf die Frage der Herrschers gibt, wird abweichend von „der Jüngste“ eingeleitet, der Name wird erst im Verlauf der Strophe wieder genannt. Damit verwendet Meyer ein weiteres Märchenstereotyp: Der jüngste, vermeintlich unerfahrene Bruder weiß doch die beste Antwort zu geben.

Weiterhin dienen die Eigennamen insgesamt - Harun, Assur, Assad, Scheherban, Bagdad - der Gestaltung der fiktiven Welt, in der die Handlung stattfindet. Sie sind die wichtigsten Träger der morgenländischen Atmosphäre, da der Rest der verwendeten Sprache nicht auf ein morgenländisches Ambiente hindeutet. Dies weist schon darauf hin, daß die Ballade keine Märchenballade im eigentlichen Sinne darstellt. Es handelt sich um eine Ideenballade, die sich aber des Handlungsschemas eines Märchens bedient. Die Zuordnung der verschiedenen Ideen zu verschiedenen Sprechern ermöglicht zum einen die imaginative Gestaltung. Zum anderen erzeugt Meyer mit seinem Text einen Spannungsbogen, der bei einer abstrakten Erörterung der Ideen nicht entstünde.

Eigennamen sind sowohl bei Kipling als auch bei Meyer Indikatoren des Handlungsverlaufs. Sie gliedern das Gedicht vermittels der ihnen zugeordneten Bedeutungselemente und ermöglichen die Positionierung und Imagination abstrakter und konkreter Inhalte. Die Orientierung an einem Handlungsverlauf teilen die untersuchten Texte mit Erzähltexten. Die Anordnung der Eigennamen in Gedichten ist aber gewöhnlich nicht (nur) an einem Handlungsverlauf orientiert. Vielmehr spielt die Form des Textes bei der Namenverteilung in vielen Gedichttexten ebenso eine Rolle. Wie wir im Folgenden sehen werden, zeigen Carmina figurata der „ikonischen Grundform“ ${ }^{185}$ dies besonders deutlich.

${ }^{185}$ Vgl. Ernst 1990, S. 209-213; vgl. auch Warnock/Folter 1970. 


\title{
4.3.1.2.3 Namenposition und Textumriß
}

J. Decker Zimmermans Een palmboom, opgericht voor Spicht, bij de uitgave van zijn gedicht, enz. ist ein Preisgedicht in der bekannten Form einer Palme. ${ }^{186}$ Zur Artistik des Textes gehört es, daß das Auftreten des Namens der geehrten Person sowohl auf den linearen, als auch auf den figuralen Lesevorgang zu beziehen ist. Der Eigenname ,Spicht' steht nicht nur an Anfang und Ende des Haupttextes, sondern bildet auch die Krone und die Wurzel des abgebildeten Baumes. Bezogen auf das Textbild symbolisiert der Eigenname sowohl die Spitze wie das Fundament des ,Ehrenmals'. Das Gedicht geht vom Namen aus und endet mit dem Namen. Die ,Namenklammer' bewirkt, daß der Eigenname vom Beginn des Textes an präsent ist und daß zugleich der ,letzte Eindruck' des Lesers wiederum der Eigenname des zu Ehrenden ist:

\author{
SPICHT! \\ Uw gedicht \\ kwam pas in't licht, \\ of ik heb het doorgebladerd, \\ en voor $u$ een krans vergaderd \\ in mijn dichtkunst minnend hart, \\ maar ik vond geen boom, o smart! \\ waar ik't palmloof plucken kon; \\ zie wat ik darom verzon: \\ 'k maakte zelf, niet loom, \\ met de pen, een boom, \\ Zie hem hier, \\ op't papier! \\ Pluk nu; \\ ruk nu; \\ draal niet; \\ maal niet! \\ Knort gij; \\ mort hij; \\ scheldt gij; \\ snelt gij \\ tot gekijf \\ mij te lijf? \\ Weet:slechts degelijk gedicht \\ Hoopt op degelijk palmloof, SPICHT! ${ }^{187}$
}

Umrißgedichte provozieren eine Rezeptionsweise, die den linearen Textlesevorgang mit der Betrachtungsweise von Bildern kombiniert: Textteile oder der gesamte Text müssen nach bildlichen Vorgaben in ungewöhnlicher Richtung gelesen werden, es gibt mehr

\footnotetext{
${ }^{186}$ Vgl. Adler/Ernst 1987, S. 87-92.

187 „Spicht! Ihr Gedicht / kam kaum ans Licht, / da habe ich es durchgeblättert, / und für sie einen Kranz geflochten / in meiner Dicktkunst mit viel Liebe, / doch ich fand keinen Baum, oh Schmerz! / wo ich das Palmblatt hätte pflücken können; / sieh, was ich darum mir ausgedacht habe: / ich machte selbst, nicht faul / mit dem Stift einen Baum. / Sie ihn hier / auf dem Papier! / Pflück' nun; / rück' nun / zaudere nicht, / mahle nicht! / Knurrt ihr; / beißt ihr; / schimpft ihr; / geht ihr / zum Gekeife / mir ans Leben? / Wisset: kaum ein derartiges Gedicht / Hofft auf einer derartiges Palmblatt, Spicht!“ Komrij 1979, S. 45.
} 
oder weniger versteckte ,Intexte' oder ungewöhnliche Positionen des Textbeginns. ${ }^{188}$ Je mehr dabei ein geschlossener Text mit gewöhnlicher Leserichtung die Kontur ausfüllt, desto stärker sind die bildliche Wahrnehmung des Gedichts und der Leseakt voneinander getrennt. Denn dann wird die ,Lesebewegung' durch die Gestalt weniger beeinflußt. Der Leseakt rückt dagegen der Wahrnehmung der Textkontur um so näher, je stärker von der gewöhnlichen Leserichtung unter bildlichen Aspekten abgewichen wird.

Die Textkontur eines Umrißgedichts exemplifiziert ein einfaches, als Umriß darstellbares Objekt. Deiktika und Appellativa der Textrede denotieren das auch vom Umriß denotierte Objekt oder den Umriß selbst (verbal und pictorial denotation). ${ }^{189}$ Daneben enthält die Textrede aber auch Ausdrücke, die das im Umriß nur grob dargestellte Objekt im Sinne der Goodmanschen representation-as spezifizieren: z.B. in dem berühmten Füllhorn des Johann Steinmann. ${ }^{190}$ Gattungsbegriffe integrieren dabei relativ einfache Darstellungselemente in das durch die Textkontur exemplifizierte Bild.

Eigennamen ermöglichen es darüber hinaus, ,komplexe' Namenträger in das Textbild zu integrieren, die sich ansonsten in einem Umrißgedicht kaum bildlich hätten darstellen lassen. So positioniert Rudolf Karl Geller in seinem Kreuzgedicht Jesus / der ein Nazarener... zunächst jene Ausdrücke, die verschiedene Körperteile und die Dornenkrone Christi denotieren, an der entsprechenden Stelle der Textkontur und macht damit aus dem Kreuz ein Kruzifix ${ }^{191}$ :

\footnotetext{
${ }^{188}$ Vgl. Ernst 1985.

${ }^{189}$ Vgl. Ernst 1986b, S. 13. Dies ist auch der Standardfall in der konkreten Poesie des 20. Jahrhunderts, die die Materialität des Sprachzeichens durch die doppelte Referenz (Denotation und Exemplifikation) hervorhebt.

${ }^{190}$ Meid 1980, S. 216;

${ }^{191}$ Vgl. Ernst 1986a, S. 179-182.
} 


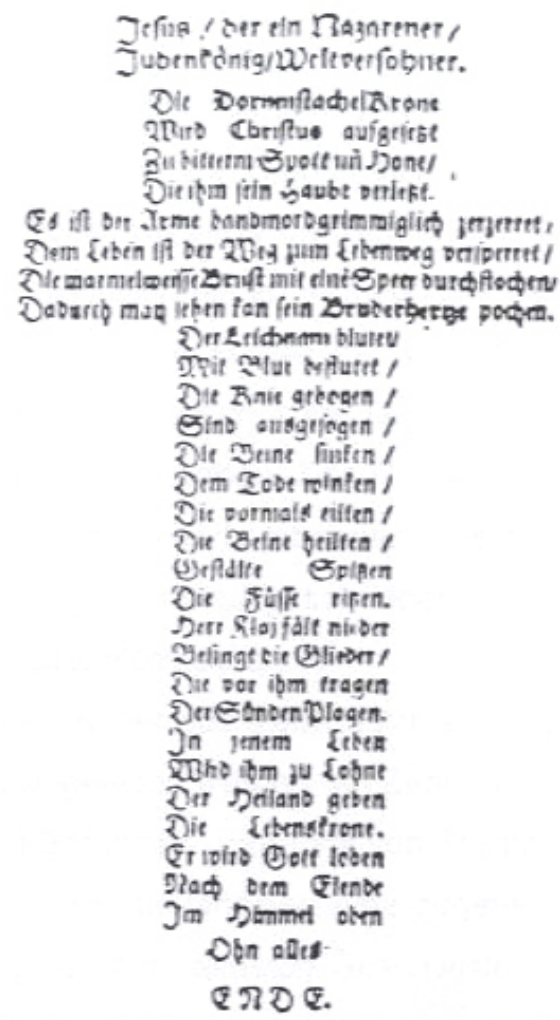

Darüber hinaus übernimmt der Familienname des Johann Klaj sowohl die eindeutige Identifizierung der darzustellenden Person als auch die Positionierung zu Füßen Jesu Christi, der ebenso durch seinen Namen (das nomen sacrum „Christus“ im oberen Teil des Kreuzes) vertreten ist.

In dieser Weise verwendete Eigennamen finden sich vor allem dort, wo konkrete Personen geehrt werden sollen und es zu den Zielen gehört, den Namen des Geehrten auf besondere Weise hervorzuheben:

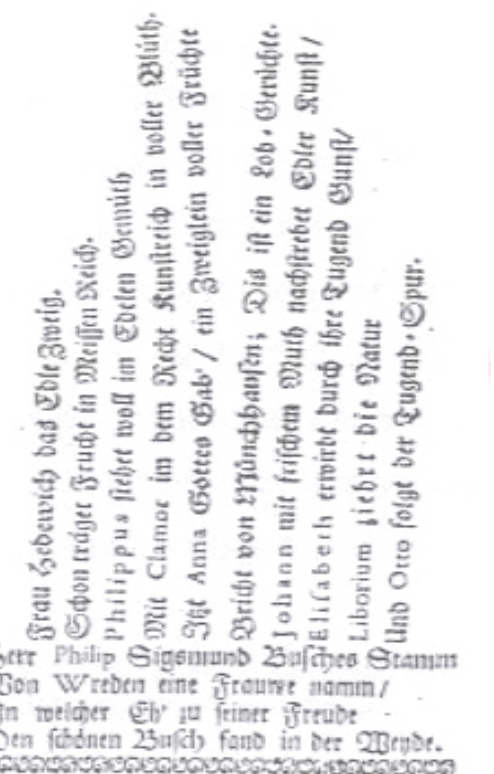

${ }^{192}$ Ernst 1986a, S. 180. 
Theodor Kornfeld läßt sich durch die Etymologie eines Namens - ,von dem Busch' - zu einem Umrißgedicht anregen, bei dem die Namen des ,Stammherrn' und seiner Frau den Stamm eines Busches bilden, während die Namen der Kinder die Zweige einleiten. ${ }^{194}$ Das Wortspiel mit dem Familiennamen wird von Kornfeld schon in der Widmung seiner Poetik, Selbst-lehrende Alt-neue Poesie der Vers-Kunst verwendet. ${ }^{195}$ Die Eigennamen jener Familienmitglieder, denen zum Teil auch die Vers-Kunst gewidmet ist ${ }^{196}$, sind durch die Antiqua hervorgehoben. Der Familienname des Bräutigams ,von Münchhausen' und der Name der auswärts lebenden (älteren?) Tochter werden dagegen in der kontextuell unauffälligen Fraktur geschrieben. Daran läßt sich ablesen, auf welche Gönner bzw. Auftraggeber Kornfeld zielte.

Darüber hinaus kann die Funktion des Hochzeitsgedichts an der Anordnung der Namen auf den ,Ästen' des Busches abgelesen werden. Im Zentrum der symmetrisch angeordneten ,Äste' stehen Braut und Bräutigam, umrahmt von Philipp, Clamor und Johann, die als ,Erbherren zur Ippenburg' auch die längsten Äste zugeteilt bekommen. Gleichzeitig geht die lineare Leserichtung von dem ältesten Geschwister links zum jüngsten Enkel des Stammherrn rechts. Die Symmetrie ist durch den Doppelast der ältesten Schwester „Frau Hedewich“ trotz der ungeraden Zahl von Personennamen aufrechterhalten. ${ }^{197}$ Das Figurengedicht integriert auf diese Weise das in der Emblematik etablierte Symbol in ein Namenspiel. Darüber hinaus kann die Familienidentität, die durch die Zusammenfassung der einzelnen Vertreter einer Familie im Familiennamen geschieht, bildlich durch die Integration der Eigennamen auch angeheirateter Familienmitglieder in den Busch dargestellt werden.

Wie besonders dieser letzte Fall eines eigennamenreichen Umrißgedichts gezeigt hat, erschöpft sich die Bedeutsamkeit der Form des Textes in Umrißgedichten keineswegs in der Silhouette des Textes ${ }^{198}$, sondern erstreckt sich auch auf die Positionierung einzelner Zeichen im Text. Die drei vorgestellten Fälle zeigen, daß Eigennamen sich durch ihre semantische Dichte und durch ihren Charakter als label und Stellvertreter des Namenträgers besonders dazu eignen, eine Verbindung zwischen Umriß und Textinhalt herzustellen. Die graphische Hervorhebung der Eigennamen in den Figurengedichten betont diesen besonderen Status als Teil des Umrißbildes und des Textes.

\footnotetext{
${ }^{193}$ Kornfeld 1685, S. 72.

194 Das Gedicht wurde zur Hochzeit der Anna Dorothea von dem Busche mit Friedrich Ulrich von Münchhausen 1661 geschrieben, der Stammherr war der Vater der Braut und zu jener Zeit schon verstorben (vgl. Meyer 1982, S. 141).

${ }^{95}$ Vgl. Meyer 1982, S.139.

196 Vgl. Meyer 1982, S. 139.

197 Zu den Familienverhältnissen vgl. Bussche 1887, o.p.

${ }^{198}$ Vgl. dagegen Ernst 1986, S.15.
} 


\subsubsection{Namenposition und Textverlauf}

\subsection{Namen im Mittelpunkt des Textes}

Wie die Untersuchung der Balladen und der Umrißgedichte gezeigt hat, ist eine Besonderheit der Rezeption von Gedichttexten, daß sie aufgrund der ,künstlichen’ Begrenzungen durch die gedichtspezifischen formalen Ordnungssysteme vom Leser als ein Ganzes wahrgenommen werden. Auf der einen Seite werden die einzelnen Elemente des Textes als Textrede im Lesevorgang linear erschlossen, auf der anderen wird ein Gedichttext - zumal bei wiederholtem, ,probierendem' oder ,meditierendem' Lesen ${ }^{199}$ figural als Textkontur wahrgenommen. ${ }^{200}$ Dies ist von Leibfried als Unterscheidung von „Verlaufsgestalt“ und „Simultangestalt“ beschrieben worden. ${ }^{201}$ Neuerdings konstatieren z.B. auch Strachan und Terry: „Poems are not merely things that we read but also things that we see“, und sie sprechen von dem „visual enactment" eines Gedichts. ${ }^{202}$ Zusätzlich zur Positionierung im linearen Verlauf des Gedichts können Eigennamen daher im Gedichttext auch mit Bezug auf den Umriß des Textes positioniert werden. Daß dies nicht nur für Umrißgedichte gilt, zeigen viele Gedichte, in denen Eigennamen auffällig positioniert werden: Aufgrund ihrer semantischen Dichte und formalen Auffälligkeit eignen Gedichte sich besonders dazu, zumal wenn sich das Gedicht - etwa als Anredegedicht oder Portraitgedicht - auf einen Namenträger konzentriert. Ein Beispiel für eine solche am Textumriß und am Textinhalt orientierte zentrale Anordnung eines Eigennamens findet man in Albert Verweys Sonett Aan Zola - Na zijn toespraak tot de jury:

Uw woorden kwamen mijn gedacht ontdooien,

En't oog waarmêe de dichter waarheid ziet

Wird klaar toen't scheen of duisters sluierplooien

Weken en't leugloos licht u helder liet.

Want wel kann elk zijn zelf in't werk vermooien-

Dichter of schrijver in verhaal of lied -

Maar schoon'k $u$ beeld bespiegelte in de tooien,

Zo na als nu, ZoLA, kwaamt gij mij niet.

Uw zachtre stem, als die van den beschroomden

Die vreest dat men zien wahrheid niet verstaat, -

Uw stellger woord, als dier die wakend droomden

Dat recht iets aardsch is dat niet ondergaat, -

Zij deden mij u nu kennen en gelooven.

\footnotetext{
${ }^{199}$ Vgl. Zymner 2003, S. 156.

200 "[...] the figured poem is in the broadest sense a lyrical text (up to modern times generally also a versified text) constructed in such a way that the words - sometimes with the help of purely pictorial means form a graphic figure which in relation to the verbal utterance has both a mimetic and symbolic function." (Ernst 1986b, S. 9); vgl. zu den Begriffen ,linear' und ,figural' Ernst 1985, S. 76.

${ }^{201}$ Vgl. Leibfried 1970, S. 301 f.; vgl. auch z.B. Killy 1972, S. 57; Warning 1997, S. 22, oder Ernst 1990, S. 207.

${ }^{202}$ Strachan/Terry 2000, S. 24, S. 29.
} 
Een woord van't hart gaat al verstand te boven. ${ }^{203}$

Der Name „Zola“ ist in dem für den Verlauf eines Sonetts wichtigen letzten Vers des zweiten Quartetts positioniert, der der Konvention der Gedichtform gemäß einen formalen und inhaltlichen Wendepunkt darstellt. Der Name ist graphisch hervorgehoben und auch im Vers mittig angeordnet. Dies ermöglicht es, den Namen als label des Gedichts anzusehen. Der Eigenname erhält Titelfunktion als „thematischer Titel“. ${ }^{204}$ Hier wird der Adressat der Äußerung vor der linearen Lektüre identifiziert. Diese Funktion des Namens fällt in Verweys Sonett mit dessen Funktion im linearen Verlauf des Gedichts als emphatische erste und einzige Anrede zusammen. Der Eigenname ist also ein makrotextueller wie auch mikrotextueller Höhepunkt des Sonetts, auf den die Quartette zusteuern und dessen Position rhetorisch wie graphisch hervorgehoben wird.

Eine solche zentrale Position eines Namens kann auch über die Gedichtgrenze hinaus wirken. In der gleichen Weise wie Verwey positioniert auch Jacques Perk den Namen ,Mathilde' im Mittelpunkt eines Sonetts:

AAN MATHILDE

Wanneer de moeder van het licht weêr licht,

En voor heur goud den zwarten mist dout wijken,

Dan laat ze 'er stralen langs de bloemen strijken,

En dankbaar doet elk bloemeke zijn plicht.

Zodra de bloem de lieve zon ziet prijken,

Dan wolkt ze wierook op in wolken dicht,

En geurenmoeder wordt het moederlicht....

Ik moet, Mathilde, u aan de zon gelijken!

Gij zijt de moeder van deez' liederkrans:

Gij hebt dien met uw zonneblik geschapen

In 't zwarte hart; zoo 't glanst, 't is door úw glans.

Met uwe bloemen krans ik u de slapen,

Uw eigen schepping leg ik om uw hoofd;

Zoo zij uw naam voor eeuwiglijk geloofd!- ${ }^{205}$

\footnotetext{
203 „Deine Worte kamen, um meine Gedanken aufzutauen, / Und das Auge, mit dem der Dichter die Wahrheit sieht / Wird klar bis dem Schein die dunklen Schleiern weichen und das lügenfreie Licht Sie heller werden läßt. / Denn gut kann jeder sein Selbst im Werk beschönigen - / Dichter oder Schreiber in Erzählung oder Lied - / Aber obwohl ich Ihr Bild im Schmuck spiegelte, / So nah wie jetzt, Zola, kamt Ihr mir nicht. / Eure leisere Stimme, wie die von dem Schüchternen / Der fürchtet, daß man seine Wahrheit nicht versteht, - Euer bestimmteres Wort, wie von denen, die wachend träumten / daß Recht etwas Erzenes ist, das nicht untergeht, - / Sie machten, daß ich Euch jetzt kennen und glauben gelernt habe / Ein Wort aus dem Herzen geht über allen Verstand“; Verwey 1899, S. 7.

${ }^{204}$ Vgl. Genette 1989, 82-89.

205 „Wann immer die Mutter des Lichts Licht wurde, / Und für ihr Gold den schwarzen Nebel weichen läßt, / Dann läßt sie ihre Strahlen die Blumen entlang streifen, / Und dankbar tut jede Blume ihre Pflicht. / Sobald die Blume die liebe Sonne hervorscheinen sieht, / Dann wolkt sie wieder auf in dichten Wolken / Und Farbenmutter wurde das Mutterlicht... / Ich muß, Mathilde, Euch mit der Sonne vergleichen! / Ihr seid die Mutter dieses Liederkranzes: / Ihr habt diesen mit Eurem Sonnenblick geschaffen / Im schwarzen Herzen; wenn er glänzt, so ist dies durch Euren Glanz. / Mit Euren Blumen bekränze ich Euch den Schlaf, / Eure eigene Schöpfung lege ich um Euer Haupt; / So sei Euer Name in Ewigkeit gelobt!-“; Perk 1971, S.79.
} 
Dieses Sonett steht an dritter Stelle eines Sonettkranzes, der einer Angebeteten Perks, Mathilde Thomas, gewidmet ist. ${ }^{206}$ Zugleich handelt es sich um das erste Gedicht, in dem ihr Rufname auftaucht. Das Sonett folgt zwei Sonetten, die Anrufungen gestalten: erst anfeuernd und personifizierend an die Sonette selbst, dann an die Jungfrau Maria gerichtet. Durch diese Position des Textes im Sonettkranz sowie durch die Namennennung in der Überschrift erhält der Name ein besonderes Gewicht. Die Anrede beim Namen in der ,Mittelposition' ist besonders dazu geeignet, die Zäsur zwischen Quartetten und Terzetten zu markieren. In den nachfolgenden Sonetten ist dann das Nachlassen der Intensität zu bemerken, mit dem der Name ausgerufen oder genannt wird. Dies drückt sich darin aus, daß er an beliebiger Stelle des jeweiligen Sonetts oder auch mehrfach genannt wird. ${ }^{207}$

Die am Textbild orientierte Namenpositionierung findet sich schließlich nicht nur in kurzen und hochnormierten Gedichtformen. Berlin von Johannes R. Becher besteht aus 21 kreuzgereimten Quartetten mit jambischen sechshebigen Versen unter denen sich zahlreiche Waisen befinden. Die ersten drei Strophen beginnen anaphorisch mit „Der Süden“ (bzw. „Des Südens“) und beschreiben einen Aufbruch, die folgenden sechs Strophen lassen die Sprecher („,wir“) der Stadt Berlin immer näher kommen. Die Strophen zehn, elf und zwölf besingen dann emphatisch den ,Moloch' Berlin und heben viermal mit der Anrufung der Stadt beim Namen an:

Berlin! Du weißer Großstadt Spinnenungeheuer!

Orchester der Äonen! Feld der eisernen Schlacht!

Dein schillernder Schlangenleib ward rasselnd aufgescheuert,

Von der Geschwüre Schutt und Moder überdacht!

Berlin! Du bäumst empor dich mit der Kuppeln Faust,

Um die der Wetter Schwärme schmutzige Klumpen ballen!

Europas mattes Herz träuft in deinen Krallen!

Berlin! In dessen Brust die Brut der Fieber haust!

Berlin! Wie Donner rattert furchtbar dein Geröchel!

Die heiße Luft sich auf die schwachen Lungen drückt.

Der Menschen Schlamm umwoget deine wurmichten Knöchel.

Mit blauer Narben Kranze ist dein Haupt geschmückt! ${ }^{208}$

Die mittlere dieser drei Strophen (zugleich bildet sie die symmetrische Mitte des gesamten Gedichts, also die elfte Strophe) ist außerdem durch die Namenanrufungen eingerahmt. Die nächsten sechs Strophen beschreiben dann wieder die Situation der Sprecher, diesmal in der Stadt. Das „wir“ der sprechenden Gruppe wird zum einzelnen aus der Außenperspektive beschriebenen Propheten reduziert (Strophe 17), bevor eine apokalyptische Weissagung in den letzten drei Strophen jeweils mit „Es wird kommen der

\footnotetext{
${ }^{206}$ Vgl. dazu den Bericht und den Kommentar in Perk 1971, S. 11 und S. 316.

207 Vgl. z.B. Perk 1971, S. 82, S. 83, S. 85.

208 Pinthus 1997, S. 43-45.
} 
Tag..." beginnt. Die Bewegung auf den ,Moloch' zu und wieder vom ,Moloch' weg erzeugt einen Spannungsbogen, dessen Höhepunkt in den drei Strophen besteht, die mit der Anrufung des Namens beginnen und die die höchste Dichte und Emotionalität des Gedichtes repräsentieren. Obwohl es sich um ein langes Gedicht handelt, gestaltet Becher mit Hilfe der Anrufung beim Eigennamen eine streng symmetrische Form, die sich sowohl auf das Textbild, als auch auf den dynamischen Verlauf des Textes beziehen läßt.

Wie wir gesehen haben, bilden Eigennamen sowohl in inhaltlich orientierten als auch in formal orientierten Texten aufgrund ihrer kommunikativen Bedeutung, ihrer oft besonderen Zeichengestalt sowie ihrer inhaltlichen Dichte herausgehobene Punkte der Textdynamik. Durch ihre unsichere Bedeutungsstruktur bedürfen Eigennamen dabei der Einbettung in Kon- und Kotexte, die ihre Bedeutung festlegen oder andeuten. Je nach Bekanntheit eines verwendeten Namens wird durch die Namenverwendung für den Rezipienten nur die Tatsache evoziert, daß ein Individuum angesprochen oder benannt wird, oder es wird der semantische Hintergrund des Namens aufgerufen. In jedem Fall bildet der Name eine Referenz, die durch enzyklopädisches Vorwissen des Lesers oder durch den Text erst mit Sinn gefüllt werden kann. Die Rolle des Namens wird also stark durch eine graduelle Abstufung zwischen der völligen Unkenntnis und der vollständigen Kenntnis bestimmt, die der intendierte Leser ${ }^{209}$ vom semantischen Namenhintergrund haben kann. ${ }^{210}$ Die Eigennamenpositionierung wirkt sich damit auch entscheidend auf den restlichen strukturellen Verlauf eines Gedichts aus. Der intendierte semantische Inhalt des Eigennamens kann (oder muß) in einem Gedicht explizit oder implizit entfaltet werden. Umgekehrt können Eigennamen als Zusammenfassung vorangegangener Informationen zu einem Namenträger dienen. Schließlich können durch die Kombination mehrerer Eigennamen bedeutungsoffene ,Zonen' in ein Gedicht eingebettet werden.

\subsection{Entfaltung des Namens}

Wird ein rein innertextlich referierender Name präsentiert, besteht am Textanfang eine völlige Unkenntnis des Namenhintergrunds. Der Name steht für eine Leerstelle, die erst durch die Zeicheneigenschaften des Namens und durch den nachfolgenden Text mit Inhalt gefüllt werden kann. ${ }^{211}$ Der Leser ist reiner Namenkonsument und ordnet dem

\footnotetext{
${ }^{209}$ Unter den historischen Lesern schwankt naturgemäß die Kenntnis des Namenhintergrunds extrem. Dies gilt sowohl für berühmte Namen als auch für unbekannte Namen.

${ }^{210}$ Vgl. Tschauder 1989, S. 17.

${ }^{211}$ Vgl. Zalta 1987. Keinesfalls läßt sich von einem „Spannungsfeld zwischen der Namenbedeutung und dem, was der Leser sonst über die Figur weiß" sprechen, wie Horstmann behauptet; vgl. Horstmann 2001, S. 97. Was der Leser über den (außertextlichen) Namenträger weiß, gehört zur Namenbedeutung dazu.
} 
Namen denjenigen semantischen Hintergrund zu, den ihm der Autor als einziger Namenproduzent liefert. Er versieht das Namenszeichen abgestimmt auf die Textbotschaft nachträglich mit einem semantischen Inhalt. Ein Beispiel dafür ist Aunt Helen von T.S. Eliot:
Aunt HELEN
Miss Helen Slingsby was my maiden aunt,
And lived in a small house near a fashionable square
Cared for by servants to the number of four.
Now when she died there was a silence in heaven
And silence at her end of the street.
The shutters were drawn and the undertaker wiped his feet-
He was aware that this sort of thing had occurred before.
The dogs were handsomely provided for,
But shortly afterwards the parrot died too.
The Dresden clock continued ticking on the mantelpiece,
And the footman sat upon the dining-table
Holding the second housemaid on his knees-
Who had always been so careful while her mistress lived. ${ }^{212}$

Der fiktionale Name ist zunächst semantisch leer. Die ersten drei Verse liefern die dem Namen zuzuordnende definite description, bevor dann - eingeleitet durch die eine Narration ankündigende Interjektion ,now' - vom Tod der Tante und dessen Folgen berichtet wird. Die Beschreibung der Tante ist spärlich und zeigt den ironischen Ton, in dem der Sprecher die zerfallende Ordnung ihres Hauses betrachtet. Die Erwähnung des kleinen Haushalts mit seinen bis zu vier Dienern in der Nähe eines ,anständigen' Viertels sowie die sorgfältige vollständige Namennennung mit dem für die ,Jungfer' adäquaten Titel „Miss“ reichen, um die Stereotype der spießigen altjüngferlichen Tante aufzurufen, die abgeschieden in ihrer beschränkten eigenen Welt lebt. Dieser Initiation folgt dann der ironische Bericht darüber, wie sich diese kleinbürgerlich anständige Welt auflöst. Ex negativo läßt dies die strenge und geistig beengte Atmosphäre des Haushalts zu ,Miss Helen Slingsbys' Lebzeiten spüren. Der kleine Ausschnitt aus dem semantischen Hintergrund des Namens, der zu Anfang präsentiert wird, steht für die Gesamtaussage des Gedichts. Eliot zeichnet eine Person, die ganz in der kleinbürgerlichen Konventionalität ihres Haushaltes aufgegangen ist.

Soll der intendierte Leser in das semantische Gefüge des Textes ganz integriert werden, muß der auftretende unbekannte Name verständlich gemacht werden. Dabei können verschiedene Strategien ausgemacht werden, die den Textverlauf bestimmen.

Die einfachste Möglichkeit besteht darin, den Text von Beginn an auf einen Angeredeten auszurichten. Die Art und Weise, wie der früh im Gedicht genannte Name dabei verwendet und mit einem semantischen Inhalt angefüllt wird oder nicht, zeigt dabei,

${ }^{212}$ Vgl. Eliot 1998, S. 22; vgl. zum Werkkontext des Gedichts Mays 1994, S. 114. 
welche Funktion der Autor sich für seinen impliziten Leser vorstellt. So zeigen John Miltons Anredesonette eine Kombination aus innertextlicher Sprechaktausrichtung und gleichzeitiger Berücksichtigung eines Publikums, das das veröffentlichte Gedicht lesen soll, obwohl es mit dem Adressaten unter Umständen nicht vertraut ist. In seinem Sonett an einen Schüler Cyriack, whose grandsire... etwa gibt Milton dem Leser die nötigen Hinweise, um die Textaussage vollständig zu verstehen:
Cyriack, whose grandsire on the royal bench
Of British Themis, with no mean applause,
Pronounced, and in his volumes tought, our laws
Which others at their bar so often wrench,
Today deep thoughts resolve with me to drench
In mirth that after no repenting draws;
Let Euclid rest [...]. ${ }^{213}$

In einem langen Relativsatz wird erläutert, wie der Leser den inm unbekannten Namenträger als Cyriack Skinner identifizieren und einordnen kann. Dieser ist der Enkel Sir Edward Cokes, eines berühmten Juristen unter James I. ${ }^{214}$ Die Erläuterung des Namens ,Cyriack' spielt auf die großväterliche juristische Tätigkeit und auf die Göttin der Gerechtigkeit den ethisch-rechtsphilosophischen Aspekt des Textthemas an. In der darauf folgenden restlichen Beschreibung der Komponenten eines ,Guten Lebens' verbindet Milton das rechtlich Gute (die Befolgung der Gesetze) mit dem moralisch Guten („,solid good“) und schließlich mit dem Genuß der schönen Seiten des Lebens („cheerful hours“). ${ }^{215}$ Auf diese Weise wird aus dem Aufruf, eine Pause zu machen, ein moralischer Exkurs; aus einer scheinbaren Anweisung an einen Schüler wird eine öffentliche Aussage allgemeiner Gültigkeit. Die Erläuterungen zum Eigennamen integrieren den unbekannten Namen so in den Text, daß er vollständig bestimmt werden kann. Mit W. V. O. Quine gesprochen: Es wird aufgeschlüsselt, was ,the thing that cyriackizes' ist.

Der Adressat kann die aufwendige Erläuterung als Vorbereitung auf die Botschaft des nachfolgenden Textes - als ,Erinnerung' - verstehen. Ihm - wie dem Leser - wird bedeutet, welchen Ausschnitt aus seiner mit dem Namen verbundenen ,idealen' definite description der Sprecher meint. Er weiß dann, unter welchem Aspekt er sich betrachten soll.

In seinem zweiten Sonett an Cyriack Skinner nutzt Milton den Rufnamen dagegen lediglich zur Anrede. Das Gedicht behandelt inhaltlich nur den Sprecher selbst:

Cyriack, this three years day these eyes, though clear

To outward view, of blemish or of spot;

Bereft of light thir seeing have forgot,

\footnotetext{
${ }^{213}$ Ferguson/Salter/Stallworthy 1996, S. 379.

${ }^{214}$ Vgl. den Kommentar in Ferguson/Salter/Stallworthy 1996, S. 379.

${ }^{215}$ Ferguson/Salter/Stallworthy 1996, S. 379.
} 
Nor to thir idle orbs doth sight appear

Of Sun or Moon or Starre throughout the year,

Or man or woman. Yet I argue not

Against heavens hand or will, nor bate a jot

Of heart or hope; but still bear up and steer

Right onward. What supports me dost thou ask?

The conscience, Friend, to have lost them overply'd

In libertyes defence, my noble task,

Of which all Europe talks from side to side.

This thought might lead me through the worlds vain mask

Content though blind, had I no better guide. ${ }^{216}$

Das Publikum des publizierten Gedichts wird hier nicht eingeweiht, welchen semantischen Inhalt der Name hat, weil dieser im semantischen Gefüge des Textes lediglich die Tatsache evoziert, daß es einen konkreten Adressaten gibt. Daß diese Tatsache für die Kommunikationssituation des Sprechers wichtig ist, hebt neben der Anrede auch die rhetorische Frage im ersten Terzett des Sonetts hervor. Doch kann sich der Leser mit dem indexikalischen Hinweis auf den ,Träger des Namens Cyriack' begnügen. Denn die emphatische Anrede beim Namen gehört hier lediglich zu den Indikatoren der mündlichen und direkten face-to-face Kommunikation. Sie knüpft ein emotionales Band zwischen Sender und Empfänger, das der nachfolgenden Selbstbeschreibung des Sprechers ein persönliches Gepräge gibt. ${ }^{217}$ Milton kennzeichnet sein Sonett als intime Ansprache an einen Freund, nicht als an die Öffentlichkeit gerichtete Klage oder Rechtfertigung seines Lebens. Gleichzeitig identifiziert Milton durch die Anrede des realen Schülers und Freundes beim Rufnamen sich selbst als den Sprecher des Gedichts. Denn die perspektivierende Funktion des Namens enthält im Verhältnis zwischen Namenträger und Namenbenutzer immer auch eine Festlegung des letzteren. Dem Leser wird die Rolle des zuhörenden Dritten zugewiesen. Da die Rede innertextlich nicht an die Öffentlichkeit gerichtet ist, kann dieser den Textinhalt nicht als Adressat kritisieren. Er kann nicht fragen ,Warum erzählst Du das einer breiten Öffentlichkeit?'.

Ein berühmter oder dem Leser bekannter Name, der über den Text hinaus referiert, hat im Gegensatz zu einem rein innertextlich referierenden Namen einen breiten semantischen Hintergrund, den der Leser zumindest aktuell wissen kann. ${ }^{218}$ Er evoziert Informationen, zu denen im Gedichttext Stellung bezogen werden muß. Dies geschieht etwa in Rollengedichten, in denen mythische Figuren sprechen oder besprochen werden. Der Autor kann mögliche Erwartungen des Lesers erfüllen oder inn durch randständige, neue oder ungewöhnliche Details aus dem Hintergrund des Namens überraschen. Der

\footnotetext{
${ }^{216}$ Vgl. Milton 1931, S. 68.

217 Milton beschreibt hier, wie er mit seiner Blindheit seit ca. 1653 umgeht; vgl. Wilson 1983, S. $168 \mathrm{f}$.

${ }^{218}$ Vgl. Shawcross 1983, S. 163.
} 
Text nimmt in jedem Fall Stellung zu dem enzyklopädischen Vorwissen des Lesers. Die Informationsverteilung zu dem figurengestaltenden Eigennamen bestimmt die Struktur des weiteren Gedichts. In einem weiteren Gedicht, in dem er Shakespeare besingt, kann Milton davon ausgehen, daß der Leser keine Erläuterungen des berühmten Namens benötigt:

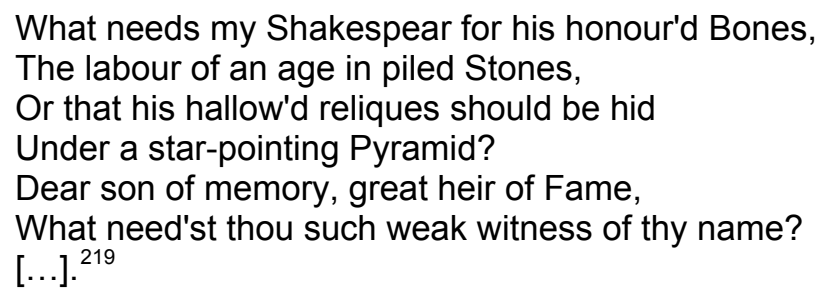

Milton geht darum einen anderen Weg der Entfaltung nicht nur des Eigennamenträgers, sondern auch des Eigennamenzeichens. Spezifiziert wird nicht der semantische Inhalt, sondern der individuelle Kommunikationswert des Namens. Die Anredefunktion des Namens und die innerfiktionale Kommunikationssituation sind durch das Possessivpronomen gekennzeichnet. Das Possessivpronomen hebt trotz der Verwendung des ,objektivierenden' und distanzierenden Eigennamens die persönliche Anrede und damit die nötige emotionale Verbindung zwischen Sprecher und Adressaten hervor. Die Kombination von Possessivpronomen und Eigennamen kennzeichnet, daß der Sprecher über eine besonders intensive Verbundenheit zum Namenträgers verfügt. Die Aussagen des Gedichts beziehen sich auf jenen Shakespeare, den Milton durch ein knowledge by acquaintance zu kennen vorgibt, das durch emotionale oder geistige Verbundenheit ermöglicht wird.

Jenseits des allgemein bekannten semantischen Inhalts eines berühmten Namens, erhält der Leser aus dem Text genau so viele Informationen zum Namenträger, wie zum Verständnis des Textes notwendig sind. ${ }^{220}$ Die Erläuterungen zu Namen in Anredefunktion geben daher nicht nur Hinweise auf den Adressaten, sondern auch auf die Position des Publikums und diejenige des impliziten Lesers, sowie auf die inhaltlichen wie funktionsbezogenen Intentionen des Sprechers.

\subsection{Namen als Zusammenfassung}

Jacques Perk, dessen Umgang mit dem Namen ,Mathilde' bereits erwähnt wurde, verwendet diesen in seinem gesamten Sonettkranz figurengestaltenden Namen im letzten Gedicht des ersten Buches als resümierenden Ausruf und Anrede seines Sonetts Scheiding (Abschied):

\footnotetext{
${ }^{219}$ Milton 1931, S. $31 \mathrm{f}$.

${ }^{220}$ Zu den Überschneidungen von realer Welt, Textwelt und ,poetischem Ich' am Beispiel Baudelaires vgl. Henry 1984, bes. S. 179-181.
} 
De voerman zwaait de zweep, ik hoor ze knallen;

De wagen rattelt langs de helling heen:

De rem knarst tegen 't weil, de schellen schallen;

De hut die haar bevat, rijst en wordt kleen:

Klein wordt de kluis, waarin de maagd verdween,

Die me als godin gedaagd is, duizendtallen

Bloesems om 't hoofd - ze is aan mijn hart ontvallen,

En 't hart, dat stierft in haar, leeft...maar alleen:

Vloeit nu gerust, gij, ingehouden tranen!

Met u moet zich de smart een uitweg banen:

Wat ware een traan, zoo daar geen ziel in trilde?

Spreekt, tranen, dan 't „varweel“, dat ik niet vinde,

Ik wilde zeggen, hoe ik haar beminde,

En alles, wat ik zeide, was: „Mathilde!“"221

Das Sonett beschreibt die Gefühle des Liebhabers beim Abschied von seiner Geliebten.

Perk gestaltet hier implizit den Unsagbarkeitstopos in der Variante der vor Emotion fehlenden Worte. ${ }^{222}$ Der Sprecher kann sein Leid und seine Liebe nicht mit Worten ausdrücken und überträgt diese Aufgabe seinen Tränen. Nur den Namen der Geliebten kann er schließlich ausrufen. Dieser stellt ein Zeichen dar, mit welchem dem Leser wie dem Sprecher nicht nur die Namenträgerin vor Augen geführt wird. Vielmehr wird in dem Ausruf des Namens die gesamte im Gedicht und sogar im gesamten Sonettenkranz gestaltete Stimmung ausgedrückt. Der Ausruf des Eigennamens am Ende dient als Zusammenfassung des Vorhergehenden und als einzig mögliche sprachliche Lösung der emotionalen Bewegtheit des Sprechers. Der Name ist hier ein Zeichen, das den Namenträger als Ganzheit und ohne beschreibende Einschränkung erfaßt.

Auf der einen Seite faßt der Name bei Perk eine Stimmung zusammen und stellt ein nicht zu objektivierendes Element dar. Auf der anderen Seite kann ein Name der objektivierenden Darstellung dienen, die in einen Gegensatz zur Subjektivität deiktischer Bezeichnungen gestellt wird:

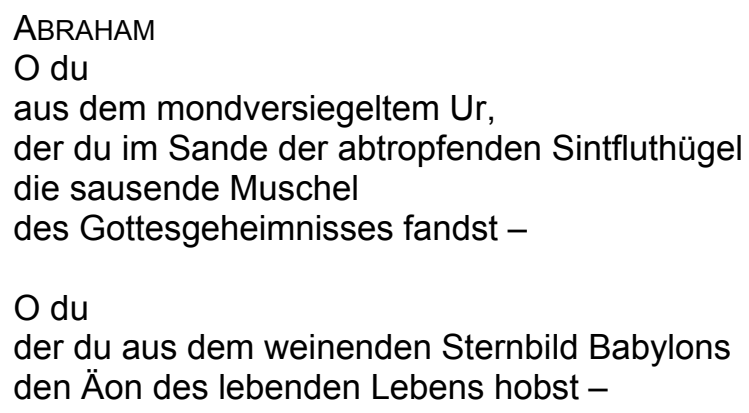

221 „Der Fuhrmann schwingt die Peitsche, ich höre sie knallen; / Der Wagen rattert den Abhang entlang: / Die Bremse knirscht gegen die Felge, die Schellen schallen; / Die Hütte, die sie enthält, erhebt sich und wird klein: / Klein wird die Klause, worin die Magd lebt, / die mir als Göttin gegeben ist, tausendfache / Blüten um das Haupt - sie ist meinem Herzen entfallen, / und das Herz, das stirbt in ihr, lebt...aber allein: / Fließt nur ruhig, Ihr, zurückgehaltene Tränen! / Mit euch muß sich der Schmerz einen Ausweg bahnen: / Was wäre eine Träne, in der keine Seele zitterte? / Sprecht, Tränen, dann das ,Lebwohl', das ich nicht finde, / Ich wollte sagen, wie ich sie liebte, / und alles, was ich sagte, war: ,Mathilde!'“; Perk 1971, S. 94.

${ }^{222}$ Vgl. Curtius 1954, S. 168 f. 
das Samenkorn des himmlischen Landmannes warfst

bis in den feurigen Abend des Heute darin die Ähre brennt.

O du

der aus Widderhörnern die neuen Jahrtausende geblasen

bis die Weltenecken sich bogen im Heimwehlaut -

O du

der die Sehnsucht an den Horizont der unsichtbaren Himmel heftete

die Engel in die Länder der Nacht berief -

die Beete der Träume bereitete

für die Schar der sich übersteigenden Propheten -

O du

aus dessen ahnendem Blut sich das Schmetterlingswort Seele entpuppte

der auffliegende Wegweiser ins Ungesicherte

hin -

O du

aus Chaldäas Sterndeuterhafen

unruhige Welle, die in unseren Adern

noch immer sucht voll Tränen ihr Meer.

O Abraham,

die Uhren aller Zeiten

die Sonnen und monddurchleuchteten

hast du auf Ewigkeit gestellt -

O dein wunderbrennender Äon,

den wir mit unseren Leibern ans Ende bringen müssen -

dort, wo alle Reife hinfällt! ${ }^{223}$

In Nelly Sachs' Portraitgedicht Abraham bildet der Name in figurengestaltender Funktion die Überschrift, durch die die Referenz der nachfolgenden Personalpronomina sichergestellt wird. Die ersten sechs Abschnitte des Gedichts beginnen mit der Anrede „O $d u$ " in einem eigenen Vers. Der vorletzte und der letzte Abschnitt dagegen beginnen mit: „O Abraham" und "O dein wunderbrennender Äon“. Diese Variation erzeugt einen Spannungsbogen, der dem einer Erzählung mit einem späten Spannungshöhepunkt und einem schnellen Abschluß entspricht.

Die ersten sechs Abschnitte stellen Ausrufe dar. Das Personalpronomen wird in den einzelnen Gedichtabschnitten in Relativsätzen mit Abschnitten einer möglichen definite description Abrahams versehen. ,Definite description' ist zwar eine stark vereinfachende Benennung der Dinge, die Nelly Sachs beschreibt, da sie die Kennzeichnungen Abraham und seine Taten hochartifiziell, symbolisch überhöht und metaphernreich präsentieren. Wichtig ist für uns jedoch nur, daß Nelly Sachs Relativsätze verwendet, die das Pronomen ergänzen. Diese lassen den Leser die gegebenen Informationen als thematische Information verstehen und daher auf eine weitergehende rhematische Information

${ }^{223}$ Sachs 1961, S. 88 f. 
warten. ${ }^{224}$ An deren Stelle steht aber zumeist nur der ,sprachlose' Gedankenstrich. Das ,du' bezieht sich jeweils nur auf den genannten Ausschnitt aus der potentiell unendlichen definite description Abrahams. Der siebte Abschnitt erst weicht in dieser Hinsicht formal ab und formuliert - mit der Anrede beim Namen ,Abraham' beginnend - einen assertorischen Satz, der eine rhematische Information zu bieten scheint und gleichzeitig das thematische Zentrum des Textes nennt: die Zeit, die auch schon in den vorherigen ,definite descriptions' benannt wurde: „O Abraham, / die Uhren aller Zeiten / die sonnenund monddurchleuchteten / hast du auf Ewigkeit gestellt -“ Auch dieser siebte Abschnitt endet mit einem Gedankenstrich. Dennoch unterscheidet sich dieser zentrale mit einem Eigennamen beginnende Abschnitt von den übrigen des Gedichts. Hier formuliert Nelly Sachs die einzige übergeordnete und zusammenfassende Aussage über Abraham. Die Anrufung beim Namen initiiert einen Wendepunkt. Die vertrauliche Anrufung mit dem Personalpronomen wird abgebrochen. Der Namenträger wird auf dem dynamischen Höhepunkt des Gedichts das erste Mal von einer identifizierenden und ,objektivierenden' Sichtweise erfaßt. Über ihn wird nur an dieser Stelle formal eine rhematische Aussage gemacht, die die vorherigen Beschreibungen der Taten Abrahams zusammenfaßt. Der Eigenname signalisiert, daß der Sprecher an dieser Stelle die ganze durch die vorherigen Beschreibungen umrissene Person meint, während sich das ,du' in den vorangegangenen Abschnitten nur auf die jeweils diskursiv im Relativsatz genannten Eigenschaften bezieht.

Der achte und letzte Abschnitt fällt dann wieder zurück in einen Ausruf mit angebundenem Relativsatz. Der Ausruf zieht eine Folgerung aus den vorherigen Strophen: Wir Menschen stehen in der ewig verpflichtenden Nachfolge Abrahams. Hier wird die Gegenwart des Sprechers und der Leser in den Blick genommen, nicht mehr die Beschreibung der Taten Abrahams.

Wenn der Eigenname wie bei Perk und bei Nelly Sachs vorher gegebene Informationen zusammenfaßt, so kann er damit auch die Verrätselung ${ }^{225}$ einer definite description auflösen. Bei Oskar Wilde ist diese Technik oft zu finden - z.B. in A Vision:

\footnotetext{
Two crownèd Kings, and One that stood alone

With no green weight of laurels round his head,

But with sad eyes as one uncomforted,

And wearied with man's never-ceasing moan

For sins no bleating victim can atone,

And sweet long lips with tears and kisses fed.

Girt was he in a garment black and red,

And at his feet I marked a broken stone
}

\footnotetext{
${ }^{224}$ Zu den Termini ,rhematisch' und ,thematisch' vgl. Heinemann/Viehweger 1991, S. 32-34.

${ }^{225} \mathrm{Vgl}$. Wittstruck 1987, S. 94 f.
} 
Which sent up lilies, dove-like, to his knees.

Now at their sight, my heart being lit with flame

I cried to Beatricé, "Who are these?»

And she made answer, knowing well each name,

»/Eschylos first, the second Sophokles,

And last (wide stream of tears!) Euripides. ${ }^{226}$

Oskar Wildes Sonett enthält eine mehrstufige Verrätselung. Zunächst wird nur die Beschreibung dreier Personen gegeben, ohne daß der Sprecher identifiziert würde. Erst die Anrede eines ,lyrischen Du' beim Namen ,Beatrice' am Ende des ersten Terzetts enthüllt den Kontext des Danteschen Werkes und damit das Jenseits als den Schauplatz der Vision. ${ }^{227}$

Erst im zweiten Terzett werden dann die Namen der beschriebenen Personen genannt. Dabei achtet Wilde sorgfältig darauf, daß Euripides, dem fast die gesamte vorhergehende Beschreibung gilt, getrennt von den beiden anderen Dichtern als letzter genannt wird. Die scheinbare Hierarchie der Beschreibung - zwei geehrte ,Könige' stehen neben einem ungekrönten und traurigen Mann - wird in der Anteilnahme des Sprechers und seines Gegenübers, die sich in der Sequenz der Namennennung ausdrückt, umgekehrt: Euripides ist unter den drei Tragikern der ,tragischste', so wie Aristoteles inn einschätzt, und hat gleichzeitig das ,tragischste' Schicksal zu erleiden. ${ }^{228}$ In inm wird die Biographie mit dem Werk zu einer Einheit verschmolzen. Er hat daher die größte Sympathie des Sprechers und Beatrices. Die auf eine Namenpointe ausgerichtete Struktur des Gedichts ist offenkundig, da der Leser buchstäblich bis zum letzten Wort des Gedichts warten muß, bevor er die Identifikation der definite description erfährt.

Schließlich kann ein überraschend auftretender Eigenname das Gedicht gänzlich neu perspektivieren. Der Name führt zu einer Neubewertung der im Gedicht gegebenen definite descriptions. Die besondere Funktionsweise eines Eigennamens liegt in diesem Fall darin, daß die unter Umständen sehr weiten Kontexte, die de Eigenname autonom in das Gedicht integriert, mit dem Inhalt des Gedichts in einen Zusammenhang gebracht werden. Der Name in der Endposition kann in diesem Fall dem Gedicht eine Wendung geben:

MASADA

Töpfe

gekittet

aus unsterblichen Scherben

${ }^{226}$ Wilde 2000, S. 32; vgl. auch den Kommentar in Wilde 2000, S. 232 f.

227 Diese Identifikation des ,Du' fehlt noch in der Erstpublikation; vgl. den Kommentar in Wilde 2000 , S. 232.

${ }^{228}$ Vgl. Aristoteles 19821453 a29; Euripides „war nicht vom Erfolg verwöhnt“ (vgl. Zimmermann 1997, S. 254). 
Eine Sandale

ein Lederbeutel mit Salz

ärmlicher Halsschmuck

Reste von Feigen

Getreide

verfärbten Schriftpergamenten

Am modernsten

die Kinderknochen

und Schädel dazwischen

Zöpfe

noch nicht einmal grau

mit etwas Kopfhaut

Nicht tausendneunhundert Jahre

nur zwanzig Jahre

nur Auschwitz ${ }^{229}$

Die zunächst scheinbar nur zur 1965 ausgegrabenen Festung Masada passende definite description, die der Text liefert, wird im Nachhinein durch den zunächst aus einem vollkommen anderen Kontext stammenden Namen ,Auschwitz' einer Revision unterworfen. Der Sprecher beginnt mit einer scheinbar harmlosen Beschreibung ,archäologischen' Charakters der Utensilien, die sich im Wüstensand erhalten haben. Zwar beschreibt Fried hier einen Ort, an dem Juden ermordet bzw. in den Tod getrieben wurden. Durch die Betonung archäologischer Funde wird dieses Ereignis aber sehr weit weggerückt. Mit der Phrase „am modernsten“ deutet er die Wendung zur Gegenwart an, wenn er die Überreste getöteter Menschen beschreibt. Doch erst der Name am Ende des Gedichts deckt die Modernität auf, die der Sprecher hier zu entdecken meint. Der Eigenname am Ende des Gedichts gibt als Chiffre für das jüdische Leiden im Holocaust dem gesamten Text eine Wendung, die ein Wiederlesen des Textes unter einem neuen Gesichtspunkt erfordert. Denn der Name ,Auschwitz' dient als Zusammenfassung der vorher gegebenen definite description, die erst nur eine Entfaltung des in der Überschrift genannten „Masada“ zu sein schien.

\subsection{Namenaufzählungen}

Die auch als ,koordinierende Häufung' bezeichnete enumeratio ist allgemein eine Form des ornatus und dient nach den Regeln der Rhetorik hauptsächlich der affektischen Beeinflussung des Publikums. ${ }^{230}$ Anders als bei Wittstrucks Analyse mittelalterlicher Namenkataloge soll hier zwischen Aufzählungen von Namen und Namenkatalogen unterschieden werden. Namenkataloge bestehen aus der ununterbrochenen Aneinanderreihung nur gleichartiger Elemente: z.B. ,Klaus, Peter, Fritz und Grete'. Namenaufzählun-

\footnotetext{
${ }^{229}$ Fried 1983, S. 23.

${ }^{230}$ Vgl. Wittstruck 1987, S. 356.
} 
gen dagegen bestehen aus Satzreihungen oder Gliedsatzreihungen, deren Elemente jeweils einen oder mehrere Namen enthalten: ,Klaus ging nach Haus, Peter kaufte ein, Fritz ging um die Ecke und Grete langweilte sich'.

In Namenaufzählungen wird der Ablauf des Gedichts von einer Namenfolge bestimmt. Das Gedicht schreitet gewissermaßen von Name zu Name voran. Das Besondere einer Namenaufzählung ist dabei, daß der für die Textaussage und Textfunktion bedeutende Ausschnitt aus der definite description des Namenträgers auf engstem Raum - zumeist nur in einem Satz - gegeben wird. In dem Nebeneinander von Eigenname und Beschreibung wird eine Aufteilung der Funktionen deutlich: Der (unbekannte) Eigenname dient dazu, den Namenträger zu konstituieren. Die den Namen begleitende Beschreibung mit Kennzeichnungen dient dazu, den „(kon-)textsensitiven“ Namen für den Leser aufzuschlüsseln. ${ }^{231}$ Aufgebaut werden auf diesem Wege Exempel, wie das ,exemplaGedicht' Goethes mit dem bezeichnenden Titel Musterbilder zu Beginn seines WestÖstlicher Divan zeigt:

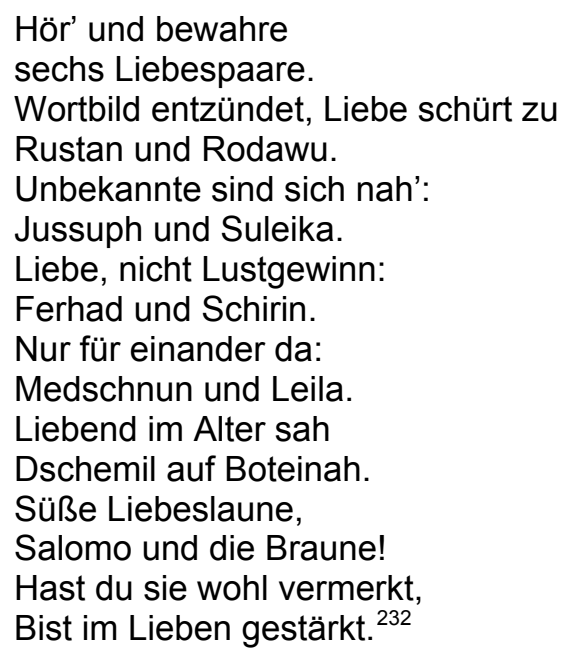

Die Namenaufzählung, mit der Goethe Schulmerkverse imitiert, versieht die figurenkonstituierenden Namen mit einem eindeutigen semantischen Hintergrund. Als Gesamtaufzählung ergeben die Namen und ihre Kennzeichnungen eine Reihe von Einzelschicksalen, die sich zu einem Panorama zusammenfügen. So gestaltet Goethe sehr bewußt einen Ablauf der immer ,reiferen' Liebe. Er beginnt mit der an einer Nebensächlichkeit, nämlich dem Namenszeichen, entzündeten Leidenschaft, geht über zur ,spontanen' Nähe, der ,Liebe auf den ersten Blick', erwähnt dann die nicht nur der Lust dienende ,höhere Liebe', die Selbstgenügsamkeit der vertrauten Liebenden, schließlich die Liebe im Alter und den ,zweiten Frühling' des Weisen (Salomo). Auf diese Weise gestalten die einzelnen Exempla in der Aufzählung einen Lebenslauf der Liebe.

\footnotetext{
${ }^{231}$ Vgl. Kalverkämper 1994, S. 210-212; vgl. Everett 2000, S. 46-55.

232 Goethe 1994, S. 27.
} 
Betrachten wir zwei weitere Beispiele für diesen Umgang mit Namenaufzählungen:

\begin{abstract}
NACHSATZ
Und daß du nicht ratlos wirst, wie Hanne Riepel, der Belesene: der einsam und schwatzhaft wie eine Drossel geworden ist! Und daß du nicht eitel wirst, wie olle Michael, der Gerechte: der die Erde kennt, und den die Sonne nicht blendet!

Und daß du nicht gerissener wirst von Tag zu Tag, wie Jub: der den Glauben verloren hat, und der wie ein Rabe klaut! Und daß du nicht schlau wirst, wie Pippe Brand - der Jüngere: der zur Nacht aufsteht, und der von den Frauen übel redet!

Und daß du nicht gemein wirst, wie Zelle, der Verworfene. Nicht wie Mike, der Einäugige. Nicht wie Jule, der Lahme. Und daß du nicht frech wirst, wie Jesse, der Nachsichtige.

Wie im Dezember der Schnee ist, möge also dein Verstand sein. Fällt Unruhe in dein Gemüt, befrage die Natur und sei still.

Arbeite mit den Händen, liebe deinen Nächsten, werde stark. ${ }^{233}$
\end{abstract}

Jesse Thoor schreibt mit seinem Sonett einen Segenswunsch, vielleicht an sich selbst, vielleicht an den Leser. Seine Wünsche kommen größtenteils in Betrachtungen von Personen zum Ausdruck, die etwas falsch machen. Dabei verwendet Thoor gezielt Übernamen, die dem Leser publizierter Gedichte unbekannt sein dürften. In den sie begleitenden Sätzen finden sich zunächst Kennzeichnungen der verschiedenen Möglichkeiten, vom ,Guten Leben' abzukommen: die Resignation, die Überheblichkeit, die Gewissenlosigkeit, die Mißgunst und schließlich die Gemeinheit. In diesem letzten Fall treten drei Exempla auf, die zusätzlich durch Epitheta gekennzeichnet sind. Im ersten Terzett wird die Aufzählung so eng, daß sie beinahe zum Katalog von Eigennamen wird. Thoor trennt hier die für die Aufzählung relevante Beschreibung der Exempla (,gemein“) von der differentia specifica. Die differenzierenden Kennzeichnungen, die auch Beinamen sein können: „der Verworfene“, „Einäugige“ oder „Lahme“, evozieren das Dekor der Lumpen- und Vagabundenwelt, das den generellen Hintergrund für die Gedichte Thoors bildet. Schließlich nennt Thoor sich selbst beim Rufnamen. Er bindet dadurch die Textwelt eng an sein biographisches Umfeld. Gleichzeitig driften in diesem Fall die differentia und die relevante Beschreibung am weitesten auseinander, da rätselhaft bleibt, warum Nachsichtigkeit zu Frechheit führen soll.

LA VIOLENCIA DE LAS HORAS

Todos han muerto

Murió doña Antonia, la ronca, que hacía pan barato en el burgo.

Murió el cura Santiago, a quien placía le saludasen los jóvenes y las mozas, respondiéndoles a todos, indistintamente: "Buenos días, José! Buenos días María!"

${ }^{233}$ Thoor 1956, S.81; ,Nachsatz' heißen bei Jesse Thoor auch durchaus eigenständige Gedichte; vgl. Marnau in Thoor 1956, S. 147. 
Murió aquella joven rubia, Carlota, dejando un hijito de meses, que luego también murió, a los ocho dias de la madre.

Murió mi tía Albina,que solía tiempos y modos de heredad, en tanto cosía en los corredores, para Isidora, la criada de oficio, la honrosísima mujer.

Murió un viejo tuerto, su nombre no recuerdo, pero dormía al sol de la mañana, sentado ante la puerta del hojalatero de la esquina.

Murió Rayo, el perro de mi altura, herido de un balazo de no se sabe quién.

Murió Lucas, mi cuñado en la paz de las cinturas, de quién me acuerdo cuando llueve y no hay nadie en mi experiencia.

Murió en mi revólver mi madre, en mi puño mi hermana y mi hermano en mi víscera sangrienta, los tres ligados por un género triste de tristeza, en el mes de agosto de años sucesivos.

Murió el músico Méndez, alto y muy borracho, que solfeaba en su clarinete tocatas melancólicas, a cuyo articulado se dormían las gallinas de mi barrio, mucho antes de que el sol se fuese.

Murió mi eternidad y estoy velándola. ${ }^{234}$

Auch César Vallejo kombiniert unbekannte Namen - diesmal sind es Rufnamen gestorbener Menschen - mit einer kurzen Kennzeichnung. Regelmäßiger als Thoor benutzt Vallejo die Kombination aus einer den Namenträger klassifizierenden differentia specifica und gedichtrelevanten Kennzeichnungen. Die den Namen beigegebenen Klassifikationen lassen ein breites Panorama einer Gesellschaft erscheinen: Männer, Frauen, Alte, Junge, ein Säugling, ein Priester, sogar ein Hund. Die Aufzählung beginnt bei namentlich genannten Personen und geht sich verdichtend über zu nicht mehr namentlich genannten Verwandten des Sprechers. Am Ende wird wieder ein dem Sprecher nicht verwandter Mensch geschildert. Vallejo kehrt damit an den Beginn seines Textes zurück.

Die Kennzeichnungen insgesamt sind weniger darauf ausgerichtet, einzelne Figuren als dazu das Panorama einer friedlichen Welt zu entwerfen. Symbolische Handlungen wie Brot backen und Musik machen, betont harmlose, wenn auch unnütze Gewohnheiten (betrunken sein, in der Sonne schlafen) sowie alltägliche Arbeiten lassen eine friedliche Alltagswelt entstehen, in die der Tod umfassend und gewaltsam einbricht. Wenn der Sprecher am Ende beklagt, daß ,seine Ewigkeit' gestorben sei, so meint er weniger die

234 „DIE GeWALt DER STUNDEN / Alle sind gestorben / Es starb Frau Antonia, die heisere, die billiges Brot buk. / Es starb der Priester Santiago, dem es Freude machte, daß ihn die Jungen grüßten und die Mädchen, während er allen unterschiedslos antwortete: ,Guten Tag, José! Guten Tag María!' / Es starb jene blonde junge Frau, Carlota, die ein Monate altes Kindlein hinterließ, das dann auch starb, acht Tage nach der Mutter. / Es starb meine Tante Albina, die vererbte Zeiten und Sitten pflegte, indem sie in den Gängen nähte, für Isodora, die Büroangestellte, die hochehrenvolle Frau. / Es starb ein krummer Alter, seinen Namen erinnere ich nicht, aber er schlief in der Morgensonne, vor der Tür des Klempners um die Ecke sitzend. / Es starb Rayo, der Hund von meiner Größe, verwundet durch einen Schuß von man weiß nicht wem. / Es starb Lucas, mein Schwager im Frieden der Gürtel, an den ich mich erinnere, wenn es regnet und es niemanden in meinem Erleben gibt. / Es starb in meinem Revolver meine Mutter, in meiner Faust meine Schwester und mein Bruder in meinen blutigen Eingeweiden, die / drei verbunden durch eine traurige Art der Traurigkeit, im Monat August aufeinander folgender Jahre. / Es starb der Musiker Méndez, groß und sehr betrunken, der auf seiner Klarinete melancholische Toccaten übte, bei / dessen Spielweise die Hühner in meinem Viertel einschliefen, viel früher als der Sonnenuntergang. / Es starb meine Ewigkeit und ich bin dabei, sie zu bewachen“; Vallejo 1996, S. 337. 
Personen, als das, was sie gemeinsam in ihrem Alltag ausdrückten: eine einfache, harmlose und wohlwollende Gesellschaft. ${ }^{235}$

Aufzählungen von Thoor und Vallejo benutzen die Reihung von Personenbeschreibungen, um eine fiktive oder reale Welt zu evozieren. Die genannten exemplarischen Namen und Fälle stehen dabei für einen umfassenden Kontext, der durch die definite description gestaltet wird. Die Verwendung unbekannter Namen ermöglicht die freie Gestaltung nach den Vorgaben dieser Textfunktion. Da Eigennamen für eine potentiell unbegrenzte und nicht eindeutige Menge von Informationen stehen, gibt der jeweilige Sprecher eine funktional begrenzte Menge von Informationen, die den Textinhalt konstituiert und den semantischen Hintergrund der unbekannten Eigennamen eindeutig macht. Die Sprecher genügen dabei durch die Namenangabe der Illusionierung sowohl in bezug auf die Ganzheit der dargestellten Welt, als auch auf den dargestellten Diskurs. Die Verwendung ,privater' Namen stützt zudem die Suggestion persönlicher Erfahrung. Die Eigennamen verweisen auf einen näheren und privaten Umgang mit den Namenträgern. Sie stehen für die persönliche Lebenswelt und das unmittelbare Umfeld des Autors. Verstärkt wird dieser Eindruck bei Vallejo noch durch die Verwandtschaftsbezeichnungen.

\subsection{Namenkataloge}

In Namenaufzählungen und einzelnen Namennennungen in Gedichten wird der Eigenname fast immer auf die eine oder andere Weise mit einem partiellen semantischen Hintergrund versehen. Der Leser erhält diese Information als Orientierung über den verwendeten Eigennamen und über jenen Ausschnitt aus dem semantischen Hintergrund des Namens, den der Sprecher für relevant hält. Anders sieht dies bei Namenkatalogen aus, die sich vor allem dadurch auszeichnen, daß kein oder kaum ein semantischer Hintergrund explizit angeboten wird.

Anhand einer Aufzählung von Autoren, die der Sprecher gelesen hat, stellt E.L. Masters in Immanuel Ehrenhardt den geistigen Werdegang eines philosophisch Dilettierenden dar. Die Dichte der diskursiv genannten Eigennamen spiegelt den immer größer werdenden Lesehunger. Der Sprecher drückt aus, daß er die Bücher besinnungslos verschlingt:

I began with Sir William Hamilton's lectures.

Then studied Dugald Stewart,

And then John Locke on the Understanding,

\footnotetext{
${ }^{235}$ Biographisch bezieht Vallejo sich vermutlich auf die Straßenkämpfe in Peru im August 1920, in die er involviert war; vgl. die Einleitung in Vallejo 1996, S.83. Zur Rolle der Enumeration für das Opfergedenken vgl. Mainberger 2003, S. 278-281.
} 
And then Descartes, Fichte and Schelling,

Kant and then Schopenhauer-

Books I borrowed from old Judge Somers ${ }^{236}$.

All read with rapturous industry,

$[\ldots] .{ }^{237}$

Am Ende des Gedichts wird ein amerikanischer Naturalist den Idealisten entgegengestellt. So wie die ersten zwei bis drei Namen am Beginn des Gedichts wird dieser Name wiederum von den übrigen durch den restlichen Text getrennt. Es handelt sich wieder um einen Autor, der nicht rasend schnell, sondern mit Bewußtsein gelesen wird:

All through the soul of William Jones

Who showed me a letter of John Muir. ${ }^{238}$

Bei Namenaufzählungen werden Eigennamen mit Kennzeichnungen kombiniert, die den für die Textaussage relevanten semantischen Hintergrund benennen. Einzelne Namen besitzen aber zumeist isoliert einen großen semantischen Inhalt, der die Textstruktur erheblich beeinflußt. Werden in einem Gedicht mehrere Namen unkommentiert nebeneinander gestellt, so bilden sich aus den semantischen Potentialen der Eigennamen implizite Bedeutungsgeflechte, die in einem Text eine eigene Dynamik entwickeln können.

Die Reihung von mindestens drei ${ }^{239}$ partiell gleichartigen Elementen ist als rhetorische Figur der adiectio oder enumeratio etabliert. Kataloge können einerseits als Einheit gesehen werden, die eine allen Elementen gemeinsame Kategorie repräsentiert. Sie können andererseits als Menge einzelner Elemente wahrgenommen werden. ${ }^{240}$ Kataloge in diesem Sinn zeigen zwei Tendenzen:

Erstens suggerieren sie oft eine Überfülle an Elementen, die noch über die benannte Mannigfaltigkeit hinausgeht. Signale der Unvollständigkeit wie „usw." oder „sampt andern“241, Einleitungen des Katalogs oder die Pluralbildung bei Appellativkatalogen deuten darauf hin, daß die gewählte Reihung für eine noch größere Menge steht. ${ }^{242}$ Katalog und Aufzählung weisen zumeist über sich selbst hinaus.

Zweitens können mittels Katalogen eine breite Informationsmenge und vielfältige Verhältnisse auf engem Raum dargestellt werden. Die Kataloge dienen der semantischen Verdichtung. ${ }^{243}$ Gleichzeitig regen die Elemente eines Katalogs aufgrund ihrer Seman-

\footnotetext{
${ }^{236}$ Einer anderen fiktiven Figur Spoon Rivers.

${ }^{237}$ Masters 1992, S. 304.

${ }^{238}$ Masters 1992, S. 304.

${ }^{239}$ Wittstrucks Argument, daß Eigennamenpaare eine besondere Verhältnisstruktur hätten (Wittstruck 1987, 357), trifft auf die hier vorliegenden Beispielfälle nicht zu. Auch drei oder mehr Eigennamen können in solchem Verhältnis stehen.

${ }^{240}$ Vgl. z.B. Schumann 1942.

${ }^{241}$ Z.B. Kelletat 1986, S. 195.

${ }^{242}$ Vgl. auch Lausberg 1963, S. 32 (§ 53,2b).

${ }^{243}$ Vgl. zur ,Raffung' in Lyrik Hühn/Schönert 2002, S. 302.
} 
tik, der mit den Gegenständen oder Wörtern verbundenen Assoziationen sowie aufgrund ihrer Zeichenstruktur oft nicht explizit genannte Verbindungen untereinander an. ${ }^{244}$

Im einfachsten Fall ,summieren' Namenkataloge als schließender oder eröffnender Teil den Gedichtinhalt. Als eröffnendes Element funktionieren Eigennamenkataloge wie einzelne Namen in Anfangsposition. ${ }^{245}$ Durch gemeinhin unbekannte Namenträger werden dem Leser zunächst weitgehend leere ,label' angeboten, die dann in den folgenden Strophen mit einem Sinn gefüllt werden. Ein Beispiel hierfür bietet die erste Strophe aus Georg Greflingers Die er geliebet:

Candida / Fillis / Ramia / Rosina /

Dido / Johanna / Fides / Catharina /

Leßbia / Dorinde / Melusina / Stella /

ELJSABELLA. ${ }^{246}$

Der Namenkatalog in der ersten Strophe ist strukturierendes Thema des Gedichtes: Jeweils eine Strophe beginnt mit einem der Stereotypennamen und entfaltet einen Abschnitt aus dem reichen Liebesleben des Sprechersubjekts. Ein solcher Eigennamenkatalog faßt den nachfolgenden Gedichtverlauf zusammen und eröffnet zugleich einen Namenraum. So verwendet Greflinger unter anderem Stereotypennamen, durch die er das Thema der ,leichtfertigen und flüchtigen Liebe' in seinem Gedicht schon andeutet. Ein Gedicht Edwin Bormanns enthält einen Namenkatalog, der diese Funktion, einen Namenraum zu eröffnen, deutlich macht: Kinderszene. Das Gedicht Bormanns versucht eine poetische Widerlegung antisemitischer Vorurteile. Es beginnt mit einer Aufzählung der Gäste eines Kindergeburtstags:

Morgen zum Geburtstagsfeste

Lädt sich Käthchen kleine Gäste:

Anni Hoffmann, Suse Beyer,

Minchen Walther, Doris Schreier,

Evchen Müller, Elsa Strauch-“

$[\ldots] .{ }^{247}$

Die Namen eröffnen den Namenraum, in dem sich die dargestellten Figuren bewegen: es sind typisch deutsche Frauennamen, es sind Namen von Kindern, wie der häufig verwendete Diminutiv zeigt. Bormanns Sprecherin ist, wie der zweite Abschnitt des Gedichts zeigt, selbst ein Kind. Ein perspektivischer Bruch läßt dabei die mit dem Gedicht verfolgte Intention deutlich werden: Durch die für ein Kindergespräch ungewöhnliche Nennung von Ruf- und Familiennamen macht der Autor deutlich, daß es sich um nicht-

\footnotetext{
${ }^{244}$ Vgl. auch Horstmann 2001, S. 104.

${ }^{245}$ Vgl. Mainberger 2003, S. 255.

${ }^{246}$ Wagenknecht 2001, S. 150.

${ }^{247}$ Vgl. Stenzel 1991.
} 
jüdische Namen handelt. Dies wird dem Leser erst dann klar, wenn er im Anschluß an die von uns zitierte Stelle den Namen des einen Mädchens liest, das ausgeschlossen werden soll: ,Rebecca Silberstein'. Sie wird vom unschuldig fragenden Mädchen (dem guten Geist des Gedichts) als „Rebekkchen“ eingeführt und von dem vorurteilsbehafteten ,Käthchen' als „Rebecca Silberstein“ distanziert ${ }^{248}$ und mit überdeutlichem sortalen Prädikat \{jüdisch\} des Ruf- und Familiennamens bezeichnet. ${ }^{249}$ Der Namenkatalog enthüllt so im Nachhinein seinen exklusiven Charakter und das von allen darin enthaltenen Namen exemplifizierte sortale Prädikat \{nicht-jüdisch\}. Der Katalog eröffnet damit einen Namenraum, in dem sich ,Käthchen' bewegt bzw. bewegen will.

Weitere Funktionen von Namenkatalogen hat Wittstruck am Beispiel der Namenkataloge in Oswalds von Wolkenstein Gedichten mit rhetorischen Kategorien beschrieben: Namenkataloge können der amplificatio dienen, wobei eine Reihe von Individuen durch das zuletzt Angesprochene übertroffen wird. ${ }^{250}$ Ein neuhochdeutsches Beispiel hierfür ist wiederum Georg Greflingers Die er geliebet, in dem der Sprecher nach der bereits zitierten ersten Strophe fortfährt:

\section{Diese benannte hatten mich besessen / Diese benannte bleiben mir vergessen / Welche vor allen noch ergetzt / ergetzte / Stehet zu letzte. ${ }^{251}$}

Des weiteren können Kataloge eine percursio darstellen, das heißt eine raffende Darstellung von Handlungsabläufen. ${ }^{252}$ Harsdörffers Lobgesang Dem Hoch-Wohlgebornen HERRN CARL GUSTAV WRANGEL USW. rafft mit Orts- und Flußnamen in der dritten Strophe eine Reihe von militärischen Siegen des schwedischen Reichsmarschalls, dessen Heldentaten den Stoff des Gedichtes ausmachen:

Brix / Doeplitz und Hoexter / Stadtbergen / Westphalen / Amoeneburg / Hessen / Rhein / Weser und Mayn / samt Bregnitz / erkennen besieget zu seyn / Von Wrangelischer Stuecke behagleten Stralen. ${ }^{253}$

Schließlich können Namenkataloge zur evidentia beitragen, indem sie das Dargestellte (wieder auf engem Raume) spezifizieren. Ein einfacher Fall ist z.B. der kleine Katalog Simon Dachs in Sehnliche Klage usw:

\footnotetext{
Was muß ich über Ohnmacht klagen?

Was lässt der Durst mir selten Ruh?

Die Freunde werden hingetragen,
}

\footnotetext{
${ }^{248}$ Vgl. dazu Stenzel 1991.

${ }^{249}$ Vgl. Bering 1996, S. 1307.

250 Vgl. Wittstruck 1987, $361 \mathrm{ff}$.

251 Wagenknecht 2001, S. 150.

252 Vgl. Wittstruck 1987, 376 ff.; vgl. Mainberger 2003, S. 251.

${ }^{253}$ Meid 1980, S. 152.
} 
Ich leb' halb tod noch immer zu.

Blum, Ribou, Roberthin sampt andern

Wo sind sie? wer kennt jhren Pfad?

Sie haben dahin müssen wandern

Wo Stille stets die Herrschaft hat. ${ }^{254}$

Hier werden die ,Freunde' durch deren Familiennamen näher spezifiziert und zur Erinnerung auch überprüfbar identifiziert. Das ,sampt andern' deutet die Offenheit dieses kleinen Katalogs an.

Namenkataloge können ein geordnetes Ganzes darstellen. In Namenkatalogen, die durch die entsprechenden rhetorischen Schemata der enumeratio geordnet sind, ist das Verhältnis zwischen den einzelnen Elementen des Katalogs in den meisten Fällen eindeutig. Diese geordnete Struktur kann auch durch die Anordnung der Namenzeichen hergestellt werden. Das gängige rhetorische Schema ist in diesem Fall die Anordnung nach dem ,Gesetz der wachsenden Glieder' des ordo naturalis ${ }^{255}$ oder ihrer (,artifiziellen') Umkehrung ${ }^{256}$, wie etwa im Falle der Aufzählung amerikanischer Staatsmänner in E.L. Masters Rebecca Wilson: „[...] Through which great figures passed like hurrying horsemen: Washington, Jefferson, Jackson, Webster, Clay." ${ }^{257}$

\subsection{Kulturelle Namenfelder}

Ein bekannter Eigenname ruft einen Kontext auf, zu dem weitere Namen gehören können. Daher kann ein solches ,kulturelles Namenfeld', in dem ein Name steht, den Textaufbau bestimmen. ${ }^{258}$ Die Namen eines kulturellen Namenfeldes sind nicht durch sprachliches, sondern durch enzyklopädisches Wissen gekoppelt: Tauchen Namen wie ,Romeo', ,David', ,Abaelard' oder ,Max' auf, wird sie der ,kultivierte Sprecher' sofort mit ,Julia', ,Goliath', ,Heloise' und ,Moritz' zu Namenpaaren ergänzen können. ${ }^{259}$ Ein kulturelles Namenfeld ist durch die mögliche Welt, der die Namenträger angehören, geordnet. Das Verhältnis der Namenträger, das Teil der umfassenden definite description eines Eigennamens ist, strukturiert die im Namenfeld vorkommenden Namen. Es gibt zudem in jeder möglichen Welt ein Zentrum und eine Peripherie des Zusammenhangs, dem der Name entstammt. Die Position des Namenträgers bestimmt den externen Bekanntheitsgrad der Eigennamen. Nimmt man etwa die Namen ,Romeo', ,Juliet', ,Mercutio', ,Friar Lawrence', ,Sampson' usw., sind die ersten beiden wohl mindestens jedem Europäer, die anderen nur einem immer kleineren Kreis bekannt, schließlich nur noch

${ }^{254}$ Kelletat 1986, S. $194 \mathrm{f}$.

${ }^{255}$ Vgl. Lausberg 1963, S. 32 (§ 53).

${ }^{256}$ Vgl. Lausberg 1963, S. 32 (§ 53).

257 Vgl. Masters 1992, S. 292.

258 Diese Beziehung ist zu unterscheiden von Gemeinsamkeiten der Namenszeichen, wie sie Sauerbeck 1996 beschreibt; vom ,onymischen Raum' spricht Blanár 2001, S. 21 f.

${ }^{259}$ Vgl. auch Sauerbeck 1996, S. 410. 
den Personen, die Shakespeares Romeo and Juliet gelesen oder gesehen haben und sich an die Namen erinnern. Namenfelder dieser Art sind wie einzelne Eigennamen durch geringere oder größere ,Lokalität' gekennzeichnet. Da die Kenntnis des semantischen Inhalts und der Referenz von Eigennamen begrenzt ist, ist auch die Kenntnis der Kontexte eines Eigennamen begrenzt.

Autoren machen sich diese Eigenschaften der Namenfelder zur Textgestaltung zunutze. Die Strategie der Namenverteilung wird auf die durch ein Namenfeld hervorgerufenen Erwartungen abgestimmt. E.L. Masters z.B. läßt seine titelgebende Figur in Lucius Atherton den Namen ,Beatrice' erwähnen, um einen anderen, im Gedicht selbst ungenannten Toten zu identifizieren, der ihm in der Unterwelt begegnet: Dante. ${ }^{260}$

Im Gegensatz zu einem Kontrast zwischen mehreren Namen, der auf den Beziehungen der Namenträger in einem Handlungszusammenhang beruht, kann durch verschiedene kulturelle Namenfelder ein Kontrast zwischen den Hintergrundwelten einzelner Namen aufgebaut werden. Sicherlich das berühmteste Beispiel für einen solchen Kontrast kultureller Felder durch Eigennamen ist Celans Todesfuge, in der die Namen "Sulamith" und "Margarete" als Anspielungen auf die deutsche und die jüdische Kultur einander gegenübergestellt werden. ${ }^{261}$

Die verschiedenen Namenfelder können wiederum zur Strukturierung von Namenaufzählungen genutzt werden. Simon Dach etwa nennt zum Lobe Martin Opitz' ${ }^{262}$ zunächst Namen antiker griechischer Exempel der Dicht- bzw. Gesangskunst, die durch Opitz übertroffen werden: die mythische Figur "Orpheus" und der römische Bukoliker Vergil („Maro"):

Orpheus gibt schon besser Kauff, Hört er dieses Mannes Seiten, Unser Maro horchet auff, Sagt: was soll mir das bedeuten? Wird der Weisen Lieder Ruhm Nun der deutschen Eigenthum? ${ }^{263}$

Drei Strophen später nimmt Dach diesen Vergleich Opitz' mit den antiken Dichtern wiederum auf, indem er Flußnamen aus dem ,kulturellen Namenfeld' der genannten Personen wählt. Die Überbietungsstruktur wird deutlich hervorgehoben:

Last den stolzen Thracer-Fluß

Nicht so trotzig sich ergiessen

Und den edlen Mincius

Was bescheidentlicher fliessen,

\footnotetext{
${ }^{260}$ Masters 1992, S. 142.

${ }^{261}$ Vgl. Celan 1991, S. 41f.

262 Gesang bey des Edlen und Hochberühmten Herren Martin Opitzen von Boberfeldt, etc. etc. hocherfreulichen Gegenwart Zu Königsbergk in Preußen Im Jahre 1638 Den 29. Tag de Hew-Monats, Gesungen von Simon Dachen (Kelletat 1986, S. 29-31).

${ }^{263}$ Kelletat 1986, S. 30.
} 
Dach spricht hier das für klassizistische Strömungen typische Konkurrenzverhältnis zwischen Antike und ihr nacheifernder Gegenwart aus. In den darauf folgenden drei Strophen wendet sich Dach jedoch dem ewigen, jenseitigen Ruhm zu, den er Opitz zuspricht bzw. prophezeit. Mit dem normativen Wert der antiken Exempel kann er frei umgehen und diese durch Opitz übertreffen lassen. Mit dem biblischen Exempel für Sangeskunst: „David“, muß Dach hingegen vorsichtiger sein. Opitz tritt nur in dessen Fußstapfen und überbietet ihn nicht:

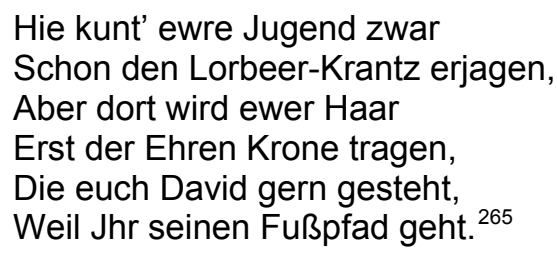

An der Makrostruktur des Gedichtes ist eine Steigerung der kulturellen Felder, für die die Namen stehen, zu beobachten. Das Namenfeld der antiken Dichtung und des antiken Mythos werden vom Feld des biblischen Mythos übertroffen, der seinerseits aber unantastbar bleibt.

Die kulturellen Namenfelder, denen die Namen entstammen, bestimmen also über die Präsenz weiterer Namen die Struktur der Gedichte und den Umgang mit Eigennamen.

\subsection{Zusammenfassung: Die Semantik des Eigennamens und der Textverlauf} In diesem ersten Abschnitt des zweiten Kapitels haben wir uns mit textstrukturierenden Funktionen beschäftigt. Es hat sich gezeigt, daß Eigennamen den Gedichtverlauf durch ihre semantische Dichte und ihre auffällige Zeichengestalt stark beeinflussen. Dabei bilden sie Konzentrationspunkte im Gedichttext sowohl bezogen auf die Gestalt des Textes als auch bezogen auf den Verlauf des Gedichts. Die implizite und unsichere Semantik von Eigennamen bewirkt, daß sie der Erläuterung in Ko- und Kontext bedürfen oder daß ein weitgehender Bezug auf das enzyklopädische Vorwissen des intendierten Lesers genommen wird. Die Art und Weise, in der Informationen zu dem Eigennamenzeichen gegeben oder auch nicht gegeben werden, bestimmt den Ablauf des Gedichts. Treten mehrere Eigennamen auf, so tritt als weiteres strukturierendes Merkmal das Verhältnis der Namen zueinander auf.

Insgesamt beruht die besondere Rolle des Eigennamens für den Ablauf des Gedichttextes in den bisher betrachteten Fällen zunächst darauf, daß das Namenzeichen auffällig ist, weil es die Aufmerksamkeit des Lesers durch seinen nicht expliziten Inhalt erfordert

\footnotetext{
${ }^{264}$ Kelletat 1986, S. 30.

265 Kelletat 1986, S. 31.
} 
und oft auch durch seine Zeichengestalt auf sich zieht. Der ,verborgene' semantische Hintergrund des Namens wird dann mit unterschiedlichen Strategien in dem Text entwickelt.

Die textstrukturierende Funktion von Eigennamen beruht vorwiegend auf dem semantischen Hintergrund des Eigennamens und dessen Entfaltung. Die eingangs untersuchten sprachphilosophischen Theorien zu Eigennamen heben als zweites wichtiges Element der Eigennamenbedeutung die Referenz des Eigennamens über mehrere Welten hinweg (transworld identification) hervor. Diese ermöglicht es einem Namenbenutzer, seinen Text mit Kontextwelten zu verbinden. Wie dies in der Funktion der Anbindung, Transposition und Ausrichtung von Texten und Textteilen geschieht, soll im Folgenden gezeigt werden.

\subsubsection{Anbindung, Transposition, Ausrichtung - die Referenz des Eigenna- mens}

\subsubsection{Die Anbindung an Kontextwelten}

\subsection{Eigennamen und die ,pragmatische Einbindung' des Gedichts}

Eigennamen dienen aufgrund ihrer Referenzeigenschaften dazu, Sprechakte zu konstituieren. Sie können deren Ausrichtung, lokale und temporale Einordnung sowie die Kommunikationsteilnehmer auf ökonomische Weise bestimmen. Eigennamen erfüllen dabei das Kriterium der optimalen Relevanz - „maximal contextual effects, minimum of procession“. ${ }^{266}$ Daher spielen sie auch eine besondere Rolle bei der Verbindung von Gedichten mit einem Kontext. ${ }^{267}$

Der wohlwollende Leser eines Gedichts muß - unter Voraussetzung von Grices cooperation principle oder jedweden Prinzips der hermeneutical benevolence - versuchen, einen Äußerungskontext zu gestalten, der den Gedichttext in bezug auf die Zwecke des Sprechers optimal erscheinen läßt. Dazu gehört es, etwaige Referenten zu identifizieren und enzyklopädisches Wissen zu aktivieren. Die Behauptung, Leser könnten grundsätzlich keinen konkreten Kontext zu Gedichten finden und müßten deshalb erst einen Kontext erschaffen ${ }^{268}$, trifft keineswegs auf alle Gedichte zu. Treten im Gedichttext über den Text hinaus referierende Eigennamen auf, so ist davon auszugehen, daß der vom Autor

\footnotetext{
${ }^{266}$ Bex 1992, S. 3.

267 Sie funktionieren als ,textorientierte intertextuelle Kategorien' (vgl. Nicolaisen 1995, S. 566).

268 Die Behauptung, daß Gedichte kontextlos seien, findet sich etwa bei Bex 1992, S. 9. Darüber hinaus ist auch für literarische Äußerungen zu beachten, daß die Griceschen Maximen keineswegs suspendiert werden. Optimierung und cooperative principle sind in Gedichten nur nach anderen Parametern zu bestimmen als in Alltagsäußerungen (s.o.).
} 
aufgerufene semantische Hintergrund des Namens vom Leser auch erkannt werden soll. Sind die Eigennamen allerdings nicht dechiffrierbar, bleibt der Leser ,außen vor'. Im Folgenden werden Fälle der Anbindung von Gedichten an spezifische Kontexte durch die Verwendung von Eigennamen untersucht. Kategorisch unterscheiden sich dabei die Verwendung und Nennung von Eigennamen, die das Gedicht an eine bestimmte Hintergrundwelt anbinden oder die dargestellten Inhalte in eine bestimmte Hintergrundwelt transponieren, von der Ausrichtung des Gedichttextes auf einen bestimmten Namenträger durch Anrede beim Namen auf der Ebene des Sprechers.

\subsection{Die Anbindung an Kontexte}

NOBLES, and HERALDS by your leave, Here* lie the Bones of MATTHEW PRIOR; The son of ADAM, and of EVE, Let BOURBON, or NASSAU, go higher. ${ }^{269}$

*Alluding to Westminster-Abbey.

In diesem in Priors Anthologie Poems on Several Occasions publizierten Epitaph ist das indexikalische Zeichen „here“ äußerst inhaltsarm. Es hat nur einen 'Charakter': \{an dem Ort, an dem der Satz geäußert wird\}. Wichtig für die Gestaltung der Hintergrundwelt des Epitaphs ist zunächst wie bei de Schoolmeesters „Hier ligt Poot [...]“ lediglich der Hinweis auf das Vorhandensein einer Umwelt überhaupt. Der indexikalische Verweis evoziert die Existenz eines bestimmten Ortes, an dem der Originaltext sich befinden soll, und regt damit die Imagination an. Daher begnügt sich das (fiktionale) Epitaph für Hubert Korneliszoon Poot mit dem unbestimmten Hinweis darauf, daß es an einem Grab angebracht sei. Dort wird kein Wert auf eine Spezifikation des Ortes gelegt, an dem Poot begraben liegt. Lediglich, daß die Schrift an dem Grab des im Gedicht Genannten angebracht ist, gehört zum game of make-believe der Fiktion dieses Textes.

Sollen nun wie bei Prior weitere Informationen zu dem Ort gegeben werden, sind Präzisierungen im Gedichttext selbst, in Paratexten oder im Kontext notwendig. Die vom Dichter Matthew Prior oder dem Herausgeber seiner Poems on Several Occasions für nötig erachtete Fußnote zum Epitaph, For Himself, Spoken Extempore ist eine - recht grobe - Möglichkeit, das indexikalische Zeichen mit situationsunabhängigem semantischen Inhalt zu füllen. Dabei wird nicht zufällig auf einen Eigennamen zurückgegriffen. Die eindeutig identifizierende Bezugnahme auf ein außerhalb des Textes existierendes Individuum ist nur durch Zeit- und Raumparameter oder Namen möglich.

In unserem Beispiel greift Matthew Prior vor allem auf die symbolische Bedeutung der Kapelle von Westminster Abbey zurück als rühmlichem Ort der letzten Ruhe für diejeni- 
gen, die sich um das Land verdient gemacht haben. Die stolze Emphase dieses Grabspruches läßt sich ohne die Angabe des Ortes, an dem der Text angebracht ist, nicht in ihrem ganzen Ausmaß erfassen. Sie beruht auf der Erlangung von Ruhm durch persönliche Leistung im Gegensatz zu dem Ruhm, der auf der Herkunft beruht. Letzterer wird durch den antiklerikalen Topos der ironischen höchsten Herkunftsherleitung von den (prähistorischen) Vorfahren Adam und Eva lächerlich gemacht. Der Erbadel wird wiederum durch zwei Eigennamen repräsentiert, deren sortale Prädikate zum einen den kontinentaleuropäischen Hochadel, zum anderen politische Rivalen Englands bedeuten. Das Gedicht hat also zugleich einen patriotischen Impetus, der durch die Eigennamen und deren kommunikativen Wert kundgetan wird. Es gestaltet nicht nur den persönlichen Stolz des Sprechers, sondern den Stolz der konstitutionellen Monarchie und des englischen Bürgertums gegenüber dem Erbadel des europäischen Kontinents.

Nötig ist die Fußnote zu Priors Epitaph, weil der semantische Inhalt der indexikalischen Ausdrücke von dem ,hier-jetzt-ich-System' abhängt. ${ }^{270}$ Indexikalische Zeichen konstituieren den „coherent enunciative act“ oder das „Zeigfeld“, von dem aus die Bedeutung des Gedichts aufgebaut werden muß. ${ }^{271}$ Das durch indexikalische Ausdrücke gebildete Zeigfeld stellt ein abstraktes Netz von Verweisen her. Weil indexikalische Ausdrücke die Referenz eines Textes nur relativ zum Sprecher und zum Kontext des Textes herstellen, gelten sie als Subjektivitätskennzeichen, die „presence“ und „immediacy“ kennzeichnen. $^{272}$

In schriftlich fixierten Texten bedürfen die indexikalischen Zeichen der Präzisierung. Die „deictic frames“ wirken daher oft mit anderen Formen der Referenz zusammen, um konkrete Anbindungen zu ermöglichen. ${ }^{273}$ Die Verwendung indexikalischer Ausdrücke verweist auf eine Sprechsituation der face-to-face communication, die im Falle des Gedichts aus dem Text und dessen weiteren referierenden Ausdrücken erschlossen werden muß. ${ }^{274}$

Auf individuelle Orte, Personen und Gegenstände referierende Ausdrücke dienen dazu, die indexikalische Struktur eines Gedichtes auszurichten. Eigennamen versehen das

\footnotetext{
${ }^{270}$ Vgl. Bühler 1965, S. 80, S. 102; vgl. Tate 1995, S. 135.

${ }^{271}$ Vgl. Culler 1975, S. 168; Bühler 1965, S. 80 passim. Man kann Deixis auf verschiedene Weise kategorisieren - im einfachsten Falle in Orts- und Zeitdeixis („hic-et-nunc-deixis“) und die personale Deixis. In einem aufwendigeren Modell werden von der „referential deixis“ referierender Ausdrücken die „origodeixis“, „spatio-temporal deixis“, „subjective deixis“, „discourse deixis“, „syntactic deixis“ unterschieden (vgl. Bex 1995, S. 169). Die Gestaltung durch Deixis und Referenz kann auf nur ein Äußerungszentrum bzw. nur ein geschlossenes Zeigfeld verweisen. Spätestens im 20. Jahrhundert kann aber nicht mehr darauf gezählt werden, daß ein und nur ein Zeigfeld etabliert wird, es ist von „deictic shifts and inconsistencies" auszugehen (vgl. Semino 1995, S. 148 und S. 150-158).

${ }^{272}$ Vgl. Tate 1995, S. 142.

${ }^{273}$ Vgl. Bex 1992, S. 2; Fleischer 1995, S. 559; Burdorf 1995, S. 169 f.

${ }^{274}$ Vgl. Semino 1995, S. 146.
} 
Zeigfeld mit eindeutiger Zeit- und Ortsdeixis. Sie helfen, die frames of reference aufzubauen, ${ }^{275}$ und eröffnen die Möglichkeit, auf „shared knowledge“ Bezug zu nehmen. ${ }^{276}$ Eigennamen geben den Pronomina und damit den Sprechern und anderen Personen eines Gedichts „klare Konturen“. ${ }^{277}$ Rein innertextlich referierende Namen geben dagegen eine Leerstelle an, die im restlichen Text gefüllt werden muß (dies gilt aus der Leserperspektive auch für unbekannte Namen). Durch diese Namen wird das indexikalische Netz lediglich um einen systemimmanenten Punkt erweitert, ohne daß es an einen weitergehenden Kontext ,angelagert' würde. Etabliert wird auf diese Weise ein fiktionales Zeigfeld. ${ }^{278}$ Je nach Eindeutigkeit und Klarheit der Identifikationsleistung des Eigennamens ist das indexikalische Netz also fest in einem Kontext verankert oder bleibt abstrakt. $^{279}$

Reale Ortsnamen wie Personennamen geben dem Leser die Möglichkeit, die dargestellte Welt über die im Text explizit gegebenen Informationen hinaus aus seinen enzyklopädischen Kenntnissen zu ergänzen. ${ }^{280}$ Die Verankerung des indexikalischen Systems in einer außertextlichen Welt ${ }^{281}$ erschließt daher auch einen Kontext, der über das indexikalische Netz des Textes hinausgeht. Das Gelingen der Textfunktion des Gedichtes setzt allerdings Grenzen für die Notwendigkeit der Eigennamenentschlüsselung. Nur ein Teil des semantischen Inhalts von Eigennamen tritt in das semantische Gefüge des Textes ein. Der vollständige semantische Inhalt des Namens dient als Rahmen, gegen den der vom Sprecher intendierte semantische Inhalt des aktuell geäußerten Namens nicht unmotiviert verstoßen sollte. Weitere Informationen über den Namenträger, die keine Auswirkungen auf den übrigen Text haben, können mit dem Argument, daß sie für den Text und die Interpretation irrelevant sind, vernachlässigt werden.

Beispiele für dieses Verhältnis von semantischem Nameninhalt und intendiertem Nameninhalt bieten viele Gedichte, die sich auf historische Ereignisse beziehen. So gestaltet etwa Heinrich Heine in seiner Ballade Karl I. eine nicht historisch zu verbürgende Situation, in der der englische König in einer Köhlerhütte einem Säugling begegnet, der

\footnotetext{
${ }^{275}$ Müller-Zettelmann 2000, S. 82 f.; vgl. Baker 1986 zu Hölderlins Versuchen, diese Anbindung zu vermeiden.

${ }^{276}$ Vgl. Tate 1995, S. 135, S. 140.

277 Vgl. Burdorf 1995, S. 207.

${ }^{278} \mathrm{Vgl}$. Anderegg 1977, S. 36-39.

279 Die Unterscheidung von durch Eigennamen bezeichneten "Generalia“ (die allgemeine Angabe von Rahmenbedingungen durch Ortsnamen etc.) und "Individua“ (alle Personennamen; vgl. Hoops 1979, S. 303; Burdorf 1995, S. 169) ist dabei nicht sinnvoll. Alle realen Eigennamen referieren auf Individuen, und alle dienen als Anschluß an eine Hintergrundwelt, in der das abstrakte Netz der deiktischen Verweise verankert wird.

${ }^{280}$ Vgl. Burdorf 1995, S. 170.

${ }^{281}$ Vgl. Shawcross 1983, S. 162.
} 
sein zukünftiger Henker ist. Es handelt sich um eine für literarische Texte typische Verfahrensweise, bei der ein Zeitabschnitt aus dem Leben einer ,Person des öffentlichen Lebens' ausgewählt wird, der nicht historisch signifikant und überliefert ist und der daher durch historische Untersuchungen nur schwer oder gar nicht widerlegt werden kann. Insofern verstößt er nicht deutlich gegen bekannte Tatsachen aus dem Leben der Hauptfigur. Walter Hinck bemerkt, daß das Gedicht Heines in einer ersten Fassung den Titel Wiegenlied trug. In diesem Fall ist der historische Bezug des Textes erloschen, denn es findet sich im Text kein Hinweis auf einen konkreten Kontext, in dem der König „im Wald, in der Köhlerhütte sitzt“. ${ }^{282}$ Der Text kann als Gestaltung jeder Situation einer (liberalen) Revolution gegen etablierte religiöse und weltliche Ordnungen interpretiert werden. Dagegen bindet der als Titel verwendete Eigenname Karls I. den Text an eine historische Situation. Auf diese Situation referiert der Text, auch wenn der recht abstrakte Inhalt, der im Gedicht gestaltet wird, keinen ausdrücklichen Bezug auf die Historie nimmt. So kann Walter Hinck über Heines Ballade schreiben:

Zum historischen Stoff genügen Hinweise: Die Auseinandersetzungen zwischen Krone und Parlament lösten die Puritanische Revolution aus, führten zum Sieg des Parlaments, zur Gefangennahme des Königs im Jahr 1648 und - auf Betreiben Oliver Cromwells - zu seiner Verurteilung und Hinrichtung im folgenden Jahr. Irgendwelche historiographischen Details [...] interessieren Heine nicht. [...] Gegenstand der - metaphorisch verschlüsselten - Reflexion [ist] das Verhältnis zwischen dem Volk (den Mäuschen) und dem Herrscher (dem Kätzchen). ${ }^{283}$

Die Anbindung an einen historischen Kontext hat dennoch eine doppelte Wirkung: Zum einen wird das Gedicht an die Geschichte Karls I. angebunden. Damit bezieht es sich auf die reale Welt und erlaubt es dem Interpreten (wie Hinck), die erwähnten Daten mental zu repetieren. Zum anderen bedeutet gerade dieser Bezug, daß die Anwendung des Textes auf Heines Gegenwart - die sich aus dem abstrakten Textinhalt ergeben kann $^{284}$ - einen anderen Weg gehen muß als bei einem Gedicht ohne historische Anbindung. Daß der Eigenname nur im Titel auftritt, verleiht ihm zusätzliches Gewicht, es legt aber auch nahe, den Haupttext als Exempel auf andere Fälle zu übertragen. Diese Übertragung ist allerdings nur möglich, wenn man die Situation als exemplification im Sinne Goodmans behandelt.

\footnotetext{
${ }^{282}$ Heine 1992, S. 26; vgl. den Kommentar in Heine 1992, S. 594-603; lediglich durch Kenntnis des Schicksals Carls I. kann vom Textinhalt auf den Kontext geschlossen werden. Heines Titeländerung macht jedenfalls deutlich, daß er den klaren Bezug auf die historische Person wünscht.

${ }^{283}$ Hinck 1995, S. 76.

${ }^{284}$ Vgl. Hinck 1995, S. 78.
} 
Auf der gemeinsamen Referenz über die einzelne Textwelt hinaus beruht auch die „zyklisierende Funktion“ von Eigennamen ${ }^{285}$. Eigennamen referieren in diesem Fall auf diejenige fiktive oder reale Textwelt, die durch alle betreffenden Texte, die von dieser Welt handeln, gestaltet wird. In diesem Fall gestalten die Texte mit Eigennamen eine kohärente Welt mit eineindeutiger Referenz der referierenden und indexikalischen Ausdrücke. Gleiche Eigennamen referieren in allen Gedichten einer entsprechenden Gruppe auch auf das gleiche Referenzobjekt.

Ein Beispiel für die zyklisierende Funktion von Eigennamen in Gedichten bietet die Spoon River Anthology Edgar Lee Masters. ${ }^{286}$ Hier wird durch den immer wieder in den Gedichten auftretenden fiktionalen Ortsnamen ,Spoon River' sowie durch das Auftreten einzelner Personennamen in mehreren Gedichten ein gemeinsamer Hintergrund evoziert. ${ }^{287}$ Alle Personen gehören der Gemeinschaft einer Kleinstadt an.

Die gleiche Rolle hat der (figurengestaltende) Name ,Mathilde' in dem bereits erwähnten Sonettenkranz Mathilde Jacques Perks. ${ }^{288}$ Der Name tritt im Titel und in unregelmäßiger Verteilung in zahlreichen der 72 Sonette auf. Dadurch wird über den gesamten Kranz die Referenz auf die gleiche besungene Person aus dem realen Umfeld des historischen Autors aufrechterhalten. Zur definite description dieser Figur wird mit jedem weiteren Gedicht etwas hinzugefügt, auch wenn die Hinzufügungen eher aus subjektiven Eindrücken des Autors bestehen: daß die Namenträgerin etwas gesagt habe, etwas getan habe oder eine bestimmte Eigenschaft habe. Aus der Gesamtheit der Texte ergibt sich so eine durchaus komplexe (in unserem Fall eher subjektiv-psychologische als materielle) Beschreibung der Namenträgerin.

In den bisher betrachteten Fällen scheint die Erschließung des durch erschließbare Eigennamen aufgerufenen Kontextes für den gebildeten Leser ohne große Schwierigkeiten möglich zu sein. Die Nennung unbekannter Eigennamen in einem Gedicht kann jedoch auch dazu dienen, auf ein dem Leser unbekanntes Zeigfeld zu verweisen und inm dadurch die kommunikative Position eines Außenstehenden zuzuweisen. Ein deutliches Beispiel dafür ist eine Widmung, die Nelson Goodman seinem philosophischen Werk Of Mind and Other Matters voranstellt: 289

To

Snubby

Tweedledee

\footnotetext{
${ }^{285}$ Vgl. Kalverkämper 1994, S. 234.

286 Vgl. Masters 1992.

287 Vgl. Masters 1992, z.B. S. 97-100, S. 118f., S. 141f. Zum realen Hintergrund der Stadt ,Spoon River' vgl. Masters 1992, S. 2-5.

${ }^{288}$ Vgl. Perk 1971, S. 73-154.

${ }^{289} \mathrm{Da}$ der Text formal überstrukturiert ist, gehe ich davon aus, daß es sich um ein Gedicht im Sinne unserer weiten Definition handelt.
} 


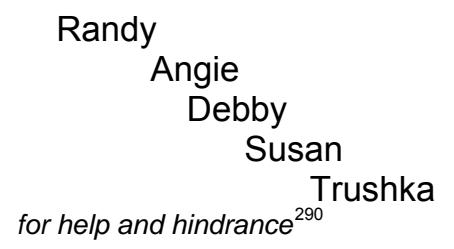

Die Textfunktion besteht hier darin, daß das Buch den Namenträgern gewidmet wird, deren Ruf- bzw. Kosenamen in dem Text genannt werden und die dem Autor vermutlich nahestehen. Die Textaussage, der alliterierende Dank für „Hilfe und Hinderung“, hat einen freundlich ironischen Unterton. Die Kosenamen sind konventionell. Die Benennung einer Person nach einer Figur aus Lewis Carrols Alice in Wonderland sowie „Susan" als Normalform eines Namens neben den Diminutiva und "Trushka" als Name russischer Herkunft fallen auf.

Der Leser dieser Widmung kann zwar die Funktion, nicht aber den Inhalt und die Anspielungen des Textes erfassen, weil er die Namenträger nicht kennt. Unter den Referenzobjekten der Namen könnten etwa der Ehepartner, Kinder, Freunde oder auch Haustiere sein. Die Treppenform kann das Alter der Personen, die Wertschätzung des Sprechers, den Grad der Verwandtschaft etc. bedeuten. Der Käufer des Buches kann aufgrund des Kontextes erraten, daß die Eigennamen auf konkrete Personen referieren. Doch muß er sich bis auf Assoziationen zu den Zeicheneigenschaften der Namen damit begnügen, eine ihm unverständliche Konversation anderer Menschen mitgehört zu haben.

Vieldeutige Eigennamen, Initialen oder weithin unbekannte Namen werden auf diese Weise zum Zeichen dafür, daß eine Adressatengruppe des Textes besteht, die dessen vollständige Bedeutung verstehen kann. Der Leser befindet sich in einer defizitären Rezeptionssituation und erhält durch die unbekannten Eigennamen einen Hinweis auf seine Situation.

\subsection{Verbindungen verschiedener Textebenen}

Die rigid designation des Namens kann auch dazu dienen, innerhalb des Gedichts verschiedene Kommunikationsebenen miteinander zu verbinden. ${ }^{291}$ Texten der Gattung ,Lyrik' wird ein mimetisches Darstellungs- und Illusionierungspotential vor allem in bezug auf das Sprechersubjekt zugesprochen. ${ }^{292}$ In neuerer Zeit erst hat man nach einer langen Debatte über das, lyrische Ich' begonnen, Gedichte in der gleichen Weise strukturell wie Erzähltexte zu analysieren. ${ }^{293} \mathrm{McHale}$ etwa nimmt drei interagierende „con-

\footnotetext{
${ }^{290}$ Goodman 1984, o.P.

${ }^{291}$ Vgl. zur Verbindung von Sprecher- und empirischer Autorebene Hühn/Schönert 2002, S. 298.

${ }^{292}$ Vgl. Bernhart 1993; Wolf 1998.

${ }^{293}$ Vgl. Schönert 1999, S. 291. Vgl. als schon ,klassischen' Entwurf Easthope 2003, S. 42-44; vgl. dazu Müller-Zettelmann 2000, S. 26, S. 66-72, S. 109; Semino 1995, S. 146.
} 
ventional levels of integration“ an: Die dargestellte Welt, die ,Stimme' und das behandelte Thema. ${ }^{294}$ Es wird also eine inhaltliche, ,abstrakte' Ebene von der Sprecherinstanz unterschieden. Burdorf und Hühn und Schönert beschäftigen sich näher mit der Frage nach der Struktur der Sprecherinstanz. In Orientierung an modernen Erzähltextanalysemethoden gehen sie von dem „realen Autor“/,empirischen Autor“, dem „Textsubjekt“/,abstrakten Autor“295, dem „artikulierten Ich“/der „Stimme“, dem „fiktiven Erzähler“ und den „Figuren“ aus, wobei ein „fiktiver Erzähler“ das „artikulierte Ich“ in Gedichten mit gestaltetem Sprecher ersetzt. ${ }^{296}$

Zunächst kann ein Eigenname in Paratexten (Titeln und Widmungen) dazu dienen, die Ausrichtung des Gedichtes auf eine Hintergrundwelt festzulegen, auf die der Text referieren soll. Der Name kann das Sprechersubjekt, das angesprochene Du, den Ort, an dem die „Rede in Versen“ (Lamping) stattfindet, oder den Namenträger angeben, der im Zentrum der gestalteten fiktiven Welt steht. Die Positionierung des Namens im Titel oder in einer vorangestellten Widmung ermöglicht es, den Eigennamen im Haupttext nicht mehr zu verwenden, ohne auf die Anbindung an einen Kontext zu verzichten. Die Versrede selbst verbleibt, im Allgemeinen'. 297

Der Paratext kann sich als Metatext auf den Haupttext als literarischen Text beziehen. Er kann aber auch schon die Welt des Haupttextes gestalten. Wird ein Name aus den Paratexten im Haupttext wiederholt, so deutet dies darauf hin, daß die Hintergrundwelten von Haupttext und Paratext identisch sind. Dabei kann die Identität von Autor und Sprecher gekennzeichnet werden, indem reale Eigennamen in Haupt- und Paratexte integriert werden. ${ }^{298}$ Durch das Auftreten eines Eigennamens können so die Ebenen des realen Autors, des Textsubjekts, des fiktiven Erzählers (der ,Stimme') und schließlich der dargestellten Welt und des behandelten Themas miteinander verbunden werden. Dies geschieht immer dann, wenn der Sprecher sich nicht nur ausdrückt (expression), sondern über sich selbst als Objekt redet und seinen eigenen Namen nennt. So

\footnotetext{
${ }^{294}$ Vgl. McHale 1992, S. 9, S. 28.

${ }^{295}$ Tritt der reale Autor in das Gedicht ein, so fällt er auch mit dem abstrakten Autor zusammen. Grundsätzlich ist die Trennung zwischen „intendiertem Leser" und „empirischem realem Leser" zwar sinnvoll, eine korrespondierende Trennung zwischen „realem“ und „abstraktem Autor" (z.B. auch bei Schönert 1999, S. 293) scheint allerdings weniger überzeugend zu sein. Während die Leser im Laufe der Geschichte des Textes vom intendierten Leser abweichen können, bleibt der Autor doch der Autor. Lediglich eine implizite Selbststilisierung kann oft konstatiert werden, diese ist aber kein literaturspezifisches Phänomen. Letztendlich löst sich der „abstrakte Autor“ in den „realen Autor“ und die Erzählinstanz (also das „artikulierte Ich" oder den "fiktiven Erzähler") auf.

${ }^{296}$ Burdorf 1995, S. 203; Schönert 1999, S. 293; Hühn/Schönert 2002, S. 296.

${ }^{297}$ Vgl. zur „Dominanz der Personalpronomina“ in Gedichttexten Burdorf 1995, S. 193.

298 Vgl. Warning 1997, 48f.; vgl. Viljoen 2002 zu der Autornamenintegration im Werk des Lyrikdichters Breyten Breytenbach.
} 
verbindet Theodor Fontane in seinem Knittelversgedicht Lebenswege durch eine einzige Anrede bei seinem nur als Initiale genannten Namen die Ebene der Figurenrede mit der Ebene der Stimme und diese gleichzeitig mit der Ebene sowohl des Textsubjekts als auch des empirischen Autors namens Fontane:

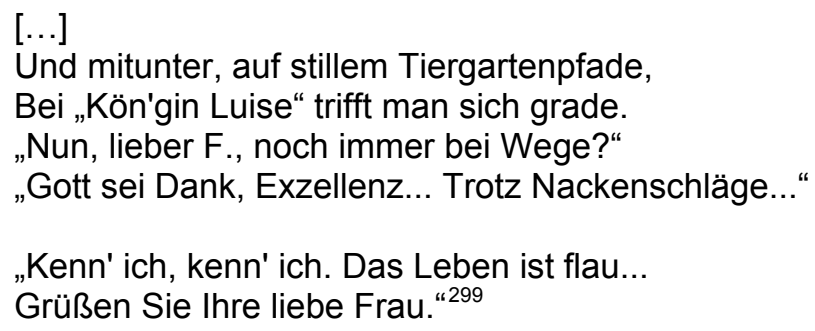

Eine vollständige Fiktionalität des Textes wird dagegen erreicht, wenn Paratexte und Haupttext durch fiktionale Eigennamen miteinander verbunden werden, wie etwa in Cervantes Einleitungsgedichten zu seinem Don Quijote. Diese werden von Paratexten begleitet, in denen die fiktionalen Sprecher genannt werden: z.B.: Orlando Furioso a Don Quijote de la Mancha. Im zweiten Quartett dieses Sonetts heißt es dann:

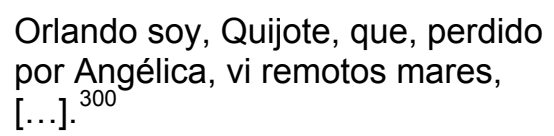

Die fiktionalen Eigennamen positionieren das Gedicht vollständig in der fiktiven Welt der Ritterromane. Dies hat auf den nachfolgenden Roman insofern Auswirkungen, als Don Quijote selbst auf eine fiktionale Ebene mit den Figuren der Ritterromane gestellt wird, obwohl diese doch als Bücher im Roman von ihm gelesen werden, also ihrerseits eine zweite Fiktionsebene des Romans eröffnen. Gleichzeitig stehen die Gedichte als ,Widmungen' am Beginn des Romans, sie befinden sich also eigentlich auf der Kommunikationsebene des Lesers. Cervantes spielt in den einleitenden Gedichten wie in seinem Roman mit der Vermischung der vielen fiktiven Welten und der einen realen Welt.

\subsubsection{Transposition}

\subsection{Transposition durch Figurennamen}

Eigennamen binden durch ihre Referenz über den Text hinaus das Gedicht an verschiedene Kontexte an. Wie wir gesehen haben, können sie dabei innertextlich wie außertextlich dazu dienen, private Handlungen auf eine öffentliche Ebene oder eine Handlung in der realen Welt auf eine Handlung in einer fiktiven Welt zu übertragen.

Ein Beispiel für die Transposition von der individuellen Ebene auf eine allgemeine durch einen figurengestaltenden Namen ist E.L. Masters Sam Hookey:

I ran away with the circus,

\footnotetext{
${ }^{299}$ Vgl. Fontane NA 20, S. 29-30.

${ }^{300}$ Cervantes 1994, S. 93.
} 
Having fallen in love with Mademoiselle Estralada,

The lion tamer.

One time, having starved the lions

For more than a day,

I entered the cage and began to beat Brutus

And Leo and Gypsy.

Whereupon Brutus sprang upon me,

And killed me.

On entering these regions

I met a shadow who cursed me,

And said it served me right....

It was Robespierre! ${ }^{301}$

Der Sprecher berichtet von einem Fehler, den er gemacht hat: Aus Unzufriedenheit mit seinem Leben mißhandelt er die Tiger seiner Geliebten, einer Löwenbändigerin im Zirkus, mit der er durchgebrannt ist. Er reizt mächtige und irrationale Wesen ohne Grund durch Nahrungsentzug und Mißhandlungen. Als Konsequenz hat eines dieser Wesen inn umgebracht. Der hier beschriebene Fehler des fiktiven Protagonisten wird nun dadurch auf eine allgemeine Ebene übertragen, daß die Figur des toten Robespierre die Handlung Sam Hookeys am Ende des Gedichts kommentiert. Hervorgehoben wird die Analogie zwischen dem Ereignis geringer Reichweite in der Kleinstadt und dem großen weltpolitischen Ereignis. Das Gedicht wird zu einer Allegorie auf die Französische Revolution.

Die bekannteste Gruppe von Eigennamen, die zur Transposition einer möglicherweise realen Handlung in einen (fiktiven) Kontext verwendet werden, sind die anakreontischen oder bukolischen Stereotypennamen. Namen wie ,Phyllis', ,Doris' oder ,Galathea' ordnen das Gedicht der Bukolik oder Anakreontik zu, indem sie eine standardisierte fiktive Welt mit standardisierten Charakteren und Themen aufrufen. Aus Sicht der literaturwissenschaftlichen Onomastik ist die Besonderheit dieser zumeist antiken Namen, daß sie eine antikisierend gestaltete mythische Welt (der griechischen Mythen oder der Pastorale) aufrufen, die das Umfeld des ursprünglichen Namenträgers bilden, dabei aber nur selten auf den ursprünglichen Namenträger referieren. Der Eigenname referiert vielmehr oft auf eine reale Person aus dem historischen Umfeld des Autors. Es handelt sich also um einen präfigurierten Namen, bei dem die Eigenschaften des ursprünglichen Namenträgers, also die mit der Originalreferenz verbundene definite description, verblaßt sind. Die Präfiguration dient dazu, den neuen Namenträger in die fiktive Welt des ursprünglichen Namenträgers zu versetzen. Wir analysieren im Folgenden exemplarisch einige für die Transpositionsfunktion literarischer Namen aufschlußreiche Namenverwendungen des Stereotypennamens ,Doris'.

${ }^{301}$ Masters 1992, S. 145. 
Wird ein bukolischer Stereotypenname simpliciter verwendet, so kann man vermuten, daß der Name in der Tradition eine zum Genre der Hirtendichtung gehörende Figur in einem einschlägigen Kontext aufruft. Der Eigenname stünde dann für eine sparsame Beschreibung wie etwa ,eine (hübsche) Hirtin' und führte im Gedicht zu einer neuen Gestaltung der Figur aus der antiken Hirtendichtung; so etwa in Friedrich Logaus Von vier Hirtinnen:

Chloris, Doris, Iris, Ciris liebten einen Hirten alle;

Ihm zu weisen mit dem Wercke, daß er ieden wol gefalle,

Krönte Chloris inn mit Blumen; Doris bracht inm Honig-Schnidte;

Iris grüsset inn mit lächeln; Ciris fasst inn in der Mitte,

Küste seinen Mund-Rubin. Ihm behagte nur das küssen,

Nam von sich und gab der Ciris Krone, Honig und das grüssen. ${ }^{302}$

In diesem Beispiel ist ,textimmanent' nicht auszumachen, ob der Text auf mehr als die antike oder antikisierte fiktive Hirtenwelt referieren soll. Würde man die Namen als rein fiktionale Namen interpretieren, so müßten zur verallgemeinernden Anwendung auf die Gegenwart im Sinne Goodmans die Figuren der antiken Schäferwelt Situationen der realen Gegenwart des Autors als Exemplifikation repräsentieren. Bekanntlich beziehen sich die erotischen Gedichte mit Hirtenfiguren jedoch zumeist auf eine viel direktere Art auf die gegenwärtige Welt des Dichters. Ein Kennzeichen bukolischer und anakreontischer Gedichte ist die Kombination von realer Autorwelt und fiktiver Hirtenwelt in der Textwelt des Gedichts. Die Namenreferenz spiegelt in den meisten Gedichten diese zweideutige Referenz des gesamten Textes. Lessing stellt diesen Vorgang in einem metapoetischen Gedicht folgendermaßen dar:

Ich fragte meine Schöne:

Wie soll mein Lied dich nennen?

Soll dich als Dorimene,

Als Galathee, als Chloris,

Als Lesbia, als Doris,

Die Welt der Enkel kennen?

Ach! Namen sind nur Töne:

Sprach meine holde Schöne.

Wähl' selbst. Du kannst mich Doris,

Und Galathee und Chloris,

Und - wie du willst mich nennen;

Nur nenne mich die Deine. ${ }^{303}$

Das Gedicht macht die onomastischen Eigenheiten der auf reale Personen angewendeten anakreontischen Namen deutlich: Die Stereotypennamen stehen für einen Kontext (Schäferleben) und ein Thema (Tändeleien der Liebe), nicht aber für eine definite description der Namenträgerin. Insofern ist die Anwendung des Namens beliebig und wenig aussagekräftig. Es handelt sich um Namenszeichen, deren dubbing in force durch wei-

\footnotetext{
302 Vgl. Logau 1967, S. 163.

${ }^{303}$ Lessing 1970, S. 49 f.
} 
tere Hinweise geklärt werden muß. Wichtig ist hingegen der Sprecherin der zweiten Strophe, daß der Sprecher seine Zuneigung zu ihr ausdrückt, indem er sie als Teil eines ,Zeigfeldes' mit dem Possessivpronomen direkt anspricht.

Stereotypennamen können direkt auf einen realen Namenträger aus dem Umfeld des Autors angewendet werden. Sie transponieren den Namenträger dann in die fiktive Hirtenwelt. Bei diesem Spiel der Transposition und Rückübertragung zwischen realer und fiktiver Welt können reale Eigennamen in Paratexten auftreten und so die Referenz des Stereotypennamens über den Text hinaus andeuten bzw. für den privaten Adressaten sichern. Die fiktive Welt des Textes und die reale Welt werden hier durch die unterschiedliche Referenz der Namen im Haupttext und im Paratext auseinandergehalten:

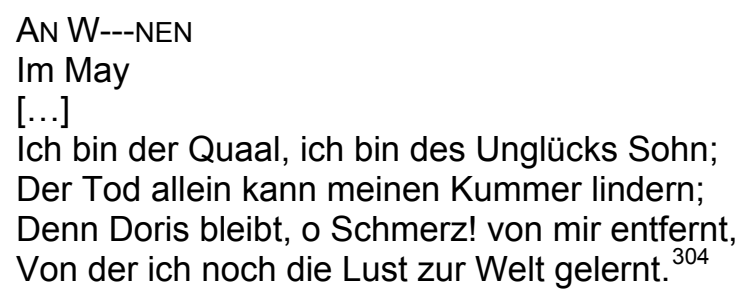

Fiktive und reale Welt, fiktionaler und faktualer Text können aber auch enger verbunden werden:

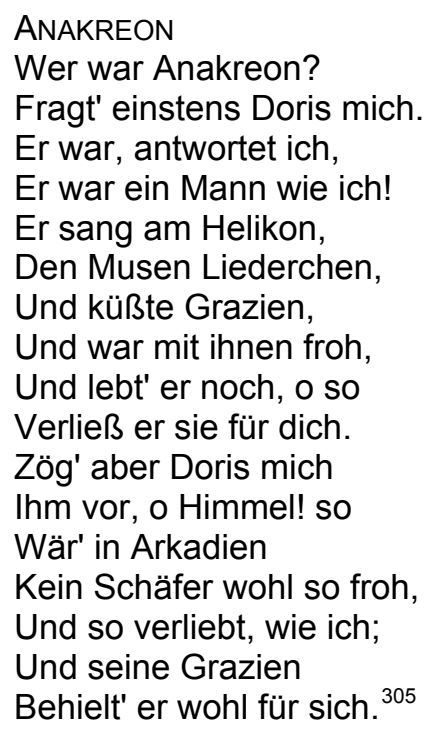

Gleim gestaltet zunächst eine einheitliche Welt, die den antiken Dichter Anakreon, Arkadien, den Autor und Doris umfaßt. Während Anakreon und der Autor aber historische Personen darstellen und Arkadien eine fiktive Welt, hat die ,Doris' Gleims eine Zwischenposition. Sie trägt einerseits einen arkadischen Namen. Andererseits gehört sie der realen Welt des Dichter-Sprechers an, denn sie kennt Anakreon nicht, zu dessen Welt sie als fiktive Figur doch gehören müßte. Demnach muß der Name auf eine Per-

\footnotetext{
${ }^{304}$ Ewald v. Kleist 1971, S. 157.

305 Gleim 2003, S. 54.
} 
son aus dem Umfeld des Sprechers referieren. Dieser charakterisiert sich selbst als Dichter, man kann also davon ausgehen, daß Gleim hier spricht und daß mit Doris eine Frau aus seinem Umfeld gemeint ist, an die das Gedicht in einer realen Kommunikationssituation gerichtet werden konnte. Der Sprecher Gleims achtet dabei darauf, sich selbst nicht eindeutig als Figur in die fiktive Hirtenwelt zu integrieren. Nirgends ist er selbst wirklich als Hirte beschrieben oder benannt, auch wenn die Vergleiche mit Hirten und mit Anakreon diesen Gedanken nahelegen. Das Gedicht gestaltet demnach keine geschlossene fiktive Welt, sondern eine Mischwelt, die reale Personen fiktionalisiert und gleichzeitig fiktionale Namen auf reale Personen referieren läßt.

Eine solche verschränkende Parallelsetzung von realer Welt und fiktiver Schäferwelt nutzt auch Goethe, um mit oder über eine fiktionalisierte Anna Katharina Schönkopf zu sprechen $^{306 .}$

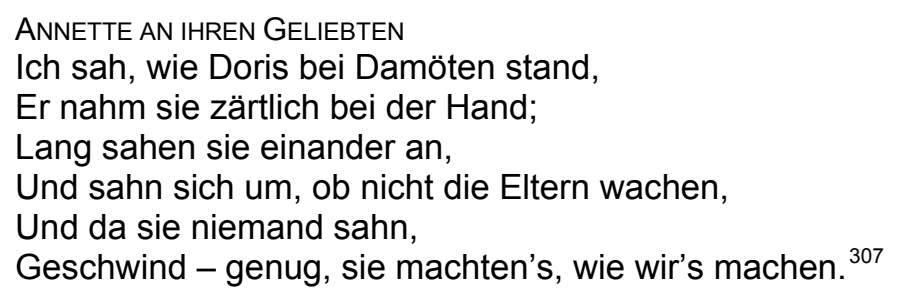

Das eigentliche Thema dieses Gedichts wird erst in der Pointe am Ende des Gedichts deutlich: die Liebkosungen der Sprecherin Annette und des Gedichtadressaten. ${ }^{308}$ Diese Handlung wird gespiegelt in der Handlung der von Annette angeblich beobachteten fiktiven Hirtenfiguren, die mit den auf die fiktive Welt der bukolischen Dichtung referierenden alliterierenden Stereotypennamen genannt werden. Die in der Überschrift genannte Sprecherin Goethes kann sowohl als weitere Hirtin Teil der fiktiven Welt Doris' und Damötens sein (der Diminutiv des Namens ,Anne' könnte dies andeuten), als auch die Beschreibung einer fiktiven Szene liefern, die sie ihrerseits betrachtet, ohne ein Teil von ihr zu sein.

Sowohl bei Gleim als auch bei Goethe wird innerhalb des Gedichts neben der Sprecherfiktion eine weitere Fiktionsebene der Hirtenwelt eröffnet. Dadurch, daß der Sprecher Gleims und Sprecherin wie Adressat bei Goethe nicht eindeutig als immigrant object in diese zweite fiktive Ebene der Hirtenwelt integriert werden, wird ihre Individualität nicht angetastet. Sie bleiben die Personen, die sie in der Realität sind. Realer Kontext des Autors und fiktiver Kontext der Schäfer werden nebeneinander gestellt und dabei weder eindeutig getrennt noch eindeutig miteinander identifiziert.

\footnotetext{
${ }^{306}$ Vgl. Luserke 1999, S. 27.

307 Goethe 1993, S. 17.

${ }^{308}$ Vgl. Luserke 1999, S. 30.
} 
Wie sich anhand der Namenverwendung in unseren Beispielen erweist, hat die fiktive Welt der Hirtendichtungen eine Besonderheit gegenüber anderen fiktiven Welten: Sie stellt eine offene Welt dar, die nie vollständig von der realen Welt getrennt ist. Sie wird auch nicht an die reale Welt angelagert, wie dies im Falle einer realistischen Dichtung der Fall wäre. Vielmehr werden reale Personen in einen fiktiven Kontext transponiert, der aber gleichzeitig als ein Teil des universe of discourse der realen Welt zu verstehen ist. Wenn hierbei fiktive Namen verwendet werden, ist die Integration vollständig. Gleichzeitig wird die Referenz der Namen auf die reale Welt aufrechterhalten. Dazu bedienen sich die Autoren realer Namen. Weiterhin kann eine Referenz auf die reale Welt dadurch nahegelegt werden, daß Sprecher oder angeredete Personen nicht gestaltet werden. So kann von der zumindest partiellen Identität von ,Sprecher-Ich' und gestaltetem Ich ausgegangen werden. Der Dichter-Sprecher handelt mit seinem Gedicht in jener Welt, die er durch das Gedicht gestaltet. Am weitesten auseinander tritt diese Verbindung in satirischen Gedichten, in denen die erotischen Qualitäten der Hirtenwelt nur noch in der Einbildung der handelnden Figuren bestehen, während der Sprecher und mit ihm der Leser diese Fiktion durchschauen und die ungeschminkte Realität erkennen. So etwa, wenn William Congreve eine alternde kokette Frau nur noch ironisch als „Doris, a nymph of riper age, [...]" anredet. ${ }^{309}$ Insgesamt gibt die Namenreferenz diese ,doppelbödige' Struktur bukolischer Gedichte wieder.

\subsection{Transposition durch diskursive Namennennungen}

In einem Gedicht können reale Eigennamen auftreten, ohne daß in der Textwelt eine mit innen verbundene Person auftritt. Die Eigennamen bilden dann einen Teil der Sprechweise des Sprechers oder einzelner Figuren. Dieser diskursive Gebrauch des Eigennamens tritt vor allem in den rhetorischen Tropen der Vossianischen Antonomasie des Vergleichs und des Exempels auf. ${ }^{310}$ Das Gemeinsame dieser Fälle hinsichtlich der Referenz der Namen ist, daß mit den Namen ein standardisierter Hintergrund verbunden wird, der aus ihrer diskursiven Verwendung resultiert. Die Namen stehen metonymisch für eine bestimmte, mit dem Namen verbundene Situation. Da diese Situation bekannt ist, eignen sich diskursiv verwendete Eigennamen in besonderem Maße dazu, ein privates Erlebnis auf eine öffentliche Ebene zu transponieren und ihm damit Ausdruck zu verleihen.

\footnotetext{
309 Lonsdale 1987, S. 39 f.

${ }^{310}$ Vgl. Kalivoda 1992, Sp. 1185 f.; Klein 1996, S. 61.
} 
So wird etwa in einem humoristischen Klink-dicht (Sonett) des Willem den Elgers die Praxis des Vergleichs einer gegenwärtigen Handlung mit berühmten Exempeln ironisch gebrochen. Deren Funktionsweise tritt dadurch aber nur desto deutlicher hervor:
Moest Alexander door vergift het leven laten?
Was dit het heerlyk eindt van zyne dapperheên,
Als hy Darius grootsch hadt op den nek getreên,
Wiens mogendheit hem voor 't verraadt ook niet kon baten?
En gy, ô Hannibal, ô schrik der Roomsche staten,
Is een vergifte ring uw toevlucht nu alleen?
Scheidt die uw dapper lyf en moed'ge ziel van een?
Ô Titus, zoetst' vermaak van al uwe onderzaten!
Ô Mitridates, ach! Wat was uw droevig endt
Een levend voorbeldt van uw onverwachte ellendt!
Ô Cato, zo uw' deugdt zo heel heeft uitgeblonken,
En schand'lyk is beloond, is 't nu geen wonder, dat
Men al de jongen van onz' gryze grauwe kat,
Zo onmeêdogend, laatst in't slikvaart heeft verdronken. ${ }^{311}$

Die chronologisch geordnete Aufzählung berühmter Exempel für die Undankbarkeit der Welt wird hier mit einem komisch unangemessenen, trivialen und privaten Ereignis beendet: mit dem Ertränken eines Wurfs junger Katzen. Obwohl das Gedicht humoristisch angelegt ist, wird deutlich, daß der Sprecher zunächst durch die Transposition ein Gefühl höchster Empörung über eine Ungerechtigkeit ausdrückt. Der Appell des Sprechers an den Leser lautet: ,Messe meine Empörung über das Ertränken der Katzenjungen an Deiner Empörung über den schändlichen Undank gegenüber jenen exemplarischen Personen der Weltgeschichte, deren Taten und Schicksale du kennst.' Die exemplarischen Namen, die herangezogen werden, sind zwar für den Leser wie den Sprecher inadäquat, weil sie für weltpolitische Greueltaten stehen, die objektiv in keinem Verhältnis zum alltäglichen Tod der Katzenjungen stehen. Dennoch läßt Elger den Leser zunächst genau die emotionale Spannung erleben, die in einem ernsten Gedicht aufgebaut worden wäre. Dann jedoch löst er durch die Diskrepanz des hohen Stils mit den trivialen letzten beiden Versen das Gefühl ${ }^{312}$ komisch auf.

Elger vergleicht die Bewertung des Katzenschicksals mit dem berühmter Männer. Transponiert wird durch die Vergleiche und Namennennungen das Gefühl, nicht aber das Objekt, die Katze.

\footnotetext{
311 „Mußte Alexander durch Gift sein Leben lassen? / War das ein herrliches Ende seiner Tapferkeiten. / Als er Darius stolz auf den Nacken getreten ist, / Dessen Macht inn vor dem Verrat auch nicht bewahren konnte? / Und Ihr, o Hannibal, o Schrecken der römischen Städte, / Ist jetzt allein ein vergifteter Ring Eure Zuflucht? / Schied dieser Euer tapferes Leben und mutiges Ziel voneinander? / O Titus, süßestes Vergnügen aller Eurer Unternehmungen! / O Mitridates, ach! Wie war Euer trauriges Ende / Ein lebendes Beispiel Eures unerwarteten Elends! / O Cato, wenn Eure Tugend sich so ganz ausgezeichnet hat, / Und schändlich belohnt wurde, so ist es jetzt kein Wunder, daß / Man all die Jungen unserer alten grauen Katze, / So unbarmherzig neulich im Graben ertränkt hat"; Komrij 1986, S. 808 f.

312 Das Gefühl findet beim Leser - zumal wenn dieser mit dem Schema des Gedichts durch andere ähnliche Texte bereits vertraut ist - natürlich nicht wirklich statt, sondern nur im Rahmen seines fictional stance oder des make believe (s.o.).
} 
Oscar Wilde dagegen entrückt in seinem Sarah Bernhardt gewidmeten Sonett Phèdre die gepriesene Schauspielerin ${ }^{313}$ durch berühmte Namen in die ferne Vergangenheit. In einen neuen Kontext gestellt wird hier nicht das Gefühl, sondern das Objekt, auf welches sich das Gefühl richtet:

\footnotetext{
How vain and dull this common world must seem

To such a One as thou, who should'st have talked

At Florence with Mirandola, or walked

Through the cool olives of the Academe:

Thou should'st have gathered reeds from a green stream

For Goat-foot Pan's shrill piping, and have played

With the white girls in that Phæacian glade

Where grave Odysseus wakened from his dream.

Ah! surely once some urn of Attic clay

Held thy wan dust, and thou hast come again

Back to this common world so dull and vain,

For thou wert weary of the sunless day,

The heavy fields of scentless asphodel,

The loveless lips with which men kiss in Hell. ${ }^{314}$
}

Wilde portraitiert Sarah Bernhardt, indem er sie nach und nach immer weiter von der ungenügenden Alltagswelt abrückt. Schon durch den Titel fiktionalisiert Wilde seine Sarah Bernhardt. Durch die diskursiv genannten Namen wird sie in neue Kontexte gestellt, die miteinander verbunden sind. Zunächst stellt Wilde die Bernhardt in den Bereich der hohen Renaissancekultur, Danach geht er über zur griechischen Philosophie Platons und Aristoteles', den Leitbildern der Renaissancephilosophie. Schließlich bewegt sich Wilde zurück bis in den literarischen und mythischen Bereich der Werke Vergils und Homers. All dies wird im Konjunktiv dargestellt. Sarah Bernhardt ,hätte in diesen Kontexten leben sollen'. Dieser Sprechakt des Wünschens in den Quartetten wird in den Terzetten vom Sprechakt des Vermutens abgelöst. Mit einem vagen Hinweis auf den attischen Raum zieht Wilde die Konsequenz aus seinen Überlegungen in den Quartetten: Die Angeredete muß wohl tatsächlich in den genannten Kontexten gelebt haben und nun aus dem Totenreich zurückgekehrt sein.

Wildes Huldigung an Sarah Bernhardt mit Hilfe diskursiver Eigennamen geht in diesem Gedicht deswegen über einen normalen Gebrauch des Vergleichs hinaus, weil er im Haupttext keinen direkten Vergleich zwischen der Angeredeten und einer Vorbildperson der angesprochenen Ebenen zieht. Statt dessen integriert Wilde die Adressantin seines Gedichts - Sarah Bernhardt in der Rolle der Phädra Racines - in die Gesellschaft bedeutender historischer Personen. Dadurch wird sie mythisch überhöht, ohne daß der Sprecher die Gehuldigte durch einen direkten Vergleich verfremdete. Wilde entgeht auf

\footnotetext{
${ }^{313}$ Das Sonett schrieb Wilde, nachdem er die Bernhardt in der Rolle der Phèdre Racines gesehen hatte; vgl. den Kommentar in Wilde 2000, S. 275 f.

${ }^{314}$ Wilde 2000, S. 116.
} 
diese Weise dem Problem, daß der Vergleich einer Person mit einer anderen stets der verglichenen Person ein Stück Individualität nimmt, auch wenn der Vergleich noch so schmeichelhaft ist. Der Sprecher stellt auf diese Weise seine Emotion dar, ohne die Individualität der Gehuldigten anzutasten.

Diskursive Namennennungen haben keine namenträgerbezogenen Funktionen, sondern repräsentieren ein Bündel von Kennzeichnungen, die auf ein im Text auftretendes Objekt oder eine Situation bezogen werden. Beim diskursiven Nennen des Namens bilden Eigennamen eine besondere Form der Bildlichkeit, weil sie durch ihren semantischen Hintergrund eine zusätzliche zeitlich und räumlich definierte Sinnebene in einen Text einfügen können. Die Funktion dieser Namennennungen ist wie bei einem appellativischen Vergleich oder einer Metapher der Ausdruck von Gefühlen oder die Gestaltung von Objekten. Der semantische Mechanismus der Bildlichkeit von Eigennamen ist aber ein anderer. Bei der diskursiven Eigennamennennung findet eine Transposition auf eine Ebene statt, die - wie der semantische Inhalt von Eigennamen - durch die Inhalte des kollektiven Gedächtnisses konstituiert wird. Nicht ein sprachlicher, sondern ein enzyklopädischer Bildbereich wird aktiviert. Das Objekt der Transposition wird dabei nicht einfach verglichen oder charakterisiert. Vielmehr wird es in einen anderen Kontext gestellt, wodurch ein neuer Blick auf das fragliche Objekt möglich wird.

\subsubsection{Ausrichtung}

\subsection{Die Anrede beim Namen und das make-believe}

Bei der Anbindung an Kontexte und der Transposition in Kontexte durch Eigennamen wird ein Gedicht gewissermaßen in einen Kontext eingebettet. Einen weiteren Fall einer solchen Einbettung stellt die Anrede mit Eigennamen dar. Im Gedicht als isoliertem Gesprächsbeitrag gibt die Anrede beim Namen ein gesprächskonstituierendes Signal. Der Eigenname dient dazu, die Rede an einen Adressaten zu richten und dessen Aufmerksamkeit zu erheischen. Darüber hinaus signalisiert sie einem möglicherweise zuhörenden Dritten den eigentlichen Empfänger der Botschaft und identifiziert inn. Das Besondere einer Anrede beim Namen ist die Ausrichtung des gesamten Textes auf die namentlich genannte Person. Als Anrede bezieht sich ein Eigenname auf die Kommunikationssituation des Sprechers. Der Namenträger ist auf der Textebene des Sprechers und des intendierten Lesers anzusiedeln. ${ }^{315}$

Die Ebene des Sprechers ist für ein Lesen, das sich die Aussage des Gedichts imaginativ zueigen machen will, von besonderer Wichtigkeit. Wenn die kommunikativen Rollen

${ }^{315}$ Vgl. auch Lamping 1983, S. 15. 
des Gesprächs, aus dem das Gedicht, isoliert wurde', nicht spezifiziert werden, hat der Leser die Möglichkeit, alle kommunikativen Rollen - also Sprecher, lauschender Dritter oder Adressat - ohne weiteres einzunehmen. Eine der Rollen einzunehmen heißt hier, die abstrakte Textaussage in den eigenen aktuellen Kontext des Lesers zu übertragen. Die Identifikation des Lesers mit dem Text erfolgt unmittelbar, da die indexikalischen Zeichen und das von ihnen aufgebaute abstrakte Zeigfeld auf den Leser des Gedichts und seine Situation bezogen werden können. ${ }^{316}$ Dazu müssen keine kontrafaktischen inhaltlichen Annahmen gemacht werden. Das game of make-believe verlangt lediglich die Vorstellung, daß der aktuelle jeweilige ,Vorleser' des Gedichts die Worte, die er spricht, ernst meint. ${ }^{317}$ Dies gilt z.B., wenn ein Liebesgedicht von einem Leser abgeschrieben und nun an seine Geliebte geschickt wird.

Werden dagegen die Rollen des Gedichts durch definite descriptions im Haupttext oder in Paratexten spezifiziert, ändern sich die Anforderungen für eine Teilnahme am game of make-believe. ${ }^{318}$ Das game of make-believe eines Anredegedichts verlangt in diesem Fall, daß sich der Leser die im Text genannten Eigenschaften kontrafaktisch zuspricht. Davon abgesehen bleibt auch hier die Möglichkeit bestehen, die indexikalischen Zeichen auf die eigene Situation zu beziehen und sich in die durch definite oder ambiguous descriptions vorgegebene Rolle hineinzuversetzen. Der Leser kann sich in diesem Fall vorstellen, er selbst hätte die beschriebenen Eigenschaften.

Noch anders sieht das game of make-believe aus, wenn Rollen durch Eigennamen bestimmt sind. Der Leser kann in diesem Falle eine nicht namentlich differenzierte Rolle wenn die Rollen des Sprechers und des Adressaten ,besetzt' sind -, die Position eines nicht genannten zuhörenden Dritten/Vierten... einer „conversation overheard“319 einnehmen. Will der Leser aber z.B. als Vorleser eines Rollengedichtes eine namentlich identifizierte Position einnehmen, muß er sich in die durch den Namen bezeichnete Figur ,verwandeln', um am game of make-believe teilzunehmen. So kann er wie ein Schauspieler am Theater die Rolle einnehmen. Er kann aber den Text nicht als seine eigene Äußerung direkt auf seinen eigenen Kontext übertragen. Ebensowenig kann er sich einfach die Eigenschaften zusprechen, die in dem Text einer Rolle zugesprochen werden. Vielmehr muß er sich selbst in den fiktiven oder historischen Kontext transponieren, den das Gedicht evoziert.

\footnotetext{
${ }^{316}$ Vgl. Bühler 1965, S. 80, S. 102.

317 Dies ist eine der Glückensbedingungen des Sprechakts. Daß die Worte ,geliehen' sind, muß nicht dazu führen, daß an ihrer Aufrichtigkeit gezweifelt wird.

${ }^{318}$ Die Möglichkeiten sind, anders als Schlaffer (1995) oder Tate (1995, S. 142) behaupten, nicht unbedingt eingeschränkt.

${ }^{319}$ Vgl. zur Überwindung dieser Vorstellung Culler 1985, S. 38.
} 
Der Anrede beim Namen kommt insofern eine wichtige Funktion für die Leseweise des Gedichts zu. Sie kann dazu dienen, dem Leser, der in ein game of make-believe eintritt, die namentlich nicht spezifizierte Rolle zuzuweisen. Anredegedichte besetzen so etwa die Rolle des Angeredeten, Rollengedichte - bei denen der Sprecher sich selbst im Haupttext anredet oder der Sprechername in einem Paratext genannt wird - die Rolle des Sprechers. Mit diesem Mechanismus kann man auch die auffällig häufige Kombination einer Namennennung in den Paratexten eines Gedichts (etwa in der Gedichtüberschrift) bei gleichzeitiger ,Namenabstinenz' im Haupttext erklären. Die Rede des Haupttextes soll in diesen Fällen trotz der Identifikation einer der kommunikativen Positionen dem aneignenden Lesen gegenüber offen bleiben. Der Leser kann so den Namen im Paratext ,ausblenden' und den Haupttext mit seinen indexikalischen Zeichen direkt auf sich beziehen. Darüber hinaus kann er einfacher von dem Kontext des Gedichts absehen, der durch die Eigennamen in den Paratexten gestaltet wird, um ,abstrakt' die Entwicklung eines „menschlich interessanten Inhalts“320 zu verfolgen.

\subsection{Private Namen und öffentliche Anrede}

Die Anrede beim Eigennamen in einem Gedicht führt für den Sprecher in ein Dilemma: Die innertextliche Situation des vom Text gestalteten Botschaftsempfängers in bezug auf den Namen unterscheidet sich epistemisch von der außertextlichen Situation möglicher intendierter oder historischer Leser eines publizierten Textes. Der mit Namen angeredete Empfänger kennt die vollständige definite description seines eigenen Namens. Er kann seinen Namen als direkt referierendes Zeichen im Sinne Russells verstehen der Referent seines eigenen Namens ist inm und nur ihm durch knowledge by acquaintance bekannt. Der Sprecher des Gedichts muß daher in der innertextlichen Kommunikationssituation den Nameninhalt eigentlich nicht erläutern. Der den Text gestaltende Autor dagegen muß - ob bei realen Namen oder fiktionalen Namen - berücksichtigen, daß weitere Leser unter Umständen weder den aktuell relevanten und intendierten, noch den vollständigen semantischen Inhalt des Namens kennen. Er muß also den Eigennameninhalt für weitere Leser erläutern. Erläutert er den Eigennamen nicht für den allgemeinen Leser, weil es inm nicht darauf ankommt, daß dieser den Eigennamen versteht, kann es durch die Verwendung von Eigennamen zu einer „gescheiterten Geschlossenheit" des literarischen Werkes kommen. ${ }^{321}$ Aus der Art und der Ausführlichkeit, mit der ein Name in einem Gedicht mit einem semantischen Inhalt versehen wird, kann daher die kommunikative Rolle der intendierten Leser erschlossen werden. Je

\footnotetext{
${ }^{320}$ Vgl. Lamarque/Olsen 1994, S. 437.

${ }^{321}$ Vgl. Anderegg 1977, S. 29-31, S. 118.
} 
mehr ein Eigenname entgegen der Konversationsmaxime der Kürze erläutert wird, desto deutlicher wird neben dem Adressaten auch noch ein anonymes Publikum als intendierter Leser in das ästhetische Gefüge des Textes integriert.

Deutlich wird dies zunächst an Gedichten, die beim Verfassen nicht zur Veröffentlichung bestimmt waren, wie etwa bei Richard Wagners Gelegenheitsgedichten:

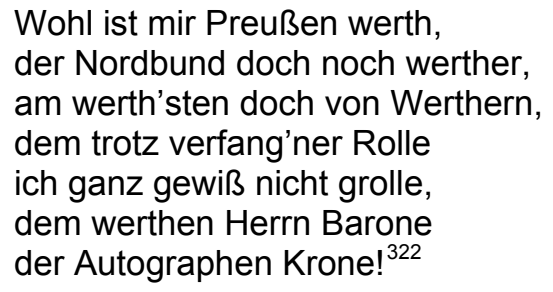

In diesem Fall ist der intendierte Leser mit dem Adressaten identisch, dessen Name daher aus Sicht des Autors und des Lesers nicht weiter erläutert werden muß. Andeutungen darauf, wer der Baron ,von Werther' war, sind rein durch die innertextliche Kommunikationssituation (Anrede, Sprechaktkonstitution und Formerfüllung) motiviert. Die Ausrichtung erklärt auch einen Code, der nur für Sender und Empfänger vollkommen verständlich ist. Das Gelegenheitsgedicht zeigt einen Eigennamengebrauch, der sich nicht an den ,Bedürfnissen' möglicher weiterer Leser orientiert.

Diese Eigennamenverwendung kann auch bei zur Veröffentlichung bestimmten Gedichten dazu genutzt werden, einen besonders, privaten Ton' anzuschlagen, an dem klar wird, daß der Leser eine persönliche und emotional private Auseinandersetzung mit bestimmten Personen miterlebt. Dies haben wir an der Widmung Goodmans gesehen.

Rudyard Kipling macht sich die genretypische kommunikative Position des Lesers von Widmungsgedichten zunutze, um mit den Lesererwartungen an Privatheit und Öffentlichkeit der Texte zu spielen. Seinen Barrack-Room Ballads stellt er ein Widmungsgedicht To T.A. voran:

I have made for you a song,

And it may be right or wrong,

But only you can tell me it it's true;

I have tried for to explain

Both your pleasure and your pain,

And, Thomas here's my best respects to you!

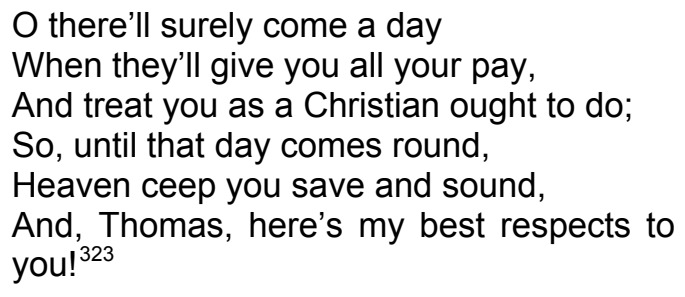

O there'll surely come a day

When they'll give you all your pay,

And treat you as a Christian ought to do;

And, Thomas, here's my best respects to you! ${ }^{323}$

Die Initialen im Titel und die auf den ,Allerweltsrufnamen' beschränkte Anrede in den beiden Strophen können den Leser vermuten lassen, daß es sich um eine private Widmung an eine dem Autor bekannte Person handelt. Die Texte der Barrack-Room Ballads zeigen allerdings, daß ,Thomas Atkins' als Sprecher und Figur der Protagonist der

\footnotetext{
322 Wagner 1905, S. 65.

${ }^{323}$ Kipling 1989, S. 2.
} 
Balladen ist. ,Thomas Atkins' steht als Stereotypenname für ,englischer Soldat' (so wie ,Gabriele Mustermann' für ,Ausweisinhaberin'). ${ }^{324}$ Kiplings Widmung ist also vollständig öffentlich. Sie gibt lediglich die kommunikative Situation einer privaten Widmung vor, in der der Leser die Referenz des Namens nicht kennt und ein ,ausgeschlossener' Dritter der Kommunikationssituation wird. Betont wird durch diese Vorspiegelung die persönliche Bekanntschaft Kiplings mit den Kontexten, in denen die ,Balladen' spielen. Kipling stilisiert sich zum Fürsprecher der Soldaten, die er im Gegensatz zu seinen kultivierten Lesern ,daheim in Großbritannien' persönlich und richtig zu kennen vorgibt und denen er in der Anrede seine Sympathie ausdrückt. ${ }^{325}$

\subsection{Der Anredewechsel}

Ein Gedichttext muß nicht einheitlich auf nur einen Adressaten oder eine Adressatengruppe ausgerichtet sein, die Anrede kann sich im Verlauf des Gedichts ändern. Um deutlich zu machen, daß bestimmte Abschnitte des Textes an verschiedene Adressaten gerichtet sind, muß der Autor Namen oder definite descriptions der Angeredeten verwenden.

Eine Auffälligkeit vieler Oden aus dem Göttinger Hain etwa ist die komplexe Anredestruktur, die die Gedichte vielfach neu ausrichtet. Dieser Anredewechsel ist eingebunden in den generellen emphatischen Ton der Freundschaftsdichtungen. ${ }^{326}$ Die Anrede bedient sich nicht immer eines Eigennamens, doch spielen Namen eine wichtige Rolle, um Personen in den schnellen Anredewechsel einzubeziehen.

Hölty etwa beginnt seine Ode Der Bund mit der Anrede an seine Harfe und einen Lindenbaum und der Selbstbenennung als „Haining“ an Stelle der topischen Musenanrufung. ${ }^{327}$ Die personifizierende Anrede an die ,Requisiten' ermöglicht es dem Sprecher, sich als souveränen Schöpfer der Szenen zu geben, die er im Folgenden gestaltet. Er zitiert die Umwelt herbei, anstatt sie zu beschreiben. Dies entspricht dem Zustand eines Dichters, der im Sinne Käte Hamburgers ein „Erlebnisgestaltungserlebnis“ gestaltet.

Die Freunde Höltys werden in der zweiten und dritten Strophe zunächst namentlich genannt, nicht angeredet. Sie treten nicht als Schöpfung des Sprechers, sondern als eigene Subjekte und Akteure auf: „Mein Gottschalk nennt mich Bruder!“; „Teuthard und Minnehold, / Das Herz im Auge, taumeln mir an die Brust“ (Gottschalk ist Johann Heinrich Voss, Teuthard Johann Friedrich Hahn, Minnehold Johann Martin Miller). ${ }^{328}$ Die

\footnotetext{
${ }^{324}$ Zum Ursprung des Namens vgl. Farwell 1981, S. 92 f.

${ }^{325}$ Vgl. Farwell 1981, S. 94.

${ }^{326}$ Vgl. Peters 1982, S. 189, der etwas übertrieben wertend von „überhitztem Pathos“ und „schwülem Sentiment" spricht.

${ }^{327}$ Hölty 1998, S. 104; vgl. Curtius 1954, S. 235-252.

${ }^{328}$ Hölty 1998, S. 104; vgl. den Kommentar in Hölty 1998, S. 495.
} 
Namennennungen sind im ersten Falle durch das Possessivpronomen, im zweiten Falle durch eine ergänzende definite description emotional aufgewertet. Die Aussagen des Sprechers werden wie eine Bühnenrede an ein nicht genanntes Publikum gerichtet. Mit dem Beginn der dritten Strophe: „Weg, Liederharfe!“, wird wiederum eine Beschreibung durch einen Befehl ersetzt. ${ }^{329}$ Die nonverbale Handlung - das Wegschleudern der Harfe - wird nicht nur beschrieben, sondern in einen explizit ausgerichteten Sprechakt umgesetzt.

Hölty steigert die emotionale Dichte weiter, indem er am Ende der dritten Strophe die Freunde anredet: „Raimund“ (Johann Thomas Ludwig Wehrs) und „Bardenhold“ (Gottlob Diederich Miller) werden in der vierten Strophe herbeigerufen. ${ }^{330}$ Dabei fallen wie bei der ,Requisitenanrede' Wunsch (Aufforderung) und Wirklichkeit zusammen. Mit dem Sprechakt wird die Handlung vollzogen. Die Strophen vier und fünf werden an „Bardenhold“ gerichtet, unterbrochen von der Anrede an die Freunde insgesamt.

In der sechsten und siebten Strophe werden wieder alle Freunde angeredet. Die Strophen kündigen einen Freundschaftsschwur an, der die folgenden Strophen bis auf die letzte füllt. Der Schwur wird durch die Anrede an „Engel“ und „Geister“ gerichtet. Er wird - in bezug auf die Magie des Schwörens korrekt - von der zweimaligen namentlichen Selbstnennung des Sprechers (als „Haining“) begleitet. Deskriptive Passagen in Strophe sechs, sieben und zwölf rahmen inn ein. Der Sprecher hat hier in der Emphase keine Kontrolle über die imaginierte Welt, besonders nicht über ihre religiösen Instanzen, „Geister“, „Engel“ und „Gott“. Er beschreibt jetzt wieder, was er ,schaut' oder fühlt, nicht was er herbeizitiert. Erst in den letzten zweieinhalb Versen der zwölften Strophe wandelt sich diese Ergriffenheit wieder in „Entzückung der Freude“ und Beherrschung der imaginierten Welt, indem "Gottschalk“ (Johann Heinrich Voss) angeredet wird. ${ }^{331}$ Gleichzeitig schließt die zweite Erwähnung Gottschalks den Kreis zum Beginn des ,Namenreigens'.

Hölty vermeidet in seiner Ode konstatierende Sprechakte. Die Gefühlsintensität ${ }^{332}$ wird durch Sprechakttypen ausgedrückt, die ein emotionales Band zwischen dem Sprecher und den Objekten seiner Rede knüpfen und die eine Handlung darstellen, z.B. durch einen Wunsch, einen Befehl oder eine Anrufung. Den Eigennamen - ob als Anrede oder Nennen des Namens - werden keine definite descriptions zugeordnet, denn nicht der Namenträger ist von Bedeutung, sondern seine Rolle in einem Handlungsgefüge,

\footnotetext{
${ }^{329}$ Hölty 1998, S. 104.

${ }^{330}$ Für „Raimund“ gilt dies nur insoweit, als sein entferntes Verweilen angesprochen wird. Auch wird sein Kommen im Gegensatz zu dem „Bardenholds“ nicht weiter gestaltet.

${ }^{331}$ Vgl. insgesamt: Hölty 1998, S. 104 f.

332 Vgl. zur Emphase und Emotionalisierung als lyriktypisches Merkmal Hühn/Schönert 2002, S. 303.
} 
welches das Gedicht vorführt. Gleichzeitig wird der Leser in die Rolle des Außenstehenden gebracht. Es spricht der Vertreter einer Gruppe mit anderen Mitgliedern der Gruppe, die ihm wohlbekannt sind. Erläuterungen der verwendeten Namen, die für ihn und seine Adressaten überflüssig sind, werden nicht gegeben. Hölty inszeniert in seiner Ode mit der Namenverwendung auch eine ,Insidergruppe', die sich vor Außenstehenden darstellt. Dies drücken auch die Bardennamen aus, die nach Art der bukolischen Stereotypennamen die realen Personen in eine fiktive Welt transponieren.

Das Anredegefüge Höltys enthält Übernamen, die als Transposition realer Personen in eine fiktive Welt verstanden werden können. Doch auch beim Umgang mit bekannten realen Namen führt die Bevorzugung der Anrede zu einer emotional dichten Atmosphäre. Die Ode Deutschland. An Friedrich Leopold Graf zu Stolberg von Johann Heinrich Voss bietet ein Beispiel für solches Vorgehen. ${ }^{333}$ Diese Ode richtet sich gegen eine Dominanz der französischen Kultur und Machtpolitik über die deutsche. Sie ist in emphatischem Ton gehalten und glänzt durch mythologische und historische Anspielungen. Die Anredesituation auch dieses Gedichts ist komplex. Die Textfunktion der Vossischen Ode ist anders als bei Hölty der Appell und nicht der Gefühlsausdruck. Doch wie bei Hölty redet der Sprecher vorwiegend nicht über die Namenträger, sondern emphatisch mit den Namenträgern.

In der Ode spricht allem Anschein nach Voss selbst. Der Sprecher fühlt sich dem ,deutschen Volk' zugehörig. Der Untertitel richtet die Ode an Stolberg, angeredet aber werden sehr verschiedene Entitäten. Zunächst richtet sich Voss offenbar an den mythisch überhöhten Hermann, den Cherusker. ${ }^{334}$ Dieser bleibt für die ersten sechs Strophen der Adressat und wird als überhistorische Instanz zur Bewertung historischer Geschehnisse angerufen. Namentlich (und emphatisch) angeredet wird er erst in der vierten Strophe. Unterbrochen wird die Wendung an Hermann von einem kurzen Schmähruf an den Mönch Einhard: „Fluch Dir, o Mönch“. ${ }^{335}$

Anschließend zeigt eine namentliche Anrede die neue Ausrichtung der Sprechhandlung auf Stolberg: „O weine, Stolberg!“ Die zehnte Strophe weitet die Anrede ironisch auf die deutschen Dichter allgemein aus: „O dichtet ihnen, Sänger Germania's; / Ein neues Buhllied!“ Die zwölfte Strophe redet personifizierend die „Schauernacht“ und die „Thrä-

\footnotetext{
${ }^{333}$ Vgl. Voss 1996, S. $96 f$.

334 Zwar deutet der Untertitel auf die Anrede an Stolberg hin. Doch trifft der Inhalt der ersten Strophe kaum auf Stolberg zu, auch wenn man inn überhöhte. Denkbar wäre, daß Voss in den ersten Strophen eine ,göttliche' Instanz anredet.

${ }^{335}$ Voss 1996, S. 96.
} 
nen“, die letzte Strophe schließlich das ebenfalls personifizierte Hexameter-Epos Klopstocks „Meßias“ an. ${ }^{336}$

Die Ausrichtung des Textes paßt zum jeweiligen Thema der Strophe, ohne daß die jeweils Angeredeten selbst zum Thema würden. Vossens Ode drückt in den häufig wechselnden Anreden die emotionale Verbindung mit den angesprochenen Themen aus. Seine Darstellung wird durch die jeweilige emphatische Anrede in den Ton der Ode eingestimmt. Die Beziehung des Sprechers zu seinen Objekten ist also klar emotional strukturiert. Gerade dort, wo der Sprecher eigentlich über die Geschichte oder eine gegenwärtige Lage berichtet, wird der Sprechakt des Berichtens vermieden zugunsten emotionaler Sprechakte wie der der Anrufung, des Verfluchens, oder des Aufrufs. Die Ode zeigt daher, wie durch die Anrede konkreter Figuren die Emotionalität eines partiell argumentativen und berichtenden Textes erhöht wird. Da im Falle emotional intensiver Sprechakte die Beziehung zwischen Sprecher und Hörer wichtig ist, benennt Voss jeweils einen Adressaten. Dies geschieht nicht immer mit dem Eigennamen, doch spielen Namen eine wichtige Rolle. So ergibt erst die namentliche Anrede Hermanns in der vierten Strophe eindeutig den Adressaten der ersten Strophen. Die namentliche Anrede Stolbergs in der Mitte des Gedichts (zu Beginn der siebten von 13 Strophen) zeigt den Wendepunkt von der historischen ,Einleitung' zum aktuellen Thema der Ode. Schließlich dient der Werkname ${ }^{337}$ „Meßias“ als letzte Steigerung in der letzten Strophe Voss zwar primär zur Anrufung des Klopstockschen Dramas, sekundär aber auch zur Anrufung Christi.

Hölty und Voss gestalten in ihren Oden einen vielfältig ausgerichteten Monolog, der den jeweiligen Objektbereich in die Kommunikationssituation integriert. Die angestrebte Intensität und Emotionalität wird durch die hohe Dichte nicht assertorischer ,Sprechakte' erreicht. Das ,Glücken' der Sprechakte hängt von adäquaten Kontextbedingungen ab, zu denen auch die richtige Ausrichtung des Sprechaktes gehört. Dazu ist die Identifikation der Angeredeten - z.B. durch Eigennamen - nötig. Weiterhin führen Hölty und Voss in ihren Oden Handlungssequenzen aus Sprechakten vor. Die unterschiedliche Ausrichtung der Sprechhandlungen bestimmt auch den Ablauf des Textes.

Unter den innertextlichen Faktoren, die Hinweise auf den Status des Sprechers und der dargestellten Welt geben, nehmen Eigennamen eine zentrale Stellung ein. Durch Ei-

\footnotetext{
${ }^{336}$ Voss 1996, S. 97.

${ }^{337}$ Man kann hier namentheoretisch darüber streiten, ob ,Meßias' ein Name oder ein Begriff ist. Als Titel des Klopstockdramas betrachten wir inn als Namen (des Werkes). Als Bezeichnung Christi ist er zumindest aus der christlichen Sicht Vossens ebenso Eigenname, weil es nur den Messias gibt. Er mag als attributiver Eigenname bezeichnet werden - im Sinne von ,wer auch immer Gottes Sohn ist, heißt ,der Messias".
} 
gennamen signalisiert der Autor eine pragmatische Einbindung seines Gedichts. Fiktive Namen dienen dazu, das Sprechersubjekt oder die dargestellte Welt vom realen Autor deutlich zu trennen. Reale Namen können die Identifikation des Autors mit dem Sprechersubjekt fördern. Auch reale Orts- und Personennamen sind allerdings nur im Rahmen eines bestimmten Textes, mit dem sie in hermeneutischer Wechselwirkung stehen, produktiv, wie Burdorf bemerkt. ${ }^{338}$ Dies beruht auf der unsicheren Bedeutungsstruktur von Eigennamen. Auch wenn der Leser eigenes Wissen über den Namenträger ergänzend einbringen darf, richtet sich die Grenze der für den Text relevanten Bedeutung nach der ermittelbaren Autorintention, nach Kotext und Kontext.

\subsubsection{Zusammenfassung: Die Eigennamenreferenz und der Kontextbezug des Ge- dichts}

Namennennungen und -erwähnungen im Haupttext und in Paratexten ordnen den Text in einen Kontext ein. Da die Namen den Kontext der Äußerung spezifizieren, schränken sie eine ,Kontextmultiplikation' ${ }^{339}$ ein und verlangen bzw. leisten eine Verallgemeinerung des Geschilderten durch die Exemplifikation des realen Ereignisses. Die Kontextanbindung ermöglicht es außerdem, eine Figur oder Person über die Grenzen des (kurzen) Gedichts hinweg zu gestalten, sei es im Zyklus mehrerer Gedichte, sei es durch die Gestaltung der Figur in mehreren Textsorten, sei es durch die Berufung auf enzyklopädisches Wissen des Lesers. Durch diese Funktionen werden kurze Texte in ein breites Feld anderer Texte eingeordnet, von dem sie dann einen Teil bilden.

Die Namenleistungen der Anbindung, der Transposition und der Ausrichtung des Textes, bzw. Textinhalts funktionieren aufgrund der besonderen Möglichkeit von Eigennamen, die transworld identification sicherzustellen, sofern die verwendeten Eigennamen dem Hörer oder Leser bekannt sind. Eigennamen dienen in diesem Fall auch der Illusionierung, denn sie lassen die von Sprechern benutzte personal deixis auf eine im Text identifizierbare Einheit referieren, machen die Objekte, auf die deiktisch verwiesen wird, identifizierbar und mentale Entitäten konzeptualisierbar. ${ }^{340}$ Da Namen das Sprechersubjekt und angesprochene Personen sowie Orte identifizierbar machen, stellt der Autor mit den Eigennamen realer Personen aus seinem engeren oder weiteren Umfeld oder mit seinem eigenen Namen das Gedicht in ein historisches privates oder öffentliches setting, bzw. er stellt seine eigene Person auf die Ebene des Sprechersubjekts. ${ }^{341}$ Insbe-

\footnotetext{
${ }^{338}$ Vgl. Burdorf 1995, S. $176 f$.

339 Zu den „multiplizierten” Kontexten eines Gedichts vgl. Stierle 1979a, S. 515-517, S. 523 f.; zur Einschränkung vgl. Shawcross 1983, S. 164 f.

${ }^{340}$ Vgl. Bex 1995, S. 166.

341 Gedichte können somit durch Eigennamen das Ich des Gedichts bestimmen, wie es in der Alltagssprache auch gefordert wird (vgl. Wolf 1998, S. 272). Die Illusionierungswirkung von Eigennamen gilt
} 
sondere beim Wechsel verschiedener Anreden kann durch die Anrede mit Namen eine Bewegung des Sprechers vorgeführt und nachvollziehbar gemacht werden. Ist die Referenz des Namens dem Leser bekannt und kann er den relevanten Ausschnitt aus dem semantischen Inhalt ermitteln, ist sein Verständnis des Namens nicht gehindert. Der Leser kann die Rolle des „sujet de l'énonciation“ übernehmen und so eine „komplexe Identität von innen erfahren“ oder sich in die Rolle des Angeredeten versetzen. ${ }^{342}$ Dazu muß er sich für das game of make-believe allerdings anders als bei der Übernahme der Kennzeichnungen einer abstrakten Rolle vorstellen, ein Anderer zu sein.

Bei Rollengedichten wird die Aneignung der Gedichtaussage trotz des Namens nicht eingeschränkt, sofern der Name eine allgemein bekannte Rolle bzw. ,Maske' ${ }^{343}$ gestaltet, die der Leser übernehmen kann. Anders sieht es aus, wenn in dem Haupttext eines Gedichts gezielt Eigennamen verwendet werden, die dem Leser unbekannt bleiben müssen. Sie erweisen sich als ein Identifikationshindernis und lassen einen privaten und unzugänglichen Kontext vermuten. ${ }^{344}$ Wenn der Name nicht als fiktionaler Name angesehen werden kann, muß der Leser von einer gespaltenen Kommunikationssituation ausgehen, bei der ein intendierter Adressat des Gedichts den Text anders liest und den Namen besser versteht. Die Anrede beim Namen dient in diesem Fall der Identifikation und Abgrenzung des Angeredeten im universe of discourse und damit der genauen Ausrichtung des Textes.

Wie bisher gezeigt worden ist, dienen Eigennamen durch ihre besondere semantische Struktur der Textstrukturierung und durch ihre besonderen Referenzleistungen der Textanbindung. Als dritte Besonderheit des Eigennamenzeichens haben wir die Zeichengestalt ermittelt. Sie kommt in Gedichten besonders in ästhetischer Funktion zum Tragen, die im Folgenden untersucht werden soll.

\subsection{3 Ästhetische Funktion: artistische und komische Formerfüllung durch das Eigennamenzeichen}

\subsubsection{1 Ästhetische Funktion und formale Artistik}

Ästhetisierung meint hier die Darstellungs- oder Betrachtungsweise, die den Namen zum Objekt eines Erlebens macht, das seinen Zweck in sich selber hat. ${ }^{345}$

lediglich für Eigennamen, die Figuren bzw. Personen und Orte denotieren. Appellativisch, etwa als Metapher, exemplum etc., verwendete Eigennamen tragen nicht zur Illusionierung im Rahmen einer fiktionalen oder realen Welt bei.

${ }^{342}$ Vgl. Stierle 1979a, S. 522.

${ }^{343}$ Vgl. Killy 1972, S. 87 f. und S. 156-186.

${ }^{344}$ Hühn 1995, S. 10; vgl. auch Burdorf 1995, S. 176; Schlaffer 1995, S. 56 f.

${ }^{345}$ Lamping 1983, S. 83. 
So beschreibt Lamping diejenige Funktion von Eigennamen, die den Blick auf den Namen und seine Zeichen- und Bedeutungsbestandteile lenkt. Er bezieht sich dabei auf das Kunstwerk als „materielles Gebilde“. ${ }^{346}$ Wir folgen Lamping sowie den Ausführungen Gombrichs und Wollheims darin, daß ein Kunstwerk unter anderem in der Auseinandersetzung des Künstlers mit den Möglichkeiten und Begrenzungen seines Materials entsteht und es somit auch aus "the confrontation of the artist and his medium" besteht. ${ }^{347}$ Eine ästhetische Funktion („relevance to form“, wie sie Gerus-Tarnawecky Eigennamen im Gedicht zuspricht ${ }^{348}$ ) kommt nicht nur Namen zu, sondern allen Elementen eines jeden Gedichts. Jedes Zeichen wird unter anderem nach formalen Gesichtspunkten in den Gedichttext integriert und kann daher auch unter diesen, vom Inhalt absehenden Aspekten betrachtet werden. Die Zeichengestalt wird damit zum ästhetischen Objekt, das in die formal-ästhetischen Ordnungsstrukturen des Gedichts eingepaßt wird.

Die ästhetische Funktion tritt dabei in unterschiedlicher Intensität zu Tage. Zum einen kann sie als bei der Konstruktion eines Gedichts latent eine Bedeutung gehabt haben, tritt aber gegenüber der semantischen Bedeutungshaltigkeit des Textes in den Hintergrund und hat unterstützende Funktion. Zum anderen können einzelne oder alle Elemente eines Textes nur oder hauptsächlich der Erfüllung einer vorgegebenen Form dienen. Dies bedeutet dann entweder eine unfreiwillige Konzession des Dichters an das Material oder einen bewußten Hinweis des Dichters eben auf das Material. ${ }^{349}$

Als Strategien der ästhetisierenden Textgestaltung mit Eigennamen, die bewußt auf das ,Material' des Textes hindeuten hat Lamping die „Isolierung“ und die „Komisierung“ der Namen bestimmt. ${ }^{350}$ Als Isolierung bezeichnet er die Betrachtung des Namens als eigenständiges vom Ko- und Kontext getrenntes Objekt, als ,Komisierung' die komische Gestaltung oder Verwendung des Eigennamens. ${ }^{351}$ Anders als Lamping meint, ist allerdings die Isolierung des Namenzeichens eine generelle Bedingung sowohl für die nicht komische Ästhetisierung als auch für die ,Komisierung' des Namens, weil die Isolierung erst die Aufmerksamkeit auf das Namenszeichen und seine Eigenschaften lenkt. Die Isolierung ist also der ,Komisierung' vorgeschaltet.

\footnotetext{
${ }^{346}$ Vgl. Lamping 1983, S. 83; vgl. auch Ashley 1979, S. 263.

${ }^{347}$ Vgl. den bei Gombrich ausgeführten Begriff der „transcription“; Gombrich 1961, S. 36-39; vgl. Wollheim 1980, S. 117.

${ }^{348}$ Vgl. Gerus-Tarnawecky 1968, S. 313, im Anschluß an Rudnyckyj 1959, S. 382.

${ }^{349}$ Daher auch der bereits erwähnte Vorwurf Müllers, formale Gattungsbestimmungen seien "ganz äußerliche Kriterien“ (Müller 1998, S. 94).

${ }_{350}$ Vgl. Lamping 1983, S. 83

${ }^{351}$ Vgl. Lamping 1983, S. 83-93.
} 


\subsubsection{2 Ästhetisierung durch Isolierung}

\subsection{Kontextisolierung}

Da die Bedeutung eines Namens auf der kontextabhängigen Referenz auf einen Namenträger beruht, hat die Isolierung eines Namens aus seinem Kontext zunächst seine Dereferentialisierung zur Folge. Ein Gedichtbeispiel für die konsequente Ästhetisierung eines Namens durch Dereferentialisierung ist Kurt Schwitters berühmte Figur Anna Blume: Schwitters ,vermerzt' den Namen und Eigenschaften ,Anna Blumes' aus seinem Gedicht An Anna Blume systematisch. Die Anrede der Geliebten durch den Sprecher zu Beginn des ,Namenursprungsgedichts' - mit dem Pronomen der zweiten Person singulär, mit verschiedenen Epitheta und mit dem Namen ,Anna Blume'352 - läßt zunächst einen gewöhnlichen und möglicherweise über den Text hinaus referierenden realen Namen vermuten. ${ }^{353}$ Auf diese Weise wird der Leser einerseits zur Imagination einer Figur angeregt. Andererseits macht die in sich widersprüchliche Beschreibung der Person die Referenz von Beginn an zweifelhaft. Der Sprecher kommt auch bald auf den Namen selbst zu sprechen: „Anna Blume, Anna, A----N----N----A! / Ich träufle Deinen Namen." und liebkost durch den Namen seine Geliebte in der alten Tradition der magischen Verbundenheit von Person und Name. Dann beginnt er, mit dem Personalpronomen auf das Namenzeichen selbst zu referieren:

\section{Und weißt Du es, Anna, weißt Du es schon, \\ Man kann Dich auch von hinten lesen. \\ Und Du, Du Herrlichste von allen, \\ Du bist von hinten wie von vorne: \\ A-----N-----N-----A. ${ }^{354}$}

Die Hervorhebung des Namenzeichens und seiner Eigenschaften lenken den Blick immer weiter weg von einer möglichen Referenz. Die Namenträgerin scheint abwesend zu sein, der Sprecher bleibt beim Eigennamen, der am Ende als „Rindertalg“ „STREICHELN“ über seinen Rücken „träufelt“. ${ }^{355}$

Der Name referiert in An Anna Blume noch auf ein Sinngebilde. Das heißt, die Eigennameneigenschaften werden im Sinne der Goodmanschen pictorial reference in einem dichten System auf die (fiktive oder reale) Figur angewendet. Im letzten Satz wird die Referenz auf eine mögliche fiktive oder reale Namenträgerin wiederhergestellt, indem der volle Name in einer letzten Liebeserklärung referierend ausgerufen wird. Insofern bleibt das Gedicht An Anna Blume in bezug auf die Referenz des Namens vergleichsweise stabil. Die zeitweise Ausrichtung auf das Namenszeichen aber bereitet schon die

\footnotetext{
${ }^{352}$ Vgl. Schwitters 1998, S. 58.

${ }^{353}$ Vgl. die plausible Argumentation in Arnold 1972.

354 Schwitters 1998, S. 59.

355 Schwitters 1998, S. 59.
} 
,Vermerzung' des Namens in anderen Texten vor. ${ }^{356}$ In den poetologischen Streitgedichten Aufruf! (Ein Epos) und Nennen Sie es Ausschlachtung wie auch in anderen Texten treten die Namen ,Anna' und ,Anna Blume' immer wieder mit so unterschiedlichen Kennzeichnungen auf, daß die eindeutige Referenz auf ein einzelnes Objekt ausgeschlossen ist. ${ }^{357}$ In Nennen Sie es Ausschlachtung z.B. nutzt Schwitters die verschiedenen Formen der Referenz von Kunstwerken, wie wir sie im Anschluß an Goodman bestimmt haben, um den Sinn des scheinbaren Unsinns in seinem Gedicht Anna Blume spöttisch auch seinen ästhetischen Gegnern vorzuhalten:

Anna Blume ist die Stimmung, direkt vor und direkt nach dem Zubettgehen.

Anna Blume ist die Dame neben Dir

Anna Blume ist das einzige Gefühl für Liebe, dessen Du überhaupt fähig bist

Anna Blume bist Du

$[\ldots]^{358}$

Hier führt Schwitters die klassischen Beziehungen eines Kunstwerkes zur Realität vor, bevor er das seinen Gegnern unterstellte böse Wort vom Ausschlachten aufnimmt. Er ignoriert die Erwartung, der Name würde eine bestimmte Person einfach denotieren. Statt dessen drückt der Name für Schwitters eine Stimmung aus, er exemplifiziert bestimmte allgemeine Eigenschaften durch den Namenträger (eine vertraute Frau zu sein), er drückt ein Gefühl aus und lädt schließlich zur aneignenden Lektüre ein. Erreicht wird damit insgesamt, daß die naive Vorstellung, ein Gedicht beschriebe eine kohärente Realität und der Name referiere einfach auf eine beschriebene (reale) Person, zugunsten der komplexen ästhetischen Anwendung des Gedichts auf eine neu gestaltete oder umgestaltete Wirklichkeit unterlaufen wird.

\subsection{Kotextisolierung}

Anders als in Prosatexten ist in Gedichten jedes Zeichen tendenziell von grammatischen und pragmatischen Zusammenhängen isoliert, weil das Prinzip der formalen Überstrukturierung generell zu einer „Entautomatisierung“ der Sprache führt und die sprachlichen Zeichen eine „iconic transmutation“ erfahren. ${ }^{359}$ Aus sprachtheoretischer Sicht sind isolierte Eigennamen in Gedichten daher semantisch weniger auffällig als in Erzähltexten. Eigennamen verlieren in Gedichten je nach den Gestaltungsprinzipien des

\footnotetext{
${ }^{356}$ Vgl. zur Verwendung des Namens auch Barni 1986.

${ }^{357}$ Vgl. Schwitters 1998, S. 60-64.

358 Schwitters 1998, S. 64.

359 Vgl. Knörrich 1992, S. XXXII; vgl. Austermühl 1981, S. 147; Hühn 1995, S. 12; generell zu isolierten Eigennamen in Lyrik vgl. auch die Bemerkung Mainbergers 2003, S. 154. Dies bedeutet auch, daß der Rezipient die Nutzung aller zentralen und marginalen Eigenschaften des Zeichens unterstellen kann und der Produzent seinerseits mit dieser Unterstellung rechnen kann und muß (vgl. Culler 1975, S. 164); zur „iconic transmutation“ vgl. Warning 1997, S. 23; Culler 1985, S. 40 f.; Bex 1995, S. 163. Hierbei handelt es sich um fließende Übergänge, da auch in Erzähltexten partiell von einer solchen „iconic transmutation” ausgegangen werden kann, die zudem nicht in allen Gedichten in gleichem Maße zu finden ist.
} 
Gedichts einen kleineren oder größeren Teil der semantischen Sonderstellung, die sie in Erzähltexten genießen.

Eigennamen können allerdings (wie jedes Zeichen) in Gedichten graphisch vom restlichen Text isoliert werden. Die graphische Hervorhebung durch besondere Schrifttypen, Schriftgrößen etc. haben wir schon anhand der am Gedichtumriß orientierten Namenpositionierung beobachtet. Auch Schwitters Gedicht An Anna Blume zeigt diese Methode.

In formal nicht streng gebundenen Gedichten kann der Name darüber hinaus durch den Zeilenumbruch hervorgehoben werden. So schreibt Hart Crane in My Grandmother's Love Letters:

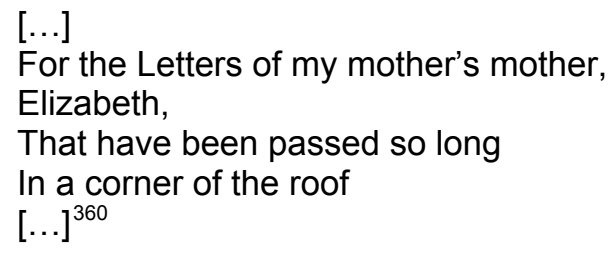

Crane bildet durch den Zeilenumbruch das Innehalten des Sprechers bei dem als Apposition eingeschobenen Namen graphisch nach. Der Sprecher und mit ihm der Leser verweilen bei dem Namenszeichen: der Sprecher wohl in Erinnerungen an die Großmutter versunken, der Leser in Betrachtung des Namenszeichens, das klangvoll und durch die englische Königin Elizabeth I. präfiguriert eine beeindruckende Persönlichkeit suggeriert.

Auch ein Ausrufen des Namens kann optisch durch eine solche isolierte Position realisiert werden, wie z.B. im Falle des Ortsnamens in Montalbáns Bilbao Song:

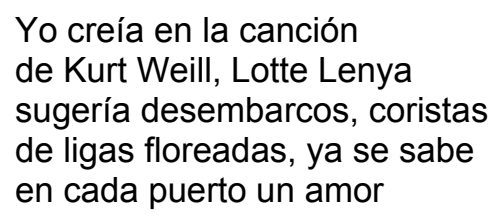

Bei Bilbao handelt es sich um einen bekannten Namen, der - zumal für eine spanische Leserschaft - einen wohldefinierten industriell geprägten Ort benennt. Hier kann der Leser einen ihm bekannten Hintergrund aufrufen und seine enzyklopädischen Kennt-

\footnotetext{
${ }^{360}$ Crane 1968, S. 6; vgl. zu dieser Stelle auch Shawcross 1978, S. 5 f.

361 „Ich glaubte an das Lied / Kurt Weills, Lotte Lenya / suggerierte Anlandungen, Chorsängerinnen / mit geblümten Strumpfbändern, man weiß schon / in jedem Hafen eine Liebe / Bilbao / unter der Baskenmütze und dem Regen / dagegen hatte ein Lachen / mit Resten von Märkten und Händlern / [...]"; Montalbán 1996, S. 102.
} 
nisse aktivieren. Der isolierte Ortsname bildet einen inhaltlichen Wendepunkt des Gedichts, an dem der Leser verharrt, bevor der Sprecher in der darauf folgenden Strophe über den Ort spricht.

Formal isolierte Eigennamen bilden einen dynamischen Höhepunkt. Sie stellen das besprochene Objekt konzentriert dar. Der Sprecher beschwört das Objekt durch den isolierten Namen und evoziert es für den Leser. Die formale Isolierung des Namens läßt Sprecher und Leser bei dem Namenzeichen einschließlich seiner auf der Referenz beruhenden Bedeutung verweilen, so daß sich das semantische Potential des Namens entfalten kann.

\subsection{Isolierung im Katalog}

Wie wir gesehen haben, treten Eigennamen in Katalogen zumeist in einer Anordnung auf, die durch die Referenzobjekte der Namen hergestellt wird. Eine andere Möglichkeit besteht darin, Aufzählungen oder Kataloge nach Eigenschaften der Namenzeichen anzuordnen.

Fehlt eine solche Ordnung innerhalb des Katalogs hingegen ganz, wird die Leserichtung nicht mehr eindeutig bestimmt. ${ }^{362}$ Die Eigennamen stehen nebeneinander, nicht mehr in einer bestimmten Reihenfolge hintereinander. Der Namenkatalog ist dabei im Gedichtkotext isoliert, ebenso der einzelne Name im Katalog, weil seine syntaktische Bindung nur noch lose oder gar nicht mehr vorhanden ist. ${ }^{363}$

In Ivan Golls Zyklus „Jean sans Terre“ wird etwa die Aufzählung zum Gestaltungsprinzip, um das ruhelose Umherirren in der verwirrenden Fülle der Welt zu gestalten. So bilden aneinandergereihte Namen eine isolierte Strophe des Gedichts La Marche de Jean sans Terre. Troisième version:

Ponte Vecchio Pont Neuf

Puente Alcantara Benkei Bashi

Kakushkin Most Teufelsbruecke

Pons Augustus Brooklyn Bridge ${ }^{364}$

Graphisch hat die Strophe die gleiche Form wie der Refrain, sie steht auch an einer Stelle, an der man den Refrain erwarten würde:

Jean sans Terre marche marche

Sa semelle claque claque

Son squelette craque craque

Et la terre tourne tourne ${ }^{365}$

\footnotetext{
${ }^{362} \mathrm{Vgl}$. auch Mainberger 2003, S. 31-36.

${ }^{363}$ Vergleichsweise intensiv untersucht sind die Kataloge und Aufzählungen amerikanischer Ortsnamen bei Walt Whitman (vgl. Hollis 1957; Read 1980; Read 1982). Thema sind Namen auch in onomastischen Gedichten Moores 1955 oder Benéts 1942, S. 367 f.; vgl. auch Mainbergers etwas übertriebene Analyse einer Notiz Hölderlins als Namengedicht in Mainberger 2003, S. 155.

${ }^{364}$ Goll 1996, S. 286.

365 "Ohneland, er läuft und läuft / Seine Sohle tappt und tappt / Sein Gerippe klappt und klappt / Und die Erde kreist und kreist”; Goll 1996, S. 286 (Übersetzung Goll 1996, S. 287).
} 
Die berühmten Namen der Brücken stehen zunächst für die vielen Länder, durch die der Protagonist Jean sans Terre ruhelos reist. Daß es sich um Brücken handelt, also ,Räume zwischen Himmel und Erde', paßt zu der Benennung des Protagonisten als ,Johann Ohneland'. Die Brücken sind mit dem lyrischen Bild der Folgestrophe verbunden, in dem Jean auf den Brücken verschiedener Flüsse Fische füttert. Die Namenaufzählung repräsentiert durch die Herkunftssprache der Namen wie durch die Lage der benannten Objekte die ruhelose und ewige Bewegung Johann Ohnelands und letztendlich: des Menschen insgesamt. Die Brückennamen sind berühmt, sie stehen auch für Landschaften und Lebensweisen. Jedoch sind die Namen nicht nur aus diesem Grunde ausgewählt worden. Vielmehr legt Goll Wert auf die redenden Bestandteile der Ortsnamen (bzw. Brückennamen). Der Schwarm bildet die wichtigen Stationen eines Universums ab: Die ,alte' Brücke steht im ersten Vers neben der ,neuen', die Teufelsbrücke nimmt das ständig präsente Thema der Verdammnis in Golls Zyklus auf. Schließlich zeigt auch die Variante des Schwarms in La Marche de Jean sans Terre. Cinquième version, wie sehr es Goll um diese Elemente ging:

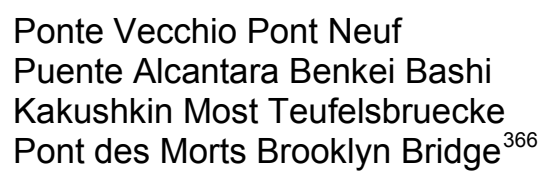

Statt der römischen Brücke des Augustus nennt Goll hier die französische ,Brücke der Toten'. Er nimmt also eine Einschränkung der ,sprachlichen Internationalität' seines Brückenschwarms in Kauf, um durch einen redenden Namen das Semem ,Tod' in den Namenkatalog aufzunehmen. Auf diese Weise kombiniert Goll in seinem Namenkatalog die ästhetische Wirkung fremdsprachiger Namen mit der Wirkung der Ursprungssemantik einiger der Brückennamen. Neben dem durch die Fremdsprachigkeit und die Sememe ,alt' und ,neu' hervorgerufenen Bild des ruhelosen Johann Ohneland werden die für den ganzen Zyklus thematischen Begriffe ,Teufel' und ,Tod' aus dem Wortfeld ,Verdammnis' und ,Tragik' aktualisiert.

Ivan Goll zeigt einen sich verselbständigenden Namenkatalog in der Funktion der percursio. In der Funktion der evidentia stellt ein ungeordneter autoreferentieller Katalog leicht einen Teil der beschriebenen Realität dar, der in das Gedicht integriert wird. Derek Walcotts $A$ Sea-Chantey beginnt mit der Aufzählung einiger Inselnamen der Antillen $^{367}$ :

\footnotetext{
${ }^{366}$ Goll 1996, S. 294.

${ }^{367}$ Zur Magie von Ortsnamen in amerikanischer Poesie vgl. Read 1982.
} 
Anguilla, Adina,

Antigua, Cannelles,

Andreuille, all the l's,

Voyelles, of the liquid Antilles,

The names tremble like needles

Of anchored frigates,

$[\ldots]^{368}$

Dieser übersichtliche Namenkatalog zu Beginn des Gedichts hat zunächst die Funktion, eine imaginierte Hintergrundwelt einzuführen. Die Zusammenfassung am Ende des Katalogs durch den Namen der Inselgruppe stellt die allgemeine Referenz der möglicherweise unbekannten Namen sicher. Es handelt sich um einen bekannten Namen, der Leser kann sich also ein ungefähres Bild machen, wovon Walcott ausgeht. Die einzelnen Inselnamen sind weniger bekannt. Die Unterbrechung des Schwarms (,all the l's, I Voyelles") zeigt, daß sie um ihres Klanges willen zusammengestellt wurden. Sie ermöglichen es Walcott, in einen englischen Text eine exotische fremdsprachige ,Sprachinsel' zu integrieren, die dem englischsprachigen Leser dennoch verständlich bleibt. ${ }^{369}$ Der ,flüssige' Klang der zahlreichen Liquide (Laterale und Vibranten) in den französischen und spanischen Inselnamen dient dem Sprecher als Übergang zu seinem lyrischen Bild der Fregatten im Hafen und der See. Die spezielle Referenz der einzelnen Namen spielt in diesem Katalog keine Rolle. Am Ende seines Gedichts wiederholt Walcott den Schwarm und wandelt inn dabei ab:

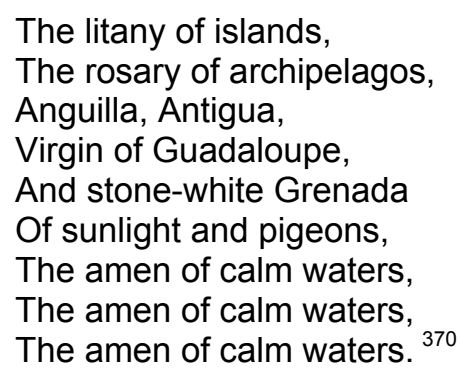

Die letzten drei Verse symbolisieren klanglich die Bewegung des Meeres, das regelmäBige Branden der Wellen am Strand. Die Inselnamen wirken wiederum durch ihren Klang, zusätzlich aber integriert Walcott jetzt einen redenden religiösen Namenbestandteil („Virgin of...") und einen Bestandteil des semantischen Hintergrunds („stone-white“). Dies entspricht dem Verlauf des Gedichts, in dem der klangliche Eindruck von einer visuellen Beschreibung abgelöst wird. Das Bild der Inselgruppe wird mit wenigen ,Pinselstrichen' zu einem Abschlußtableau erweitert.

\footnotetext{
${ }^{368}$ Walcott 1986, S. 44.

${ }^{369}$ Vgl. dazu Walcotts Äußerungen in seiner Nobel Lecture: „I stand here in their name, if not their imagebut also in the name of the dialect they exchange like the leaves of the trees whose names are suppler, greener, more morning-stirred then English-laurier canelles, bois-flot, bois-canot-[...]." Walcott 1992, o.P. Zur Fremdsprachigkeit in Texten durch Eigennamen vgl. Aschenberg 2002, S. 118-120.

${ }^{370}$ Walcott 1986, S. 46.
} 
Während Walcott den Klang der Namen nutzt, bringt Ivan Goll die Namenherkunft und die redenden Bestandteile der Namen zur Geltung. Bei beiden Schwärmen spielt die Referenz der Namen eine Rolle, sie ergibt aber keine eindeutige Ordnung des Namenkatalogs. Daher können sich Assoziationen zu den Elementen des Schwarms und zu deren Verbindung untereinander entfalten. In Pablo Nerudas Como era España, einem Abschnitt aus España en el corazón wird dieses Prinzip auf die Spitze getrieben. Das Gedicht markiert als Abschnitt aus España en el corazón eine Wende Nerudas von einem apolitischen Symbolisten zu einem dezidiert politischen Dichter. ${ }^{371}$ Neruda bespricht die politische Situation Spaniens im Bürgerkrieg. In den ersten drei Abschnitten drückt der Sprecher seine Liebe zu einem herben, kargen, leidgeprüften und proletarischen Spanien aus. An diese Liebeserklärung schließen sich 14 vierzeilige Strophen mit unregelmäßigen Metren an, die nur aus Spanischen Ortsnamen bestehen. ${ }^{372}$ Wir zitieren hier lediglich die Strophen eins, zwölf und dreizehn, die das Prinzip der Aufzählung verdeutlichen:

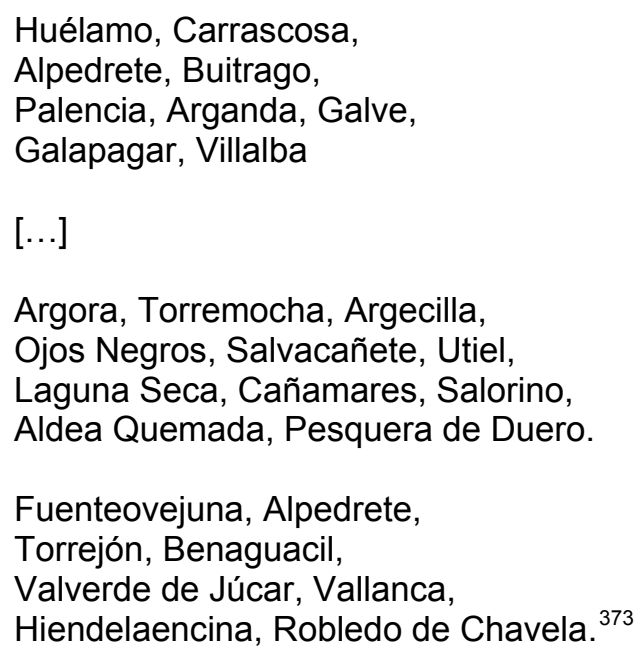

Anhand einschlägiger Atlanten und Enzyklopädien kann man sich davon überzeugen, daß alle Ortsnamen für reale Orte Zentralspaniens stehen. Es handelt sich größtenteils um kleine Flecken und Ortschaften, teilweise mit nur wenigen Hundert Einwohnern. Eine geographische Ordnung ist in der Aufzählung nicht festzustellen. Auch die Formerfüllung kann nicht das Motiv der Aufzählung sein, da weder ein Reimschema noch ein eindeutiges Metrum zu erkennen sind. Wozu also diese lange Aufzählung?

Wie Walcott gestaltet Neruda einen Namenkatalog im Dienste der evidentia. Die Namen überwältigen zunächst den Leser durch ihre schiere Menge. ${ }^{374}$ Sie belegen aber vor

\footnotetext{
${ }^{371}$ Costa 1979, S. 93.

372 Zur Aufzählung von Ortsnamen allgemein vgl. Utley 1968, bes. S. 290-292.

${ }^{373}$ Neruda 1957, S. 279-281.

${ }^{374}$ Vgl. Costa 1979, S. 96f.
} 
allem als Teil der beschriebenen Realität die Charakterisierung Spaniens in den ersten drei Strophen. Da Ortsnamen vielfach deutlich semantisch motiviert sind und zudem alte Sprachschichten und Benennungskonventionen konservieren, kann Neruda mit der Namenaufzählung jenes alte Spanien erstehen lassen, das er gegen die faschistoiden Franquisten halten will. Es handelt sich um kastilische Namen. Sie konservieren das ,alte Spanien', eine ,große und dauerhafte Tradition' der Spanier, die Neruda auch in seinen einleitenden Strophen beschwört und die er den sich traditionalistisch gebenden Franquisten nicht überlassen will. Hatte er zuvor seine Liebe zu Spanien ausgedrückt, so ,meditiert' Neruda nun die Ortsnamen jenes Spanien. Damit ästhetisiert er sie im Dienste der Gedichtaussage. Hier wie bei Walcott tritt der Sprecher bei der Namenbetrachtung zurück an die Seite des Lesers. Die Fülle der Namen entfaltet unabhängig von den Intentionen des Sprechers ihre Wirkung. Sprecher (Autor) und Leser können sich, am Klang der Namen berauschen. Das ,alte Spanien' wird schon in der Einleitung als ,einzigartig, lebendig, schläfrig und klangvoll' beschrieben ${ }^{375}$. Autor, Sprecher, impliziter und historischer Leser können Komponenten der Ursprungssemantik aktualisieren, wie sie besonders in der Mikrotoponymie üblich sind, z.B. bei „Ojos Negros“ (schwarze Augen), „Villalba“ (Weißstadt), „Laguna Seca“ (trockene Lagune), „Aldea Quemada“ (verbranntes Dorf) usw. Schließlich erinnern die Namen auch an die kulturelle Bedeutung einzelner Orte, z.B. besonders „Fuenteovejuna“, das an das gleichnamige kanonische Drama Lope de Vegas (1619) erinnert und zugleich an dessen Stoff: den (als heldenhaft interpretierten) Aufstand der Bewohner einer Stadt gegen die tyrannische Obrigkeit 1476. Durch den gemeinsamen Blick von Autor und Leser auf die Namen erreicht Neruda an dieser Stelle, daß der Leser seine Erfahrungen teilt. ${ }^{376}$

Diese Anspielungen und Verweise werden in dem unkommentierten Schwarm nicht angesprochen. Jedoch ergeben sie zusammen das Bild des alten kastilischen Spaniens, das Neruda in seinem Gedicht beschwört. Der ungeordnete Namenkatalog bietet Raum für allgemeine, aber auch okkasionelle und subjektive Assoziationen unter der Vorgabe der Gesamtfunktion des Katalogs.

Namen sind in den Gedichten Walcotts, Golls und Nerudas sowohl Teil der benutzten Sprache als auch eine Eigenschaft des besprochenen Gegenstandes, der den Namen trägt. Insofern kann der Autor einen Teil der besprochenen Realität als Beweis für das Gesagte in sein Gedicht integrieren. In dieser Verwendungsweise verlieren Eigennamen partiell ihren Zeichencharakter. Betrachtet werden die Namenzeichen selbst, ihre

375 „única / viva, soñolienta y sonora“ Neruda 1957, S. 279; Hervorhebung: JG.

${ }^{376}$ "Vgl. zu diesem generellen Ziel von España en el corazón Costa 1979, S. 97. 
Referenz als angeheftetes label des Namenträgers ist dabei Bedingung für die Anbindung an die besprochene Realität. ${ }^{377}$ Insofern sind diese Eigennamen auch Beispiele dafür, daß selten oder nie eine komplette Ästhetisierung des Eigennamens stattfindet.

\subsection{Formerfüllung}

Ein weiterer Aspekt insbesondere des Eigennamenkatalogs bei Neruda ist sicherlich auch die Originalität der Namen. Da es sich vorwiegend um Namen der Mikrotoponymie handelt, kann Neruda davon ausgehen, daß für viele seiner Leser ein Teil der Namen unbekannt ist und er damit eine sprachliche Neuigkeit mitteilt. Gerade bei redenden Namen ist damit zu rechnen, daß der Leser von den Zeichen überrascht wird. Das Gedicht gewinnt auch daraus seine Bedeutung.

Die „décimas onomásticas“378 eines anonymen puertoricanischen Dichters nutzen ebenso den Formenreichtum der Kategorie ,Eigenname'. Wir zitieren hier lediglich das Thema der Glosse ${ }^{379}$ und die letzte der vier darauf folgenden Strophen aus jeweils zehn Versen, um einen Eindruck des Gedichts zu vermitteln: ${ }^{380}$

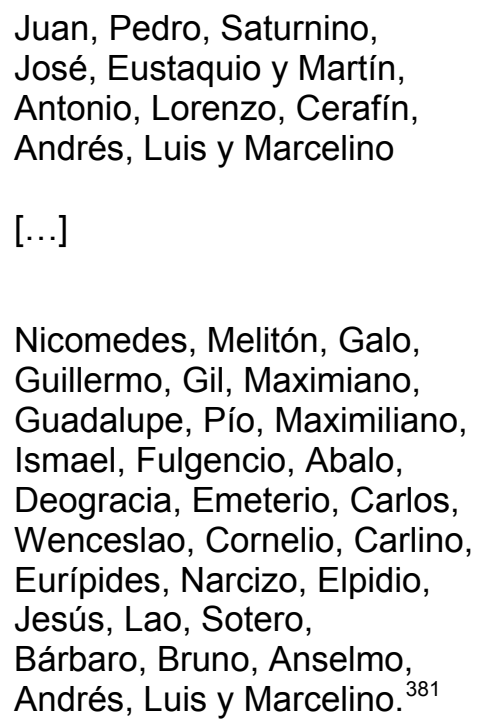

Dem Gedicht kommt es auf die kunstvolle Erfüllung einer vorgegebenen Form an. Die Zeilenzahl und -anordnung sowie die Reimstruktur einer spanischen Glosse aus décimas wird hier aus Rufnamen und gelegentlich der Konjunktion ,y' gebildet. Die Formerfüllung wird dadurch erleichtert, daß weder eine inhaltliche Struktur, noch ein thematischer Zusammenhang über die Auflistung von Personennamen hinaus die Auflistung beschränkt. Darüber hinaus handelt es sich um lauter Namen, die zwar als Taufnamen spanischsprachiger Männer denkbar sind. Insofern ist tatsächlich „every single word of

\footnotetext{
377 Zu einem weiteren Fall, Brechts „Gedenktafel für 12 Weltmeister“, vgl. Mainberger 2003, S. 275 f.

${ }^{378}$ Vgl. Mook 1968, S. 294.

379 Eine vierzeilige einführende Strophe stellt die jeweils letzte Namenszeile der darauf folgenden vier zehnzeiligen Strophen; vgl. Mook 1968, S. 295.

${ }_{380}$ Mook 1968, S. 296 f. präsentiert das Gedicht und zitiert alle fünf Strophen.

${ }^{381}$ Vgl. Mook 1968, S. 296 f.
} 
each line of each stanza [...] a Spanish-American personal name“. ${ }^{382}$ Schon eine oberflächliche Betrachtung zeigt aber, daß der Autor zur Formerfüllung etliche ,hispanisierte' Namen nichtspanischen Ursprungs verwendet hat. Die Formerfüllung fällt daher durch die freie Verfügbarkeit eines nahezu unbegrenzten Rufnamenschatzes vergleichsweise leicht.

Doch hat die Frage ,Wie gelingt dem Autor die Formerfüllung?', die den Text im Sinne Herrnstein-Smith' vorantreibt, noch einen weiteren Aspekt. Die Glosse ist rein ,autoreferentiell', da die Rufnamen keine nachvollziehbare definite Referenz auf bestimmte Namenträger haben. ${ }^{383}$ Insofern handelt das Gedicht von Namenszeichen in ästhetischer Funktion. Die décimas onomásticas zehren von dem ästhetischen Reiz der Verwendung von Zeichen, die dem Leser zumindest teilweise neu sind. Während der Standardzeichenbestand einer Sprache dem kompetenten Sprecher bekannt sein dürfte, kann der Autor der décimas davon ausgehen, daß unter den vielen aus formalen Gründen ausgewählten und teilweise ungewöhnlichen Namen einige unbekannte sind, an die der Leser von neuem erinnert wird oder die er neu erfährt. Die Frage ,Wie wird er wohl die Gedichtform erfüllen?' impliziert also die Frage ,Welche (überraschenden) Namenzeichen wird der Autor präsentieren?' Das Gedicht erhält einen Reiz ähnlich jenem, den auch ein ungewöhnliches und manieriertes Vokabular bewirken würde.

Das folgende Beispiel zeigt ein verbreitetes sprachliches Spiel mit Eigennamen, das darin besteht, aus scheinbar bedeutungslosen Eigennamen bedeutungshaltige Sätze zu formen. Ein Beispiel dafür ist die Imitation eines berühmten englischen Kinderreims, die ein Herr Archie R. McCrady in der amerikanischen Zeitschrift für Onomastik Names von 1955 veröffentlicht:

\footnotetext{
Simm Pell Simon Mette Pye Mann Goin Tudor Fair

Said Simm Pell Simon Tudor Pye Mann

Lett Mee Tay Sturr Ware

Said Derr Pye Manta Simm Pell Simon

Show Mee Furst Yure Penney

Said Simm Pell Simon Tudor Pye Mann

Deed Aye Haven Tenney ${ }^{384}$
}

\author{
Simple Simon met a pieman, \\ Going to the fair; \\ Says Simple Simon to the pieman \\ "Let me taste your ware." \\ Says the pieman to Simple Simon, \\ "Show me first your penny." \\ Says simple Simon to the pieman, \\ Indeed I have not any." 385
}

Um dem Text McCradys überhaupt einen Sinn zu entnehmen, muß der Leser zunächst erkennen, daß er aus Eigennamen zusammengesetzt wurde. Der ,Witz' des Textes besteht darin, daß aus den eigentlich intensionsleeren Namenszeichen unter Ausnutzung

\footnotetext{
382 Mook 1968, S. 296

383 Lediglich im Rahmen des Vortrags vor einem eng begrenzten Publikum ließe sich eine Referenz denken, wenn der Dichter seine Namen aus seinem persönlichen Umfeld ausgewählt hätte.

384 McCrady 1955, S. 171.

385 Mother Goose 1994, S. 92.
} 
der zufälligen Klangähnlichkeit mit nomina appellativa sinnvolle Sätze gebildet werden. Möglich ist ein solches Spiel nur mit Eigennamen - zum einen wegen ihrer Bedeutungsstruktur, zum anderen, weil nur die offene Klasse der Eigennamen über einen derart großen und nicht notwendig in das System der Gemeinsprache eingebundenen Formenreichtum verfügt.

Der Autor gibt sich damit aber nicht zufrieden. Vielmehr weist er in einem begleitenden Satz auf einen zusätzlich einschränkenden Faktor hin, der dem Leser ansonsten wohl verborgen geblieben wäre: „The following rhyme is made up of surnames found in the Los Angeles telephone directories". ${ }^{386}$ Er lenkt also die Aufmerksamkeit des Lesers darauf, daß er referierende Eigennamen aus einem beschränkten Vorrat gewählt hat. Wäre das Gedicht aus spontan erfundenen Eigennamenzeichen konstruiert, wäre es technisch trivial, weil jede Lautkombination in der Funktion ,Eigenname' verwendet werden kann. Auch eine Nachahmung des Kinderreims mit völlig beliebigen oder aus dem Familiennamenrepertoire der gesamten USA ausgewählten realen Eigennamen würde wahrscheinlich wegen der zur Verfügung stehenden Menge von Namen nur wenig Erstaunen hervorrufen. Der Autor schränkt sich also wohlweislich soweit ein, daß das Auffinden passender Namen überraschend genug ist, um theoretisch den Leser zu verblüffen und zu amüsieren. Der potentiell unendliche Formenreichtum der Kategorie ,Eigenname' nötigt den Autor dazu, diesen zusätzlichen Hinweis zu geben. Denn seine künstlerisch-technische Leistung besteht gerade im Einpassen der Zeichen aus einem künstlich beschränkten Vorrat in eine komplexe vorgegebene Struktur.

Die Besonderheit der Kategorie ,Eigenname', die sie für die formale Einpassung in eine vorgegebene Struktur geeignet macht, ist also die große Menge an Zeichen, die bei minimalen semantischen Unterschieden frei zur Erfüllung formaler Vorgaben zur Verfügung steht. Diese Menge ist nur dann deutlich eingeschränkt, wenn man nicht von den Eigennamenzeichen, sondern von einer Menge referierender (das heißt: an einen Namenträger vergebener) Eigennamen ausgeht.

Die Formerfüllung bildet die wichtigste besondere Norm des Namengebrauchs in Gedichten. Kommt es an einer bestimmten Stelle eines Textes nur darauf an, eine unspezifische Klassifikation auszudrücken (etwa: ,es handelt sich um einen Mann / eine Frau'), so sind die Möglichkeiten, diese semantische Stelle mit einem Eigennamen zu füllen, unendlich groß. Dies bedeutet, daß der Dichter ohne Schwierigkeiten alle formalen Vorgaben an einer bestimmten Gedichtstelle - wie etwa den Rhythmus, den Reim,

${ }^{386}$ McCrady 1955, S. 171. 
Alliterationen etc. - erfüllen kann. Vor allem viele Kinderreime bedienen sich solcher offenkundig formal motivierter, semantisch beliebiger Eigennamen ${ }^{387}$ :

Mary, Mary, quite contrary

How does your garden grow?

Sticks and stones and wallaby bones

And wattles wherever you go. ${ }^{388}$

\author{
BONES IN A POT \\ Little Billy Button \\ Said he wanted mutton; \\ Miss Betty Bligh \\ Said she wanted pie; \\ But young Johnny Jones \\ Said he wanted Bones- \\ Bones in a pot, \\ All hot! ${ }^{389}$
}

Die Namen in diesen Gedichten sind nach minimalen semantischen Vorgaben ausgewählt. Es sind Namen, die wenig mehr Informationen als das sortale Prädikat \{Mann/Frau/Kind\} und evtl. \{angelsächsisch\} über den Namenträger preisgeben. Maßgeblich für die Auswahl der Namen sind statt dessen die Reime bzw. die Möglichkeit zu reimenden Klangspielen und Alliterationen. Grundsätzlich ist die formale Motivation besonders deutlich, wenn zwischen den beschriebenen Handlungen und Situationen und den Verweisen, die die Namenszeichen nahelegen, keine sinnvolle Verbindung hergestellt werden kann; so z.B. beim redenden Familiennamen ,Button' oder dem religiös präfigurierten Namen ,Mary’.

Nicht nur Kinderreime bedienen sich inhaltsarmer Eigennamen zur formalen Gestaltung und zur Komisierung. Wenn Friedrich von Logau in seinem bereits zitierten Gedicht mit einer Aufzählung von Schäferinnennamen beginnt, zeigt er durch die Anordnung der Namen nach Binnenreim, daß deren Auswahl und Reihenfolge nicht aus inhaltlichen, sondern aus formalen Gründen geschieht. Nach inhaltlichen Gründen für die Namenverteilung zu fragen hat hier keinen Sinn. Die Namen stehen alle lediglich für das sortale Prädikat \{Hirtinnen\} und leiten durch ihren Binnenreim den unbekümmerten Ton des Gedichts ein:

Chloris, Doris, Iris, Ciris liebten einen Hirten alle;

Ihm zu weisen mit dem Wercke, daß er ieden wol gefalle, $[\ldots] .{ }^{390}$

Die gewählten formalen Einbindungen stehen als latente Motivation für eine Zeichenwahl stets in Konkurrenz zur inhaltlichen Einbindung. Dies zeigen z.B. das Seemannslied aus Shakespeares The Tempest, wenn man es mit der ,Schlegel-TieckBaudessinschen' Übersetzung ins Deutsche vergleicht:

\footnotetext{
${ }^{387}$ Vgl. Aschenberg 1991, S. 63 f.

388 Holden 1992, S. 47.

389 Holden 1992, S. 78 f.

390 Logau 1967, S. 163, vgl. den Kommentar S. 274 f.
} 
The master, the swabber, the boatswain, and I,

The gunner and his mate,

Lov'd Mall, Meg, and Marian, and Margery,

But none of us car'd for Kate;

For she had a tongue with a tang,

Would cry to a sailor, 'Go hang!'

She lov'd not the savor of tar nor of pitch,

Yet a tailor might scratch her where e'er she did itch.

Then to sea, boys, and let her go hang! (191 $^{39}$

Der Meister, der Bootsmann, der Konstabel und ich,

Wir halten's mit artigen Mädchen,

Mit Lieschen und Gretchen und Hedewig;

Doch keiner fragt was nach Käthchen.

Denn sie macht ein beständig Gekeifel;

Kommt ein Seemann, da heißt's: geh zum Teufel!

Den Pech- und den Teergeruch haßt sie aufs Blut;

Doch ein Schneider, der juckt sie, wo's nötig ihr tut,

Auf die See, Kerls, und hol' sie der Teufel! ${ }^{392}$

Berücksichtigt werden die formalen Vorgaben des Metrums und des Reims. Lediglich der abgesetzte Name ,Kate' wird übersetzt. Die Übersetzer ignorieren die Anzahl der Namen im dritten Vers bei Shakespeare, interpretieren also die Aussage des Schwarms unspezifisch im Sinne von ,mehrere Frauen'. Dagegen beachten sie den unreinen Reim " " I "Margery“ und übertragen inn ins Deutsche: „Ich“ / „Hedewig“. Gleichzeitig ersetzen sie die Alliteration der englischen Frauennamen durch die Häufung des Diminutivsuffix, das die Namenträgerinnen hier als (sexuell), erreichbare' Frauen kennzeichnet. Sie beachten also den einzigen besonderen inhaltlichen Hinweis, den die Namen zur Charakterisierung der Namenträgerinnen geben, unter Hintansetzung der Form. Dies fällt besonders beim ordo naturalis länger werdender Zeichen auf, den Shakespeare einhält. Die einzelnen Eigennamen mit möglichen weitergehenden Hinweisen auf mögliche Namenträgerinnen spielen offenbar keine Rolle für die Übersetzung des Seemannsliedes.

Besonders strenge und besonders ausgefallene Formvorgaben lassen sich oft nur mit erfundenen oder realen Eigennamen erfüllen. Daher sind gewisse Namen bekannter exempla in streng normierten, aber spielerischen Gedichtformen (und damit wären wir wieder bei den Kindergedichten) oft anzutreffen. Es sind dies etwa berühmte Namen, die mit dem Buchstaben , $X$ ' beginnen, in Abecedarien oder Alphabet-Lehrgedichten. ${ }^{393}$ So dichten Karl Philipp Moritz, Jean Paul oder der "Siege of Belgrade“ in ihren Abecedarien zum Buchstaben ,X':

\footnotetext{
${ }^{391}$ Shakespeare 1974, S. 1622 (II, 2).

392 Shakespeare 1975, S. 629.

${ }^{393}$ Man könnte dies das ,Stadt-Land-Fluß-Syndrom' der Formerfüllung nennen. Zu Abecedarien vgl. Liede 1992, S. 82-120.
} 
Wenn dieser Weltbau einst zerfällt,

Ist dann wohl Xerxes noch ein Held? ${ }^{394}$

$[\ldots]$

Wherefore welcome were

Xerxes, Ximenes, Xanthus, Xaviere?

$[\ldots]^{396}$

Auch Edward Lear weiß sich selten anders zu helfen:

$X$ was King Xerxes,

Who more than all Turks is

Renown'd for his fashion

Of fury and passion.

$\mathrm{x}$ !

Angry old Xerxes! $!^{397}$

$X$ was King Xerxes, whom

Papa much wished to know;

But this he could not do, because

Xerxes died long ago. ${ }^{399}$

Alle Autoren müssen für den

sprache beginnt, auf nicht deutsche bzw. englische Namen bekannter exempla zurückgreifen. Da die Namenverwendung deutlich durch die formalen Einbindungsmöglichkeiten motiviert ist, wird die inhaltliche Motivation der Namenverwendung zweitrangig. Die Kunst des Autors besteht darin, einen adäquaten Namen für die schwierige Formerfüllung zu finden und diesen auch in das inhaltliche Gefüge des Textes einzubinden. Die wenigen Namen, die den Autoren der Abecedarien für kritische Buchstaben zur Verfügung stehen, führen dazu, daß die entsprechenden exempla stereotyp auftreten. Edward Lears verschiedene Versuche zu ,Xerxes' zeigen aber auch, daß er bemüht ist, wenigstens neben den konventionellen auch überraschende und komisch-willkürliche Bestandteile des semantischen Namenhintergrunds der berühmten Namen zu gestalten. Die Verwendung der römischen zehn („X“) bei Jean Paul oder der Mengenangabe („XX“) bei Edward Lear schließlich zeigen, daß die Dichter die Stereotypen manchmal auch mit allen Mitteln zu vermeiden suchen. Mit der Erfüllung einer Norm durch Eigennamen stellt der Dichter seine Kreativität beim Finden formal und inhaltlich passender Eigennamen unter Beweis.

\footnotetext{
${ }^{394}$ Moritz 1980, o.P.

395 Jean Paul 1963, S. 562.

396 Poetisches Abracadabra, S. 43.

397 Lear 2001, S. 133.

398 Lear 2001, S. 302.

${ }^{399}$ Lear 2001, S. 317.

400 Lear 2001, S. 421.
} 
Die deutlichste Formvorgabe, an der mit Eigennamen artistisches Können vorgeführt werden kann, ist der Reim. Viele Beispiele für solch einen artistischen Einsatz realer Namen im Reim bietet etwa Ludwig Harig in seinen Sonetten. In den Hundert Gedichten etwa, auf deren „strenge Form“ schon im Untertitel des Bandes hingewiesen wird, richtet der Leser sein Augenmerk von vornherein auf die Formerfüllung und den Reim. Bei Harig findet man dann auch zahlreiche ungewöhnliche Namenreime in den von der strengen Gedichtform geforderten Reimreihen. So reimt er in Das Pantoffeltierchen ,mikroskopisch' : ,zyklopisch' : ,subtropisch' : ,Kopisch'; in Weinbergschnecke, links gewunden ,Fluß' : ,Zuckerguß' : ,Hieronymus' : ,Nuß' (sowie ,Pratt' : ,hat' und ,Zeus' : ,Gehäus'); in Die Flunder ,Davidis-Holle' : ,Scholle' : ,wundervolle' : ,Kartoffelknolle'; in Die Erdkröte ,böte' : ,Goethe' : ,Kröte' : ,Morgenröte' usw. ${ }^{401}$

Die Vielzahl verfügbarer Namen macht es möglich, die schwierigen Vorgaben der italienischen Sonettform zu erfüllen. Da sich hinter einem referierenden Namen ein unendlich großer Kontext verbirgt, sind Eigennamen als Metapher oder exemplum in beinahe jeden Kontext einzubinden. Harig bettet die Namen oft auf eine charakteristische Weise inhaltlich in das Gedicht ein, nämlich durch einen transponierenden Vergleich: „wie im Gedicht von Kopisch“, „wie ein Hieronymus“, „Kollege von Herrn Pratt“, „das Weltgesetz des Zeus“, „im Hexentanz bei Goethe“. ${ }^{402}$ Die genannten Einbindungen haben gemeinsam, daß sie das im Gedicht angesprochene Objekt (die ,niederen' Arten Pantoffeltierchen, Weinbergschnecke, Flunder und Erdkröte) durch die Erwähnung berühmter exempla komisch überhöhen.

Harigs Namenreime verweisen auf die andere Seite der formal motivierten Namenverwendung im Reim. Die Zusammenstellung der Begriffe und der Namen von teilweise hohem kommunikativen bzw. kulturellen Wert ("Goethe“) oder provozierender Unbekanntheit („Pratt“) zeigt eine Technik Harigs, mit der er seine Gedichte vorantreibt: Es geht um die möglichst ungewöhnliche Erfüllung der vorgegebenen strengen Form bei gleichzeitiger inhaltlicher Kohärenz. Die Artistik Harigs erstreckt sich auf die Ausdruckswie die Inhaltsseite der Namen, denn die gewagten, aber in jedem Fall inhaltlich wie formal passenden Integrationen der Namen von hohem kommunikativem Wert in die Beschreibung niederer Tiere überraschen den Leser.

Reime auf Eigennamen sind dabei zumeist originell. Während Reime inhaltlich zueinander passender Appellativa oft weit verbreitet zu finden sind und ihre inhaltliche Verbindung dann mehr oder weniger stereotyp wirkt, bieten Reime auf Namen wegen der

\footnotetext{
${ }^{401}$ Harig 1988, S. 7, S. 8, S. 9, S. 10.

402 Harig 1988, S. 7, S. 8, S. 10.
} 
Vielfalt der Namen und der immer neuen Namenträger oft einen neuen inhaltlichen Aspekt oder eine formale Überraschung.

Wie Ludwig Harig nutzt Ringelnatz das Überraschungspotential realer Eigennamen dort, wo er mit Namen Reime erfüllt, die sich auch einfach mit Appellativa hätten erfüllen lassen. So reimt er ,Lina' : ,China', ,hat' : ,Kattegatt', „Artist' : ,Christ' : ,Mist' : ,bist' : ,Franz Liszt', ,interessant' : ,(Immanuel) Kant', ,drei' : ,(Karl) May’ oder ,einundzwanzig' : ,Danzig'. 403

Bei einem Reim auf einen fiktionalen oder realen Namen besteht die artistische Leistung des Autors auch darin, einen bisher von niemandem verwendeten Reim und damit eine originelle sprachliche bzw. ästhetische Leistung vollbracht zu haben. Dies zeigt Joachim Ringelnatz, wenn er scherzhaft den Reim auf den Namen der Kathi Kobus, ,Globus' : ,Kobus', in einer Fußnote als „gesetzlich geschützt“ bezeichnet, wodurch er neben seiner formalen Findigkeit auch eine süffisante Anspielung auf die Angemessenheit des Reimes für die Namenträgerin macht. 404

Bei verbreiteten und formal gewöhnlichen Namen wie ,Scholz' oder ,Cohn' oder auch ,Pratt' mag dies weniger auffallen. Bei formal für die Sprache des Gedichts ungewöhnlichen Namen dagegen kann der Reim zur Demonstration von Kunstfertigkeit werden. Der Dichter bietet auf formaler Seite etwas Neues und verstärkt dadurch die Wirkung des Reims, wie z.B. auch Goethe in seinem von uns bereits zitierten Gedicht Musterbilder: ${ }^{405}$ Goethe nutzt für seine Musterbilder die Erinnerungswirkung des Reims. Da die Namen für exempla memoriert werden sollen, müssen sie auch selbst im Reim stehen. Besonders kunstvoll ist dabei die Kombination aus fremdsprachigen Namen mit einer Lautstruktur, die im Deutschen ungewöhnlich ist und den dazu passenden einfachen und nicht künstlich wirkenden deutschen Reimwörtern.

Die Anerkennung für die Erfüllung schwieriger Reime bezieht sich auf die Leistung, ein formal ungewöhnliches, womöglich fremdsprachiges Zeichen in die Form integriert zu haben. Weil die formale Motivation der Wortwahl offenkundig ist, verliert der Text oder die Textstelle zumeist an inhaltlicher Aussagekraft.

\subsubsection{Komisierung}

Betrachten wir nun als weitere, aber gegenüber der Isolierung nachrangige Strategie der ästhetischen Funktion die Komisierung, die in den eben genannten Gedichten schon eine wichtige Rolle spielt. Lamping unterscheidet die Komisierung des Namen-

\footnotetext{
${ }^{403}$ Ringelnatz 1984 Bd. 1, S. 8, S. 80,S. 258, S. 242, S. 68, S. 74; vgl. Gottschalk 2000.

404 Vgl. Ringelnatz 1984 Bd. 2, S. 139; vgl. auch Ringelnatz 1982, S. 289-296; vgl. Gottschalk 2000.

405 Goethe 1994, S. 27.
} 
zeichens von der Komisierung der Beziehung des Namens zum Namenträger. ${ }^{406}$ Für unseren Zweck gehen wir von einer ,Komisierung' des Namens aus, wenn eine oder mehrere Eigenschaften oder Verwendungsweisen isolierter oder isoliert gesehener Eigennamen im Sinne der ,komischen Transgression' übertrieben werden. ${ }^{407}$ Dies können Eigenschaften der Namengestalt sein, Aspekte des Bezugs zwischen Namenzeichen und Namenträger (Lautsymbolik, sortale Prädikate, Präfigurationen, redende Komponenten, Referenz) oder Aspekte der pragmatischen Rolle des Namens bei der Gestaltung des Textes (etwa die übertrieben häufige Namenverwendung). Die Transgression besteht in allen Fällen darin, daß gegen die üblichen, ästhetisch oder grammatisch normierten Verwendungsweisen von Eigennamen einschließlich der Namengebungskonventionen verstoßen wird, indem ein Potential des Eigennamens übertrieben ausgeschöpft wird. ${ }^{408}$

Der für Gedichttexte wichtigste komisch wirkende Verstoß gegen Verwendungsweisen von Eigennamen ist die übermäßige Betonung der Formerfüllung. Der betont kunstvolle Umgang mit einer sprachlichen Begrenzung durch formale Ordnungsstrukturen stellt eine besondere „Artistik auf der Ausdrucksseite“ dar. ${ }^{409}$ Artistik auf der Ausdrucksseite, ästhetische Funktion und „Komisierung“ liegen dabei nicht zufällig nahe beieinander. Wie die oben angeführten Beispiele schon zeigen, wirkt Artistik auf der Ausdruckseite in den meisten Fällen unernst, weil sie das einem literarischen Text unterstellte Ziel des docere (die Entwicklung eines „menschlich interessanten Inhalts“410) zugunsten des delectare (einer formalen Spielerei) zurückstellt. Auch wenn die Artistik letztendlich einen ernsten Hintergrund haben sollte ${ }^{411}$, schränkt die aufwendige und spielerische Erfüllung formaler Vorgaben zum Beweis des Könnens des Künstlers - sei es als Nonsens, als ,Witz' oder als Ironie - den Ernst der Mitteilung ein. ${ }^{412}$ Insofern finden sich Beispiele, in denen die ästhetische bzw. formerfüllende Funktion von Eigennamen deutlich wird, zum großen Teil in unernsten Gedichten.

\footnotetext{
${ }^{406}$ Vgl. Lamping 1983, S. 89-91.

407 Zum Begriff des Komischen als ,nicht sanktionierte Transgression' und für einen Überblick über Komiktheorien vgl. Lohse 2001, S. 17-47; vgl. des weiteren zum Komischen auch Köhler 1989, S. 17-20.

${ }^{408} \mathrm{Vgl}$. etwa: "Comic can be found in perceiving the tension between this artificial delimitation and the need to organize life through names, just as the deliberative departure from the convention of a genre is comic." (Burelbach 1983, S. 207).

${ }^{409}$ Zur ,Artistik auf der Ausdrucksseite’ vgl. Zymner 1995, S. 63; „'Literarischer Manierismus' ist eine globale Schreibweise mit der Funktion, bei gewahrter konventioneller Basis poetische Artistik auf der Bedeutungsebene und/oder der Ausdrucksebene eines Textes vorzuführen und dadurch eine Rezipientenreaktion auf diese Artistik herauszufordern." (Zymner 1995, S. 65).

${ }^{410}$ Vgl. Lamarque/Olsen 1994, S. 437.

411 Zu Jean Paul vgl. auch Braungart 1998.

412 Zur Unterscheidung vgl. Köhler 1989, S. 29-35.
} 
Aus Sicht der literaturwissenschaftlichen Onomastik ist dabei weniger die grundlegende Tatsache interessant, daß Eigennamen wie alle anderen Wörter eines Gedichts auch in die vorgegebene bzw. aufgebaute Vers-, Strophen- oder Gedichtform eingepaßt werden müssen oder daß sie mit übertriebenen Eigenschaften komisch eingesetzt werden können. Vielmehr stellen sich die Fragen, was die besonderen ästhetischen Qualitäten des Eigennamens sind und was die besonderen Bedingungen für die Einpassung eines Eigennamenzeichens in eine formale Ordnungsstruktur.

\subsection{Komische Häufung}

Namen können aufgrund ihrer Verwendungsweise komisch wirken. In diesem Fall ist nicht der Name selbst komisch, sondern die Art und Weise, wie er im Textverlauf oder im Kontext eingesetzt wird. T.S. Eliots The ,Boston Evening Transcript' etwa scheint ein typisches leicht melancholisches Gedicht zu sein, wenn man nur die Vergleiche und Metaphern in Versen wie „[they] Sway in the wind like a field of ripe corn“ oder „When Evening quickens faintly in the street, Wakening the appetites of life in some" liest. ${ }^{413}$ Nimmt man das gesamte Gedicht in den Blick, wird dagegen sofort der ironische Ton des Sprechers greifbar:

The readers of the Boston Evening Transcript

Sway in the wind like a field of ripe corn.

When evening quickens faintly in the street,
Wakening the appetites of life in some
And to others bringing the Boston Evening Transcript
I mount the steps and ring the bell, turning
Wearily, as one would turn to nod good-bye to La Rochefoucauld,
If the street were time and he at the end of the street,
And I say, "Cousin Harriet, here is the Boston Evening Transcript."

Die dreifache Nennung des Zeitungsnamens, die das Gedicht als Namenklammer einrahmt, individuiert das Blatt in übertriebener Weise, weil es die üblichen Ersetzungen durch koreferierende Ausdrücke mißachtet. Dies und die Kursivsetzung des Namens geben diesem ein Gewicht, das dem ansonsten ,lyrischen' Ton des Gedichts nicht entspricht. Die Häufung des Namens markiert den ironischen Ton, in dem Eliot die Stimmung Neuenglands beschreibt. Ihr stellt er den aufklärerischen und ,lebendigen' Geist entgegen, der durch La Rochefoucauld personifiziert wird. Eliot stellt durch das Insistieren auf dem Namen die Ernsthaftigkeit des Sprechers in Frage.

\footnotetext{
${ }^{413}$ Eliot 1998, S. 21.

414 Eliot 1998, S. 21.
} 


\subsection{Komische Namenreime}

Humoristische Gedichte, Kinderreime und Nonsensgedichte sind aus den oben genannten Gründen oft von formal motivierter Namengebung und -verwendung geprägt. Besonders deutlich wird die ästhetische Funktion, wenn der Name im Reim steht:

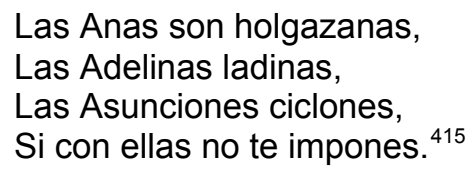

In dieser volkstümlichen canarischen ,copla' ist die Auswahl der Charakterisierung deutlich durch den Binnenreim zwischen logischem Prädikat und dem Eigennamen motiviert. Die Übereinstimmung der Sprachzeichen amüsiert, jedoch ist sie zu offenkundig willkürlich, als daß von einer ernstzunehmenden Namenmagie die Rede sein könnte. Die Reime sind hier reine Klangspiele. Die Verbindung zwischen dem durch das Reimwort denotierten Begriff und dem durch den Namen benannten Namenträger ist doppelt willkürlich. Zum einen ist der Reim auf das Namenszeichen inhaltlich willkürlich, zum anderen ist der Eigenname selbst willkürlich für den Namenträger gewählt worden. ${ }^{416}$

Wenn auf ein formal ungewöhnliches Wort gar nicht oder nur schwer gereimt werden kann bieten sich Eigennamen auch hier zur einfachen Formerfüllung an. Die Erfüllung von Formvorgaben, die in der dominierenden ,natürlichen' Sprache des Gedichts eigentlich nicht zu erfüllen sind, kann mit formal ungewöhnlichen Namenszeichen geleistet werden. So enthalten etwa viele der humoristischen Gedichte Christian Morgensterns beliebige Figurennamen, die bedeutungsarm und deutlich durch den Reim motiviert sind. Es reimt sich „Fips“ auf „Schlips“ und „stolz“ auf „Scholz“. Es treten der „Pudel Pax“ und der „Kaufmann Sachs“ gemeinsam im Klabautermann auf, „Borowsky, Heck“ reimt auf „Fleck“ in Die Behörde, in Auf einer Bühne tritt ein „Cohn“ im Reim auf „Illusion" auf, ohne daß auf den Inhalt oder das deutliche sortale Prädikat des Namens fjüdisch\} eingegangen würde. ${ }^{417}$

Explizit wird diese formale Motivation eines Namens in Das Böhmische Dorf zum begleitenden Scherz ausgeführt: „Herr v. Korf“ begleite Palmström „nur des Reimes wegen“. Auch wenn Morgenstern die formale Motivation des Namens hier anspricht, gibt er dem Scherz mit dem Reim die gleiche Note wie in dem bekannteren Das ästhetische

\footnotetext{
415 „Die Anas sind Faulenzerinnen, / Die Adelinas sind verschmitzt, / Die Asunciones sind Ziklone, / Besser du drängst dich nicht auf"; Trapero 1995, S. 28 (leider ohne eine nachvollziehbare Quellenangabe).

${ }^{416} \mathrm{Zu}$ Letzterem vgl. auch Wimmer 1995, S. 377.

417 Morgenstern 1990, S. 506, S. 97, S. 120, S. 178.
} 
Wiesel, in dem das Tier ,um des Reimes willen' auf einem Kiesel sitzt. ${ }^{418}$ Im Falle des Wiesels ist es die Gattung, die unter den Tieren aus formalen Gründen ausgewählt wird. Aber auch im Falle Korfs wird scheinbar nicht ein Name, sondern eine Person ausgewählt - ,um des Reimes Willen'. Namenwahl und Personenkreation fallen also zusammen. Morgenstern vermeidet es hier, die willkürliche Namenwahl anzusprechen. So vermeidet er es, die evozierende und illusionierende Wirkung des Namens zu durchbrechen. Diese Wirkung wird dadurch unterstützt, daß Korf als wichtige Figur in Morgensterns humoristischen Gedichten auch weiterhin auftritt.

An den Limericks Edward Lears kann der Unterschied zwischen einem Appellativreim und einem Namenreim in bezug auf den Anspruch auf Artistik deutlich gemacht werden:

[1.]

There was a Young Lady whose nose, Was so long that it reached to her toes; So she hired an Old Lady, whose conduct was steady, To carry that wonderful nose. ${ }^{419}$

[3.]

There was a Young Person of Smyrna, Whose Grandmother threatened to burn her; But she seized on the Cat, and said, "Granny, burn that! You incongruous Old Woman of Smyrna! « ${ }^{421}$
[2.]

There was an Old Man on some rocks, Who shut his wife up in a box, When she said, "Let me out, « he exclaimed, »Without doubt, You will pass all your life in that box. ${ }^{420}$

[4.]

There was an Old Man of Vesuvius, Who studied the works of Vitruvius; When the flames burnt his book, to drinking he took, That morbid Old Man of Vesuvius. ${ }^{422}$

Die Dynamik aller vier Limericks liegt in der Spannung, die durch die ersten beiden Verse aufgebaut wird. Im ersten Vers wird eine Person eingeführt, im zweiten Vers eine (möglichst skurrile) Eigenschaft der Person genannt. Im dritten und vierten Vers ${ }^{423}$ beginnt dann die Auflösung der Spannung in eine komische Situation. Dies geschieht, indem eine Gewohnheit oder eine Handlung beschrieben wird, die den Umgang der Person mit ihrer zumeist seltsamen Eigenart schildert oder die die aufgeworfenen Probleme auf ebenso seltsame Weise beendet. Der fünfte Vers schließlich führt im Blockreim die Lösung fort oder wiederholt mit Variationen den ersten Vers und läßt die Spannung abklingen. ${ }^{424}$

Neben dieser makrotextuellen Dynamik wird zwischen den ersten beiden Versen eine Spannung aufgebaut. Der erste Vers nennt zumeist harmlose grundlegende Eigen-

\footnotetext{
418 Morgenstern 1990, S. 109, S. 69.

419 Lear 2001, S. 91.

420 Lear 2001, S. 170.

${ }^{421}$ Lear 2001, S. 159.

422 Lear 2001, S. 83.

423 Diese beiden Verse werden häufig graphisch als eine Zeile gedruckt. Die Reimstruktur soll uns hier aber als Indikator der Struktur des Gedichts gelten.

${ }^{424} \mathrm{Vgl}$. dagegen die nicht ganz zutreffende dynamische Einschätzung bei Köhler 1989, S. 18 f.
} 
schaften des jeweiligen ,Protagonisten': Es handelt sich um junge oder alte Männer und Frauen, die sich an einem beliebigen Ort befinden oder etwa ,eine Nase haben'. Dies sind nicht besonders aufregende Mitteilungen. Der Leser wird also den zweiten Vers mit Spannung erwarten, in dem die eigentlich wichtige Mitteilung über die Figur gemacht wird. Diese grundsätzliche Spannung wird normalerweise durch den Inhalt der Verse produziert. Im Falle der Limericks mit Ortsnamen tritt allerdings das Interesse an den Reimen auf die im ersten Vers genannten Ortsnamen desto mehr in den Vordergrund, je ungewöhnlicher die Zeichenstruktur des Namens für die Sprache des Gedichts ist. So ist der Reim ,Smyrna' / ,burn her' als gespaltener Reim auffällig, als Reim auf ,Vesuvius' weiß Lear sich nur durch einen weiteren lateinischen Eigennamen auf die lateinische Endung zu helfen. Mehr oder weniger starke Aufmerksamkeit dieser Art erregen die meisten der Ortsnamenreime aus dem Repertoire des A Book of Nonsense, etwa ,Chertsey' / ,curtsey', ,Portugal' / ,nautical', ,Moldavia' / ,behavior', ,Peru' / ,should do', ,Columbia' / ,some beer' oder ,Marseilles' / ,veils'. ${ }^{425}$ Zwar sind auch nicht alle Reime auf Ortsnamen auffällig, aber umgekehrt zeigen diejenigen Limericks, die nicht auf Ortsnamen reimen, nur selten solche gewagten Reime.

Die Verwendung von Ortsnamen ist diesem formalen Spiel dienlich, da die Namen und ihre Referenz in Nachschlagewerken für jeden kompetenten Sprecher zu verifizieren oder sogar allgemein bekannt sind. Darüber hinaus steht dem Dichter auf diese Weise eine sehr große Menge an beliebig ungewöhnlichen fremdsprachigen Zeichen zur Verfügung, die alle die für den ersten Limerick-Vers charakteristisch magere Bedeutung haben: \{ein Ort, aus dem N.N. stammt\}. In diesen Fällen hat es offensichtlich wenig Sinn, nach dem inhaltlichen Grund für die Verwendung bestimmter Ortsnamen oder von Ortsnamen überhaupt zu fragen, wie es etwa Ord diskutiert. ${ }^{426}$ Die Komik der Namenverwendung liegt hier gerade darin, daß Name und Inhalt offensichtlich nichts oder wenig über den gewagten, originellen oder betont ungeschickten Reim hinaus miteinander zu tun haben. Die Motivation liegt ganz in der formalen Spannung der ersten beiden Verse.

Weitergehend noch als in den Limericks, die Ortsnamen enthalten, dominiert in der Nonsensgedichtform ,Clerihew' ${ }^{427}$ der Eigennamenreim die Form des Gedichts. Der Clerihew wird zumeist definiert als humoristischer pseudo-biographischer Vierzeiler mit

\footnotetext{
${ }^{425}$ Lear 2001, S. 161, S. 163, S. S. 82, S. 72 , S. 76 , S. 80.

${ }^{426}$ Vgl. etwa Ord 1985, S. 101; unsinnig erscheint die Frage, ob Lear mit seinen Limericks für Kinder Geographie lehren wollte; vgl. Ord 1985, S. 103 f. und S. 105 f.

${ }^{427}$ Zum Clerihew vgl. auch Burelbach 1984, S. 211.
} 
prosanahen paargereimten Versen unterschiedlicher Länge, benannt nach Edmund Clerihew Bentley, der inn als Schüler erfunden haben will. ${ }^{428}$ Die formalen Einschränkungen sind durch die prosanahe Versstruktur einfach zu erfüllen. Es gilt aber als zusätzliche Bedingung, daß der erste oder zweite Vers auf einen Namen endet. ${ }^{429}$ Der schwierige Reim auf die oft formal ungewöhnlichen Eigennamen bildet eine zusätzliche Norm des Gedichts, die nicht unwesentlich zu dessen Attraktivität beiträgt. Denn die Aufgabe des Dichters ist es in diesem Fall, eine mehr oder weniger sinnvolle biographische Anspielung mit dem für den Namen notwendigen Reimwort zu verbinden:

Dante Alighieri

Seldom troubled a diary.

He wrote the Inferno

On a bottle of Pernod. ${ }^{430}$

\author{
It was rather disconcerting for Hannibal \\ To be introduced to a cannibal \\ Who expressed the very highest opinion \\ Of cold pickled Carthaginian. ${ }^{431}$
}

Der Reiz dieser Verse beruht wiederum auf der technischen Leistung, auf einen der Gedichtsprache oft fremden Namen sinnvoll zu reimen. Das zeigt z.B. der Clerihew auf Dante besonders, weil er gleich noch zwei Namen in den Reim stellt. Da es sich auch hier um humoristische Verse handelt, kann ,sinnvoll' sehr weit ausgelegt werden. Dennoch wird deutlich, daß sich Bentley um eine minimale Kohärenz bemüht, wenn er etwa Voltaire mit Religionskritik und Hannibal mit Kannibalen in Verbindung bringt. ${ }^{432}$ Je schwieriger dabei der Namenreim ist, desto höher wird die Anerkennung des gelungenen Clerihew, wie Bentleys eigene Bewertung eines Clerihew von James E. Flecker zeigt: „(I wish I had thought of that.)“ Der hatte den schwierigen Reim auf Nietzsche gleich mehrfach durch einen Haufenreim bewältigt:

The sad feature

About Nietzsche

Was that the creature

Thought he was a teacher. ${ }^{433}$

Clerihews und Limericks beziehen ihre komische Wirkung oft genau daraus, daß sie die Verbindung zwischen den Namen und den passenden Reimwörtern inhaltlich gezwungen wirkt. Der Reim auf einen Eigennamen erscheint dann inhaltlich willkürlich, wenn

\footnotetext{
${ }^{428}$ Vgl. z.B. Bentley 1981, S. ix.

429 Soweit zitiert Gavin Ewart, der Herausgeber der „Complete Clerihews“, das Lexikon „The Poet's Manual and Rhyming Dictionary“ von 1966. Er führt aber selbst vorher an, daß „the element of absurdity was there from the first $[. .$.$] , along with the challenge of names that were hard to rhyme [...]." Vgl. die Einlei-$ tung in Bentley 1981, S. xiii.

430 Bentley 1981, S. 37.

431 Clerihew 1981, S. 55.

432 Bentley selbst schreibt: „Such care of historical accuracy did not mark all the biographies [das sind alle Clerihews aus Biography for Beginners (...)]; but in many of them its presence can, I hope, be recognized." Vgl. Bentley 1940, S. 150; vgl. auch Bentleys weitere scherzhafte Ausführungen in Bentley 1940, S. $155-158$.

${ }^{433}$ Bentley 1940, S. 152; daß die Reime auf fremdsprachige Namen selten elegant waren, hat offenbar schon der Herausgeber des „Punch“, in dem sie erschienen, kritisiert; vgl. Bentley 1940, S. 165.
} 
ein ungewöhnliches Namenszeichen verwendet wird, auf das nur sehr schwer gereimt werden kann. So z.B. im Falle zweier scherzhafter namenverbindender Gelegenheitsgedichte G. Chr. Lichtenbergs in einem Brief an seinen Freund und Verleger Dieterich:

\author{
Als Herr Bahrdt \\ Ehmann ward, \\ Freute sich \\ Dieterich.
}

Ich hätte noch mehr in Versen gemacht, allein Bahrdt klingt so hart und Dieterich so wunderlich. ${ }^{434}$

In seinen Darstellungen fiktiver und realer Personen nutzt auch T.S. Eliot vielfach Reime auf fremdsprachige Namen, um eine unernste Wirkung zu erreichen; so z.B. in Burbank with a Beadeker Bleistein with a Cigar (in der Reimform: abcb):

The horses under the axletree

Beat up the dawn from Istria

With even feet. Her shuttered barge

Burned on the water all the day. ${ }^{435}$

oder in Sweeney Erect:

Morning stirs the feet and hands

(Nausicaa and Polypheme).

Gesture of orang-outang

Rises from the sheets in steam. ${ }^{436}$

oder in A Cooking Egg:

I shall not want Honour in Heaven

For I shall meet Sir Philip Sidney

And have talk with Coriolanus

And other heroes of that kidney. ${ }^{437}$

Reime auf formal gewöhnliche Namen dagegen können auch in ernsten Gedichten eingesetzt werden. So reimt etwa Jesse Thoor in Sonett vom guten Willen, das seine Emigration beschreibt:

$[\ldots]$

So habe ich das Sterben fürchterlich und tausendfach erlitten,

da ich - nicht Mensch noch Tier mehr - stöhnend aufgeschrien,

als sie, die Tollen, mir das Herz in meiner Brust entzweigeschnitten.

War es an jenem Tage der Gewalt im März, war es in Wien?

Ich sah um nichts mich weniger gehetzt im Narrenspiegel von Paris,

Oh minder nicht gelähmt in Rotterdam, in Basel oder Prag -

und dort, wo Unverstand mir noch das Eingeweide ganz zerstieß.

Nun mag der arge Reigen dann beendet sein, wie dieser Tag.

$[\ldots]^{438}$

\footnotetext{
${ }^{434}$ Vgl. Brief G. Chr. Lichtenbergs an Johann Chr. Dieterich von 1771, in: Lichtenberg 1967, S. 25.

435 Eliot 1998, S. 36.

${ }^{436}$ Eliot 1998, S. 38.

${ }^{437}$ Vgl. auch Scofield 1988, S. 55.

438 Thoor 1956, S. 47.
} 
Hierbei wird der Ernst der Aussage durch die mehrfachen Namenreime nicht angetastet, da die Namen formal einfach zu integrieren sind. Eine formale Motivation tritt daher nicht in den Vordergrund.

\subsection{Durch Änderung des Namenzeichens erfüllte Formen}

An Namenzeichen können Veränderungen vorgenommen werden, um die Formvorgabe zu erfüllen. So werden etwa Namenvarianten - hier in zwei Strophen aus Ewald v. Kleists Ode an die preußische Armee - so eingesetzt, wie der Reim oder das Metrum es verlangen:

\footnotetext{
Verdopple deinen Muth! Der Feinde wilde Fluthen

Hemmt Friedrich und dein starker Arm;

Und die Gerechtigkeit verjagt den tollen Schwarm.

Sie blitzt durch dich auf ich und seine Rücken bluten.

Die Nachwelt wird auf dich, als auf ein Muster sehen;

Die künfftgen Helden ehren dich,

Ziehn dich den Römern vor, dem Cäsar Friederich,

Und Böhmens Felsen sind dir ewige Trophäen. ${ }^{439}$
}

Diese formmotivierte Namenveränderung eignet sich dazu, übertrieben zu werden. Die Artistik, die die Erfüllung einer Gedichtform mit formal ungewöhnlichen Zeichen ansonsten kennzeichnet, wird dann durch eine übertrieben grobe Erfüllung ad absurdum geführt. ${ }^{440}$ Das kann sich sowohl auf die Metrik, als auch auf den Reim beziehen. Georg Christoph Lichtenberg etwa gestaltet einen ,Merkvers' zum großen Teil im Hexameter nach der Quantitätsprosodie akkurat mit zeitgenössischen Dichternamen ${ }^{441}$ :

Klopst, Ramler, Wieland, Uz, Voss, Kloz Rostque, Jacobi,

Bis Stolberg, Schmidt quinque, Goecking Lavaterque materque

Karschia, post Pfeffel, Marantchen cum sua Nantchen,

Rauffseisen, Göth', Löw, ad Bürg- Gott- Kling- Gessn- adde Er.

Et his portentum! Bardorum adde agmina centum.

Suspirant, cantant et amant. Dum spirant cantant, dum amant spirant. ${ }^{442}$

Hier kann ein Ansatz zur Ordnung in der ersten Zeile gesehen werden: Die berühmtesten Dichter stehen voran: die ,Ahnväter' des Göttinger Hain, Klopstock und Ramler, ebenso der berühmte ,Erzfeind' des ,Bundes', Wieland. Dann aber löst sich die Ordnung zugunsten der Prosodie auf. Es werden dabei mehrere formale Ordnungen erkennbar: Assonanz, Binnenreim, vor allem aber die scherzhaften und künstlichen SuffixParallelen im vierten Vers. Aus der formalen Erfüllung des schwierigen Hexameters bei gleichzeitiger gewaltsamer Veränderung der Eigennamen gegen die sprachliche Konvention und auch aus den daraus entstehenden semantischen Assoziationen schöpfen die Verse ihre Komik.

\footnotetext{
${ }^{439}$ Ewald v. Kleist 1971, S. 94.

${ }^{440}$ Zu sprachlichem Nonsense vgl. Horlacher 2003, Sp. $302 \mathrm{f}$.

${ }^{441}$ Vgl. Wagenknecht 1992, S. 61.

442 Wagenknecht 1992, S. 61
} 
Die Schwierigkeit, bestimmte Zeichen in einen Reim einzubinden, kann auf grobe Weise umgangen werden, indem eines oder beide Reimzeichen formal krude verändert werden. Ein Gelegenheitsgedicht Richard Wagners zeigt die Übertreibung des Umgangs mit ,formal schwierigen' Eigennamenreimen. Die betont unreinen Reime heben die übertriebene Formerfüllungsfunktion deutlich hervor:

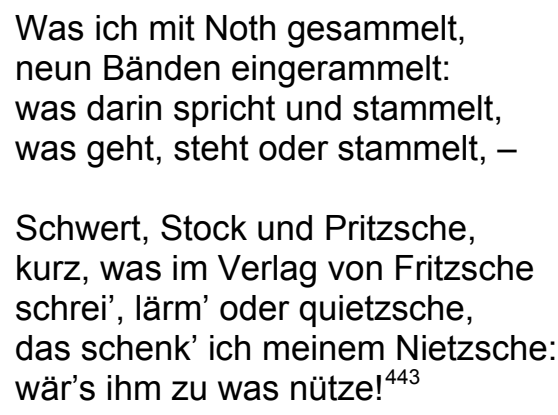

Auch Christian Morgensterns, Joachim Ringelnatz' und Kurt Schwitters' Nonsensgedichte sind reich an solchen Konstruktionen. So tritt bei Morgenstern etwa der komischwillkürlich konstruierte Ortsname ,Odelidelase' auf, der im Verlauf des Gedichts Korfs Verzauberung nach Maßgabe des Reims in ,Odeladeliese' : ,bliese', und ,Odeladeluse' : ,Bluse' geändert wird. ${ }^{444}$ Ringelnatz reimt vor allem reale Namen gerne so überraschend wie grob - etwa (des) ,Starkmehles' : ,Südwales', ,Kitzebühel' : ,Kühel', ,Gnu' : ,Jeru- (Salem Aleikum!)', ,Emanuel Pips' : ,Mississips', ,Gibson' : ,stipsen', ,Graz' : ,tat's', ,llse' : ,Pilze'. ${ }^{445}$

Schwitters verstößt zugunsten einer vollständigen Aufzählung unbedeutender massenhaft verbreiteter Familiennamen gegen die semantische Kohärenz , wenn er „Frau Müller, Frau Meier, Frau Schulze, Frau Schmidt, die saßen zusammen beim Kaffee zu dritt.“446 reimt. Er verwendet unnötigerweise Neologismen um auf ohnehin frei erfundene Namen zu reimen wie bei ,knurzig' : ,Fräulein Purzig' ${ }^{\prime 47}$ Schließlich bildet auch Schwitters unrealistische Namen, die auf grobe Weise reden und gewünschte Reime ermöglichen oder wandelt Namen so ab, daß sie auf einen geforderten Reim passen: „Heini' : ,Beini', ,Ida' : ,wieder', ,Herr von Doppelmoppel' : ,doppel', ,Kinderbuch' : „Herr Kuch[-en]', ,Fräulein Franke Piesewitt' [eine dem Metrum adäquate Abwandlung von 'Piewitt'] : ,(nahm ...) mit', ,Mannsarde' : ,Frau Sarde'; ,Frau Sardine' : ,Gardine'. 448

\footnotetext{
443 Wagner 1905, S. 103.

444 Morgenstern 1990, S. 253.

445 Ringelnatz 1984, S. 94 , S. 256, S. 252, S. 14 , S. 88, S. 241 , S. 16 ; vgl. auch Gottschalk 2000, S. 76.

446 Schwitters 1998, S. 126.

447 Schwitters 1998, S. 144. Dies wirkt vor allem deshalb absurd, weil Schwitters den erfundenen Namen ja ohne Probleme dem Reim gemäß hätte umwandeln können.

${ }^{448}$ Schwitters 1998, S. 182, S. 101, S. 103, S. 141, S. 195, S. 160.
} 
Die grobe Veränderung der Namen und die willkürliche Auswahl oder Erfindung von Namen rein aus formalen Gründen dient in diesen Fällen der Autoreferentialisierung der Gedichte. Da die Motivation für die Namenwahl oder die Namensuche rein formal ist, wird der Bezug auf die Welt negiert. Dabei bewirkt der formal motivierte NamenNonsens weniger eine „Dekomposition der Individualität“ oder die „Liquidation der Subjektivität“449 als eine Dekomposition von Sprache. ${ }^{450}$ Die Namen dienen hier der Sinnverweigerung. Gleichzeitig machen sie auf die sprachlichen Mechanismen der Namengebung, der Namengestaltung und des Namenreims (bzw. der Reimtechnik insgesamt) aufmerksam.

\subsection{Komische Namenzeichen}

Zur komischen Ästhetisierung eines Namens kann auch das Namenszeichen selbst dienen. Namen eines Gedichts, deren Namenzeichen auf übertriebene Weise von den für den impliziten Leser gewöhnlichen Namenbildungskonventionen einer Sprache abweichen, bestimmen in großem Maße die unernste Stimmung des Textes. Humoristische und satirische Gedichte sind daher oft von ungewöhnlichen Namen geprägt. Dabei entsteht der komische Eindruck des Namens durch die Überschreitung der Namengebungs- und Namenbildungsgewohnheiten einer Gruppe oder einer Sprache. So übertreibt etwa der amerikanische Librettist W.S. Gilbert Namengebungskonventionen, indem er an Gedichtanfängen überlange Namen nennt, die jeweils vollständige metrische Einheiten erfüllen: „Macpherson Conglockety Angus McClan“, oder:

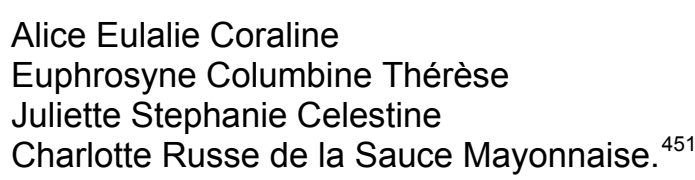

Scheerbart weicht mit dem Namen „Rixráx, der Sonnenbruder“452 in übertriebenem Maße vom Klang gewöhnlicher Namen ab. Auch Morgenstern benutzt gerne auffällig klingende Namen wie ,Palm Palmström', und „Palma Kunkel'. ${ }^{453}$ In seinen Kindergedichten finden sich zudem übertrieben deutlich redenden Namen: Eine Figur heißt ,Wunderlich'454, ein Diener stammt aus der Stadt ,Swakopmund' (,Schlag auf den Mund') und trägt den Namen ,Hans Immerdreist Mogel'. ${ }^{455}$ An diesem letzten Namen wird die Namengebungspraxis Morgensterns besonders deutlich: Der Name wird als übertrieben

\footnotetext{
${ }^{449}$ Vgl. Fuß 2001, S. 176.

${ }^{450}$ Vgl. auch Whiteside 1987, S. 189.

${ }^{451}$ Vgl. Bowman 1978, S. 5, S. 11

${ }^{452}$ Scheerbart 1994, S. 15.

${ }^{453}$ Morgenstern 1990, z.B. S. 124 f. Zu Palma Kunkels redendem Familiennamen vgl. auch Morgenstern 1990, S. 71.

${ }^{454}$ Morgenstern 1990, S. 485. Zu redenden Namen in Kinderdichtung vgl. auch Aschenberg 1991, S. 6569.

${ }^{455}$ Morgenstern 1990, S. 436.
} 
redender Name deskriptiv charakterisierend wahrgenommen. Für die weitere Darstellung des Dieners in zwei Gedichten spielt diese Charakterisierung allerdings keine Rolle. Morgenstern gestaltet mit seinen Namen vom übrigen Gedichtinhalt unabhängige Scherze. Die Motivation seiner Namengebung nennt Morgenstern in der Einleitung zu seinen Galgenliedern: „Wer heißt überhaupt? Man nennt ihn.“456 Der Name verliert hier jeden ernsten Bezug zum Namenträger und wird zum Übernamen. Er ist eine temporär von anderen verwendete Bezeichnung. Hervorgehoben wird durch diese Namen die Willkür der Zeichenkonstruktion, eine tiefe Symbolik wird abgelehnt. ${ }^{457}$ Diese Negation wird nicht durch unauffällige Namen erreicht, vielmehr wird die Eigennamendeutung gerade durch die überdeutliche symbolische Überladung des Textes und der Namen ironisiert. So läßt Morgenstern etwa den Namen „Sophie, mein Henkersmädel“ in seinen scherzhaften Kommentaren sowohl auf die fiktive Figur referieren als auch symbolisch die Weisheit (,sophia') exemplifizieren. ${ }^{458}$ Eine Figur im modischen fernöstlichen Ambiente wird mit einem übertriebenen sortalen Prädikat \{chinesisch\} „Tang-ku-ei-i“ genannt ${ }^{459}$, fromme Nonnen machen aus der funktionalen Aufschrift auf Versandkisten „espedito“ einen „St. Expeditus“, der Bach „Elster“ verwandelt sich in einen Vogel usw. ${ }^{460}$ In all diesen Fällen wird durch die Übertreibung sprachlicher Mechanismen der Eigennamenbildung und -verwendung jede epistemische Leistung der Eigennamen in Frage gestellt.

Auch das Namenzeichen realer Eigennamen kann komisch wirken. Die ,Feier' formal auffälliger Namenzeichen findet sich mehrfach bei John Updike, der Namen in den Medien sucht und jeweils ein Gedicht zu dem gefundenen Namenzeichen gestaltet. Den Leser informiert Updike dabei in Paratexten über die Herkunft der Namen. In V.B. Nimble, V.B. Quick z.B. mißversteht Updike absichtlich die Gewohnheit amerikanischer Universitäten, Lehrstühle nach Begründern zu benennen. Er zitiert in einem Paratext eine Buchrezension „[...] V.B. Wigglesworth, F. R. S., Quick Professor of Biology [...]“ und gestaltet dann im Haupttext einen besonders schnellen und hastigen Biologieprofessor. ${ }^{461}$ In I Missed His Book but I Read His Name meditiert Updike einen für europäische Ohren besonders auffälligen indischen Namen als refrainartiges jeweiliges Strophenende seines Gedichts:

\footnotetext{
${ }^{456}$ Morgenstern 1997, S. 192.

${ }^{457}$ Morgenstern 1997, S. 391, S. 394f.

${ }^{458}$ Morgenstern 1997, S. 217.

459 Morgenstern 1990, S. 128. Zur Nachahmung fremdsprachiger Namen in Kindergedichten vgl. Aschenberg 1991, S. 60-63.

${ }_{460}$ Morgenstern 1990, S. 142, S. 133.

${ }^{461}$ Ferguson/Salter/Stallworthy 1996, S. 1739.
} 
Though authors are a dreadful clan

To be avoided if you can,

l'd like to meet the Indian,

M. Anantanarayanan. ${ }^{462}$

Komisch wirkende Namen zeichnen sich durch Übertreibungen einer Komponente der Zeichenqualitäten des Namens aus. So können übertrieben deutlich redende Namen oder mit überdeutlichen sortalen Prädikaten ausgestattete Namen verwendet werden. Diese Namen lassen das Gedicht deswegen unernst erscheinen, weil der Leser am Namenszeichen sofort sehen kann, daß der (literarische) Namengebungsakt, dem der Eigenname entstammt, als Teil der Komposition des Gedichts unernst ist oder unernst betrachtet wird.

Beliebig ausgewählte oder situationsgemäß erfundene Eigennamen sind sehr einfach in eine Form zu integrieren. Formal auffällige Eigennamen sind dagegen oft sehr schwierig einzupassen. In beiden Fällen ist die Verwendung von Eigennamen in formal überstrukturierten Texten deutlich formal motiviert und in beiden Fällen entstehen (partiell) komische oder autoreferentielle Gedichte. Die formale Motivation ist stets nur ein Grund für die Auswahl, die Positionierung oder die Gestaltung eines Elements. Sie steht in Konkurrenz zur semantischen Motivation. Die mehrfache formale Einbindung eines Namens lenkt stets die Aufmerksamkeit des Lesers auf die Sprache, weil der Name deutlich erkennbar willkürlich gebildet oder eingesetzt wird und weil seine Integration in die Form ein besonderes ,materielles' Hindernis darstellt, dessen Überwindung als ,Artistik' gewertet werden kann. Gedichte, die eine unernste Rede exemplifizieren, nutzen das Potential des Namenzeichens und der Namenverwendung, um durch Übertreibungen den Unernst der Rede oder deren selbstreferentielle Funktion hervorzuheben.

\subsubsection{Zusammenfassung: Das Eigennamenzeichen und die ästhetische Gestaltung} des Gedichts

Die textstrukturierende Funktion beruht hauptsächlich auf dem semantischen Hintergrund, die Funktion der Anbindung auf der Referenz des Namens. Namen in ästhetischer Funktion heben als dritte textbezogene Funktion des Eigennamens das Eigennamenzeichen hervor. In Gedichten als formal überstrukturierten Texten spielt diese Funktion naturgemäß eine besondere Rolle. Gedichttexte legen es durch ihren ,Lakonismus' nahe, einzelne Zeichen ästhetisch zu isolieren. Der Gebrauch von Eigennamen in ästhetischer Funktion ist darüber hinaus vor allem durch eine starke Neigung zur Komik gekennzeichnet. Die Hervorhebung artistischen Könnens durch die Formerfül-

${ }^{462}$ Ferguson/Salter/Stallworthy 1996, S. 1739. 
lung mittels realer oder fiktionaler Eigennamen trägt fast immer den Makel inhaltlicher Willkür und Kennzeichen spielerischen Umgangs mit Sprache. Textbezogen bewirken Eigennamen in ästhetischer Funktion in der überwiegenden Zahl der Fälle, daß der Gedichttext als unernster Text wahrgenommen wird.

Eigennamen wirken sich daher nicht nur auf den Aufbau und Ablauf eines Textes sowie auf seine Einbettung in Kontexte aus, sondern auch auf den Anspruch des Textes, etwas über die Wirklichkeit auszusagen, auf die die Eigennamen referieren. Die ernste und die komische Betrachtung des Zeichens selbst sagt etwas über die sprachliche Wirklichkeit aus, in der das Gedicht sich bewegt. Die verschiedenen Besonderheiten von Eigennamen im Zeichensystem der natürlichen Sprachen bieten sich für derartige Hinweise des Textes an.

Mit der Textstrukturierung durch die Semantik des Namens, der Verbindung von Texten mit Kontexten durch die Referenz und der ästhetischen Gestaltung durch das Eigennamenzeichen haben wir die textbezogenen Funktionen von Eigennamen mit Bezug auf die besondere Struktur der Kategorie ,Eigenname' erläutert. Es hat sich gezeigt, daß alle Eigenschaften des Eigennamens sich in erheblichem Maße textgestaltend auswirken. Vor dem Hintergrund dieser von der literaturwissenschaftlichen Onomastik oft vernachlässigten Funktionen wenden wir uns nun der ,klassischen' Funktion von Eigennamen zu: der Gestaltung von Figuren durch Eigennamen. Auch hier treten in Gedichten Besonderheiten auf, die durch die Eigenschaften der Gattung bedingt sind. Die wichtigste Besonderheit ist dabei, daß in Gedichten das Sprechersubjekt zumeist im Mittelpunkt steht. Neben der Gestaltung von Figuren durch ihren eigenen Eigennamen müssen wir im Folgenden daher besonders die Gestaltung eines Subjekts durch die Eigennamen, die dieses verwendet, berücksichtigen. 


\subsection{Figurenbezogene Funktionen}

\subsubsection{Direkte Evokation des Namenträgers}

\subsubsection{Name und Figur}

Wie oben ausgeführt wurde, repräsentieren Eigennamen - auch und gerade in literarischen Texten - sprachlich einen Namenträger. Für den Leser des Textes (unter Umständen auch für den Autor) haben Eigennamen daher auch die Funktion, den Namenträger zu evozieren. Als Evokation verstehen wir eine Präsentation, die es dem Leser ermöglicht, sich den Namenträger vorzustellen. Da das Eigennamenzeichen semantisch zunächst leer ist, kann durch einen Namen nicht, wie im Falle eines Appellativs eine garantierte Minimalvorstellung aufgerufen werden, die alle kompetenten Sprecher teilen. ${ }^{463}$ Vielmehr beruhen Evokationen durch Eigennamen auf der knowledge by acquaintance des Namenträgers, auf der Kenntnis von Beschreibungen des Namenträgers oder auf Eigenschaften des Namenzeichens, die auf den Namenträger verweisen. Bei berühmten oder dem Leser bekannten Eigennamen werden enzyklopädische Wissensbestände aufgerufen. ${ }^{464} \mathrm{Da}$ hier reichhaltige Informationen und auch bildliche Darstellungen oder der Namenträger selbst Teil des Wissens sein können, fördert ein bekannter Name die bildliche Vorstellung des im Text gemeinten Objekts erheblich. Weiter beruht die Evokationskraft von Eigennamen auf der Einschätzung der Namengebungsund Namenverwendungskonventionen, die den Autor oder einen anderen Namengeber und Namenverwender bestimmt haben mögen, einen Namen zu wählen.

Das durch einen solchen isolierten Namen hervorgerufene Bild kann je nach Kenntnis des Namenhintergrunds daher äußerst vage, unsicher und variabel, aber unter Umständen auch äußerst detailliert und präzise sein. Besonders im ersten Fall bedarf der Eigenname der Unterstützung durch Kotexte, wie sich an vielen Beispielen schon gezeigt hat. Da die figurenbezogenen Eigennamenfunktionen fiktionaler Eigennamen in der literaturwissenschaftlichen Onomastik längst ausführlich untersucht worden sind (s.o.), werden wir hier nur einige wenige Beispiele betrachten, in denen die verschiedenen Funktionen des Eigennamens ${ }^{465}$ in der besonderen textlichen Umgebung von Ge-

\footnotetext{
${ }^{463}$ Im Falle des Wortes ,Hund' (um unser anfängliches Beispiel noch einmal aufzugreifen) stellen sich alle kompetenten Sprecher des Deutschen ein vierbeiniges Säugetier mit Fell und Fängen vor, auch wenn jeder Sprecher individuell und okkasionell dieser Minimalstereotype zahlreiche weitere Eigenschaften hinzufügen kann, die sein im Geiste entstehendes Bild letztlich ausmachen.

${ }^{464} \mathrm{Vgl}$. auch Aschenberg 1991, S. 73-81. Horstmann bezieht die ,evokative Funktion' auf reale Eigennamen, die einen Kontext evozieren; vgl. Horstmann 2001, S. 45.

${ }^{465}$ Das sind nach dem Modell Lampings: Identifizierung, Illusionierung, Akzentuierung, Perspektivierung, Konstellierung, Charakterisierung. Ästhetisierung und Mythisierung berücksichtigen wir hier nicht; vgl. Lamping 1983.
} 
dichten zum Tragen kommen: das heißt, in knappen Ko- und Kontexten und mit nur wenigen Namentokens.

\subsubsection{Edgar Lee Masters fiktive Namenträger}

Figurenbezogene Funktionen fiktionaler Eigennamen sind außergewöhnlich häufig in Edgar Lee Masters Spoon River Anthology zu finden. Diese Gedichtsammlung besteht (vorwiegend) aus fiktionalen Reden gestorbener Personen der fiktiven amerikanischen Kleinstadt „Spoon River“. Es reden in den Gedichten die Toten aus ihren Gräbern mit dem Leser der Texte. Eine Besonderheit der Namenverwendung in dieser Anthologie ist, daß Masters eine einheitliche fiktive Hintergrundwelt gestaltet. ${ }^{466}$ Die einzelnen Gedichte stehen nicht isoliert, auch die Eigennamen werden zum Teil in mehreren Gedichten verwendet und die Figuren werden zueinander in eine Beziehung gebracht. Spoon River und die Gesamtheit der Bewohner Spoon Rivers sind der ständige Hintergrund der Gedichte. Dennoch können die einzelnen Texte auch isoliert betrachtet werden, zumal ihre Erstpublikation häufig isoliert in Zeitschriften stattfand. Die gemeinsame Hintergrundwelt ermöglicht es uns, auf Funktionen wie die Konstellierung, Perspektivierung und die Akzentuierung zu achten.

Masters ,Grabgedichte' bestehen immer aus einem Namentitel ${ }^{467}$ und einem ungereimten Verstext, in dem die im Titel genannte Person über sich spricht. Es handelt sich also um Rollengedichte. Masters orientiert sich sehr frei an historischen Vorbildern seiner Heimatstadt. Die Namen ergeben das erste Bild, das der Leser von der Person erhält. Sie dienen als erstes Zeichen des Textes der Identifizierung des Namenträgers und erwecken Erwartungen in bezug auf den Haupttext.

Betrachten wir zunächst einige der Überschriften: Robert Fulton Tanner, Hod Putt, Constance Hately, Kinsey Keene, Voltaire Johnson, Emily Sparks, Yee Bow, Chase Henry, 'Indignation' Jones, Judge Somers, Fiddler Jones, Andy the Night Watch, Theodore the Poet, The Town Marshal, Adam Weirauch, Homer Clapp, Minerva Jones, Immanuel Ehrenhardt, Percy Bysshe Shelley. ${ }^{468}$

Masters Mittel zur CHARAKTERISIERUNG mit Namen sind leicht zu erkennen: Er verwendet redende Namen (,Hod Putt' = hard put = benachteiligt / ,Constance Hately' = Constance haßerfüllt / ,Kinsey Keene' = Kinsey leidenschaftlich / ,Emily Sparks' = Emily Funken, ,Yee Bow' = Tee / Verbeugung) präfigurierte Namen (,Voltaire Johnson', ,Minerva Jones', ,Immanuel Ehrenhardt', ,Percy Bysshe Shelley’), Berufsbezeichnungen als Ü-

\footnotetext{
${ }^{466}$ Vgl. Harder 1983, S. 41: „Fictions [...] have to be tied to, nested in, swallowed up by, smeared over by or enlivered in space." Zur Lokalisation dieser Hintergrundwelt im realen Raum der USA vgl. Read 1982, S. $45 \mathrm{f}$.

467 Zu Namentiteln vgl. auch Sorgenfrei 1970; Shawcross 1983.

${ }^{468}$ Vgl. das Inhaltsverzeichnis in Masters 1992, S. 83-86.
} 
bernamen (,Judge Somers', ,Fiddler Jones', ,Andy the Night Watch', ,Theodore the Poet', ,The Town Marshal'), Spitznamen (,Chase Henry', ,'Indignation” Jones'), klanglich dominierte Namen (,Kinsey Keene' (alliterierend) und klassifizierende Namen (,Adam Weirauch', ,Yee Bow', ,Immanuel Ehrenhardt'). Schließlich treten auch unauffällige Namen auf (,Robert Fulton Tanner').

Die Namen wirken alle realistisch, besonders jene, die aus der gewöhnlichen Kombination von Ruf- und Familiennamen bestehen. Bei den redenden Namen hat Masters offenbar darauf geachtet, daß der jeweils korrespondierende konventionelle Ruf- oder Familienname den unwahrscheinlichen anderen Namenbestandteil ausgleicht. Selbst im Falle von ,hard put' wird durch die Verfremdung ein realistischer Name erreicht. Die Namen haben also auch die Funktion der Illusionierung. Die verschiedenartigen Benennungen (Name, Berufsbezeichnung, Kombination von Name und Berufsbezeichnung, Spitzname) deuten eine erste Perspektivierung und Akzentuierung an. Schließlich ermöglicht der gemeinsame Hintergrund eine einfache Konstellierung über die Familiennamen: So schreibt Masters etwa Gedichte über ,Flossie Cabanis' und ,John Cabanis', über ,Frank Drummer' und ,Hare Drummer' etc.

Die Namen erfüllen zunächst viele der figurenbezogenen Namenfunktionen isoliert, ohne Hilfe des Kontextes. Die doppelte Funktion des Eigennamens bei Masters als Titel und als Name des Sprechers bewirkt dabei, daß die Namen grundsätzlich figurengestaltende Funktion erhalten. ${ }^{469}$ Der metakommunikative Status der Überschrift - es spricht nicht der Namenträger, sondern eine andere ,Stimme' - bewirkt, daß die Namen als Hinweis der Erzähler- oder Autorebene verstanden werden können. Masters gestaltet mit den Namen eine Erwartung, mit der der Leser den nachfolgenden Haupttext liest. Die Namenträger und Sprecher bei Masters erfüllen die Erwartungen, die durch ihre Namen geweckt werden, indem sie nicht abstrakt, sondern als die Person sprechen, die durch den Namen charakterisiert, perspektiviert oder akzentuiert wird. Mit anderen Worten, der Name der Figur bestimmt den Schwerpunkt ihrer Existenz. Insofern wird hier durch die Akzentuierung und Perspektivierung, bei den redenden Namen auch durch eine Mythisierung, ein Hinweis auf die Wurzel des Charakters des Sprechers und seines Selbstbildes gegeben.

Dieses Selbstbild kann sich in der Haltung des Sprechers ausdrücken: Richter Somers (,Judge Somers') etwa spricht von sich mit dem überzeugten Ton des erfolgreichen Juristen. Er sieht sich primär als jemand, der eine ehrbare juristische und gesellschaftliche Karriere gemacht hat. Voltaire Johnson stellt sich selbst als ironischen Gesellschaftskri-

${ }^{469}$ Vgl. auch Aschenberg 2002, S. 114 f. 
tiker dar, der siegreich lachend inmitten ,ironischer Blitze' steht - man beachte die Lichtmetaphorik, die Masters in diesem Gedicht verwendet. Immanuel Ehrenhardt verschlingt (auch deutsche) philosophische Klassiker. Bei ,Yee Bow' führt ebenfalls das sortale Prädikat zum Textthema: die Assimilation der Chinesen in den Vereinigten Staaten. ,Faith Matheny' hat religiöse Visionen. Der Name ,Percy Bisshe Shelley’ führt einen Bewohner Spoon Rivers, der im Leben ein ungebildeter Nichtsnutz war, dem aber nach seinem Tod ein prächtiger Grabstein gebaut wurde, dazu, über den gebildeten Shelley zu triumphieren, dessen Asche ,bloß' verstreut wurde. ${ }^{470}$

Das Selbstbild drückt sich auch und vor allem in der benutzten Metaphorik aus: Emily Sparks etwa bedient sich einer exzessiven Lichtmetaphorik, um ihre Liebe zu ihren Schülern zu beschreiben: „Nothing but light!“. Constance Hately beschreibt, daß sie ihre Wohltaten für ihre Ziehkinder mit „constant reminders of their dependence“ vergiftet habe. ${ }^{471}$ „Trainor, the druggist“" vergleicht - darin Goethe ähnlich - die menschlichen Beziehungen mit chemischen Reaktionen und scheut selbst jede menschliche Verbindung. ${ }^{472}$

Auch wenn die Namen bei Masters als auktorialer Hinweis wirken, haben sie durch die Kombination von realistischen und redenden Namenelementen eine deutliche illusionierende Funktion. Alle Namen spielen als psychische Gegebenheit der fiktiven Welt auf die generelle Haltung des Sprechers zu seinem Leben an. Dadurch haben sie auch thematische Funktion. Die Eigennamen erhalten von den schmalen Kotexten Unterstützung, soweit sie das Thema des Textes andeuten und weil sie Teil der Gedankenwelt des dargestellten Subjekts und damit der fiktiven Welt des Textes sind. Betrachtet man die Gestaltung eines Subjekts als die Hauptaufgabe eines Gedichts, so wird an Masters deutlich, wie ein Name mit seinen namenträgerbezogenen Funktionen an der Gestaltung des Sprechersubjekts teilhaben kann, ohne zum deskriptiv redenden Namen zu werden: Der Name benennt das Thema des Textes, wenn bzw. weil das Subjekt Thema des Textes ist, und er ist Teil der Rede wie auch Teil der Welt des Sprechersubjekts.

\footnotetext{
${ }^{470}$ Vgl. Masters 1992, S. 99, S. 246, S. 304, S. 185 , S. 310, S. 121.

${ }^{471}$ Masters 1992, S. 96

472 Eine Ausnahme machen jene Namen, die auf unbekannte reale Vorbilder zurückgehen, wie etwa ,Robert Fulton Tanner'. Ihnen fehlt die starke charakterisierende Komponente der anderen Namen zugunsten der realistischen Illusionierung. Diese schwache Wirkung beruht aber lediglich auf der Unbekanntheit der ansonsten thematisch ausgewählten Vorbilder.
} 


\title{
4.4.2 Indirekte Evokation: Name und Idiolekt
}

Die Auswahl der Namen, die ein Sprecher verwendet, charakterisiert inn, weil sie einen Teil seines Idiolekts darstellen. Dies gilt besonders dann, wenn man Texte der Gattung Lyrik vorwiegend als „Medium für die Selbst-Artikulation und Selbst-Konstitution des Sprechers" versteht. ${ }^{473}$ Wir beginnen die Darstellung dieses Aspekts mit drei poetologischen Beispielen, bevor wir zu den Gedichten E.L. Masters' zurückkehren.

\subsubsection{Namenkataloge als Programm}

José Cadalso füllt in seinem ,Autorgedicht' Refiere el autor los motivos que tuvo para aplicarse a la poesía die grundlegende Formeinheit des Gedichts, eine gereimte Doppelzeile aus zwei endecasillabos im Paarreim, (fast) nur mit Eigennamen:

\author{
Caro lector, cualquiera que tú seas, \\ que estos mis Ocios juveniles veas, \\ no pienses encontrar en su lectura \\ la majestad, la fuerza, la dulzura \\ que llevan los raudales del Parnasso, \\ Mena, Boscán, Ercilla, Garcilaso, \\ Castro, Espinel, León, Lope y Quevedo: \\ no ofrezco asuntos que cumplir no puedo. ${ }^{474}$
}

Die eingesetzten kanonischen Eigennamen evozieren keine Figuren, die in den Text integriert werden, sie ordnen vielmehr den Autor in das literarische Feld seiner Zeit ein. ${ }^{475}$ Der Sprecher bekennt sich mit der Namennennung der kanonischen klassizistischen Autoren zur Tradition der an Petrarca orientierten Lyrik (der ,claros') und setzt sich von den an Gongora und dessen Manierismus ausgerichteten ,culteranos' ab. ${ }^{476}$ Das Gedicht entwickelt ein poetisches Programm der spanischen neo-klassizistischen Anakreontik. Im nachfolgenden Gedicht treten weitere Namen auf, die eine für den Neoklassizismus bezeichnende kulturelle Trias bilden: Griechenland, Italien und das Spanien des 16. Jahrhunderts. Diesen klassischen Autoren spricht der Sprecher eine therapeutische und didaktische Wirkung zu: Garcilaso und Ovid stehen für ,Zartheit' („terneza“), die den durch das Leben enttäuschten Sprecher tröstet, Ovid und Tasso für Gelehrtheit, an der er sich orientiert. Der Namenkatalog und die einzeln genannten Namen bilden das Fundament und die Grenzen, innerhalb derer sich die eigene Poetik und die eigenen Werke des Sprecher-Autors entwickeln. So wie sie unbeschwert und

\footnotetext{
${ }^{473}$ Hühn/Schönert 2002, S. 290.

474 „DER AUtOR NENNT DIE GRÜNDE, DIE ER HATTE, SICH DER POESIE ZU WIDMEN [...] / Geschätzter Leser, wer auch immer du bist, der meine jugendlichen Mußestunden sieht, denke nicht, beim Lesen die Großartigkeit, die Kraft, die Süße zu finden, die der Schwarm des Parnaß in sich trägt, / Mena, Boscán, Ercilla, Garcilaso, / Castro, Espinel, León, Lope und Quevedo: / ich biete keinen Stoff, dem ich nicht gewachsen bin [...]“; Reyes 1993, S. 137 f.

${ }^{475}$ Vgl. zur Enumeration in dieser Funktion auch Mainberger 2003, S. 272 f.

${ }^{476}$ Vgl. die Einleitung zu: Reyes 1993, S. 31.
} 
fröhlich dichteten, will auch Cadalso nun bukolische statt philosophischer oder tragischer Themen behandeln:

Todos de risa son, gustos y amores, no tocaré materias superiores.

De los supremos dioses y reyes, ${ }^{477}$ la obscura voz y las secretas leyes, los arcanos, enigmas y misterios, no digo con osados versos serios.

Mit der langen Reihe seiner Vorbilder kann Cadalso den zweifelnden Leser im Brustton der Überzeugung seiner ,guten poetischen Kinderstube’ beruhigen „No leas con temor. Ni voz ni idea verás en mí que indecorosa sea, [...].“ Die Namennennung ist als poetologisches Manifest wichtig, weil sie Grenzen zieht und den Sprecher und sein Werk für den Leser klassifiziert.

Eine solche Selbstcharakterisierung kann auch ohne die scharfe Abgrenzung gegen andere Strömungen stattfinden. In diesem Fall wird sie zu einer individuellen Selbstdarstellung durch die genannten Namen. Der Sprecher eröffnet dem Leser mit den Namen sein ,Diskursuniversum', das durch die Namen als ,Knoten des Diskurses' ausgemessen wird. Als Beispiel hierfür dient ein scheinbares Widmungsgedicht, das Manuel Vázquez Montalban an den Anfang einer Anthologie stellt:

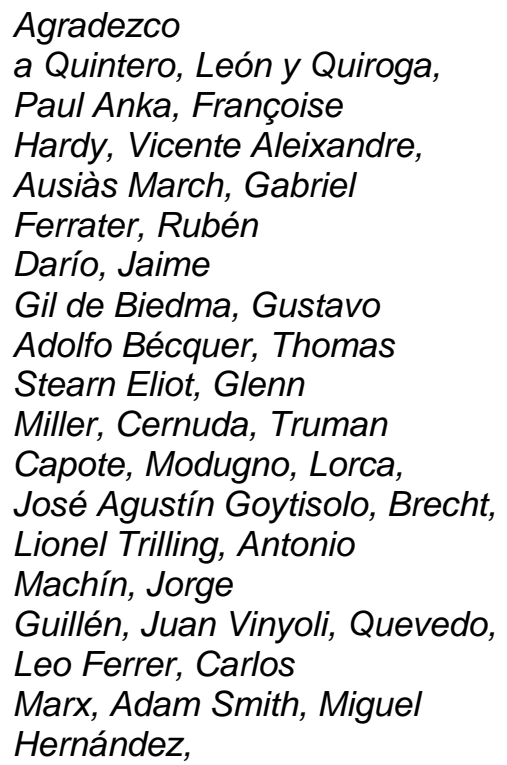

\footnotetext{
477 „Alle handeln vom Lachen, von Freuden und von der Liebe, / ich werde höhere Stoffe nicht berühren. / Von den hohen Göttern und Königen, / der dunklen Stimme und den geheimen Gesetzen, / den Arkanischen Weisheiten, Geheimnissen und Misterien, / rede ich nicht mit kühnen ernsten Versen“; Reyes 1993, S. 140.
} 
Alle hier verwendeten Eigennamen gehören berühmten Personen. Dabei fällt auf, daß Montalbán sowohl die Namen von Zeitgenossen als auch die Namen längst verstorbener Personen verwendet. Montalbán verwendet außerdem jeweils unterschiedliche Anteile der vollständigen Namen. So stehen z.B. „Brecht“ und „Quevedo“ alleine, während „Carlos Marx“ oder „José Agustín Goytisolo“ mit vollem Namen genannt werden. Allerdings verwendet Montalbán die Familiennamen aller genannten Personen. Eine Perspektivierung in Richtung auf die persönliche Beziehung oder Bekanntschaft findet also nicht statt. Statt dessen werden Schriftstellernamen, die Schlagwortcharakter haben, präsentiert. Durch das Ausbuchstabieren und die graphische Anordnung der Vornamen wird dem Namen hie und da ein gewisses Gewicht gegeben, wie im Fall von „Thomas / Stearn Eliot“, der gemeinhin zu ,T.S. Eliot' abgekürzt wird. Darüber hinaus wird die Verwechslung - etwa mit George Eliot, den Marx-Brothers oder Juan Goytisolo - vermieden. Der ungewöhnliche Zeilenumbruch qualifiziert den Text formal als Gedicht in unserem Sinne. Die Zäsuren des Zeilenwechsels sind bewußt gegen die Zusammengehörigkeit mehrteiliger Eigennamen gesetzt. Dadurch wird die Aufmerksamkeit auf die einzelnen Namen und Namensbestandteile gerichtet. Bei einem ersten ,linearen' Lesen ergeben sich kleinräumige Verrätselungen. Nur ein Name: ,Ovid', ist graphisch herausgehoben, er sticht als antiker Klassiker auch inhaltlich hervor.

Ein Spannungsbogen über das gesamte Gedicht entsteht durch die Satzklammer, die erst nach der ungewöhnlich langen Reihe von Eigennamen preisgibt, was eigentlich Montalbán den Genannten verdankt. Er habe - so die Textaussage - deren Worte und Verse verwendet. Die Danksagung ist also ein Hinweis auf Zitate in den darauf folgenden Gedichten des Bandes. Das postscriptum schließlich löst das Pathos des vorhergehenden Textes, indem es dem Gedicht die Aura eines spontanen und nicht mehr korrigierbaren Briefes gibt.

Die Namen bezeichnen jene Autoren, aus denen Montalban in seiner Gedichtanthologie zitiert. Die ,Widmung' stellt gewissermaßen eine kollektive umfassende Fußnote zu den nicht gekennzeichneten Zitaten der Gedichte dar. Montalban gestaltet in diesem Gedicht aber auch den typischen geistigen Horizont eines Linksintellektuellen: Neben den klassischen spanischen Autoren und Ovid treten avantgardistische kulturelle Größen auf: Truman Capote, Bertolt Brecht, Autoren der spanischen Gegenwart, Autoren der politischen Philosophie, ein Jazzmusiker. Eigennamen sind auch hier Teil eines Idiolekts. Die Namen referieren über den Text hinaus auf die von Sprecher, Hörer, Autor

\footnotetext{
478 „Ich danke [...] / Wörter, / ganze Verse von mir geraubt. / P.D.- Und dem dynamischen Duo [...]”; Montalbán 1996, o.p.
} 
und Leser geteilte kulturelle Welt. Sie legen das Gedicht aber nicht auf die Zeit und den Kontext der genannten Dichter fest. Hier ist es nicht der Namenträger, der durch den Namen näher bestimmt wird, sondern der Namenbenutzer, der sich und sein gedankliches Universum, seine Intentionen und sein Weltbild durch die Auswahl der realen Namen gestaltet.

\subsubsection{Die Charakterisierung fiktiver Sprecher durch die Namenverwendung}

Auch Masters' Sprecherfiguren verwenden neben den Eigennamen der fiktiven Sprecher reale Eigennamen in seinen Gedichten. Hier charakterisieren die Namen den fiktiven Sprecher. Zunächst gibt wie in unseren poetologischen Beispielen die Auswahl der Namen einen Hinweis auf den Sprecher. Der Chinese in Yee Bow stellt Konfuzius gegen Christus und sehnt sich nach seiner Heimatstadt Peking. Immanuel Ehrenhardt beschreibt seinen intellektuellen Werdegang durch philosophische Namen: Sir William Hamilton, Dugald Steward, Descartes, Fichte, Schelling, Kant, Schopenhauer, John Muir. Seine Namenwahl suggeriert den Gang von der schottischen Moralphilosophie und Metaphysik hin zum Deutschen Idealismus und seinen Nachfolgern, bevor der Sprecher vom amerikanischen Naturalismus auf den Boden der Tatsachen zurückgeholt wird. Ehrenhardt gestaltet sich selbst konform mit seinem Namen, besonders durch den breiten Raum, den der deutsche Idealismus in seiner Namenauswahl einnimmt.

Weiterhin werfen Veränderungen am Namen, die den Namenträger perspektivieren können, auch ein Licht auf den „Namenveränderer': „Aner Clute“ (vielleicht von „Anakoluth', weil ihr Leben einen tiefen Bruch aufweist) etwa beginnt die Beschreibung ihrer Werdegangs als Prostituierte so:

Over and over they used to ask me

[...]

In Peoria first, and later in Chicago,

Denver, Frisco, New York, wherever I lived,

How I happened to lead the life,

And what was the start of it." ${ }^{479}$

Die Namenwahl beschreibt ihren Gang von der neuenglischen Kleinstadt in die Großstädte der USA. Gleichzeitig gibt der Namenkatalog einen kleinen Hinweis auf den sozialen Status bzw. das Selbstbild der Sprecherin: Frisco statt ,San Francisco'. Die Abkürzung steht für einen kolloquialen und nachlässigen Stil. Masters gestaltet die Reden der Toten in seinen Gedichten in einem einheitlichen Ton der Hochsprache. Er verwendet weder Dialekte noch Soziolekte oder gar ,slang'. Daher sind seine Mittel zur individuellen Gestaltung des Sprechers durch seine Sprache gering, wenn man von der inhaltlichen und metaphorischen Selbstgestaltung absieht. Der Eigenname ,Frisco' ist

${ }^{479}$ Masters 1992, S. 141. 
einer der seltenen Fälle, in denen ein sprachliches Phänomen zur Charakterisierung eines Sprechers genutzt wird.

Auch die Wahl bestimmter Namen aus einem kulturellen Namenfeld gibt einen Hinweis auf den Namenverwender: Lucius Atherton, ein ,Frauenheld', der nicht in Würde gealtert ist, spricht von sich selbst - konventionell genug - als gealtertem ,Don Juan'. Im Jenseits, aus dem er spricht, trifft er auf einen anderen Toten, der aus der Liebe, die Atherton zum „trick“ herabgewürdigt hat, seine ganze Größe schöpfte: Dante. Während Atherton mit ,Don Juan' sich selbst benennt und die vielen von inm verführten Frauen namenlos läßt (unter anderem Aner Clute, die ihn in ihrem Gedicht erwähnt [s.o.]), benutzt er zur Identifikation Dantes den Namen ,Beatrice', also den Namen des von diesem geliebten Wesens:

There is a mighty shade here who sings

Of one named Beatrice;

And I see now that the force that made him great

Drove me to the dregs of life. ${ }^{480}$

Die Geliebte bleibt bei Dante namentliches Subjekt, während Atherton nur Objekte benutzt. Das ist der Unterschied, der den einen in der (sündigen) Liebe groß macht, den anderen einen Lustgreis werden läßt.

Eigennamen werfen stets ein Licht auf den Eigennamenbenutzer und Eigennamengeber. Die besondere inhaltliche Struktur von Gedichten, sofern sie „the language of performance" und das Innere eines Subjekts darstellen, unterscheidet sie von Erzähltexten, in denen die erzählte und gestaltete Welt dominiert. Eigennamen sind Teil eines Diskurses, der im Gedicht als isoliertem Gesprächsbeitrag gestaltet wird. Daher wird in Gedichten die Verweisfunktion des Namens auf den Namenbenutzer und Namengeber stärker in den Vordergrund gestellt.

\subsubsection{Zusammenfassung: Name, Figur und Idiolekt}

Figurengestaltende Funktionen von Eigennamen erhalten in Gedichten gesteigerte Bedeutung, weil sonstige Hinweise auf den Namenträger anders als bei Erzähltexten in der Regel spärlich ausfallen müssen. Insofern sind für den Leser die Hinweise, die ein Eigenname mit seinen unterschiedlichen Bedeutungselementen gibt, besonders fruchtbar. Da in Gedichten aber gestaltete Figuren vergleichsweise selten vorkommen, ist ein anderer Weg der Figurengestaltung wesentlich wichtiger. Im Zentrum des Gedichts steht das Sprechersubjekt - das, lyrische Ich'. Der Sprecher gestaltet sich selbst durch die Eigennamen, die er verwendet. Diese indirekte Evokation eines Sprechers durch

\footnotetext{
${ }^{480}$ Masters 1992, S. 142.
} 
Eigennamen beruht auf der kommunikativen Stellung von Eigennamen, die durch das Aufrufen weiter und normativ eindeutig besetzter Kontexte wiederum im Rahmen des ,Iyrischen Lakonismus' eine besonders vielfältige Charakterisierung des Namenbenutzers ermöglichen. Der Namenbenutzer ordnet sich selbst in ein kulturelles Namenfeld ein. An dieser Stelle berühren sich textbezogene und figurenbezogene Namenfunktionen.

\subsection{Das Potential von Eigennamen}

Die in diesem Kapitel untersuchten und beispielhaft angeführten Eigennamen in Gedichttexten lassen sich nicht zusammenfassend auf einen Nenner bringen. Sie zeigen dagegen die Vielfalt sehr verschiedener Funktionen, mit denen Eigennamen in literarischen Texten eingesetzt werden können. Gemeinsam ist diesen verschiedenen Funktionen, daß sie sich aus der sprachsystematischen und kommunikativen Sonderrolle der Zeichenkategorie ,Eigennamen' in den natürlichen Sprachen ergeben. Die Analyse der verschiedenen Funktionen von Eigennamen zeigt, wie vielfältig die Besonderheit der Zeichenkategorie ,Eigenname' im Textzusammenhang umgesetzt werden kann.

Das wichtigste Ergebnis dieses Kapitels ist, daß der Einsatz von Eigennamen im Gegensatz zu den Vorannahmen der meisten bisherigen Untersuchungen nicht nur eine Angelegenheit zwischen Namenträger und Namenszeichen, nicht nur eine Angelegenheit zwischen Namengeber bzw. ,Namenveränderer' und Namenträger ist. In einem Eigennamen zeigt sich vielmehr das simultane und komplexe Zusammenspiel der Einflüsse von Namengeber(n), Namenträger(n), Namenverwender(n), dem Namenszeichen, den Kontexten und dem Kotext einschließlich anderer, mit dem Namen verbundener Namenszeichen. Alle diese Instanzen haben von Fall zu Fall unterschiedlichen Einfluß auf die Funktionen, mit denen Eigennamen im Gedicht eingesetzt werden. Nirgendwo tritt diese Vielfalt so deutlich und so fordernd auf wie im Gedicht, das durch seine lakonische Kürze und die enge Anbindung an nicht gestaltete Kontexte das Potential jedes verwendeten Zeichens und jeder verwendeten Zeichenkategorie ausschöpft. Die Ermittlung aller Funktionen einzelner Eigennamenverwendungen in einem Gedicht ist daher notwendiger Bestandteil der Interpretation eines Gedichts mit Eigennamen.

In den letzten zwei Kapiteln wurden zunächst der vollständige sprachsystematische Spielraum und anschließend der vollständige Spielraum der poetischen Anwendung von Eigennamen an möglichst deutlichen Beispielen ausgelotet. Vor diesem Hintergrund soll nun die Untersuchung der Verwendung von Eigennamen im größeren Werk- 
kontext stattfinden, so daß Stilzüge und Gewohnheiten zweier Autoren an ihrem gesamten Werk aufgezeigt werden können.

Die Gewohnheiten der Eigennamenverwendung eines Autors - untersucht an seinem Gesamtwerk - geben darüber Auskunft, welche Einstellungen, Konzepte, Kontexte den Hintergrund seiner Gedichte bilden. An der semantisch auffälligen Kategorie ,Eigenname' drückt sich darüber hinaus die Einstellung des Autors zur Sprache aus. Insofern dient die onomastische Untersuchung zweier Autoren, deren Gedichtwerk eigennamenreich ist, dazu, den Umgang dieser Autoren mit Sprache grundsätzlich zu untersuchen. Nicht zufällig zeigen beide im Folgenden untersuchten Autoren, Theodor Fontane und Edwin Arlington Robinson, an der unsicheren Kategorie ,Eigenname' ihre grundlegende Sprachskepsis. 


\section{Eigennamengebrauch als Stilzug bei Theodor Fontane und Edwin Arlington Robinson}

\subsection{Plauderei mit Namen - der Gebrauch realer und realistischer Namen zur indirekten Evokation des Sprechers in Theodor Fontanes Gedichten}

\subsubsection{Fontanes Dichtwerk und seine Alterslyrik}

Theodor Fontane macht in seinen Gedichten eine Wandlung der Geisteshaltung durch, die sich am deutlichsten in einem Gattungswechsel manifestiert: Von der heroischhistorischen und numinosen Ballade wendet sich Fontane der sozialen Ballade ${ }^{1}$ und der kleinen und formal scheinbar anspruchslosen ${ }^{2}$ Spruch- und Knittelversdichtung zu. Das balladeske Erzählen wird durch das prosanahe und aufzählende Darstellen und Berichten abgelöst. Die Haltung des Sprechers der späten Gedichte, der oft als Fontane selbst erkennbar ist, ist geprägt durch Gelassenheit und der Wendung zu einer ironischen Bescheidenheit. ${ }^{3}$

Diese Einschätzungen verdanken sich nicht zuletzt den klaren Äußerungen in Fontanes später Dichtung, in der der Sprecher immer wieder betont, daß inm am Großen und Bedeutenden nicht mehr liege und er sich lieber in die kleine Alltagswelt zurückziehe. Im Folgenden soll anhand des Eigennamengebrauchs in Fontanes Lyrik gezeigt werden, wie sich der Wandel in Fontanes Einstellung auf seine Sprachverwendung auswirken und wie im Eigennamengebrauch des späten Fontane Sprach- und Gesellschaftskritik zusammentreffen. Die verwendeten Eigennamen - so wird dieses Kapitel zeigen - machen durch ihren aktualisierten semantischen Hintergrund und durch ihren kommunikativen Wert sowohl Stilzüge als auch Haltungen eines Autors deutlich.

\subsubsection{Das Poetische am Namen}

\subsubsection{1 „Epigramm“ und "Gedicht“ - redende Namen bei Fontane}

Man möchte meinen, daß redende Figurennamen in der Dichtung des Realismus, die ihre Figuren mit realistischen Eigennamen bestückt, wenig zu suchen haben. ${ }^{4}$ Doch läßt sich Fontane von redenden Beinamen durchaus poetisch inspirieren: In einem der poetologischen Gespräche in Vor dem Sturm erörtern Fontanes Figuren bei einem Tischgespräch ausführlich, wie die alten skandinavischen Königsbeinamen auf einen Hörer wirken - genannt werden „Thyra Danebod“, „Sigurd Ring“, „König Helge“, „Ragnar Lod-

\footnotetext{
${ }^{1}$ Vgl. Richter 2000, S. 742-746.

2 Zur wohlbedachten Komposition dieser Knittelverse vgl. Richter 2000, S. 737.

${ }^{3}$ Vgl. z.B. Bickmann 1989, S. 203.

${ }^{4}$ Birus 1978, S. 38.
} 
brok“, „Harald Hyldetand“. Zum einen „entzücken“ sie durch den „bloßen Klang“. So bekennt die Figur Hansen-Grell: „sooft ich dieselben höre, ist es mir, als teilten sich die Nebel und als sähe ich in eine wundervolle Nordlandswelt [...]." ${ }^{5}$ Zum anderen sollen diese Namen „ihren Zauber“ daher erhalten, daß sie „Menschen, Erscheinungen, ja ganze Epochen in einem Beiwort“ charakterisieren. ${ }^{6}$ Die Exotik des Klangs spielt für die Beteiligten des Tischgesprächs nur bei oberflächlicher Betrachtung die Hauptrolle. Es sei zwar „der fremde Klang, der unser Ohr gefangennimmt“, aber: „Epigrammatischer als ein Epigramm, ist mancher dieser Namen doch zugleich wie ein Gedicht, rührend oder ergreifend, je nachdem.." Der Verweis auf das Epigramm zeigt, daß die Beinamen es erlauben, etwas pointiert darzustellen. Doch sind nach dem vorher Gesagten die alten Beinamen nicht nur deswegen poetisch und anschaulich, weil sie den Träger mit den typischen Namensfunktionen Lampings ,charakterisieren' und ,evozieren'. Vielmehr verweisen sie der Struktur der Eigennamenbedeutung entsprechend auf bestimmte Taufsituationen, die ihrerseits vor dem Auge des Lesers die Situation des Namenträgers (bis hin zu „ganze[n] Epochen“) erstehen lassen und auch die Gesellschaft, in der diese Eigennamen gegeben wurden, charakterisieren.

Die Nordischen Königsnamen preist Fontane auch in der gleichnamigen Ballade von $1885^{\circ}$, die eben jene in Vor dem Sturm behandelten Eigennamen verwendet. Das mehr oder weniger nachträglich zu den Balladen verfaßte „humoristische Einleitungsgedicht“9 enthält im Lob der alten anschaulichen Namen die Poetik Fontanes in nuce. Die imaginative Gestaltung der Geschichte soll die systematische, aber unanschauliche Schilderung der korrekten Tatsachen ersetzen. Wichtig in theoretischer Hinsicht ist hier auch, daß Fontane sich nicht auf die Literatenlizenz, etwas Unwahres zu sagen, beruft, sondern lediglich die Anschaulichkeit ins Feld führt:

„... Da (so heißt es in hochgelahrten Schriften)

Begann das heillose Beinamenstiften;

Statt Zahlen, die klarer doch und reeller,

Kam Auceps, Finkler, Vogelsteller,

Kam Löwe, Rotbart. Und gar nicht lange,

Gab's einen „mit der gebissenen Wange“,

Dazwischen, blasphemisch und wie zum Spott,

Sogar einen Heinrich Jasomirgott.

So ging es in Deutschland. Anderswo

War's, wenn nicht schlimmer, ebenso;

Geschmacklos war die ganze Zeit,

Und die Dänen waren die Führer im Streit.

Thyra Dänentrost oder "Danebod“,

Erik Seelensgut oder „Eiegod“,

\footnotetext{
${ }^{5}$ Fontane HFA III, S. 414.

${ }^{6}$ Fontane HFA III, S. 414.

${ }^{7}$ Fontane HFA III, S. 414.

${ }^{8} \mathrm{Vgl}$. den Kommentar in Fontane HFA I, 6, S. 1019.

${ }^{9}$ Vgl. den Kommentar Fontane HFA I, 6, S. 909.
} 
Erik Hasenfuß oder Laufgeschwind,

Erik Lamm, Erik Pommer, Erik Kind,

Erik Pflugpfennig, Erik Pfaffentort,

Erik Mendved oder Manneswort,

Erik Glipping, der mit den Wimpern glippt,

Erik Kipping, der die Münzen kippt,

Ein Glück, daß der Eriks nicht mehr gewesen,

Wir würden sonst noch viel Schlimmeres lesen."

So die Hochgelahrten, die Weisen und Alten.

Ich kann es für so schlimm nicht halten,

Geschicht' und Dichtkunst sind zweierlei Zünfte,

Mir gefällt nicht der „Erste“, der „Dritte“, der „Fünfte“,

Zahlen und wieder Zahlen bloß

Scheinen mir tot und charakterlos.

Ragnar Pechhos' und Iwar Klaftergriff

Haben schon andern Schneid und Schliff,

Harald Blauzahn und Rolf Krake der Zwerg

Helfen schon anders über den Berg,

Swend Gabel- und Hakon Borkenbart,

Das sind Namen nach meiner Art,

Fleckauge, Schönhaar, Sigurd Ring,

Alles schon ein ander Ding,

Gorm Grymme, Frede Harde-Schnut,

Olaf Hunger vor allem gefällt mir gut,

Und zum letzten: Olaf Kragebeen -

Tretet vor und verneigt euch und laßt euch sehn. ${ }^{10}$

Der Sprecher gibt den Beinamen die Funktion, ihren Träger vor dem Leser anschaulich erstehen zu lassen (Evokationsfunktion). Jene Beinamen, die der Sprecher nennt, sind geprägt durch eine deutlich redende Ursprungsemantik sowie durch die Wirkung einzelner (z.B. archaischer) Lautkombinationen oder der Herkunftssprache der Zeichen. Die Rufnamen, die der Sprecher zum Teil nennt, tragen zu diesem exotischen Klang bei. Er veranschaulicht durch die Reihung der dänischen Königsnamen, die alle durch den monoton wiederholten Rufnamen ,Erik' verbunden sind, die Notwendigkeit der redenden Beinamen. Diese haben hier eine deutliche individuierende Funktion und ersetzen die augenscheinlich notwendige Zahlenreihe, die die zitierten Wissenschaftler angeblich vorzögen.

Den naiven Schluß vom Namen auf den Namenträger verhindert Fontane, indem er den Sprecher ironisch von der Gegenposition der Geschichtswissenschaftler ausgehen läßt, die den ästhetischen und epistemischen Wert der Beinamen bezweifeln und sich lieber an die Systematik der Ordnungszahlen halten. Beinamen werden hier nicht als ,wahre Worte', sondern als Symptome einer bestimmten Zeit, eines Charakters oder einer Situation behandelt.

Wie wichtig es Fontane war, daß die in dieser Weise verstandene imaginationsstiftende und charakterisierende Ursprungssemantik der Namen seiner Protagonisten verstanden würde, wird an der graphischen Hervorhebung erklärender Appellativa in den Balladen

\footnotetext{
${ }^{10}$ Fontane HFA I, 6, S. 167 f.; vgl. den Kommentar in Fontane GBA Gedichte 1, S. 487.
} 
deutlich: Olaf Kragebeen (Krähenfuß) fragt seine „Krähn“ um Rat, Waldemar Atterdag „schiebt" es „auf den andern Tag [...]: 'Atterdag'“. ${ }^{11}$ Die Gründe, die die Beinamenvergabe bestimmt haben könnten, spricht Fontane in den Balladen dann explizit an, wenn der Leser die Ursprungssemantik unter Umständen mißverstehen könnte. So „prangt“ Hakon Borkenbart „Von Narben von den Dänen her“; Gorm Grymme „liebt“ „In Grimme drein zu schaun". ${ }^{12}$ Solche Erklärungen fügt Fontane aber nur dort ein, wo der Beiname zusätzlich auf eine handlungsrelevante charakterisierende Angewohnheit, ein Ereignis oder ein Handlungselement referiert. Dort, wo der Name die Person ohne Beziehung zur dargestellten Handlung beschreibt, spart Fontane die Erklärung aus (z.B. bei ,Swend Gabelbart'), selbst wenn der Name den Lesern auf diese Weise unverständlich bleiben kann wie im Falle von ,Harald Harfagar' (Schönhaar). ${ }^{13}$

Die Begeisterung Fontanes für redende Beinamen erstreckt sich auch auf nicht genuin redende neuere Familiennamen. Deren Ursprungssemantik sucht er bisweilen im Wortspiel zu aktualisieren. So beginnt ein Gedicht An Storm harmlos ,komisierend' mit „O Heiligenstadt, du heil'ge Stadt" ${ }^{\text {“4 }}$; oder der Sprecher zieht in Über ein Weilchen den Reichstagsabgeordneten Berthold von Plötz seines redenden Namens wegen als abschließendes Beispiel heran: „Und wohl auch für Herrn von Plötz / Kommen plötzlich Plötzlichkeiten.“15

Fontane setzt die Interpretation der Ursprungssemantik von Eigennamen auch gezielt zur Handlungsgestaltung und zur humoristischen Darstellung kriegerischer Geschehnisse ein. Der grobe Scherz mit eigenen und fremden Namen, die ,Ästhetisierung' inmitten des blutigen Schlachtengeschehens wird bei Fontane zum Topos: In seiner Ballade Herr Seydlitz auf dem Falben, der ersten aus der Trilogie Seydlitz, erwähnt der Erzähler die Wirkung der Namen auf die Kämpfer in der Schlacht bei Zorndorf:

Das waren Seydlitz' Späße;

Bei Zorndorf galt es Zorn,

Als ob's im Namen säße,

Nahm man sich da aufs Korn;

$[\ldots] .{ }^{16}$

\footnotetext{
${ }^{11}$ Fontane HFA I, 6, S. 173-175, S. 176-178.

${ }^{12}$ Fontane HFA I, 6, S. 168 f., S. 169-171.

${ }^{13}$ Fontane HFA I, 6, S. 175-176, S. 171-173; vgl. den Kommentar in Fontane HFA I, 6, S. 912. Harald Harfagar zeigt allerdings auch, wie ein Element der Namenursprungssemantik absichtlich oder unabsichtlich in die Ballade einwandert. Die Frauen Haralds einschließlich der ,Zukünftigen', Rynhilde, werden mit Bezug auf ihr Haar beschrieben („blond und stolz“ bzw. mit „Korallen im Goldhaar"); vgl. Fontane HFA I, 6, S. 171.

${ }^{14}$ Fontane HFA I, 6, S. 324.

${ }^{15}$ Vgl. Fontane HFA I, 6, S. 391 und den Kommentar, S. 993.

${ }^{16}$ Fontane HFA I, 6, S. 211; zur Aktualisierung der Namenursprungssemantik in den Romanen vgl. auch Hebekus 2003, S. $181 \mathrm{f}$.
} 
In der patriotischen Heldenballade Der Tag von Düppel evoziert Fontane in erster Linie durch die Namen bürgerlicher Soldaten ,das gemeine Volk', das die Schlacht geschlagen hat. ,Piefke', ,Probst', ,Schneider', ,Klinke' repräsentieren durch ihre sortalen Prädikate die kleinen Berliner Helden. Wie man Fontanes Bericht Der SchleswigHolsteinische Krieg im Jahre 1864 entnehmen kann, sind die Eigennamen annähernd historisch korrekt wiedergegeben, und auch die geschilderten Ereignisse liegen nahe an der Realität. ${ }^{17}$ Mit Hilfe der Ursprungssemantik dieser Namen gestaltet Fontane die Details des Schlachtgeschehens aber anekdotisch und von der Wahrheit abweichend, indem er den heldenhaften Handlungen passende Namenträger zuordnet und diese über ihre Namen scherzen läßt. Durch die derben ,soldatischen' Scherze verherrlicht Fontane den Heldenmut der deutschen Soldaten, die mit ihren witzigen Namenspielen ihre Bereitschaft hervorheben, mit der Begeisterung christlicher Märtyrer für das ,Vaterland' in den Tod zu gehen ${ }^{18}$ :

Da springt von achten einer vor:

"Ich heiße Klinke ich öffne das Tor!“

Und er reißt von der Schulter den Pulversack,

Schwamm drauf, als wär's eine Pfeif' Tabak.

Ein Blitz, ein Krach - der Weg ist frei -

Gott seiner Seele gnädig sei.

Solchen Klinken für und für

Öffnet Gott selber die Himmelstür. ${ }^{19}$

Auf die gleiche Weise begleitet der Erzähler das Wortspiel einer weiteren Soldatenfigur der Ballade mit ihrem bürgerlichen Namen, indem er die vermeintliche Ursprungssemantik des Namens ${ }^{20}$ und jene des dänischen Leutnants Anker ${ }^{21}$ aktualisiert:

Da donnert's: „Ergib dich tapferes Blut,

Ich heiße Schneider, und damit gut!“.

Der preußische Schneider, meiner Treu,

Brach den Dänischen Anker entzwei.

Die Selbstcharakterisierung der Soldaten durch ihren Namengebrauch setzt der Erzähler jeweils fort. Er legt den Namen als redenden Namen aus, der der Handlung angemessen ist, und überhöht so das grob-witzige Namenspiel des Soldaten patriotischreligiös.

Die Namenspiele sind Teil der humoristisch-anekdotischen Schilderung der Heroen und heroischen Ereignisse. Dadurch, daß er unter anderem den Akteuren selbst das Spiel

\footnotetext{
${ }^{17} \mathrm{Vgl}$. den Kommentar in Fontane HFA I, 6, S. 933 f.

${ }^{18}$ In Unsere lyrische und epische Poesie seit 1848, Fontane NA 21, 1, S. 23, erkennt Fontane „selbst das Recht des soldatischen Humors bereitwillig an“.

${ }^{19} \mathrm{Vgl}$. Fontane HFA I, 6, S. 234-237.

20 ,Schneider' als (kleinbürgerliche) Berufsbezeichnung zu sehen, liegt in diesem Kontext nahe; auch eine Anspielung auf das ,tapfere Schneiderlein' ist möglich; vgl. zur Märchenfigur und ihrer Verbreitung Diederichs 1995, S. 329.

${ }^{21}$ Zum ,Anker' als Symbol des „festen Haltes“: Chapeaurouge 1987, S. 117.
} 
mit den Namen in den Mund legt, verhindert Fontane, daß seine Namenspiele als ein dem Ereignis unangemessener Scherz des Sprechers gewertet werden. Zugleich verwendet er die Namendeutung als ein Handlungselement, das die Figuren charakterisiert, weil sie selbst Bezug darauf nehmen. Den realen Namen wird auch hier 'Epigramm-Qualität' gegeben, weil ihre Auslegung sowohl die Einstellung der Figuren als auch die Stimmung der Ereignisse konzentriert wiedergibt. ${ }^{22}$

,Epigrammatische' Namen benutzt Fontane auch in den späten Balladen, die sich mit dem kleinbürgerlichen Alltag beschäftigen. ,Fritz Katzfuß ${ }^{23}$, die Witwe ,Marzahn'24 und ,Wurzel' lassen trotz der gänzlich anderen Sphäre, der ihre Träger entstammen, die formalen Namengebungsprinzipien der Nordischen Königsnamen anklingen. Diese Namen beschreiben den Namenträger nicht als deskriptiv redende Namen, sondern charakterisieren ihn indirekt, indem sie eine Sphäre evozieren, mit der das zugrundeliegende Appellativ verbunden ist. Ihre Namen gestalten die Atmosphäre der Gedichte. Fontanes Realismus schreckt dabei nicht vor deutlich redenden Namen zurück. Auch unter Berücksichtigung realer Konventionen der Namengebung kann er Namen wie „Katzfuß“ verwenden, ${ }^{25}$ die lediglich der symbolischen Charakterisierung des Namenträgers dienen und die auch als reale Namenszeichen möglich sind oder tatsächlich existieren.

Insgesamt stehen Ruf- wie Beinamen für Fontane zunächst „nach Klang und Inhalt“ „auf dem Boden der Poesie“", ${ }^{26}$ weil durch sie die Imagination der Figur, ihres Umfelds und der Stimmung des Gedichts angeregt wird. Ohne innerfiktional, poetologisch oder gar außerfiktional einem magischen Namenverständnis Vorschub zu leisten, berücksichtigt und nutzt Fontane das Wirkungspotential des Eigennamens mit allen Zeicheneigenschaften.

\subsubsection{2 „Kein bloßer Ballast“ - die Aufzählung von Namen}

Eine Besonderheit der Fontaneschen Namenverwendung, die sich auch in den Nordischen Königsnamen findet, ist das häufige Auftreten von Namenaufzählungen und Namenkatalogen. Diese Techniken der Textstrukturierung sind ein Aufbauprinzip vieler

\footnotetext{
${ }^{22}$ Vgl. Fontanes Einschätzung Der Schleswig-Holsteinische Krieg im Jahre 1864, in: Fontane HFA III, 5 , S. 109: „So war das Leben auf Vorposten und Cantonnements; neben dem Ernst des Krieges ging der Humor in seiner Schellenkappe her."

${ }^{23}$ Fontane HFA I, 6, S. 364-366; aktualisiert im Gedicht selbst in Vers 16.

${ }^{24}$ Nach dem damaligen Vorort Berlins; vgl. auch Havelland, Fontane HFA I, 6, S. 253-255.

${ }^{25} \mathrm{Vgl}$. Ertl 1982, S. 210-213. Auch die Frage nach dem 'Abbild' des Namenträgers, das sich in den Fontaneschen Namen der Romane findet, kann durch dieses Modell zum Teil beantwortet werden; vgl. Böschenstein 1996, S. 53-55.

${ }^{26}$ Fontane HFA III, S. 416.
} 
später Gedichte Fontanes, sie tauchen aber vereinzelt schon in den früheren Balladen auf. Statt der Beschränkung auf den beispielhaften Einzelfall wird in diesen Gedichten eine Reihe von Objekten geboten. Die Aufzählungen und Schwärme haben die Funktion der evozierenden Zusammenfassung ${ }^{27}$ und dienen der detailgenauen Darstellung in historischer und epischer Breite auf dem vergleichsweise engen Raum des Gedichts. ${ }^{28}$ Seine Neigung zu Namenkatalogen tut Fontane in einem Brief an Detlev von Liliencron vom 11.9.1888 kund:

Für mich sind Namenaufzählungen kein bloßer Ballast, im Gegenteil, operiert man geschickt damit, so wird eine große Wirkung erzielt. Aber die wenigsten haben ein Gefühl dafür. Für was überhaupt? ${ }^{29}$

Fontanes Bemerkung gilt einer Aufzählung von Eigennamen am Ende einer halbdokumentarischen Novelle Liliencrons über die Schlacht bei Hemmingstedt. ${ }^{30}$ Funktion der als Quellentext angehängten Liste mit den Namen der in der Schlacht gefallenen holsteinischen Adligen ist neben der historischen Dokumentation und Anbindung die Individualisierung eines Massenschicksals und die Darstellung der Größe des Ereignisses. Die Eigennamenliste setzt fort, was die fiktionale Ausgestaltung beginnt, in der Liliencron von der allgemeinen Geschichte Dithmarschens nach und nach in die narrativ und fiktiv ausgestaltete Gefühls- und Gedankenwelt einzelner namentlich genannter historischer und halb mythischer Protagonisten wechselt.

Von Interesse sind für Fontane dabei auch die den Eigennamen beigegebenen kurzen Schilderungen der benannten Personen. Sie repräsentieren das Eigennamenwissen des kulturell kompetenten Sprechers in der Gesellschaft, zu der die Namenträger gehörten. Die Erläuterungen sind nötig und „hochinteressant“31. Denn der semantische Hintergrund der Familiennamen und die Beinamen gestalten ein Bild der Gesellschaft, aus der die Personen stammten. So wird durch die Eigennamenreihe die Struktur der Gesellschaft sichtbar, ohne daß es der Gestaltung einer Handlung bedürfte.

Fontane ging zum Zeitpunkt seiner Äußerung irrtümlich davon aus, Liliencron habe die Namenaufzählung einer Ballade beigefügt. ${ }^{32}$ Seine Vorstellung von der Eigennamenwirkung bezieht sich also primär auf Gedichte bzw. Balladen. Fontane hatte die betref-

\footnotetext{
${ }^{27}$ In den späten Gedichten findet besonders eine „Rückschau und Lebensüberschau“ statt, die diese Sprechweise befördert; vgl. Richter 1980, S. 119.

${ }^{28}$ Vgl. Richter 1980, S. 132.

${ }^{29}$ Fontane HFA IV, 4, S. 638. Dies äußert Fontane in einem Brief an Detlev v. Liliencron anläßlich dessen Prosastücks über eine Befreiungsschlacht der Dithmarschen, dem die Wiedergabe einer als Gedenktafel gestalteten Liste der gefallenen holsteinischen Adligen folgt; vgl. Liliencron 1912, S. 158-176. Die Aufzählung war von der Redaktion des „Zur guten Stunde“ gestrichen worden. Fontane ist „hingerissen“ von der Schilderung der Schlacht und von der Eigennamenliste; vgl. Fontane HFA IV, 4, S. 639.

${ }^{30} \mathrm{Vgl}$. Liliencron 1912, S. 158-176, die Namenaufzählung findet sich auf S. $175 \mathrm{f}$.

${ }^{31}$ Fontane HFA IV, 4, S. 639 (Brief an Detlev von Liliencron vom 15.9.1888).

${ }^{32}$ Vgl. Fontane HFA IV, 4, S. 639 (Brief an Detlev von Liliencron vom 15.9.1888).
} 
fende Schlacht in der Ballade Der Tag von Hemmingstedt dichterisch verarbeitet und dort selbst Namenaufzählungen verwendet. Einleitend nennt er nach dem Vorbild der antiken Kriegerkataloge etwa Homers das ,deutsche Truppenkontingent' auf dänischer Seite:

Von Deutschland auch viele edele Herren hernieder ins Lager [der Dänen] kamen:

Zwei junge Grafen von Oldenburg, Adolf und Otto mit Namen,

Mit innen zugleich manch Holstein-Geschlecht um den Danebrog sich scharte:

Fünf Rantzaus, sieben von Ahlefeld und vierzehn Wackerbarte. ${ }^{33}$

Fontane hält hier einen mehrschichtigen ordo ein. Der Schwarm im engeren Sinne, der die letzte Zeile der Strophe bildet, ist nach dem ,Gesetz der wachsenden Glieder' des ordo naturalis aufgebaut ${ }^{34}$, sowohl inhaltlich auf die Zahl der Ritter als auch formal auf die Silbenlänge der Namen bezogen. Gleichzeitig ist der Schwarm in eine größere Aufzählung eingebettet, die der Hierarchie der Teilnehmer folgt und die bedeutenderen zuerst und individuell mit Ruf- und Familiennamen nennt, anschließend nur noch die Familiennamen mit einer Zahlenangabe. In der darauffolgenden Strophe werden die Söldner nur noch nach Herkunftsregionen geordnet:

Und Söldner auch; - Gesindel war's aus Rheinland, Franken und Sachsen,

All' hatten sich längst, durch Mord und Brand, in die Schlinge hineingewachsen. ${ }^{35}$

Erst nach dem „Gesindel“ kommt deren Anführer, „Junker Slenz“. Er wird auf diese Weise von den ehrenhaften Adligen als unehrenhafter Anführer der Söldner getrennt.

Am Ende der Ballade und der Schlacht wird dann der „viel Hundert tapfere[n] Namen“ gedacht, die auf dem Schlachtfeld blieben:

Das war das Ende von Jürgen Slenz; mit inm zu Tode kamen

- Die Knechte und Söldner ungezählt - viel hundert tapfere Namen,

Zumal auch, was von Holstein her um den Danebrog sich scharte:

Fünf Rantzaus, sieben von Ahlefeld und vierzehn Wackerbarte. ${ }^{36}$

Die formal gleiche Wiederholung des Namenkatalogs „Fünf Rantzaus, sieben von Ahlefeld und vierzehn Wackerbarte" betont die fast vollständige Vernichtung der Holsteiner, die in den Krieg zogen. Die Kombination von den Individualität signalisierenden Namen mit Zahlen bewirkt den Eindruck großer Verluste für die Familien und weist auf die Bedeutung der Familiennamen und der in innen verborgenen Tradition hin. Die Namennennung in dieser vorletzten Strophe spiegelt darüber hinaus die Funktion der Figuren für den Aufbau der Ballade. Namentlich genannt werden der ,Antipathieträger', der die balladeske bzw. dramatische Handlung trägt („Jürgen Slenz“); der Anführer der Truppen, als Träger der historischen Handlung („Danebrog“); schließlich die holsteinischen

\footnotetext{
${ }^{33}$ Fontane HFA I, 6, S. 196.

${ }^{34}$ Vgl. dazu Lausberg 1963, S. 32 (§ 53).

${ }^{35}$ Fontane HFA I, 6, S. 196.

${ }^{36}$ Fontane HFA I, 6, S. 200.
} 
Familien, für die sich Fontanes Publikum und Fontane selbst besonders interessierten, auch wenn sie im historischen Ereignis keine herausragende Rolle gespielt haben mögen. Die Individualität der genannten Holsteiner reduziert sich in diesen Fällen auf die größere Einheit der Familie, die allein als Referenzobjekt eine Rolle spielt. Die Familien sind individuiert, weil sie wichtig für die Gesellschaft wie für die poetische Gestaltung der Szene und des Umfeldes sind.

Ohne einen Namenkatalog zu gestalten, zeigt Fontane diese besondere evozierende Funktion von Eigennamenkatalogen auch in der ,Schlußbesprechung' der Shakespeareschen Hexen seiner späten Ballade Die Brück' am Tay:

"Wann treffen wir drei wieder zusammen?"

„Um Mitternacht, am Bergeskamm.“

„Auf dem hohen Moor, am Erlenstamm.“

"Ich komme."

„Ich mit.“

"Ich nenn' euch die Zahl.“

„Und ich die Namen."

„Und ich die Qual.“" ${ }^{37}$

Die Katastrophe - gestaltet anhand eines Einzelschicksals - wird durch die Hexen der Rahmengeschichte 'verarbeitet', die das von innen produzierte Unglück resümieren und dazu drei aufeinander aufbauende Faktoren aufrufen: erst die reine Zahl als Ausdruck des schrecklichen Massenunglücks, dann die (dem Leser nicht genannten) Eigennamen, die deutlich machen, daß nicht abstrakte Entitäten, sondern konkrete Personen die Opfer sind. Diese werden auch im Massenunglück identifiziert - sei es auch nicht für den Leser, sondern nur in der fiktionalen Welt der Hexen. Die "Qual“ jedes einzelnen, summiert in der Masse der Verunglückten und der um sie Trauernden ist die letzte Steigerung der Lust dieser Hexen. Übertragen auf die ,moderne Welt' ist die Funktion der archaischen Hexen der von Medien und Publikum gebildeten Öffentlichkeit vergleichbar. In der sensationslüsternen ,Besprechung' eines Unglücks fungieren Namennennungen und Namenaufzählungen, z.B. die für die Angehörigen veröffentlichten Listen der Unfallopfer als schauderhafte Datensammlungen, die gleichzeitig dem zweifelhaften Vergnügen an der Suche nach bekannten Namen dienen. Vor allem aber sind Eigennamen ein wichtiger Bestandteil der erzählten Welt. Die vielen ungenannten Opfer eines Massenunglücks werden als Namenträger gekennzeichnet, auch wenn ihre Namen selbst nicht genannt werden (können).

${ }^{37}$ Fontane HFA I, 6, S. 286 f. 
Von einer genuin ,lyrischen' Wirkung längerer Namenaufzählungen spricht Fontane in seinem Aufsatz Die alten englischen und schottischen Balladen von 1861, in dem er eine schottische Ballade, die er nur übersetzt präsentiert, kommentiert ${ }^{38}$ :

Die Duncans kommen, die Donalds kommen, Die Colins kommen, die Ronalds kommen, Es kommen die Kenmures Sohn und Vater, Lord Foster und Lord Derwentwater,

Und Jack und Tom und Bobby kommen Und haben die blaue Blume genommen. ${ }^{39}$
Duncan's coming, Donald's coming,

Colin's coming, Ronald's coming,

Dougal's coming, Lauchland's coming,

Alaster and a's coming,

Little wat ye wha's coming,

Jock and Tam and a's coming ${ }^{40}$

Fontanes Kommentar lautet kurz: „Ich beginne mit einem merkwürdigen Liede, das eigentlich nur ein Aufzählen der Clane und Stuartschen Streitkräfte ist und doch einen so kräftigen und hinreißenden Schwung hat, daß es wie eine lyrische Dichtung wirkt.“41 Offenbar ist für Fontane das Aufzählen von Namen eigentlich keine Dichtung mit „lyrischem Klang“. Diesen charakterisiert er an anderer Stelle folgendermaßen:

Kürze, Knappheit des Ausdrucks, der Zauber des Halbdunkels, Simplizität und Wohlklang, Tiefe der Empfindung, natürliche Grazie und Schelmerei. ${ }^{42}$

Doch immerhin zitiert und übersetzt Fontane das Gedicht vollständig. Dabei scheint inm allerdings die Struktur des Originals zu monoton für einen wirklichen „Iyrischen Klang“ gewesen zu sein. Die Originalballade aus David Herds Ancient and Modern Songs, Heroic Ballads, etc. begnügt sich neben einem Refrain über vier Strophen mit dem gleichmäßigen Aufzählen der Namen. Fontane bemüht sich dagegen, die Verse drei und vier jeweils abwechslungsreicher nach einem anderen Schema zu füllen. Doch gestaltet er in den ersten beiden Versen den „hinreißenden Schwung“, der durch die Eigennamen ausgelöst wird. Die unterschiedlichen, aber klanglich verwandten Namen, die zum Teil im Reim stehen, treiben das Gedicht an, während die monotone Wiederholung des immergleichen Prädikats „kommen“ für einen semantischen wie rhythmischen Takt sorgt. Textstrukturierende und ästhetisierende Funktion treten zusammen auf. Auch wenn dem Leser die Referenz der Namen nicht bekannt ist, reichen der Kontext und die Aura außerdem aus, um vermittels der Namen die Atmosphäre des schottischen Hochlandes im „Zauber des Halbdunkels“ erstehen zu lassen. Mögliche Aussagen des Gedichts, die über die Namennennung hinausgehen, scheinen Fontane nicht besonders wichtig gewesen zu sein, wie seine stark abweichende Übersetzung des Refrains zeigt. Fontane verzichtet außerdem auf die schottische Schreibung der stereotypen Rufnamen des

\footnotetext{
${ }^{38}$ Fontane NA 21, 1, S. $383 \mathrm{f}$.

${ }^{39}$ Fontane NA 21,1, S. 383.

${ }^{40}$ Herd 1776, S. $117 \mathrm{f}$.

${ }^{41}$ Fontane NA 21,1, S. 383.

42 Fontane NA 21,1, S. 371.
} 
Refrains und ergänzt zudem den zwar typisch englischen, aber keineswegs typisch schottischen Namen „Bobby“. Seinem deutschen Publikum wird es ausgereicht haben, daß englischsprachige Namen genannt werden.

Daß Fontane den Abschnitt seines Aufsatzes über die ,Stuart-Balladen' bzw. seine „Jakobitenlieder" ${ }^{43}$ mit diesem Gedicht beginnt, hat einen weiteren Grund. Der ,Namenreigen' berichtet nicht von einer Handlung. Er wirkt ästhetisierend und beschwört durch den fremden Klang der Namen eine Stimmung. Als eine Art Personenverzeichnis bildet der Reigen einen Hintergrund für die folgenden Balladen. Die Namenballade konzentriert die Stimmung, die die einzelnen Eigennamen jeweils zu der archaischen oder exotischen Ausstattung eines Textes beitragen. Die Stuart-Ballade ähnelt in dieser textstrukturierenden zusammenfassenden und evozierenden Funktion dem Gedicht Nordische Königsnamen. Dort bilden 32 Personennamen den Auftakt zu nur wenigen Balladen mit entsprechenden Namen (sechs Balladen mit elf einschlägigen Beinamen), hier 25 Personennamen zu elf Liedern und Balladen mit elf Personen- und Ortsnamen. Der weit ausholende Namenkatalog eröffnet einen Namenraum, in den die in den nachfolgenden Balladen auftretenden Namen eingebettet sind.

\subsubsection{Der Kommunikationswert der Namen}

\subsubsection{1 „Wie heißt?“ - Fontanes Eigennamenpolitik}

Bisher haben wir uns vorwiegend mit Bedeutungskomponenten des Namenszeichens beschäftigt, die der inner- und außerfiktionalen Charakterisierung des Namenträgers oder der Hintergrundwelt dienen. Wie sich schon in einigen Fällen gezeigt hat, berücksichtigt Fontane neben diesen Komponenten des semantischen Hintergrunds eines Namens aber auch und vor allem den Kommunikationswert, den Namenszeichen in einer Gesellschaft haben.

Ein Beispiel hierfür ist die Charakterballade bzw. ,preußische Ballade' Und Calcar, das ist Sporn, in der zunächst der Erzähler refrainartig die den Reitergeneral Friedrich Wilhelm von Seydlitz aus Calcar anfeuernde Namendeutung des Titels wiederholt. Als Pointe der Ballade und in Endstellung läßt Fontane schließlich auch die Hauptfigur selbst den Namen in der gleichen Weise auslegen und sterbend ausrufen: „Denn Calcar, das ist Sporn“". ${ }^{44}$ So weit handelt es sich um einen weiteren der ,epigrammatisch' redend gedeuteten Namen. In Fontanes Vor dem Sturm trägt die Figur Hansen-Grell ihr Gedicht General Seydlitz vor (das Fontane in seine Gedichtausgabe aufgenommen

${ }^{43}$ So ist der Abschnitt in der Gedichtsammlung von 1898 überschrieben; vgl. Fontane GBA Gedichte 1, S. 321; Fontane NA 20, S. $351 \mathrm{f}$.

${ }^{44}$ Vgl. Fontane HFA I, 6, S. $213 \mathrm{f}$. 
hat). Die Figur Tubal kritisiert die fehlende allgemeine Verständlichkeit des Gedichts, doch wird Hansen-Grell von einer Figur verteidigt:

[Tubal:] „Jedes Kunstwerk, so wenigstens stehe ich zu diesen Dingen, muß aus sich selber heraus verstanden werden können, ohne historische oder biographische Notizen. Diesen Anspruch aber seh' ich in diesem Gedichte nicht erfüllt. Es ist eminent gelegenheitlich und auf einen engen oder engsten Kreis berechnet, wie ein Verlobungs- oder Hochzeitstoast. Es hat die Bekanntschaft mit einem halben Dutzend Seydlitzanekdoten zur Voraussetzung, und ich glaube kaum zuviel zu sagen, wenn ich behaupte, daß es nur von einem preußischen Zuhörer verstanden werden kann. Lesen Sie das Gedicht, auch in bester Übersetzung, einem Engländer oder Franzosen vor, und er wird außerstande sein, sich darin zurechtzufinden." $[\ldots]$

[Bninski:] „Ich kann mich auf wenige Bemerkungen beschränken“, [...]. „Ich kenne von General Seydlitz nichts als seinen Namen und seinen Ruhm, glaube aber das Gedicht [...] vollkommen verstanden zu haben. Ich ersehe aus seinen Strophen, daß Seydlitz zu Calcar geboren wurde, daß er das Lernen nicht liebte, aber desto mehr das Reiten. Dann folgen Anekdoten, die deutlich für sich selber sprechen, zugleich auch seine Reiterschaft glorifizieren, bis er in der letzten Strophe jenem besseren Reiter erliegt, dem wir alle früh oder spät erliegen. Dies wenige ist genug, weil es ein Ausreichendes ist. Hier steckt das Geheimnis. [...] Die Phantasie muß nur den richtigen Anstoß empfangen; ist dies geglückt, so darf man kühn behaupten: ,Je weniger gesagt wird, desto besser."“45

Fontane läßt hier das mit der Eigennamenverwendung eng verbundene Problem des privaten Bedeutungsüberschusses eines literarischen Textes ansprechen. Da die Seydlitz-Ballade einen berühmten Namen verwendet, ist dieser nicht nur einem privaten Kreis bekannt. Dennoch kritisiert die Figur Tubal, daß die Bedeutung des Textes nicht allein textimmanent festgestellt werden kann, da der Text auf zahlreichen enzyklopädischen mit dem Eigennamen verbundenen Bedeutungsbestandteilen beruht. Die Verteidigung, die Fontane gestaltet, wird nicht zufällig einem Polen in den Mund gelegt. Er kann als Ausländer glaubhaft behaupten, daß die Ballade nicht nur für Preußen verständlich ist. Da er keine Kenntnis der besagten Anekdoten hat, kann er die Ballade textimmanent verstehen. Der Eigenname wird dabei zum rein innertextlich referierenden Namen, orientiert am Leitmotiv des Reitens. Alle Informationen, die der Leser aus dem semantischen Hintergrund des Namens braucht, um den Text zu verstehen, werden auch im Text geliefert. Der Name kann daher seine figurenbezogenen Funktionen erfüllen, ohne daß seine textbezogene Funktion der ,Anbindung' an einen außertextlichen Hintergrund von dem Leser realisiert wird. Der abstrakte Inhalt des Textes beruht nach dieser Interpretation nicht auf jenen enzyklopädischen Kenntnissen der Leser, die diese zusätzlich an den Text herantragen können.

Diese Interpretation paßt zu der Vorliebe Fontanes für redende Namen. Sie lassen sich textimmanent auflösen und bedürfen keines enzyklopädischen Zusatzwissens. Doch weist der Dialog, den Fontane gestaltet, darauf hin, daß der Text über den Kommunikationswert auch von der außertextlichen Referenz des Namens und der ,anbindenden'

${ }^{45}$ Fontane HFA I, 3, S. S. 385 f. 
Funktion zehrt. Die jubelnden Zuhörer in Vor dem Sturm schöpfen ihre Begeisterung aus der Begeisterung für das Reiten, aber auch aus ihrer militärischen Ausbildung. Sie wissen als Preußen, von wem die Rede ist und goutieren die an bekannten Anekdoten ausgerichtete preußische Heldenverehrung.

Die Werbewirkung des Kommunikationswerts eines Namens - wie sie Vor dem Sturm vorführt - wird von Fontane ganz pragmatisch mit Blick auf den ,Literaturmarkt' eingeschätzt. Er betreibt in und fordert von Kunstwerken eine strategische Eigennamenpolitik auf der Grundlage der ästhetischen Funktion. ${ }^{46}$ Die Grundlage des Interesses an Eigennamen in historistischer Kunst klingt schon bei Fontanes Bildbesprechungen zu den Berliner Akademie-Ausstellungen an, in denen er an einem realistischen Schlachtenbild kritisiert:

Wir sehen eine Menge kämpfender Figuren, aber zu keiner einzigen fühlen wir uns hingezogen, da ist nicht eine, die den Wunsch in uns weckt, ihre Geschichte näher kennenzulernen. ${ }^{47}$

Dagegen lobt Fontane im unmittelbaren Kontext ein anderes Bild und identifiziert dabei zunächst Gruppen und hervorragende Persönlichkeiten mit ihren Namen, um dann zu den Genretypen überzugehen, die er durch Angabe ihres Typus charakterisiert und mit einer Geschichte versieht. ${ }^{48}$ Hier drückt sich das Interesse an dem einzelnen und besonderen Fall auch in der Kenntnis der Namen und der mit ihnen verbundenen Ereignisse aus. ${ }^{49}$

Berühmte Eigennamen haben aus diesem Grunde eine Werbewirkung für die Rezeption des Kunstwerks, die auf ihrer Anbindungsfunktion beruht. So rät Fontane Georg Friedländer 1895:

Und im Februar Vorlesung in Hirschberg! Ich finde den 2. Titel: „Fritz Reuter und Heinrich Seidel etc." viel besser. Das Publikum macht sich nichts aus Abstraktionen. Namen, da sieht man doch wo und wie. ${ }^{50}$

Und gegenüber Ernst Heilborn mokiert er sich 1898 im gleichen Geiste:

Ihre Bedenken teile ich vollkommen. Wer ist Lepel? und schließlich - für die Welt draußen wer ist Fontane? Und einer wenigstens muß berühmt sein, der Beschriebene oder der Beschreiber. Versagen Beide, so heißt es: „wie heißt?" 51

\footnotetext{
${ }^{46} \mathrm{Vgl}$. auch Aust 2000, S. $417 \mathrm{f}$.

47 Die Berliner Kunstausstellung 1860, in: Fontane HFA III, 5, S. 475; Fontane betrachtet in diesem Zusammenhang Werke der bildenden Kunst und Werke der Literatur unter dem gleichen Blickwinkel; vgl. Aust 2000, S. 407.

${ }^{48}$ Die Berliner Kunstausstellung 1860, in: Fontane HFA III, 5, S. 477. Auch sein Gedicht an Menzel, Auf der Treppe von Sanssouci, wo das Sprechersubjekt den Maler mit seinen berühmten Stoffen identifiziert, zeigt diese Haltung.

${ }^{49}$ Vgl. auch Brinkmann 1977, S. 37.

${ }^{50}$ Vgl. Fontane 1954, S. 277 f. (Brief an Georg Friedländer vom 8.1.1895).

${ }^{51}$ Fontane HFA IV, 4, S. 712 (Brief an Ernst Heilborn vom 25.4.1898); es geht um die Korrekturfahnen zu einem Kapitel aus Der Tunnel über der Spree, das unter dem Titel Bernhard von Lepel einzeln veröffentlicht wurde; vgl. den Kommentar, ebendort, S. 1004.
} 
Die von ihm selbst gewählten Namentitel vieler seiner historischen Balladen haben daher wohl auch die deutlich intendierte Wirkung, das Publikum in Gérard Genettes Sinne durch die ,Anbindung' zu „verführen“. ${ }^{52}$ In diesen Balladen sind es die identitätsbildenden Mythen des preußischen Militärs, die Fontane zu nutzen weiß. ${ }^{53}$

Diese Einstellung dem Kommunikationswert berühmter Namen gegenüber wird im ,Dichtergedicht' Es soll der Dichter mit dem König gehen ${ }^{54}$ thematisch. Geschildert wird der ,poetisch-idealische' Niedergang eines Dichters bei gleichzeitigem bescheidenen gesellschaftlichen Aufschwung. ${ }^{55}$ Die Stationen dieser Entwicklung werden anhand von Königsnamen gestaltet, die die Sphäre andeuten, in der der Dichter sich jeweils bewegt. So nennt Fontane in der zweiten Strophe „Thoas“. Dieser steht für mythische Stoffe, vor allem aber für die Sphäre des Klassischen, da er die Iphigenie auf Tauris Goethes evoziert. Der Dichter will selbst ein ,Klassiker' von überzeitlichem Wert werden. In der dritten Strophe werden historische Ereignisse des hohen Mittelalters durch Heinrich den Finkler (Heinrich I.; 919-936), seine Nachfolger, Otto I., II. und III. (936-1002), Mathilde von Tuszien (1046-1115), Heinrich IV. (1056-1106), Canossa (1077) und Friedrich Barbarossa (1152-1190) evoziert. Es handelt sich um weit zurückliegende Stoffe ohne aktuelle Anbindung oder um ,ausgelaugte' Stoffe. Die Namenauswahl verrät dabei Fontanes eigene Namenpraxis: Statt ,Heinrich I.' wählt der Sprecher wie Fontane in Nordische Königsnamen einen sprechenden Beinamen. ${ }^{56}$ Die übrigen ,Könige' werden familiär nur mit einem Namen oder nur als Gruppe identifiziert, das heißt ohne Ordnungszahlen, ohne Beinamen oder leicht spöttisch abfällig als der „ew'ge alte Barbarossa“.

Die Aufzählung wirkt zunächst willkürlich als chronologische Inventur der historischen Stoffe. Es fällt aber schnell auf, daß Fontane seinen Namenkatalog weiter strukturiert bzw. zur Textstrukturierung nutzt. Er trennt die einzelnen Namengruppen nach historischen Zusammenhängen ${ }^{57}$ und organisiert die Namen wie in fast all seinen Namenaufzählungen und Schwärmen als Klimax der Berühmtheit der Eigennamen - ausgehend von einem relativ unbekannten Beinamen Heinrichs I. und der Benennung der Ottonen

\footnotetext{
${ }^{52}$ Vgl. Genette 1989, S. 77.

53 Dies belegen viele seiner frühen Gedichttitel, die er für eine Veröffentlichung so erwähnt: „2. Vaterländisches (würde bestehen aus: Derfflinger, Dessauer, Zieten, Seydlitz, Graf Schwerin, York und der alte Fritz). "Vgl. Fontane HFA IV, 1, S. 327 (Brief an Friedrich Witte vom 4.12.1852).

${ }^{54}$ Fontane HFA I, 6, S. $384 \mathrm{f}$.

${ }^{55}$ Vgl. dazu Plett 1991, S. 18-22.

${ }^{56}$ Ein ,Finkler' ist ein Vogelsteller, vgl. den Kommentar in Fontane HFA I, 6, S. 1019.

${ }^{57}$ Heinrich I. und Otto I-III. als sächsische Kaiser - Mathilde von Tuszien, Heinrich IV. und Canossa (25.28.1.1077) im Investiturstreit.
} 
nur als Gruppe, weiter über das sprichwörtlich gewordene Canossa bis hin zum auch für den deutschen Nationalmythos wichtigen Friedrich Barbarossa. ${ }^{58}$

Die letzten drei Strophen zeigen den Protagonisten als patriotischen Dichter, der sich endlich der mageren Anerkennung der Staatsorgane erfreut. Bezeichnenderweise nennt Fontane hier keine Namen mehr. Er ist vorsichtig genug, die berühmten Personen und lieux de mémoire seiner unmittelbaren Gegenwart nicht in den Namenspott einzubeziehen. ${ }^{59}$ Die Namenpraxis sowie die abfällige Erwähnung des „Kronenorden 4ter Klasse“ enthüllen dabei, daß auch dieses Gedicht vom Dichter Fontane selbst handelt. $^{60}$

In Fontanes Äußerungen zum Kommunikationswert der Namen klingt immer die inm eigene Ironie an, mit der er sich selbst von der Menge, die sich von Namen verführen läßt, abzusetzen sucht. Doch weiß er um die Wirkung der Namen als Signale, die besonders in den Paratexten die Neugierde und die Anteilnahme des Publikums reizen und die Rezeption des Werks fördern können. Er nutzt Namen also in ästhetischer Funktion, die nicht auf der isolierten Zeichengestalt des Namens beruht, sondern gerade auf seiner Referenz über die Textgrenze hinaus.

\subsubsection{Verabschiedete Vorbilder}

Eine ironische Haltung dem Kommunikationswert der Namen gegenüber prägt besonders den Umgang des späten Fontane mit berühmten Namen. Dies wird besonders an der vielgenannten Wende Fontanes in seiner Alterslyrik deutlich, die in einer gewandelten Einschätzung des poetischen und gesellschaftlichen Werts von Eigennamen ihren Ausdruck findet.

Zur ,Selbstironisierung' des Sprechers in Fontanes Gedichten gehört die Stilisierung früherer Positionen anhand von Eigennamen, wie sie in Es soll der Dichter mit dem König gehen thematisiert wird. Fontanes Sprecher stellt sein früheres ,Ich' als jemanden dar, der Namen und damit die Namenträger überhöhte und nun mit der Weisheit des Alters auf diese jugendliche Heldenverehrung blickt. So werden schon in An Klaus Groth von 1878 die Namen der schottischen Balladen (,Percy' und ,Douglas'61) abgewertet gegenüber der dem Adressaten schmeichelnden Trias „Goethe, Mörike un Klaus

\footnotetext{
${ }^{58}$ Die innere Ordnung der Namen einer Aufzählung nach der Chronologie und der Berühmtheit der Namen zeigt auch die scheinbar ungeordneten ,Trödel' aufzählende Huldigungsgedicht Walter Scotts Einzug in Abbotford; vgl. Fontane HFA I, 6, S. 159-161.

59 Dennoch konnte er das Gedicht zu Lebzeiten nicht veröffentlichen; vgl. den Kommentar in Fontane 1998, S. 160; vgl. zum Umgang Fontanes mit den deutschen lieux de mémoire Hebekus 2003, S. 174 f.

${ }^{60} \mathrm{Vgl}$. den Kommentar in Fontane 1998, S. 161.

${ }^{61}$ Percy ist außerdem noch der Name des Herausgebers der Balladensammlung Percys Relics af ancient English Poetry, die Fontane unter seinen wichtigsten Büchern erwähnt; vgl. Theodor Fontane: Literarische Essays und Studien, S. 498.
} 
Groth“. ${ }^{62}$ Hier betrachtet Fontane ironisch seine frühere Verzauberung durch die Aura der Ritternamen und ersetzt die historische und numinose Ballade durch die liedhafte Dichtung Goethes und Mörikes. ${ }^{63}$ In Auch ein Stoffwechsel aus den 1890ern treten ,Percy' und ,Douglas' zusammen mit zwei Schlüsselnamen der preußischen Gedichte und Romane (,Seydlitz' und ,Sedan') auf. ${ }^{64}$ Deren Kommunikationswert werden die Namen der Meistersinger ,Rosenplüt' und ,Hans Sachs' entgegengehalten. Letztere stehen im Gedicht für die politisch wie künstlerisch unambitionierte Darstellung des Einfachen, Unbedeutenden. ${ }^{65}$ Weitergehend ist die „Zunft der Handwerksmeister“ ein Bild für eine betont bürgerliche Dichtung. Die Welt der historischen Größe, die den früheren Fontane begeistert, ist dagegen auch die Welt des Glanzes und des Adels. Die Namen stehen als indirekt evozierende Namen in mehr als einer Hinsicht für einen ,Stoffwechsel'.

Die Namen berühmter Figuren und Personen werden rückblickend achtlos ,ins Gespräch geworfen', wobei besonders die aufzählenden Namenkataloge den Eindruck vermitteln, der Sprecher halte nicht mehr viel von den großen Stoffen seiner Vergangenheit. In Fester Befehl etwa schreibt Fontane sich eine frühere Bewunderung der modischen liberalen politischen Publizisten und Schriftsteller zu:

Ich haßte Schranzen und Fürstenschmeichler,

Glaubte beinah an Held und Eichler,

Und Herwegh, Karl Beck und Dingelstedten

Erhob ich zu meinen Leibpoeten. ${ }^{66}$

Daß er nur „beinah“ an Friedrich Wilhelm Alexander Held und Ludwig Eichler geglaubt haben will, zeigt auch hier wieder die ironische Position des Sprechers den ,Helden' seiner Jugend gegenüber. Vor allem aber werden die einstigen dichterischen Vorbilder nicht durch neue Namen ersetzt. Der Hochschätzung bestimmter Namen in den „tempi passati“ folgt keine Hochschätzung anderer Namen in der Gegenwart, sondern die ernüchterte Vorbildlosigkeit. ${ }^{67}$

Der späte Fontane sieht daher auch Hinweise Dritter auf Ähnlichkeiten mit anderen Autoren eher als Versuch, ein Lob zu vermeiden (Nur nicht loben). ${ }^{68}$ Den Vergleich seiner Dichtung mit der Dichtung kanonischer Autoren wehrt er ab, indem er scherzhaft und ironisch behauptet, eine Sammlung von Werbetexten sei sein wichtigstes stilistisches

\footnotetext{
${ }^{62}$ Fontane HFA I, 6, S. 325.

${ }^{63}$ Auch seine begeisterte Hymne auf Jung-Bismarck sah Fontane später kritisch; vgl. Nürnberger 2000, S. $91 \mathrm{f}$.

${ }^{64}$ Fontane HFA I, 6, S. 344; vgl. die Balladen zu Seydlitz in: Fontane HFA I, 6, S. 210-212. "Sedan“ ist (nicht nur) für Fontane der lieu de mémoire preußischer Kriegsgeschichte schlechthin.

${ }^{65} \mathrm{Vgl}$. Richter 1980, S. 120; daß just die Meistersänger für den von Fontane benutzten Knittelvers stehen, wird kein Zufall sein.

${ }^{66}$ Vgl. Fontane HFA VI, S. 323 und in Theodor Fontane 1998, S. 61 - vgl. dort den Kommentar S. 146 f.

${ }^{67}$ Vgl. auch Plett 1991, S. 17, zu Fontanes Abneigung gegenüber der „euphorischen Huldigung auf deutsche Dichter".

${ }^{68}$ Fontane HFA I, 6, S. 376 f.
} 
Vorbild gewesen. Die Goldene Hundertzehne und Die Goldne Hundertzehn ${ }^{69}$ zeigen, daß durch die Fülle der in einem Schwarm oder in einer Aufzählung genannten Namen der einzelne Name marginalisiert wird. Ganz im Geiste der anxiety of influence $(\mathrm{H}$. Bloom) verweist Fontane in diesen Gedichten auf die vielfältigen Einflüsse zahlreicher Autoren, um sich gegen den Eindruck der Anlehnung an einen einzigen Übervater zu verwahren. Die generelle Bewertung, daß der eigene berühmte Name und der berühmte Name anderer nur Schall und Rauch seien, leistet sich Fontane nicht ohne ironischen Seitenblick auf die eigene Eitelkeit - denn sein Name steht schließlich in „Artikel[n] im Brockhaus und im Meyer...". ${ }^{70}$

\subsubsection{Der Kampf um den Kommunikationswert der Namen}

\subsubsection{Cliquen und Klüngel}

Die generelle Ironie des späten Fontane gegenüber klangvollen Familiennamen spielt nicht nur im literarischen Feld eine Rolle. Fontane beschäftigt sich vielmehr mit einem gesellschaftlichen Phänomen, das als ,Kampf um den Kommunikationswert der Eigennamen' bezeichnet werden kann. Dieser Kampf ist Ausdruck einer sich wandelnden, vormals streng geregelten Gesellschaft, in der der Platz des einzelnen in der Gesellschaft nicht mehr automatisch durch die Abstammung festgelegt ist. Der Eigennamengebrauch in Fontanes Gedichten ist nur vor dem Hintergrund der in Fontanes Romanen dargestellten sozialen Umwelt verständlich. Die Romane zeigen den kommunikativen Wert, der Namen in Fontanes Gesellschaft zugemessen wurde.

Paradigmatisch für den Wandel ist eine der vielen Namendiskussionen in Fontanes Romanen. In L'Adultera fordert die Protagonistin, Melanie van der Straaten, die Musiklehrerin und Gesellschafterin des Hauses auf, ihren vollen Namen zu nennen:

Aloysia Friederike Sawat von Sawatzki, genannt Sattler von der Hölle, Stiftsanwärterin auf Kloster Himmelpfort in der Uckermark.

Sie kommentiert diesen wahrhaft adligen Namen:

,Wunderschön', sagte Melanie. ,Wenn ich doch so heißen könnte! Und du kannst es glauben, Riekchen, das ist es, was einen Eindruck auf inn [ihren Mann, Ebenezer van der Straaten] macht. ${ }^{, 71}$

Der Klang des prächtigen Namens und der mit ihm angemeldeten Ansprüche entspricht aber der wahren Situation der Namenträgerin nicht. Diese - auch familiär von Melanie „Riekchen“ genannt - merkt selbst „den Gegensatz zwischen dem Anspruch meines Namens und dem, was ich bin: arm und alt und einsam und ein bloßes Figürchen“. Der

\footnotetext{
${ }^{69}$ Fontane GBA Gedichte 2, S. 465 f.

${ }^{70}$ Aus: Summa Summarum, in: Fontane HFA I, 6, S. 339; vgl. auch Jens 2004.

${ }^{71}$ Fontane HFA I, 2, S. 44.
} 
bürgerliche Ebenezer van der Straaten dagegen ist intellektuell und ökonomisch wohlgestellt.

Die streng ständisch orientierte Ordnung wird durch „bourgeoise Parvenüs“ auf der einen und verarmte „adlige Kompromißmacher" auf der anderen Seite aufgeweicht. ${ }^{72}$ Eigennamen werden mit ihrem Kommunikationswert zum Schauplatz gesellschaftlicher Auseinandersetzungen. In Die Poggenpuhls läßt Fontane die Tochter des Hauses in einer bürgerlichen und einigermaßen wohlhabenden Familie eine mit dem klangvollen Namen der „Pogge von Poggenpuhls“ gespickte Todesanzeige gefühlvoll vortragen mit zweifelhaftem Erfolg:

Agnes [...] legte das Blatt aus der Hand, während der Alte mit breitem Behagen sagte: „Na so was von Poggen; ich hör' es ordentlich quaken“, - ein Witz, der von dem johlenden Beifall seiner beiden Jungens (echter Nebelungs) sofort begleitet wurde. Die Tochter aber, die sich von ihrem dramatischen Vortrag eine ganz andere Wirkung versprochen hatte, stand auf und sagte, während sie hinausging, zu der etwas seitab sitzenden Mutter: „Ich weiß nicht, Vater ist heute wieder so ordinär" [...]. Nebelung selbst aber rief der in der Tür eben verschwindenden Tochter nach: „Sei nich so frech, Kröte; - noch bist du nich dabei. “" ${ }^{73}$

Während die Tochter sich durch den Klang der adligen Namen und der Rangbezeichnungen beeindrucken läßt und damit der traditionellen gesellschaftlichen Bedeutung des Adels huldigt, sieht der betont ungebildet redende Vater am Namen nicht die ehrwürdige Tradition, sondern nur die lächerliche Hintergrundsemantik des Namenzeichens (,Poggen' sind niederdeutsch 'Frösche', ,puhl' ist niederdeutsch für ,Teich' oder ,Pfuhl'). ${ }^{74}$

Fontane skizziert mit den Positionen der Tochter und des Vaters Nebelung die Wirkungsmöglichkeiten von Eigennamen. Einerseits haben bedeutende Eigennamen gesellschaftliches Gewicht, das bei offiziellen Anlässen mit dem Verkünden der Namen ausgespielt werden kann. Die Namen erhalten aufgrund der hinter dem Namen vermuteten langen Tradition und der Zugehörigkeit zu einer exklusiven Gruppe eine Aura. Andererseits droht das Pochen auf den Namen zum ,Ridikül' zu werden, wenn die aktuelle Lebensweise der Namenträger und die Ordnung der Gesellschaft diesem Anspruch auf Exklusivität und Superiorität nicht mehr entsprechen. ${ }^{75}$ Dann erhält der ,Bürgerliche' die Gelegenheit, die Ursprungsemantik des Namens auszuspielen, die den Beginn der Namen- und Familientradition in ein zweifelhaftes Licht stellt, bei einem Namen mit ho-

\footnotetext{
${ }^{72}$ Brinkmann 1977, S. 25.

${ }^{73}$ Fontane HFA I, 4, S. $571 \mathrm{f}$.

${ }^{74}$ Vgl. dazu und zur Namenkomik dieser Textstelle Kopelke 1990, S. 81. Daraus erklärt sich auch die Anspielung Nebelungs auf die "Kröte“, die sich Hoffnungen macht dazuzugehören und doch einfach nicht dazu paßt. Zum Spiel mit der Ursprungssemantik von Namen bei Fontane vgl. auch Lowsky 2000, S. 138 f.

${ }^{75}$ Dies gilt wenn - wie in diesem Fall - der Adel verarmt ist, sich recht und schlecht durchschlägt und ein bürgerliches Leben führt, das sich nur durch den Dünkel, einige Familienerbstücke und einige Erinnerungen unterscheidet.
} 
hem Kommunikationswert aber überdeckt wird. ${ }^{76}$ Besonders die Aufzählung der Namen in der Todesanzeige, die sich eigentlich besonders prächtig ausnehmen soll, provoziert durch die Häufung diese Behandlung des Namens.

Handlungen und Reflexionen dieser Art stehen nicht für eine eindeutige auf Autorintentionen beruhende Einheit von Name und Namenträger. Sowohl der den Adel verachtende ordinäre Vater als auch die den Adel verherrlichende lächerliche Tochter werden ironisch dargestellt. Sie sind beide keine Identifikationsfiguren. ${ }^{77}$ Die Reflexionen über Eigennamen machen vielmehr deutlich, welche Beziehungen für Fontane zwischen der Zeichensemantik, dem Kommunikationswert oder Anspruch des Familiennamens und der individuellen Verfassung des Trägers bestehen: Der Familienname ist ,symbolisches Kapital', dessen Wert auf der Anerkennung durch die Gesellschaft beruht. Wandelt sich die feste Struktur der Gesellschaft, beginnen Kämpfe um die Bewertung von Eigennamen. Ob dabei der Adel gegen das wirtschaftlich potentere Bürgertum mit dem exklusiven alten Namen auftrumpft, ob das Bürgertum seinerseits neue auf geistigen und wirtschaftlichen Leistungen gegründete Traditionen mit bürgerlichen Namen zu beginnen sucht, ob Geburtsnamen eine Figur ,einholen' oder ob aus der vermeintlichen Ursprungssemantik unbedeutender bürgerlicher Namen eitel bedeutsame, nur scheinbar adlige Namen gemacht werden - in den Romanen Fontanes ist der Kampf mit und um Familiennamen ein die Handlungen mitbestimmendes Prinzip. ${ }^{78}$

Auch Fontanes Briefe zeigen, wie wichtig ihm der Kommunikationswert der Namen zur Ordnung seiner gesellschaftlichen Lebenswelt ist:

Zehn Generationen von 500 Schultzes und Lehmanns sind noch lange nicht so interessant wie drei Generationen eines einzigen Marwitzzweiges. Wer den Adel abschaffen wollte, schaffte den letzten Rest von Poesie aus der Welt, ${ }^{79}$

behauptet er 1860 und gibt damit dem Klang des alten Namens einen deutlichen Vorrang vor den ,Allerweltsnamen' der Bürgerlichen, die mit solchen nichtssagenden Na-

\footnotetext{
${ }^{76}$ Fontane steht aber auch den Methoden der neuen Berühmtheiten, sich einen Namen zu machen, kritisch gegenüber, wie seine fragmentarischen Reflexionen über den Berliner Lokalpatriotismus und den Namen „Hildebrandt“ verdeutlichen; vgl. Fontane HFA I, 6, S. 813 f.; Ertl 1982, S. 207 f.

77 Der implizite Kommentar des Autors läßt sich an verschiedenen Hinweisen ablesen. Der „Witz" des Vaters wird von „Gejohle“ quittiert, das dem ordinären Familiencharakter der „Nebelungs“ entspricht. Der Vortrag der Tochter ist andererseits „dramatisch“, also übertrieben und vom heimlichen Wunsch getragen, durch Heirat dazuzugehören. Nicht zuletzt der Familienname „Nebelung“, der unangenehme Assoziationen zum Wetter hervorrufen mag, deutet auf eine abfällige Bewertung hin.

${ }^{78} \mathrm{Vgl}$. etwa die Rolle Thereses in Die Poggenpuhls, in: Fontane HFA I, 4, S. 528, den Kampf von Jenny Treibel mit Corinna Schmidt in Frau Jenny Treibel, in: Fontane HFA I, 4, S. 432, 448; Frau Jenny Treibels eigenen Namen: geborene Bürstenbinder, in Frau Jenny Treibel, in: Fontane HFA I, 4, S. 445, oder den Brief der Mutter, eine „Geborene Printz“, an Mathilde in Mathilde Möhring, in: Fontane HFA I, 4, S. 661 bis hin zur Erwähnung der Rückseite von „Schulzes Bonbonfabrik“ in Die Poggenpuhls, in: Fontane HFA I, 4, S. 479, die den finanziellen und gesellschaftlichen Niedergang der Poggenpuhls symbolisiert.

${ }^{79}$ Fontane HFA IV, 1, S. 705 (Brief an Fontanes Mutter vom 28.5.1860).
} 
men augenscheinlich für Fontane keine eigene Tradition aufbauen können. Der späte Fontane scheint zwar zunächst die adligen und die bürgerlichen Namen ganz anders einzuschätzen:

Die Bülows und die Arnims sind 2 ausgezeichnete Familien, ist es nicht blos für die Welt (da nun schon ganz gewiß) sondern auch für Preußen und die preußische Armee ganz gleichgültig und die Müllers und die Schultzes rücken in die leergewordenen Stellen ein. ${ }^{80}$

Doch läßt der späte Fontane die poetische Wertschätzung des Adels nicht fallen, wie die berühmte Briefstelle aus dem Briefwechsel mit Georg Friedländer zeigt:

[...] aber der ,Junker', unser eigentlichster Adelstypus, ist ungenießbar geworden. Als Kunstfigur bleibt er interessant und Historiker und Dichter können sich freun, daß es solche Leute gab und giebt; [...] Aber was ist damit bewiesen! [...] jeder Hochstapler ist novellistisch angesehen ein Gott. Im Uebrigen ist er ein Greul. Und zu solchem Greul entwickeln sich auch die Junker. [...] Der x-beinige Cohn, der sich ein Rittergut kauft, fängt an, mir lieber zu werden als irgendein Lüderitz oder Itzenplitz, weil Cohn die Zeit begreift und alles thut, was die Zeit verlangt, während Lüderitz an der Lokomotive zoppt und ,brr' sagt und sich einbildet, sie werde still stehn wie sein Ackergaul. ${ }^{81}$

Fontane behält sein grundsätzliches ästhetisches Argument ${ }^{82}$ bei, das seine Einstellung gegenüber den offensichtlich gesellschaftlich überholten traditionellen Institutionen seiner Gesellschaft kennzeichnet. Auf der einen Seite ist die Welt der Pferde und Kutschen die für Fontane eigentlich ,poetische' Welt, auf der anderen Seite entspricht seine gegenwärtige sich rasant entwickelnde Welt eben nicht mehr diesem poetischen Zustand. Während der frühe Fontane die von inm beschriebene glanzvolle Tradition und seine Gegenwart eng miteinander verbunden sieht, unterscheidet der spätere Fontane zwischen immer noch poetisch gesehener Tradition der großen Familien und dem verfehlten Anspruch auf Superiorität eben dieser Familien in der Gegenwart. ${ }^{83}$ Dabei zeigen die Namen, daß das Ziel seiner Kritik nie der Hochadel ist. Fontane beschränkt sich auf die märkischen Junker, bei denen er eine Diskrepanz zwischen Anspruch und Benehmen erkennt.

Zudem neigt der späte Fontane insgesamt zur heftigen Ablehnung der Eigennamenpolitik, die von exklusiven in-groups betrieben wird. Dazu zählt er dann auch die jüdischen Deutschen:

Diese elende Ebertyrerei, diese bornierte Vorstellung von einer Breslauer Familienwichtigkeit ist an allem Schuld [...]. Denn ich vermuthe, sämtliche Ebertys glauben noch immer an sich. Alle Klüngel sind schlimm, aber die Judenklüngelei ist die schlimmste. ${ }^{84}$

${ }^{80}$ Fontane 1954, S. 254 (Brief an Georg Friedländer vom 12.4.1894).

${ }^{81}$ Fontane HFA IV, 4, S. 352 (Brief an Georg Friedländer vom 14.5.1894).

${ }^{82}$ Vgl. z.B. Aust 2000, S. 387.

${ }^{83}$ Vgl. z.B. auch Brinkmann 1977, S. 29 f. und S. 32 f.

${ }^{84}$ Fontane HFA IV, 4, S. 460 (Brief an Georg Friedländer vom 8.7.1895). Fontane reproduziert mit seiner Kritik bestehende Vorurteile seiner Zeit. Auch Richard Wagner etwa läßt in einem Gelegenheitsgedicht, Die 3 Jota, erkennen, daß diese gesellschaftlichen Gruppen von den Außenstehenden mißgünstig betrachtet wurden: „Ich nenne Dir drei Jot' / Die stünden gern für Gott: / Du triffst sie sicher an, / den Junker, wo er kann, / den Juden, wo er will, / den Jesuit - schweig' still.“; vgl. Wagner 1905, S. 48. 
In jedem Fall spielt bei Fontanes Kommentaren zum Adel und der bürgerlichen Schicht die traditions- und Identitätsstiftende Memorialfunktion der Familiennamen eine wichtige Rolle. Er greift selbst in seinen Briefen immer wieder zu Argumenten, die sich auf im Namen transportierte Familientraditionen ${ }^{85}$ stützen. In Meine Kinderjahre erwähnt er eine Episode aus seinem Elternhaus, die er als Kennzeichen eines „humoristischen Visionärs" wertet:

Diese Tradition wurde durch allerhand Schriftstücke bestätigt, mein Vater aber ging weiter und nahm, weil es ihm so paßte, den durch die Schriftstücke geführten Beweis des Nebensächlichen zugleich als Beweis für die Hauptsache, mit andern Worten, die bewiesene Namensvetterschaft als bewiesene Blutsverwandtschaft. ${ }^{86}$

Fontanes Vater macht sich die ,unendliche Vieldeutigkeit' (Quine) des Eigennamens zunutze, um eine vermeintliche Verwandtschaft der ,Fontane' mit bekannten französischen ,Fontanes' zu beweisen und so eine große Familientradition aufzubauen, die Theodor Fontane als „Phantasiebeziehungen“ bezeichnet. ${ }^{87}$

Doch auch wenn Fontane diese Namenbewertungen stets ironisch betrachtet, ist er selbst der recht flachen namenspielenden Schmeichelei eines Huldigungsgedichts durchaus zugänglich, das er als „nichts Besonderes, aber doch ganz nett“ beschreibt:

Fontane ist nun schön heraus,

Doktor wurde das alte Haus,

Und will er nicht bürgerlich mehr bleiben,

So kann er sich von Tane schreiben. ${ }^{88}$

\subsubsection{Die Aura berühmter Namen ${ }^{89}$}

Kehren wir zurück zum Namenkatalog in Der Tag von Hemmingstedt. Dieser fällt dadurch auf, daß er nicht nur aus Namen besteht, sondern auch aus Zahlen. Solche ,Namen-Zahlen-Schwärme' dienen Fontane in besonderem Maße der direkten Evokation einer geordneten, durch Familienzugehörigkeiten bestimmten Gesellschaft.

So geschieht es z.B. in Adlig Begräbnis (aus dem Zyklus Märkische Reime) von 1888:

\footnotetext{
Sechs Rohr'sche Vettern ihn tragen

Sechs andere nebenher,

Dann folgen drei von der Hagen

Und drei von Häseler.

Ein Ribbeck, ein Stechow, ein Zieten,

Ein Rathenow, ein Quast,

Vorüber an Scheunen und Mieten

Auf den Schultern schwankt die Last.

[...]

Eine dreizehner Landwehrfahne
}

\footnotetext{
${ }^{85}$ Vgl. z.B. unter vielen anderen Beispielen Fontanes Brief an Georg Friedländer vom 18.10.1895, Fontane 1954, S. 289; vgl. zur Bedeutung der Familiengeschichte für nationale Mythen in „Die Poggenpuhls“ Hebekus 2003, S. $193 \mathrm{f}$.

${ }^{86}$ Fontane NA 14, S. 19.

${ }^{87}$ Fontane NA 14, S. 19.

${ }^{88}$ Vgl. Fontanes Brief an Georg Friedländer vom 9.12.1894, Fontane 1954, S. 276; zu Fontanes Haltung gegenüber den späten Ehrungen vgl. Wruck 1999, S. 19 f.

89 Zu berühmten Namen in Fontanes Erzähltexten vgl. die kurze Passage bei Sauerbeck 2000, S. 24.
} 
Der alte von Bredow trug,

Und Hans Rochow von Rekahne

Schloß ab den Trauerzug.

Die Beschreibung des Begräbnisses ist spärlich und gestaltet vor allem stimmungsvoll die herbstliche Jahreszeit. Fontane feiert hier die märkischen adligen Namen. Die 'prominenten' Repräsentanten der adligen Gesellschaft zählen und erhöhen die Bedeutung des Ereignisses und des Toten. Die Familiennamen lenken den Blick auf die durch sie heraufbeschworene Tradition Preußens, die durch die Familiengeschichte der aufrechterhalten wird. Dies zeigt der zusätzliche Hinweis auf die Befreiungskriege 1813-1815 durch die Erwähnung der Landwehrfahne. Das Gedicht erhält seinen eigenen ,lyrischen Charakter' wie die von Fontane übersetzte schottische Ballade durch die Eigennamen. Es genügt, wenn wenige der Namen überregional bekannt sind, um dem gesamten Namenkatalog eine Aura bzw. einen poetischen Klang auch für den nichteingeweihten Leser ohne Produzentenstatus (im Sinne Evans') zu verleihen. Die Familiennamen sind „Zertifikate“90, die den Träger nicht nur identifizieren, sondern deren Besitz ein Prädikat ist. Sie haben appellativischen Charakter, denn sie benennen die Eigenschaft, Mitglied einer bestimmten Familie zu sein. Fontane benutzt die Namen im Plural und in Kombination mit Zahlwörtern, wodurch der appellativische Charakter dieser namentlichen Bezeichnungen weiter hervorgehoben wird. Dabei ist die den Familiennamen zugeordnete Bedeutung relativ unklar. Die Namen schreiben durch ihren Kommunikationswert vor allem gesellschaftliche Wichtigkeit zu. Ein ,von Rochow' zu sein ist das Prädikat, das mit dem Familiennamen zugesprochen wird. Die gesellschaftliche Wertschätzung des Namens trägt dazu bei, daß mit diesem Prädikat positive Eigenschaften diffus dem Namenträger zugeschrieben werden.

Fast gleichzeitig mit Adlig Begräbnis kritisiert Fontane in Kirchenumbau von 1889 aus dem Zyklus Aus der Gesellschaft ironisch die Achtlosigkeit der neuen bürgerlichen Gutsbesitzer gegenüber den ,poetischen' Traditionen der adligen Familien:

„Nu Ritter, ein Stücker sieben,

Ich hab' ihre Namens aufgeschrieben,

Bloß, wo sie gestanden, da sind ja nu Löcher:

1 Bredow, 1 Ribbeck, 2 Rohr, 3 Kröcher;

Wo soll'n wir mit hin? wo soll ich sie stell'n?"

„Stellen? Nu gar nich. Das gibt gute Schwell'n.

Schwellen für Stall und Stuterei,

Da freun sich die Junkers noch dabei." ${ }^{~} 91$

Das Gedicht schildert, wie der Aufsteiger und trotz seines Namens no-name „Herr Schultze" und sein Polier mit den Grabplatten der alten Gutsbesitzer umgehen. Die ver-

\footnotetext{
${ }^{90} \mathrm{Vgl}$. Fontane HFA 1, S. 360.

${ }^{91}$ Fontane HFA I, 6, S. 374.
} 
ächtliche Einstellung der Namenverwender wird wiederum mit einem Namen-ZahlenSchwarm deutlich gemacht - mit der achtlosen, an die Lagerhaltung einer Firma erinnernden Addition der Namen. Das Gewicht der Verbindung von ,Grabschändung' und Pferdestall darf dabei nicht unterschätzt werden. Sie hatte der frühe Fontane noch in sehr ernstem Ton in der numinosen Ballade Swend Gabelbart beschrieben. ${ }^{92}$

Dargestellt wird hier der Umgang mit einer ganzen, exklusiven Lebenswelt. Der NamenZahlen-Schwarm repräsentiert Tradition und Familiengeschichte, die vom bürgerlichen Parvenü ignoriert werden. Die Kombination von Namen und Zahlen steht hier auch für die Reichweite der Tradition, mit der Schultze ,aufräumt'. Mitglieder der bedeutenden, auf ihre Tradition achtenden Geschlechter sind im Leben wie im Tod in ihre Familientradition eingebunden.

Daß die glanzvollen Zeiten des Adels vorbei sind, deutet Fontane durch die geschilderte ,Sepulchralkultur' an. Die Feier der adligen Namen findet - neben einer leicht boshaften Schadenfreude - in wehmütigem Ton statt. Denn die Tradition wird nicht fortgesetzt. Die auf ehrwürdigen Traditionen beruhende Memorialfunktion der Namen auf Grabplatten in den Kirchen wird nicht mehr beachtet. Nur mehr bei einem Adlig Begräbnis wird die Namentradition inszeniert.

Das Exemplarische des Vorgangs wird durch den Namenkatalog hervorgehoben. Nicht um die Kränkung der Familienehre einer Familie geht es Fontane, sondern um die Ablösung der traditionellen poetischen Welt von Rittern und Religion durch die prosaische der Schultzes. Deren neue, kleine und wenig aufregende Welt wird in Tu ich einen Spaziergang machen mit den landläufigen Stereotypennamen ,Müller', ,Schulze' und ,Meyer' beschrieben:

\footnotetext{
Warum sind die Müllers ausgeblieben?

Warum hatte Schulze nicht geschrieben?

Werd' ich der Meyer im Park begegnen?

Wird es schön Wetter oder wird es regnen? ${ }^{93}$
}

„Allerkleinste Sachen“ des Alltags, nichtige Sorgen, werden durch die Aufzählung von ebenso nichtigen Allerweltsnamen exemplifiziert, die auf keine berühmte individuelle Familie mit Tradition referieren, sondern nur auf eine gesichtslose Menge. ${ }^{94}$ Es handelt

\footnotetext{
${ }^{92} \mathrm{Vgl}$. Fontane HFA I, 6, S. $175 \mathrm{f}$.

${ }^{93}$ Fontane HFA, S. 336. Hettche 2002, S. 90, behauptet, daß die vielen imaginär antizipierten Begegnungen im Park ein Hinweis auf das Großstadtleben seien.

${ }_{94}$ Ob durch ,die Meyer' das Stereotyp der ,schönen Jüdin' erfüllt wird - der Name ist für Fontane offensichtlich deutlich jüdisch konnotiert - kann nicht entschieden werden. In Wurzels widerspricht der Mann jeweils als Antwort auf eine Strophe der Frau aus purer Widerspruchslust. Diese Tatsache wird deutlich bei den Eigennamen, die von Frau und Mann gegeneinander gestellt werden und die jeweils doch nur den gleichen semantischen Hintergrund vertreten: „Heringsdorf“ und „Ahlbeck“ stehen für Usedomer Ferienorte, „Joachimstal“ und „Steglitz“ für gleichrangige Gymnasien, „Levysohns“ und „Meyers" schließlich
} 
sich um Stereotypennamen, die das Bürgerliche ironisch hervorheben. So verwendet sie auch Fontanes ,medisierende' Figur Turgany in Vor dem Sturm:

Nicht zufrieden damit, für sein eigen Teil der Pastor Schmidt von Werneuchen zu sein, ist sein bester Freund auch noch der Pastor Schultze von Döbritz. Nomen et omen. Er raucht aus langer Pfeife und trägt Käppsel und Schlafrock, und wenn er den letztern ausnahmsweise nicht trägt, so macht er den Eindruck, als trüge er zwei. ${ }^{95}$

\subsubsection{Der heroische Einzelne und der Aufstand der Massen}

Bürgerliche und adlige Namen stehen jeweils exemplarisch für eine soziale Schicht, die sie evozieren. Während die Namen der Adelsgeschlechter aber definit auf bestimmte, Fontane und seinen Briefempfängern zumindest diesem Namen nach bekannte Familien referieren, bezeichnen die bürgerlichen Stereotypennamen mit indefiniter Referenz beliebige Personen mit der Eigenschaft, diese Namen zu tragen. Einer begrenzten Menge wird eine unbegrenzte und trotz des Namens anonyme Menge gegenübergestellt.

Dies ist auch das Prinzip, das Fontane im Gedicht Arm oder reich verfolgt. Fontanes Sprecher stellt sich in ironischem Größenwahn dar. Er will (angeblich) entweder reich und berühmt nach Art der ganz großen Welt werden oder arm bleiben. Dazwischen gibt es für ihn nichts. Die von ihm verachteten kleinen Geschäftemacher in der mediokren Anonymität werden durch pejorative Appellative nach Geschäftssparten in einem Schwarm zusammengefaßt. Durch die Appellative im Singular werden Stellvertreter der Zunft vor Augen geführt. Den Berufsständen wird ein negativer Kollektivcharakter zugesprochen:

Was, um mich herum hier, mit Golde sich ziert,

Ist meistens derartig, daß mich's geniert;

Der Grünkramhändler, der Weißbierbudiker,

Der Tantenbecourer, der Erbschaftsschlieker,

Der Züchter von Southdownhammelherden,

Hoppegartenbarone mit Rennstallpferden,

Wuchrer, hochfahrend und untertänig -

Sie haben mir alle viel, viel zu wenig.

Fontane stellt innen die Größe einzelner, angeblich vorbildhafter und vorwiegend durch ihre Eigennamen repräsentierter Familien aus der internationalen glänzenden Welt der Reichen entgegen:

Mein Interesse für Gold und derlei Stoff

Beginnt erst beim Fürsten Demidoff,

Bei Yussupoff und bei Dolgorucky,

Bei Sklavenhaltern aus Süd-Kentucky,

Bei Mackay und Gould, bei Bennet und Astor

- Hierlandes schmeckt alles nach Hungerpastor -

Erst in der Höhe von Van der Bilt

für jüdische Familien (die vom übrigen Namenkatalog als zweifelhafter Besuch getrennt werden): „Also Scherzers, Kopisch, Liliencron / Und vielleicht die Familie Levysohn..." Fontane HFA I, 6, S. 359 f.

${ }_{95}$ Fontane HFA I, 3, S. 112; vgl. auch den komisch diskrepanten Namen ,Immanuel Schultze' (aus ,Immanuel Kant' und ,Schultze') in Frau Jenny Treibel,vgl. Fontane HFA I, 4, S. 346 passim. 
Die Eigennamenverwendung des späten Fontane ist hier geleitet vom Gegensatz zwischen der individuellen Größe und der massenhaften Mittelmäßigkeit. Die Namen mögen zwar für eine Gruppe oder noch allgemeiner für eine Lebenswelt stehen. ${ }^{97}$ Gleichwohl orientiert sich der Sprecher an einzelnen Familien, die sich durch ihre Leistung so hervorgetan haben, daß ihre Namen berühmt geworden sind. Sie schwimmen nicht in der anonymen Masse der „Tantenbecourer“ mit. Deren Mittelmäßigkeit ist vor allem dadurch gekennzeichnet, daß sie nur unter pejorativen Appellativa zusammengefaßt sind. Die Reihenfolge der beiden kleinen Namenkataloge des zweiten Gedichtabschnitts bildet eine gegen die gesellschaftliche Norm gerichtete Klimax. Erst werden die Namen von europäischen (russischen) Familien des Hochadels genannt, die sich auch durch ihren Reichtum hervorgetan haben, zusätzlich aber über die gesellschaftliche Berühmtheit der Adelswelt verfügen. ${ }^{98}$ Sie heben den Kontrast zu den Neureichen des Appellativschwarms hervor. Danach wechselt Fontane über das Appellativ ,Sklavenhalter' zu Namen, die für die Bourgeoisie der nicht feudalistischen nordamerikanischen Welt stehen. ${ }^{99}$ Dieses Vorgehen enthält einen zusätzlichen Affront gegen die Werteordnung der eigenen alten Welt und beginnt die übertriebenen Vorstellungen im letzten Abschnitt des Gedichts. Daß Fontane unter den berühmten Namen just auch die Sklavenhalter aufführt, zeigt die Ironie, mit der die Namen gepriesen werden. ${ }^{100}$ Die Konzepte historischer individueller Größe und Berühmtheit werden scheinbar resignierend in Zweifel gezogen.

Die Welt, die der Sprecher hier zeichnet, ist für inn unerreichbar. Ihre Abgeschlossenheit wird durch die auf Entferntes referierenden Eigennamen hervorgehoben. Der Zugang zu einer exklusiven Familie ist noch schwieriger zu erlangen als die Zugehörigkeit zu bestimmten, durch ihre jeweiligen Tätigkeiten gekennzeichneten Gruppen. Ein Teil der Selbstironisierung des Sprechersubjekts liegt darin, daß mit Hinweis auf die ohnehin unerreichbare Exklusivität fremder und berühmter Welten, jede Bemühung um Reichtum in den erreichbaren Grenzen abgelehnt wird - unter der ironischen Entlarvung der mittelmäßigen Bemühungen anderer. Fontane ironisiert sowohl das Streben nach gesellschaftlicher Berühmtheit als auch die Haltung des Sprechers, der allem früheren

\footnotetext{
${ }^{96}$ Fontane HFA I, 6, S. 337.

${ }^{97}$ Vgl. Richter 1986, S. 435-446.

${ }^{98}$ Sie sind hervorragende ,Partien', wie Die Poggenpuhls zeigen; vgl. Fontane HFA I, 4, S. 501; zu den Namen vgl. den Kommentar, Fontane HFA I, 6, S. 976 f.

${ }^{99}$ Vgl. zu ,Mackay' und ,Vanderbild' als Synonyme für ,Reichtum': Fontane HFA I, 1, S. 359.

100 Zur ironischen Übertreibung des gewünschten Reichtums vgl. Richter 1980, S. 137.
} 
Ehrgeiz zugunsten eines biedermeierlichen Rückzugs auf das Einfache entsagt. Fontanes eigene Namenbewertung bleibt also auch hier ambivalent.

\subsubsection{Pollacks und die Ribbecks}

Hundert Briefe sind angekommen, Ich war vor Freude wie benommen, Nur etwas verwundert über die Namen, Und über die Plätze, woher sie kamen.

Ich dachte, von Eitelkeit eingesungen:

Du bist der Mann der „Wanderungen“,

Du bist der Mann der märk'schen Geschichte,

Du bist der Mann der märk'schen Gedichte,

Du bist der Mann des Alten Fritzen

Und derer, die mit inm bei Tafel sitzen,

Einige plaudernd, andre stumm,

Erst in Sanssouci, dann in Elysium,

Du bist der Mann Jagow und Lochow,

Der Stechow und Bredow, der Quitzow und Rochow,

Du kanntest keine größren Meriten

Als die von Schwerin und vom alten Zieten,

Du fandst in der Welt nichts so zu rühmen

Als Oppen und Groeben und Kracht und Thümen,

An der Schlachten und meiner Begeisterung Spitze

Marschierten die Pfuels und Itzenplitze,

Marschierten aus Uckermark, Havelland, Barnim,

Die Ribbecks und Kattes, die Bülow und Arnim,

Marschierten die Treskows und Schlieffen und Schlieben,

Und über alle hab ich geschrieben.

Aber die zum Jubeltag da kamen,

Das waren doch sehr sehr andre Namen,

Auch „sans peur et reproche“, ohne Furcht und Tadel,

Aber fast schon von prähistorischem Adel:

Die auf „berg" und auf „heim" sind gar nicht zu fassen,

Sie stürmen an in ganzen Massen,

Mayers kommen in Bataillonen,

Auch Pollacks und die noch östlicher wohnen;

Abram, Isack, Israel,

Alle Patriarchen sind zur Stell,

Stellen mich freundlich an ihre Spitze,

Was sollen mir da noch die Itzenplitze!

Jedem bin ich was gewesen,

Alle haben sie mich gelesen,

Alle kannten mich lange schon,

Und das ist die Hauptsache..., „kommen Sie, Cohn“. ${ }^{101}$

Auch An meinem 75ten (bzw. Als ich 75 wurde ${ }^{102 ;}$ 1894) gehört zu den späten Gedichten Fontanes, in denen dieser sich mit seiner eigenen Rolle bzw. der Rolle des Dichters in der Gesellschaft ironisch auseinandersetzt. ${ }^{103}$ Der Sprecher ist durch die Erwähnung der Wanderungen durch die Mark Brandenburg als Fontane identifiziert. Der Ton ist -

${ }^{101}$ GBA Gedichte 2, S. 466 f.

102 Zu dieser Schreibung der Überschriften vgl. Karl Richters Ausgabe der Fontane-Gedichte: Fontane 1998, S. 100 f. und den Kommentar, S. 163.

${ }^{103}$ Vgl. zu diesem Themenbereich Plett 1991. 
besonders durch den freien Knittelvers und die unregelmäßigen Abschnitte, ferner durch die Selbstanrede, das Understatement, die Übertreibung und den Bildbruch ironisch und plaudernd prosanah. ${ }^{104}$

Das Dichter-Ich stellt dar, wie inn zu seinem Geburtstag seine jüdischen bürgerlichen Leser beglückwünschen, von denen er dies nicht erwartet hatte. Die Menschen der in seinen Werken behandelten Sphären (,das alte Preußen') beachten inn dagegen nicht. Im ersten Abschnitt werden Geburtstagsgratulationen als Anlaß des Gedichts genannt. Im zweiten Abschnitt wird mit Eigennamen die Sphäre der früheren Werke des Sprechers indirekt evoziert. Im dritten Abschnitt schließlich werden die Namen derjenigen aufgezählt, die den Dichter mit Gewinn lesen und bewundern. Der Dichter findet sich mit den Gratulanten ab und schließt scheinbar zufrieden damit, daß die Hauptsache sei, er werde gelesen und gebraucht.

Auf den ersten Blick ließe sich am Aufbau des Gedichts eine Überbietungsstruktur ablesen. Dem Dichter scheinen Leser wichtig zu sein, ganz gleichgültig aus welcher gesellschaftlichen Sphäre sie stammen. Das Lesen, die Kultiviertheit scheint den Maßstab der adligen „Geburtsüberlegenheit“ abzulösen. ${ }^{105}$ Betrachtet man die Namenverwendung und die Selbstdarstellung Fontanes ${ }^{106}$ in seinen späten Gedichten genauer, ist allerdings zu vermuten, daß hier vorwiegend der Adel mit Hilfe gesellschaftlich negativ konnotierter Eigennamen kritisiert werden soll. Durch die Eigennamen wird eine kritische Haltung indirekt evoziert. Theodor Fontane nutzt hierzu das kommunikative Potential der Eigennamen, ohne das normative Weltbild, auf dem die Namenbewertungen beruhen, in Frage zu stellen. Er ist sich dabei besonders der kommunikativen Wirkungen von Eigennamenkatalogen bewußt, wenn er zwei Namensysteme einander gegenüber stellt. ${ }^{107}$ Die Namengruppen des Gedichts exemplifizieren den ostelbischen Adel und das jüdische deutsche Bürgertum. Zusätzlich unterscheiden sie die „Massen“ von berühmten Personen und Familien mit Tradition.

\footnotetext{
${ }^{104}$ Vgl. Mecklenburg 2001, S. 233.

105 Vgl. Brinkmann 1977, S. 28.

${ }^{106}$ Daß es sich hier um eine Selbststilisierung handelt, wird auch von Mecklenburg 2001, S. 235, vertreten. Dort wird die Stilisierung auf zwei Positionen der Werkrezeption bezogen: als Familiengeschichte und als Literatur. Dieser Ansicht soll hier zugestimmt werden. Allerdings ist sie nur im Rahmen der umfassenderen Selbststilisierung Fontanes als ,bescheiden gewordener berühmter Autor' zu verstehen.

${ }^{107}$ Vgl. hierzu und generell zum Kontext des Gedichts Mecklenburg 2001. Das Gedicht entstand um die Jahreswende 1894/95. Es war zur Veröffentlichung bestimmt, wurde von Fontane aber zurückgehalten, weil er eine Düpierung seiner jüdischen Leser fürchtete. Das prosaisch-kunstlos wirkende und archaisierende Versmaß deutet einen ironischen Ton an. Auf keinen Fall kann von einer "hämmernden Litanei“ gesprochen werden (so hingegen Reich-Ranitzky 1999, S. 98).
} 
Die Einleitung des ersten Abschnitts verweist darauf, daß die von Fontane in seinem Werk $^{108}$ gezeichnete ruhmreiche Welt des Adels vergangen ist. Die Familiennamen sind - wie der Sprecher selbst sagt - vor allem auf die Wanderungen und die „märk'schen Gedichte" bezogen, in denen z.B. Schwerin und Zieten verherrlicht wurden (der ,alte Fritz' ohnehin). ${ }^{109}$ Die Namen greifen durch den Bezug auf die Wanderungen weit hinter die Zeit Friedrichs II. zurück. ${ }^{110}$ Der beschriebene Kreis wird dennoch gesellschaftlich wie zeitlich durch die Hervorhebung Friedrichs II. eingegrenzt. Fontane bezieht sich hier auf jene Zeit, auf die das preußische Junkertum (also der niedere Adel) in seiner Gegenwart, aber auch der preußische Staat insgesamt mit Stolz zurück blicken. Die Kritik am Adel der Gegenwart findet ihren Ausdruck, indem Fontane die eher unmittelbaren Vorfahren aus jener Zeit feiert, die das normative, traditionelle und mythische Fundament für den märkischen Adel und den preußischen Staat zu Fontanes Zeiten bilden. ${ }^{111}$ Die erste Aufzählung von Namen beginnt allgemein mit Familiennamen auf/-ow/, die das topographische sortale Prädikat \{ostelbisch\} exemplifizieren und den Leser auf den gemeinten Kreis einstimmen. ${ }^{112}$ Da es Fontane vordringlich um die Darstellung der Junker insgesamt geht, folgt die Auswahl und Reihenfolge der Namen vor allem lautlichen ${ }^{113}$ und metrischen Aspekten. Die übertrieben deutlich dargestellte Ähnlichkeit der Namen hat einen komischen Beiklang, der durch Assonanzen und Alliterationen im weiteren Verlauf unterstrichen wird. Die Verse mit Eigennamenkatalogen betonen einen gleichmäßigen Rhythmus, so daß der Namenklang sich ,schwungvoll' entfalten kann und die ästhetische Funktion voll entfaltet werden kann. Die definite Referenz der einzelnen Namen wird damit zugunsten der Evokationskraft ihres gemeinsamen Klangs zurückgestellt. Wie in Fontanes Übersetzung der schottischen Ballade oder in Havelland evozieren die Namenkataloge auch hier einen Namenraum und dadurch einen kulturellen Raum. Dennoch können die Namen dies nur bewirken, weil sie tatsächlich bestimmte Geschlechter identifizieren, die dem Leser zumindest zum Teil bekannt sind. Daß (berühmte) Adelsgeschlechter gemeint sind, hat Fontane schon zu Beginn des Gedichts durch den Hinweis auf das ,Tafeln' mit dem ,Alten Fritzen' deutlich gemacht. Auch wird der zeitgenössische Leser zumindest den Namentypus und einige der im

\footnotetext{
108 Hier ist vor allem Fontanes frühes Werk gemeint, gerade seine Balladen, die nach seiner eigenen Ansicht zum Bleibenden seines Werks gehörten und die inn ,volkstümlich' gemacht hatten; vgl. Scheuer 2001, S. 15.

${ }^{109}$ Fontane HFA I, 6, S. 214 f. und $208 \mathrm{f}$.

110 Vgl. Mecklenburg 2001, S. 232.

111 Vgl. Mecklenburg 2001, S. 233. Mecklenburgs Hinweis auf Hermann von Tresckow („Bismarckzeit“) und andere neuere berühmte Vertreter aus der für Fontane noch jüngeren Vergangenheit ist insofern irreführend, als Fontane in diesen Fällen nur den Familiennamen im Plural verwendet, also nicht auf die Individuen referiert.

${ }_{112}$ Vgl. Mecklenburg 2001, S. 233.

${ }^{113}$ Vgl. Mecklenburg 2001, S. 233.
} 
Schwarm aufgeführten Namen gekannt haben, so daß das den Schwarm verbindende Prädikat \{ostelbische Junker\} leicht zu erkennen war. ${ }^{114}$ Fontane stützt sich also auf reale Eigennamensysteme und deren gesellschaftliche Funktion.

Die Namennennungen sind jeweils durch einleitende Passagen getrennt, so daß mehrere kleine Namenkataloge entstehen. Diese sind durch die Verwendung des Namensingulars bzw. -plurals so gegliedert, daß zunächst auf ganze Familien, dann auf einzelne (bekannte und nicht so bekannte) Familienvertreter und zuletzt wieder auf ganze Familien referiert wird. ${ }^{115}$ Während ,Schwerin' und ,der alte Zieten' als bekannte Militärs tatsächlich durch ihren Namen im universe of discourse identifiziert werden, können mit „Oppen und Groeben und Kracht und Thümen“ jeweils mehrere mehr oder weniger ruhmreiche Vertreter der Familie gemeint sein. Die fehlende Spezifizierung führt zu einer singulär indefiniten Referenz der Namen, die wiederum auf die Familien und deren Namen als Ordnungskategorie verweist. Energetisch wie semantisch macht der Gedichtabschnitt also einen Bogen hin zur Individuation und wieder weg von ihr.

Trotz der Anordnung vieler Familiennamen nach lautlichen Eigenschaften ist von zahlreichen Verbindungen zwischen den Namenträgern im kulturellen Namenfeld auszugehen, da die benannten Familien einem engen sozialen Kreis angehören. Fontane kann offenlassen, welche Assoziationen beim Leser angeregt werden sollen. So sind z.B. die „Stechow und Bredow" und die „Quitzow und Rochow" durch den gemeinsamen Aufstand gegen Friedrich I. miteinander verbunden ${ }^{116}$ und bilden eine eigene Untergruppe. Besonders ,Katte' und die ,Quitzow' tauchen auch in den Romanen Fontanes als Signal für wichtige Ereignisse der preußischen Geschichte auf. Sie stehen für die „Dekapitation" des Freundes Friedrichs II., Hans Hermann von Katte, durch Friedrich I. und für den Quitzow-Widerstand gegen Friedrich I. ${ }^{117}$ Die Namen bilden zusammen mit den übrigen Namen wie den ,Jagows' oder den ,Bredows' einen konstanten Hintergrund der Romane, ohne daß unbedingt Hauptfiguren dieses Namens auftreten würden. Sie evozieren indirekt eine traditionsbewußte Haltung des jeweiligen Sprechers. Auch die Ortsbezeichnungen stehen für Fontanes frühe Gedichte und deren Begeisterung für Militärisches. Z.B. werden in Einzug die Uckermark mit dem 64. und Barnim mit dem 60. Re-

\footnotetext{
114 Das Problem, daß nicht immer am Eigennamen (ohne ,von') zu erkennen ist, ob jemand adlig ist, spricht Fontane in seinen Romanen an; vgl. z.B. Fontane HFA I, 4, S. 595.

115 Der Plural zeigt die Referenz auf die ganze Familie, auch wenn einzelne Familienmitglieder sicherlich dem Leser sofort als exemplarische Vertreter vor Augen standen.

${ }^{116}$ Vgl. Fontane GBA, Wanderungen durch die Mark Brandenburg 3, S. 63, S. 222; Fontane HFA I, 6 , S. 813.

${ }^{117}$ Vgl. z.B. die Enthauptung Hans Hermann Kattes, wie sie leitmotivisch in Vor dem Sturm, Fontane HFA III, immer wieder angesprochen wird; ebenso Der Quitzowen Fall und Untergang in: Fontane HFA I, 6, S. 188-192 und den dazugehörigen Kommentar; vgl. auch Fontane GBA, Wanderungen durch die Mark Brandenburg IV, S. 299-339, zu Hans Hermann Katte und den Kattes.
} 
giment verbunden, in Havelland das Havelland mit dem preußischen Sieg von Fehrbellin. ${ }^{118}$ Die geographischen Namen stehen gleichzeitig für militärische Ordnungskategorien und lieux de mémoire.

Die Familiennamen individuieren die jeweilige Familie. Dies ist an der Verwendung des definiten Artikels - also an der singulär definiten Referenz - erkennbar, der wiederum auch die Appellativierung der Eigennamen anzeigt. Sie bezeichnen die Eigenschaft, Mitglied einer Familie zu sein. Angesprochen sind dadurch immer die gesamten Familien - von der tiefen Vergangenheit bis zur aktuellen Gegenwart. Wie die einleitende Erwähnung des „Alten Fritz“ zeigt, referieren die Namen allerdings vorwiegend auf die historischen Vertreter der Familien. ${ }^{119}$

In den Romanen werden die Namen zumeist nur erwähnt, z.B. wenn es um die Abstammung einer Nebenfigur oder um Militärisches geht. Daher stellen sie durch ihre uneingeschränkte Referenz über den jeweiligen Text hinaus eine Verbindung zwischen der fiktiven und der realen Welt dar. Sie sind „Nahtstellen, an denen Gegebenes und Gemachtes zusammenkommen" und damit ein essentielles Element des realistischen Schreibens. ${ }^{120}$

Der im zweiten Abschnitt noch einmal auftretende adlig-märkische Name ,Itzenplitz' schließlich verdankt seine Hervorhebung vermutlich dem auffälligen Klang, und darüber hinaus der Gewohnheit Fontanes, Standardnamen und Standardnamenkombinationen mehrfach zu verwenden. Dies gilt etwa für die Ortsnamenkombination „Sanssouci und Elysium“ mit der Fontane seine Formel aus Auf der Treppe von Sanssouci aufgreift ${ }^{121}$, für die märkischen Namen ,Katte’ und ,Quitzow’, den „alten Zieten“ oder für die Namenkataloge auf ,-ow' in den Romanen, und es gilt schließlich auch für die Gegenüberstellung von ,Cohn' und ,Itzenplitz' bzw. für den Namen ,Itzenplitz' als Vertreter des ostelbischen Junkertums insgesamt. ${ }^{122}$,Itzenplitz' wird hier zu einem Stereotypennamen gemacht.

Im zweiten Abschnitt werden die Namen derer genannt, die Fontane zu seinem „75ten“ überrascht haben. Seine jüdischen Bewunderer führt Fontane mit einer Phrase ein, die mit dem Hinweis auf die Adelsherleitung aus der biblisch-mythischen Zeit auf den ers-

\footnotetext{
${ }^{118}$ Fontane HFA I, 6, S. 239 f. und 255.

119 So kann z.B. der Name „Schlieffen“ durchaus durch Wilhelms II. Generalstabschef Alfred von Schlieffen motiviert sein, er referiert aber nicht auf diese Person, sondern auf seine Familie als Vertreter des märkischen Junkertums; vgl. Mecklenburg 2001, S. 233.

${ }^{120} \mathrm{Vgl}$. Aust 2000, S. 413, zu Fontanes Realismus.

${ }^{121}$ Vgl. Fontane HFA I, 6, S. 264: „Ich lüd' inn ein nach Sanssouci; sie nennen's / Elysium droben, doch es ist dasselbe."

${ }_{122}$ Vgl. z. B. Fontane HFA IV, 4, S. 352 (Brief an Georg Friedländer vom 14.5.1894); vgl. Mecklenburg 2001, S. 243.
} 
ten Blick nur auf die enge namentliche Verbindung der jüdischen Deutschen zur Thora (bzw. zum alten Testament) verweist. Doch verbirgt sich hinter dieser Formel mehr. Zunächst läßt Fontanes Konstatierung eines „prähistorischen Adels“ an den antifeudalistischen, den „historischen“ Adel überbietenden Topos der Abstammung der Bürgerlichen von Adam und Eva denken. ${ }^{123}$ Die Passage aus Fontanes Geburtstagsgedicht hat wie dieser Topos die Funktion, den Adelsbegriff ad absurdum zu führen. Die polemische bürgerliche Herleitung eines allgemeinen Adels führt den Adelsbegriff gerade dadurch ad absurdum, daß allen Menschen eine nur scheinbar exklusive Abstammung aus dem prähistorisch-mythischen und eben deshalb in der Gesellschaft nicht ganz ernst genommenen Bereich zugesprochen wird. Der Wert des ,etwas anderen', prähistorischen Adels ist zweifelhaft, denn der Adelsbegriff ist gerade an die Historie gebunden. Dem ironischen Ton des gesamten Gedichts entsprechend handelt es sich hier also nicht um eine einfache Überbietungsstruktur. Dies zeigt zuallererst die Präsentation des vermeintlichen Adelsprädikats:

Aber die [...] da kamen,

Das waren doch sehr sehr andere Namen

Auch [...] ohne Furcht und Tadel

Aber fast schon von prähistorischem Adel.

Diese zögerliche Einleitung kann einerseits so verstanden werden, daß die Juden ,nur fast von Adel' seien, andererseits so, daß ihr Adel ,nur fast prähistorisch' (und damit ein echter historischer Adel) sei. Eine solche ambivalente Haltung gegenüber einem ,jüdischen Adel' zeigt Fontane schon in seiner Besprechung zur Berliner AkademieAusstellung von 1862. Dort lobt er eine Genrestudie jüdischen Lebens mit einer bezeichnenden Denkfigur:

Die ganze Erscheinung [die „Prachtfigur" eines Rabbiners] ein Stück uralte Vornehmheit; ein Repräsentant jener ältesten aller Aristokratien; in dieser Figur noch echt, noch wirklich, in nichts, weder äußerlich noch innerlich, durch den Schmutz des Daseins gezogen.“ ${ }^{124}$

Das Lob enthält gleichzeitig einen weniger freundlichen Hinweis auf den ,Schmutz', in dem Fontane das übrige Judentum zu sehen scheint. Weniger sympathetisch sind denn auch in zwei Randfiguren die angeblich dauernden Qualitäten des, jüdischen Geistes': Geldhunger und Wissensdurst, dargestellt. ${ }^{125}$ Die Wertschätzung der ehrwürdigen alttestamentarischen Patriarchen - deren Namen auch Christen trugen und tragen - lie-

\footnotetext{
${ }^{123}$ Fontane selbst nennt die niederländische Formel „Als Adam grub und Eva spann, wo war da der Edelmann?" in L'Adultera, Fontane HFA 2, S. 100. Bezeichnend ist in diesem Roman die zweifelhafte Herkunft „Ezechiel van der Straatens“, der das Sprichwort zitiert. Dieser ,Mann von der Straße' weist „trotz seines Namens" eine jüdische Herkunft von sich, mit dem Hinweis darauf, daß er getauft worden sei - er, nicht seine Vorfahren.

${ }^{124}$ Fontane HFA III, 5, S. 526 f.

${ }^{125}$ Fontane HFA III, 5, S. 527: „Beide sind etwa im zwölften Jahre und repräsentieren typisch die beiden immer nebeneinander herlaufenden Richtungen des Judentums: den Hang nach Gold und den Hang nach Wissen; Schacher und Idealität."
} 
ßen sich auf diese Weise durchaus mit der Verachtung ihrer Nachkommen vereinbaren. 1898, in seinem vielzitierten Brief an Friedrich Paulsen, zeigt Fontane dann auch keine Sympathie für die ,altehrwürdigen' Juden mehr und nennt sie „ein Volk, dem von Uranfang an etwas dünkelhaftes Niedriges anhaftet“. ${ }^{126}$

Die Hervorhebung des „prähistorischen Adels“ enthält also einen Affront gegen den Adel in Fontanes Gesellschaft, ohne den jüdischen Deutschen damit unbedingt Wertschätzung entgegenzubringen. Vom Beginn der Aufzählung an betont Fontane dementsprechend die „Massen“ der jüdischen Namen, die „gar nicht zu fassen“ gewesen seien und in „Bataillonen“ ,anstürmten'. Gegenüber der wohldefinierten, exklusiven und begrenzten Welt des Adels wird eine nicht genau zu definierende und nicht exklusive Masse gezeichnet.

Die an diese Passage anschließende Aufzählung besteht aus Eigennamen, die wie die Adelsnamen-Schwärme von einleitenden Phrasen begleitet werden. Der Sprecher zählt jüdisch-deutsche Eigennamen auf. Wie im Falle der preußischen Junker gestaltet Fontane auch hier Personengruppen. Allerdings werden nicht die „Meriten“ einzelner historischer Persönlichkeiten oder der Ruhm und die Traditionen einzelner Geschlechter erwähnt, sondern ausschließlich sortale Prädikate genutzt. Auch werden zunächst gerade nicht jene Namen genannt, die auf einen ,prähistorischen jüdischen Adel' hinweisen würden. Fontane beginnt vielmehr analog zur Aufzählung der Adelsgeschlechter mit relativ unspezifischen, weitestgehend assimilierten jüdischen Eigennamen, die nur noch durch die ihnen gemeinsamen Namenbestandteile zusammengefaßt werden: die Familiennamen „auf ,-berg' und ,-heim”“. Diese beginnen eine Klimax hin zu den deutlicher jüdischen und deutlicher negativ konnotierten Eigennamen. ,Meyer' erscheint in diesem Kontext als jüdischer Familienname ${ }^{127}$, ist aber zugleich ein betont unbedeutender bürgerlicher ,Allerweltsname' - ohne eine Familien- bzw. Namengeschichte. Damit reiht er sich ein in die ,massenhaften“ Familiennamen. Die sich anschließenden ,Pollacks' bezeichnen zusätzlich die nicht-deutsche Herkunft des osteuropäischen Judentums. ${ }^{128}$ Der Name ,Pollack' wird wenig später zu den ,Leidensnamen' der jüdischen Deutschen um die Jahrhundertwende zählen. ${ }^{129}$ Danach nennt Fontane die deutlich jüdischen Voroder auch Familiennamen als kleinen Namensschwarm und distributio des „prähistori-

\footnotetext{
${ }^{126}$ Vgl. Fontane HFA IV, 4, S. 714 (Brief an Friedrich Paulsen vom 12.5.1898). Zu antisemitischen Äußerungen in der Korrespondenz des späten Fontane vgl. Horch 2000a, S. 289-298.

${ }_{127}$ Er nimmt eine mittlere Position auf der Rangliste jüdischer ,Fluchtnamen' ein; vgl. Kunze 1998, S. 168.

128 Vgl. Mecklenburg 2001, S. 242.

129 Unter den häufigsten in Judenwitzen um 1900 vorkommenden Stereotypen-Familiennamen befinden sich an erster Stelle ,Cohn' (s.u.), an dritter ,Pollack'; unter den am häufigsten geänderten jüdischen Namen nach ,Cohn' u.a. an 7., 8. und 10. Stelle „Abraham', ,Isaak' und 'Israel', ,Isaak' und ,Abraham' auch an Stelle zwei und drei der belasteten Rufnamen; vgl. Bering 1996, S. 1307 und 1306.
} 
schen“ Adels der jüdischen Bürgerlichen. Leicht spöttisch läßt Fontane die Patriarchen dort auftreten, wo eigentlich nur ihre Namen als Ruf- oder Familienname oder als Namenbestandteil getragen werden. Die scheinbar parallel zu den preußischen Helden auf die ,Patriarchen' referierenden biblischen Namen sind in Wirklichkeit Stereotypennamen, die dem Namenträger keine Individualität garantieren. Mit dieser Aufzählung der Namen der alttestamentarischen Patriarchen führt Fontane eine Tradition fort, die diese Eigennamentrias als Synonym für ,die Juden' gebraucht - nach der alttestamentarischen Generationenfolge in einer Namensphrase zusammengefaßt und oft negativ konnotiert. ${ }^{130}$ Die Verkürzung der Eigennamen läßt ein eingängiges alternierendes Versmaß entstehen, das in ästhetischer Funktion den gleichmäßigen ,Daktylen' der Schwärme im zweiten Abschnitt entspricht und an die Anfänge von Kinder- und Spottversen erinnern mag. ${ }^{131}$

Auch das summierende Ende des zweiten Abschnitts ist parallel zum ersten Abschnitt gestaltet. Hier stellen ihn die vom Adel verachteten Stände an ihre Spitze, dort beklagt Fontane, daß er die ihn nicht hofierenden Adligen „an seiner Begeisterung Spitze gestellt hatte“. Hier haben „alle“ inn gelesen und ist er allen „was gewesen“, dort summiert Fontane, „über alle“ geschrieben zu haben. Am Ende des Gedichts steht die in Anführungszeichen stehende Wendung „kommen Sie, Cohn“, die wie die Patriarchennamen einen Stereotypennamen, zudem auch einen ,Standardnamen' aus Fontanes NamenRepertoire darstellt. Im Zusammenhang mit dem Namen ,Cohn' ist auf die Bekanntschaft Fontanes mit Juden namens ,Cohn' hingewiesen worden. ${ }^{132}$ Die Briefe Fontanes zeigen jedoch, daß er auch den Namen ,Cohn' als Stereotypennamen verwendet. ${ }^{133}$ Derartige Stereotypennamen haben die Eigenschaft, daß sie tatsächlich von vielen realen Individuen getragen werden. Die Referenz wird aber gerade durch die Häufigkeit der Eigennamen, die sie zu Stereotypennamen gemacht hat, verhindert, sofern nicht weitere Hinweise zur individuellen Identifikation vorhanden sind. Menschen, die einen solchen Eigennamen tragen, leiden dann unter der Anwendung der Stereotype auf ihre

\footnotetext{
${ }^{130}$ Vgl. etwa Georg Christoph Lichtenbergs Äußerung: „In Göttingen liegen Schindanger, Judenkirchhof und Galgen nahe beisammen, Judenkirchhof, Schindanger und Galgen, sagte jemand $(\pi \mu)$, klingt fast wie Abraham, Isaak und Jakob. Sic pagina jungit amicos."; Lichtenberg 1968, J[911]. „Israel“ ist ein Beiname Jacobs und für die diskriminierende Stereotypenbildung besonders geeignet, da er auch das ,Volk Israel' bzw. die ,Israeliten' insgesamt bezeichnet; ,Jacob' taucht unter den jüdischen ,Fluchtnamen' nicht auf, wohl weil er von zu vielen nicht-jüdischen Deutschen getragen wurde und sich nicht zur Abgrenzung eignet; vgl. auch Kunze 1998, S. 168 und Brechenmacher 2001, S. 35.

${ }_{131}$ óoóoóoó; vgl.: „Abraham und Isaak / Schlugen sich mit Zwieback / Der Zwieback ging entzwei / Abraham legt ein Ei.“" (Zit. nach: Rühmkorf 1969, S. 35 (Nr. 36)).

${ }^{132}$ Am stärksten wohl von Marcel Reich-Ranitzky, der den Eigennamen direkt (wenn auch exemplarisch) auf Fritz Theodor Cohn, „Mitarbeiter des Verlags von Fontanes Sohn“ referieren läßt; vgl. Reich-Ranitzky 1999, S. 98.

${ }^{133}$ Vgl. Horch 2000b, S. 171-174.
} 
Person. ${ }^{134}$ Die Parallele unter den Adelsnamen ist für Fontanes literarischen wie nichtliterarischen Namengebrauch der Name ,Itzenplitz' (s.o.).

Die Anführungszeichen weisen zunächst auf einen Adressatenwechsel hin. Der Sprecher spricht hier nicht mehr den Leser an. Der Eigenname referiert als Stereotypenname auf eine Figur, die in der Gesellschaft ausgestaltet wurde und der man Sprüche und Aussagen zuordnen oder mit der man fiktive Situationen bzw. Gespräche gestalten konnte. Dies zeigt etwa auch ein nicht zur Veröffentlichung bestimmtes Gelegenheitsgedicht Richard Wagners An Hans Richter von 1879:

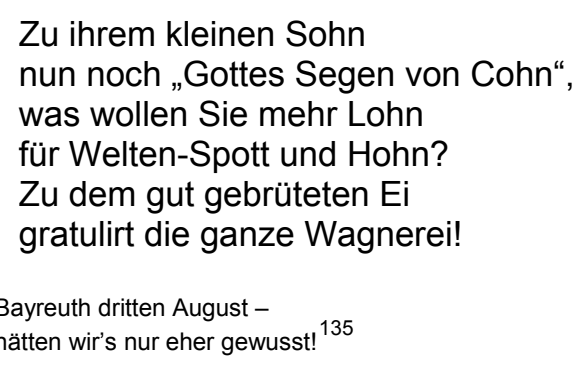

Sowohl in bezug auf die kommunikative Reichweite als auch hinsichtlich der negativen Konnotationen ist ,Cohn' bei Fontane der umfassendste Eigenname des zweiten Abschnitts und damit die Spitze der Klimax. Mit der Personifikation in einer Stereotypenfigur redet Fontane zwar ähnlich dem „Alten Fritzen“ und dem „alten Zieten“ ein berühmtes Individuum an. In diesem Falle ist aber eine Karikatur gemeint, die jeder Zeitgenosse vor Augen gehabt haben wird und die wie die Namen der Patriarchen eine Individuation des Namenträgers eher verhindern. Die Anrede jener Figur, die Fontane in seinem Brief als „X-beinigen Cohn“136 beschreibt, ist dadurch ambivalent, daß sie einerseits durch das (herablassend) freundliche Herbeirufen den üblichen Spottworten gegen die Figur entgegentritt, andererseits aber die Spottfigur selbst als Repräsentanten ,der Juden' anerkennt.

Daß Fontane diese Klimax sorgfältig konstruiert, zeigt ein früherer Entwurf des Gedichts, in dem der zweite Abschnitt des Gedichts anders aufgebaut ist ${ }^{137}$ :

25 Aber die zum Jubeltag da kamen, das waren doch sehr sehr andere Namen, Auch „sans peur et reproche“, ohne Furcht und Tadel, Aber fast schon von prähistorischem Adel: Joel, Jaffe, Lewi, Lewin

30 Seh ich zum Völker Feste ziehn. Auch Pollacks und die noch östlicher wohnen; Meyers kommen in Bataillonen,

\footnotetext{
${ }^{134}$ Cohn steht an der Spitze der jüdischen ,Fluchtnamen'; vgl. Kunze 1998, S. 168.

135 Wagner 1905, S. 135. Vermutlich meinte Wagner mit der entsprechenden Phrase den Geldsegen.

${ }^{136}$ Vgl. Fontanes Brief an Georg Friedländer vom 14.5.1894, in: Fontane HFA IV, 4, S. 352.

137 Ich rekonstruiere diesen Gedichtabschnitt nach den Angaben aus dem Kommentar in Fontane GBA Gedichte 2, S. 683
} 
Die auf „-berg“ und -,,heim“ sind gar nicht zu fassen,

Sie stürmen an in ganzen Massen,

35 Abram, Isack, Israel,

Alle Patriarchen sind zur Stell,

Jedem bin ich was gewesen,

Alle haben mich gelesen,

Alle kannten mich lange schon,

40 Und das ist die Hauptsache..., „kommen Sie, Cohn“.

Stellen mich freundlich an ihre Spitze,

Was sollen mir da noch die Itzenplitze!

Als wichtigster Unterschied dieser Variante zur publizierten Fassung ist die Namenaufzählung ungeordnet in bezug auf den ,Massencharakter' der Namen. Die Klimax von den nicht einmal vollständig genannten Namen „auf ,-berg' und ,-heim'“ über die Namenplurale der ,Meyers' und ,Pollacks' hin zu den personifizierenden Stereotypennamen „Abram, Isack, Israel“ und ,Cohn' ist hier nicht zu finden.

Die Verse 29 und 30 - in die publizierte Fassung nicht aufgenommen - sind strukturell nicht so stringent aufgebaut wie die endgültige Fassung des Gedichts. Zunächst evoziert Fontane besonders durch den Vers 30 und den Namen des alttestamentarischen Propheten Joel die apokalyptischen alttestamentarischen Szenen des Buches Joel. Dort werden die Heiden von Gott wegen ihrer Taten den Juden gegenüber gerichtet. Diese Polemik mag Fontane zu scharf gegenüber den Adligen erschienen sein, zumal in einer solchen Allegorie er selbst bzw. sein Sprecher die Position des richtenden Gottes eingenommen hätte.

Der Namenkatalog ist wie die Namenkataloge des ersten Abschnitts in ästhetischer Funktion primär durch die Lautgestalt der Namen (Assonanzen, Alliterationen bzw. Namenverwandtschaft) motiviert. Doch er beeinträchtigt durch seine semantische bzw. referentielle Uneinheitlichkeit die inhaltliche Struktur der gesamten Aufzählung. Formal geschieht dies durch den Namensingular. Weiterhin sind ,Joel' und ,Levi' durch alttestamentarische Figuren präfiguriert, ,Levin' ist eine Abwandlung von ,Levi', ,Jaffe' schließlich hat keine biblische Präfiguration. ${ }^{138}$ Es findet also keine Steigerung zum Ende der Aufzählung statt. Zum Teil handelt es sich um Stereotypennamen wie die „Meyers", die aber durch ihren Singular eine singulär definite Referenz andeuten. Allerdings spricht Fontane hier nur von den Namen und nicht von den Namenträgern. Fontanes Namengebrauch ist ambivalent wie der Gebrauch der Trias „Abram, Isack, Israel“, denn er kann sowohl auf Namenträger als Personifikationen des Judentums als auch auf die Namenszeichen selbst referieren. Die Änderungen des Fontaneschen Gedichts sind

\footnotetext{
138 ,Joel' taucht vielfach in der Bibel auf; vgl. Schmoldt 1990, S.135. Levi bzw. Levin ist der Stammvater der Leviten; vgl. Schmoldt 1990, S. 157 f. Zu ,Jaffe' vgl. z.B. Bahlow 1972, S. 261.
} 
also wohlmotiviert durch den formalen wie inhaltlichen Aufbau der Namenaufzählung im zweiten Abschnitt.

Die Ambivalenz des Namengebrauchs im zweiten Abschnitt der publizierten Fassung von An meinem 75ten wird schon durch die Einleitung gekennzeichnet, der sich entnehmen läßt, von welchem zentralen Unterschied zwischen den beiden einander gegenübergestellten Namensystemen Fontane ausgeht: Es sind im Falle der Juden die „Namen“ auf den Briefen, aber auch mit der in der Beschreibung der Schlacht von Hemmingstedt verwendeten Metonymie die „Namen“, die „Zum Jubeltag da kamen“. Hier spricht der berühmte Autor, der seine Bewunderer nicht mehr persönlich kennt und daher die Referenz des Namens nicht feststellen kann. Die jüdischen Eigennamen haben nur insoweit einen semantischen Hintergrund für Fontane, als er sich auf die sortalen Prädikate beziehen kann. Durch die gesellschaftlich streng reglementierte Namenvergabepraxis identifizieren die Familiennamen für Fontane die gesellschaftliche Gruppe, zu der die Gratulanten gehören, nicht aber die Eigennamenträger selbst. Die Namen werden zwar ebenso wie die Namen der ostelbischen Junker als Quasi-Appellative verwendet. Doch referiert der Namenplural im Falle der ostelbischen Junker auf die Angehörigen der jeweiligen identifizierbaren und samt ihrer für das Land bedeutenden Historie bekannten Familien ${ }^{139}$ und zusätzlich auf allgemein bekannte berühmte Individuen. Es ist dies eine begrenzte gesellschaftliche Gruppe. Nicht ohne Grund zeigt sich Fontane als Sprecher des Gedichts schon zu Beginn des Textes verwundert nicht nur über die Namen, sondern auch über die Orte, an denen die Briefe abgesendet wurden. Fontane stellt sich hier als Chronist einer eng definierten Gruppe dar, der seine Leser in einem eng begrenzten Gebiet suchte. Den appellativierten jüdischen Familiennamen und den ,Wohnorten' der Absender fehlt dagegen diese gesellschaftliche und räumliche Abgrenzung. Sie stehen nicht für die Angehörigen jeweils einer bestimmten Familie. Sie referieren lediglich indefinit. Dies wird an der Erwähnung der vielen und ungenannten Namen mit einheitlichen Suffixen deutlich, zumal im Vergleich mit der langen Aufzählung der Eigennamen auf ,-ow'. Fontane spricht hier tatsächlich nur noch über Personen mit der Eigenschaft, ,einen Namen zu tragen', während er vorher über ,Angehörige einer Familie' sprach. Dem entspricht die Verwendung des Namenplurals ohne Artikel: man heißt ,Meyer', man ist ein (von) Ribbeck.

Fontane spricht den jüdischen Deutschen, die sich verhältnismäßig kurze Zeit zuvor erst deutsche Eigennamen gewählt hatten, implizit ein gebrochenes Verhältnis zur Ei-

${ }^{139}$ Vgl. Horch 2000a, S. 288 f. 
gennamen- und Familientradition zu. ${ }^{140}$ Diese Juden tragen einem Vorurteil zufolge beliebige Namen, deren Namengeschichte keine Bedeutung hat. Doch ,verraten' sich nach Ansicht der Vertreter des Namenvorurteils die assimilierten jüdischen Namenträger gerade dadurch, daß sie auf die Namentradition keinen Wert legen und sich durch unauffällige Namen assimilieren wollen. Die angeblich typisch jüdischen Namen seien gerade durch dieses Fehlen einer Familientradition bzw. durch ihre Beliebigkeit erkennbar. Daß Fontane diesen Vorwurf gut kennt, zeigt ein Namengespräch in L'Adultera. Dort läßt er die Protagonistin Melanie van der Straaten (geb. de Caparoux) über den Namen ,Ebenezer Rubehn' folgendermaßen sinnieren:

'Ich bekenne dir offen, daß mir etwas christlich-germanisches lieber gewesen wäre. [...] Mit einem $\mathrm{h}$ ! Du wirst doch nicht verlangen, daß ich dies $\mathrm{h}$ für echt und ursprünglich nehmen soll? Einschiebsel, versuchte Leugnung des Tatsächlichen, absichtliche Verschleierung, hinter der ich nichtsdestoweniger alle zwölf Söhne Jakobs stehen sehe.' ${ }^{141}$

Hier wird hinter einem nicht eindeutig jüdischen Familiennamen sofort eine ,betrügerische' Absicht vermutet, die davon ausgeht, daß der Name willkürlich umgestaltet werden kann und zu den Zwecken des Namenträgers auch umgestaltet wird.

Eine solche ,Namenverleugnung' ist auch die Pointe des letzten Verspaars in Fontanes oft zitiertem antisemitischen Entwurf Entschuldigung:

Die Meyerheims - man verstehe mich recht -

Die Meyerheims sind ein Weltgeschlecht,

Sie sitzen im Süden, sie sitzen im Norden,

Ums goldne Kalb sie tanzen und morden,

Name gleichgültig, ist Rauch und Schall!

Wohl, wohl, der ,Meyerheim' sitzt überall. ${ }^{142}$

Fontane beginnt in diesem Gedicht mit einer singulär definiten ,Familienreferenz' nach dem Modell der „Quitzows und Rochows“. Das heißt, er identifiziert scheinbar das den Namen tragende Geschlecht. Diese Zusammengehörigkeit wird dann gegen die Juden gewendet, indem Fontane den Namen zum Stereotypennamen macht. Er heftet ihn als Prädikat \{Jude\} allen Juden an, die nicht als Angehörige einer Religion, sondern als Angehörige einer weltumspannenden ,Sippe' betrachtet werden. Die verschiedenen Namen, die sie de facto tragen, sollen als „Rauch und Schall“ nur den wirklichen gemeinsamen Namen und die wirklichen gemeinsamen (und verworfenen) Interessen verdecken.

Der ambivalente Gebrauch der jüdischen Namen in An meinen 75ten ist durch deren Funktion für den Gesamttext zu erklären. ${ }^{143}$ Fontane stellt hier zwei Namengebungssys-

\footnotetext{
${ }^{140}$ Vgl. Bach 1953, S. 222-225; Bering 1996, S. 1304.

${ }^{141}$ Fontane HFA 2, S. 19.

142 Fontane HFA I, 6, S. 818; vgl. auch Mecklenburg 2001, S. 239 f. Dies ist anders, als Mecklenburg 2001, S. 242, behauptet, kein „riskantes Hinüberspielen“ des Signifikanten zum Signifikat etc.
} 
teme gegenüber, die sich auf die Bedeutung der vergebenen Familiennamen auswirken. Auf der einen Seite stehen die tradierten Namen, deren Namengeschichte auch eine Familiengeschichte ist. Ihre Bedeutung wird dominiert durch die historischen Ereignisse, die mit dem Namen verbunden werden. Auf der anderen Seite stehen willkürlich vergebene Namen, die lediglich die (aktuellen) Interessen der sich selbst benennenden Namengeber spiegeln und die keine große Tradition haben. Da es einen Kanon der traditionsreichen Familiennamen gibt, sind die Namen der jüdischen Bürgerlichen ex negativo zu erkennen. Außerdem ,verraten sich' diese durch den Bezug auf die ihnen eigenen Gewohnheiten der Namengebung (etwa durch religiöse Präfigurationen). Diese Konventionen ergeben aber keine Namentradition im Sinne einer Familientradition, Sie führen lediglich zu einem Bezug auf Vorbilder. Auch in diesem Sinne ist Fontanes Rede von einem „prähistorischen Adel“ äußerst ironisch zu verstehen.

Der Grund der Gegenüberstellung ist die Selbststilisierung des Sprechers in der Rolle des reichen Mannes, wie man sie aus dem biblischen Gleichnis, Lukas 14, 16-24, kennt. Dessen zunächst geladene Gäste kommen nicht, worauf er seine Diener losschickt, um „die Armen, Verkrüppelten, Blinden und Lahmen“ von den Gassen zu holen. Diese kommen auch und nehmen an seinem Geburtstagsfest teil. ${ }^{144}$ Der Sprecher wendet sich ,in einem Kraftakt' den Parias ${ }^{145}$ und den no-names seiner Gesellschaft zu, benennt sie aber auch als solche. Es geht inm primär nicht um die jüdischen Deutschen, sondern darum, das „alte Preußen“ mit dem Vorziehen des jüdischen Bürgertums zu kritisieren. Diese Kritik ist eingebettet in die Selbststilisierung als ehemals ambitionierter Autor, der sich nun auf das Kleine und Unbedeutende beschränkt.

Es ist daher die Unzulänglichkeit, mit der der Adel die ihm eigentlich zukommende Rolle ausfüllt, die Fontane und seinen Sprecher in An meinem 75ten dazu bringt, sich auch mit der Bewunderung der jüdischen und bürgerlichen kulturellen Avantgarde abzugeben. Im scheinbaren Geständnis des Gedichts, die Hauptsache sei Fontane nun, daß er gelesen werde, egal von welcher Gesellschaftsschicht, schwingt auf diese Weise eine ,gelinde Verachtung' für die jüdischen Deutschen mit. Zum Ausdruck kommt darin die Haltung eines in ironischer Resignation bescheiden gewordenen Dichters, der die Grundlagen des bestehenden Normensystems nicht anzweifelt. Nur als Kritik am Adel

\footnotetext{
143 Das Gedicht ist meist mit Bezug auf Fontanes Antisemitismus gelesen worden; so von Bering 1987 , S. 21 f., Fleischer 1998, S. 127; Reich-Ranitzky 1999, Horch 2000b oder Mecklenburg 2001.

${ }^{144}$ Es gibt keinen intertextuellen Hinweis auf einen solchen Subtext. Insofern ist die Rolle mit Vorsicht auf das biblische Gleichnis anzuwenden, das dem bibelfesten Fontane aber sicherlich bekannt gewesen ist. ${ }^{145}$ Vgl. Horch 2000a, S. 288 f.
} 
erkennt Fontane hier die neuen Traditionen an, die einflußreiche bürgerliche und jüdische Familien begründen. ${ }^{146}$

\subsubsection{Orte und Sphären}

\subsubsection{Glanzvolle Ortsnamen}

Die Wirkung der Eigennamen in Fontanes Gedichten beruht zu einem guten Teil auf den topographischen sortalen Prädikaten der adligen Namen und dem Fehlen solcher sortalen Prädikate bei den bürgerlichen ,Allerweltsnamen'. Daher überrascht es nicht, daß Fontane auch Ortsnamen ausgiebig einsetzt, um seine Welt und seine Weltsicht zu gestalten. Ortsnamen haben eine überaus wichtige Bedeutung nicht nur als Benennung von lieux de mémoire, sondern auch als Indikatoren der lieux sociales derer, die an den Orten wohnen. ${ }^{147}$ Sie dienen in indirekt evozierender Funktion dazu, einen gesellschaftlichen Raum zu gestalten und sich darin zu orientieren. Ebenso wie die Familiennamen in einer geordneten Gesellschaft sehr viel über den Stand des Namenträgers aussagen, geben auch Ortsnamen viel preis über die Personen, die sich an diesem Ort aufhalten. So erkennt man am Vorschlag eines Arztes an den Sprecher von Flickwerk das langsame Herunterstufen der vorgeschlagenen Kurorte nach ihrem Sozialprestige:

\footnotetext{
Versuch doch irgendwas nur,

Davos oder Nizza, Sylt oder Föhr,

Oder bloß auch Mampes Magenlikör. ${ }^{148}$
}

Das sinkende Prestige der Namen weist voraus auf den Schluß des Gedichts: „,Wirklich, es lohnt sich nicht mehr."'149

Fontanes Ortsnamenkataloge lassen dabei Räume und Landschaften entstehen, deren Beschreibung einen breiten Raum einnehmen würde. Darüber hinaus besitzen Ortsnamen wie auch berühmte lokalisierbare Familiennamen eine intensive Aura, die es ermöglicht, auf das Lesepublikum einzuwirken. Diese Aura erhalten die Ortsnamen durch ihre Lautstruktur und durch den semantischen Hintergrund, den berühmte Namen durch die an sie gebundenen Geschichten erhalten. Wie Fontane mit diesen Möglichkeiten von Ortsnamen umgeht, zeigt sich etwa in Havelland. Hierbei handelt es sich wiederum

\footnotetext{
146 „Zunächst freue ich mich immer, wenn ich Namen lese wie Lisco, Lucä, Gropius, Persius, Hensel, Thaer, Körte, Diterici, Virchow, Siemens, weil ich mir dabei bewußt werde, daß in diesen, nun in zweiter und dritter Generation blühenden Familien, ein neuer Adel, wenn auch ohne ,von' heranwächst, von dem die Welt wirklich was hat, neuzeitliche Vorbilder (denn dies ist die eigentliche Adelsaufgabe), die moralisch und intellektuell, die Welt fördern und ihre Lebensaufgabe nicht in egoistischer Einpökelung abgestorbener Dinge suchen“; Fontane HFA, IV, 4, S. 459 (Brief an Georg Friedländer vom 8. 7.1895); zu Fontanes ,selbstverständlichem Antisemitismus' vgl. Balzer 2000.

${ }^{147}$ Vgl. Scherpe 2000, S. 167 f.; zu Fontanes Verwendung nationaler lieux de mémoire Preußens vgl. Hebekus 2003, S. $174 \mathrm{f}$.

${ }^{148}$ Fontane HFA I, 6, S. 345.

${ }^{149}$ Fontane HFA I, 6, S. 345
} 
um ein Einleitungsgedicht - zu den Wanderungen durch die Mark Brandenburg - in dem durch Namenkataloge ein Namenraum geöffnet wird, von dem die inm nachfolgenden Texte handeln:

Es spiegeln sich in deinem Strome

Wahrzeichen, Burgen, Schlösser, Dome:

Der Julius-Turm, den Märchen und Sagen

Bis Römerzeiten rückwärts tragen,

Das Schildhorn, wo, bezwungen im Streite,

Fürst Jazko dem Christengott sich weihte,

Der Harlunger-Berg, des oberste Stelle

Weitschauend trug unsre erste Kapelle,

Das Plauer Schloß, wo fröstelnd am Morgen

Hans Quitzow steckte im Röhricht verborgen,

Die Pfaueninsel, in deren Dunkel

Rubinglas glühte Johannes Kunkel,

Schloß Babelsberg und »Schlößchen Tegel»,

Nymphäen, Schwäne, blinkende Segel

Ob rote Ziegel, ob steinernes Grau,

Du verklärst es, Havel, in deinem Blau.

[...]

Und an dieses Teppichs blühendem Saum

Die lachenden Dörfer, ich zähle sie kaum:

Linow, Lindow,

Rhinow, Glindow,

Beetz und Gatow,

Dreetz und Flatow,

Bamme, Damme, Kriele, Krielow,

Petzow, Retzow, Ferch am Schwielow,

Zachow, Wachow und Groß-Bähnitz,

Marquardt an der stillen Schlänitz,

Sentzke, Lentzke und Marzahne,

Lietzow, Tietzow und Rekahne,

Und zum Schluß in dem leuchtenden Kranz:

Ketzin, Ketzür und Vehlefanz. ${ }^{150}$

In diesem Gedichtausschnitt wird durch die Namen in der Tradition der enumeratio als percursio die Zusammenfassung einer imaginären Reise auf der Landkarte präsentiert. Deutlich ist in dem Gedicht eine Aufzählung mit Kommentar von einem Namenkatalog zu unterscheiden. Während die ,touristischen' und historischen Attraktionen mit einem semantischen Hintergrund versehen werden, der ihre Wichtigkeit erklärt, werden die kleinen Orte an der Havel nur im Schwarm aufgereiht. Die lokal berühmten Erinnerungsorte der Aufzählung stehen für Ereignisse und sind nach diesen chronologisch geordnet. Die kommentierte Aufzählung stellt eine kurze Reise durch die märkische Geschichte von der Römerzeit bis zur Gegenwart Fontanes dar. Bei dem Namenkatalog der kleinen Orte kommt es dagegen auf die Lautsymbolik der Namen an. Diese sind daher nach lautlichen Aspekten alliterierend, assonierend, reimend und binnenreimend, nach dem ,Gesetz der zunehmenden Länge' und durch den Gleichklang jeweils zweier Namen in der verbreiteten Kombination dreier Namen zu ,2+1' (,Senzke, Lenzke und

${ }^{150}$ Fontane HFA I, 6, S. 253-255. 
Marzahne / Lietzow, Tietzow und Rekahne") geordnet. Durch die übertriebene Häufung der Klänge und Reime erhält die Aufzählung einen humoristischen Beiklang. Die einzeln nicht auffälligen, aber durch topographische sortale Prädikate gekennzeichneten $\mathrm{Na}$ men werden erst im Schwarm und durch die Zusammenstellung nach rhythmischen und lautlichen Aspekten bedeutsam. Nicht die einzelnen Dörfer, sondern die Gesamtheit der Landschaft steht im Mittelpunkt. Fontane nutzt den suggestiven Analogieschluß vom angenehmen Klang des Namens auf die Qualitäten des Namenträgers. Es wird eine Fülle suggeriert, die die Schönheit der besungenen Gesamtlandschaft und nicht etwa einzelner Orte in der Landschaft bedeuten soll. Die Attraktionen stehen als Einzelereignisse, die ihrerseits eine Geschichte ergeben. Der ,Dörferschwarm' meint dagegen eine ganze Kulturlandschaft.

Wirkt Havelland wie ein ,Baedecker-Gedicht', das an einen nicht Ortskundigen gerichtet ist ${ }^{151}$, bedient sich Fontane in Welches von Beiden der Aura von Orten, die dem Leser bekannt sind, um den Topos, Warum in die Ferne schweifen, wenn das Gute liegt so nah' zu gestalten. Dabei nutzt er den Unterschied zwischen Namen, die die meisten Leser nur als Namenkonsumenten gekannt haben werden, und Namen, die innen als Namenproduzenten bekannt waren:

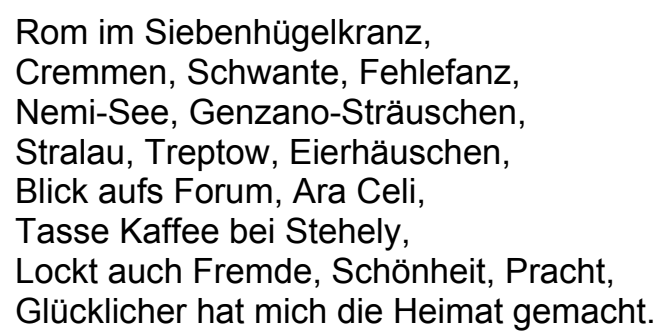

Fontane reiht beliebte Ausflugsziele in Rom und in Berlin stichisch, wobei zunächst eine komische Differenz durch das unkommentierte und durch den Reim enge Nebeneinander der mit Glanz versehenen römischen Orte und der fast schon alltäglichen ,Naherholungsziele' um Berlin entsteht. Die Differenz geht zunächst scheinbar zu Lasten Berlins - die implizite Erwartung an den Leser ist, daß dieser die wenig sensationellen Berliner Namen zuerst als Mesalliance mit den klangvollen italienischen Namen betrachtet. ${ }^{152}$ Dies verstärkt die Wirkung der Pointe, die Heimatverbundenheit am Ende hervorzuheben. Gleichzeitig werden aber die Wende am Ende des Gedichts und die zu erwartende Zustimmung des Publikums durch die Atmosphäre der genannten Berliner Orte vorbereitet. Diese waren für Fontanes Berliner Publikum durch zahlreiche Ausflüge - wie sie Fontane in seinen Romanen schildert - wohl positiv konnotiert.

\footnotetext{
${ }^{151}$ Vgl. Hettche 2000, S. 150 zu den Wanderungen.

152 Zur sozialen Bedeutung von Ortsnamen allgemein vgl. auch Nicolaisen 1979, S. 100.
} 
Die einzelnen Namenkataloge sind auch hier geordnet. Fontane nennt zunächst brandenburgische Sommerfrischen als symbolische Orte für die märkische Gesellschaft und vermutlich auch für eine kleine Reise. ${ }^{153}$ Dann wechselt er zu den populären und näher gelegenen Tagesausflugszielen auch der bürgerlichen Berliner, die in seinen Romanen - in dieser Kombination - auftreten. ${ }^{154}$ Mit jedem Vers des Gedichts können sich mehr Leser stärker mit den Ausflugsorten identifizieren. Es sind ,ihre’ Orte. ,Rom’ dagegen steht für ein eher selten oder gar nicht erreichtes Ziel mit dementsprechend geringem Identifikationspotential - eben für die aufregende Fremde. ${ }^{155}$ Diese Perspektive des Erzählers und des impliziten Lesers wird schon an der Einleitung der Namenkataloge deutlich. Während der Name ,Rom' der Identifikation der folgenden Ortsnamen dient, kann der Sprecher die Orte in und um Berlin ohne einleitende Identifikation nennen. Der implizite Leser kennt die einzelnen Namen selbst.

Zusätzlich nennt die Aufzählung mehr Berliner (sieben) als italienische (vier) Orte beim Namen. Rom wird eher abstrakt, Berlin durch die vielen Namen eher konkret evoziert. Die Vertrautheit und Regelmäßigkeit der Ausflüge erzeugt das ,Heimatgefühl' des Feiertagslebens in geordneten Bahnen jenseits des aufregenden, aber eben auch unsicheren Ausnahmezustandes einer Reise. Gleichzeitig wird durch die Parallelstellung der römischen und der berlinerischen Orte die Exotik der ersteren herabgestimmt. Sie erscheinen als gar nicht so viel aufregender als die alltäglich bekannten Namen.

Die Beschreibung der Reisevorlieben geschieht in einer Entsagungshaltung, die die kollektiven Wünsche nach dem Außergewöhnlichen durch die bescheidene Anerkennung des mehr oder weniger Alltäglichen und leicht und für alle Erreichbaren ersetzt. ${ }^{156}$ Das Individuelle der nur wenigen zugänglichen Reise steht dabei gegen das Gemeinschaftserlebnis der regelmäßigen und von der großen Masse genossenen 'Naherholung'. ${ }^{157}$

Auch Fontanes Afrikareisender benutzt humoristisch heimische und exotische Namen, um fernen Orten die ,Aura' des Gefährlichen und Abenteuerlichen zu nehmen:

„... Meine Herren, was soll dieser ganze Zwist,
Ich habe drei Jahre, von Krankheit verschont,
Am Grünen und Schwarzen Graben gewohnt,
Ich habe das Prachtstück unsrer Gossen,
Die Panke, dicht an der Mündung genossen
Und wohne nun schon im fünften Quartal
Noch immer lebendig am Kanal.

\footnotetext{
${ }^{153}$ Fontane HFA I, 6, S. 251 f. und S. 253-255.

${ }^{154}$ Fontane HFA 2, S. 52; Fontane HFA 2, S. 516; Fontane HFA I, 4, S. 441; das Café Stehely taucht auch in Berlin auf, Fontane HFA I, 6, S. 298.

${ }^{155}$ So ist Rom z.B. in L'Adultera Fluchtort für Rubehn und Melanie; vgl. Fontane HFA I, 2, S. 105.

${ }^{156}$ Vgl. auch Parr 2002, S. 216-221.

157 Über die Antithese als Prinzip der späten Lyrik Fontanes vgl. Richter 1980, S. 131.
} 
Hier oder da, nah oder fern,

Macht keinen Unterschied, meine Herrn,

Und ob Sie's lassen oder tun,

Ich gehe morgen nach Kamerun.“ ${ }^{158}$

Fontanes Gedicht zeigt deutlich den isolierten Gesprächsbeitrag, den Gedichte unserer Definition zufolge generell darstellen. Dies heben die Anführungszeichen und der die Sprecherrolle identifizierende Titel hervor. Wieder werden vertraute heimische Orte der Mikro- und Makrotoponymie Berlins ${ }^{159}$ zwei exotischen Namen gegenübergestellt. Dabei verwendet Fontane zunächst den berühmten Namen ,Kongo', der als pars pro toto für Afrika stehen kann. Der zweite exotische Name wird inhaltlich betont willkürlich in den Reim gestellt, so daß die formale Motivation die Beliebigkeit der Ankündigung des Sprechers unterstreicht: er reist ,wohin auch immer'. Die Gegenüberstellung der Namen geschieht diesmal, um über die hygienischen Zustände Berlins zu spotten. Die symbolisch und abstrakt für exotische Gefahr und (pragmatischer) für gesundheitliche Gefahren stehenden afrikanischen Namen werden auf eine Ebene mit den vertrauten und vom Leser leicht mit einem semantischen Inhalt zu versehenden heimischen Namen gestellt - zum Schaden der heimischen Namen. ${ }^{160}$ Vielleicht spottet der Autor Fontane aber auch über das lustvolle Gruseln, das Berliner „Herrn“ dazu anregen mag, über die gesundheitlichen Gefahren des Kongo zu diskutieren.

Mit dem Nennen der Orte inszeniert Fontane die Gemeinsamkeit des Autors mit seinen Lesern und versucht, eine sympathetische und zustimmende Lektüre zu erreichen. Der Gegensatz zwischen dem Massenerlebnis und dem Einzelerlebnis mit Tradition wird wieder hervorgehoben. Dem ungewissen Fernen steht das gar nicht positive Nahe gegenüber, das aber alle Leser kennen und an dessen poetischer Gestaltung sie durch ihre knowledge by acquaintance, an die Fontane appelliert, teilnehmen können.

Mit deutlich gesellschaftskritischem Ton setzt Fontane exotische Ortsnamen in der Brunnenpromenade ein. Der Sprecher wandelt auf der Promenade eines Kurortes und bewundert die implizite und explizite Selbstdarstellung, die auch durch den Einsatz exotischer Ortsnamen betrieben wird:

[...]

Eine lange Reihe der schönsten Damen,

Wer zählt die Völker, wer nennt die Namen!

Eine ganz Teint und Taille war,

$[\ldots]$

Typus einer Engländerin,

\footnotetext{
${ }^{158}$ Fontane HFA I, 6, S. 389; GBA Gedichte 1, S. 44; vgl. auch Richter 2000, S. 719.

${ }^{159}$ Vgl. den Kommentar in der GBA Gedichte 1, S. 463.

${ }^{160}$ Wie Parr 2002, S. 221, hier das „positive Nahe“ vermuten kann, ist unverständlich.
} 
Aber solcher, die Palankin-überdacht

Weit draußen ihre Tage verbracht,

In Hongkong oder Singapor

(Ihr Diener Malaie halb, halb Mohr),

Und neben ihr plaudert ein junger Lord

Von Lachsfang im Stavanger-Fjord,

Alles albionmäßig abgestempelt,

Die Beinkleider unten umgekrempelt.

[...]

Die Damen schließen einen Kreis,

Und in den Kreis, auf den Schlag des Gong,

Tritt jetzt die Schönheit der Saison.

[...]

Rot alles, worauf die Blicke fall'n,

Eine Römerin (flüstert man) soll es sein,

Andre sagen: aus Frankfurt am Main.

[...]

Ist es nahzu vorbei mit meinem Bangen;

Mummenschanz alles und Fastnachtsorden,

Selbst der rote Hut ist mir komisch geworden,

Ob aus Rom oder Frankfurt - ich seh' in Ruh'

Jetzt lieber dem Paukenschläger zu,

[...]

Ich bin wieder zu mir selbst gekommen,

Und während mir Scheuheit und Demut entschlummern,

Zähl' ich mich zu den „besseren Nummern“. ${ }^{161}$

Dabei fängt der Sprecher eingeleitet von dem namenkatalogbezogenen Unsagbarkeitstopos aus Schillers Die Kraniche des Ibykus die Aura ein, die sich die Menschen auf der Brunnenpromenade zu geben suchen. Er benutzt exotische Eigennamen („Honkong oder Singapor"), um die Exotik der Person für den Leser hervorzurufen. Der Grund für den Namengebrauch ist die Selbstdarstellung der betreffenden Dame, die durch ihren modisch-exotischen Diener vervollständigt wird. Anschließend berichtet der Sprecher von dem Namengebrauch der Figuren selbst. Die Promenierenden prunken mit dem Klang der Namen der fernen oder näheren interessanten Orte („Stavanger-Fjord“), die sie einmal besucht haben. Sie stellen so ihre Weltläufigkeit und ihren Wohlstand zur Schau. Im Falle der „Schönheit der Saison“ schließlich teilt sich die allgemeine Meinung der Bewunderer, die die Schönheit der Dame durch einen angemessenen Hintergrund aufwerten wollen. Jene, die ihre Schönheit betonen, nennen sie eine „Römerin“ und spielen damit auf die sprichwörtliche Schönheit der Römerinnen an. Jene, die den Wohlstand hervorheben, vermuten als Herkunftsort „Frankfurt am Main“, der schon bei Fontane für geschäftliche Angelegenheiten steht. ${ }^{162}$

Doch auch auf der Brunnenpromenade läßt sich der Sprecher nur zu Beginn und nur scheinbar von den exotischen Namen und dem exotischen Flair der Promenierenden täuschen. Schon bald, so sein ironischer Kommentar, ist inm alles „Mummenschanz"

\footnotetext{
${ }^{161}$ Fontane HFA I, 6, S. 377 f.; vgl. auch den Kommentar in Fontane 1998, S. 187.

${ }^{162} \mathrm{Vgl}$. etwa Fontanes L'Adultera, 21. und 22. Kapitel.
} 
und „Fastnachtsorden“. Die Namen, mit denen sich die Menschen schmücken, sind wie die Äußerlichkeit der Kleidung ${ }^{163}$ aufgesetzt. Sie dienen nur der eitlen Selbstdarstellung.

\subsubsection{Orte und Personen}

In der Bismarck-Ballade Zeus in Mission setzt Fontane Ortsnamenkataloge zur Vorbereitung der Balladenhandlung und zur Einleitung der Balladenstimmung ein. Die Handlung beginnt in einem gemischten Himmel, in dem der christliche Gott die antiken Götter verdrängt hat. Jehova gibt Zeus, den er nach Berlin schicken will, militärisch knappe Anweisungen:

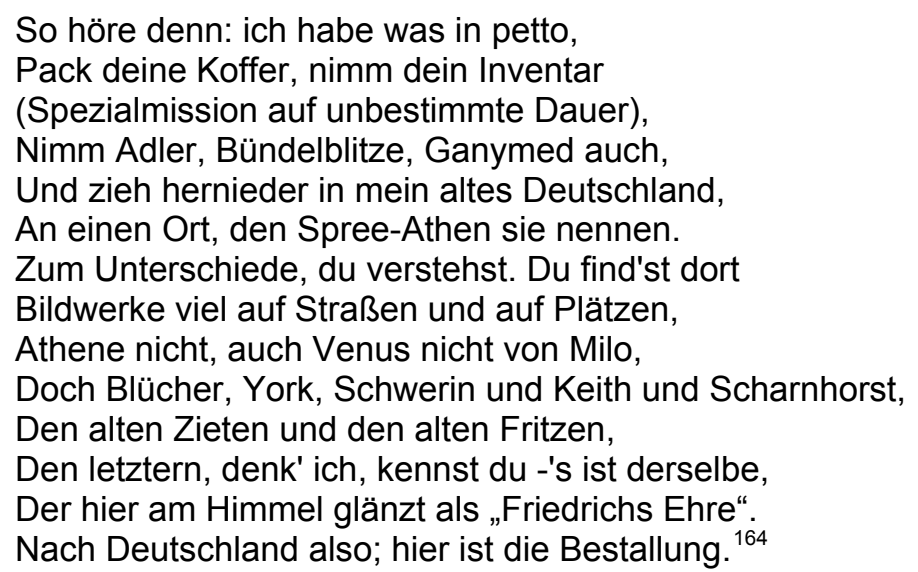

Berlin wird mit der philhellenistischen Metapher mit dem antiken Athen verglichen. Die scheinbare Benennung der Denkmäler in Athen und Berlin ist vor allem eine scherzhafte indirekte Gleichstellung antiker Götter mit den preußischen Heerführern. Da nur Monumente (Orte) verglichen werden, umgeht Fontane eine Überhöhung (immerhin spricht Jehova!) und kann dennoch die Namenträger bzw. das preußische Militär ehren. Lediglich beim „alten Fritzen“ gestattet sich Fontane eine tatsächliche annähernde Gleichstellung mit den antiken Göttern als Höhepunkt des Namenkatalogs. Durch diese Einleitung bereitet Fontane auch die Exemplifikation Bismarcks durch die Figur Zeus vor.

Wie in den Namenkatalogen von Nordische Königsnamen, Havelland und Die Duncans kommen, die Donalds kommen... werden durch die Eigennamen Sphären indirekt evoziert. Durch die Namen berühmter Kunstwerke und Denkmäler stellt Fontane ein feminines Athen einem kriegerischen Berlin gegenüber, das der darauf folgenden Beschreibung einen angemessenen Hintergrund gibt.

In Zeus in Mission referieren die Orts- bzw. Denkmalsnamen indirekt über eine Referenzkette (Goodman) auf die preußischen Heerführer und die griechischen Götter. An anderer Stelle evozieren umgekehrt Personennamen, die für Orte stehen, indirekt ein

\footnotetext{
${ }^{163}$ Vgl. Fontane 1998, S. $187 \mathrm{f}$.

${ }^{164}$ Fontane HFA I, 6, S. 574-577.
} 
lokal begrenztes Leben dar: Dabei hält Fontane zunächst den berühmten Personenund Ortsnamen eine anonyme Menge oder ,einfache' Ortsnamen entgegen. Entsprechend kontrastieren in Was ich wollte, was ich wurde ${ }^{165}$ der „Chan“, „Marco Polo“, „Dante“, „Cervantes“, „Schiller“ und seine „Kunigonden“ mit „Treptow und Stralau“ und „Kalau“. In Meine Reiselust ${ }^{166}$ stehen zunächst dem „Tsad-See“, dem „Kongo“ und „Kapstadt“, dann aber auch „Bürgers Lenore“ und „Freiligraths ,Löwenritt'“, die „Link- und Eichornstraße“, das Königin-Luise-Denkmal, das Goethedenkmal und die Bismarckpforte am Wrangelbrunnen gegenüber. ${ }^{167}$ Am deutlichsten orientiert sich der Sprecher an seinem lokalen Umfeld in Spätes Ehestandsglück. ${ }^{168}$ Er bevorzugt „Pankow, Schönhausen, Tegel“ und „Sacrow und Pichelswerder“ gegenüber „Schelling und Hegel“, „Wieland und Herder“. Gegen Goethe hält er die Lustspieldichter „Putlitz, Moser, Lubliner“, die den regelmäßigen aber unambitionierten Theaterbesuch exemplifizieren.

Besonders auffällig ist diese Kontrastierung in Was mir gefällt. Hier stehen Personennamen - der „alte Moltke“, der „alte Kaiser“ (Wilhelm I.) - und der „Schapersche Goethekopf" für die Orte, an denen man diesen Personen (ihren Abbildern) begegnen konnte - also für Regierungsgebäude und Denkmäler, an denen das Sprechersubjekt vorbeispaziert. ${ }^{169}$ Es handelt sich um Aufzählungen von Ortsnamen bzw. Ortsbezeichnungen im weiteren Sinne. Das Gedicht imaginiert Spaziergänge. Der Spaziergang und die damit verbundene Hervorhebung von Ortsnamen ist Symbol für die bereits genannte Haltung des Sprechers in Fontanes Gedichten. Der späte Fontane grenzt hier die Eckdaten zweier Lebensweisen voneinander ab. Der seiner kulturellen und politischen Welt zugewandte ehrgeizige Jüngling wird vom Spaziergänger abgelöst, der durch sein gewohntes Quartier flaniert und dabei dessen Lokalitäten im Vorbeigehen wohlgefällig oder kritisch, aber unambitioniert betrachtet. Der Haltung des Flaneurs ${ }^{170}$ ist diejenige des ,Spaziergängers' verwandt. Sie löst nicht nur die gefahrvolle und aufregende wirkliche Reise in die ,weite Welt' ab (in Meine Reiselust oder Welches von Beiden), sondern auch die ernsthafte und ambitionierte imaginative Reise durch die Welt des Geistes. Der Sprecher gibt sich mit der leichten Muse, dem Theaterbesuch und der Betrachtung der vertrauten - teilweise lebenden - Denkmäler zufrieden. So wie die berühmten Balladen Bürgers, Freiliggraths und Chamissos in Meine Reiselust für literarisch präfigu-

\footnotetext{
${ }^{165}$ Fontane HFA I, 6, S. $338 \mathrm{f}$.

166 Fontane HFA I, 6, S. $342 \mathrm{f}$.

167 Vgl. Wülfing/Bruns/Parr 1991, S. 212

168 Fontane HFA I, 6, S. $358 \mathrm{f}$.

${ }^{169}$ Vgl. z.B. L'Adultera, Fontane HFA 2, S. 37; zu dieser Haltung Fontanes vgl. Wülfing/Bruns/Parr 1991, S. 212 f.; Hettche 2000, S. 156; Hettche 2002, S. 89 f.

${ }^{170} \mathrm{Vgl}$. Hettche 2000 und Hettche 2002, bes. S. $90 \mathrm{f}$.
} 
rierte Reisewünsche stehen, meinen die bekannten Personennamen, mit denen das zurückgezogene Leben beschrieben wird, immer wieder in Wirklichkeit Orte.

\subsubsection{Plauderei mit vielen Namen}

\subsubsection{Mit Namen plaudern}

Eines der beliebten Themen der neueren Fontaneforschung sind Funktionen und Kategorien der Gespräche in seinem Prosawerk. Als fontanescher Gesprächstyp par exellence wird dabei die ,Causerie', die gefällige Konversation oder Plauderei, auch der Klatsch gesehen. In diesem Kommunikationstyp ${ }^{171}$ können Eigennamen eine besondere Rolle spielen, wie zwei Beispiele zeigen sollen:

In unserem ersten Beispiel läßt Fontane seine Figur Woldemar ein Telegramm - im Stechlin Inbegriff der modernen Kommunikation ${ }^{172}$ - aus London schicken:

London, Charing-Cross Hotel. Alles über Erwarten groß. Sieben unvergeßliche Tage. Richmond schön. Windsor schöner. Und die Nelson Säule vor mir. Ihr v. St.

Die Botschaft wird vom Grafen Barby gegen die Kritik verteidigt, sie sei zu unpersönlich:

Was verlangt Ihr? Es ist umgekehrt ein sehr gutes Telegramm, weil ein richtiges Telegramm; Richmond, Windsor, Nelsonsäule. Soll er etwa telegraphieren, daß er sich sehnt, uns wiederzusehen? ${ }^{173}$

Fontane läßt seine Figur Barby den ohnehin kurzen Text auf einen Ortsnamenkatalog reduzieren. Die berühmten Ortsnamen evozieren ein objektives und für den Gebildeten Leser nachvollziehbares Bild der Reise mit allen nötigen Hintergrundinformationen, die die Leser aus ihrem Weltwissen zu den Namen selbst ergänzen können. Mit den allen bekannten Namen ist eine Verständigung auf engstem Raum möglich. Die Erwähnung bekannter Eigennamen ohne nähere Erläuterungen des semantischen Hintergrunds beigefügt werden von Woldemar lediglich kürze, wenig aussagende Bewertungen - ermöglicht zudem einen schnellen Themenwechsel, wie ihn die leichte Plauderei erfordert.

Darüber hinaus zeigt die Namenverwendung hier auch eine normative Funktion in der Selbstdarstellung des Namenbenutzers. Woldemar schreibt durch die passende Verwendung der korrekten Namen auch das passende Telegramm. Denn die korrekte Namenerwähnung zeigt, daß er London auf die von allen approbierte Art und Weise besichtigt. Persönliche Mitteilungen und Stimmungen - die von den Kritikern des Telegramms gefordert zu werden scheinen - werden durch die namentlich vorgezeichnete Standardroute des Touristen ersetzt.

\footnotetext{
${ }^{171}$ Ich ziehe diesen Begriff hier dem ,Gespräch' vor, da die Plauderei auch in Briefen oder - wie im nachfolgenden zu sehen - in Telegrammen erfolgen kann.

${ }_{172}$ Vgl. Hebekus 2003, S. 267-269.

${ }^{173}$ Fontane HFA I, 5, S. 234.
} 
Diese beiden evozierenden Funktionen - die direkt evozierende, auf den Namenträger bezogene Funktion und die als normative Selbstdarstellung indirekt evozierende Funktion - prägen auch den Namengebrauch in Fontanes face-to-face-Gesprächen. So etwa an zwei Stellen des Stechlin an denen Namen thematisiert werden:

„Wie glücklich bin ich“, sagte Woldemar, „Sie allein zu finden! Das klingt freilich sehr selbstisch, aber ich bin doch vielleicht entschuldigt. Wenn Besuch da wäre, nehmen wir beispielsweise Wrschowitz, und ich ließe mich hinreißen, von der Prinzessin von Wales und in natürlicher Konsequenz von ihren zwei Schwestern Dagmar und Thyra zu sprechen, so hätt ich vielleicht wegen Dänenfreundlichkeit heut abend noch ein Duell auszufechten. Was mir doch unbequem wäre. Besser ist besser. “174

Woldemar macht hier eine etwas boshafte und scherzhafte einleitende Bemerkung als captatio benevolentiae, die auch von seinem Gastgeber amüsiert honoriert wird. Die Bemerkung bildet einen typischen einleitenden Gesprächsbeitrag der gefälligen Konversation. Sie erreicht ihr Ziel, weil Woldemar in der Namenkenntnis und der Namenbewertung sich mit seinen Gesprächspartnern einig weiß. Er kann über einen abwesenden (offenbar übermäßig dänenfeindlichen) Dritten spotten, der in der Bewertung der entsprechenden Namen bzw. der Namenträger nicht mit den Gesprächsteilnehmern übereinstimmt. Dies geschieht durch einfache Erwähnung der Namen. Sie ergeben für den gebildeten Gesprächsteilnehmer sofort einen vollständigen Hintergrund, der die reibungslose Kommunikation über entsprechende Ereignisse und Selbstdarstellungen ermöglicht. Eine wichtige Rolle spielen dabei nicht die Eigennamen der Kommunikationsbeteiligten, sondern bekannte Orts- und Personenamen. Der Sprecher kann sich ohne weitere Erklärungen durch diese Eigennamen auf gemeinsames Wissen beziehen. Er tut dies in dem Bewußtsein, daß der Hörer inn versteht, weil dieser den semantischen Hintergrund und den Kommunikationswert der Eigennamen kennt. In solchen Plaudereien fehlen daher ausführliche Namenerklärungssequenzen, die bei der Verwendung unbekannter Namen nötig wären. Die passende Themen- und Namenwahl zeigt hier die normative Übereinstimmung der Gesprächspartner.

Fontanes späte Lyrik, die ihren Charakter als jeweils ,isolierter Gesprächsbeitrag' deutlich hervorheben, zeigen, daß die Wende von der erzählenden Ballade zum Knittelversgedicht parallel zum Wandel der in den Romanen stattfindenden Gesprächen vom zweckgebundenen informierenden Gespräch zum geselligen Gespräch als Selbstzweck verläuft. ${ }^{175}$

Unkommentierte Eigennamen sind dabei auch in den Gedichten ein wichtiges - platzund zeitsparendes informationsreiches - Element, das gesellige Konversation mit

\footnotetext{
${ }^{174}$ Fontane HFA I, 5, S. 214 f.

${ }^{175}$ Vgl. Hasubek 1998, S. 219-224.
} 
schnellen Themenwechseln auf einer breiten gemeinsamen Wissensbasis signalisiert. Sie sind allerdings nur jenem Empfänger verständlich, der einen ähnlichen Wissenshintergrund hat wie der Sender. Die unkommentierten Eigennamen sind bei Fontane ein Appell an eine besondere Verstehensleistung des Empfängers. ${ }^{176}$ Fontanes eigennamenreiche Texte beruhen auf einer zeitlich wie räumlich begrenzten Kommunikationsgemeinschaft, wie sie sich in der situationsabhängigen Alltagskommunikation konstituiert. Insofern tragen Namen dazu bei, daß der Fontane der späten Gedichte „ein ,unschriftlicher', d.h. ,mündlicher' Autor“ ist, der „mit einer gemeinsamen Wahrnehmungssituation rechnet, die ihn mit seinem Publikum kommunikativ ,von Angesicht zu Angesicht' verbindet.“177 Der Einwurf berühmter Namen ermöglicht es Fontane darüber hinaus, zeitgenössisches politisches Weltgeschehen in die dichterischen Texte - und das gilt auch für das Prosawerk - zu integrieren, ohne die Ereignisse selbst gestalten zu müssen. ${ }^{178}$ So kann Fontane eine fiktive Sprechweise des Gedichtsprechers bzw. eine fiktive Handlung eng mit der aktuellen Wirklichkeit verbinden. ${ }^{179}$

\subsubsection{2 „Brockhaus“ statt „Doktorthema“: normatives Eigennamenwissen}

Fontane setzt Eigennamen als Gesprächselement ein, das durch seine Aura und die mit ihm verbundenen weiten Kontexte den jeweiligen Sprecher positionieren soll. Der Sprecher in Auf der Treppe von Sanssouci führt mit ironischer Bescheidenheit den Wissenstyp an, auf dem dieser Eigennamengebrauch basiert:

Die Frag' ist schwer, das ist ein Doktorthema;

Mein Wissen reicht bis Pierer nur und Brockhaus. ${ }^{180}$

Gegenübergestellt werden hier das gesellschaftlich hochgeschätzte systematisch im institutionellen Rahmen erworbene Wissen und das unsystematische Wissen des (sich ironisch bildungsbeflissen gebenden) Autodidakten. ${ }^{181} \mathrm{Im}$ gleichen Geiste äußert Fontane 1894 gegenüber Ernst Wichmann:

Es mag das nach den Naturen verschieden sein, aber ich für mein Theil habe von sogenannten ,gründlicheren Studien' gar nichts gehabt und schiebe mein leidliches Zuhausesein in Welt, Leben und Geschichte darauf, daß ich mich immer nur vom unterhaltlichen Stoff, von Anekdoten, Memoiren und Briefen genährt habe. ${ }^{182}$

Der Bemerkung Fontanes gegenüber Wichmann merkt man die Kritik am systematischen Wissenserwerb an. Sie stimmt überein mit den früheren Einstellungen Fontanes,

\footnotetext{
${ }^{176}$ Vgl. Kalverkämper 1994, S. 225.

177 Vgl. Aust 2000, S. 420.

${ }^{178}$ Vgl. etwa auch Storch 2000a, S. $119 \mathrm{f}$.

179 Vgl. Richter 1966, S. 149: „Es [das „Iyrische Sprechen“ Fontanes] gewann bei aller scheinbaren Privatisierung an Zeitnähe; [...]".

${ }^{180}$ Fontane HFA I, 6, S. 262-264.

181 Fontane schmeichelt gleichzeitig Menzel, indem er die Artikel über inn in den Konversationslexika erwähnt.

${ }^{182}$ Fontane HFA IV, 4, S. 372 (Brief an Ernst Wichmann vom 7.7.1894); vgl. dazu Wruck 1999, S. 21 f.
} 
der etwa in Unsere lyrische und epische Poesie seit 1848 den „Realismus“ seiner Gesellschaft als Verwerfen aller „Schlüsse und Kombinationen“ zugunsten der „Erfahrung“ charakterisiert. ${ }^{183}$

Auf den ersten Blick scheinen Fontanes Eigennamenaufzählungen dabei Kennzeichen des negativ bewerteten empirischen Wissens, eines Sammelsuriums an gewußten einzelnen Tatsachen zu sein. ${ }^{184}$ Doch sind die Auflistungen Fontanes selten so unsystematisch, wie sie sich geben. Eine scheinbar willkürliche Auflistung aus Meine Kinderjahre etwa ist mehrfach geordnet:

Was ich dahin mitbrachte, war etwa das Folgende: Lesen, Schreiben, Rechnen; biblische Geschichte, römische und deutsche Kaiser; Entdeckung von Amerika, Cortez, Pizarro; Napoleon und seine Marschälle; die Schlacht bei Navarino, Bombardement von Algier, Grochow und Ostrolenka; Pfeffels Tabakspfeife, „Nachts um die zwölfte Stunde«, Holteis Mantellied und beinah sämtliche Schillersche Balladen. Das war, einschließlich einiger lateinischer Brocken, so ziemlich alles, und im Grunde bin ich nicht recht darüber hinausgekommen. Einige Lücken wurden wohl zugestopft, aber alles blieb zufällig und ungeordnet, und das berühmte Wort vom »Stückwerk« traf auf Lebenszeit buchstäblich und in besonderer Hochgradigkeit bei mir zu. ${ }^{185}$

Fontane ordnet seine Aufzählung zunächst nach Wissensgebieten. Als wichtigstes tritt nach der Trias der kulturtechnischen Grundfertigkeiten die Religion auf, gefolgt von der Geschichte, der wiederum die kanonische Kultur folgt. Die historischen Ereignisse und Namen werden chronologisch vorgetragen: Prähistorie, Antike, Weltgeschichte, preußische Geschichte. Lediglich die Reihung literarischer Kenntnisse erscheint als willkürlich und lückenhaft. Eigennamenaufzählungen bei Fontane gehören also keineswegs uneingeschränkt zum humoristischen und „göttlichen Durcheinanderschmeißen von groß und klein“. 186

Die Kenntnis der Namen, ihres Kommunikationswertes und ihrer richtigen Bedeutung und damit der richtigen Ordnung zwischen den aufgezählten Namen steht vielmehr beim späten Fontane trotz der Kritik am Kommunikationswert des Namens für eine bestimmte Form von Bildung und Wissen:

Unser Lebens- und namentlich unser Gesellschaftsweg ist ja mit Quatschköpfen gepflastert. Die meisten - unglaubliches Resultat unserer höheren Geheimratsbildung - wissen gar nichts, wissen nicht wo der Tanganjika-See liegt (dafür verzapfen sie ein paar alte Hegelsche Phrasen), wissen zwischen Scheffel und Wolff nicht zu unterscheiden und halten Stinde für einen bedeutenden Schriftsteller [...]. ${ }^{187}$

Fontane demonstriert in diesem Brief die in seinen Gedichten poetisch umgesetzte ,Arbeit mit Namen'. Über die Anspielung mittels Eigennamen verständigt man sich unter

\footnotetext{
${ }^{183}$ Fontane HFA III,1, S. 236; vgl. Aust 2000, S. 413 f.

${ }_{184}^{18}$ Vgl. auch Hebekus 2003, S. 1 f. zur ,Anekdotologie' Fontanes.

185 Fontane NA 14, S. 185.

${ }^{186}$ Fontane HFA IV,1, S. 140 f.; vgl. Aust 2000, S. 431.

${ }^{187}$ Fontane HFA IV, 4, S. 710 (Brief an Guido Weiß vom 14.7.1889). Fontanes hier geäußerte Kritik entspricht seiner Ablehnung der durch staatliche Approbation gestützten ,Fachleute', die sich in Literaturkritik üben; vgl. Nürnberger 1997, S. 337.
} 
,Bildungsinsidern', ohne ausführlicher werden zu müssen. Das bruchstückhafte und unsystematische Wissen des gebildeten Laien, das sich an Namen und an Ereignissen oder Bildern orientiert, die diesen Namen zugeordnet werden, steht dem Wissen scholastischer Lehrsätze gegenüber. Die Kenntnis der historischen Realien und ihrer Namen wird von Fontane über die Kenntnis wissenschaftlicher Lehren gestellt. ${ }^{188}$

Das Wissen um Realien aus dem Konversationslexikon ist der Typ Wissen, der nötig ist, um Fontanes Arbeit mit Namen zu verstehen. ${ }^{189}$ Denn das vorausgesetzte Namenwissen nimmt durch den mittels der Medien erweiterten Blick auf die Welt und die Geschichte immer mehr zu. Es umfaßt in immer größerem Maße Personen und Objekte, die dem Namenkonsumenten nur noch durch den Namen selbst und durch Bilder und Beschreibungen bekannt sind. Mit Namen als ,Knotenpunkten der Diskurse' (Foucault) organisiert Fontane dieses Wissen. Dabei hält der frühe Fontane sich an oft unbekanntes historisches Wissen, das dann meist der Erläuterung bedarf. ${ }^{190}$ Der späte Fontane verwendet in seinen Gedichten dagegen immer mehr die Namen, die seine moderne Welt bzw. deren Gespräche bestimmen - z.B. den „Tanganjika-See“, den „Yang-tseKiang“, den „Tsad-See“, den „Kongo“ oder „Kapstadt“, die aus den deutschen und europäischen Kolonien über die Medien ins Tagesgespräch gedrungen sind. ${ }^{191}$ Bei diesen Eigennamen entfernter Orte und Personen beschränkt sich die Namenkenntnis auf Konversationslexikons- und Zeitungswissen. Die Namen demonstrieren die empirischen Wissensbereiche der modernen politischen Welt, die eine auf abstrakten Lehrgebäuden ruhende universitäre Philosophie als paradigmatisches Wissen ablösen. ${ }^{192}$ Doch auch bei diesen Namen gilt, daß das durch Namen im Text Mitgeteilte nur von demjenigen voll gewürdigt werden kann, der die namentlich genannten Individuen so gut kennt, wie der Namenbenutzer. ${ }^{193}$ Gleichzeitig handelt es sich hier um Alltagswissen, das nichts mit dem intensiven wissenschaftlichen (oder vermeintlich wissenschaftlichen) Erkenntnisgewinn zu tun hat.

\footnotetext{
${ }^{188}$ Vgl. Parr 2002, S. 216; dies paßt zu der frühen ,Sozialisation' Fontanes, dessen Eltern inn offenbar eher mit Lexika und Atlanten, als mit Romanen oder Gedichten versorgten; vgl. Wruck 1999, S. 25.

${ }_{189}$ Zu Fontanes Haltung zur Autodidaktik, die eng mit dem Wissen aus dem Konversationslexikon verbunden ist, vgl. Stüssel 2000, bes. S. $119 \mathrm{f}$.

${ }^{190} \mathrm{Vgl}$. z.B. Fontane HFA IV, 1, S. 704 (Brief an Julius Springer vom 13.5.1860).

${ }^{191}$ Vgl. Zeitung, Fontane HFA I, 6, S. 333, Meine Reiselust, Fontane HFA I, 6, S. 342 und etwa Die Poggenpuhls, Fontane HFA I, 4, S. 550; Klug 1999. Afrikanische Kolonien in den 1880ern waren DeutschSüdwestafrika, Kamerun, Togo, Deutsch-Ostafrika. 1884/85 fand die Kongo-Konferenz in Berlin statt.

192 Die neuen gesellschaftlichen Normen einer globalisierten Gesellschaft mag die Vorstellung Ezechiel van der Straatens in L'Adultera vorwegnehmen; vgl. Fontane HFA 2, S. 7.

${ }^{193}$ So etwa, wenn Fontane in Zeitung, Fontane HFA I, 6, S. 333, mit "Liu-Tang“, „Liu-Tschang" und dem reimenden „Yang-tse-Kiang" scheinbar beliebige oder gar um des leichtläufigen Gleichklanges Willen ausgewählte Eigennamen verwendet, die aber in Wirklichkeit die aktuelle Situation im Japanischchinesischen Krieg und die Kolonialisierungsversuche Europas in China zusammenfassen; vgl. Storch 2000b, S. 118.
} 
Bei Eigennamen nahegelegener Orte und Familien versteht der Empfänger den Sender vollständig nur, wenn er auch Namenproduzent (im Sinne der knowledge by acquaintance) ist. Fontanes Gedichten und ihrer Namenverwendung kann in vielen Fällen die Ausrichtung auf ein begrenztes und bekanntes Publikum - sei es der märkische Adel, seien es die Berliner - abgelesen werden. Sein impliziter Leser muß die Namenträger selbst kennen. Diese Insider-Lektüre schätzt Fontane auch an den Texten anderer Schriftsteller. So bescheinigt er einem ,kulturwissenschaftlichen' Aufsatz, er enthalte

eine ganze Welt von Weisheit; nur wer in all diesen Dingen und Fragen [...] so zu Hause ist wie ich, kann da folgen und würdigen. Man muß Berlin und Mark und Wedding und Voigtland und die Biers und die Fischers und Kleist und Wilibald Alexis und Franz Ziegler und Niendorf kennen, um zu wissen, wie treffend das alles ist. ${ }^{194}$

In An meinem 75ten etwa schreibt Fontane tatsächlich für eine ganz bestimmte Zielgruppe. ${ }^{195}$ Sein Sprecher ist keineswegs „ort- und heimatlos.“196 Vielmehr wendet Fontane sich an diejenigen, die die von ihm verwendeten Eigennamen zu würdigen wissen. Das sind jene, die die Namenbedeutung am besten als Namenproduzenten, notfalls als Namenkonsumenten kennen. Erst wenn Sender und Empfänger das symbolische Eigennamenuniversum teilen, trägt die Benutzung von Eigennamen zur Anschaulichkeit bei. ${ }^{197}$

Der Name steht dabei nicht nur für seine Bedeutung, sondern auch für die Position des Namenbenutzers, der sich durch sein Namenuniversum in Gruppen einordnet: "Sage mir, mit wem du umgehst, und ich will dir sagen, wer du bist." ${ }^{198}$ Deutlich wird dies etwa in Neueste Väterweisheit, wenn der Sprecher (ein Vater an seinen Sohn) rät:
Zieh nun also in die Welt,
Tue beharrlich, was dir gefällt,
Werde keiner Gefühle Beute,
Meide sorglich arme Leute,
Werde kein gelehrter Klauber,
Wissenschaft ist fauler Zauber,
Sei für Rothschild statt für Ranke,

\footnotetext{
${ }^{194}$ Fontane HFA 1, S.710 (Brief an Guido Weiß vom 14.7.1889).

195 Vgl. Mecklenburg 2001, S. 237.

${ }^{196}$ So Bickmann 1989, S. 207; Brinkmann 1977, S. 16, spricht von den „kulturgeschichtlichen Requisiten“ und "historischen Quisquilien“, die Fontanes Romane enthielten und von denen sich "manches“" "heute nicht mehr ohne weiteres verstehen" lasse; vgl. auch Hettche 2000, S. 154.

${ }_{197}$ Berühmte Eigennamen dienen Fontane auch in seinen Romanen immer wieder dazu, Sachverhalte mit gesteigerter Intensität und Anschaulichkeit darzustellen. Eine solche Steigerung wird bemüht, wenn eine umfassende Welt assoziiert werden soll oder wenn ein schwer faßbarer bewertender Eindruck erklärt wird. So geschieht es - durchaus harmlos - z.B. in L'Adultera, wenn der ,Legationsrat Duquede' äußert: „Aber Taten mit gar keiner oder mit erheuchelter oder mit erborgter Idee haben etwas Rohes und Brutales, etwas Dschingiskhanartiges.“; Fontane HFA 2, S. 29. Im Namen ist hier die ambivalente Größe einer beeindruckenden, aber ,unkultivierten' Gewalt mit militärischen und weltpolitischen Wirkungen ausgesprochen.

${ }_{198}$ Fontane HFA I, 6, S. 564
} 
Nimm den Main und laß die Panke,

Nimm den Butt und laß die Flunder,

Geld ist Glück, und Kunst ist Plunder,

Vorwärts auf der schlechtsten Kragge,

Wenn nur unter großer Flagge.

Pred'ge Tugend, pred'ge Sitte,

Millionär ist dann das dritte,

Quäl dich nicht mit 'wohlerzogen'.

Vorwärts mit den Ellenbogen,

Und zeig jedem jeden Falles:

,Du bist nichts, und ich bin alles.' 199

In dieser „Klimax schneidender Kontraste“ ${ }^{200}$ - wenn man denn so will - stehen die gegensätzlichen alliterierenden Namen ,Rothschild' (durch Handel erworbener Reichtum) und ,Ranke' (historische Gelehrsamkeit) sowie ,Main' (für Frankfurt am Main = Finanzzentrum; s.o.) und ,Panke' (für Berlin = ,Kulturstadt') für die möglichen Lebenswege. Der Sohn muß sich unter anderem für Namen entscheiden, zu denen er stehen will und die sein Selbstbild und sein Bild in der Öffentlichkeit bestimmen werden. Daß Fontane dabei den prestigeträchtigen, wenn auch nicht modischen Leopold von Ranke und die Heimatstadt Berlin auf die scheinbar negative Seite stellt, gehört zur Strategie der Ironisierung.

Über ständige Bewertungen von Eigennamen beschreibt Fontane die normative Wirklichkeit seiner Gesellschaft und betreibt eine sich wandelnde Politik der Namenverwendung. ${ }^{201}$ So gefällt Fontanes Sprecher sich einerseits in der Demonstration patriotischer Namendetailkenntnis bis hin zum Namen der Lieblingshündin Friedrichs des Großen. ${ }^{202}$ Auch beklagt er sich über einen zunehmenden Verlust an Namenkenntnis und Namenwürdigung - nicht nur in Briefen, sondern auch in Gedichten, wie seine Fragmente Berliner Lokalpatriotismus und Neuestes oder Modernstes zeigen. ${ }^{203}$ Andererseits belächelt der späte Fontane seine eigene frühere Begeisterung für die klangvollen Namen.

Fontanes Sprecher revidiert vor allem in seinen Gedichten der 1890er Fontanes frühere Eigennamenbewertung vor dem Hintergrund dessen enttäuschter Erwartungen und enttäuschter Ansprüche sowie eines stilisierten „Drüberstehens“. ${ }^{204}$ Vorbereitet wird diese

\footnotetext{
${ }^{199}$ Fontane HFA I, 6, S. 388.

${ }^{200}$ Reuter 1995, S. 789.

${ }^{201}$ Vgl. zu Normen als Teil der Wirklichkeit des Realismus Aust 2000, S. 423. Die Selbsteinordnung in die Gesellschaft durch Eigennamen schließt wiederum an Fontanes Vorstellungen zum Realismus an, nach denen die gestalteten Entitäten so sein müssen, als könnten sie jederzeit in einem realen Umfeld auftreten. Man meint sie also in der Realität jederzeit finden zu können; vgl. Aust 2000, S. 449.

202 In Auf der Treppe von Sanssouci, Fontane HFA I, 6, S. 262.

${ }^{203}$ Fontane HFA I, 6, S. 813 f.; S. 816. Hatte der frühe Fontane noch die Poesie der adligen Geschlechter gegenüber den bourgeoisen gepriesen (s.o.), sieht er später die neuen Namenkämpfe in der Gesellschaft und beklagt immer noch die Ablösung alter Traditionen: „Immer diesselbe Geschichte. Was sind alle berühmten Hildebrandts gegen den Pfefferküchler, dessen Pfeffernüsse noch dazu schlecht sind." (Fontane HFA IV, 4, S. 353 - Brief an Georg Friedländer vom 14.5.1894; vgl. auch Die Poggenpuhls, in: Fontane HFA I, 4, S. $528 \mathrm{f}$.
}

${ }^{204}$ Vgl. Völkel 1983, S. 340. 
Entwicklung durch die stete Ironie gegenüber der eigenen Begeisterung für den „Klang’ exotischer oder anderer Namen. Sowohl seine großen Sujets (Kaiser, Schlachten und Generäle) und literarischen Vorbilder als auch die Gesellschaftsschicht des niederen Adels, die vorher in Namenkatalogen oder als gesellschaftlicher Hintergrund in seinen Gedichten, Erzählungen und Romanen auftrat, bewertet Fontane neu.

\subsubsection{Eigennamenskepsis und Resignation}

Die Verwendung vieler unkommentierter Eigennamen zeigt Fontanes Bestreben, alltagsnah zu sprechen. ${ }^{205}$ Solche Alltagslyrik und „betonte Unfeierlichkeit“ kann als Versuch zur Erneuerung der Lyrik, orientiert an den Normen des Realismus, gewertet werden. ${ }^{206}$ Nicht als fiktionales realistisches Erzählen, sondern als realistischer Beitrag zu einem fiktionalen Dialog müssen diese Gedichte verstanden werden. Das bedeutet auch eine Absage an eine vom Altagston entfernte poetische Rede. ${ }^{207}$ Humor und Resignation, die Fontanes später Dichtung zugeschrieben werden, ${ }^{208}$ drücken sich im beiläufigen Sprechen, besonders in der Aufzählung oft scheinbar unverbundener Dinge aus. $^{209}$ Der späte Fontane zeigt dabei eine stilisierte resignierende Haltung und einen skeptischen Blick auf seine Gesellschaft, ihre Werte und Umtriebe. ${ }^{210}$ So mischt sich ein resignierender Pessimismus mit einer „heiteren Gelassenheit“ (einer „Lebens- bzw. Sinndiät“), der die „lose gefügten Einzelteile“ der Welt „in ihrer prinzipiellen Gleichrangigkeit zur Sprache“ bringt. ${ }^{211}$ Die Verwendung von Eigennamen in seinen späten Gedichten spiegelt diese Haltung Fontanes. Bei allem Skeptizismus den überkommenen gesellschaftlichen Werten gegenüber, die sich in der Bewertung von Eigennamen ausdrücken, holt Fontane doch die Realität, die nach einem dem Autor und den Lesern gemeinsamen Wissens- und Wertungssystemen geordnet ist, durch die auf die außertextliche Welt referierenden realen Eigennamen in die gestaltete literarische Welt hinein. Dabei dient die Eigennamenverwendung Fontanes zunächst vor allem der Kritik an bestimmten Systemen. Die Normen der auf Renommee und Glanz bedachten Gesellschaft des Adels, der vermeintlichen Gelehrten und der Politik bilden die Grundlage eines festgefügten Eigennamenfeldes. Die allgemeine Kritik am Glanz der klangvollen

\footnotetext{
205 Vgl. Völkel 1983, S. 349 f. Auch Fontanes variable und prosanahe Verwendung des freien Knittelverses nähert seine Gedichte der Alltagssprache an; vgl. z.B. Fontane 1998, S. 182, S. 191.

${ }^{206}$ Nürnberger 1997, S. 337; vgl. Völkel 1983, S. 341 f.; Plett 1991, S. 21; Richter 1966, S. 149-152: „In allem aber trug sie dazu bei, daß sich die Dichtung in der Aufnahme der Wirklichkeits- und Zeiterfahrung zugleich als Dichtung bewährte."

207 Vgl. auch Aust 2000, S. 424 f.

208 Vgl. Richter 1966, S. 142 passim.

${ }^{209}$ Vgl. Richter 1966, S. 143.

${ }^{210}$ Vgl. Richter 1966, S.156-160; Richter 1980, S. 119; Bickmann 1989; im Verhältnis zu Schopenhauers Philosophie vgl. Aust 2000, S. 397.

${ }^{211}$ Vgl. Bickmann 1989, S. 203 und S. 215.
} 
Namen geht an den Lebensnerv derer, denen die Namen viel bedeuten ${ }^{212}$ - zumal „auch die Klugen und Klügsten auf diesen Punkt [ihren Namen] hin immer empfindlich sind“. ${ }^{213}$ Auch sie schmücken sich mit Namen und legen Wert darauf, „Ein bißchen Namen, ein bißchen Ehre" (oder auch viel) zu bekommen. ${ }^{214}$

Fontane kritisiert die ihm gegenwärtige Gesellschaft weniger mit einem progressiven als mit einem rückwärtsgewandten Blick. ${ }^{215}$ Die kritische Strategie des späten Fontane beruht auf einem argumentum ad hominem, das mit Eigennamen auf jene lieux de mémoire zielt, die den kritisierten gesellschaftlichen Gruppen das scheinbare moralische und sittliche Fundament geben. Ausgangspunkt der Kritik ist die mehr oder weniger unmittelbare Vergangenheit, in der die charaktervollen Persönlichkeiten („der alte Fritz“, „Der alte Dessauer“, „Der alte Zieten“, aber auch „der alte Moltke“ und der „Alte Kaiser“) und großen patriotischen Taten angesiedelt sind. ${ }^{216}$ Das durch Namen vermittelte Normensystem selbst wird - wie besonders die Ambivalenz von An meinem 75ten zeigt - dabei weniger angegriffen als die ungenügende Erfüllung der Normen und Ansprüche, die die Namenträger mit der Namentradierung und -verwendung selbst gesetzt haben. Auch in diesem Punkt ist Fontanes Spätwerk zugleich Verherrlichung wie Kritik des Adels. ${ }^{217}$ Fontanes Entzauberung der berühmten Eigennamen erstreckt sich auch auf das Geschichts- und Mythenverständnis seiner Zeit. Wenn der Name zum Allgemeingut der Sprache geworden ist, dann wirkt er genauso flach auf den Zuhörer wie eine verblaßte Metapher. Der späte Fontane verwendet die Namen, die Anspruch auf historische Größe erheben, in seinen Gedichten vielfach auf diese Weise. Er nutzt sie nicht als ,Chiffre' für einen Inhalt, sondern zitiert sie als Teil einer Kultur, die der Sprecher der Gedichte nicht mehr ganz ernst nimmt.

Fontane deckt dabei die Diskrepanz zwischen im Namensystem geäußerten Ansprüchen und der Wirklichkeit durch die ironische Behandlung der berühmten und bedeutenden Namen auf. Darin äußert sich seine Sprachkritik, die Gesellschaftskritik ist. Die

\footnotetext{
212 Besonders, wenn man annimmt - wie Brinkmann 1977, S. 24, behauptet -, daß Fontane keine gemeinschaftlichen, sondern nur gesellschaftliche Beziehungen beschreibt, die geprägt sind von „kreuz und quer fordernden Konventionen, Rechten, verboten, Tabus, Vorstellungen, mit Gesetz, Sitte, Brauch, Strafe."

213 So Melanie zu Ebenezer Rubehn in L'Adultera, Fontane HFA 2, S. 70.

${ }^{214}$ Vgl. Summa Summarum, in Fontane HFA I, 6, S. 339.

215 Vgl. auch Brinkmann 1977, S. 122 f.; auch wenn Fontane sich selbst durchaus als dem „Rückwärtsgewandten" abgeneigt beschreibt; vgl. Storch 2000a, S. $116 \mathrm{f}$.

216 Deutlich wird dies z.B. auch in der berühmten Ballade des Herrn Ribbeck auf Ribbeck im Havelland: Dort „knausert und spart“ der „eigene“ Sohn des „alten“ Ribbeck (!), der so kinderlieb und freigiebig war; vgl. Fontane HFA I, 6, S. 256.

${ }^{211}$ Diese Ambivalenz aus grundsätzlicher Begeisterung für den Adel bei gleichzeitiger Enttäuschung über dessen Vertreter wird in einer Tagebucheintragung zum Roman Die Poggenpuhls deutlich: „Es ist eine Verherrlichung des Adels, der aber, so viel kann ich zugeben, klein und dumm genug empfindet, um das Schmeichelhafte darin nicht herauszufühlen." Fontane, GBA Tagebücher 1866-1822/1884-1898, S. 263.
} 
Kritik Fontanes hebt den Status des Eigennamensystems einer Gesellschaft als Teil der parole hervor, während ,Namengläubige' einen Teil der langue daraus machen wollen. Fontane geht es dabei nicht um ein metaphysisches Ungenügen der Sprache, sondern um ein Ungenügen der adligen Namenträger und der namengläubigen Namenbenutzer gegenüber ihren eigenen Ansprüchen auf Superiorität und Weltwissen. Der Überheblichkeit dessen, der auf seine Namentradition oder seine Namenkenntnisse pocht, korrespondiert die Naivität dessen, der sich unreflektiert vom Klang der berühmten oder exotischen Namen gefangennehmen läßt.

Doch führt Fontanes Umgang mit Namen nicht zur generellen Sprachskepsis der Jahrhundertwende oder zum teilnahmslosen „Beiseitestehen“. ${ }^{218}$ Im Eigennamenwissen als ,Informiertheit über die Welt' findet Fontane einen sprachlichen Halt. Die „Kohärenzstiftung“219 zwischen den namentlich und begrifflich aufgezählten Objekten, Orten und Personen gelingt daher nur scheinbar nicht. Fontane benutzt zwar die Namen, zumal in den Namenkatalogen, in einem beiläufigen, Beliebigkeit vortäuschenden Ton. Die genaue Betrachtung zeigt, daß der Sprecher jederzeit über alle verwendeten Namen genauestens informiert ist und sie ihrer Bedeutung gemäß einsetzt. ${ }^{220}$ Die Kohärenz wird durch die einheitliche Perspektive des nicht involvierten, aber in jedem Fall informierten Betrachters aufrechterhalten. ${ }^{221}$ Dazu gehört auch, daß Fontanes ,Flanieren' keineswegs das „ziellose Schlendern und Spazierengehen“ der Décadence ist. ${ }^{222}$ Vielmehr handelt es sich um ein Kreisen um immer die gleichen Orte, die das unmittelbar vergangene Preußen sowie den Berliner Alltag symbolisieren. Fontane erreicht auch durch den Bezug auf diese traditionellen Orte eine Kohärenz der ,lieben alten Gewohnheit', die dem Schlendern des Flaneurs fehlt.

Darüber hinaus führt das am - häufig lokal begrenzten - Eigennamen orientierte empirische Wissenssystem Fontanes vor, wie trotz des Skeptizismus gegenüber ,ewigen Wahrheiten'223 oder Werten an einem die Welt organisierenden sprachlichen Paradigma festgehalten werden kann. Durch die Integration der realen Welt in seine Gedichte kann Fontane seine Position der Ironie skizzieren, die weder den völligen Rückzug und die „Konzentration auf das Nächstliegende, Begrenzte und Überschaubare“224 noch die

\footnotetext{
${ }^{218}$ So aber Richter 1966, S. 144.

${ }^{219}$ Hettche 2002, S. 92.

${ }^{220}$ Fontane ist also anders, als Czucka 2000, S. 29, behauptet, keineswegs ein Verfechter des sprachkritischen ,Beliebigkeitstheorems'.

${ }^{221}$ Etwa in Würd es mir fehlen, würd ich's vermissen HFA I, 6, S. 340; vgl. auch Richter 1966, S. 147 f.; vgl. dagegen Hettche 2002, S. $91 \mathrm{f}$.

${ }^{222}$ Vgl. dagegen Hettche 2002, S. $92 \mathrm{f}$.

${ }^{223}$ Vgl. Bickmann 1989, z.B. S. 208.

${ }^{224}$ Vgl. Bickmann 1989, S. 213.
} 
ambitionierte Teilnahme an der Schaffung großer Monumente und ewiger Wahrheiten bedeutet.

Wie sehr Fontane dabei Aufzählungen und Schwärme berühmter Eigennamen benutzt, um seine Gedichte zu strukturieren, macht der Entwurf zu seinem unvollendet gebliebenen Noch Leb ich oder Aber, ach wie lange noch deutlich:

\author{
Noch leb ich. Noch tret ich Jahr um Jahr \\ im Ausstellungspark vor den Kunstaltar, \\ Noch seh ich von den ewig verwechselten beiden \\ Bilder, von Otto und August v. Heyden, \\ Noch seh ich in einem anderen Fache \\ Andreas und Oswald Aschenbache, \\ Noch seh ich kleine und große Dinger \\ und Heroisches (?) auch vom Maler Max Klinger.
}

Weiter aufzählen: Carl Becker, Anton v. Werner, ein Strand von Eschke, eine Mondscheinlandschaft von Douzette, von Bennewitz v. Loefen von Scherres etc. von Menzel und lese von Karl Frenzel etc. etc.

Aber ach wie lange noch?

Noch leb ich. Noch geh ich ein und aus

Hinter Schillers Rücken im Schauspielhaus,

Noch, vom Parquet Nummer 23,

Seh ich Gäste aus Königsberg, Posen, Danzig;

Noch hör ich bei jeder Geburtstagsfeier

Einen Prolog von Clara Meyer,

Noch seh ich Krause, Direktor Anno,

Noch seh ich Müller und Müller-Hanno.

Aber ach wie lange noch?

In der dritten Strophe die Stadt, Schloß, Linden, das historische Fenster, der Alte Fritz. Und wieder zurück durch das Brandenburger Tor. Renz, Agentur von Bloch (vielleicht bei Strophe 2)

Aber ach wie lange noch?

Koch, Joch, Bloch, Loch, Poch, gepoch, Woch, ein Jahr, ein Mond, eine Woch. ${ }^{225}$

Das Gedicht stellt schon mit dem Titel die dem späten Fontane so oft zugeschriebene Haltung der Gelassenheit gegenüber den Weltläufen dar. Die Vorarbeiten Fontanes zu noch nicht geschriebenen Teilen des Gedichts bestehen praktisch nur aus Hinweisen zu Namenaufzählungen. Sie zeigen, daß der Textverlauf durch die Abfolge bekannter Namen bestimmt wird. Dabei werden die Namen zwar nach dem subjektiven Blick des Sprechers aufgezählt, die Gruppierung der Eigennamen nach verschiedenen Tätigkeiten des Sprechers (Ausstellungsbesuche, Lektüre, Spaziergänge) lassen diese Subjektivität aber nicht willkürlich erscheinen. Besonders die Bemerkungen zu den ,Spaziergängen' zeigen, daß Fontane sich der räumlichen Anordnung jederzeit bewußt war und mit den Aufzählungen von Ortsnamen Bewegungen im Raum zusammenfaßte. Die häufige und teilweise betont künstliche Positionierung von Namen im Reim (etwa „23“ / „Danzig“ oder „Direktor Anno“ / „Müller-Hanno“) zeigt aber auch, daß mit der ,sachorien-

${ }^{225}$ Fontane GBA Gedichte 2, S. 459 f. 
tierten' Anordnung der Namen die ästhetisch motivierte formal orientierte Auswahl und Anordnung konkurriert. Hier wird die Willkür der Aufzählung deutlich.

Diese Konkurrenz der vorgeführten Motivation zur Namenauswahl gehört zu der von Richter beschriebenen „Ambivalenz“ in der späten Fontaneschen Lyrik. ${ }^{226}$ Allerdings verkennt Richter die genuine Rolle der berühmten bzw. bekannten Eigennamen in Fontanes Gedichten als Symbol der ,großen Welt' des öffentlichen Lebens. Nie wird in den Gedichten wirklich nur „Heterogenes“ aneinandergereiht ${ }^{227}$, sondern es werden fast immer die beiden Sphären des Öffentlichen und des Privaten gegeneinandergehalten, die den Sprecher trotz seiner scheinbaren Gleichgültigkeit noch interessieren. Die Sphäre des distanziert betrachteten öffentlichen Lebens vertreten dabei regelmäßig berühmte Eigennamen.

Die ironische Bescheidenheit gegenüber dem eigenen ,Pierer- und Brockhauswissen'228 und die Skepsis gegenüber bedeutenden Namen verhindern, daß Fontane zu sehr in das Treiben der Welt involviert wird. Der Spaziergänger und Zeitungsleser nimmt nicht aktiv an den großen und kleinen Ereignissen der Welt teil und verfolgt sie doch nicht ohne Interesse.

\section{2 „A toy made out of letters?“ - Schwierige direkte Evokationen mit Ei- gennamen bei Edwin Arlington Robinson}

\subsection{1 „A poem in itself“ oder „oddish proper names“}

Die Figurennamen in den narrativen Gedichten Edwin Arlington Robinsons haben vielfach die Aufmerksamkeit seiner Leser gefunden. Zeitgenössische Kritiker wie auch spätere Interpreten bezeichnen seine Namen als auffällig. ${ }^{229}$ Doch die nach Ansicht der Kritiker poetisch-klangvollen, symbolischen und charakterisierenden Namen werden nicht systematisch analysiert. So schreibt ein früher Rezensent lobend, aber wenig differenziert:

One of the most characteristic and striking of Mr. Robinson's gifts is his way of coining musical and suggesting names for his poetic characters [...] each is a perfect symbol and almost a poem in itself, and they cling potently to the memory. ${ }^{230}$

Auch in den späteren Monographien folgen die Interpreten zumeist einem undifferenzierten Eindruck:

\footnotetext{
${ }^{226}$ Vgl. Richter 1966, S. 146.

227 Vgl. Richter 1966, S. $147 \mathrm{f}$.

${ }^{228}$ Vgl. zu Fontanes „Bildungsmisere“ auch Wruck 1999, bes. S. 15 f.

229 Für eine Zusammenschau dieser Einschätzungen vgl. Cary 1974a, S. 14-16 (Preliminary Vistas Nomen Est Omen).

${ }^{230}$ Greenslet 1974 [Rezension v. 1905], S. 198.
} 
Even the names of Robinson's people, it may be noted, often suggest by their sound what their possessors are like. "Flammonde" could be the name of no ordinary mortal; it strikes the ear with overtones of the remote and heroic [...]. "Miniver Cheevy" [...] could only belong to a man whom fate had sentenced never to be taken seriously. Aaron Stark, we scarcely need to be told, is a "meagre man" and a miser [...]. ${ }^{231}$

Diejenigen Interpretationen, die versuchen, Eigennamen genauer auszulegen, wagen sich hingegen weit vor. Die Jagd nach redenden Namen in Robinsons Werk verführt schon mal einen Interpreten, den Gedichttitel Ben Trovato als redenden Figurennamen zu interpretieren, ohne die Anlehnung an das italienische Sprichwort zu bemerken. ${ }^{232}$ Andere führen den Namen ,Pamela' auf die vielfältigen und widersprüchlichen Ursprünge ,meléa' (Apfelbaum), ,melon' (Apfel), ,malum' (das Böse), ,pan' (das All, vollständig) und ,pammelas' (ganz schwarz, ganz dunkel) zurück, so daß aus einer harmlosen Neuengländerin schon durch ihren Namen eine verruchte zweite Eva wird. ${ }^{233}$

Diese Namenauslegungen werden durch die spärliche Darstellung der Gedichtkontexte möglich, die weiten Raum für Spekulationen läßt. Ihnen scheint die irrige Annahme zugrunde zu liegen, Eigennamen lieferten durch ihre charakterisierende Funktion stets einen kunstvoll versteckten Hinweis auf die Essenz zu den im Gedicht gestalteten Figuren. Solch aufwendige, aber monofunktionale Interpretation der Eigennamen als autoritativer Hinweis auf den Charakter oder Schlüssel zum Gedicht wird den vielfältigen Funktionen und Wirkungsweisen der Eigennamen in Robinsons Texten nicht gerecht. Dies wird im Folgenden ausgehend von Robinson Konzeption poetischer Rede zu zeigen sein.

\subsubsection{Die Rolle poetischer Rede bei Robinson}

Edwin Arlington Robinson gilt als einer der Revolutionäre der überkommenen genteel poetry der Jahrhundertwende. ${ }^{234}$ Während andere - Ezra Pound, T.S. Eliot - nur wenig

\footnotetext{
${ }^{231}$ Barnard 1952, S. 57. Sogar Cary 1974a, S. 15, kritisiert die Oberflächlichkeit einer Rezension zu Fleming Helphenstine, die den Namen als Verschreibung des deutschen ,helfen' \&, stein' (= ,Stein der Hilfe') betrachtet, und bemerkt dann selbst ebenso kryptisch: „The palpitating next layer [of the name F.H.] was never exposed [by the critic]", ohne diesen Hinweis selbst weiter auszuführen.

${ }_{232}$ So Robert Mezey in: Robinson 1999, S. 236, oder Donaldson 1966, S. 226. Daß es sich bei ,Ben Trovato' nicht um einen Figurennamen, sondern nur um einen Gedichttitel nach dem italienischen Sprichwort handelt, hat Robinson schon früh als Reaktion auf Clement Woods Kritik an seinen Namen angedeutet: „Next time you see Clement Wood, tell him for me that Ben Trovato is not a man but a fairly common - I might say, well found - Italian phrase [gemeint ist: ,Si non è vero, è ben trovato']." Wood hatte geschrieben: "It has bothered some commentators that so many of his New England characters have names as odd to it as they would be to Old England / Flammonde, Bokardo, Briony, Argan, Ben Trovato, PennRaven, Umfraville, Lorraine, Gabrielle."; Robinson 1975, S. 205 [62]. Man bemerke, daß hier sehr ungewöhnliche und deutlich redende Namen wie Penn-Raven neben vollkommen gewöhnlichen, aber französischen Namen stehen. Der Kommentator scheint sich mit der Verbreitung fremdsprachiger Namen in Nordamerika nicht ausgekannt zu haben; vgl. Robinson 1975, S. 163 [62]. Andere Gedichttitel dieser Art sind etwa Siege Perilious oder Pasa Thalassa Thalassa; Robinson 1954, S. 41 und S. 335.
}

${ }^{233}$ Vgl. Cervo 1995, S. 29 f.; vgl. etwa auch McFarland 1974, S. 365 f.

${ }^{234}$ Vgl. etwa die Zusammenstellung in der Monographie Stanfords 1983. 
später den free verse eroberten und so einen umfassenden Bruch mit der Tradition wagten, hält Robinson an den traditionellen poetischen Formen fest. ${ }^{235}$ Die Prinzipien der Dichtung Robinsons bleiben sein Leben lang fast unverändert. Sein Schaffen beschränkt sich auf Gedichte, auf mittlere und lange Blankverserzählungen, sowie auf wenige Dramen. Das Werk Robinsons ist überwiegend deutlich fiktional und narrativ. ${ }^{236}$ Dies gibt besonders seinen frühen Gedichten eine starke Spannung zwischen traditioneller Gedichtform (besonders dem Sonett) und narrativem Inhalt. Beim späteren Robinson ist dieser Neigung entsprechend eine deutliche Tendenz zur ausführlicheren Narration in prosanahen Blankversen erkennbar. Die kurzen und mittleren Gedichtformen bleiben aber von 1897 bis 1932 zumindest in den sprachlichen Grundzügen gleich. Robinson schrieb nach eigenem Bekunden von Beginn an in einem ,ausgereiften Stil'. ${ }^{237}$

Seiner Abneigung gegen Theoriebildung entsprechend halten sich Robinsons Äußerungen über seine Poetik und Sprachtheorie in Grenzen. ${ }^{238}$ Aus den verstreuten Bemerkungen ergeben sich nur vage Ansätze zu einer Poetik, in denen Robinson die Intuition und die sprachlich strenge Bearbeitung dieser Intuition hervorhebt. ${ }^{239}$ Eine Bemerkung Robinsons zur poetischen Sprache zeigt, daß diese seiner Ansicht nach darauf zielt, den Leser emotional zu beeinflussen:

Poetry is a language that tells us, through a more or less emotional reaction, something that cannot be said. ${ }^{240}$

Kern dieser ,Wirkungsästhetik' Robinsons ist, daß er das nicht Benennbare zum Ziel poetischer Rede erklärt. Die Nichtreferenz poetischer Rede liegt für ihn darin begründet, daß gerade dasjenige mitgeteilt (,to tell') werden soll, was sich mit denotierender bzw. referierender Sprache nicht sagen (,to say') läßt. ${ }^{241}$

Interessant für die Beurteilung der Namen in den Robinsonschen Gedichten ist die Leseweise, die er dem Leser im Sinne seiner Sprachvorstellungen vorschlägt. Poetische Rede im Selbstverständnis Robinsons gibt dem Leser die Möglichkeit einer emotional gewonnenen Erkenntnis, indem der Leser seine Reaktion auf den Text erlebt. Er nimmt daher die Rolle des Adressaten oder des Mithörenden einer Äußerung in einer fiktiven Situation ein. Er versetzt sich nicht in eine der gestalteten Figuren, sondern muß sich

\footnotetext{
${ }^{235}$ Vgl. den berühmten Ausspruch Robert Frosts: „Robinson stayed content with the old fashioned way to be new." In: Robinson 1999, S. 206.

${ }^{236}$ Vgl. Callow/Reilly 1977, S. 60; Donaldson 1966, S. 219 f.; vgl. auch Robinson 1979, S. 102 (Brief an L. N. Chase vom 11.6.1917).

${ }^{237}$ Vgl. Robinsons eigene Beurteilung in Robinson 1975, S. 79.

${ }^{238}$ Vgl. z.B. W. R. Robinson 1967, S. 11 f.; Stevick 1969, S. 295-297; Weeks 1969 b.

${ }^{239}$ Vgl. Stevick 1969; Weeks 1969b, S. 229.

${ }^{240}$ Robinson 1975, S. 124 [5]; vgl. auch Weeks 1969b, S. 233 und S. 238; Free 1969, S. 17-19.

${ }^{241}$ Vgl. W. R. Robinson 1967, S. 12.
} 
als Gesprächspartner des Sprechers dessen fiktive Welt imaginieren. Dabei geht es Robinson primär nicht um den Inhalt des Erzählten, sondern um die Erzählweise und die Reaktion des Lesers auf den Sprecher. Robinsons Fiktion ist damit prototypisch für das Vorgeben eines Erzählvorgangs im Sinne Gareth Evans'.

Robinson folgt mit seinen poetologischen Vorstellungen der romantischen Poetik Ralph Waldo Emersons, die eng mit dessen Idealismus zusammenhängt. ${ }^{242}$ Emerson nimmt in seinem Essay The Over-Soul an, daß in jedem Menschen das allgemeine ,Licht' einer Seele verborgen ist, die er mit den anderen Menschen teilt. ${ }^{243}$ Dieses tiefste Innere, die eigentliche ,reine Natur' des Menschen könne aber die denotierende Sprache nicht erfassen. ${ }^{244}$ Die Aufgabe des Dichters sieht Emerson darin, das anderweitig nicht Benannte zu benennen und nach Kriterien des Gefühls passende Begriffe zu finden. ${ }^{245}$ Die über die materielle Wirklichkeit hinausgehende seelische Wirklichkeit teilt das Gedicht dem Leser auf emotionalem Wege mit, statt sie mit konventionell denotierenden Begriffen zu beschreiben. Das Gedicht selbst tritt dabei zurück hinter das, was es den Leser an sich selbst erfahren läßt. ${ }^{246}$

Auch Edwin Arlington Robinson betont das Ungenügen der Sprache:

As I see it, my poetry is not pessimistic, nothing of an infinite nature can be proven or disproven in finite terms-meaning words-and the rest is probably a matter of one's individual ways of seeing and feeling things. ${ }^{247}$

\footnotetext{
${ }^{242}$ Robinson hat Emersons Essays sehr früh rezipiert, wenn er sich auch erst nach und nach für inn begeisterte. Vor bzw. zur Veröffentlichung seiner ersten Gedichtbände kannte er zumindest die Gedichte Emersons sowie die Essays Friendship, Prudence, Heroism und The Over-Soul;vgl. Robinson 1947, S. 83 (Brief an H. de Forest Smith vom 5.2.1893) und S. 274 (Brief an H. de Forest Smith vom 3.2.1897); vgl. auch Fussell 1954, S. 25-33; Free 1966; Free 1969, S. 17-19; zu Emerson vgl. Richardson 1999, S. 103; Morris 1999.

${ }^{243}$ „From within or from behind, a light shines through us upon things, and makes us aware that we are nothing, but the light is all. A man is the façade of a temple wherein all wisdom and all good abide. What we commonly call man, the eating, drinking, planting, counting man, does not, as we know him, represent himself, but misrepresents himself. Him we do not respect, but the soul, whose organ he is, would he let it appear through his action, would make our knees bend." Emerson 1979, S. 161 (The Over-Soul).

${ }^{244}$ "Of this pure nature every man is at some time sensible. Language cannot paint it with his colours. It is too subtle. It is undefinable, unmeasurable, but we know that it pervades and contains us. We know that all spiritual being is in man." Emerson 1979, S. 161 (The Over-Soul).

245 "By virtue of this science the poet is the Namer, or Language-maker, naming things sometimes after their appearance, sometimes after their essence, and giving to every one its own name and not another's, thereby rejoicing the intellect, which delights in detachment or boundary." Emerson 1983, S.13 (The Poet); vgl. dazu auch Hagenbüchle 1979, S. 137 f.

${ }^{246}$ "The soul is superior to its knowledge; wiser than any of its works. The great poet makes us feel our own wealth, and then we think less of his compositions. His best communication to our mind is to teach us to despise all he has done." Emerson 1979, S. 171 (The Over-Soul). Der Begriff ,to communicate' ohne begleitende Epitheta taucht bei Emerson vielfach als Bezeichnung für die ,reibungslose' Übertragung von nicht sprachlich Auszudrückendem auf; vgl. etwa unter den Gedichten, die Robinson sehr schätzte, aus The Celestial Love: „They can parley without meeting; / Need is none of forms of greeting; / They can well communicate / In their innermost estate“; Emerson 1902, S. 127.

${ }^{247}$ Vgl. Robinson 1979, S. 165 f. (Brief an Bess Dworsky vom 7.12.1931).
} 
Und auch er geht davon aus, daß über die emotionale Wirkung poetischer Rede das grundsätzlich nicht Benennbare zumindest vage erfahrbar gemacht werden kann. ${ }^{248} \mathrm{Er}$ spricht insoweit von einem ,Nimbus', in dem das Unsagbare ausgedrückt wird:

In real poetry you find that something has been said, and yet you find also about it a sort of nimbus of what can't be said. ${ }^{249}$

oder von den ,Obertönen' eines Gedichts:

They [the overtones] might be defined as the fringe of what isn't said. ${ }^{250}$

Die kritische Haltung Robinsons gegenüber der denotierenden Sprache findet ihren Widerhall auch im Fazit seines poetologischen Credo The Man Against the Sky:

Shall we, because Eternity records

Too vast an answer for the time-born words

We spell, whereof so many are that once

In our capricious lexicons

Were so alive and final, hear no more

The Word itself, the living word

That none alive has ever heard

Or ever spelt,

And few have ever felt

Without the fears and old surrenderings

And terrors that began

When death let fall a feather from his wings

And humbled the first man? ${ }^{251}$

Mit religiösen Obertönen ${ }^{252}$ wird hier das gesuchte ,lebendige Wort' genannt, dessen wichtigste Bedeutung das durch das Wort vermittelte Gefühl ist. Dieses Wort, das den „time-born words“ der denotierenden Sprache gegenübersteht, ist der Prüfstein des Dichters. Für den frühen Robinson bedeutet dies eklektisch in einem an Emerson orientierten und emphatisch-idealistischen Sinne, daß sich dem genialen Ohr der feine Widerhall des richtigen Wortes erschließt:

To mortal ears the plainest word may ring

Fantastic and unheard-of, and as false

And out of tune as ever to our own

Did ring the prayers of man made maniacs;

But if that word be the plain word of Truth,

It leaves an echo that begets itself,

Persistent in itself and of itself,

Regenerate, reiterate, replete. ${ }^{253}$

\footnotetext{
${ }^{248}$ Vgl. Robinsons Einschätzung der Nähe von ,poetry' und Musik in: Robinson 1975, S. 69 f. (Music and Poetry). Das grundsätzliche Ungenügen des Menschen verhindert für Robinson ein wirkliches Aufdecken der Wahrheit; vgl. Stevick 1969, S. 305-308; vgl. auch Shucard 1998, S. 366.

${ }^{249}$ Robinson 1975, S. 126 [5].

${ }^{250}$ Robinson 1975, S. 129 [6].

${ }^{251}$ Robinson 1954, S. 68; vgl. auch L'Envoi in: Robinson 1954, S. 108 f.; zur Stellung des Gedichts vgl. Robinson 1975, S. 148 [35]; vgl. zur Interpretation des Gedichts Stanford 1983, S. 145-148, der die Hauptfigur als Jedermann, der sich mit den Begrenzungen des mechanischen Materialismus auseinandersetzen muß, interpretiert. Robinson betrachtete sein Gedicht als Ablehnung einer materialistischen Weltanschauung (ebdort).

${ }^{252}$ Vgl. auch Burton 1969, S. 285.

${ }^{253}$ Robinson 1975, S. 45 (Robinsons Octaves I).
} 
Der spätere Robinson betont eher die technischen Fertigkeiten des Dichters. Doch sucht er nach wie vor nach dem richtigen Wort und dessen Echo. ${ }^{254}$ Auch hier hebt Robinson das epistemische Ungenügen des Menschen hervor. Die denotierend gebrauchten Wörter der Gemeinsprache sind zeitlich begrenzt und erscheinen damit nicht geeignet, eine transzendente Wirklichkeit zu ermessen - so es sie denn gibt. ${ }^{255}$ Besonders der Metaphysiker gerät auf der Suche nach der Wahrheit an das Ende seiner denotierenden Sprache und kann die von ihm erkannte Wahrheit demnach nicht an andere weitergeben: „He has come to the end of his words [...]":

To a realm that his word may not reach

He may lead none to find him;

An adept, and with nothing to teach,

He leaves nothing behind him. ${ }^{256}$

Damit vertritt Robinson einen von romantischen Poetiken geprägten Nominalismus. Er geht davon aus, daß die denotierende Sprache gegenüber dem Gefühl und der Wahrheit defizitär ist. ${ }^{257}$

Im Vergleich zu Emerson ist Robinsons Glaube an eine transzendente Wirklichkeit lediglich deutlicher durch die Position des Materialismus geschwächt. ${ }^{258}$ Die religiöse Wahrheit selbst, die durch poetische Texte fühlbar gemacht werden soll, steht für inn in Frage, so daß auch das Ziel der Texte stets zweifelhaft ist. Emerson gesteht der Sprache immerhin zu, eine über der „rohen [materiellen] Natur“ stehende Instanz der menschlichen Erkenntnis zu sein, die magisch-religiös mit der ewigen Wahrheit verbunden ist, und sieht gleichzeitig aus allem (Natur, menschliche Handlung und Sprache) eine gemeinsame religiöse ,All-Einheit' hervorscheinen. ${ }^{259}$ Für Robinson dagegen bleibt eine ewige, religiös verstandene Wahrheit grundsätzlich unbeweisbar, nicht mitteilbar und bestenfalls vage erfahrbar. ${ }^{260}$

\footnotetext{
${ }^{254}$ Vgl. Robinson 1975, S. 78-81 (Robinsons My Methods and Meanings) und S. 123 [4] (Good poetry must have...); vgl auch Weeks 1969b, S. 236; W.R. Robinson 1967, S. 71.

${ }^{255} \mathrm{Vgl}$. auch Donaldson 1966, S. 228.

${ }^{256}$ The Burning Book, Or the Contented Metaphysician, Robinson 1954, S. 47.

${ }^{257}$ Vgl. die Beschreibung der literarischen Sprache des 19. Jahrhunderts bei Bateson 1934, S. 98 f.

${ }^{258}$ Vgl. z.B. Robinson 1979, S. 163 f. (Brief an Dr. Will Durant vom 18.9.1931); Robinson 1979, S. 165 f. (Brief an Bess Dworsky vom 7.12.1931).

${ }^{259}$ Vgl. etwa die Äußerung Emersons in seinem Essay Nature: „Words are finite organs of the infinite mind. They cannot cover the dimensions of what is in truth. They break, chop, and impoverish it. [...] Words and actions are not the attributes of brute nature. They introduce us to the human form, of which all other organizations appear to be degradations. When this appears among so many that surround it, the spirit prefers it to all others. [...] Unfortunately, every one of them bears the marks as of some injury; is marred and superficially defective. Nevertheless, far different from the deaf and dumb nature around them, these all rest like fountain-pipes on the unfathomed sea of thought and virtue whereto they alone, of all organizations, are the entrances." Emerson 1971, S. 28.

${ }^{260}$ Vgl. Fussell 1954, S. 28 f. Vgl. auch Kaplan 1940, S. 30 f. und S. 32-34; Weeks 1969b, S. 240; Free 1969, S. $16 \mathrm{f}$.
} 
In den Texten Robinsons finden sich daher auch immer wieder Stellen, in denen von nicht in Worte zu fassenden Zuständen die Rede ist. So spricht Robinson gerne und durchaus traditionell und konventionell ${ }^{261}$ von „nameless pity“ oder „nameless passion“. ${ }^{262}$ In The man against the sky räsoniert der Sprecher über eine Figur, die am Horizont auf einem Hügel zu sehen ist und in die Abendsonne auf Landschaften blickt, die für den Sprecher nicht sichtbar sind: „As if there were to be no last thing left / Of a nameless unimaginable town,-“. ${ }^{263}$ Mit diesem Vergleich illustriert der Sprecher die nicht sprachlich mitteilbare oder darstellbare Erfahrung des (künstlerischen) Individuums. In The Flying Dutchman schließlich werden die unbenannten Welten zum Symbol der Unerreichbarkeit der Künstlerpersönlichkeit, die das „verschwundene Land“ erreicht und in der Dunkelheit allein „unseren“ Ursprung sucht, „Fearless of in what coil he may be caught / On seas that have no name“. ${ }^{264}$

Die durch die Lektüre des poetischen Werkes emotional gewonnene Erkenntnis entzieht sich der Benennung oder Beschreibung durch die denotierende Sprache. Sie ist eher vage und keiner sprachlichen Analyse zugänglich. ${ }^{265}$ Daher ist es nicht verwunderlich, daß die zeitgenössische Literaturkritik Robinson Dunkelheit vorwirft, Robinson seinerseits diesen Vorwurf nicht versteht und eine Erläuterung seiner Gedichte immer wieder mit dem Hinweis auf den Text selbst ablehnt. ${ }^{266}$

Auch in Robinsons spärlichen Äußerungen über die Funktion einzelner Gedichte kommt die genannte wirkungsästhetische Idee zum Ausdruck. So verteidigt er sich 1924 gegen den Angriff eines verletzten ,Patrioten', der glaubte, das Gedicht New England richte sich gegen die Neuengländer:

$\mathrm{He}$ [der Angreifer] will see that the whole thing is a satirical attack not upon New England, but upon the same patronizing pagans, whom he flays [...]. Apparently Mr. Darling has fallen into the not uncommon error of seizing upon certain words and phrases without pausing to consider just why and how they are used. ${ }^{267}$

Robinson will offensichtlich in seinem Gedicht all jene Vorurteile aussprechen, die gegenüber Neuengland gehegt wurden. Der Leser soll nun das Berechtigte oder Unberechtigte an den Vorurteilen gegen Neuengländer fühlen, indem er auf die ironische

\footnotetext{
${ }^{261}$ Vgl. Danneberg 1996, S. 1541.

262 Vgl. etwa Robinson 1975, S. 34 und S. 35 (The Night Before).

263 Robinson 1954, S. 60.

264 Robinson 1954, S. 473. Wichtig an allen diesen Stellen ist, daß 'name' natürlich für ,nomen' und nicht für ,nomen proprium' steht.

${ }^{265}$ Vgl. Robinson 1947, S. 109 (Brief an H. de Forest Smith vom 1.10.1893); vgl. Robinson 1979, S. 67 (Brief an L. V. Ledoux vom 20.6.1910).

266 Z.B. Robinson 1975, S. 78; vgl. Stevick 1969, S. 295 f. Das Unverständnis gegenüber dieser Methode Robinsons zieht sich bis in wissenschaftliche Analysen, die behaupten, Robinson würde in allen seinen Gedichten eine (präzise) Paraphrase des nicht Gesagten herausfordern; vgl. etwa Moran 1967, S. 385.

267 Robinson 1975, S. 83 f. (E.A. Robinsons On my „New England“ Sonnet); vgl. Donaldson 1969, S. 42; vgl. Stanford 1983, S. 158-160.
} 
Äußerung der Vorurteile emotional reagiert. Dies kann durchaus eine ambivalente Position sein, die gegenüber den Neuengländern nicht unkritisch ist. Die Lektüre des Texts als konventionell denotierende Äußerung des Autors mit Wahrheitsanspruch führt zu jenem Irrtum, dem „Mr. Darling“ erlegen ist.

Auf ein Verständnis poetischer Rede als ,wirkungsorientierter Rede' weist auch Robinsons Bemerkung in einem Brief zu seinem Gedicht Edward Alphabet hin:

Look at Edward Alphabet

Going home to pray!

Drunk as he can ever get,

And on the Sabbath day! - ${ }^{268}$

Robinson geht in einem erklärenden Satz von einer Ironisierung der Position des Sprechers aus: „You may not think it from the first lines but the poem is an argument against the present attitude of the females." ${ }^{269}$ Da der Protagonist ein Mann ist, kann Robinsons Bemerkung nur meinen, daß der Fokus des Gedichtes auf dem Sprecher liegen soll. Der Leser soll durch seine ablehnende oder humoristische Haltung gegenüber dem Sprecher emotional eine Erkenntnis gewinnen. Ihm mag etwa die Ablehnung bösartigen Moralisierens vermittelt werden. Kern des Gedichts ist also nicht die Beschreibung eines Sachverhalts, sondern die Art und Weise der Beschreibung durch den fiktiven Sprecher. ${ }^{270}$ Der Leser kann sich dabei auf die Wahrheit, Unvoreingenommenheit oder Vollständigkeit des Dargestellten nicht verlassen, denn die Darstellung des Sachverhalts hängt von den Interessen des durch seine Rede implizit gestalteten Sprechers ab. ${ }^{271}$ Die Beschreibungen der Figuren und der Situationen gehören zur Sphäre der von Robinson gestalteten fiktiven Gesellschaft und sagen insgesamt mehr über das beschreibende Subjekt als über die beschriebenen Objekte aus. ${ }^{272}$

Die skizzierten Eigenschaften von Robinsons poetischer Rede stehen in enger Verbindung mit Robinsons Umgang mit Eigennamen. Denn an Namen als vorwiegend durch ihre Referenz inhaltsreichen Zeichen wird sowohl auf der Ebene des Sprechers und der Figuren als auch auf der Ebene des (historischen) Autors Robinsons poetischer Umgang mit Sprache manifest.

\subsubsection{Namen in ästhetischer Funktion}

\footnotetext{
268 Robinson 1947, S. 238 (Brief an H. de Forest Smith vom 14.12.1894). Das Gedicht ist lediglich als Fragment in diesem Brief Robinsons überliefert. ${ }^{269}$ Robinson 1947, S. 238 (Brief an H. de Forest Smith vom 14.12.1894).

270 Vgl. Donaldson 1966, S. 220: „Never in his best work does Robinson yield to the temptation of the omniscient narrator and tells us what to think." Vgl. auch Nicolaisen 1978, S. 149; eine Ausnahme von dieser Regel ist allerdings Robinsons The Tree in Pamela's Garden (s.u.).

${ }^{271} \mathrm{Da}$ der Sprecher Robinsons meist nicht vertrauenswürdig ist, wurde verschiedentlich konstatiert; vgl. etwa Levenson 1969, S.165-167.

${ }^{272}$ Vgl. etwa Donaldson 1966, S. 221; Free 1969, S. 23 f.
} 
Ein erster Aspekt Robinsonscher Namen ist ihre Lautgestalt. Sie wird besonders in frühen Interpretationen erwähnt, So z.B. in der Robinson-Monografie Neffs:

The name Luke Havergal with its dying fall and associated rhymes and assonances sets the tone from the first line $e^{273}$

oder in einer anonymen zeitgenössischen Rezension:

The most characteristic thing in Mr. Robinson's verse is his complete appreciation of the music in a proper name - and not the music merely, but its general poetic value. ${ }^{274}$

Robinsons Namen sind zunächst vor allem eingängig. Die Gestalt seiner Namen hat vor allem ästhetische Funktion. Der Biograph Neff kolportiert über das Kind Robinson:

At ten, he was collecting words. With Gus and Alice Jordan he made a game of seeing who could find the biggest: long Bible names like Melchizedek and Nebuchadnezzar, words from Shakespeare that sounded grand even though you didn't know what they meant. ${ }^{275}$

Am Klang des Namens begeistern Robinson - so wie ihn Neff darstellt - offensichtlich die Fremdartigkeit und das Pompöse der ungewohnten Lautkombinationen. Die von Robinson für seine Figuren gewählten Namen sind dementsprechend klangvoll. So sind bei mehrteiligen Namen oder Namenpaaren häufig Alliterationen, Assonanzen und Graphemwiederholungen anzutreffen: ,Miniver Cheevy’, ,Cliff Klingenhagen', „Aaron Stark', ,Reuben Bright', „Ham Amory', „Bewick Finzer', ,Charles Carville', ,Fleming Helphenstine' oder ,Lisette' und ,Eileen', ,Isaac' und ,Archibald', ,LLewellyn' und ,Priscilla' oder ,John Gorham' und ,Jane Wayland'. 276

Auch Namenkataloge sind von Alliterationen und Assonanzen oder von Echos geprägt: „Noah, / Or Nathan, or Abimelech, / Or Lamech“ bzw. „Caligula, maybe, or Caliban, Or Cain." ${ }^{277}$

Eine große Rolle spielt für Robinson ferner die Prosodie des Namens. Daß Robinson sehr auf die Prosodie seiner Namen achtete, belegt eine Äußerung zum Namen der Titelfigur seiner Blankverserzählung Matthias at the Door:

There is a tendency to mispronounce Matthias, and I wonder if in parentheses under the title in the first advertisements, and in a short paragraph of publisher's news, you could say (pronounced Matthi-as). An accent on the first syllable completely destroys the metre of many of the lines. ${ }^{278}$

\footnotetext{
${ }^{273}$ Neff 1948, S. 68, vgl. auch S.7; McFarland 1974, S. 365; Weeks 1969b, S. 229.

${ }^{274}$ Aus einer anonymen Rezension in Cary 1974a, S. 94. Barnard z.B. behandelt Robinsons Eigennamen insgesamt in einem Kapitel über "Words and Music"; Barnard 1952, S. 57. Barnards Begriff des ,Klangs' (,sound") eines Namens umfaßt das gesamte semantische Potential.

${ }^{275}$ Neff 1948, S. 7. Die Wirkung dieser Sammelfreude kann man an den exempla im Gedicht The Voice of Age von 1916 nachvollziehen; vgl. Robinson 1954, S. 42 f.

${ }^{276}$ In den Blankverserzählungen finden sich z.B. ,Avenel Gray' und ,Seneca Sprague' oder ,Oakes' und ,Oliver'.

277 Robinson 1954, S. 456 (The Wandering Jew) und S. 40 (Theophilus).

${ }^{278}$ Vgl. Robinson 1975, S. 147 [32].
} 
Die längeren Namen sind meist durch das alternierende Versmaß gekennzeichnet, das eingängig wirkt und Robinsons Gedichte und Verserzählungen prägt: ,Aaron Stark' (óo/ó), ,Reuben Bright' (óo/ó), ,Eben Flood’ (óo/ó), ,Hector Kane’ (óo/ó), ,Richard Cory’ (óo/óo), ,Bewick Finzer' (óo/óo), ,Priscilla’ (oóo), ,LLevellyn’ (oóo), ,Edward Alphabet’ (óoóoó), ,Augustus Plunket’ (oóoóo), ,Theophilus’ (oóoó), ,Ananias’ (óoóo), ,Fleming Helphenstine’ (óoóoó), ,Cliff Klingenhagen’ (oóoóo), ,Leonora’ (óoóo), ,Pamela’ (óoó), ,Amaryllis' (óoóo), ,Leffingwell' (óoó), ,Clavering' (óoó). ${ }^{279}$

Dabei werden die mehrteiligen Namen wie Komposita behandelt, denn der Rufname bildet im Kontext des Satzes eine Senkung: „Cliff Klingenhagen [oóoóo] had me in to dine [...]“, „A melancholy face Charles Carville [oóo] had; [...]“, „I'm over here to tell you what you are, Jane Wayland, [...]" (oóo), Tell me what you're doing over here, John Gorham, [...]" (oóo), There is the western gate, Luke Havergal, [...]” (oóoó), "[...] / They told about James Wetherell. (oóoó), [...] the ghost / Of old Ham Amory [oóoó], the murdered host, [...]". Einsilbige Rufnamen - ,Job' - werden variabel auf einer Hebung oder Senkung eingesetzt.

Im Falle von ,Shadrach O'Leary' (óooóo) wird sogar die doppelte Senkung, die durch den mehrteiligen Namen entsteht, im Haupttext vermieden. Der Name tritt dort nur geteilt auf.

Die Berücksichtigung der Prosodie des Namens wird auch in den Namenpaaren (die häufig den Titel des Gedichts bilden) sehr deutlich. Die Namen der Paare sind fast immer prosodisch identisch. Mit der metrisch variabel einsetzbaren Konjunktion ,and' sind die Namenpaare zudem oft eingängig alternierend: ,Lisette' und ,Eileen' (oó), ,Isaac' und ,Archibald' (óoó) ${ }^{280}$, ,LLewellyn' und ,Priscilla' (oóo), ,John Gorham' und ,Jane Wayland' (oóo), ,Alexis' und ,Evander' (oóo), ,Morgan' und ,Fingal' (óo).

Wenige Namen haben auch eine doppelte Senkung. Diese macht das gleichmäßige Metrum des Gedichts im Fall der lächerlichen Figur Miniver Cheevy (óooóo) unregelmäßig und perspektiviert die Figur. In den anderen Fällen (,Hannibal Brown [óooó] oder ,John Evereldown' [oóooó]) entspricht der Name dem übrigen Versmaß der jeweiligen Gedichte.

Robinsons Bemühen um eine gleichmäßige prosodische Gestaltung der Gedichte prägt die Lautgestalt seiner Namen. Ihre Lautgestalt hat ästhetische Funktion. Eine charakterisierende Bedeutung der Klanggestalt kann nur eindeutig festgestellt werden, wenn

279 ,Leffingwell' und ,Clavering' ließen sich auch (óoo) lesen. Zur metrischen Anpassung von Namen in Kinderliteratur vgl. Aschenberg 1991, S. 57 f.

${ }^{280}$ Diese Namen, die auch mit mehrfacher Senkungsfüllung gelesen werden könnten (etwa 'Isaak' und 'Archibald' als óoo), werden durch die gleichmäßige Alternation des Kotexts ebenfalls alternierend: óoó. 
sich ein Klang häuft. So heißt es in LLewellyn and the Tree von einer Frau, die sich aufgeregt ihrem Mann entgegenstellt: „Priscilla, warmer than her name / And shriller than the sound of saws“. ${ }^{281}$ Der Bezug zu dem bei den amerikanischen Puritanern beliebten Namen der devoten, treuen und stillen Anhängerin Paulus'282 stimmt nicht mit dem Charakter der Robinsonschen Figur überein. Dafür charakterisiert anscheinend die Lautgestalt des Namens (also der r-, i- und s-Laute in ,Priscilla') die schrille Stimme der Frau. In anderen Fällen teilen sich tragische wie glückliche, positive wie negative Figuren die gleichen Laute. ${ }^{283}$

Die Untersuchung von Eigennamen kann sich nach unseren theoretischen und systematischen Vorüberlegungen nicht mit dieser ästhetischen Funktion zufriedengeben. Robinsons Namen wurden, wie gezeigt, vor allem deswegen gelobt, weil die Namen zu den Figuren paßten. Im Folgenden soll daher das Verhältnis vom Namenzeichen zum Namenträger und zu der gestalteten Welt betrachtet werden.

\subsubsection{Realistische Namen}

\subsubsection{Tilbury Town als gemeinsamer wirklichkeitsnaher Hintergrund}

Bei Robinsons allgemein so genannten ,Tilbury Town-Gedichten' handelt es sich um Texte aller seiner Schaffensperioden. ,Tilbury Town' dient den Interpreten zumeist als unspezifische Hintergrundwelt für alle jene Gedichte, die nicht in einer näher spezifizierten Welt spielen. ${ }^{284}$ Eine Analyse der fiktiven Eigennamen in Robinsons Gedichten muß daher zunächst die Verwendung und die Reichweite des Ortsnamens Tilbury Town erklären. ${ }^{285}$

Es besteht Einigkeit darüber, daß Robinsons Gedichte zu einem großen Teil durch die neuenglische Stadt Gardiner (Maine) angeregt wurden, in der Robinson aufgewachsen ist und die zusammen mit New York auch die Vorbilder für viele der von inm gestalteten

\footnotetext{
${ }^{281}$ Robinson 1954, S. 50-55.

${ }^{282}$ Vgl. die Erwähnung Priscas/Priscillas in Römer 16,3, I. Korinther 16,19, und II. Timotheus 4,19. Die nachfolgenden Hinweise auf die Bibel beziehen sich auf ,The Holy Bible' 1902, die auch Robinson besaß; vgl. Cary 1969, S. 335.

${ }^{283}$ Sowohl der negative Aaron Stark (aus Aaron Stark) als auch der positive Archibald (aus Isaac and Archibald) sind durch ,a' gekennzeichnet. Die eher negative Priscilla (aus Llevellyn and The Tree), aber auch der deutlich positiv gesehene Cliff Klingenhagen (aus Cliff Klingenhagen) tragen i-geprägte Namen, usw.

${ }^{284} \mathrm{Vgl}$. Zietlow 1967, S.188.

${ }^{285}$ Die Tilbury Town-Gedichte werden hie und da als Robinsons bedeutendste gefeiert und generell den späten Blankverserzählungen vorgezogen; vgl. etwa Donaldson 1966, S. 223. Die narrativen Gedichte des späten Robinson beschäftigen sich mit Figuren verschiedener Hintergrundwelten. So ist sein berühmtes Tristram, für das er den Pulitzer Preis erhielt, Teil mehrerer Blankversepen, die die Welt der Artussage gestalten. Nicodemus aus der gleichnamigen Gedichtsammlung behandelt ein biblisches Thema; vgl. Robinson 1954, S. 595-732, S. 1159-1169.
} 
Figuren geliefert haben soll. ${ }^{286}$ Konkrete Beschreibungen einer Außenwelt fehlen aber oder treten doch so marginal auf, daß sie keine eindeutige Identifizierung ermöglichen. Tilbury Town bleibt deshalb ein abstrakter Hintergrund: „Tilbury Town is a world of people, not of places and the essentially human is not dependent on place or time. ${ }^{\text {"287 }}$ Der semantische Hintergrund wird von einer durch den Sprecher repräsentierten und evozierten ,Wertegemeinschaft' gebildet. Dadurch unterscheidet Robinson sich von den typischerweise als ,regional poets' bezeichneten Dichtern. ${ }^{288}$

Trotz der Vagheit der Hintergrundwelt gelingt es Robinson, für viele Gedichte eine gemeinsame Welt zu evozieren. Er erreicht dies dadurch, daß sein Sprecher regelmäßig gegen Konversationsmaximen verstößt, indem er die Bekanntheit seiner Umwelt voraussetzt. Vornehmlich referiert der Sprecher mit Personalpronomina (besonders in der ersten Person Plural) auf eine nicht näher definierte, aber als bekannt vorausgesetzte Gemeinschaft. Dieser scheint er sich ebenso oft zugehörig zu fühlen (z.B. in Richard Cory), wie er sich von ihr distanziert (z.B. in Captain Craig). ${ }^{289}$ Auch die unvermittelte Erwähnung scheinbar bekannter Eigennamen sowie die gelegentliche gedichtübergreifende Verwendung von Eigennamen bzw. Figuren ist Teil dieser Strategie. So taucht John Evereldown aus dem gleichnamigen Gedicht (1897) als Zeuge eines geheimnisvollen Geschehens in The Tavern (1897) wieder auf. George Annandale aus der Blankverserzählung The Book of Annandale (1902) wird im Sonnet How Annandale Went Out (1910) und im Gedicht Annandale Again (1932) wieder erwähnt. Isaac aus Isaac and Archibald (1902) erscheint in Recalled (1921) nochmals. Sein Kompagnon Archibald tritt in Stafford's Cabin (1916) als Zeuge und in Archibald's Example (1920) als Sprecher wieder auf. „Stafford's Cabin“ wiederum wird schon in Isaac and Archibald genannt. ${ }^{290}$

\footnotetext{
${ }^{286}$ Vgl. Thakur 1977, S. 54; vgl. auch Weeks 1969a oder Anderson 1980, S. 54. Mit der Offenbarung realer Inspirationen seiner Figuren ist Robinson stets äußerst zurückhaltend, obwohl von zeitgenössischen Biographen die Existenz solcher Vorbilder stets vermutet wird. Vgl. die Anekdote zu Robinsons Isaac and Archibald bei Hagedorn 1938, S. 168. Vgl. außerdem Robinson 1975, S. 158 [53] oder Robinson 1947, S. 119: „The people who interest me are my close associates and the creatures of my own fancy. I have a dozen or so of the latter who have kept me company for a long time. Now I want to see them on paper [...]." Vgl. auch die falsche Auslegung dieser Sätze durch Anderson 1967, S. 119. In Robinsons Gedichten spricht jeweils ein Sprecher (oft als Teil eines normativ stark geprägten 'Wir'), der als Teil der fiktiven Welt zu verstehen ist.

${ }^{287}$ Anderson 1968, S. 79; vgl. auch Thakur 1977, S. 56-63, bes. S. 56 und S. 65: „[It] is just a landscape of the mind rather than a photographic replica of the earth."; vgl. auch Coffin 1964, S. 29 f.; W. R. Robinson 1967, S. $75-78$.

${ }^{288}$ Vgl. Zietlow 1967, S. 198: „Tilbury Town stands for the here and now; its tradition is materialism, its destiny downfall and oblivion." Vgl. auch Thakur 1977, S. 65. Selbst jene Gedichte, die sich auf historische Personen beziehen, enthalten außer den realen Namen kaum weitere historische Referenzen. Sie befassen sich mit den allgemeinen und abstrakten Eigenschaften einer idealtypischen Figur - 'dem Dichter', 'dem Künstler' etc.

${ }_{289}$ Vgl. Robinson 1954, S. 82, S. 113; Zietlow 1967, S. 192 f.; vgl. auch Kruse 1974, S. 179.

${ }^{290}$ Vgl. Robinson 1954, S. 73 f., S. 93, S. 195-211, S. 346, S. 1200-1206, S.169-181, S. 14 f., S. 492.
} 
Zum Teil wird die Stadt in Erinnerung gebracht, indem sie namentlich erwähnt wird. Robinson verwendet den Namen ,Tilbury Town' zwar sparsam und hauptsächlich in den frühen Gedichten. Gerade die unsystematische Erwähnung des Ortsnamens trägt aber dazu bei, daß der gleiche Hintergrund für viele Gedichte angenommen wird. ${ }^{291}$ Dies legt es nahe, alle Gedichte, die eine ähnliche Figuren- oder Sprecherkonstellation zeigen, vor dem gemeinsamen Hintergrund ,Tilbury Town' zu sehen. Zweifel an der Einheitlichkeit der Welt spielen kaum eine Rolle, weil keine eigentliche Fiktion aufgebaut wird.

Da Robinson das nicht spezifizierte inklusive Personalpronomen ,we' so verwendet, daß es auch ,die Menschheit' umfassen kann, muß allerdings für die Gedichte ohne einen Ortsnamen ungeklärt bleiben, welche Hintergrundwelt sie haben sollen. Tilbury TownGedichte im engeren Sinne sind also nur jene Gedichte, in denen der Ortsname verwendet wird. Besonders in den späten Gedichten mit unspezifischem Hintergrund kommt als Hintergrundwelt etwa New York (wo Robinson lebte) ebensogut in Betracht wie Neuengland. In diesen Fällen ist es plausibel, die Gedichte dem jeweiligen räumlichen und zeitlichen Umfeld Robinsons zuzuordnen. Alle Gedichte, auch diejenigen, die in New York (etwa The Wandering Jew) oder an anderen Orten spielen, zeichnen eine ähnliche Gemeinschaft, wie sie das Personalpronomen ,we' in den eindeutig in Tilbury Town spielenden Gedichten repräsentiert.

Der Name ,Tilbury Town' ist auf unterschiedliche Weise erklärt worden. Hagedorn geht von der Ursprungssemantik „till“ aus - eine (vergrabene) Geldkassette, die für den Materialismus der Neu-Engländer stehen kann; Neff wiederum vermutet, „the name [...] presumably comes from the Tilbury, a smart two wheeled open carriage of those days“; Anderson schließlich entdeckt einen „fashionable stockist that supplies prestigious luxury items“ mit Namen ,Tilbury' im Roman Pendennis von William Makepeace Thackeray. ${ }^{292}$ Der Name würde in jedem Fall auf ein Statussymbol deuten und so die materialistisch gesinnte Bevölkerung in Robinsons fiktiver Welt charakterisieren. ${ }^{293}$

Jedoch sollte nicht vergessen werden, daß in Großbritannien ein Ort ,Tilbury' an der Themse mit den ,Tilbury Docks' existiert, der den Namen angeregt haben könnte. Diese Verbindung liegt nahe, da Robinsons Heimatstadt Gardiner, das Vorbild für Tilbury

\footnotetext{
291 Der erste Hinweis auf die Stadt findet sich in John Evereldown (1897); vgl. auch Thakur 1977, S. 57 f. Danach tritt der Ortsname unsystematisch in weiteren Gedichten und Blankverserzählungen auf; so z.B. in The Tavern (1897), Flammonde (1916), Captain Craig (1902), Lisette an Eileen (1916), Old King Cole (1916), Mr. Floods Party (1921), The Tree in Pamela's Garden (1921) und Mortmain (1925); vgl. Robinson 1954, S. 93 , S. 3, S. 113 , S. 49 f.,S. 17 , S. 573 , S. 576 , S. 899

${ }^{292}$ Vgl. Hagedorn 1938, S. 87; Neff 1948, S. 61; Anderson 1968, S. 79-80 und zusammenfassend Thakur 1977 , S. 54 f.

${ }^{293}$ Dieses Urteil Robinsons über seine Heimat ist vielfach belegt oder kolportiert worden. Vgl. z.B. Cary 1974b, S. 377 (Brief Robinsons an Arthur Davis Variell vom 7.1.1926).
} 
Town, ebenfalls eine Hafenstadt ist. ${ }^{294}$ Auch in dieser Interpretation ist der Name charakterisierend, wenn auch ohne Wertung.

In jedem Fall aber ist der Name ,Tilbury Town' realistisch im anglo-amerikanischen Raum, wo die Benennung amerikanischer Orte nach europäischen Vorbildern üblich war. Robinson zeigt mit seinem Ortsnamen eine den Bildungen von ,New England' bis ,New York' verwandte Namengebungspraxis. Das faible seiner dichterischen Zeitgenossen wie Walt Whitman, Carl Sandburg oder James Fenimore Cooper für indianische Namen teilt Robinson offenbar nicht. ${ }^{295}$

\subsubsection{Wirklichkeitsnähe durch die Gestalt der Namen}

Zur Annahme eines gemeinsamen realistischen Hintergrundes der Tilbury TownGedichte tragen neben dem Ortsnamen vor allem die Figurennamen bei. Die von Thakur angeführte Ähnlichkeit unter den skizzierten Charakteren, „those that have gone down and out in their struggles with environment" ${ }^{296}$, ist nur ein schwacher Hinweis auf den gemeinsamen Hintergrund. Erstens sind auch Figuren anderer Bereiche (etwa in Robinsons Artus-Erzählungen) nach diesem Menschenbild ${ }^{297}$ Robinsons gestaltet, und zweitens werden die Figuren Tilbury Towns (etwa in Archibald's Example) keineswegs so einheitlich gezeichnet. Es sind vielmehr die Figurennamen in den Gedichten, die einen kontinuierlichen Hintergrund evozieren. Die häufige unvermittelte Benutzung von Namen, die dem Leser noch unbekannt sind, deutet einen Sprecher an, der sich in einem ihm vertrauten und kontinuierlichen Raum bewegt. ${ }^{298}$ Die Auswahl der Namen läßt sich aus der Namengebungspraxis im Umfeld Robinsons erklären. Die Eigennamen weisen durch ihre sortalen Prädikate nicht nur auf einen den Gedichten gemeinsamen Hintergrund, sondern - weitergehend - auf den onomastischen Raum in Robinsons Heimatstadt Gardiner. ${ }^{299}$

\footnotetext{
294 Thakur 1977, S. 57, spottet: "Many students of Robinson's poetry have had to become historians of his home town [Gardiner, Maine] gathering ample information in the process." Robinson selbst hat wenngleich ungern - zugegeben, daß Gardiner ein vages Vorbild war; vgl. etwa Robinson 1975, S. 146 [30]; vgl. auch Nivison 1960, S. 170.

${ }^{295}$ Vgl. dazu auch Robinsons Bemerkung zur Unverständlichkeit indianischer Charaktere für ,den weißen Mann' in Robinson 1947, S. 131 (Brief an Harry de Forest Smith vom 18. Februar 1894).

${ }^{296}$ Thakur 1977, S. 56.

${ }^{297}$ Vgl. auch Aiken 1970, S. 26.

${ }^{298}$ Vgl. zur unvermittelten Einführung realer und fiktionaler Eigennamen auch Tschauder 1989, S. 139141.

299 In Übereinstimmung mit dieser These wagt Coxe die Vermutung, „had Robinson given them [John Evereldown, Richard Cory, Reuben Bright, Luke Havergal] foreign names and put them somewhere in Provençe or the Mediterranean basin, what a difference it might have made“; vgl. Coxe 1969, S. 50; vgl. auch Coffin 1964, S. 38. Von Interpreten und Kritikern wird allerdings auch immer wieder behauptet, daß Robinson sehr ungewöhnliche Namen verwendet habe: „The names of Robinson's characters are frequently unusual, either to symbolize the character or to achieve particularization without any possibility of identification with actual people." Anderson 1968, S. 79; vgl. auch Barnard 1952, S. 57 oder Cary 1974a, S. 14f., und die dort abgedruckten Rezensionen.
} 
Daß ein Großteil der Namen in Robinsons Gedichten realistisch sind, kann anhand realer Eigennamen aus Robinsons Umfeld festgestellt werden. Robinson erwähnt in seinen Briefen Namen wie ,Eben Holden', ,Winthrop Ames', oder ,John Tarbox'. Er schreibt an ,Lewis M. Isaacs' oder ,John Hays Gardiner'. ${ }^{300}$ Hermann Hagedorn nennt ,Israel Jordan' oder zählt als illustre Bewohner Gardiners z.B. ,Sarah' und ,Nathaniel Whitmore', ,Horatio Alger' oder in einem Namenkatalog ,Shakespearescher' Namen „Talbot, Tudor, Howard, York, Lancaster, Flewellyn“ auf. ${ }^{301}$

Von besonderem Interesse in diesem realen onomastischen Raum um Robinson ist die Erwähnung eines Nachbarn der Eltern Robinsons in Gardiner. Dessen Name könnte das strukturelle Vorbild für einen Teil der Robinsonschen Namen gewesen sein: ,Hezekiah Dorn'. ${ }^{302}$ Der Name ist aufgebaut aus einem alttestamentarisch präfigurierten Rufnamen (aus ,Ezechiel') und einem Familiennamen, der in Hinblick auf seine (deutsche) Ursprungssemantik gerade noch transparent ist. Nach diesem Modell eines neuenglischen Namens sind bei Robinson offensichtlich gebildet: ,Aaron Stark', ,Reuben Bright', ,Eben[ezer] Flood'. Ähnlich sind ,Shadrach O'Leary', ,Ham Amory’303 und ,Luke Havergal' aus alttestamentarischen Rufnamen, aber undeutlicheren Familiennamen zusammengesetzt. Schließlich sind Namen mit ähnlichem Aufbau, aber wie etwa beim realen „Horatio Alger' mit literarisch-historischen Präfigurationen zu finden: ,Hector Kane’, ,Hannibal Brown' oder ,Augustus Plunket'.

Eine weitere Untergruppe der realistischen Namen bei Robinson repräsentiert die respektablen Rufnamen nach dynastischen englischen Königsnamen, die mit einem üblichen amerikanischen Familiennamen kombiniert sind. Diese sind zu weit verbreitet, um semantisch durch eine spezifische Präfiguration jenseits der Respektabilität markiert zu sein: ${ }^{304}$,Richard Cory', ,Charles Carville', ,James Wetherell', ,Jane Wayland', ,John Gorham'305, ,John Evereldown', ,Edward Alphabet'. Zu ihnen gehören daher auch Kombinationen aus nicht präfigurierten Ruf- und Familiennamen: ,Cliff Klingenhagen', ,Fleming Helphenstine'.

In die Gruppe der im neuenglischen Raum zumindest möglichen und daher realistischen Namen gehören schließlich auch die Namen einiger Figuren, deren ,respektabler'

\footnotetext{
${ }^{300}$ Vgl. z.B. Robinson 1979, S. 78 (Brief an Lewis M. Isaacs vom 7.3.1913 und Brief an John Hays Gardiner vom 9.3.1913); vgl. auch S. 51 (Brief an Laura E. Richards vom 9.3.1902).

${ }^{301}$ Hagedorn 1938, S. 237 und S. 51.

${ }^{302}$ Vgl. Robinson 1947, S. 256 (Brief an Harry de Forest Smith vom 15.10.1896).

${ }^{303}$ Vgl. zu ,Ham' Genesis 9,18-29.

${ }^{304}$ Als Kriterium für einen realistischen Namen wird hier die Tatsache angesehen, daß eine reale Person dieses Namens existiert oder existiert hat. Das setzt voraus, daß der Name in Enzyklopädien, im Internet oder in Namenlexika zu finden ist.

${ }^{305}$ In diesen Fällen ist aufgrund der weiten Verbreitung der Namen nicht eindeutig zu entscheiden, ob es sich um biblische Präfigurationen (der Evangelist oder der Täufer 'Johannes' etc.) oder um einen dynastischen Königsnamen handelt.
} 
Ruf- oder Familienname allein steht: ,Theophilus', ,Eileen', ,Leonora', ,Lorraine'306, ,Pamela', ,Cassandra', ,Job', ,Amaryllis', ,Priscilla', ,Stafford', ,Leffingwell', ,Clavering', ,Lingard’307, ,LLevellyn’308, ,Nimmo'309, ,Francesca', ,Morgan', ,Vickery', ,Vanderberg'. ${ }^{310}$

Robinsons Figurennamen sind also durch das topographische sortale Prädikat $\{\mathrm{Neu}-$ Engländer\} oder zumindest \{nordamerikanisch\} und vermutlich durch das soziale sortale Prädikat \{(klein-)bürgerlich\} gekennzeichnet.

Wie Robinson seine realistischen Namen findet, zeigt dabei eine kurze Bemerkung Robinsons über die Hauptfigur der Blankverserzählung Captain Craig. In einem Brief an William Vaughn Moody vom 10.5.1900 schreibt Robinson:

But fort the present I can do nothing but stay here and find out what is to be done with a more or less valuable piece of property called 'Captain Craig'. When I was in Cambridge the application of a Divinity School man who gloried in the name of Louis Craig Cornish, and the Craig part stuck. ${ }^{311}$

Was mit dem Namensvorbild Captain Craigs nun geschah, wird von Robinson in seinem defizitären Satz leider nicht berichtet. Doch für unsere Überlegungen ist wichtig, daß Robinson einmal gehörte Namen in Erinnerung bleiben. Er benutzt reale Eigennamen, die er gehört hat, ohne daß deren reale Namenträger etwas mit den gestalteten Figuren zu tun haben müssen.

Doch beschränkt sich der Eindruck der Eigennamen nicht auf lautliche Elemente. Robinsons ironische Bemerkung zu ,Louis Craig Cornish', der ,mit seinem Namen glänzt', weist darauf hin, daß dem Namen entweder aufgrund der Person oder aufgrund des Klanges für Robinson eine Aura des Grandios-Komischen anhaftet. Diese Aura wird die Namenwahl für den genialischen „pauper“ ,Captain Craig' mitbestimmt haben.

Ausdruck der Wichtigkeit in Robinsons neuenglischer Gesellschaft, einen 'anständigen' (Ruf-)Namen zu tragen, ist die seit Herman Hagedorns zeitgenössischer Biographie kolportierte Anekdote, Edwin Arlington Robinson sei durch das Losen einer Feriengesellschaft zu seinem ihm angeblich verhaßten Rufnamen gekommen, da seine Eltern

\footnotetext{
${ }^{306}$ Robinson setzt den Namen im Titel The Growth of ,Lorraine' in Anführungszeichen, was von den Interpreten als Zeichen dafür gesehen wird, daß es sich um den ,professionellen' Namen einer Prostituierten handelt; vgl. etwa Satterfield 1981, S. 8.

${ }^{307}$ Zu den ,New Yorker Charakteren' Clavering, Leffingwell und Lingard vgl. Donaldson 1969, bes. S. 49.

${ }^{308}$ Llewellyn ist ein walisischer dynastischer Name. Robinson besaß ein in New York gedrucktes Werk von Llewellyn Jones (allerdings von 1925 - Llewellyn and the Tree wurde 1916 veröffentlicht). Ihm wird der Name als realistischer bekannt gewesen sein; vgl. Cary 1967, S. 408.

${ }^{309}$ Dies ist Z.B. der Familienname des Herausgebers von John Bunyans The Pilgrims Progreß, London 1874, das Robinson besaß, vgl. Cary 1967, S. 402.

${ }^{310}$ Einige nicht englische Namen wie ,Lisette' und ,Lorraine' sind leicht zu integrieren, wenn man bedenkt, daß die USA ein Einwanderungsland sind, in dem Namen aller europäischen Sprachen vertreten sind. Auch diese französischen Namen sind daher im amerikanischen Raum realistische Namen.

${ }^{311}$ Fussell 1951/52, S. 178 (Brief an Moody vom 10.5.1900).
} 
keine Lust gehabt hätten, ihm einen Namen zu geben. ${ }^{312}$ Uns interessiert nicht so sehr, ob diese Anekdote stimmt. Wichtig ist vielmehr, daß Robinsons amerikanische Biographen den beschriebenen Vorgang als eine schändliche Namenvergabepraxis betrachten und daraus schließen, ein solcher Name müsse dem Poeten verhaßt gewesen sein. Die Gesellschaft um Robinson achtet offenbar stark auf eine der Konvention genügende Symbolik und Tradition und auf die Aura der vergebenen Rufnamen. Darauf deutet z.B. auch der Glückwunsch Robinsons an Herman Hagedorn hin, dem er zur Geburt des Sohnes und gesondert zu dessen Namen ,Oakley Hagedorn' gratuliert. ${ }^{313}$

Die Bereiche, aus denen Robinson die Namen schöpft, spiegeln die (religiösen) Normen der neuenglischen bürgerlichen Gesellschaft. Es handelt sich um alttestamentarische und historische wie literarische heroische Vorbilder. ${ }^{314}$ Daher kommt die oft auffällige Kombination aus klangvollem Rufnamen und profanem Familiennamen zustande. Die in den USA sehr freie Namenwahlpraxis vereinfacht die Selbstdarstellung des Namengebers bzw. die Wunsch-Charakterisierung des Namenträgers durch einen Eigennamen. Der Glanz des heroischen, literarischen, frommen oder redenden Rufnamens ersetzt womöglich den Glanz eines adligen Familiennamens, den die bürgerliche Gesellschaft nicht mehr zu bieten hat.

Robinson nutzt die Namengebungspraxis Neuenglands, um seine zumeist scheiternden Figuren $^{315}$ ironisch zu gestalten. Mit Bezug auf dieses regelmäßige Scheitern der Robinsonschen Figuren beschreibt Coffin in seiner Vorlesung 1964 dessen Realismus der Namengebung - polemisch, aber aus relativ großer kultureller Nähe zu Robinsons gesellschaftlichem Umfeld folgendermaßen:

If you wish to know what happens to people in big houses when their fortunes and philosophies ebb away, go and live in any small New England place. The people are there, though they may not all have the ironical names Robinson gives them. They have some that are ironical enough though. For the older New England ran to Old Testament names that are right ones for heads of clans and givers of laws. These people have no laws to give now and no clans to head. [...] There is irony in Robinson's use of the old romantic names, which once meant whole charters of salvation, on the small and defeated people of today. Big names are often hard burdens to bear $[\ldots]^{316}$

Die Präfigurationen der Eigennamen Robinsons sind weniger als Charakterisierungen zu verstehen. Vielmehr dienen seine realistischen Namen dazu, die namengebende

\footnotetext{
${ }^{312}$ Vgl. Hagedorn 1938, S. 13; vgl. bes. Waggoner 1968, S. 283; vgl. auch Coxe 1969, S. 31; McFarland 1974, S. 375 Fn. 1; Cary 1974a, S. 15. Daß sein Name Robinson verhaßt war, ist bei Hagedorn noch nicht zu lesen.

${ }^{313}$ Vgl. Robinson 1979, S. 112 (Brief an Hermann Hagedorn vom 8.9.1918).

${ }^{314}$ Robinsons Biograph Hagedorn betont, daß die Kleinstädter Gardiners sehr belesen waren, vgl. Hagedorn 1938, S. 3. Die Bibel war für Robinson eine wichtige Inspirationsquelle; vgl. Ayo 1969.

${ }^{315}$ Vgl. etwa Stanford 1983, S. 155.

${ }^{316}$ Coffin 1964, S. 38 und S. 47.
} 
Gesellschaft Robinsons durch die Differenz zwischen dem semantischen Potential des Namens und dem Namenträger ironisch in Frage zu stellen. Deutlich wird diese Namenironie in den Fällen, in denen die Namensemantik im Gedicht auf humoristische Weise ausgeführt wird:

a)

Although his wish was never to baffle us Hannibal Brown was dolichocephalous. His head reached half way up to heaven. Hannibal's hat was a number seven. ${ }^{317}$ b)

Augustus Plunket, Ph.D., And oh, the Bishop's daughter; A very learned man was he And in twelfe weeks he got her;

And oh, she was a fair to see As pippins on the pippin tree... $\mathrm{Tu}$, tui, tibi, te,- - chubs in the mill of water. ${ }^{318}$

So verraten ,Hannibal Brown' (aus Hannibal Brown) und auch „Augustus Plunket, Ph.D." (eine Dichtung der Titelfigur aus Captain Craig) schon durch die starke Diskrepanz zwischen heroischem Rufnamen und betont profanem Familiennamen, daß die Präfiguration ironisch ist. Hinzu kommen weitere Anspielungen, wie etwa, daß der langschädelige Hannibal Brown den Namen jenes Heerführers trägt, mit dem die karthagischen Kriegselefanten assoziiert werden. Ebenso verwendet Robinson in Augustus Plunket, Ph.D. lateinische Demonstrativa im Stile grammatischer Merkverse, die den präfigurierten Namen lächerlich erscheinen lassen.

Einige wenige Namen schließlich, die tatsächlich aufgrund ihres Aufbaus oder ihrer Präfiguration als reale Taufnamen unwahrscheinlich sind, können als Übernamen interpretiert werden. Sie haben insofern eine Sonderstellung im Namensystem Robinsons, als sie deutlicher charakterisierende Funktion haben. Dies gilt etwa für ,Flammonde’, ,Miniver Cheevy', ,Uncle Ananias', ,Old King Cole', ,Saint-Nitouche', oder ,Bokardo'.

In einen realistischen onomastischen Raum können sie als Übernamen integriert werden. Robinson neigte dazu, situationsabhängig Übernamen anzunehmen. Dies wird an seinen spielerischen Pseudonymen in Briefunterschriften deutlich, die Robinson je nach Briefinhalt, seinem aktuellen Gemütszustand und seinen momentanen literarischen Vorlieben variierte. So nennt er sich einer Frau gegenüber „Hank Felio (not Figlio)“, nach-

\footnotetext{
${ }^{317}$ Hannibal Brown: An Alcaic, in: Robinson 1975, S. 50.

${ }^{318}$ Augustus Plunket wird in Captain Craig von einer Figur gedichtet (Robinson 1954, S.139); Anderson 1980, S. 58 f., vermutet, daß Robinson hier frühere Gedichtentwürfe, die als eigenständige Texte von inm selbst , ausgesondert wurden', weiterverarbeitete.
} 
dem er über sein Gedicht Vickery's Mountain geredet hat, „P. Vickery Esquire“ oder in einer schwierigen Situation „R. Crusoe“ oder „Torquato Tasso“. 319

Auch seine Benennungen in den Gedichten, etwa einer untreuen Frau als ,SaintNitouche' (die französische Personifikation der Scheinheiligkeit) oder einer unergründlichen Figur als ,Bokardo' (ein logisch nur ex negativo zu beweisender Syllogismus), sind als kurzzeitige Übernamen zu verstehen, die der Sprecher vergibt. ${ }^{320}$

Die realistischen Eigennamen in Robinsons Texten bewirken durch ihre sortalen Prädikate und durch ihre Gestalt, daß der reale Hintergrund des Autors auch als Hintergrund seiner Gedichte evoziert wird. Gleichzeitig wird eine Anwendung auf Individuen oder individuelle Situationen der Realität - die Robinson nur ungern zugegeben hat ${ }^{321}$ - dadurch verhindert, daß Robinson keine bekannten realen Namen aus Gardiner verwendet. Robinson konstruiert eine wahrheitsähnliche, aber betont fiktive Parallelwelt zu seiner Heimatstadt und macht damit die Anwendung seiner Gedichte auf sein Umfeld möglich, ohne den Sätzen Wahrheitswerte zuzuordnen. Die Namen dienen der Transposition der Figuren in diese den Gedichten gemeinsame fiktive Parallelwelt. Sie haben keine Anbindungsfunktion an die Realwelt.

\subsubsection{Die suggestive Wirkung realistischer Namen}

Die Wahl bereits existierender realistischer Namen schließt figurenbezogene Charakterisierungen nicht aus. Neben den sortalen Prädikaten und Präfigurationen wirkt besonders die Ursprungssemantik von Namenbestandteilen suggestiv auf den Leser und gibt dem Namen eine bestimmte Aura. ${ }^{322}$ Robinsons Namen enthalten oft Komponenten, die den Namen zu einem partiell redenden Namen machen. Diese Bestandteile dürften Robinson bei der Auswahl der gefundenen oder bei der Konstruktion der realistisch gebauten Namen ebenso beeinflußt haben wie sie den Leser beeinflussen. Sie benennen prima facie die Aura des Namenträgers. So ist etwa in ,John Evereldown' (John Evereldown) das ,-down' im Eigennamen einer Figur, mit der es bergab geht, semantisch signifikant. In ,Cliff Klingenhagen' (Cliff Klingenhagen) stehen das ,Kliff' wie auch die ,Klin-

\footnotetext{
${ }^{319}$ Robinson 1979, S. 55 (Brief an Josephine Preston Peabody vom 26.1.1905), S. 68 (Brief an Louis V. Ledoux vom 20.8.1910), S. 100 (Brief an Josephine Preston Peabody vom 31.3.1917) und S. 110 (Brief an Laura E. Richards vom 29.8.1918).

${ }^{320}$ Vgl. Bokardo, Robinson 1954, S. 56-59. Childers 1955, S. 224, geht fälschlicherweise davon aus, daß Bokardo ein Mathematiker war; Robinson verfaßte offensichtlich auch ein leider nicht überliefertes $\mathrm{Ge}$ dicht unter dem Titel Barbara, der ebenso einen logischen Modus gemeint haben könnte; vgl. Anderson 1980, S. 58; Saint-Nitouche, Robinson 1954, S. 211-217.

${ }^{321}$ Vgl. etwa Robinson 1979, S. 50 f. (Brief an Laura E. Richards vom 9.3.1902); vgl. auch Robinson 1975 , S. 137 f. [20].

${ }^{322}$ Diese Vorgehensweise findet sich vor allem bei Charles Dickens, den Robinson schätzte. Vgl. Childers 1955, S. 229.
} 
ge' und der deutsche Klang des Familiennamens für einen schroffen Menschen. Die deutlich redenden Familiennamen (,Aaron') ,Stark' (Aaron Stark) oder (,Reuben') ,Bright' (Reuben Bright) sprechen für sich. In ,Bewick Finzer' (Bewick Finzer) steht das ,wick(ed)' für einen niederträchtigen Menschen, Finzer mag entfernt an den ,financer' erinnern. ${ }^{323}$ Leffingwell (Calverly's und Leffingwell (1910)), dessen Namensbestandteil ,well' positive Assoziationen wecken mag, wird gegen alle Verurteilung durch andere vom Sprecher in Schutz genommen, Clavering (von ,to clave' - ,tratschen'; Calverly's und Clavering (1910)) hat wenig geglückte poetische Versuche unternommen. ${ }^{324}$

Durch diese Namenbestandteile, die ursprünglich Wörter oder Morpheme waren, wird eine Aura des Namens erzeugt, der suggestiv wirkt, ohne eine eindeutige Beschreibung des Charakters zu geben. Die Bedeutung solcher auratischen Wirkung von Namen für Robinsons Namenwahl zeigt sehr deutlich eine Bemerkung zum symbolisch redenden Namen 'Bokardo':

I took a course in logic once at Harvard. Palmer said the Bokardo was a figure which no one understood, and I took it as a symbol of the mystery of things. ${ }^{325}$

Die Präfiguration des Namens muß auf die nicht nur im Gedicht Bokardo thematische 'Mystik' des anderen Menschen, dessen Essenz nicht durchschaut wird, angewendet werden. Ausschlaggebend für die Wahl Robinsons war offenbar nicht die genaue Präfiguration des Namens, sondern das Unverständnis, das die Bedeutung des Namens hervorruft. Dieses Gefühl, das mit dem Namen zusammenhängt, wird von Robinson zur Grundlage der symbolischen Bedeutsamkeit des Namens gemacht. Da die subjektiv symbolische Bedeutung des Namens situationsunabhängig vielgestaltig eingesetzt werden kann, emanzipiert sich der Name vom Ursprungskontext. Um die Wirkung von Robinsons Namen nachzuvollziehen, muß daher weniger von eindeutig redenden, lautsymbolischen oder präfigurierten Namen ausgegangen werden, als von einer mehr oder weniger diffusen Gesamtwirkung aller Zeichenqualitäten des Namens. Diese Wirkung, die auch die anfangs zitierten Urteile der Interpreten dokumentieren, ist vage und beschränkt sich meist auf die Wertung des Namenträgers.

Die Namen lächerlicher Figuren werden oft selbst zum Scherz in ästhetischer (,komisierender') Funktion. Robinson konstruiert z.B. betont absurde Etymologien, wie sein Brief an Laura E. Richards zeigt:

If I am spared for another half of a decade I expect to do a book of mixed up short things that will probably please you, and incidentally a Trilogy. (Trill = a pretty noise and orgy $=$ the very

\footnotetext{
${ }^{323}$ Zum Gedichtinhalt vgl. Stanford 1983, S. 157.

${ }^{324}$ Vgl. Robinson 1954, S. 73 f., S. 87 (vgl. auch Childers 1955, S. 228 f.), S. 86, S. 92, S. 55 f., S. 330332, S. 330 f. und 333 f. (bes. die sechste Strophe).

${ }^{325}$ Robinson 1975, S. 162 [59]; diese Bemerkung paßt zu Hagedorns Bericht, Robinson sei die Logik generell verschlossen geblieben; vgl. Hagedorn 1938, S. 78.
} 
devil of a time. I turn it into ojy for phonetico-linguistic reasons which you will understand.) [...] It will be as comical as the deuce and, somewhat unlike C[aptain]. C[raig]., almost wholly objective. $^{326}$

Die vermeintliche Etymologie wird gerade dadurch entwertet, daß sie so offen willkürlich und gegen die wahre Etymologie des Begriffs gerichtet ist. Sie ist lediglich ein absurdes Spiel mit Klangähnlichkeiten der Sprache, das keinen Anspruch auf magischen Tiefsinn erhebt. Dagegen werden die konventionelle Bedeutung des Begriffs und seine denotierende Wirkung durch das Wortspiel verwirrt. Der Briefempfängerin dürfte nicht mehr klar gewesen sein, ob Robinson tatsächlich eine Trilogie zu schreiben vorhatte oder nicht. Vorbild der aufwendig redenden Namen Robinson könnte „Birdofreedom Sawin“ aus den Biglow Papers sein, die Robinson lobend in einem frühen Brief als „ridiculously satirical“ erwähnt. ${ }^{327}$ In diesem Sinne sind auch Robinsons deutlich redende Namen zu verstehen:

So kann ,Eben Flood' - aus Mr. Flood's Party - mit einiger der Interpreten Robinsons als „ebb and flood“ gedeutet werden. ${ }^{328}$ Der Name - der allerdings nur einmal zu Beginn des Gedichts vollständig genannt wird - verwiese damit auf die zwei Seiten der Figur, die als ,Eben' und als ,Flood' miteinander sprechen. Das Gedicht handelt von einem vereinsamten Mann, der eine einsame nächtliche Party auf einem Hügel außerhalb Tilbury Towns hält. ${ }^{329}$ Man könnte auch hinzufügen, daß die Dynamik des Gedichts auf das Hin- und Herschwanken des betrunkenen Mr. Flood ebenso wie auf das Schwanken seiner Stimmung vom stillen Resignieren zum kämpferischen Selbstgespräch hindeutet. ${ }^{330}$ Sicherlich weist die Wassermetaphorik (,Flood' = ,Überschwemmung') auf das Trinkgelage Eben Floods. Dem stehen die unterschiedliche Aussprache von /'i:bən/ und leb/ ebenso wie die ungewohnte Zusammenstellung (sonst: ,ebb and flow') dieser Interpretation des Namens allerdings in einem gewissen Maße entgegen. Robinson hat sich in jedem Falle die Mühe gemacht, die redenden Komponenten in einem möglichst realistischen Namen - ,Eben[-ezer] Flood' - zu verstecken.

Unrealistische Eigennamen gehören meist einer komischen Figur. So steht etwa ,Edward Alphabets' Familienname (s.o.) scherzhaft für ein ganzes Alphabet möglicher Initialen - nicht zuletzt wohl für Edwin Arlingtons eigene. Doch ist anzunehmen, daß auch der charakterisierende Wert deutlich redender Namen eher gering ist. Die Funktion ei-

\footnotetext{
${ }^{326}$ Robinson 1979, S. 50 (Brief an Laura E. Richards vom 9.3.1902).

327 Vgl. Robinson 1947, S. 120f. (Brief an Harry de Forest Smith vom Dezember 1893).

${ }^{328}$ Vgl. Childers 1955, S. 225 f.; vgl. auch Neff 1948, S. 198; Free 1966, S. 81; Baker 1974, S. 330, nennt nach den Notizen einer Cousine einen ,John Esmond' als Vorbild Eben Floods. Dessen Name hat offensichtlich nicht zum Figurennamen beigetragen.

${ }^{329}$ Vgl. auch Stanford 1983, S. $151 \mathrm{f}$.

330 Zur Dopplung von Text- und Bedeutungselementen in Mr. Floods Party vgl. Davis 1976.
} 
nes solchen Namens ist es, einen eigenen Scherz zu machen (ein ,Gedicht im Gedicht') und die Figur als lächerlich aus Sicht des Namengebers zu perspektivieren. Ob nun John ,ever held down' oder John ,ever hell down' - der Name erschließt nicht die Essenz der Figur, sondern zeigt die Ironie Robinsons in bezug auf seine Figur und das Gedicht. Das deutlichste Beispiel für Robinsons Ironie ist Miniver Cheevy. Miniver Cheevy, ein ,Nichtsnutz', der sich für Altertum und Mittelalter begeistert ${ }^{331}$, trägt zwar einen eindeutigen Rufnamen, der das mittelalterliche ,Grauwerk' bezeichnet. Der Familienname aber ist vieldeutig und könnte sowohl auf den Chevy Chase der englischen Volksballade, auf einen englischen Diminutiv des, chevalier' oder auf einen mittelalterlichen Gürtel (,chevesaile') verweisen. ${ }^{332}$ Der Name perspektiviert die Figur als komisch, gibt aber darüber hinaus wenig Aufschluß über den Namenträger. Er beschreibt lediglich Äußerlichkeiten, die mit der Darstellung der Figur im übrigen Gedicht in Einklang stehen. ${ }^{333}$ Da es sich aber um einen so deutlich redenden Namen handelt, der außerdem recht profane Gegenstände benennt, die nur durch die übertriebene Begeisterung für die Romantik vergangener Epochen eine Aura erhalten, wirkt der Name lächerlich. Doch hat Robinson bei der Wirkung des Namens durchaus berücksichtigt, daß auch Miniver Cheevy nicht nur eine lächerliche Figur ist. Dessen Begeisterung für die vergangenen heroischen Zeiten wird im Gedicht zwar immer ironisch, aber doch auch durch die Erwähnung berühmter Eigennamen zelebriert, die auch auf den Leser wirken müssen:

Miniver sighed for what was not,

And dreamed, and rested from his labours;

He dreamed of Thebes and Camelot,

And Priam's neighbors. ${ }^{334}$

Ebenso wirkt auch die Ursprungssemantik des Namens, die heutzutage ungebräuchliche Kleidungsstücke (oder ,Berufe') mit ungebräuchlichen oder fremdsprachigen Namen ,exotisch' belegt. Der Leser kann durch seine Einstellung gegenüber den von Robinson zum Namen zusammengestellten Begriffen und ebenso durch die berühmten Namen Sympathie für den Protagonisten empfinden und ihn so partiell verstehen.

Doch nicht nur deutlich lächerliche Figuren verraten diese humoristische ästhetische Funktion ihres Namens. Auch der Name ,Luke Havergal' aus dem gleichnamigen ,sym-

\footnotetext{
${ }^{331} \mathrm{Vgl}$. Anderson 1968, S. 107.

${ }^{332}$ Vgl. Childers 1955, S. 226; vgl. auch Perrine 1962, S. 72, der ,Cheevy' u.a. auf ,chevalier', ,chivalry', ,cheve' oder ,chevesaile' zurückführt. Den Spekulationen scheint dabei kaum eine Grenze gesetzt zu sein: Richards 1971, S. 367 f., spekuliert, ob ,Miniver' auf ,Minerva', ,Cheevy' auf ,achievement' anspielt, Sullivan berichtet über eine gesprächsweise Auslegung durch Ellsworth Barnard als „minimal achievement“", vgl. Sullivan 1986, S. 185.

${ }^{333}$ Auch der Diminutivklang von ,Cheevy' trägt zur Komik des Namens und der Figur bei.

334 Robinson 1954, S. 347.
} 
bolistischen' Gedicht Robinsons ${ }^{335}$ kann weit ausgelegt werden: Der Name eines Mannes im Selbstgespräch, der mit Selbstmordgedanken ringt ${ }^{336}$, wurde als Kombination aus einer Ableitung von ,St. Luke' 337 oder ,lukewarm' und ,have a girl' oder ,have a gall' gelesen. ${ }^{338}$ Diese Deutungen des Rufnamens sind zwar willkürlich und dem ernsten Thema des Gedichts unangemessen. Aber Luke Havergal provoziert zumindest die Auslegung seines Familiennamens als redenden Namen. Der Dimeter am Ende der ersten und der letzten Strophe, der nur von dem Eigennamen gebildet wird, ergibt einen zum Gedicht passenden Satz: ,Luke, have a girl!'339

Festzuhalten ist, daß auch Robinsons redende Namen vorwiegend ästhetische und perspektivierende Funktion haben. Sie passen sich insofern der poetischen Rede Robinsons an, die auf Wirkung und nicht auf präzise Beschreibung mit denotierenden Begriffen ausgerichtet ist.

\subsubsection{Das problematische Verhältnis der Namen zur Wirklichkeit}

Um zu zeigen, daß das semantische Potential der Figurennamen Robinsons nicht ungebrochen auf seine Figuren verweist, soll im Folgenden die Rolle der Namen in einzelnen Gedichten näher untersucht werden. Ausgegangen wird dabei von der Einbettung der Namen in Handlungskontexte aus Robinsons Blankverserzählungen, in deren breiterer Gestaltung die Stellung des Namens in Robinsons poetischer Sprache deutlich wird.

\subsubsection{Namen als Problem der Handlung in Robinsons Verserzählungen}

\subsection{Der Kommunikationswert des Namens}

Eigennamen dienen dem Sprecher wie den Figuren in den fiktiven Welten Robinsons als wichtiges Mittel zur Identifikation anderer Figuren. Die Benennung der Figur mit Hilfe des Namens zu Gesprächsbeginn und in hoher Frequenz im Verlauf der Blankverserzählungen verweist auf die große Bedeutung, die der Name als Symbol der Person für

\footnotetext{
${ }^{335}$ Vgl. Anderson 1968, S. 116-118; Dunn 1973, S. 17.

${ }^{336}$ Vgl. Stanford 1983, S. 148-150.

${ }^{337}$ Genauer gesagt zieht Richards etwas willkürlich eine Verbindung zwischen einem Arzt, der sich selbst heilen soll, in Lukas 4,23; vgl. Richards 1971, S. 368. Auch wenn Robinson seine Begeisterung für die Bibel immer wieder betont (vgl. Robinson 1947, S. 226 [Brief an Harry de Forest Smith vom 20.5.1895]), erscheint McFarlands Deutung 1974, S. 365 f., der ,Luke Havergal' unter anderem vom verlorenen Sohn (,the prodigal son') aus dem Lukasevangelium ableitet, ebenso willkürlich wie Richards' Spekulation.

${ }_{338} \mathrm{Vgl}$. Richards 1971, S. 368. Zu den vielfältigen und nicht immer sinnvollen Interpretationen dieses symbolistischen Versuchs Robinsons; vgl. Gierasch 1944; Raven 1944; Parlett 1945; Crowder 1948; vgl. auch Neff 1948, S. 68; Dunn 1973, S. 21, S. 25; Richards 1971, S. 369; Moran 1967, S. 388-390.

${ }_{339} \mathrm{Vgl}$. auch Richards 1971, S. 370 und Moran 1967, S. 391 zur Individualisierungsfunktion des Namens und zum Dimeter in Luke Havergal.
} 
soziale Interaktionen hat. ${ }^{340}$ Die Namen werden durch häufige Wiederholung in den Titeln, der Erzählerrede und den Figurenreden der Blankverserzählungen wie auch der Gedichte hervorgehoben.

Robinson gestaltet in seinen Blankverserzählungen zahlreiche Situationen, in denen Eigennamen den Handlungsverlauf mitbestimmen. Schon alltägliche Verwendungen von Eigennamen - die gesetzlich besiegelnde Kraft einer Unterschrift oder die Frage, ob dem Familiennamen einer Figur durch eine geplante Handlung Schande droht - sind Robinson eine ausführliche Erwähnung wert. ${ }^{341}$

In den Figurenreden finden sich zahlreiche Meditationen über (geliebte) Namen. Den poetischen Umgang mit Namen führt Robinson z.B. in Isaak and Archibald vor. Die Namen der beiden Protagonisten tun durch ihre berühmten Namen unterschiedlicher Provenienz die Qualität der menschlichen Größe und des ehrwürdigen Alters kund. Darüber hinaus machen sie es dem kindlichen Erzähler leicht, die Namenträger in seinen Tagträumen mit heroisch-mythischen Gestalten zu verbinden:

And ages coming forward: Archibald

And Isaac were good fellows in old clothes,

And Agamemnon was a friend of mine;

Ulysses coming home to shoot

With bow and feathered arrows made another,

And all was as it should be. I was young.

[...]

Isaac and Archibald, the burning bush,

The Trojans and the walls of Jericho,

Were beautifully fused; [...]

[...]

Likewise I made Ulysses, after Isaac,

And a little after Flaxman. ${ }^{342}$ Archibald

Was injured when he found himself left out,

But he had no heroics [...]. ${ }^{343}$

Während Isaac sich körperlich wie namentlich in die imaginierte mythische Welt der Bibel und Homers einpaßt, wird bei Archibald schon ein kleiner Bruch zwischen dem heroischen schottischen Namen und der Erscheinung deutlich.

${ }^{340}$ Der Name ,Flammonde' etwa wird in zwölf Oktaven siebenmal erwähnt, ,John Gorham' und ,Jane Wayland' jeweils fünfmal in zehn Quartetten, vgl. Robinson 1954, S. 3-6 und S. 13 f. - in den CharakterSonetten steht der Name zumeist im ersten Satz des jeweiligen Gedichts: „Whenever Richard Cory went down town, [...]" in Richard Cory; „Withal a meagre man was Aaron Stark [...]“ in Aaron Stark; „Cliff Klingenhagen had me in to dine [...]" in Cliff Klingenhagen; „A melancholy face Charles Carville had; [...]" in Charles Carvilles Eyes; ,[...] I would not have to think that Reuben Bright / was any more a brute as you and I;[...]" in Reuben Bright; „Pamela was too gentle to decieve / her roses [...]" in The Tree in Pamelas Garden, vgl. Robinson 1954, S. 82, S. 86, S. 87, S. 92 und S. 576. Auch in den nicht erhaltenen Prosaskizzen spielen die Namen der Protagonisten eine große Rolle, wie Robinsons Erwähnungen in seinen Briefen zeigen. Dort treten z.B. ,Hendricks', ,Lévy Condillac', ,Theodore', ,Lachesis' oder ,John Town' auf, vgl. Anderson 1967, S. 501-503.

${ }^{341}$ Vgl. etwa Robinson 1954, S. 1070, S. 1269-1270 und S. 1279.

${ }^{342}$ Gemeint ist der amerikanische Maler und Bildhauer John Flaxman (1755-1826), der einen stark antikisierenden Stil pflegte und dessen Ruhm zu Robinsons Zeiten schon stark verblaßte, vgl. Irwin 1979, bes. S. 3.

${ }^{343}$ Vgl. Robinson 1954, S. 178f. und S. 180, vgl. auch Stanford 1983, S. 164. 
An vielen anderen Stellen der Robinsonschen Blankverserzählungen rufen Figuren Namen hoffnungsvoll, innig oder hoffnungslos aus und drücken ihre Seelenlage aus, indem sie sich auf Namen beziehen. ${ }^{344}$ So bekundet z.B. Robinsons Rahel Varnhagen ihre Gleichgültigkeit gegenüber dem Urteil der Gesellschaft mit Bezug auf ihren Namen:

And let the lash of a tongue-weary town

Fall as it might upon my blistered name $[\ldots] .{ }^{345}$

Aus dieser kommunikativ wichtigen Rolle des Namens folgt ein großes Interesse der Figuren, den Namen ihres Gegenübers zu erfahren, wie es etwa die Frage Fargos an den ihm begegnenden Amaranth in der Blankverserzählung Amaranth ausdrückt:

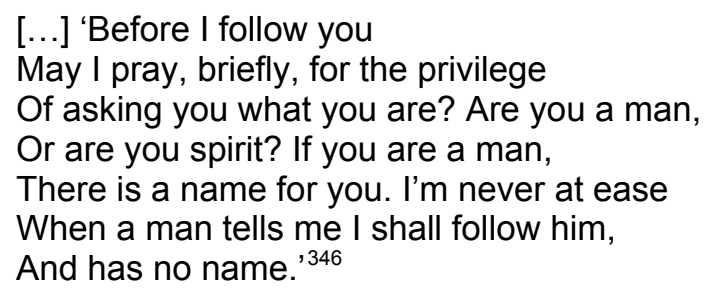

Der wichtigen Funktion des Namens als Identifikations- und Ausdrucksmittel steht aber entgegen, daß in der Majorität der Fälle, wo Namen explizit oder implizit kommentiert werden, die Leistung der Namen eher in Frage gestellt als bestätigt wird. Auf die Frage Fargos antwortet Amaranth, sich scheinbar selbst charakterisierend:

[...] Man or Spirit,

He has a name. The name is Amaranth-

The flower that never fades. ${ }^{347}$

Gerade diese Namenauslegung im Sinne der griechischen Ursprungssemantik des Namens wird nun aber am Ende der Handlung ad absurdum geführt, als Amaranth, ersterbend gegenüber Fargo ausruft:

\footnotetext{
[...] You are not here

To stay with us; and you are wiser now

For your return. You will not come again.

Remember me ... The name was Amaranth ...

The flower ... that never ... fades... ${ }^{348}$
}

Amaranth löst sich mit diesen Worten gerade so auf, wie er es seinem Namen nach nicht tun sollte, und macht der Figur Fargo damit die Fragwürdigkeit der Scheinwelt, in der sie sich bewegt hat, deutlich. ${ }^{349}$ Der Name erfüllt also die Erwartungen nicht, die vom Namenträger wie vom Namenbenutzer in ihn gesetzt werden.

\subsection{Probleme mit Namen}

${ }^{344}$ Z.B. in Robinsons Gestaltung der Artussage Tristram oder Merlin, vgl. Robinson 1954 S. 604, S. 613, S. 625, S. 638f., S. 665, S. 676 und S. 273.

${ }_{345}$ Robinson 1954, S. 513-520.

${ }^{346}$ Robinson 1954, S. 1317.

${ }^{347}$ Robinson 1954, S. 1317.

${ }^{348}$ Robinson 1954, S. 1392.

${ }^{349}$ Vgl. auch Joyner 1972, S. 453. 
Die sprachliche Einführung der Person durch einen Eigennamen ist so zwar eine wichtige Bedingung für den sozialen Umgang zwischen Menschen. Das Schicksal und die soziale Bedeutung des Namens sind jeweils ein Bericht zur Lage der Figur. Der Name ist aber auch nur für die materielle Gesellschaft wichtig und nicht für die ideale und überdauernde Sphäre des Menschen, für seine Seele. Die Frage Fargos an Amaranth deutet an, daß ein rein geistiges Wesen („spirit“) im Gegensatz zum körperlichen Menschen („man“) keinen Namen haben muß. Hier ist der Bezug von Robinsons Namenverwendung zu einem romantisch orientierten dualistischen Weltbild erkennbar, das neben dem materiellen und bürgerlichen Menschen mit seinem bürgerlichen Namen ein namenloses Geistwesen annimmt.

Es verwundert daher nicht, daß die Verbindung zwischen Namenszeichen, Namenträger und Namenbenutzer bei Robinson häufig gestört ist. Robinsons Figuren vergessen Eigennamen schnell oder finden den richtigen Namen nicht, ${ }^{350}$ sie verwechseln Namen wegen ihrer Klangähnlichkeit oder sie verwechseln die Namenträger bei Namengleichheit mehrerer Figuren. ${ }^{351}$ Diese Mißgeschicke zeigen eine ,Tücke' der Sprache, die die Figuren nicht beherrschen können. Die Namenszeichen genügen der Intention des Sprechers nicht, der mit innen eine Entität bzw. eine Identität beschreiben und festlegen will.

Dieses Ungenügen des Namenzeichens erstreckt sich auch auf die Intentionen des Namengebers und die interpretierende Auslegung von Namen durch die Namenbenutzer. Bei näherer Betrachtung sind die häufig stattfindenden Aktualisierungen der Ursprungssemantik von Namen durch Figuren oder durch den Erzähler der Blankverserzählungen betont willkürlich, situational begrenzt oder oberflächlich. Die Namenauslegungen und -begründungen erscheinen nur als zeitweilige Laune und nicht als magische und durch den Willen des Autors gültige Charakterisierung, so z.B. wenn in Amaranth eine Katzenbesitzerin ihren Kater nach der Ähnlichkeit mit dem Zeichen ,\&' (,the ampersand') benennt:

His name was Ampersand, she said, because

He looked like one when he sat still and held

His tail around him. ${ }^{352}$;

oder in Tristram:

The sorrow in his name

Came out, and he was Tristram, born for sorrow

\footnotetext{
${ }^{350}$ Vgl. Robinson 1954 S. 273, S. 1016, S. 1022, S. 1024 und S. 1279.

${ }^{351}$ Vgl. den Dialog in Robinson 1954, S. 290 f. und: „Cloud after cloud came fast, / Obliterating before leaving clear / The word that he had lost. It was a name / Of some one far behind him in the gloom, / [...] / 'Isolt!'" oder: "You will go back / To Brittany after this, and there Isolt— / That other Isolt—' she said [...]"; Robinson 1954, S. 245 und S. 359 f.

${ }^{352}$ Robinson 1954, S. 1338.
} 


$$
[\ldots] .{ }^{353}
$$

Auch in der Blankverserzählung Mortmain bleiben die aus dem Namen abgeleiteten Beobachtungen der Gemeinschaft über den Namenträger betont oberflächlich:
Avenel Gray at fifty had gray hair,
Gray eyes, and a gray cat-coincidence
Agreeable enough to be approved
And shared by all her neighbors; or by all
Save one, who had, in his abused esteem,
No share of it worth having. Avenel Gray
At fifty had the favor and the grace
Of thirty-the gray hair being only a jest
Of time, he reasoned, whereby the gray eyes
Were maybe twenty or maybe a thousand.
$[\ldots]^{354}$

Bei der von der Gemeinschaft wohlwollend zur Kenntnis genommenen Übereinstimmung handelt es sich um ein ,angenehmes', da vollkommen harmloses und triviales Zusammentreffen. Zweifel daran, daß die Person Avenel sich in solch harmloser Übereinstimmung erschöpft, hat nur ein wiederum von der Gemeinschaft abweichendes Individuum, das einige Verse später als ,Seneca Sprague' eingeführt wird. Seneca betont die Unfaßbarkeit des Wesens von Avenel Gray, das unter der oberflächlichen Übereinstimmung liegt, und bleibt im Zweifel über die wahre Person Avenel Grays. ${ }^{355}$

Eine mögliche tiefere Bedeutung des Familiennamens ,Grau' als Ausdruck der Nichtgreifbarkeit der Figur bleibt der Gemeinschaft verborgen. Doch auch diese Namenbedeutung zeigt nur, daß die Figur gerade nicht festzulegen ist.

Gleiches gilt für Senecas traurige oder bittere Überlegungen, die die Präfiguration seines eigenen Rufnamens aktualisieren:

[...] Yet there they sat,

A woman and a man, beyond the range

Of all deceit and all philosophy. ${ }^{356}$

Senecas präfigurierter Name spottet über sein Streben. Avenel selbst schließlich betont die Oberflächlichkeit von Eigennamen, indem sie ihre Katze ,Pyrrhus' nennt - „Pyrrhus because he purrs“, wie wiederum Seneca bitter bemerkt. ${ }^{357}$ Dieser wendet vergleicht sich mit der Katze bei seiner Beschreibung des Versuchs, Avenels Wesen zu ergründen. Doch selbst dort, wo er vermeintlich siegt, bleibt er der Verlierer. Avenel nimmt diesen Vergleich auf:

„You would be like a cat in a strange house-

\footnotetext{
${ }^{353}$ Robinson 1954 S. 612; vgl. dazu auch eine Randbemerkung Horstmanns 2001, S. 31, die etymologische Rückführung auf „triste“ sei „völlig in Vergessenheit geraten“.

354 Robinson 1954, S. 889.

355 Sie scheint für ihn ein „sphinx-child“ zu sein: „Never could he persuade himself to say / How old or young they [die Augen Avenels] were, or what was in them [...]"; Robinson 1954, S. 890.

356 Robinson 1954, S. 897.

357 Robinson 1954, S. 897.
} 
Like Pyrrhus here in yours. [...]." ${ }^{“ 358}$

Seneca scheint sich gerade darüber zu ärgern, daß Avenel eine so einfache und oberflächliche Erklärung für den Namen gibt oder - wie er vermutet - geben würde. ${ }^{359} \mathrm{Se}-$ neca als derjenige, der nach Erkenntnis seines Gegenübers und seiner selbst strebt, scheitert an der spielerischen Oberflächlichkeit der Eigennamen, die einen Bezug des Namens zur Essenz des Namenträgers negiert.

Diese Oberflächlichkeit von Namen macht Robinson auch an der Diskrepanz zwischen ursprünglicher Benennungsmotivation und gewandeltem Namenträger deutlich. Er negiert ironisch die Namenbedeutung unter Hinweis auf den Namengebungsakt. So beginnt die Blankverserzählung Ponce de Leon mit der ironischen Erwähnung einer Namengebung. Der Protagonist liegt zu Tode verwundet in dem Land, dem er einst wegen seiner vielversprechenden und üppigen Landschaft den deutlich positiv redenden $\mathrm{Na}$ men ,Florida' gegeben hat:
In Florida, the fair land he had named
In admiration of its many blossoms,
And for its opulence of promises,
De Leon, with an arrow in his thigh,
Lay stricken on the shore of his new world,
Cursing it while he groaned $\left[\ldots . .{ }^{360}\right.$

Die Tragik des Ereignisses und die Ironie des Schicksals De Leons wird deutlich an der Diskrepanz zwischen seinen Hoffnungen, die die Namenvergabe motivierten, und seiner darauf beschriebenen traurigen Lage, in der er die „new world“ verflucht.

Robinsons Namen verwirren die Figuren seiner Blankverserzählungen vor allem dadurch, daß sie etwas über den Namenträger auszusagen scheinen. Der Namenträger entzieht sich aber dem Versuch, durch den Namen festgelegt zu werden. Das Namenszeichen entpuppt sich als Irreführung.

\subsection{Erfolglose Evokationsversuche mit Namen}

Das Namenzeichen gibt keinen endgültigen Aufschluß über das Wesen des Namenträgers. Der Name eignet sich infolgedessen besonders dann nicht dazu, den Namenträger zu evozieren, wenn der Namenbenutzer keinen aktuellen Zugriff auf das benannte Objekt hat. Beim Beispiel des evokativen Namengebrauchs, dem Ausrufen eines geliebten Namens, scheitern Robinsons Figuren immer wieder.

So läßt Robinson in einer mit Lichtsymbolik ${ }^{361}$ gefültten Szene in The Glory of the Nightingales den Protagonisten Malory abends mit seiner verstorbenen Frau an ihrem Grab

\footnotetext{
${ }^{358}$ Robinson 1954, S. 897.

359 Robinson 1954, S. 897.

360 Robinson 1954, S. 1187.
} 
sprechen. Malory versucht, sie durch ihren Namen imaginativ erstehen zu lassen. Diese Hoffnung scheint sich zunächst zu erfüllen, sogar in größerem Umfang als Malory erwartet hatte:

[...] He could see now

A carved white name; and he began to see

More than a name, more than a shadowy face,

More than he came to find. [...]. ${ }^{362}$

Der Namenszug auf dem Grabstein aber verschwindet bald darauf langsam in der zunehmenden Dämmerung:

Her name had now a dimness in a light that faded slowly

Into a twilight that would not last long ${ }^{363}$,

so daß er ihn am Ende nur noch mit dem Tastsinn wahrnehmen kann:

He felt her glimmering name on the cold stone

With chilly fingers. ${ }^{364}$

Malory imaginiert den Geist seiner verstorbenen Frau und seine Rachegefühle gegenüber dem Mann, der inn und seine Frau ruiniert hat. Die Denotation wie die persönlichen Assoziationen zum Namen seiner Frau entgleiten Malory schon hier, bis nur noch das Namenszeichen des Namens übrig bleibt, ein rein materiell vorhandenes Objekt.

Genauso schwindet dem Rächer nach und nach die Kraft für die Rache, die er aus den Gemeinheiten des anderen in der Vergangenheit geschöpft zu haben glaubte. ${ }^{365}$ Für Malory reicht der Name daher allein nicht aus, sich den Namenträger zu vergegenwärtigen:

There was only a name

There now; and he would leave it. [...]. ${ }^{366}$

Es offenbart sich wiederum die schwache Leistungsfähigkeit der konventionellen denotierenden Sprache. Genauso ergeht es auch anderen Figuren Robinsons. Tristan aus Tristram muß erkennen:

It was the only name left in the world,

And that was only a name. 'Isolt! Isolt!' ${ }^{367}$

Der resignierende Protagonist in Talifer reflektiert über seine Familienehre:

What was a name,

A shield, or a tradition, or a legend

Worth now. ${ }^{368}$

\footnotetext{
${ }^{361}$ Vgl. auch Anderson 1968, S. 120 f.

${ }^{362}$ Vgl. Robinson 1954, S. 1021.

${ }^{363}$ Robinson 1954, S. 1022.

${ }^{364}$ Robinson 1954, S. 1023.

${ }^{365}$ So wie ein paar Verse später der Rächer den geliebten Namen murmelt und schon nicht mehr weiß warum; vgl. Robinson 1954 S. 1024.

${ }^{366}$ Robinson 1954, S. 1023.

${ }^{367}$ Robinson 1954, S. 639.

${ }^{368}$ Robinson 1954, S. 1279.
} 
Die im Gedicht unausgesprochene Antwort schöpft er in der folgenden Handlung aus der Imagination der heimlichen Geliebten: Nichts.

Die enge Verbindung von Name und memoria („a tradition or a legend“) in Talifer ist dabei kein Zufall. Für Robinson teilen Berichte über „imagined or dimly remembered events“"369 und Namen als Teil der Sprache die Eigenschaft, jeden Zugriff auf die Wahrheit scheitern zu lassen.

\subsection{Namen und die materielle Welt}

Während der Name und seine Semantik auf der Figurenebene einerseits sehr wichtig für den gesellschaftlichen Umgang sind, bleibt er von geringem epistemischen Wert für den Namenbenutzer. Die ambivalente Rolle des Namens beruht auf dem von Robinson gestalteten Verhältnis von Namen, Namenträger und Gesellschaft zueinander.

Ein Abschnitt aus Robinsons poetologischem Gedicht The Man Against the Sky deutet die aus der Zeitlichkeit der Sprache für Robinson resultierende kurze gesellschaftliche ,Halbwertszeit' auch des Eigennamens an, die dem Ungenügen des Namens zugrunde liegt. Die Vorfahren des Protagonisten lassen nach ihrem Tod ihre Namen als Teil ihrer irdischen Körperlichkeit hinter sich:

\footnotetext{
Why question of his ease of whom before him, In one place or another where they left

Their names as far behind them as their bones,

And yet $[\ldots]$

Carved hard the way for his ascendancy

Through deserts of lost years? ${ }^{370}$
}

Wie das Ablegen des Namens zusammen mit dem materiellen Körper zu verstehen ist, wird in der Eingangssequenz der frühen Blankverserzählung Captain Craig als Teil der Handlung präzise dargestellt: Der Vagabund und Außenseiter Captain Craig wird nie in die Kommunikationsgemeinschaft Tilbury Towns aufgenommen. ${ }^{371}$ Der Sprecher konstatiert daher schon zu Beginn des Textes:

I doubt if ten men in all Tilbury Town

Had ever shaken hands with Captain Craig,

Or called him by his name, or looked at him

So curiously, or so concernedly,

As they had looked at ashes; but a few-

Say five or six of us - had found somehow

The spark in him and we had fanned it there,

Choked under [...] by Tilbury prudence. ${ }^{372}$

Geschildert werden versuchte Kontaktaufnahmen zwischen der Gemeinschaft und Captain Craig. Auf den ersten Blick wird eine Antiklimax gestaltet: Die Intensität der nicht

\footnotetext{
${ }^{369}$ Zietlow 1967, S. 199.

370 Robinson 1954, S. 61.

${ }^{371}$ Vgl. dazu auch W. R. Robinson 1967, S. 76 f.

372 Robinson 1954, S. 113.
} 
stattgefundenen Kontakte zwischen der Gemeinschaft und Captain Craig vom körperlichen Kontakt über den distanzierten sprachlichen Kontakt zur einseitigen Observation nimmt ab. Auf den zweiten Blick erkennt man daneben eine Klimax, die das Ignorieren der Person Captain Craigs vom materiellen Körper über den Eigennamen bis zum inneren Wesen, dem metaphorischen geistigen Funken in der materiellen Asche, zeigt. Die Anrede beim Namen ist jeweils das Symbol für die sprachliche Integration auf einer mittleren Ebene. ${ }^{373}$ Durch sie wird auch die Person in die Kommunikationsgemeinschaft aufgenommen und von dieser anerkannt. Die Verwendung des Namens zeigt die Bereitschaft zur Interaktion mit dem Namenträger. Sie bedeutet aber noch nicht die ideale Seelengemeinschaft. Die besorgte Beobachtung einer Person wie Asche, aus der ein Funken emporschlagen könnte, erkennt dagegen gleichzeitig an, daß sich hinter der Asche des Äußeren noch etwas weitergehendes Seelisch-Geistiges verbergen könnte.

\subsection{Bürgerlicher Name und Übername}

Im Falle Captain Craigs kommt für die fiktive Gesellschaft wie für den Leser das Problem hinzu, daß der kommunikative Status des Namens ,Captain Craig' höchst zweifelhaft ist. Dies wird an der Art und Weise deutlich, in der Craig sich selbst mit seinem Namen bei der Gesellschaft einführt:

\section{[...] 'My Name is Captain Craig,' \\ He said, 'and I must eat.' $[\ldots]^{374}$}

Die Szene ist auf eine für die Gedichte Robinsons typische Art tragisch und komisch zugleich. Einerseits spiegelt sie höchste Not, andererseits wird das Nameninitiationsritual überraschend abgebrochen und durch die Direktheit der angeschlossenen Bitte bzw. Forderung komisch entwertet. Die durch die Konvention geforderten Sprechaktsequenzen der weiteren Identifikation - des ,Woher?' und ,Wohin?' - werden nicht vollzogen. Der Eigenname wird nicht gesellschaftlich nutzbar gemacht, ein semantischer Hintergrund nicht hinzugefügt. Er läßt Zweifel daran aufkommen, daß es sich um den ordnungsgemäßen Rang und Namen handelt. Die Kombination aus einer nicht bewiesenen Rangbezeichnung und einem (Ruf- oder Familien-)Namen weist zusammen mit dem schäbigen Äußeren der Person ${ }^{375}$ viel eher auf einen selbst gewählten 'Vagabundennamen' hin. Captain Craig - the pauper, wie das Gedicht ursprünglich heißen sollte -

\footnotetext{
${ }^{373}$ Dies ist auch der Hintergrund einer Bemerkung im Gedicht Lisette and Eileen, Robinson 1954, S. 49f., in dem Robinson die Geliebte eines Mannes, der offenbar in der Vorgeschichte der dargestellten Szene starb, zu ihrer Rivalin sagen läßt: „And what you see might be Lisette, / Instead of this that has no name“. Ihre Namenlosigkeit entspricht ihrer gesellschaftlichen Außenseiterposition und dem Rückzug auf das innerste Ich, während ihre Rivalin als ,sittlich Überlebende' ihren Namen behält und gleichzeitig ,menschlich' tot ist. Deutlicher noch wird die Entsprechung, wenn man die Sprecherin selbst als Tote sieht. Dann ist es ein ,Geist', der mit der überlebenden Rivalin spricht und der keinen ,bürgerlichen' Namen mehr hat.

${ }_{374}$ Robinson 1954, S. 113.

${ }^{375}$ Robinson 1954, S. 113.
} 
trägt seinen Namen als Künstlernamen wie die von ihm eingeführte Figur „Count Pretzel von Würzburger, the Obscene“, zu der er bemerkt: „(The beggar may have had another name, / But no man to my knowledge ever knew it)“. ${ }^{376}$ Der bürgerliche Name und damit die Geschichte der Person sowie ihre gesellschaftliche Identität werden verschwiegen. Der Übername ist in gewissem Maße ein redender Name. ,Count Pretzel' ist schon für sich betrachtet lächerlich. Gesteigert wird dieser Eindruck durch den Beinamen „the Obscene“. ${ }^{377}$ Daß sich hinter solchen charakterisierenden Übernamen ein anderes nur vage oder gar nicht erkennbares Wesen mit einer eigenen Geschichte verbirgt, betont Captain Craigs Bemerkung zu Count Pretzel. Die Unkenntnis der unter der Oberfläche verborgenen Identität trägt zu der Unsicherheit der übrigen Figuren wie des Lesers bei, die das Wesen der Figur nicht endgültig bestimmen können.

Der Versuch, eine eindeutige Charakterisierung mit einem Namen zu verbinden und einem Übernamen eine eindeutige Bedeutung zu geben, scheitert auch in Tasker Norcross. Als der Ich-Erzähler sich weigert, die verzweifelte Situation einer vom Protagonisten Ferguson beschriebenen Person namens ,Tasker Norcross' uneingeschränkt anzuerkennen, ruft Ferguson ungehalten aus:

\section{[...] Have I said nothing- \\ Nothing at all-of Norcross? Do you mean \\ To patronize him till his name becomes \\ A toy made out of letters? If a name \\ Is all you need, arrange an honest column \\ Of all the people you have ever known \\ That you have never liked. You'll have enough; \\ And you'll have mine, moreover. [...]. ${ }^{378}$}

Ferguson scheint eine andere Person zu beschreiben. In Wirklichkeit spricht er über sich selbst, denn er hat sich einen charakterisierenden Übernamen gegeben. ${ }^{379}$ Nach dem Tod Fergusons findet der Sprecher niemanden, der diesen ,Tasker Norcross' gekannt hat: „Others, I found, remembered Ferguson, / But none of them had heard of Tasker Norcross. “380

Ferguson will unter diesem Namen eine für seinen Gesprächpartner eindeutig definierte, verzweifelt unglückliche Person zeichnen und alle Ambivalenz seiner realen Person tilgen. Der Name weist dabei wohl auf die Tatsache hin, daß der Namenträger weder

\footnotetext{
${ }^{376}$ Robinson 1954, S. 135.

377 Im Falle Captain Craigs wird zudem eine Bemerkung Robinsons über das Vorbild, Alfred H. Louis, kolportiert. In ihr enthüllt er die Funktion der Rangbezeichnung als Charakterbeschreibung: „He is Craig. Of course he wasn't a captain of anything. He didn't belong to the navy, never had sea-faring experience. He was a Captain of souls so to speak, a General of Philosophy, [...]"; vgl. Robinson 1975, S. 138 [20]. ${ }^{378}$ Robinson 1954, S. 504.

${ }^{379}$ Vgl. auch Cestre 1930, S. 173.

${ }^{380}$ Robinson 1954, S. 504.
} 
eine Aufgabe (,task') zu erfüllen, noch eine Last (,cross') zu tragen hat. ${ }^{381}$ Mit Hilfe dieses Pseudonyms will Ferguson sein wahres Wesen erklären - das eines Mannes, der jeglichen ideellen Halt im Leben, sei es einen Glauben, sei es einen geistigen Genuß, verloren hat. Doch scheitert sein Versuch, dem Namen eine feste Bedeutung zu geben, denn der Sprecher glaubt inm nicht und mutmaßt, daß Ferguson die beschriebene Figur - hinter der er keine Introspektion Fergusons vermutet - nur nicht richtig kennt. Er geht von einem konkreten und ambivalenten Menschen aus und nimmt die einseitige Abstraktion nicht an. ${ }^{382}$ Auch der selbstgegebene scheinbar deutlich charakterisierende Übername scheitert also. Die Figur Tasker Norcross muß an der zitierten Stelle erkennen, daß sie ihr Innerstes weder durch den Inhalt ihrer Rede noch durch den redenden Übernamen mitteilen kann. Ihr wahres Wesen kann im Umgang mit dem Namenträger nur erahnt werden, da auch der unter Umständen redende Übername lediglich einen durch die Sicht der selbstbenannten Figur beschränkten Hinweis auf den Namenträger gibt.

Insgesamt läßt sich feststellen: Die Häufigkeit, mit der Namen in Robinsons Gedichten und Blankverserzählungen von Figuren ausgerufen oder genannt werden, entspricht nicht ihrer epistemischen Leistungsfähigkeit. Der Versuch, mittels der Namenverwendung, der Namenvergabe oder der Namenauslegung den Namenträger emotional oder gar magisch zu erfassen, scheitert stets. Namen haben in Robinsons fiktiven Welten generell zwar einen hohen gesellschaftlichen und kommunikativen, gleichzeitig aber einen geringen informativen Wert. Die Bemerkungen zu Namen lassen dementsprechend weit eher Schlüsse auf den Zustand des Namenbenutzers oder des Namengebers als auf den Zustand des Namenträgers zu. Der Name ist bedeutungsreich je nach seiner Verwendung durch den Sprecher. Er spiegelt daher die Intentionen und die (epistemischen) Fehler des Sprachbenutzers. Außerfiktionale Intentionen des namengebenden Autors sind durch den Deckmantel der realistischen Namen und durch die vagen Hinweise im Text nicht eindeutig zu bestimmen.

\subsubsection{Intentionale Namenbedeutungen und die Wahrheit}

Die an den Blankverserzählungen gezeigten Brüche zwischen der Suggestion des Namenszeichens und der Wahrheit sind auch in Robinsons Gedichten ein strukturbildendes Element. Das wichtigste Kennzeichen der Namen in Robinsons Gedichten ist wie in den Blankverserzählungen ihr Hinweis auf die Intentionen des Namengebers und des

\footnotetext{
${ }^{381}$ Vgl. Donaldson 1966, S. 227: „[...] (and Ferguson knows, for he is Tasker Norcross) [...].“

${ }^{382} \mathrm{Ob}$ der Sprecher am Ende die Selbstgestaltung Fergusons erkennt und anerkennt, oder die Gestalt Norcross als reine Fiktion (zweiten Grades) abtut, läßt der Text offen.
} 
Namenbenutzers bei gleichzeitig problematischer Beziehung zwischen Namenszeichen und Namenträger. Dies zeigen sowohl die Handlungen der Gedichte als auch das semantische Potential der von Robinson gewählten Namen. In den folgenden Gedichtinterpretationen wird sich zeigen, daß die verschiedenen Portraits und Situationen, die Robinson gestaltet, als ein wesentliches Element den Namen der Figur enthalten, daß aber dieser Name wie der gesamte Text keine unhinterfragte Wahrheit darstellt. Namen dürfen ebensowenig wie Beschreibungen bei Robinson als statements des Autors zur Figur gelesen werden.

[Robinsons Gedichte] zeigen in der Tat, daß das erzählende „we" [der Sprecher und die Gemeinschaft] die beschriebenen Titelfiguren nur insoweit erfassen kann, als sie sich in allgemeine, auch für andere Figuren gültige und daher die Individualität des betreffenden Charakters verkennende Kategorien einordnen lassen. ${ }^{383}$

\subsection{Eigenname und memoria: Stafford's Cabin}

Die scheinbar unschuldigste Intention eines Namenbenutzers ist es, den Namen zu benutzen, um Vergangenes zu ordnen und zu vergegenwärtigen. Das Namenszeichen in Stafford's Cabin von 1916 steht für ein Ereignis, dessen Aura intensiv erfahren wird, aber nicht von der denotierenden Sprache erfaßt werden kann. Der Name bleibt insoweit leer, als er keinen signifikanten semantischen Hintergrund erhält.

Von der geheimnisvollen Geschichte um „Stafford's Cabin“ ist schon 1906 in Isaac and Archibald die Rede:

While Archibald said nothing-merely told

The tale of Stafford's Cabin, which was good,

Though 'master chilly'-after his own phrase-

Even for a day like that. ${ }^{384}$

Stafford's Cabin erzählt eben diese Begebenheit. Das Gedicht in alternierenden Septenaren beginnt nach Art eines Märchens mit

\footnotetext{
Once there was a cabin here, and once there was a man,

And something happened here before my memory began.

Time has made the two of them the fuel of one flame

And all we have of them is now a legend and a name. ${ }^{385}$
}

Der Sprecher befindet sich an einem Ort, mit dem sich offenbar eine geheimnisvolle Geschichte verbindet. Im Folgenden wird aber jeglicher Wissensdrang enttäuscht und eine Sinnfüllung der Ortsbezeichnung trotz neuer Informationen konsequent verweigert. Während in Isaac and Archibald nur der Leser nicht erfährt, was die Erzählung enthält, wissen in Stafford's Cabin noch nicht einmal die Figuren der fiktiven Welt selbst etwas Genaues über das eigentliche Ereignis. Übrig bleiben ein sinnloser Name und eine sinnlose dazugehörige Legende. Denn die versprochene "Legende“ - von der Figur Ar-

\footnotetext{
${ }^{383}$ Kruse 1974, S. 183 unter Bezug auf Josiah Royces ,all-inclusive Mind'.

${ }^{384}$ Robinson 1954, S. 176.

${ }^{385}$ Robinson 1954, S. 14.
} 
chibald im Folgenden auf einer weiteren Fiktionsebene erzählt - spricht nur von den materiellen Überresten einer nicht zu verstehenden Begebenheit:

All I have to say is what an old man said to me,

And that would seem to be as much as there will ever be.

"Fifty years ago it was we found it where it sat."-

And forty years ago it was old Archibald said that

"An apple tree that's yet alive saw something, I suppose,

Of what it was that happened there, and what no mortal knows

Some one on the mountain heard far off a master shriek,

And then there was a light that showed the way for men to seek.

"We found it in the morning with an iron bar behind,

And there were chains around it; but no search could ever find,

Either in the ashes that were left, or anywhere,

A sign to tell of who or what had been with Stafford there. ${ }^{386}$

Auch der Eigenname ,Stafford' gehört einer Figur, deren Wesen für den Erzähler Archibald nicht zu verstehen ist und die dem Leser und dem Sprecher nur in Ansätzen näher gebracht wird:

"Stafford was a likely man with ideas of his own-

Though I could never like the kind that likes to live alone;

And when you met, you found his eyes were always on your shoes,

As if they did the talking when he asked you for the news.

"That's all my son. Were I to talk for half a hundred years

l'd never clear away there the cloud that never clears.

We buried what was left of it,- - the bar, too, and the chains;

And only for the apple tree there's nothing that remains."

Das Gedicht Stafford's Cabin bezieht seine Spannung von der Überschrift an daraus, daß eine semantische Füllung des Namens erwartet wird. Der Name wird erst als Teil eines Orts- und Ereignisnamens, dann als alleinstehender Personenname eingeführt, der Text aber leistet die erwartete Sinnfüllung nicht. Die Erzählung wie der Name teilen diese Sinnlosigkeit mit den materiellen Überresten des Ereignisses:

Forty years ago it was I heard the old man say,

"That's all my son."-And here again I find the place to-day

Deserted and told only by the tree that knows the most,

And overgrown with golden-rod as if there were no ghost. ${ }^{387}$

In Stafford's Cabin wird ein bedrohliches Gefühl mit dem Ort, an dem sich der Sprecher befindet, und mit einem Namen verbunden. ${ }^{388}$ Dieses Gefühl findet aber in der beschriebenen materiellen Welt und in der Sprache keinen Halt. Weder das Ereignis noch die Person, die sich hinter dem Namen 'Stafford' verbergen, werden von Robinson

\footnotetext{
${ }^{386}$ Robinson 1954, S. $14 \mathrm{f}$.

387 Robinson 1954, S. 15.

${ }^{388}$ Als ,Nebenschauplatz' einer Gedichthandlung wird dieses Versagen des Namens auch in The Tavern mit dem vermeintlichen, aber leeren exemplum „old Ham Armory, the murdered host“ vorgeführt: Der Eigenname deutet eine individuelle Geschichte mit bekannten Beteiligten an, die Erzählung enttäuscht dann aber die dadurch aufgebauten Erwartungen: „The Tavern has a story, but no man / Can tell us what it is“, vgl. Robinson 1954, S. 93.
} 
greifbar dargestellt. Namen können nach Robinson wie alle „time-born words“ die Essenz der Wirklichkeit, in diesem Falle besonders der Vergangenheit, weder erfassen noch vermitteln. Sie gehören für inn zum äußerlichen Korsett, hinter dem sich eine erahnte, aber nicht greifbare Wirklichkeit verbirgt.

5.2.5.2.2 Versuchsweise Namenvergabe: Theophilus und The Wandering Jew (1920)

Nicht nur die Absicht, mit Namen ein vergangenes Ereignis wieder hervorzurufen und zu erklären, scheitert bei Robinson. Auch der Versuch, durch die Vergabe eines deutlich charakterisierenden Namens eine Person zu erfassen, gelingt den Figuren Robinsons nicht:

\footnotetext{
By what serene malevolence of names Had you the gift of yours, Theophilus? Not even a smeared young Cyclops at his game Would have you long,- -and you are one of us.

Told of your deeds I shudder of your dreams And they, no doubt, are few and innocent. Meanwhile I marvel; for in you, it seems, Heredity outshines environment.

What lingering bit of Belial, unforeseen, Survives and amplifies itself in you? What manner of devilry has ever been That your obliquity may never do?

Humility befits a father's eyes,

But not a friend of us would have him weep.

Admiring everything that lives and dies,

Theophilus, we like you best asleep.

Sleep-sleep; and let us find another man

To lend another name less hazardous:

Caligula, maybe, or Caliban,

Or Cain, —but surely not Theophilus. ${ }^{389}$
}

Die umfassende moralische Verurteilung der Hauptfigur in Robinsons Gedicht Theophilus geht vom Namen aus, der ein Dilemma des Sprechers ausdrückt: Theophilus müßte aufgrund seiner Taten aus der Gemeinschaft und ihrem Handeln vollkommen ausgeschlossen sein (,nicht einmal ein schmieriger Zyklop würde sich zum Spaß mit dir abgeben... ${ }^{390}$ ) und gehört doch - wie schon sein vertrauter Name ausdrückt - unwiderruflich zur Gemeinschaft dazu.

Die Verurteilung des Theophilus ist dezidiert. Den Sprecher schaudert angesichts der manifesten Taten („deeds“) der Figur vor ihren inm unfaßbaren Vorstellungen („dreams“). Bitter spekuliert er über die Unschuld der Träume (möglicherweise Pläne)

\footnotetext{
${ }^{389}$ Robinson 1954, S. 39 f.

390 Zur Rolle des Zyklopen als Liebender vgl. Theokrits Idylle Der Zyklop in: Theokrit 1970, S. 69-73. Zyklopen waren die Helfer des Hephaistos - daher sind sie ,schmutzige Schmiedegesellen'.
} 
des Theophilus. Er verweist den Grund für die unbegreiflichen Taten des Bösewichts in den mythischen Raum („bit of Belial“) und möchte inn ruhiggestellt sehen („we like you best asleep“), um in der letzten Strophe im Anschluß an die Suche nach einem passenden Namen durch die Wiederholung seiner ,Namenkritik' die Namenklammer zu schließen.

Als Stellvertreter der Gesellschaft auftretend, möchte er in der vierten und fünften Strophe Theophilus in einem ungefährlichen Zustand sehen. Alles, was lebt und stirbt, gibt der Sprecher vor zu bewundern. Der gleichwohl verabscheute Theophilus soll an diesen natürlichen und gesellschaftlichen Vorgängen nicht mehr teilhaben. Aus Rücksicht auf den Vater, aus angeblicher Sanftmut und christlicher Liebe zur Schöpfung („admiring everything..."), wünscht der Sprecher sich einen außergesellschaftlichen Zwischenzustand - einen komatösen Schlaf -, in dem Theophilus verharren soll. Bei genauem Hinsehen erfährt der Leser aber nichts über die Taten des Theophilus, die den Sprecher zu seiner Verurteilung veranlassen. Mehr noch: Auch der Sprecher ist innerfiktional lediglich durch Dritte informiert worden.

Aufschluß über die Figur und ihre angeblichen Sünden könnte man nun von den im Gedicht verwendeten Namen erwarten. Der Name des im Gedicht Theophilus Angesprochenen hat eine fromme Ursprungssemantik (,der Gott Liebende'). Außerdem verweist er auf den Adressaten des Evangeliums nach Lukas $(1,3)$. Die letzte Strophe spielt darauf an, daß der Sprecher und seine Gemeinschaft den Namen innerfiktional als präfigurierten Namen verstehen („,and let us find another man / To lend another name“).

Robinsons Präfiguration des Namens könnte ein bekehrter Sünder sein. So wird ein karrieresüchtiger mittelalterlicher St. Theophilus, der einen Teufelspakt schloß, dann aber reuig durch die Jungfrau Maria gerettet wurde, z.B. bei François Villon als frivoles exemplum verwendet. ${ }^{391}$ A. Ch. Swinburne erwähnt als Gegenspieler der Heiligen Dorothea einen Theophilus, der sich am Ende seiner Ballade St. Dorothy bekehrt. ${ }^{392}$ Robinson mag sich daran gestört haben, daß in beiden Fällen den Heiligen in spe ihre äußerst verworfenen Taten vergeben werden, weil sie tätige Reue zeigen. Der fromme Name Theophilus nimmt gegen alle (modern verstandene) Wahrscheinlichkeit das Bekehrungsereignis schon vorweg.

Zumindest läßt der Name mit seiner frommen Tradition eine Person aus einem frommen Umfeld erwarten. Diese Erwartung erfüllt der Namenträger bei Robinson aber offensichtlich nicht. Der Sprecher äußert sein Erstaunen hierüber, indem er die Namen-

\footnotetext{
${ }^{391}$ Vgl. Villon 1988, S. 140 f. (Verse 883-893), und den zugehörigen Kommentar S. 289; vgl. auch Robinson 1968, S. 83, Fn. 3.

392 Swinburne 1925, S. 1-15.
} 
verteilung mystifiziert. Er geht offenbar davon aus, daß ,normalerweise' passende oder zumindest konforme Namen vergeben werden. Der Glaube an passende Namen beruht dabei auf dem Fundament der sozialen Kontrolle. Ein Mensch, der bis hin zum Namen „one of us" ist, müßte eigentlich durch das „environment“ so weit diszipliniert werden, daß keine Abweichungen von den geltenden Normen vorkommen. Ein fremder Name dagegen würde auf eine Person deuten, die auch anderen Einflüssen ausgesetzt war oder ist.

Doch ist der Name vor allem eine ,Gabe' eines anderen. Daher leistet sich der Sprecher in der vierten Strophe auch einen hämischen Blick auf den so vollmundige Namen vergebenden Vater des Theophilus, dem ein wenig Demut seiner Ansicht nach gut anstehen würde. Doch ist der Vater immerhin in die Gemeinschaft integriert - denn keiner will ihn weinen sehen - und drückt durch die Namenwahl seine eigene Integration in die normative Welt aus, der sein Sohn dann nach Ansicht des Sprechers nicht entspricht. Die Personifikation des Namensystems („malevolence of names“) kann damit erklärt werden, denn die unpassende Namenvergabe erscheint als eine Böswilligkeit der ansonsten funktionierenden gesellschaftlichen Namenordnung.

Der Sprecher drückt sein Unverständnis, wie ein Mensch trotz seines anständigen Umfelds so unanständig sein kann, mit einem weiteren normativ markierten Namen aus: ,Belial'. Er spielt dabei deutlich auf die Diskussion um angeborene oder durch das soziale Umfeld beeinflußte Neigungen zum Verbrechen an, die Cesare Lombroso angezettelt hatte. ${ }^{393}$ Lombroso zeichnet vor allem für die umstrittene Annahme verantwortlich, daß es eine vererbte Anlage zum Verbrechen gebe, die sich nicht unbedingt in tatsächlichen Verbrechen äußern müsse. Das soziale Umfeld ist dieser Theorie zufolge zwar entscheidend dafür, ob jemand wirklich zum Verbrecher wird, die Anlage zum Verbrechen schlummert aber im Menschen unabhängig von diesen äußeren Einflüssen. Diese Theorie Lombrosos muß für Robinson äußerst attraktiv gewesen sein, weil sie eine Diskrepanz zwischen einem unter Umständen friedlichen und normalen Äußeren und Lebensweg eines Menschen und den dahinter verborgenen Abgründen der Seele konstatiert. So liegt es nahe, einen Verweis auf Lombroso zu vermuten, wenn Robinson seinen Sprecher erstaunt ausrufen läßt, im Falle des Theophilus sei Vererbung des Bösen stärker als die Wirkung des guten Umfeldes: „Heredity outshines environment“. Der Sprecher bedient sich zur Erklärung der Quelle dieser Vererbung einer biblischen Personifikation des Bösen, ,Belial': „What lingering bit of Belial, unforeseen, / Survives and

\footnotetext{
${ }^{393}$ Vgl. Lessico Universale 1973, S. 310. Robinson kannte zumindest Artikel von Cesare Lombroso und scheint inn ähnlich wie Max Nordau geschätzt zu haben, vgl. Robinson 1947, S. 233 (Brief Robinsons an Harry de Forest Smith vom 6.10.1895).
} 
amplifies itself in you?" Er vermischt hier eklektizistisch die Vererbungslehre Lombrosos bzw. Darwins mit traditionellem Vererbungs- und Bibelglauben sowie mit dem puritanischen Glauben an die überragende Rolle der Erziehung durch die Gemeinschaft. ${ }^{394}$ Damit verleiht er seiner umfassenden Verurteilung des Theophilus Ausdruck. Auch der Name ,Belial' gibt dabei die Sünde Theophilus' nicht eindeutig wieder. Robinson verwendet hier einen eindeutig wertenden, aber inhaltlich vagen Namen, der die Verworfenheit Theophilus' nicht erklärt, sondern in dem sich wiederum nur dessen Verurteilung ausdrückt. ${ }^{395}$

Da der Name ,Theophilus' nun nicht passend zu sein scheint, sucht der Sprecher in der letzten Strophe des Gedichts einen anderen Namen, der die Person charakterisieren soll. Die negativen exempla, die einen passenden Namen liefern sollen, haben allerdings sehr verschiedene Schlechtigkeiten begangen - Caligula Machtmißbrauch und Gotteslästerung, Caliban Undankbarkeit, allgemeine Barbarei und eine versuchte Vergewaltigung, Kain als Gipfel der Aufzählung den Brudermord. Auch diese Namen geben kein eindeutiges Bild der Taten oder des Delinquenten wieder.

Zwar beschreiben die alternativ erwogenen Namen den Verurteilten nicht eindeutig. Sie charakterisieren aber sehr wohl eine Figur - nämlich den Sprecher und Namenbenutzer. Dieser wird geleitet durch das Verlangen, daß die Sprache - und das sind in diesem Fall besonders die Eigennamen - die Wahrheit korrekt wiedergibt. Daher stört ihn der fromme Name für eine Person, die diesem frommen Bild nicht entspricht. Ausdruck dieses Vertrauens in die Sprache und die Sprechergemeinschaft ist auch, daß der Sprecher die Information, die er durch Dritte erhalten hat, unbesehen für bare Münze nimmt.

Um Theophilus zu charakterisieren, bedient sich der Sprecher eines ,Dreiklangs' stark normativ besetzter exempla aus der Bibel, der (antiken) Geschichte und der kanonischen Literatur. ${ }^{396}$ Die Namen umreißen seine normative Welt. Die exempla des neuenglischen Bildungskanons für Gut und Böse dienen ihm zur Festlegung der gesellschaftlichen Ordnung. Sie werden zur Verurteilung dort eingesetzt, wo ein abweichendes Verhalten festgestellt wird.

Robinson gestaltet die Verurteilung mit Namen dabei so, daß eines deutlich wird: Wirklich entsetzt ist der Sprecher darüber, daß jemand, der mit seinem frommen Namen zur

\footnotetext{
${ }^{394}$ Vgl. z.B. Herget 1987, S. 387 f. zur Rolle der Gemeinschaft bei den Puritanern.

${ }^{395} \mathrm{Vgl}$. z.B. 1. Samuel, 2,12, 2. Korinther, 6,15; vgl. auch die Einträge ,Belial' in Toorn 1999; Freedman 1992; Ashley 1986, S.141 f. Childers 1955, S. 224, übernimmt die Verurteilung und bedenkt nicht die Perspektive eines fiktiven Sprechers.

${ }^{396}$ Dieser ,Dreiklang' begegnet einem auch in anderen Gedichten Robinsons, etwa wenn in Nimmo erwähnt wird, was ein Künstler alles malen könnte: „He'd paint you Daniel in the lion's den, / Beelzebub, Elaine, or William Tell“; Robinson 1954, S. 521.
} 
Gemeinschaft gehört, den Normen der Gemeinschaft nicht entspricht. Ein tertium comparationis besteht lediglich darin, daß die drei genannten Namen exempla gehören, die für den Aufstand gegen Gott und die etablierte (religiöse) Ordnung stehen. ${ }^{397} \mathrm{Be}-$ sonders der rebellische Kain ${ }^{398}$ verkörpert diese durchaus auch positive Konnotation. Die Namenaufzählung weist daher darauf hin, daß es hier um einen 'Rebellen' wider die Ordnung geht. Dem Sprecher als Vertreter der Gemeinschaft geht es vorwiegend darum, einen sozialen, moralischen und sprachlichen Systemfehler durch eine Übernamenvergabe zu heilen. Es soll eine alternative Namentradition zum Taufnamen begonnen werden, so daß in der Sprachgemeinschaft Tilbury Towns der Verurteilte einen Haßnamen tragen muß. ${ }^{399}$ Doch der Heilungsversuch im Sinne der etablierten Namenordnung bleibt schwierig. Denn der Taufname steht nun einmal fest. Dem Sprecher bleibt nach der versuchten Benennung mit anderen Namen nichts übrig, als die Namenklammer zu schließen und die einzig sichere, aber negative Tatsache zu wiederholen - daß des Theophilus Taufname jedenfalls nicht paßt.

Bemerkenswert ist, daß der Sprecher nur auf der Ebene des Namens, der Identifikation im universe of discourse argumentiert. Die verworfenen Taten selbst scheinen eine sekundäre Rolle gegenüber dem Tatbestand der Rebellion gegen die etablierte Ordnung und gegen den ,anständigen' Namen zu spielen. Die Verurteilung beschäftigt sich damit, daß Theophilus zum Außenseiter geworden und damit die (repressive) Erziehung durch das Kollektiv Tilbury Towns gescheitert ist. Aufgrund von Gerüchten wird dem outlaw alles Böse zugetraut.

Die Suche des Sprechers nach einem passenden Namen für eine Figur endet in Theophilus mit dem hilflosen Verweis auf das Ungenügen des vorhandenen Namens. Ebenso scheitert die Suche nach passenden Namen für eine Figur in The Wandering Jew. Allerdings tritt hier eine anderes Ungenügen der Namen zu Tage.

Robinsons Gedicht in zwölf Oktaven, das nicht in Tilbury Town, sondern in New York spielt und dennoch den typischen Ton der Gedichte Robinson beibehält, beschreibt die Begegnung des Sprechers mit einer Gestalt, die er zunächst nicht einordnen kann:

\footnotetext{
I saw by looking in his eyes

That they remembered everything;

And this was how I came to know

That he was here still wandering.

For though the figure and the scene
}

\footnotetext{
${ }^{397}$ Im Falle des Römers Caligula: die aus heutiger jüdisch-christlicher Sicht ,wahre' Ordnung.

${ }^{398}$ Vgl. z.B. Baudelaire1991, S. 172 f. und den Kommentar S. 314 f.

${ }^{399}$ Vgl. Tschauder 1989, S. 27, der Namenverwendungen de facto, in denen der Sprecher die Namen als gegeben hinnimmt, von Namenverwendungen de jure unterscheidet, in denen der Sprecher die Namen aktuell vergibt.
} 
Were never to be reconciled,

I knew the man as I had known

His image when I was a child.

With evidence at every turn,

I should have held it save to guess

That all the newness of New York

Had nothing new in loneliness;

Yet here was one who might be Noah,

Or Nathan, or Abimelech,

Or Lamech out of ages lost,-

Or, more than all, Melchizedek.

Assured that he was none of these, I gave them back their names again,

To scan once more those endless eyes

Where all my questions ended then.

I found in them what they revealed

That I shall not live to forget,

And wondered if they found in mine

Compassion that I might regret. ${ }^{400}$

In den übrigen neun Strophen des Gedichtes bemüht der Sprecher sich mit großer Unsicherheit darum, aus der Tiefe der Augen - dem topischen Spiegel der Seele - das Gegenüber zu erfassen, in dem er den ,Ewigen Juden' erkannt zu haben meint. Doch letztendlich entziehen sich die Augen dem Betrachter und geben ihr Geheimnis (die Reue über die Verspottung Jesu ${ }^{401}$ ) nicht preis: „Those old, unyielding eyes may flash, / And flinch-and look the other way." ${ }^{402}$

In der ersten Strophe ändert sich dabei deutlich die Perspektive. In den ersten vier Versen weiß der Sprecher um die Identität des ,Wandering Jew' („still wandering“) und gibt damit die Perspektive ex post preis. Die übrigen Verse und Strophen schildern den Weg des Sprechers zum Erkennen des ,Ewigen Juden' und den erfolglosen Versuch, sein Gegenüber zu verstehen.

Der Sprecher geht von dem Gefühl aus, sein Gegenüber zu kennen, und sucht zu Beginn des Gedichts nach passenden Namen. Dabei geht es innerfiktional nicht wie in Theophilus darum, einen passenden präfigurierten Übernamen zu vergeben, sondern darum, das Gegenüber zu identifizieren. Der Sprecher fragt sich also, ob der andere Noah ist, nicht ob man inn ,Noah' nennen könnte.

Für die Robinsonsche Namengebungspraxis ist dieser Vorspann, der den Prozeß einer Namengebung schildert, äußerst aufschlußreich. Sie zeigt das Verschwimmen zwischen der Zuschreibung von Eigenschaften mit einem präfigurierten Namen und der Identifizierung einer auch außertextlich existierenden Figur bzw. Person. Der Sprecher

\footnotetext{
${ }^{400}$ Robinson 1954, S. 456-459; vgl. dazu auch die ausführliche Interpretation (ohne Namenanalyse) von Stanford 1983, S. 171-180, die auch auf das vermutliche reale Vorbild des ,Wandering Jew', Alfred H. Louis, eingeht (S.177-180).

${ }^{401}$ Vgl. Stanford 1983, S. 172.

${ }^{402}$ Robinson 1954, S. 459.
} 
trifft einen Menschen und erkennt in ihm etwas Überindividuelles, das wiederum durch die überlieferten mythischen oder historischen exempla personifiziert ist. Es erkennt also etwas wieder, was inm schon bekannt war - „when I was a child“ -, und was er erkennt, ist nicht neu: „All the newness [...] had nothing new“. Das exemplum und das Gegenüber verschmelzen in der Imagination des Sprechers. Auf diese Weise kann man sich auch Robinsons poetischen Umgang mit seiner realen Umwelt vorstellen.

Zur Einordnung des, Ewigen Juden' bedient sich der Sprecher wie in Theophilus eines Namenkatalogs, mit dem er das Wesen der Figur näher zu erklären versucht. Zunächst drücken die Namen alttestamentarischer Figuren die mythische Aura seines Gegenübers aus. ${ }^{403}$ Die aufgezählten Namen haben das sortale Prädikat \{jüdisch\} gemeinsam, zumindest ,Noah', ,Nathan' und ,Abimelech' auch die Konnotation \{weise\}. Im Gegensatz zur ursprünglichen Legende, die den ,Ewigen Juden' zumeist als verfluchten Übeltäter sieht, sucht der Sprecher also nach positiven Präfigurationen. Während nun im Falle von ,Theophilus' der Namenkatalog die angebliche Verworfenheit der Figur immer höher treibt, beschreibt dieser Schwarm eine Antiklimax hin zu bedeutungsärmeren Namen. ,Noah' und ,Nathan' sind noch bekannte und kultisch wichtige Namen des alten Testaments. ,Abimelech' und ,Lamech' sind nur jeweils mit einer kurzen Episode im Alten Testament vertreten. ${ }^{404}$ Vor allem aber endet die Aufzählung mit einem Namen, der für Robinson neben der vagen positiven Einschätzung gerade die Nichtgreifbarkeit symbolisiert. Die Klimax der Namenaufzählung, als Zusammenfassung der Bemühungen des Sprechers von den übrigen Namen abgetrennt, bildet der alttestamentarische Name „Melchizedek“. An anderer Stelle (Two men, 1897) hatte Robinson von diesem Namen schon bekannt:

\section{There be two men of all mankind \\ That I should like to know about; \\ But search and question where I will, \\ I cannot ever find them out.}

Melchizedek he praised the Lord,

\footnotetext{
${ }^{403}$ Vgl. Anderson 1968, S. 83.

${ }^{404}$ Noahs Bedeutung als Protagonist der Sintflut-Episode (Genesis 6-9) ist deutlich. Nathan ist ein Prophet der Bibel zu König Davids Zeiten, der als Begleiter und Mahner Davids funktional erwähnt wird, ohne eine vollständige Gestalt zu erhalten (I 1. Samuel 7,12, I. Kings 1). Abimelech ist in Genesis 20 der König von Gerar, der ahnungslos die Frau Abrahams in sein Zelt führt, sie aber auf einen von Gott geschickten warnenden Traum hin sofort wieder freigibt. Dieser Abimelech paßt in seiner inhaltlichen Vagheit zum am Ende der Kette erwähnten Melchizedek (s.u.). Die zweite biblische Figur dieses Namens ist der Sohn Jerubbaals, der sich in einem ungerechten Akt zum Alleinherrscher der ,Männer von Sichem' aufschwingt und am Ende getötet wird. In diesem Fall wird der Name mit größerem Inhalt gefüllt. Im Gegensatz zu den übrigen Namen handelt es sich um einen deutlich negativ konnotierten Namen. Insofern ist es wahrscheinlicher, daß Robinson an den Abimelech Abrahams gedacht hat. Ein ,Lamech' schließlich taucht zum einen in der Genealogie des Kain auf, als ein kämpferischer Nachkomme desselben, der zwei Frauen hatte und als Stammvater der Nomaden, Musikanten und Schmiede gilt (Genesis 4,18-24); zum anderen in der Genealogie der übrigen Söhne Adams, wo er als der Vater Noahs geführt wird (Genesis 5, 28 f.).
} 
Robinson erwähnt hier eine biblische Episode aus dem alten Testament, in der Melchizedek Abraham freundlich empfängt. ${ }^{406}$ Der Name hat also einen ähnlich kargen semantischen Hintergrund wie Abimelech und Lamech. Das Gedicht in insgesamt vier Kreuzreimstrophen fragt aber nach einem umfassenderen semantischen Hintergrund des Namens, wie inn ein producer überliefert haben könnte, und konstatiert sogleich, daß dieser Hintergrund nicht zu erfahren ist. Die referierenden Namen, die keinen semantischen Hintergrund preisgeben, obwohl sie suggerieren, daß es einen solchen vollständigen Hintergrund gibt (sie verleihen den „äußeren Habitus der Realität“407), „jagen“ aufgrund dieses Mißverhältnisses des Sprechers: „They chase me everywhere I go,-/ Melchizedek, Ucalegon.“ ${ }^{408}$

Die versuchsweise Benennung des ,Ewigen Juden' mit ,Melchizedek' erlaubt gerade keinen Zugang zum Wesen der Figur. Die eigentliche gemeinsame Konnotation des Namenkatalogs ist die Unerschließbarkeit der Figuren. Der Versuch der identifizierenden und festlegenden Namengebung wird aufgegeben. Der Sprecher wendet sich den Augen der Figur zu und beginnt in den folgenden Strophen, das und nur das zu erkennen, was diese Augen preisgeben. Dementsprechend wird im Haupttext die Benennung ,Wandering Jew' nicht verwendet. Lediglich auf das kennzeichnende Ereignis - die Verhöhnung Jesu und die Strafe ewiger Wanderschaft - wird hingewiesen, um das Gegenüber zu identifizieren. Die Benennung bleibt auf die Überschrift beschränkt, die nicht zur Textfiktion gehört.

Auch in diesem Fall sagt die Namengebung also nichts über die Figur aus. Die Namenaufzählung spiegelt vielmehr die religiöse Erziehung, die Ratlosigkeit des Sprechers, sowie den Eindruck, den er von seinem Gegenüber hat.

\subsubsection{3 ,Selbsttaufe': Fleming Helphenstine}

Die Verlagerung des Namengebungsaktes in die fiktive Welt nimmt dem Namen seine Stellung als endgültige Charakterisierung durch den Autor. Die Intention des Namengebers bei der Namengebung, auf der die namenträgerbezogenen Funktionen (besonders

\footnotetext{
${ }^{405}$ Robinson 1954, S. 80.

${ }^{406}$ Der biblische Fürst Melchizedek wird außerdem nach dem 110. Psalm für unsterblich gehalten. Er fügt daher dies als weitere Konnotation zur Charakterisierung des Ewigen Juden hinzu. Diese Konnotation tritt in Two Men hinter die Abraham-Episode zurück.

${ }^{407}$ Ingarden 1965, S. 261.

${ }^{408}$ Robinson 1954, S. 80; Ucalegon ist ein Trojaner, der in Vergils Aeneis als Randfigur erwähnt wird, vgl. Vergil 1989, I, v. 311
} 
die Charakterisierung) beruhen, wird dadurch ein Teil der Fiktion, daß der Namengeber eine Figur ist.

Am auffälligsten ist dies, wenn der Namenträger selbst sich einen Namen beilegt. ${ }^{409}$ Im Sonett Fleming Helphenstine ist die bezweifelte Namenträgerschaft eines Unbekannten das Element einer Handlung, die eine nur geahnte dunkle Wahrheit hinter einer harmlosen Oberfläche aufdeckt:

\footnotetext{
At first I thought there was a superfine

Persuasion in his face; but the free glow

That filled it when he stopped and cried, „Hollo!“

Shone joyously, and so I let it shine.

He said his name was Fleming Helphenstine,

But be that as it may;-I only know

He talked of this and that and So-and-So,

And laughed and chaffed like any friend of mine.
}

But soon, with a queer, quick frown, he looked at me,

And I looked hard at him; and there we gazed

In a strained way that made us cringe and wince:

Then, with a wordless clogged apology

That sounded half confused and half amazed,

He dodged,- - and I have never seen him since. ${ }^{410}$

Das Sonett beschreibt, wie die höfliche Dissimulation zwischen zwei Gesprächspartnern aufgedeckt wird. Über die Augen - wiederum der topische ,Spiegel der Seele' - wird die vage gegenseitige Antipathie einen kurzen Moment lang festgehalten, bevor die Kommunikation abgebrochen wird. Der Blick hinter die jeweilige Fassade zerstört die durch das verbale und nonverbale Verhalten aufgebaute Illusion der Jovialität.

Der Name selbst ist ambivalent. Er ist auf der einen Seite ein fremder Name: Der Rufname ,der Flame' und der in englische Schreibweise übertragene deutsche oder flämische Familienname weisen auf eine dem Sprecher wie dem Leser fremde und damit verdächtige Person hin. Dagegen ist die Präfiguration des Namens ,Helphenstine' ,Stein der Hilfe' entspricht dem etablierten und frommen Namen Ebenezer ${ }^{411}$ - vertrauenserweckend. Gleiches gilt für die positive Nationalstereotype, die in Neuengland zu Robinsons Zeiten mit dem deutschen Klang vermutlich verbunden war. Der Fremde trägt einen ,anständigen' Namen. Insgesamt bleibt der Name mit seiner Struktur von Ruf- und Familienname im Rahmen der möglichen neuenglischen Namen Robinsons.

Die Preisgabe seines Namens ist Teil der vom Gegenüber aufgebauten jovialen Selbstpräsentation. Die übliche Intention der Nennung des eigenen Namens ist es, das Vertrauen zu fördern, die weitere Kommunikation zu ermöglichen. Das Gegenüber des Sprechers ,macht sich bekannt'. Doch scheitert Fleming Helphenstine offenbar. Denn

\footnotetext{
${ }^{409}$ Vgl. zur Rolle von Übernamen auch Hamilton 1986, S. 65.

${ }^{410}$ Robinson 1954, S. 90.

${ }^{411}$ Er verweist auf den Stein ,eben-ezer' aus I Sam. 7,12.
} 
die möglicherweise positive Bewertung des Namens wird durch die Handlung entwertet. Die Positionierung des Namens bringt den Leser dazu, die Einstellung des Sprechers gegenüber dem Fremden nachzuvollziehen. Der Eigenname wird erst ,nachgereicht', nachdem die Figur im ersten Quartett des Sonetts unter dem mißtrauischen Blick des Sprechers als Unbekannter eingeführt wurde. Sobald der Name fällt, wird er angezweifelt. Die volle Verantwortung für die Nameninitiation wird der Figur von zweifelhafter Verläßlichkeit selbst zugeschrieben. Damit wird sehr deutlich eine Primäreinführung des Namens vorgeführt. ${ }^{412}$ Es handelt sich nicht um einen bereits eingeführten und daher im sozialen Umgang als verläßlich geprüften Namen, sondern um eine aktuelle Selbsttaufe, deren Gültigkeit für den Sprecher noch nicht erwiesen ist. Der augenblickliche Zweifel des Sprechers am Namen korrespondiert mit dem im ersten Quartett geäußerten anfänglichen Zweifel an der wahren Natur der Person, der dann zum treibenden Element der Terzette wird.

Robinson gestaltet hier eine Begegnung zwischen zwei Menschen, die Ralph Waldo Emersons Zweifel, ob Menschen ihr wahres innerstes Wesen zu verbergen vermögen, zum Ausdruck bringen:

We pass for what we are. Character teaches above our wills. Men imagine that they communicate their virtue or vice only by overt actions and do not see that virtue or vice emit a breath every moment. ${ }^{413}$

Die Wahrheit über die Figur, ihr möglicherweise mißtrauisches und mißgünstiges Wesen oder auch unerkannte und unnennbare Abgründe scheinen hervor zwischen den willentlich gesteuerten Hinweisen im Verhalten und in der Rede. Daß Fleming Helphenstines Verhalten von Beginn an bewußt und auf ein Ziel hin gestaltet wird, zeigt die Feststellung des Sprechers, er habe in seinem Gesicht von Anfang an einen ,feinen Zug des festen Willens zu überzeugen' entdeckt. Der selbstgegebene Name gehört bei Robinson zu den intentionalen „overt actions”, die etwas anderes verbergen sollen. Die Vertrauenswürdigkeit des Sprechers ist damit allerdings ebensowenig bewiesen. Er meint etwas zu beobachten, kann dies aber nicht verifizieren. Auch der Moment des Abbruchs der Kommunikation gibt keinen Anhaltspunkt dafür, daß Fleming Helphenstine tatsächlich eine in welcher Weise auch immer übelgesonnene Person ist. Beide Gesprächspartner zucken unter dem Eindruck, daß ,etwas nicht stimmt' zusammen, ohne daß dieses ,etwas' definiert worden wäre. Innerfiktional scheint es durchaus möglich, daß der Sprecher eine wirklich freundliche Person unbegründet ,auflaufen' und verwirrt

${ }^{412}$ Zur Unterscheidung von Primär- und Sekundäreinführung vgl. Tschauder 1989, S. 18 f.

${ }^{413}$ Vgl. Emerson 1979, S. 34 (Self-Reliance); vgl. auch Cavell 1985. 
und verwundert davongehen läßt. Das Mißtrauen sogar dem Namen des Unbekannten gegenüber vermag dieser durch kein Verhalten zu überwinden.

Auch in diesem Fall versagt die vermeintliche gesellschaftliche Kraft eines (scheinbar) anständigen Namens vor den ungreifbaren Intuitionen der Menschen. Der Name ist nur eine Äußerlichkeit.

\subsubsection{Das Vorurteil der Anderen und die Auslegung des Namens}

Die bisher dargestellten Fälle haben einen definierten Namengeber oder Namenbenutzer, der mit dem Namen eine bestimmte Intention verband. Die namengebende, namenbenutzende und namenauslegende Gesellschaft Tilbury Towns insgesamt wird dagegen zumeist durch Robinsons unspezifisches, wir' repräsentiert, ohne daß sie näher spezifiziert würde. Sie tut sich durch ihre Art zu sprechen hervor ${ }^{414}$, wozu auch die Namenbenutzung und -auslegung gehört. In den folgenden Fällen wird sich zeigen, wie gut Robinsons Figurennamen in das Bild passen, das sich die Gesellschaft von einer Figur, bzw. Person macht. Die Namen repräsentieren das Vorurteil der Gesellschaft gegenüber dem jeweiligen Namenträger.

5.2.5.3.1 Schein und Sein: Richard Cory, The Tree in Pamela's Garden, Mr. Flood's Party und Hector Kane

Daß Robinson Vorurteilen als gesellschaftlichen Faktoren eine große Bedeutung beimaß, zeigen nicht nur die Äußerungen zu seiner Wirkungsästhetik. Auch in einer Bemerkung zur Erkennbarkeit von Fremdpsychischem weist er auf ein von ungeahnten Tragödien gebeuteltes Inneres des Menschen, das dem oberflächlichen und vorurteilsbeladenen Blick des, wir' entgeht:

There is more in every person's soul than we think. Even the happy mortals we term ordinary or commonplace act their own mental tragedies and live a far deeper and wilder life than we are inclined to believe possible in the light of our prejudices. ${ }^{415}$

Nimmt man diese Sätze als Teil seiner gesamten Wirkungsästhetik ernst, so darf man erwarten, daß Robinson nicht nur solche Charaktere darstellt, sondern auch die Verborgenheit ihrer „own mental tragedies“. Die Rolle der Eigennamen in Robinsons Verserzählungen läßt erwarten, daß dabei den Namen der Figuren eine ambivalente Rolle zukommt.

\footnotetext{
RICHARD CORY

Whenever Richard Cory went down town,

We people on the pavement looked at him:

He was a gentlemen from sole to crown,

Clean favored, and imperially slim.
}

\footnotetext{
${ }^{414}$ Vgl. auch Kruse 1976, S. 184.

${ }^{415}$ Robinson 1947, S. 134; vgl. auch Anderson 1967, S. 51.
} 
And he was always quietly arrayed,

And he was always human when he talked;

But still he fluttered pulses when he said:

"Good-morning," and he glittered when he walked.

And he was rich-yes, richer than a king-

And admirably schooled in every grace:

In fine, we thought that he was everything

to make us wish that we were in his place.

So on we worked, and waited for the light,

And went without the mead, and cursed the bread;

And Richard Cory, one calm summer night,

Went home and put a bullet through his head. ${ }^{416}$

Das erste Beispiel für den vorurteilsbeladenen Blick auf einen scheinbaren „happy mortal" ist das wohl bekannteste Gedicht Robinsons: Richard Cory. In inm wird aus der Sicht der Gemeinschaft ein von allen beneideter, mit allen Gaben versehener Mann geschildert, der sich am Ende des Sonetts aus dem Sprecher völlig unverständlichen Gründen, aber vielleicht sehr zu seiner inneren Befriedigung umbringt.

Der Name ,Richard Cory' stützt hier suggestiv ein Vorurteil, das der Namenträger selbst am Ende der Handlung widerlegt. Mit seiner deutlichen Pointe und einfachen Sprache bietet das Sonett kaum Dunkelheiten, wenn man von der von Robinson als Unbestimmtheitsstelle gelassenen Motivation Richard Corys zum Selbstmord absieht. Die meisten Interpretationen sind sich einig darüber, daß das Gedicht eher die Sicht der Gemeinschaft auf den Protagonisten beschreibt als diesen selbst. ${ }^{417}$ Bezeichnend für die von Robinson in diesem Gedicht gestaltete Welt ist dabei die oberflächliche und neidische Sicht der Gemeinschaft, die nur das äußere Auftreten der Person sieht, ohne nach seinem Inneren, seinem Seelenleben zu fragen. Daher kommt innen der Selbstmord völlig überraschend, der im Innenleben der Figur folgerichtig sein mag. Der Name fügt sich in das Bild der Gemeinschaft, ohne einen Hinweis auf das der Gemeinschaft wie dem Leser verborgen bleibende Innere der Figur zu gestatten. Richard als dynastischer Vorname der englischen Könige korrespondiert mit der Beschreibung des königlichen Auftretens. ${ }^{418}$ Cory als üblicher amerikanischer Familienname, möglicherweise eine Abkürzung des arkadischen ,Corydon' aus Vergils Bucolica, paßt in dieses Bild. ${ }^{419}$

\footnotetext{
${ }^{416}$ Robinson 1954, S. 82

${ }^{417}$ Vgl. etwa Burkhart 1960, Morris 1965, Nicolaisen 1978. Das Interesse am Grund für Richard Corys Selbstmord treibt manchmal seltsame Blüten, vgl. z.B. Kavka 1975.

${ }^{418}$ Besonders in diesem Fall ist zu beachten, daß Robinsons Verweis auf ,Könige' in seinen Gedichten allgegenwärtig ist. Die Erwähnung einer Krone ist also anders, als Childers 1955, S. 224 f., meint, nicht unbedingt eine Aktualisierung der Präfiguration des Rufnamens ,Richard'; vgl. etwa Flammonde, Robinson 1954, S. 3-6, oder The Wandering Jew, Robinson 1954, S. 456-459; vgl. auch Slethaug 1971, S. 45 f. zu Robinson's Texten Old King Cole, The Old King's New Jester und King Jasper; Turner 1970 deutet ohne erkennbare inhaltliche Folgen Richard Cory als „the core of Richard“.

${ }^{419}$ Vgl. Vergil 2001, S. $17(2,1)$ passim.
} 
Der Name zeigt einen ,anständigen' und die Normen der Gemeinschaft erfüllenden Menschen. Möglicherweise werden tragische Obertöne durch die negative Aura, die Shakespeares Dramen und die exemplarische Bedeutung Corydons als schmachtender Liebhaber impliziert. Letztlich entspricht der Eigenname dem äußeren Zustand des Namenträgers, der sich auch aus der übrigen, die Essenz der Figur verfehlenden Beschreibung durch den Sprecher ergibt.

Ist der Sprecher im Falle von Richard Cory ein Teil der vorurteilsbeladenen Gesellschaft, nimmt er in unserem zweiten Beispiel, dem Sonett The Tree in Pamela's Garden, eine auktoriale Position ein. Auf diese Weise wird an der vom Namengeber intendierten Namenbedeutung die Differenz zwischen der beschriebenen Wirklichkeit (dem Sein) und dem Vorurteil der Gesellschaft, der der Namengeber angehört ${ }^{420}$, deutlich:

Pamela was too gentle to deceive

Her roses. "Let the men stay were they are,"

She said, "and if Apollo's avatar

Be one of them, I shall not have to grieve."

And so she made all Tilbury Town believe

She sighed a little more for the North star

Than over men, and only in so far

As she was in a garden was like Eve.

Her neighbours-doing all that neighbours can

To make romance of reticence meanwhile-

Seeing that she had never loved a man,

Wished Pamela had a cat, or a small bird,

And only would have wondered at her smile

Could they have seen, that she had overheard. ${ }^{421}$

Beschrieben wird die Verwunderung der Gesellschaft gegenüber einer sexuell abstinenten Frau, die sich ihrerseits über diese Verwunderung und die unbeholfene Hilfe der Gemeinschaft nur amüsieren kann. Im ersten Vers deutet der Erzähler mit einer ironischen Metapher an, daß Pamela einen Grund hat, abstinent zu bleiben. Der Leser kann jedoch die Metapher nicht endgültig auflösen. Ob der Rosenstock (,rose tree') in Pamelas Garten symbolisch für die Kunst steht, für vorherige sexuelle Erlebnisse oder für die Schönheit der Natur, ist unklar, und es kann auch dahingestellt bleiben. Wichtig ist, daß Robinsons Blick im Verlauf des Gedichts nicht nur auf der Figur ruht, sondern auch auf der Gesellschaft und ihrem Fehlurteil. Die Gemeinschaft von Tilbury Town mißversteht die Zurückhaltung und ,Schweigsamkeit' Pamelas über ihr Seelenleben und ihre ,Erfahrungen' und versucht, sie romantisch zu verklären.

\footnotetext{
${ }^{420}$ Namengeber können die Gesellschaft oder der Sprecher des Gedichts sein, wenn es sich um einen Übernamen handelt, oder vom Leser supponierte Eltern, wenn es ein Taufname ist.

${ }^{421}$ Robinson 1954, S. 576.
} 
Robinson wählt für seine ironische Gestaltung eines Vorurteils - nämlich, daß man abstinent nicht erfüllt leben kann - den Namen der Heldin aus Samuel Richardsons berühmtem gleichnamigen Roman, der paradigmatisch für eine moralisierende und tränenreiche Tugendhaftigkeit steht. ${ }^{422}$ Dieser Name ist ebenso ironisch, wie die vage Andeutung, Pamela wolle ihre Rosen nicht (mit einem Mann) betrügen. Er gehört als Übername oder als Taufname mit aktualisierter Präfiguration zu jenen Äußerlichkeiten, die die falsche Sicht der Gesellschaft auf die Figur ${ }^{423}$ kennzeichnen. Robinson gibt mit ihm daher nicht das wahre Wesen der Figur Pamela preis. Das Wesen der Figur - nämlich ihre Zufriedenheit ${ }^{424}$ mit ihrer Lebensweise, ohne daß es der Kompensation durch ,ein Objekt der Liebe' bedürfte - kann der Leser nur emotional erfassen. Das Wesen Pamelas bleibt der denotierenden Sprache einschließlich des von der Gesellschaft charakterisierend verwendeten Eigennamens verborgen. Dagegen bietet der Sprecher dem Leser das biblische exemplum ,Eva' zur Erklärung an, wenn auch nur sehr indirekt. ,Pamela' macht der Gesellschaft weis, sie sei kaum mit der biblischen Eva zu vergleichen, d.h. sie teile die Leidenschaften und Sehnsüchte der Frauen nicht. Da sie der Gesellschaft nur etwas vorspielt („made all Tilbury Town believe“), liegt am Ende des Gedichts der Schluß nahe, daß sie doch mehr Gemeinsamkeiten mit Eva und anderen Frauen hat, als die Gesellschaft ahnt.

Im dritten Beispiel für die Differenz zwischen Schein und Sein, die sich im Namengebrauch zeigt, verrät ein exemplum des Sprechers, daß der Name und seine Auslegung mehr vom Blick des Sprechers auf die Figur als von dem wahren Sein der Figur abhängen. Daß der Name ,Eben Flood' in Mr. Floods Party möglicherweise redende Komponenten enthält, wurde bereits erläutert (s.o.). ${ }^{425}$ Der Name ,Ebenezer' (,stone of

\footnotetext{
${ }^{422}$ Robinson erwähnt ironisch Richardsons Briefstil als Beispiel für aufrichtiges ("sincere") Schreiben (Robinson 1968, S. 83, Brief an Edith Brower vom 26.8.1898); er wird zumindest dem Titel nach dessen bekanntestes Werk, Pamela: or, Virtue Rewarded, kennen. Diese Präfiguration wird von den Interpreten ignoriert, die statt dessen zu Spekulationen über die Ursprungssemantik oder über den Ursprung der Abstinenz Pamelas neigen. So leitet etwa Cervo 1995, S. 29 f., den Namen äußerst aufwendig aus meléa $=$ Apfelbaum, melon = Apfel, malum $=$ das Böse, Pan $=$ das All, vollständig usw., aus pammelas = ganz Schwarz, ganz dunkel ab und kommt zu dem Ergebnis, daß Pamela eine der Robinsonschen gefallenen Frauen sei. Sie soll darüber hinaus selbst den Baum (der Erkenntnis) aus dem Gedichttitel darstellen, der demnach kein Rosenstock (rose tree), sondern ein Apfelbaum wäre. Nebenbei ist noch zu bemerken, daß Cervo seine Interpretation fehlerhaft auf eine Äußerung Robinsons stützt, die auf dessen Sonett New England bezogen ist. Eine aufwendige Etymologie des Namens Pamela mag Richardson vorgeschwebt haben. Bei Robinson ist sie unwahrscheinlich, da er einen schon vorhandenen Namen benutzt. Wahrscheinlicher ist, daß Robinson einfach die Möglichkeit betont, auch auf alternative Weise (eben nicht in der Ehe) sinnlich glücklich zu werden, ohne dabei bigott oder frigid zu werden.

${ }^{423}$ Vgl. Etwa Donaldson 1966, S. 228; Levenson 1969, S. 165 f.

${ }^{424} \mathrm{Ob}$ das Lächeln Pamelas Zufriedenheit anzeigt oder ob es ein bitteres desillusioniertes Lächeln ist, bleibt unter den Interpreten umstritten; vgl. etwa Donaldson 1966, S. 228; Weil 1993, S. 230-232. In jedem Fall zeigt es aber ein amusement der Protagonistin über die Fehleinschätzung ihrer wahren Beweggründe und ihres wahren emotionalen Zustandes durch die Bewohner Tilbury Towns.

${ }^{425}$ Vgl. Robinson 1954, S. 573-575; vgl. auch Stanford 1983, S. 151 f., zum Gebrauch des Exempels.
} 
help') ist zudem als Rufname verbreitet. Er verweist auf 1. Samuel 7,12, wo Samuel die Benennung des Ortes einer gewonnenen Schlacht mit dem Namen ,eben ezer' von dem Satz: „Hitherto hath the Lord helped us" begleiten läßt. Sollte Robinson diese Anspielung intendiert haben, ist der hoffnungsvoll redende Name, dessen Ursprungssemantik in der Bibel genannt wird, in bezug auf den allein verbliebenen ,Mr. Flood' sicherlich ironisch gemeint. Gott hat Eben Flood ,dazu verholfen', seine desolate Lage auf regelmäßigen solitären Saufgelagen zu meditieren. Während der Ort eben ezer in der Bibel Zeichen einer Wendung vom Bösen zum Guten ist, spricht Eben Flood selbst von einer Wendung vom Guten zum Schlechten:

Well, Mr. Flood, we have not met like this

In a long time; and many a change has come

To both of us, I fear, [...]. ${ }^{426}$

Zudem ist der klangvolle und heroische Name ,Ebenezer' zu Eben gekürzt und wird vom profanen Familiennamen Flood begleitet (s.o.). ${ }^{427}$

In der dritten Strophe vergleicht der Sprecher die Figur Flood mit dem Geist Rolands, der sein Horn zum letzten vergeblich hilfesuchenden Ruf erhebt. Doch Eben Floods Schattenriß, der diesem exemplum ähnelt, gehört in Wirklichkeit zu einem einsam sich betrinkenden Mann, der den Krug ansetzt. Der Vergleich ist offensichtlich ironisch und tragisch zugleich. Der Sprecher stellt einen offenbar inadäquaten und deshalb komischen Vergleich an und zeigt doch eben dadurch die versteckte Größe und die versteckte (tragische) Poesie in dem alltäglichen Leiden des Trunkenbolds Eben Flood auf. Gleichzeitig wird das exemplum in Frage gestellt. Der Sprecher vergleicht nicht Eben Flood mit Roland, sondern dessen Schatten mit dem Geist Rolands. Dieser bläst in ein nicht mehr tönendes Horn - während der Olifant der Sage doch gerade für seine Reichweite berühmt ist. Der Sprecher relativiert den begonnenen Vergleich dadurch, daß er nicht die Personen, sondern nur deren unwirkliche Abbilder miteinander vergleicht.

In unserem vierten Beispiel für eine Differenz zwischen Schein und Sein im Namen Hector Kane - entspricht der Name prima facie dem Bild, das der Namenträger und die

\footnotetext{
${ }^{426}$ Loges 2000, S. 93, verweist auf die Bedeutung von Eben(ezer). Er ignoriert allerdings weitgehend die humoristische Ironie Robinsons, wenn er Eben Flood wie auch den Stein der Bibel als Monument der Vergangenheit, als Schlachtfeld und Ort einer Tragödie sieht. Loges ignoriert außerdem, daß der Ort Ebenezer natürlich zur Zeit der Niederlage der Israeliten nicht so hieß. Der Erzähler der Bibel erzählt die Geschichte ex post. Denn den Namen erhält der Ort erst nach dem Sieg der Israeliten über die Philister; vgl. I Sam. 4, 5, 7 .

${ }^{427}$ Loges 2000, S. 93, bezieht die Ursprungssemantik von ,eben' ein und sieht Eben Flood als toten Stein ohne Hilfe. Außerdem bezieht er ,Flood' auf die Sinflut. Beide Interpretationen haben allerdings keine Stütze im Text.
} 
Gesellschaft sich machen, und verrät doch in einem zweiten Schritt eine tiefere Wahrheit, die weder dem Sprecher, noch dem Namenträger bewußt sind. ${ }^{428}$ Hector Kane glänzt dadurch, daß er trotz seines hohen Alters von 85 Jahren äußerst jugendlich wirkt und von geradezu klassischer Schönheit ist. Stolz verteilt er weise Ratschläge, wie man den Einfluß des Alters, aber auch der Wahrheit und des Todes vermeidet. Ironischerweise ereilt inn just in dem Moment der Tod, in dem er über die eher triviale Erkenntnis: ,Lebe und denke einfach und ignoriere die (Suche nach der) Wahrheit mit allen ihren Sorgen', hinausgehen und in seine Zukunft und die der anderen blicken will. Hector Kane kann sein Horazzitat („Cras ingens iterabimus aequor“429), das seinen uneingeschränkten diesseitigen Optimismus ausdrücken sollte, nicht mehr vollenden.

In welcher Weise Hector Kane sich in seinem Leben fehlerhaft verhalten hat, zeigt seine ,Gegenfigur' Llewellyn aus Llewellyn and the Tree . Von diesem als Ehebrecher charakterisierten Mann berichtet der Sprecher, er habe trotz seines äußerlichen Alterns „something of immortal youth“ an sich. Die ,innere' Jugendlichkeit Llewellyns beruht darauf, daß er zwar ein Leben gegen die Gesetze der puritanischen Gemeinschaft wagt, damit aber seinen wahren Bedürfnissen gerecht wird. ${ }^{430}$ Während Hector Kane versucht, sich vom Leben fern zu halten, ${ }^{431}$,stürzt Llewellyn sich ins Leben'. Dies gibt der Sprecher sich und dem Leser als Lehre mit: „Pour not the wine of life too thin / If water means the death of you. “432

Die Beschreibung Hectors durch den Sprecher ist wie üblich bei Robinson durch zahlreiche Zweifel über das Gesehene geprägt. Man nimmt wahr, daß Alter und äußere Erscheinung der Person nicht übereinstimmen, kann jedoch nicht erklären, ob die Erscheinung trügt oder das Alter falsch angegeben wurde. Die ganze Person wird zweifelhaft, weil der Sprecher immer wieder betont, wie unglaubwürdig sie ist. Im Vergleich zu den früheren Charakterisierungen (etwa in Richard Cory) fällt hier allerdings auf, daß die Beschreibung sich nicht auf Äußerlichkeiten beschränkt. Robinson gibt hier ausnahmsweise auktorial das Innere seiner Figur preis: Hector Kane ist ein kindliches, ganz am Diesseits orientiertes Gemüt, das sich durch seine Naivität den Auswirkungen des Alterns zu entziehen sucht.

Der Name scheint zunächst das positive Bild der ewigen Jugend Hector Kanes zu stützen. Präfiguration des Rufnamens ist der trojanische Held Hektor aus Homers llias, der die Jugendlichkeit des Körpers Hector Kanes verkörpert. Die Beschreibung Hector Ka-

\footnotetext{
${ }^{428}$ Vgl. Robinson 1954, S. 1210-1212.

${ }^{429}$ Horaz 1981, S. 20 (Oden 1, 7): "morgen werden wir wieder befahren die unendliche Weite“.

430 Robinson 1954, S. 54.

${ }^{431}$ Vgl. auch Robinson 1947, S. 285 (Brief an Harry de Forest Smith vom 24.4.1897).

432 Robinson 1954, S. 54; vgl. auch Bedell 1979, S. 31.
} 
nes mit seinen „snowy crown of curls“ und "his cheeks that might have been a girl's” erinnert einen Moment lang an klassische Darstellungen antiker Helden. ${ }^{433}$

So wie der Leichnam (also der materielle Teil der Person) des trojanischen Hector durch den Schutz der Götter unversehrt bleibt, obwohl Achilles inn mit seinem Wagen um Troja schleift, scheint auch Hector Kane von den Einwirkungen des Lebens verschont zu bleiben. Gleichzeitig wirft das Schicksal des originalen Hector ein bedenkliches Licht auf die Sorglosigkeit Hector Kanes. Des Trojaners Tod ist schon vor dem letzten Kampf mit Achilles von den Göttern beschlossen. Beide können dem Tod nicht entgehen. Die Unversehrtheit des Körpers bedeutet nicht einen Überfluß an Leben. Selbst die Hoffnung auf ein ,anderes (jenseitiges) Salamis', die die Horazische Ode in der Strophe, der Robinson das Zitat entnimmt, ausspricht, ist durch das Unvollendete des Zitats getrübt.

Auch in diesem dritten Fall bestätigt der Name auf den ersten Blick ein Vorurteil der Gesellschaft gegenüber dem Namenträger. Doch enthält der Name Elemente, die eine weitergehende, nicht mit dem Vorurteil übereinstimmende Namendeutung nahelegen und eine andere Wahrheit hinter dem Augenschein andeuten.

\subsection{Die Gleichgültigkeit der Gesellschaft: Job the Rejected}

Die Vorurteile der Gesellschaft gegenüber den Figuren Robinsons drücken sich in den bisher behandelten Gedichten darin aus, daß der Taufname der Figuren als „coincidence agreeable enough" zum vermeintlichen Wesen des Namenträgers passen soll. In einem realistischen onomastischen Raum, wie ihn Robinson in seinen Gedichten eröffnet, lassen sich deutliche Hinweise auf die Ansichten der Gesellschaft zu einer Person in Übernamen entdecken. Dies hängt damit zusammen, daß der Namengebungsakt bei Übernamen konventionell eine deutlich charakterisierende Funktion des Namens begründet. Daß ein Name als vom Sprecher vergebener Übername fungiert, erkennt man z.B. an der engen Verbindung zwischen der Bildwelt des Gedichts und dem Namenzeichen im Sonett Job the Rejected:

\footnotetext{
They met, and overwhelming her distrust

With penitence, he praised away her fear;

They married, and Job gave him half a year

To wreck the temple, as we knew he must.

He fumbled hungrily to readjust

A fallen altar, but the road was clear

By which it was her role to disappear

That evening when Job found him in the dust.

Job would have deprecated such a way

Of heaving fuel on a sacred fire,

Yet even the while we saw it going out,
}

${ }^{433}$ Robinson 1954, S. 1210. 
Hardly was Job to find his hour to shout;

And Job was not, so far as we could say,

The confirmation of her souls desire. ${ }^{434}$

Robinson benutzt hier den Namen des biblischen Beispiels für ungerechtfertigte Leiden und das fromme Erdulden dieser Leiden. Robinsons Job betrachtet erst tatenlos, wie ein anderer Mann eine von inm geliebte Frau und sich selbst ruiniert, dann, wie die Dorfgemeinschaft ihr Urteil zur Vernichtung der Frau fällt. Jobs Haltung ist duldend, sein Rettungsversuch „to readjust / A fallen altar" scheitert.

Der Sprecher, der seinerseits Teil einer die Dreieckskonstellation beobachtenden Gemeinschaft ist, beschreibt diese Handlung mit religiöser Metaphorik. Die Frau, deren Ruin Job mit ansehen muß, ist "the temple“ und „a fallen altar". Der andere Mann wird am Ende des zweiten Quartetts biblisch „in den Staub“ geworfen. Die Terzette beenden die Handlung mit einem Brandopfer, wie auch die Geschichte des biblischen Hiob mit einem Brandopfer endet (Hiob 8-10). Dabei bleibt unklar, ob es sich in der fiktiven Welt Robinsons um einen echten Brand handelt, bei dem die Frau umkommt, oder um ein symbolisches Feuer, das sie psychisch vernichtet. Die Zuschauer aus Tilbury Town jedenfalls scheinen das vom Schicksal und innen selbst beschlossene Ende im Opferfeuer zu beschleunigen, „heaving fuel on a sacred fire“. Die Parallele zum biblischen Hiob wird am Ende des Gedichts vom Sprecher noch einmal aktualisiert. Es wird ausdrücklich festgestellt, daß Job kaum eine Gelegenheit zur jener großen Klage findet: „Hardly was Job to find his hour to shout". Hier wird vorausgesetzt, daß Job seiner Rolle als Hiob gemäß klagen will. Der Sprecher konstatiert schließlich ebenso unbarmherzig wie religiös, er sei einfach nicht der geeignete Mann für die moralische Festigung der ,Seele' der gescheiterten Frau gewesen.

Der Status des Namens ,Job' wird dadurch beeinflußt, daß er sich in die Metaphorik des Sprecher einpaßt. Er ist weniger ein Taufname, als ein Übername, den die Sprechergemeinschaft oder der Sprecher vergeben haben. Der Name charakterisiert daher die Figur nur nach Maßgabe der Gemeinschaft. Gleichzeitig drückt sich in inm diese namengebende Gemeinschaft Tilbury Town aus. Diese ordnet ihre Welt normativ nach biblischen exempla und nimmt doch eine unbarmherzige Haltung ein. Sie betrachtet gleichgültig den Vollzug dessen, was sie zum Schicksal erklärt hat. Der Name schreibt der Figur Job eine Rolle zu, die er nicht mehr ablehnen kann - "the road was clear“. Das Achselzuckende der letzten Verse des Sonetts macht die self-fulfilling prophecy des vergebenen Namens deutlich. Einmal durch den Namen ,Hiob' auf seine duldende

${ }^{434}$ Robinson 1954, S. 577. 
und leidende Rolle festgelegt, erhält Job von der Gemeinschaft keine Gelegenheit mehr, in die Handlung einzugreifen.

\subsection{Die Ratlosigkeit der Gesellschaft: Flammonde}

Die bisher betrachteten Gedichte haben im Namen ausgedrückte Vorurteile einer Gesellschaft gezeigt, die nicht hinter die von ihr postulierten oberflächlichen Ansichten der Figuren blicken kann oder will. Im Falle eines weiteren Namens - Flammonde - drückt nun der Sprecher im Namen der Gemeinschaft sein Mißtrauen gegenüber dem von der Gemeinschaft vergebenen Übernamen aus. In Flammonde wird der Namenträger - wie Fleming Helphenstine - trotz seines „festen Auftretens“ mißtrauisch als von dubioser Herkunft und fremdem Gebaren eingeführt: „The man Flammonde, from God knows where, With firm address and foreign air, [...].“435 Der ungewöhnliche, französische und als reiner Ruf- oder Familienname unvollständige Name paßt nicht in das Feld der anständigen Namen Tilbury Towns. Er erlaubt keine Identifikation durch sortale Prädikate, zu denen auch der Ruf der Herkunftsfamilie gehörte, und ist dementsprechend als Familienname untauglich. Dies macht auch die kontinuierlich den Namen begleitende Spezifizierung "the man“ deutlich. Daher wirkt der Eigenname eher wie ein Übername. Er basiert auf der Selbstbezeichnung Christi als „flamme du monde“ (Licht der Welt) und beschreibt damit einen idealen Christenmenschen in der imitatio christi oder einen in die moderne Welt zurückgekehrten Christus. ${ }^{436}$ Unterstützt wird dieser religiöse Oberton auch durch die zwölf Strophen des Gedichts - nach den zwölf Jüngern Jesu -, durch die ironische Wendung "from God knows where“437 und durch das den Eigennamen fast stets begleitende Epitheton „the man“, das auf das ,ecce homo' Christi hinweist. $^{438}$

In der elften Strophe bezieht der Sprecher die Bewohner Tilbury Towns in sein „we“ ein, um eine allgemeine Weisheit auszusprechen:

\footnotetext{
„How much it was of him we met

We cannot ever know; nor yet

Shall all he gave us quite atone

For what was his and his alone;

Nor need we now, since he knew best,

Nourish an ethical unrest:

Rarely at once will nature give

The power to be Flammonde and live. ${ }^{4339}$
}

\footnotetext{
${ }^{435}$ Robinson 1954, S. 3.

${ }^{436}$ Vgl. Childers 1955, S. 226 f., der ,Flammonde' als Christus nach Johannes 8,12 und 9,5 interpretiert. $\mathrm{Daß}$ die Bezeichnung auch allgemein auf einen Christen angewendet werden kann, zeigt Matthäus 5,14; vgl. W. R. Robinson 1967, S. 91 f. Irreführend ist die Übersetzung des Namens von Hirsch 1969, S. 32, als "world on fire“.

${ }^{437}$ Vgl. Childers 1955, S. 226.

${ }^{438}$ W. R. Robinson 1967, S. 14 interpretiert das Epitheton als Hinweis auf Robinsons Interesse an der allgemeinen Natur des Menschen.

${ }^{439}$ Robinson 1954, S. 5 f.
} 
Daß Robinson den Eigennamen ,Flammonde' hier ohne Artikel verwendet, entspricht zwar der Konvention, ist aber deshalb auffällig, weil er in dem Gedicht das einzige Mal ohne das Epitheton „the man“ erscheint. Dies zeigt, daß Robinson den Namen an dieser Stelle appellativisch verwendet. Der Gedanke Robinsons ist hier, daß es kaum einen Menschen gibt, der die Kraft hat, ein ,Licht der Welt' zu sein, und trotzdem sein eigenes Leben vernünftig zu gestalten. Die Verwendung eines Eigennamens würde eine Formulierung wie ,to be like Flammonde' nahelegen. Im letzten Vers der zwölften Strophe, der wieder zur Figur 'Flammonde' zurückkehrt, ist dann wieder von „the man Flammonde“ die Rede. 440

In diesem Fall eines deutlich redenden Namens könnte man davon ausgehen, daß der Name das Wesen der Figur preisgibt. Doch der Sprecher sät auch hier von Anfang an Zweifel. Schon in der dritten Strophe fragt er, warum Flammonde wohl aus seiner ursprünglichen Heimat ausgestoßen wurde, und betont, dieser habe nie seine Lebensgeschichte erzählt, also nie seinen Namen mit einer Namengeschichte versehen. Er hat der Gesellschaft seine Identität nicht preisgegeben. Der Einführung der Figur haftet der Zweifel an, ob Flammonde seine Heiligkeit nur spielt oder ob er tatsächlich heilig ist: „In fine, one pauses, half afraid / To say for certain that he played."441

Nach der Beschreibung der ungewöhnlich christlichen Taten Flammondes wird ähnlich wie im Falle Fleming Helphenstines (s.o.) dann wieder auf etwas Dunkles gewiesen, das sich unter der Oberfläche verbergen könnte:

$\begin{array}{ll}{[\ldots]} & \text { What was he, when he came to sift } \\ \text { But what of him- } & \text { His meaning, and to note the drift } \\ \text { So firm in every look and limb? } & \text { Of incommunicable ways } \\ \text { What small satanic sort of kink } & \text { That make us ponder while we praise? } \\ \text { Was in his brain? What broken link } & \text { Why was it that his charm revealed } \\ \text { Withheld him from the destinies } & \text { Somehow the surface of a shield? } \\ \text { That came so near of being his? } & \text { What was it that we never caught? } \\ & \text { What was he, and what was he not? }{ }^{442}\end{array}$

Diese Strophen können als mißgünstiger Blick der Bewohner Tilbury Towns gewertet werden. ${ }^{443}$ In diesem Fall ist der ,satanische Knoten' nicht in Flammonde zu finden, sondern in den Bewohnern Tilbury Towns. Diese können einen wahrhaft guten Menschen einfach nicht anerkennen, solange er ihnen ein Rätsel aufgibt, auch wenn sie am Ende des Gedichts nach Menschen seinesgleichen suchen. Der Leser bleibt aber ebenso wie der Sprecher im unklaren darüber, ob Flammonde eine dunkle Vergangenheit, eine ,satanische' Abartigkeit hat, die inn in die Fremde treibt. Der Name gibt zwar

\footnotetext{
${ }^{440}$ Robinson 1954, S. 6.

441 Robinson 1954, S. 6.

442 Robinson 1954, S. 6.

${ }^{443}$ Vgl. etwa Childers 1955, S. 227.
} 
Aufschluß über die Figur, indem er diese in eine enge Verbindung zum Christus des Johannesevangeliums stellt. Dennoch ermöglicht die Entschlüsselung des (Über)Namens keine Entschlüsselung der Figur. Auch der Name gehört nur zur Oberfläche, zum ,festen Auftreten' und ,kräftigen Körper', hinter dem sich das wahre Wesen des Namenträgers nur erahnen läßt. Möglicherweise handelt es sich sogar um einen Übernamen, den die Bewohner von Tilbury Town dem Außenseiter halb ironisch, halb bewundernd gegeben haben - die Figuren, der Sprecher und auch der Leser können nicht hinter diese Oberfläche sehen. Der Übername ist Teil eines beschränkten Blicks. ${ }^{444}$

An den bisher betrachteten Gedichten hat sich gezeigt, daß Robinson die namenträgerbezogenen Funktionen von Tauf- und Übernamen nicht dazu nutzt, die Figur direkt und auktorial zu charakterisieren. Vielmehr gehören die Namen zu einer Reihe von vieldeutigen Hinweisen auf den Namenträger. Die Einbeziehung der diversen Intentionen des jeweiligen Namengebers verhindert eine verbindliche und eindeutige ,Aufhellung' des Namenträgers durch das semantische Potential des Eigennamens. Zurück bleibt die Ratlosigkeit des Lesers und des Sprechers bezüglich der wahren Natur der Figuren, die zu Robinsons Wirkungsästhetik des Unbegreiflichen gehört.

\subsubsection{Immigrant objects oder native objects? Die Namenreferenz}

Wie wenig Robinsons Namen über seine namentragenden Figuren und wie viel sie über die Namengeber und -benutzer sagen, hat sich in den bisher betrachteten Gedichten gezeigt. Der Sprecher bei Robinson ist nun nicht nur Teil der namenbenutzenden Gesellschaft, sondern auch poetischer (kreativer) Namengeber. Als poetischer Namengeber gibt er in The Wandering Jew und Theophilus einem Gegenüber Namen, um es einzuordnen. In vielen Fällen läßt Robinson dabei die Referenz des präfigurierten Namens im unklaren und nutzt so die Ambivalenz eines Namens, der auf eine innertextliche Figur referiert und dabei eine außertextliche Figur konnotiert. In Flammonde haben sich erste Zweifel aufgetan, ob der Name auf eine außertextliche Entität (Christus) referiert, die in die fiktive Welt integriert wird, oder ob er präfiguriert ist und daher rein innertextlich referiert. Durch die Verwendung eines auf Christus oder seine Anhänger verweisenden Übernamens wird eine ambivalente Referenz des Namens geschaffen. Ob die Figur und damit der Name Christus meint oder nur einen Christen oder gar einen neuen Christus, bleibt unklar. Dieser Zweifel beruht zum einen auf der Namengebung, wie sie in The Wandering Jew geschildert wird: Robinsons Sprecher erkennt in den Menschen seiner Umwelt die überlieferten mythischen und historischen exempla und

${ }^{444}$ Vgl. etwa W. R. Robinson 1967, S. 92 f. 
benennt sie entsprechend. Zum anderen scheint Robinson bekannte exempla so zu gestalten, daß sie sich in seine an der Gegenwart orientierte fiktive Welt einfügen. Dies zeigt eine Briefstelle aus einem Brief an Laura E. Richards, die sich mit dem realen Ursprung seiner Figuren beschäftigt. Dort schreibt Robinson:

If the time comes for me to do Alcibiades, Owen Glendower, and three or four other gentlemen, you will find the original ME as far away from the text as you find it now in little John Evereldown. ${ }^{445}$

Robinsons Figuren sollen also äußerlich nicht viel mit ihrem textexternen Ursprung gemein haben. Wichtig ist allein das Wesen einer berühmten Figur, das in eine moderne fiktive Umwelt übertragen wird. Dadurch erhält der Figurenname eine unklare Referenz. Denn er referiert weder nur auf das außertextliche Vorbild, noch rein innertextlich auf die Figur.

\subsection{Exemplum oder Übername? Uncle Ananias (1910)}

In Uncle Ananias weist Robinson der Hauptfigur durch den Namen in der Überschrift eine Rolle zu. Die Figur wird damit im Sinne des Sprechers perspektiviert:

His words were magic and his heart was true, And everywhere he wandered he was blessed. Out of all ancient men my childhood knew I choose him and I mark him for the best. Of all authoritative liars, too, I crown him loveliest.

How fondly I rememeber the delight That always glorified him in the spring; The joyous courage and the denegight Profusion of his faith in everything! He was a good old man, and it was right That he should have his fling.

And often, underneath the apple-trees, When we surprised him in the summer time, With what magnificence and ease He sinned enough to make the day sublime! And if he liked us there about his knees, Truly it was no crime.

All summer long we loved him for the same Perennial inspiration of his lies;

And when the russet wealth of autumn came, There flew but fairer visions to our eyesMultiple, tropical, winged with a feathery flame, Like birds of paradise.

So to the sheltered end of many a year He charmed the seasons out with peageantry Wearing upon his forehead with no fear, The laurel of approved iniquity.

And every child who knew him, far or near, Did love him faithfully. ${ }^{446}$

${ }^{445}$ Brief an Laura E. Richards vom 9.3.1902, in Robinson 1979, S. 50. Owen Glendower war Robinson vermutlich als Figur aus Shakespeares Henry IV. bekannt. 
Ananias, der nach der Bibel Gott und die Gemeinde betrügen wollte, ist in Tilbury Town kein gemeiner Lügner mehr, sondern ein Fabulierer. ${ }^{447}$ Er macht den Alltag durch seine Lügen(-geschichten) erhaben („sublime“). Die scherzhaft-freundliche Beschreibung des Lügners als Mann, der „the laurel of approved iniquity“ trägt, spielt auf die seit Platon oft als lügnerisch bezeichneten Dichter und ihre Werke an. Robinson deutet das biblische exemplum also neu als positives Beispiel für einen sympathischen Geschichtenerfinder - einen Literaten.

Der Name erscheint nur in der Überschrift. Die deskriptiven Bezeichnungen für Ananias zu Beginn des Haupttextes: „loveliest of all ancient men“ (1. Strophe), "good old man“ (2. Strophe), zeigen bei gleichbleibender Wertschätzung einen gleitenden Übergang der Namenreferenz. Denn die Gruppe der „ancient men“, der ,historisch alten Männer', die der Sprecher als Kind kannte, spielt auf die exempla der Bibel und des Altertums an. Der Sprecher redet also in der ersten Strophe auch von der biblischen Gestalt, dem exemplum für ,die schändliche Lüge’ und hebt sie über die anderen exempla („all authoritative liars"). Auch die zweite Strophe kann auf das biblische exemplum angewendet werden. Der Sprecher entscheidet sich noch nicht deutlich für die rein innerfiktionale Referenz. Der familiär-vertraute Ton der Phrase „good old man“ läßt dagegen schon eine gegenwärtige Figur in der Welt des Sprechers erahnen. Doch erst in der dritten Strophe wird der Sprecher eindeutig mit der Figur verknüpft und diese auf der fiktionalen Ebene angesiedelt. Durch diese Vorgehensweise verleiht Robinson der Figur eine ambivalente ,Seinsweise', die sie zwischen der außertextlichen Präfiguration und einer rein innertextlichen Figur oszillieren läßt. Der Sprecher gibt seiner Figur durch den Namen nicht nur bestimmte Eigenschaften, sondern eine Identität. Diese Ambivalenz drückt nicht zuletzt auch der Name in der Überschrift mit seiner Kombination aus dem familiären Morpholexem und dem bekannten Namen aus.

\subsection{Exemplum oder konventioneller Name? Amaryllis}

Im Sonett Amaryllis trägt ein alter Mann abseits vom geschäftigen Betrieb der Welt seine geliebte Frau zu Grabe. Die materialistische Welt und ihr „bold / Incessant scream“, ihre „trumpets“ werden vom Sprecher, der mit dem alten Mann abseits im Wald spazierengeht, kritisch betrachtet. Doch auch der alte Mann wirkt auf inn nur kläglich. Der Sprecher gerät mit ihm am Ende in Trauer darüber, daß die Verstorbene der Vergänglichkeit preisgegeben ist.

\footnotetext{
${ }^{446}$ Robinson 1954, S. ???.

${ }^{447}$ Vgl. auch Childers 1955, S. 224.
} 
Once, when I wandered in the woods alone,

An old man tottered up to me and said,

"Come, friend, and see the grave that I have made

For Amaryllis." There was in the tone

Of his complaint such quaver and such moan

That I took pity on him and obeyed,

And long stood looking where his hand had laid

An ancient woman, shrunk to skin and bone.

Far out beyond the forest I could hear

The calling of loud progress, and the bold

Incessant scream of commerce ringing clear;

But though the trumpets of the world were glad,

It made me lonely and it made me sad

To think that Amaryllis had grown old. ${ }^{448}$

Das Gedicht ist auch poetologisch zu deuten. Der literarisch viel verwendete Stereotypenname ,Amaryllis' macht es Robinsons Interpreten möglich, durch die Frau symbolisch die Poesie repräsentiert zu sehen. ${ }^{449}$ Als Hirtenname deutet ,Amaryllis' zusätzlich darauf hin, daß Robinson der Untergang der Lyrik in ihren überkommenen Formen vorschwebt. ${ }^{450}$ Die sich auf idealische Gegenwelten zurückziehende Poesie ist für Robinson überholt. Die arkadische Dichtung wird von ihren Dichtern (dem alten Mann), die sich nicht in die Alltagswelt begeben wollen, abseits der Welt begraben. Robinson betrachtet deren Untergang wehmütig, aber auch nicht ohne Ironie, wie die süffisante Beschreibung des 'poetischen' Leichnams, „shrunk to skin and bone“, andeutet. ${ }^{451}$

Der Hinweis auf die poetologische Deutbarkeit wird erst durch die Verwendung des Namens im vierten Vers des ersten Quartetts und im dritten Vers des zweiten Terzetts gegeben. Die Raffinesse der Namenverwendung besteht darin, daß Robinson die innerfiktionale Namenreferenz (auf die verstorbene Frau eines alten Mannes) und die außertextliche Referenz (auf die arkadische Hirtin Vergils und anderer) miteinander vermischt. Der alte Mann des Gedichts referiert in der in direkter Rede wiedergegebenen Äußerung ,innertextlich' auf seine Frau und verwendet den Namen dabei wie einen bekannten Namen ohne Einführungssequenz. Der Sprecher verwendet den Namen seinerseits ebenso selbstverständlich. Zu erwarten wäre eher, daß der Sprecher die ihm Unbekannte distanzierter oder differenzierter (mit ,dessen Amaryllis' etwa) benennt. Die Namenverwendung des Sprechers legt daher nahe, daß der Name hier in seiner Verwendung auf die ursprüngliche und berühmte arkadische Namenträgerin referiert. Der Sprecher eignet sich den Namen an. Die Aussage des letzten Verses läßt sich nur auf die symbolische und poetologische Bedeutung bezogen erklären, denn aus der fiktiven

\footnotetext{
${ }^{448}$ Robinson 1954, S. 84.

${ }^{449}$ Vgl. Childers 1954/55, der sich in Childers 1955, S. 223, auf Lawrance Thompson beruft.

${ }^{450}$ Vgl. Childers 1954/55.

451 In Theokrits Das Ständchen wird Amaryllis als „Rundum Mollige du, schön blickende, Mädchen mit dunklen / Brauen..." angerufen, vgl. Theokrit 1970, S. 75.
} 
Handlung könnte nicht motiviert werden, weshalb der Sprecher traurig über das Altern und den Tod einer inm unbekannten Frau ist.

Die Namenverwendung ist also in der Gedichtüberschrift ambivalent, während Sprecher und Figur im Text den Namen jeweils eindeutig verwenden.

\subsection{Die Fortgestaltung eines außertextlichen Objekts: Old King Cole}

Das Gedicht Old King Cole in kreuzgereimten Oktaven beginnt mit der Integration des Protagonisten in die Welt Tilbury Towns:

In Tilbury Town did Old King Cole

A wise old age anticipate,

Desiring, with his pipe and bowl,

No Khan's extravagant estate.

No crown annoyed his honest head,

No fiddlers three were called or needed;

For two disastrous heirs instead

Made music more than ever three did. ${ }^{452}$

Ein alter verwitweter König, Old King Cole, hat Probleme mit seinen auf Abwege geratenen Söhnen. Er leugnet weder die Schandtaten seiner Söhne, noch sein Leid darüber, bleibt aber gleichmütig und greift nicht ein. Den Grund dafür behält er allerdings für sich. Dies hinterläßt beim Leser das für Robinsons Werke typische Gefühl des Zweifels. Robinson gestaltet einmal mehr eine freundlich-fatalistische Figur, die sich trotz ihrer Sorgen nicht anmaßt, ein objektives Urteil zu fällen: Old King Cole zweifelt an seinen Kindern, aber er ist sich nicht darüber im klaren, ob dieser Zweifel berechtigt ist. ${ }^{453}$

Der gleich zu Beginn genannte Ortsname stellt klar, daß Tilbury Town die Hintergrundwelt dieses Gedichts ist. ${ }^{454}$ Dies ist auch nötig, denn der Personenname verweist auf eine außertextliche Figur, den König aus dem Kinderreim Old King Cole ${ }^{455}$ :

Old King Cole

Was a merry old soul,

And a merry old soul was he;

He called for his pipe

And he called for his bowl,

And he called for his fiddlers three.

Every fiddler he had a fiddle,

And a very fine fiddle had he;

Twee tweedle dee, tweedle dee, went the fiddlers.

Oh, there's none so rare

As can compare

With Old King Cole and his fiddlers three! $!^{456}$

\footnotetext{
${ }^{452}$ Robinson 1954, S. 17.

${ }^{453}$ Für Frees 1966, S. 81, Vermutung, Old King Cole habe Einsicht in „the polarity of nature” können wir keinen Beleg finden. Eher wahrscheinlich scheint uns, daß Old King Cole einen resignierenden Blick in die von Robinson befürchtete Sinnlosigkeit getan hat. Die Einstellung der ,gleichmütigen Gestalten' bei Robinson, die die Sinnlosigkeit dieser materiellen Welt erkannt zu haben scheinen und sie daher mit Gleichmut betrachten, wird exemplarisch in The Burning Book, Or the Contented Metaphysician, Robinson 1954, S. 47 f., beschrieben.

${ }_{454}^{4}$ Robinson 1954 , S. 19.

${ }^{455} \mathrm{Vgl}$. auch Slethaug 1971, S. 45.
} 
Robinson nennt in seinem Gedicht die wichtigsten Epitheta des Königs: „pipe“, „bowl“ und das aus dem Namen abgeleitete hohe Alter. Die (aus dem Namen abgeleitete) Krone und der Ruf nach den „three fiddlers“ werden negativ, aber dennoch explizit genannt und verweisen damit ebenso auf den König des Kinderreims. Robinson versetzt also eine bekannte und klar identifizierbare außertextliche Figur nach Tilbury Town. ${ }^{457}$ Robinson nutzt es aus, daß der Kinderreim keinen ausgeprägten semantischen Hintergrund evoziert, und gestaltet die Figur großzügig in seinem Sinne um. Er kann eine verstorbene Frau und zwei mißratene Söhne hinzuerfinden, ohne gegen die vorgegebenen Eigenschaften aus dem Kinderreim zu verstoßen. Robinson gestaltet das Altenteil des Kinderreimkönigs („a wise old age anticipate“). Die Fortgestaltung ist von der Ursprungsgestalt weitgehend autonom. Die Referenz des Eigennamens ist gespalten. Robinson gestaltet ,seinen' Old King Cole', der damit eine Instanz der berühmten Kinderreimfigur ist, nicht aber die Originalfigur selbst. Der Name referiert auf die Instanz eines Netzwerks von Gestaltungen.

Die Referenz über den Text hinaus dient Robinson zusammen mit weiteren Namen dazu, der Handlung poetologische Obertöne zu verleihen. Zunächst läßt er Old King Cole explizit auf alle Extravaganzen verzichten, die er wohl dem Kubla Khan Samuel Taylor Coleridges zuschreibt („Desiring [...] / No Khan's extravagant estate“), und versetzt damit den englischen Romantikern einen Seitenhieb.

Sodann tragen Old King Coles mißratene Söhne nicht ohne Grund präfigurierte „arcadian names“458 - sie heißen Alexis und Evander nach der Hirtenfigur Alexis aus Vergils Bucolica, und dem griechischen Helden Evander aus Vergils Aeneis. ${ }^{459}$ Die Namen der Söhne sind den Namenträgern unangemessen, denn sie drücken einen Wunsch des Vaters (und der Gesellschaft) aus, den die Söhne nicht erfüllen wollen. Old King Coles Söhne geben sich statt dessen dem Verbrechen hin. Das Weltbild, das in ihren Namen ausgedrückt wird, ist für Robinson nicht mehr zeitgemäß.

Old King Cole wartet - sich zurückhaltend - darauf, daß sich seine vielleicht nur scheinbar vom rechten Weg abgekommenen Söhne bewähren:

And if he doubted his two sons,

\footnotetext{
${ }^{456}$ Diese Version findet sich in Mother Goose 1994, S. 144-149. Sie wird dort von mehreren Strophen begleitet, die nach und nach weitere Instrumente und deren Geräuschnachahmungen hinzufügen. Robinson kannte die Kinderverssammlung Mother Goose; vgl. Robinson 1968, S. 19 (Brief an Edith Brower vom 19.2.1897).

${ }^{457}$ Auch Charles Dickens erwähnt Old King Cole in seiner Erzählung The Curiosity Shop. Der amerikanische Dichter Winthrop Mackworth Praed gestaltet inn in einem Gedicht, vgl. dazu Hudson 1943, S. 614. Es gibt dabei keinen Hinweis darauf, daß Robinson, wie Slethaug 1971, S. 45 f., meint, den König von einem „merry old soul“ zu einem alten, ohnmächtigen und langweiligen Dorfkaziken umgestalten würde, dessen Söhne vielleicht ein neues Leben ohne 'kapitalistische' alte Machtstrukturen andeuten würden. ${ }^{458}$ Slethaug 1971, S. 46.

${ }^{459}$ Vgl. Vergil 2001 (Bucolica), 2,1 passim; Vergil 1989 (Aeneis), VII, 52 passim.
} 
And heirs, Alexis and Evander,

He might have been as doubtful once

Of Robert Burns and Alexander. ${ }^{460}$

Der Sprecher vergleicht - wie immer bei Robinson mit leichtem Zweifel - die Söhne Old King Coles mit dem schottischen Dichter Robert Burns und dem Heerführer Alexander dem Großen. Die exempla stehen zunächst für ,große Leistungen schon in jugendlichem Alter'. ${ }^{461}$ Sie sind sorgfältig gewählt, denn Robert Burns ist wegen seiner zahlreichen moralisch nicht einwandfreien Affären berühmt, und Alexander der Große begann seine Karriere unter anderem mit der Beseitigung seiner Gegner. ${ }^{462}$ Sie sind also angemessene Vergleichsobjekte für die beiden Diebe und Lügner:

Alexis, in the early youth,

Began to steal-from old and young.

Likewise Evander, and the truth

Was like a bad taste on his tongue. ${ }^{463}$

Wie schon ,Kubla Khan' verweist das exemplum Robert Burns darüber hinaus auf poetologische Inhalte: Diebstahl (Plagiat oder Eklektizismus) und Lüge (Fiktion) sind durchaus Vorwürfe, die der Literatur insgesamt bzw. bestimmten Literaten gemacht werden können. Robinson mag sich hier äußerst ironisch auf die schlechten Literaten bezogen haben. In diesem Zusammenhang nutzt Robinson die Integration der außertextlichen Figur Old King Cole für die symbolische Bedeutung des Gedichts. Die Kinderreimfigur steht für eine vergangene und veraltete poetische Welt. Der harmlose freundliche König - durch die "fiddler" mit den Künsten eng verbunden - sieht sich in ein neues Umfeld versetzt, das seinem ursprünglichen Wesen feindlich ist. Die kindliche Ruhe des sinnarmen, aber eine heile Welt zeigenden Kinderreims ist in der fiktiven Welt Robinsons nicht mehr möglich. Pfeife und Alkohol werden zu unwirksamen Drogen für den Verzweifelten, die Jovialität des „merry old soul“ beruht auf seinem Fatalismus.

Wie in Amaryllis kritisiert Robinson die von der Dichtung und den Dichtern in der Gegenwart entworfenen realitätsfernen Welten. Die Integration der in der realen Welt allgemein bekannten Figur bietet für inn ein Mittel, die Dichtung und seine reale Welt in die fiktive Welt hineinzuholen, ohne reale Figuren immigrieren zu lassen. Tilbury Town bleibt abstrakt und enthält dennoch den realen geistigen Horizont Gardiners.

\footnotetext{
${ }^{460}$ Robinson 1954, S. 18.

461 Die exemplarische Bedeutung dieser Namen in Robinsons Horizont zeigt z.B. ein Essay Emersons: "We have, it is true, examples of accelerated pace by which young men achieved grand works; as in the Macedonian Alexander, in Raffaelle, Shakespeare, Pascal, Burns, and Byron; but these are rare exceptions. Nature, in the main, vindicates her law."; Emerson 1968, S. 321.

${ }^{462}$ Zu Robert Burns Kirchenpolitik und seinen frühen Affären mit Frauen vgl. The New Encyclopaedia Britannica 2002, S. 662-664; Behar charakterisiert inn als „outspoken and rebellious“; Behar 1999, S. 17; zu den politischen Kämpfen und Morden im Leben des frühen Alexander dem Großen vgl. Kinder/Hilgemann 1986, S. 65.

${ }^{463}$ Robinson 1954, S. 18.
} 


\subsection{Vermischte Vorbilder: John Evereldown und Aaron Stark}

Die meisten der bisher untersuchten Namen aus Robinsons Gedichten referieren nicht eindeutig über den Text hinaus, da stets die innertextlich gestaltete Figur ,in Konkurrenz' zum außertextlichen Vorbild oder Namenspaten steht. Eine weitere Möglichkeit der unklaren Referenz über den Text hinaus besteht darin, daß mehrere Vorbilder zu einer Figur verschmolzen werden.

Im Gedicht John Evereldown könnte der Name zunächst als redender Name der Charakterisierung der Figur dienen. Das Gedicht beschreibt einen Mann, der in der Nacht mitten durch die Wildnis unterwegs nach Tilbury Town ist, um den eingebildeten ständigen Rufen der Frauen dieser Stadt zu folgen. Er kann sich von diesen Rufen nicht befreien, obwohl er sein Leben verflucht:

"Where are you going to-night, to-night,--
Where are you going, John Evereldown?
There's never the sign of a star in sight,
Nor a lamp that's nearer than Tilbury Town.
Why do you stare as a dead man might?
Where are you pointing away from the light?
And where are you going to-night, to-night,-
Where are you going John Evereldown?"

"Right through the forest, where none can see, There's where I'm going, to Tilbury Town.

The men are asleep,- - or awake, may be,-

But the women are calling John Evereldown.

Ever and ever they call for me,

And while they call, can a man be free?

So right through the forest, where none can see,

There's where I'm going, to Tilbury Town."

"But why are you going so late, so late,-

Why are you going, John Evereldown?

Though the road be smooth and the way be straight,

There are two long leagues to Tilbury Town.

Come in by the fire, old man, and wait!

Why do you chatter out there by the gate?

And why are you going so late, so late,-

Why are you going, John Evereldown?"

"I follow the women wherever they call,-

That's why l'm going to Tilbury Town.

God knows if I pray to be done with it all,

But God is no friend to John Evereldown.

So the clouds may come and the rain may fall,

The shadows may creep and the dead men crawl,-

But I follow the women wherever they call,

And that's why l'm going to Tilbury Town." 464

In einem Brief an Laura A. Richards äußert sich Robinson genauer zu den Vorbildern seiner Figur John Evereldown:

${ }^{464}$ Robinson 1954, S. 73. 
I call him little because he isn't big. He is merely John Tarbox plus a superannuated projection of ... [Henry S. Webster ${ }^{465}$ ]. I go into these details only because of your persistent failure to 'understand'. ${ }^{466}$

Wenn man Robinsons Angaben traut, hat die Figur John Evereldown ihren Rufnamen von dem neuenglischen Kongreßabgeordneten John Tarbox ${ }^{467}$ übernommen. Dieser Bezug ist wegen der weiten Verbreitung des Rufnamens ohne den expliziten Hinweis Robinsons nicht zu rekonstruieren. Demnach handelt es sich nicht um einen intertextuellen Verweis. Der Name des angeblichen zweiten Vorbilds, Henry S. Webster, scheint nichts zum Figurennamen beigetragen zu haben. Insofern dienen die Vorbilder dieser Figur Robinson zwar als Anregung. Sie gehören aber nicht mehr zur Textbedeutung, denn mit dem zur überregionalen Veröffentlichung bestimmten Text ist keine Anspielung intendiert. Auch der übrige Gedichttext scheint keine versteckten Hinweise auf die Vorbilder zu geben. Selbst eine Person aus dem Umfeld Robinsons muß über die Vorbilder informiert werden, und Robinson gibt die Vorbilder nur preis, um seiner Korrespondentin deutlich zu machen, daß seine Figur kaum noch Ähnlichkeit mit ihnen hat. Die Struktur des Namens ,John Evereldown' entspricht dem Vorbildnamen ,John Tarbox’ (,Johann Teerkiste'). Dies läßt ebenso wie die Tatsache, daß der Name ,Evereldown' in der Realität nicht verbreitet zu sein scheint, vermuten, es handele sich bei Evereldown um einen redenden Namen. Eine weitgehende Deutung des Namens Evereldown legt zwar auch der obengenannte Brief Robinsons an Laura A. Richards nahe, der seine scherzhafte Benennung und pseudoetymologische Deutung eines Projektes als „trill“-„orgy“ vorführt (s.o.). Doch sind die Möglichkeiten vielfältig, den Namen ,Evereldown' in Übereinstimmung mit dem Gedichtinhalt auszulegen. Der Name mag als John ,ever held down' - ,der von den Frauen stets unterdrückte Mann' oder ,die stets unterdrückten Triebe' - zu lesen sein. ${ }^{468}$ Ebensogut ließe sich der Name als ,ever hell down' oder ,over all down' verstehen. Er beschriebe dann den Weg der Figur durch die Hölle seines unglücklichen Lebens oder ihren allgemeinen Niedergang. ${ }^{469}$ Schließlich könnte man noch einen Schritt weitergehen und den Namen der „superannuated projection“ als ,my ever eld own self', das immerwährende Greisenalter des Autors oder einer

\footnotetext{
${ }^{465}$ Wie Cary 1974a, S. 94 Fn. 2, berichtet, bewahrt Laura Richards den Namen, den der Herausgeber von Robinson 1979 unterdrückt, in ihrer maschinenschriftlichen Kopie des Briefes.

${ }^{466}$ Vgl. Robinson 1979, S. 50 f. (Brief an Laura E. Richards vom 9.3.1902).

${ }^{467}$ Aus dessen Biographie auf der Internet-Homepage des amerikanischen Kongresses ist keine Korrespondenz mit Robinsons Gedicht zu erkennen. Daher kann der Hinweis Robinsons entweder scherzhaft gemeint sein oder sich auf einen Ruf oder Ereignisse der Tagespolitik beziehen, die nicht überregional bekannt wurden.

${ }^{468}$ So etwa Childers 1955, S. 225. Damit stimmt Robinsons Bemerkung in Robinson 1947, S. 238 (Brief an Harry de Forest Smith vom 14.12.1895) überein.

${ }_{469}$ Die diesseitige Hölle auf Erden ist für Robinson ein Grundthema seiner „Children of the Night“.
} 
realen Person interpretieren. ${ }^{470}$ Offenkundig ist nur, daß der Namenbestandteil „down“ dem Leser wohl einen Niedergang und damit die Aura einer gescheiterten Person suggeriert.

John Evereldown wird durch die Vermischung mehrerer Vorbilder sowie durch die fiktive Alterung von seinen außertextlichen Anregungen entfernt. Er wird in einen fiktiven Zustand ,projiziert'. ${ }^{471}$ Allerdings sind die Vorbilder in diesem Fall nur regional bzw. Robinson privat bekannte Menschen. Die Gestaltung der Äußerlichkeiten entfernt Robinsons Figuren nach seinem Bekunden weit vom Original. Im Text übrig bleibt ein abstraktes ,Selbst'. Scheinbar redende, betont künstlich gebaute Namen sind bei Robinson zudem eher spielerisch-humoristisch als tiefsinnig-charakterisierend zu betrachten. Die Differenz zwischen der wirklichen Bedeutung des Namens bzw. der Bezeichnung ,Trilogie' und der pseudoetymologischen Auslegung ist so groß, daß letztere nicht wirklich ernst genommen werden kann.

Auch in seinem Sonett Aaron Stark vermischt Robinson die Vorbilder der Figur, um einem Namen seine eindeutige Referenz zu nehmen ${ }^{472}$ :

Withal a meagre man was Aaron Stark,

Cursed and unkempt, shrewd, shrivelled and morose.

A miser was he, with a miser's nose,

And eyes like little dollars in the dark.

His thin, pinched mouth was nothing but a mark;

And when he spoke, there came like sullen blows

Through scattered fangs e few snarled words and close,

As if a cur were chary of its bark.

Glad of the murmur of his hard renown,

Year after year he shambled through the town,

A loveless exile moving with a staff;

And oftentimes there crept into his ears

A sound of alien pity, touched with tears,-

And then (and only then) did Aaron laugh. ${ }^{473}$

Robinsons Aaron ist ein bösartiger alter Mann, der am Stock geht und nur lacht, wenn er fremdes Leid hört. Aaron Stark wird mit den Epitheta des antisemitischen Stereotyps beschrieben (u.a. „cursed, unkempt, shrewd, shrivelled, and morose“, „with a miser's nose“, „a loveless exile“). Das sortale Prädikat \{jüdisch\} des Rufnamens wird daher partiell aktiviert. Der Familienname kann sowohl redend auf dem englischen „stark“ für „starr“ beruhen als auch als Grundlage eines Namenspiels im ersten Vers dienen - das

\footnotetext{
${ }^{470}$ Robinsons Hauptfiguren sind sehr oft betont alte Figuren. So z.B. in Aaron Stark, Uncle Ananias, Aunt Imogen, Isaac and Archibald oder Old King Cole.

${ }^{471}$ Im Gedichttext selbst wird John Evereldown als „old man“ angesprochen, vgl. Robinson 1954, S. 73; vgl. zu diesem Verfahren auch die Anekdote bei Hagedorn 1938, S.168.

${ }_{472} \mathrm{Daß}$ Aaron Stark nicht von einer unbekannten Person aus Robinsons Umfeld inspiriert ist, behauptet Robinson zumindest in Robinson 1979, S. 51 (Brief an Laura E. Richards vom 9.3.1902).

${ }^{473}$ Robinson 1954, S. 86.
} 
deutsche „stark“474 widerspricht in diesem Fall ironisch der mageren Erscheinung der Figur.

Einen Hinweis auf ein mögliches Vorbild Aaron Starks gibt Robinson mit der Erwähnung des Stocks, der zusammen mit dem Rufnamen an Aarons Stab erinnert (vgl. 4. Mose 17,16-25). ${ }^{475}$ Daß Aaron Stark „cursed“ und ein „exile“ ist, spielt daher auf den biblischen Aaron an, ${ }^{476}$ der das israelitische Volk zwar an das gelobte Land führen, selbst aber das Land als Strafe für seine Verfehlungen nicht mehr erreichen durfte. ${ }^{477}$

Zwar wird so die Verbindung zum biblischen Vorbild hergestellt. Die übrige Beschreibung scheint aber eher ein ,Negativ' der bekannten Eigenschaften des biblischen Hohenpriesters zu sein. So betont Robinson das derangierte Äußere seines Aaron Stark („unkempt“) - im Alten Testament werden dagegen Aarons prachtvolle Priesterkleider ausführlich beschrieben (Exodus 28). Robinson benutzt das gesamte zweite Quartett, um die karge und explodierende Redeweise Aarons Starks zu beschreiben - im Alten Testament wird dagegen Aaron an Moses Seite gestellt als jemand, der über die Gabe der Rede verfügt (Exodus 4,14-16). Schließlich mögen auch die wie Dollar leuchtenden Augen und der Geiz Aaron Starks als negativ auf den Reichtum und besonders auf die berühmten Gemmen der hohepriesterlichen Kleidung sowie auf die Abgaben an den Hohenpriester anspielen (Exodus 28; Numeri 3, 44-51).

Es ist denkbar, daß Robinson in diesem Fall nicht nur einen präfigurierten Namen verwendet, sondern eine Referenz des Namens über den Text hinaus intendiert. Aaron Stark wäre der nach Tilbury Town versetzte biblische Aaron. Eine gewisse Kohärenz mit der Originalgestalt würde dadurch gewahrt, daß (den Tod der Ausgangsgestalt ignorierend) die außertextliche Figur in hohem Alter gestaltet wird. ${ }^{478}$ Eine eindeutige Referenz auf den biblischen Aaron wird jedoch durch ein weiteres berühmtes exemplum in Frage gestellt. Die Pointe des Sonetts, der im zweiten Terzett zynisch über fremdes Leid lachende Aaron, verweist auf den Mohren Aaron aus Shakespeares The Tragedy of Titus Andronicus. Dieser beschreibt als Gipfel seiner zynischen Selbstcharakterisie-

\footnotetext{
${ }^{474}$ Robinson lernte spätestens seit 1892 Deutsch, vgl. Robinson 1947, S. 68 (Brief an Harry de Forest Smith vom 1.10.1892).

${ }^{475}$ Childers' 1955, S. 228, Interpretation, daß ,Aaron Stark' in ,Aaron's [t] ark' = ,Aaron's rod' aufzulösen sei, kann hier wohl vernachlässigt werden.

${ }^{476}$ Beides mag auch auf eine Figuration des ,Ewigen Juden' hindeuten, der Robinson stark interessiert hat (s.o.).

477 Diese Interpretation muß ignorieren, daß Aaron vor Erreichen des gelobten Landes starb oder sie muß Tilbury Town als eine Art Hades verstehen, in dem die verschiedenen Seelen herumirren.

${ }^{478}$ Vgl. daß Aaron Stark als „shrivelled“ beschrieben wird; vgl. auch Weeks 1969a, S. 326, der meint, daß das Alter der Robinsonschen Figuren auf das Vorbild Maine hinweist: „The typical Maine ,character' is often old. Is it because time is necessary to form character, or do we need the prominent features that time seems to sharpen $[\ldots]$ ?"
} 
rung gegenüber Marcus, dem Sohn des Titus Andronicus, sein Lachen über das unsägliche Leid des Titus, das er, Aaron, verursacht hat:

I play'd the cheater for thy father's hand,

And when I had it, drew myself apart,

And almost broke my heart with extreme laughter. ${ }^{479}$

Auch daß der Sprecher die Redeweise Aaron Starks mit dem Bellen eines „Köters' („cur“) vergleicht, spielt unter Umständen auf Shakespeares Aaron an, der sich an der genannten Stelle ebenso mit einem schwarzen Hund vergleicht.

Robinson läßt durch die Ambivalenz Aaron Starks den Leser wieder an seinen Möglichkeiten zweifeln, die Essenz der Figur zu erfassen. Er nimmt durch die Vermischung zweier höchst verschiedener Vorbilder außerdem Stellung zu den überlieferten exempla selbst. Die normative Funktion und die Eindeutigkeit beider exempla werden durch die Kontamination der Vorbilder unter dem vieldeutigen Namen in Frage gestellt. Die Übertragung außertextlicher Objekte in die fiktive Welt Tilbury Towns zerstört die überkommene eindeutige Funktion, die die verschiedenen exempla als Bestandteil der kulturellen (spezieller der literarischen) Welt hatten.

\subsubsection{Eigennamen - „time-born words“}

Robinsons Umgang mit Eigennamen führt in das Zentrum seiner epistemologischen und poetologischen Überlegungen. Er spiegelt Robinsons Bemühen um eine Erneuerung der Poesie im Rahmen des alten Formenkanons. ${ }^{480}$

Von besonderer Bedeutung ist in dieser Hinsicht Robinsons Interesse an alläglichen, modernen Figuren, die er für genauso poetisch hält wie die Stoffe der traditionellen Dichtung: "There is poetry in all types of humanity-even in laywers and horsejockeys—if we are willing to search it out.“481 Sein Begriff des ,Poetischen' aber ist der romantische Begriff etwa Ralph Waldo Emersons, der auf ein transzendentes geistigseelisches ,Mehr' der nur materiellen Außenwelt abzielt. Robinson sieht in seinem realen Umfeld Personen, deren Schicksal, Verhalten und Charakter er mit den überlieferten Mythen seiner Kultur: mit der Bibel und der kanonischen Literatur, mißt. Auf diese Weise verleihen seine Gedichte den dargestellten alltäglichen Individuen eine an überlieferten Vorbildern orientierte, überindividuelle Bedeutung. ${ }^{482}$ Diese Qualität der dargestell-

\footnotetext{
${ }^{479}$ Shakespeare 1974 , S. $1045 \mathrm{f}$.

480 Vgl. Levenson 1969; Stanford 1983, S. 137-142.

${ }^{481}$ Vgl. Robinson 1947, S. 108 (Brief an Harry de Forest Smith vom 1.10.1893); vgl. auch Weeks 1969b, S. 235; vgl. Anderson 1967, S. 504.

${ }^{482}$ Vgl. auch Stanford 1983, S. 139 f., S. 189; Anderson 1968, S. 79, betont unter Bezug auf Robinsons Figurennamen eher die Symbolik der Figuren, Donaldson 1966, S. 222, eher die Individualität.
} 
ten Figuren wird durch die präfigurierten und die auf Außertextliche Entitäten referierenden Namen ausgedrückt.

Robinson führt mit seiner Namenverwendung zunächst eine lange Tradition der lyrischen Dichtung fort. Das Vorbild mag zunächst die antike arkadische Dichtung gewesen sein, mit deren Übersetzung sich der frühe Robinson erfolglos beschäftigt hat. Für Robinson ist die namentliche Identifikation am Gedichtanfang von Bedeutung gewesen, wie seine Übersetzungen bzw. Übertragungen zeigen. Aus diesen Texten sind inm Zeilen vertraut wie „I pray you not, Leuconoë, to pore / With unpermitted eyes on what may be [...]“; oder: „The day when Charmus ran with five / In Arcady as i'm alive; [...]”; oder: „Eutychides, who wrote the songs, / Is going down where he belongs [...]”. 483

Die Benennung der Figuren evoziert eine geschlossene Welt, in der die Namenträger bekannt sind, und ermöglicht es dem Autor, eine Reihe von Figuren auftreten zu lassen und zu unterscheiden. Weiter erhalten die Figuren durch die Benennung eine deutliche Individualität, wie sie bei einer rein pronominalen Anrede nicht anzutreffen ist.

Während die Geschlossenheit der antiken Schäferwelt durch bekannte Stereotypennamen hervorgerufen wird, sind Robinsons Namen zunächst unbekannt und treten, von wenigen Ausnahmen abgesehen, auch jeweils nur in einem Gedicht auf. Erst der Vergleich der Darstellungen und der Namenstruktur sowie die unvermittelte Nameneinführung und die Familiarität, mit der Namen, Namenteile und Personalpronomina verwendet werden, lassen auf einen gemeinsamen Hintergrund und eine gemeinsame Kommunikationssituation schließen.

Viele Eigenschaften der Robinsonschen Namen erinnern außerdem an die Namen in William Cullen Bryants großer Anthologie vorwiegend romantischer Dichtung, A New Library of Poetry and Song, die als maßgeblicher Einfluß Robinsons genannt wird. ${ }^{484}$ Dort finden sich neben minimalen Stereotypennamen wie ,Ben', ,John', ,Sally Brown’ und ,Nelly Gray' oder ,Jack'485 alliterierende und partiell redende Namen wie z.B. ,Evelyn Hope', ,(Orator) Puff', ,Ben Battle', ,(Miss) Flora McFlimsey’ oder ,(Miss) MacBride' („personification of pride“). ${ }^{486}$ Diese vorwiegend in den Humorous Poems auftretenden Namen sind vor allem ,harmlos' und komisch, oft werden sie deutlich zur Erfüllung der Form gewählt oder konstruiert.

\footnotetext{
${ }^{483}$ Horace to Leuconoë, Robinson 1954, S. 91; vgl. auch die abweichende Fassung in Robinson 1947, S. 19 (Brief an Harry de Forest Smith vom 21.5.1891); A Mighty Runner, Robinson 1954, S. 226; Eutychides, Robinson 1954, S. 227.

${ }_{484}$ Vgl. Hagedorn 1938, S. 16; Fussell 1954, S. 12; Smith 1965, S. 73.

485 Aus Faithless Sally Brown und Faithless Nelly Gray, von Thomas Hood, Little Billee von William Makepeace Thackeray, in: Bryant 1895, S. 963.

${ }^{486}$ Aus Evelyn Hope von Robert Browning, Orator Puff und Faithless Nelly Gray von Thomas Hood, Nothing to Wear von William Allen Buttler, The Proud Miss MacBride von John Godfrey Saxe in: Bryant 1895 , S. 284 , S. 285 f., S. 964 , S.981-985, S. 985-987.
} 
Des weiteren integriert Robinson traditionelle exempla in sein ,geschlossenes Universum'. In der Lyrik vor und um Robinson ist die Imagination mythischer oder historischer exempla in ihrem ursprünglichen Umfeld üblich. Gedichte wie Emersons Mithridates, William Butler Yeats Leda and the Swan oder die einschlägigen Gedichte aus Bryants New Library of Poetry and Song führen dies vor. ${ }^{487}$ Diese Autoren gestalten die überlieferten Figuren in ihrem ursprünglichen Umfeld. Neu mag jeweils die Interpretation der Figur sein, die aus dem weltanschaulichen Umfeld des historischen Autors geboren ist. Die gestaltete oder evozierte Hintergrundwelt bleibt die alte. Robinson dagegen geht von seiner Beobachtung der Realität aus und überträgt die überlieferten exempla in diese. Während der Umstand, daß die Figuren realistische Taufnamen oder zumindest realistisch erklärbare Übernamen tragen, auf die reale und gegenwärtige Umwelt Robinsons verweist und die Gedichte auf Neuengland anwendbar macht, ordnet das semantische Potential der Namen die dargestellten Figuren in die mythische Welt ein, die die literarische Tradition vor Robinson aufgebaut hat. ${ }^{488}$ Die emphatische Anwendung eines charakterisierenden präfigurierten Namens auf ein Objekt (auch im alltäglichen Leben) hat dabei Konsequenzen für die Referenz des Namens. Der Namenträger repräsentiert einen Typus, ohne in diesem Typus aufzugehen. Durch die Benennung wird eine unsichere Position der jeweiligen Figur zwischen drei ,Identitätszuschreibungen' erreicht - eine Figur ist wie Aaron, sie ist ein Aaron, sie ist Aaron.

Durch diese Wirkung der Übernamen kann Robinson seinem Tilbury Town und auch seinen anderen Hintergrundwelten (etwa New York (s.o.)) insgesamt eine besondere Stellung geben. Robinsons Gedichte spielen in einer Welt, die durch den kulturellen Hintergrund des Sprechers mit der kulturellen Tradition so eng verbunden wird, daß sie trotz der Anbindung an Robinsons Gegenwart zeitlos erscheint. Die Figuren bewegen sich materiell in der realen Gegenwart oder unmittelbaren Vergangenheit Robinsons, außerdem in einer relativ genau bestimmten Region (Neuengland einschließlich New Yorks). Dennoch sind sie gleichzeitig Teil einer abstrakten mythischen Welt. Die Gestaltung seiner fiktiven Umgebung als ,Hades der Gescheiterten' korrespondiert mit häufigen Wendungen, die die diesseitige Welt als Dunkel und Hölle auf Erden bezeichnen, von der ersten Erwähnung der „shadows“ und „dead men“ in John Evereldown an. 489 Auch in seinen Briefen bezeichnet Robinson seine fiktive Welt als Hölle, die „excee-

\footnotetext{
${ }^{487}$ Emerson 1902, S. 28 f.; Ferguson/Salter/Stallworthy 1996, S. 1095; Bryant 1895.

488 Dies ist die konkrete Beschreibung dessen, was Stanford beschreibt als „Robinson's best poetry is about human experience in [...] the world of everyday life. There are references to a trancendential world but [...this...] does not [...] occupy much of his time [...]", vgl. Stanford 1983, S. 189.

${ }_{489}$ So etwa in The Growth of 'Lorraine', Robinson 1954, S. 191 f., Luke Havergal, Robinson 1954, S. 74 f. oder The Children of the Night , Robinson 1975, S. 25 f.; vgl. auch Donaldson 1966, S. 224 f.
} 
dingly worldly and transitory“ ist. ${ }^{490}$ Auch die fiktive Alterung vieler seiner von außertextlichen Vorbildern abgeleiteten Figuren und die häufige Gestaltung von Todes- und Selbstmordszenen haben die besondere Funktion, gescheiterte Leben an ihrem Ende zu zeigen. ${ }^{491}$ Robinson setzt seine Figuren - überlieferte exempla oder alltägliche Charaktere - der Spannung zwischen der Hoffnung auf ein jenseitiges Leben und der verzweifelten Unsicherheit unzulänglicher Wesen darüber aus, ob ihre Hoffnung nicht töricht ist.

Daß Robinson über die romantische Tradition wie auch den Realismus seiner Zeit ${ }^{492}$ hinausgeht, zeigt sich darin, daß er die Funktionsfähigkeit der Sprache - und das heißt auch: seiner Namen - vor dem Hintergrund einer auch mit dem Gefühl nicht mehr verifizierbaren metaphysischen ,höheren Wahrheit' radikal in Frage stellt. Das ,mächtige Alphabet der Natur', das Emerson noch beschwören kann, ist für Robinson sprachlich nicht mehr darstellbar und auch epistemisch nicht mehr zu erfassen. ${ }^{493}$

Der metaphysische Sprachzweifel Robinsons, der den Zweifel der Romantiker am Genügen der Sprache radikalisiert, wird im Falle der Eigennamen zu einem universellen pragmatischen Zweifel. Ein deutliches Beispiel dafür ist die Thematisierung der Namengebung. Da die metaphysische Willkür von Eigennamen ohnehin offen zutage liegt, bezieht sich der Zweifel auf moralische Sachverhalte: auf Aufrichtigkeit, Vernunft oder Redlichkeit von Namengeber, Namenverwender und Namenträger.

Der Zweifel an der Leistungsfähigkeit der Namen bei gleichzeitiger Hervorhebung und häufigem Gebrauch eben dieser Namen ist für Robinson ein wichtiges Mittel, um seine Figuren und seine Leser in sprachlicher und epistemischer Unsicherheit zu belassen. Ihnen wird in bzw. mit den Gedichten nur ein vages Gefühl für das eigentliche Wesen der Figuren vermittelt. ${ }^{494}$ Die Wahrheit über die Figuren bleibt trotz der Individualisierung durch Eigennamen für die denotierende Sprache unerreichbar. ${ }^{495}$ Robinson nutzt dazu

\footnotetext{
${ }^{490}$ Vgl. Robinson 1947, S. 108 (Brief an Harry de Forest Smith vom 1.10.1893).

${ }^{491}$ Vgl. besonders die frühen Gedichte John Evereldown (1897), Robinson 1954, S. 73; Luke Havergal (1897), Robinson 1954, S. 74 f.; Richard Cory (1897), Robinson 1954, S. 82; The Dead Village (1897), Robinson 1954, S. 88; aber auch Hector Kane (1932), S. 1210 f.; vgl. auch Stanford 1983, S. 148 f.

${ }^{492}$ Vgl. W.R. Robinson 1967, S. 56 f.

${ }^{493}$ Vgl. zu Emerson Hagenbüchle 1979, S. 141.

494 Die Aura eines Namens ist dessen (schwache) Leistung für das kollektive Gedächtnis. Auch in den Gedichten über reale Personen wird dies immer wieder deutlich. Durch den Namen des Dichters George Crabbe fühlt der Sprecher eine aufrüttelnde Kraft, die von der Kenntnis eines semantischen Hintergrundes ausdrücklich abgekoppelt ist: „Whether or not we read him, we can feel / From time to time the vigor of his name / Against us like a finger for the shame / And emptiness of what our souls reveal / [...]; vgl. George Crabbe, Robinson 1954, S. 94.

${ }^{495}$ Dazu, daß Robinsons Figuren nicht vollständig erschließbar sind, vgl. etwa Free 1969, S. 29; Donaldson 1969, S. 48; Barnard 1952, S. 169; Donaldson 1966, S. 223. In diesem Sinne äußert sich auch Nicolaisen 1978, S. 150 f. und S. 153, zu Richard Cory.
} 
die besondere Stellung des Namens im Sprachsystem, die einen Rückschluß vom Namenzeichen auf die Situation der Namengebung und des Namengebers erlaubt.

Seine Namenverwendung ,unter epistemisch erschwerten Umständen' weist dabei in ihrer Problemstellung auf die Versuche der nordamerikanischen Philosophie um die Jahrhundertwende hin, den philosophischen Fragen nach der Religion, der Gewißheit und des menschlichen Ich nach einer Ära des Materialismus wieder auf die Spur zu kommen. Mit William James' radikalem Empirismus oder Josiah Royces „greater-thanindividual loyalty“ versuchen amerikanische Philosophen vor dem Hintergrund eines naturwissenschaftlichen und materialistischen Weltbildes die Rolle des menschlichen Inneren wissenschaftlich aufzuhellen. ${ }^{496}$ So fragt William James in seinem berühmten Essay The Will to Believe:

Objective evidence and certitude are doubtless very fine ideals to play with, but where on this moonlit and dream-visited planet are they found? ${ }^{497}$

Und er antwortet am Ende seines Essays auf diese von ihm als Glaubensfrage behandelte Frage mit einem Zitat von Fitzjames Stephen:

If a man chooses to turn his back altogether on God and the future, no one can prevent him. No one can show beyond reasonable doubt that he is mistaken. If a man thinks otherwise, and acts as he thinks, I do not see how any one can prove that he is mistaken. Each must act as he thinks best. ${ }^{498}$

Robinson, der in seiner Universitätszeit in Harvard (1891-1893 ${ }^{499}$ ) Vorlesungen von Royce und James las und hörte, drückt in seinen Gedichten eben den Geist dieser Suche nach sicherer Erkenntnis über ein individuelles und auch überindividuelles ,Mehr' neben der Materie poetisch aus und übernimmt den Zweifel, nicht aber die pragmatistischen philosophischen Lösungen. ${ }^{500}$ Dem Eigennamen kommt dabei eine große Bedeutung zu, weil er für das äußerliche ,endliche' und gesellschaftliche Ich eine hohe Bedeutung hat und doch das Wesen des Namenträgers nicht erfassen kann. Dies liegt bei Robinson nicht zuletzt daran, daß das innere Ich für ihn transzendent und religiös in der romantischen Tradition von Emersons Over-Soul ist und nicht im Sinne Meads ein Teil eines sozial aufgebauten Selbstbewußtseins. ${ }^{501}$ Robinson greift also auf die ältere ro-

\footnotetext{
${ }^{496}$ Kuklick 2001, S. 166; vgl. generell Kuklick 2001, S. 111-128, S. 150-178.

497 James 1979, S. 22

498 James 1979, S. 33.

499 Vgl. Barnard 1969, S. viii-ix.

${ }^{500}$ Vgl. W. R. Robinson 1967, S. 80 und Fußnote 2; vgl. auch: „The spirit enters only through specific persons, only in a dialogue between men, and is communicable only between individuals. And then it cannot enter directly or be straightforwardly communicated; it can enter only indirectly through an infinitesimal gap provided by compassion, the glint of eyes or the tone of voice. [...]; and the Wandering Jew, Ponce de Leon, Rembrandt, and numerous others communicate spiritually through their eyes, not through language." W. R. Robinson 1967, S. 87 f.; zum Verhältnis Robinsons zu William James vgl. Blumenthal $1991 / 92$.

${ }^{501}$ Vgl. W.R. Robinson 1967, bes. S. 51-63.
} 
mantische Theorie zurück, um dem Materialismus zu begegnen, erkennt aber gleichzeitig die Unbeweisbarkeit dieser Theorien an.

Robinsons Ironie, von inm selbst immer wieder betont, betrifft besonders die geltenden gesellschaftlichen Normen, wie sie sich in der schnellen, oberflächlichen und vorurteilsbeladenen Sicht auf das ,Me' abweichender Individuen äußern. Die vorschnelle Deutung von Eigennamen, die voreingenommene Ordnung der Welt durch exempla sowie die naive Motivation bei der Vergabe von Namen drücken diese für Robinson unangemessene Sicht der Gesellschaft sprachlich aus. Insofern zieht Robinson sowohl die eindeutige Bedeutung redender Namen als auch den Kommunikationswert berühmter Namen in Zweifel. Seine Sprecher und Figuren zeigen mit ihrer Namenverwendung, daß Namen - wie die Sprache allgemein - in bezug auf ,die Wahrheit' nicht zuverlässig sind, sondern von den Vorstellungen und Interessen des Namengebers, des Namenträgers und des Namenverwenders abhängen und somit eine große Menge unterschiedlicher und teilweise widersprüchlicher overtones beinhalten. Sie ergeben ein nicht leicht zu deutendes Bild des Referenzobjekts. Namen gehören besonders deutlich zu den von Robinson so genannten „time-born words“ (s.o.), da sie in bezug auf ihre temporal und lokal beschränkte Applikation durchsichtig sind. So wie die Figurenbeschreibung bei Robinson nie ausreicht, um Persönlichkeit und Wesen der Figuren zu erkennen, genügen auch die Hinweise der Namen nicht oder führen den Namenbenutzer und Namendeuter in die Irre. Die Welt, die Robinson mit seinen Namen zeichnet, wird durch seine Gedichte in Frage gestellt, die Figuren bleiben mysteriös, auch nach der vermeintlichen Entschlüsselung ihrer Namen. Letztlich zeigen die Namen nur die Kapitulation der Sprache vor der nicht-materiellen Wirklichkeit, der wie in Russells Eigennamentheorie die Kapitulation des menschlichen Erkenntnisvermögens an der Seite steht:

It seems that, when we make a statement about something only known by description, we often intend to make our statement, not in the form involving the description, but about the actual thing described. That is to say, when we say anything about Bismarck, we should like, if we could, to make the judgement which Bismarck alone can make, namely, the judgement of which he himself is a constituent. In this we are necessarily defeated, since the actual Bismarck is unknown to us. ${ }^{502}$

\subsection{Die kommunikative Unsicherheit von Namen bei Fontane und Robin-} son

Sowohl Theodor Fontane als auch Edwin Arlington Robinson verwenden Namen, um ihre Gedichte zu gestalten. Die Untersuchung der Namenverwendung beider Autoren gab uns Gelegenheit, die Rolle des Namens bei der Gestaltung von Diskursen und bei der Selbstgestaltung von Sprechern zu betrachten. Die Namen und ihre Funktionen sa-

${ }^{502}$ Russell 1980, S. 31. 
gen etwas aus über das sprachliche Universum (universe of discourse), das der Sprecher gestaltet und in das der Sprecher sich einordnet.

So zeigen die Gedichte des späten Theodor Fontane, wie sich ein dem historischen Autor sehr naher Sprecher durch die Verwendung realer Namen aus seinem realen Umfeld selbst gestaltet. Fontane kritisiert in seinen Gedichten diejenigen, die sich vom ,guten Klang' berühmter, angeblich traditionsreicher oder exotischer Namen gefangennehmen lassen, ohne den Anspruch der Namenträger und Namenverwender auf Exklusivität an der Realität zu überprüfen. Er gestaltet seinen Sprecher dabei mit Ironie als jemanden, der selbst vom Klang berühmter Namen fasziniert war und nun im Rahmen seiner allgemeinen Desillusioniertheit auch den Wert der Namen in Zweifel zieht. Fontanes Gedichte gestalten daher eine Wendung von einem mehr oder weniger naiven Namenglauben hin zu einer umfassenden Skepsis am Kommunikationswert des Namens. Die in einer Gesellschaft mit einem Namen verbundenen Ansprüche und die Eigenschaften des Namenträgers stimmen vielfach nicht überein. Die Aura eines Eigennamens gibt keinen sicheren Aufschluß über den Wert des Namenträgers. Dies ist die Lehre, die Fontane aus seinem eigenen Namenglauben zieht - nicht ohne ironisch durchblicken zu lassen, daß auch er immer noch den Kommunikationswert von Namen zu schätzen weiß.

Edwin Arlington Robinsons Umgang mit Eigennamen läßt eine andere Unsicherheit des Namens deutlich werden: Eigennamen stehen für einen Namenträger, geben über diesen aber nichts preis. Im Rahmen einer metaphysisch sprachskeptischen Position verwendet Robinson fiktionale Eigennamen, um die Unmöglichkeit des Zugriffs auf die Realität durch Sprache zu demonstrieren. Die von ihm verwendeten Namen scheinen auf vielfältige Weise Hinweise auf den Namenträger zu geben, ohne jedoch jemals die Essenz des Namenträgers zu treffen. Vielmehr müssen Namenverwender und Namenrezipienten stets erkennen, daß auch der Name keinen uneingeschränkt gültigen Hinweis auf den Namenträger gibt. Namen können die Sicht eines Namengebers auf eine Figur enthüllen, sie können einen Aspekt des Namenträgers deutlich machen, doch wird der Namenträger über seinen Namen nie erfaßt. In der Tradition einer romantischen Sprachskepsis macht Robinsons Namensgebrauch deutlich, daß Eigennamen keinen besonderen, direkten Zugang zum Namenträger ermöglichen. Sie unterliegen dem metaphysischen Ungenügen der Sprache ebenso wie alle anderen Sprachzeichen. Das Besondere von Eigennamen ist, daß sie durch den Namengeber motiviert sind und deshalb seinen Blick auf den Namenträger enthüllen. Am Namen kann daher abgelesen werden, welche Rolle die Gesellschaft der Namengeber einem Namenträger geben will. Der Name ist insofern bestenfalls eine dem Namenträger oktroyierte Charakterisierung 
durch die Gesellschaft. Schlimmstenfalls führt der den naiven Namengläubigen hoffnungslos in die Irre.

Sowohl Fontane als auch Robinson stehen Namen kritisch gegenüber, allerdings aus unterschiedlicher Perspektive: Fontane zweifelt an der Berechtigung des Kommunikationswertes, den die Gesellschaft vielen Eigennamen beimißt, Robinson zweifelt an der Berechtigung des semantischen Werts, der Eigennamen beigemessen wird. Doch haben beide Autoren gemeinsam, daß sie die Bedeutung, die ein Name hat, auf der pragmatischen Ebene ansiedeln: Eigennamen erhalten ihre semantische wie ihre kommunikative Bedeutung durch den Gebrauch des Namens in der Gesellschaft. Sie bieten weder einen privilegierten Zugang zur Realität, noch ein dauerhaftes Wertesystem, sondern offenbaren lediglich die Ansichten und Ideologien einer aktuellen Sprechergemeinschaft. Damit ziehen Fontane und Robinson am Ende die gleiche Konsequenz aus der Unsicherheit des Eigennamenzeichens. Die naive Magie der Eigennamen verabschieden beide auch aus dem Reich der Poesie und aus der Realität.

\section{Eigennamen und Lyrik}

He olvidado tu nombre, Melusina, Laura, Isabel, Perséfona, María, tienes todos los rostros y ninguno, eres todas las horas y ninguna, $[\ldots]$. $^{503}$

In unseren sprachphilosophischen Analysen und Beschreibungen hat sich erwiesen, daß der semantische Inhalt, die Referenz und der Kommunikationswert des Namens sowie die sortalen Prädikate des Namenzeichens von den Gewohnheiten zeitlich und räumlich stark begrenzter Sprechergemeinschaften abhängen. Für den Interpreten eines Gedichtes ist deshalb bei Eigennamenzeichen die Verbindung zwischen signifiant und signifié unsicher. Wegen dieser Unsicherheit müssen Eigennamen semantisch und pragmatisch unterstützt werden. Der Autor kann die zusätzliche Information im Kotext bereitstellen. Dann ist der Leser entweder reiner consumer der Namenbedeutung, oder er vergleicht als producer sein Vorwissen mit den inm vermittelten Informationen. Der Autor kann aber auch die Kenntnis des Namenträgers als producer oder consumer beim impliziten Leser voraussetzen. Dann prägt die Namenverwendung den kommunikativen Status des Textes und die Rolle des Lesers.

Ist die Referenz eines Eigennamens einmal bekannt, kann dieser in einem Gedicht vielfältige Aufgaben erfüllen: So geben die in einem Gedicht verwendeten Eigennamen

\footnotetext{
${ }^{503}$ Paz 2000, S. 24 f.; „Vergessen hab ich deinen Namen, Laura, / Melusine, Isabel, Persephone, Maria, / alle Gesichter hast du, alle, keines, / bist alle Stunden und zugleich doch keine [...]." (Übersetzung von Vogelsang/Wittkopf).
} 
Aufschluß über den Bezug des Gedichts auf eine fiktive oder reale Welt und über die Wahrheitsansprüche, die der Autor mit seinem Gedicht erhebt. Äußerungen, die einen allgemein überprüfbaren Wahrheitsanspruch erheben, Äußerungen, die keinen Wahrheitsanspruch erheben, und Äußerungen, deren Wahrheitsanspruch nicht überprüft werden kann, sind häufig daran erkennbar, ob sie berühmte oder unbekannte, reale oder fiktionale Eigennamen enthalten.

Eigennamen wirken sich durch ihren besonderen kommunikativen Status - durch ihre semantische Kontextabhängigkeit bei gleichzeitig großer Bedeutung für die Kommunikation - auf die gesamte Gestaltung eines Gedichts aus. Die Analyse der Funktionen von Eigennamen im Textverlauf, bei der Anbindung an Kontexte, bei der ästhetischen Gestaltung und bei der Evokation fiktiver oder realer Entitäten hat gezeigt, daß die kommunikativen Strategien eines Gedichts durch den Namengebrauch entscheidend geprägt werden.

In Gedichten als isolierten Gesprächsbeiträgen gewinnt die Evokation eines Sprechers bzw. seiner Haltung mit Hilfe von Eigennamen eine besondere Bedeutung. Dies zeigt sich an der Rolle von Eigennamen als wichtigem Diskurselement in den Gedichten von Theodor Fontane und Edwin Arlington Robinson. Der Name wird bei beiden Dichtern nicht als auktorialer Hinweis auf einen Namenträger oder als nicht zu hinterfragendes label des Namenträgers verwendet. Vielmehr behandeln Fontane und Robinson den Eigennamen als Ausdruck, dessen Verbindung zum Sprecher, sei dieser der Namengeber oder ein Namenverwender, wesentlich enger ist als die semantische Bindung an den Namenträger. Daher betrachten beide Autoren die Funktionen und die Funktionsweise des Namens mit besonderer Skepsis. Fontane stellt die normative Gestaltung der Welt durch Namensysteme in Frage, Robinson die absolute Evokations- und Charakterisierungsleistung des Eigennamens.

Die Ergebnisse dieser Untersuchung zeigen für die Interpretation von Gedichten: Eigennamen in Gedichten dürfen nicht naiv als namenträgerbezogene Zeichen interpretiert werden, weil der Eigenname in bezug auf den Namenträger ein unsicheres Zeichen ist. Er gibt Hinweise auf diesen nur über den Umweg des Namengebers und des Namenbenutzers. Sowohl das semantische Potential rein innertextlich referierender Eigennamen als auch die Verwendung, Bewertung und Auslegung realer oder fiktionaler Namen, die über den Text hinausweisen, sagen stets etwas über den Namenbenutzer aus. Der Eigenname als unsicheres Zeichen in bezug auf den Namenträger wird hier zum sicheren Zeichen zur Charakterisierung eines Sprechers. 


\section{Literaturverzeichnis}

Ackermann 1989 Felicia Ackermann: Content, Character, and Nondescriptive Meaning. In: Joseph Almog, John Perry, Howard Wettstein (Hg.): Themes from Kaplan. Oxford, New York 1989, S. 5-21.

Rühmkorf 1969 Peter Rühmkorf: Über das Volksvermögen. Exkurse in den literarischen Untergrund. Reinbeck/H. 1969.

Adler/Ernst 1987 Jeremy Adler/Ulrich Ernst: Text als Figur. Visuelle Poesie von der Antike bis zur Moderne. Ausstellung im Zeughaus der Herzog August Bibliothek vom 1. September 1987- 17. April 1988. Weinheim 1987 (= Ausstellungskataloge der Herzog August Bibliothek 56).

Adorno 1991

Theodor W. Adorno: Rede über Lyrik und Gesellschaft. In: T.W.A.: Noten zur Literatur. Hrsg. v. R. Tiedemann. 5. Auflage. Frankfurt/M. 1991, S. 48-68.

Aiken 1970

Conrad Aiken: Three Reviews [1927]. In: Francis Murphy (Hg.), Edwin Arlington Robinson. A Collection of Critical Essays. Englewood Cliffs, N.J. 1970 (= Twentieth Century Views), S.15-28.

Anderegg 1977 Johannes Anderegg: Fiktion und Kommunikation. Ein Beitrag zur Theorie der Prosa. 2. Auflage. Göttingen 1977.

Anderson $1967 \quad$ Wallace L. Anderson: Edwin Arlington Robinson: A Critical Introduction. Boston 1967.

Anderson 1967 Wallace L. Anderson: E. A. Robinson's "Scattered Lives". In: American Literature 38 (1967), S. 498-507.

Anderson $1968 \quad$ Wallace L. Anderson: Edwin Arlington Robinson. A Critical Introduction. Cambridge/Mass. 1968.

Anderson 1980 Wallace L. Anderson: The Letters of E. A. Robinson: A Sampler. In: Colby Library Quarterly 16 (1980), S. 51-62.

Ruiz Casanova 1998 Joe F. Ruiz Casanova (Hg.): Antología Cátedra de Poesía de las Letras Hispanicas. Madrid 1998.

Aristoteles $1982 \quad$ Aristoteles: Die Poetik. Hrsg. v. M. Fuhrmann. Stuttgart 1982.

Arnold 1972

Arntzen 1984

Armin Arnold: Kurt Schwitters' Gedicht „An Anna Blume“: Sinn oder Unsinn? In: Text + Kritik 35/36: Kurt Schwitters (1972), S. 13-23.

Helmut Arntzen: Der Literaturbegriff. Geschichte, Komplementärbegriffe, Intention. Eine Einführung. Münster 1984 (= Literatur als Sprache 1).

Arntzen 2002

Helmut Arntzen: Das Wort in der Dichtung. In: D. Alan Kruse et al. (Hg.): Lexikologie. Ein internationales Handbuch zur Natur und Struktur von Wörtern und Wortschätzen. 1. Hbd. Berlin, New York 2002 (= HSK 21.1), S. 106-113.

Aschenberg 1991 Heidi Aschenberg: Eigennamen im Kinderbuch: eine textlinguistische Studie. Tübingen 1991 (=Tübinger Beiträge zur Linguistik 351).

Aschenberg 2002 Heidi Aschenberg: "Niemand ist mein Name" - zur Diskursfunktion von Eigennamen. In: Archiv für das Studium der neueren Sprachen und Literaturen 239 (2002), S.104-127.

Ashley 1979

Ashley 1980

Leonard R. N. Ashley: Mudpies which Endure: Onomastics as a Tool of Literary Criticism. In: Literary Onomastics Studies 6 (1979), S. 261-292.

Leonard R. N. Ashley: Names into Words, and Other Examples of the Possibilities of Extending the Boundaries of Literary Onomastics. In: Literary Onomastics Studies VII (1980), S. 1-32.

Ashley $1986 \quad$ Leonard R. N. Ashley: Names of the Devil and Some New Applications of Literary Onomastic Investigation. In: Literary Onomastics Studies XIII (1986), S. 127-170. 
Aust 2000

Austermühl 1981

Austin 1972

Ayo 1969

Bach 1953

Bach 1987

Bach 2002

Backus 1967

Bahlow 1972

Baker 1974

Baker 1986

Balzer 2000

Barnard 1952

Barnard 1969

Barni 1986

Bateson 1934

Baudelaire 1991

Beckmann 1991

Bedell 1979

Behar 1999

Benét 1942

Bentley 1940

Bentley 1981

Berend 1942
Hugo Aust: Kulturelle Traditionen und Poetik. In: Christian Grawe/Helmuth Nürnberger (Hg.): Fontane Handbuch. Stuttgart 2000, S. 306-565.

Elke Austermühl: Poetische Sprache und lyrisches Verstehen. Studien zum Begriff der Lyrik. Heidelberg 1981.

John L. Austin: Theorie der Sprechakte (How to do things with words). Hrsg. v. E. v. Savigny. 2. Auflage. Stuttgart 1972.

Nicholas Ayo: Robinson's Use of the Bible. In: Richard Cary (Hg.): Appreciation of Edwin Arlington Robinson. Waterville (Maine) 1969, S. 263275.

Adolf Bach: Deutsche Namenkunde. Die deutschen Personennamen 1, 2. Heidelberg 1953.

Kent Bach: Thought and Reference. Oxford 1987.

Kent Bach: Giorgione Was So-Called Because of His Name. In: Philosophical Perspectives 16 (2002), S. 73-103.

Joseph M. Backus: Two „No-Name“ Poems. In: Names 15 (1967), S. 17.

Hans Bahlow: Deutsches Namenlexikon. Frankfurt/M. 1972.

Carlos Baker: "The Jug Makes the Paradise": New Light on Eben Flood. In: Colby Library Quarterly 10 (1974), S. 327-336.

John Jay Baker: The Problem of Poetic Naming in Hölderlin's Elegy „Brod und Wein“. In: MLN 101 (1986), S. 465-492.

Bernd Balzer: „Zugegeben, daß es besser wäre, sie fehlten, oder wären anders, wie sie sind“ - Der selbstverständliche Antisemitismus Fontanes. In: Hanna Delf von Wolzogen $(\mathrm{Hg}$.): Theodor Fontane. Am Ende des Jahrhunderts. Internationales Symposion des Theodor-FontaneArchivs zum 100. Geburtstag Theodor Fontanes 13.-17. September 1998 in Potsdam. Bd. I: Der Preuße. Die Juden. Das Nationale. Würzburg 2000, S. 197-210.

Ellsworth Barnard: Edwin Arlington Robinson. A Critical Study. New York 1952.

Ellsworth Barnard: Edwin Arlington Robinson: A Chronology. In: Ellsworth Barnard (Hg.): Edwin Arlington Robinson. Centenary Essays. Athens 1969, S. vii-ix.

Sara Barni: Dama di lettere. Anna Blume di Schwitters e la logica della forma. In: Annali. Studi Tedeschi XXIX (1986), S. 271-284.

F. W. Bateson: English Poetry and the English Language. An Experiment in Literary History. Oxford 1934.

Charles Baudelaire: Les Fleurs du Mal. Hrsg. v. Jacques Dupont. Paris 1991.

Ulrich Beckmann: Text und Textwelt. Zur Problematik der Bedeutungskonstituierung zu Texten. Hamburg 1990 (= Papiere zur Textlinguistik $67)$.

R. Meredith Bedell: Perception, Action, and Life in The Man Against the Sky. In: Colby Library Quarterly 15 (1979), S. 29-37.

Sasha Behar: Robert Burns. A Biography With Selected Poems. London 1999.

Stephen Vincent Benét: Selected Works. Vol. 1: Poetry. New York 1942.

Edward Clerihew Bentley: Those Days. London 1940.

Edward Clerihew Bentley: The Complete Clerihews. Hrsg. v. Gavin Ewart. Oxford u.a. 1981.

Eduard Berend: Die Namengebung bei Jean Paul. In: Publications of the Modern Language Association of America LVII (1942), S. 820-850. 
Bering 1987

Bering 1996

Bernhart 1993

Bertills 2002

Bertills 2003

Bex 1992

Bex 1995

Bickmann 1989

Bierwisch 1965

Birus 1978

Birus 1987

Blanár 2001

Blumenthal 1991/92

Böschenstein 1996

Bowman 1978

Braun 2002

Braungart 1998

Brechenmacher 2001

Brinker 1992
Dietz Bering: Der Name als Stigma. Antisemitismus im deutschen Alltag 1812-1933. Stuttgart 1887.

Dietz Bering: Die Namen der Juden und der Antisemitismus. In: Ernst Eichler et al. (Hg.): Namenforschung. Ein internationales Handbuch zur Onomastik. 2. Hbd. Berlin, New York 1996, S. 1300-1310.

Walter Bernhart: Überlegungen zur Lyriktheorie aus Erzähltheoretischer Sicht. In: Herbert Foltinek, Wolfgang Riehle, Waldemar Zacharasiewicz (Hgg.): Tales and „their telling difference“. Zur Theorie und Geschichte der Narrativik. Festschrift zum 70. Geburtstag von Franz K. Stanzel. Heidelberg 1993, S. 359-376.

Yvonne Bertills: Intertextualities, Continued. The Connotations of Proper Names in Tove Jansson. In: Roger D. Sell ( $\mathrm{Hg}$.): Children's Literature as Communication. The ChilPA project. Amsterdam, Philadelphia 2002 (= Studies in Narrative 2), S. 71-83.

Yvonne Bertills: Beyond Identification. Proper Names in Children's Literature. Åbo 2003.

A.R. Bex: Genre as Context. In: Michael Toolan (Hg.): Language, Text and Context. Essays in stylistics. London, New York 1992, S. 1-16.

Toni Bex: Keats and the Disappearing Self: Aspects of Deixis in the Ode. In: Keith Green $(\mathrm{Hg}$.): New Essays in Deixis. Discourse, Narrative, Literature. Amsterdam, Atlanta 1995, S. 161-179.

Claudia Bickmann: "So banne dein Ich in dich zurück". Zum gedanklichen Gehalt der Spätlyrik Fontanes. In: Text und Kritik Sonderband "Theodor Fontane“. München 1989, S. 203-217.

Manfred Bierwisch: Poetik und Linguistik. In: Helmut Kreuzer/Rul Gunzenhäuser (Hg.): Mathematik und Dichtung. München 1971, S. 49-66.

Hendrik Birus: Poetische Namengebung. Zur Bedeutung der Namen in Lessings "Nathan der Weise“. Göttingen 1978 (= Palaestra 270).

Hendrik Birus: Vorschlag zu einer Typologie literarischer Namen. In: Zeitschrift für Literaturwissenschaft und Linguistik 67 (1987), S. 38-51.

Vincent Blanár: Theorie des Eigennamens. Status, Organisation und Funktionieren der Eigennamen in der gesellschaftlichen Kommunikation. Hildesheim u.a. 2001 (= Germanistische Linguistik 164-165).

Anna Sabol Blumenthal: Edwin Arlington Robinson's Tilbury Town Poems and William James. In: Dalhousie Review 71 (1991/92), S. 411-439.

Renate Böschenstein: Caecilia Hexel und Adam Krippenstapel. Beobachtungen zu Fonatens Namengebung. In: Fontane Blätter 62 (1996), S. 31-57.

Walter P. Bowman: Gilbert Without Sullivan. In: Literary Onomastics Studies 5 (1978), S. 1-13.

Manuel Braun: Unzuverlässige Zeugen. Exemplum und Geschlechterverhältnis im 16. Jahrhundert. In: Scientia Poetica 6 (2002), S. 1-27.

Wolfgang Braungart: Manierismus als Selbstbehauptung: Jean Paul. In: ZiF Mitteilungen 4 (1998), S. 4-14.

Thomas Brechenmacher: Zur Vornamengebung der Juden in Deutschland zwischen Emanzipation und Vernichtung. In: Jürgen Eichhoff, Wilfried Seibicke/Michael Wolffsohn (Hg.): Name und Gesellschaft. Soziale und historische Aspekte der Namengebung und Namenentwicklung. Mannheim u.a. 2001 (= Thema Deutsch, 2), S. 32-51.

Klaus Brinker: Linguistische Textanalyse. Eine Einführung in Grundbegriffe und Methoden. 3. Auflage. Berlin 1992 (= Grundlagen der Germanistik 29). 
Brinkmann 1977

Brock 2002

Bryant 1895

Bühler 1965

Burdorf 1995

Burdorf 2000

Burelbach 1983:

Burelbach 1984:

Burelbach 1986:

Burkhart 1960

Burks 1985

Burton 1969

Bussche 1887

Callow/Reilly 1977

Carl 1974

Cary 1967

Cary 1969

Cary 1974a

Cary 1974b

Cassirer 2003

Castañeda 1979

Cavell 1985

Celan 1991
Richard Brinkmann: Theodor Fontane. Über die Verbindlichkeit des Unverbindlichen. 2. Auflage. Tübingen 1977 (= Untersuchungen zur deutschen Literaturgeschichte 19).

Stuart Brock: Fictionalism about Fictional Characters. In: Nous 36 (2002), S. 1-21.

William Cullen Bryant: A New Library of Poetry and Song. New York 1895.

Karl Bühler: Sprachtheorie. Die Darstellungsfunktion der Sprache. 2. Auflage. Stuttgart 1965.

Dieter Burdorf: Einführung in die Gedichtanalyse. Stuttgart, Weimar 1995 (= Sammlung Metzler 284).

Dieter Burdorf: [Artikel] Lyriktheorie. In: Harald Fricke (Hg.): Reallexikon der deutschen Literaturwissenschaft 2. Berlin, New York 2000, S. 503505.

Frederik M. Burelbach: An Inquiry Into Comic Naming. In: Literary Onomastics Studies X (1983), S. 201-209.

Frederik M. Burelbach: Literary Terms: Limitations of Naming. In: Literary Onomastics Studies XI (1984), S. 209-227.

Frederik M. Burelbach: Names as Distance Controllers in Literature. In: Literary Onomastics Studies XIII (1986), S. 171-182.

Charles Burkhart: Robinson's RICHARD CORY. In: The Explicator XIX, 2 (1960), Nr. 9.

Arthur W. Burks: Eine Theorie der Eigennamen. In: Ursula Wolf (Hg.): Eigennamen. Dokumentation einer Kontroverse. Frankfurt/M. 1985, S. 135-148.

David H. Burton: E. A. Robinson's Idea of God. In: Colby Library Quarterly 8 (1969), S. 280-294; wieder abgedruckt in: Richard Cary (Hg.): Appreciation of Edwin Arlington Robinson. Waterville (Maine) 1969, S.276-288.

Gustav von dem Bussche (Hg.): Stammtafeln der von dem Bussche. Hildesheim 1887.

James T. Callow, Robert J. Reilly: [Artikel] Edwin Arlington Robinson. In: J.T.C., R.J.R.: Guide to American Literature from Emily Dickinson to the Present. New York u.a. 1977.

Wolfgang Carl: Existenz und Prädikation. Sprachanalytische Untersuchungen zu Existenz-Aussagen. München 1974.

Richard Cary: The Library of Edwin Arlington Robinson: Addenda. In: Colby Library Quarterly 7 (1967), S. 398-415.

Richard Cary: Robinson's Books and periodicals: II. In: Colby Library Quarterly 8 (1969), S. 334-343.

Richard Cary: Early Reception of Edwin Arlington Robinson: The First Twenty Years. Waterville, Maine 1974.

Richard Cary: Robinson's Friend Arthur Davis Variell. In: Colby Library Quarterly 10 (1974), S. 372-385.

Ernst Cassirer: Gesammelte Werke (Hamburger Ausgabe). Hrsg. v. Birgit Recki. Hamburg 2003 [CD-ROM-Ausgabe].

Hector-Neri Castañeda: Fiction and Reality: Their Fundamental Connections. An Essay on the ontology of total experience. In: Poetics 8 (1979), S. 31-62.

Stanley Cavell: Emerson, Coleridge, Kant. In: John Rajchman/Cornel West (Hg.), Post-Analytic Philosophy. New York 1985, S.84-107.

Paul Celan: Gedichte I. 10. Auflage. Frankfurt/M. 1991. 
Cervantes 1994

Cervo 1995

Cestre 1930

Chapeaurouge 1987

Childers 1954/55

Childers 1955

Christmann/Schreier 2003

Cobb-Stevens 1990

Coffin 1964

Combrink 1983:

Conrady 1994

Conrady 2000

Coseriu 1975

Costa 1979

Cowie 1989

Coxe 1969

Crane 1968

Crittenden 1982

Crittenden 1991

Crowder 1948

Culler 1975

Culler 1985
Miguel de Cervantes: El Ingenioso Hidalgo Don Quijote de la Mancha I. Hrsg. v. Jon Jay Allen. Madrid 1994.

Nathan Cervo: Robinson's THE TREE IN PAMELA'S GARDEN. In: The Explicator 54, 1 (1995), S. $29 \mathrm{f}$.

Charles Cestre: An Introduction to Edwin Arlington Robinson. New York 1930.

Donat de Chapeaurouge: Einführung in die Geschichte der christlichen Symbole. 2. Auflage. Darmstadt 1987.

William C. Childers: Robinson's AMARYLLIS. In: The Explicator XIII (1954/55), Nr. 34 [Reprint 1965].

William C. Childers: E. A. Robinson's Proper Names. In: Names 3 (1955), S. 223-229.

Ursula Christmann/Margrit Schreier: Kognitionspsychologie der Textverarbeitung und Konsequenzen für die Bedeutungskonstitution literarischer Texte. In: Fotis Jannidis et al. (Hg.): Regeln der Bedeutung. Zur Theorie der Bedeutung literarischer Texte. Berlin, New York 2003 (= Revisionen 1), S. 246-285.

Richard Cobb-Stevens: Husserl and Analytic Philosophy. Dordrecht 1990 (= Phaenomenologica 116).

Robert P. Tristram Coffin, New Poetry of New England. Frost and Robinson. New York 1964.

Johan Combrink, Aspects of Emotive Forms of Address in Afrikaans Literature. In: Literary Onomastics Studies X (1983), S. 87-132.

Karl Otto Conrady: Kleines Plädoyer für Neutralität der Begriffe Lyrik und Gedicht. In: Joseph Kohnen et al. (Hg.): Brücken schlagen..."Weit draußen auf eigenen Füßen“. Festschrift für Fernand Hoffmann. Frankfurt/M. u.a. 1994, S. 35-57.

Karl Otto Conrady: Einleitung. In: C.O.K. (Hg.): Der neue Conrady. Das große deutsche Gedichtbuch von den Anfängen bis zur Gegenwart. München 2000, S. 7-27.

Eugenio Coseriu: Der Plural bei den Eigennamen. In: E.C. (Hg.): Sprachtheorie und allgemeine Sprachwissenschaft. München 1975 (= Internationale Bibliothek für allgemeine Linguistik 2), S. 234-252.

René de Costa: The Poetry of Pablo Neruda. Cambridge/Mass. u.a. 1979.

A. P. Cowie (Hg.): Oxford Advanced Learner's Dictionary of Current English. 4. Auflage. Oxford u.a. 1989.

Louis Coxe: Edwin Arlington Robinson. The Life of Poetry. New York 1969.

Hart Crane: The Complete Poems and Selected Letters and Prose of Hart Crane. Hrsg. v. Brom Weber. London 1968.

Charles Crittenden: Fictional Characters and Logical Completeness. In: Poetics 11 (1982), S. 331-344.

Charles Crittenden: Unreality. The Metaphysics of Fictional Objects. Ithaca u.a. 1991.

Richard Crowder: Robinson's LUKE HAVERGAL. In: The Explicator, VII, 1 (1948), Nr. 15.

Jonathan Culler: Structuralist Poetics. Structuralism, Linguistics and the Study of Literature. London 1975.

Jonathan Culler: Changes in the Study of the Lyric. In: Chaviva Hosek/ Patricia Parker ( $\mathrm{Hg}$.): Lyric Poetry. Beyond New Criticism. Ithaca, London 1985, S. 38-54. 
Culler 1988

Currie 1988

Currie 1990

Currie 1997

Curtius 1954

Czucka 2000

Danneberg 1996

Davidson 2000

Davies 1997

Davis 1976

Debus 1985

Debus 1995

Debus 2002

Dennett 1976

Deutsch 1989

Deutsch 2000

Diederichs 1995

Dilworth 2002

Donaldson 1966
Jonathan Culler: The Modern Lyric: Generic Continuity and Critical Practice. In: Clayton Koelb/Susan Noakes (Hg.): The Comparative Perspective on Literature. Approaches to Theory and Practice. Ithaca, London 1988, S. 284-299.

Gregory Currie: Fictional Names. In: Australian Journal of Philosophy 66 (1988), S. 478-488.

Gregory Currie: The Nature of Fiction. Cambridge u.a. 1990.

Gregory Currie: On Being Fictional. In: The Journal of Aesthetics and Art Criticism 55 (1997), S. 425-427.

Ernst Robert Curtius: Europäische Literatur und lateinisches Mittelalter. 2. Auflage. Bern 1954.

Eckehard Czucka: Faktizität und Sprachskepsis. Fontanes Stechlin und die Sprachkritik der Jahrhundertwende. In: Hanna Delf von Wolzogen (Hg.): Theodor Fontane. Am Ende des Jahrhunderts. Internationales Symposion des Theodor-Fontane-Archivs zum 100. Geburtstag Theodor Fontanes 13.-17. September 1998 in Potsdam. Bd. II: Sprache. Ich. Roman. Frau. Würzburg 2000, S. 27-40.

Lutz Danneberg: Sprachphilosophie in der Literatur. In: Marcelo Dascal et al.: Sprachphilosophie. Ein internationales Handbuch zeitgenössischer Forschung. Hbd. 2. Berlin, New York 1996 (= Handbücher zur Sprach- und Kommunikationswissenschaft 7,2), S. 1538-1566.

Mathew Davidson: Direct Reference and Singular Propositions. In: American Philosophical Quarterly 37 (2000), S. 285-300.

Stephen Davies: Introduction. In: S.D. (Hg.): Art and its Messages. Meaning, Morality, and Society. University Park Pennsylvania 1997, S. 1-16.

William V. Davis: "Enduring to the End": Edwin Arlington Robinson's "Mr. Flood's Party”. In: Colby Library Quarterly 12 (1976), S. 50 f.

Friedhelm Debus: Zur Pragmatik von Namengebung und Namengebrauch in unserer Zeit. In: Beiträge zur Namenforschung. Neue Folge 20 (1985), S. 305-343.

Friedhelm Debus: Soziolinguistik der Eigennamen. Name und Gesellschaft (Sozio-Onomastik). In: Ernst Eichler et al. (Hg.): Namenforschung. Ein internationales Handbuch zur Onomastik. Hbd. 1. Berlin, New York 1995 (= Handbücher zur Sprach- und Kommunikationswissenschaft 11.1), S. 393-399.

Friedhelm Debus: Namen in literarischen Werken. (Er-)Findung - Form - Funktion. Stuttgart 2002 (= Akademie der Wissenschaften und der Literatur. Abhandlungen der Geistes- und sozialwissenschaftlichen Klasse 2).

Daniel Dennet: Conditions of Personhood. In: Richard Rorty (Hg.): The Identities of Persons. Berkeley 1976, S. 178-193.

Harry Deutsch: On Direct Reference. In: Joseph Almog/John Perry/Howard Wettstein (Hg.): Themes from Kaplan. Oxford, New York 1989, S. 167-195.

Harry Deutsch: Making up Stories. In: Anthony Everett/Thomas Hofweber (Hg.): Empty Names, Fiction, and the Puzzles of Non-Existence. Stanford 2000, S. 149-182.

Ulf Diederichs: Who's who im Märchen. München 1995.

John Dilworth: The Fictionality of Plays. In: The Journal of Aesthetics and Art Criticism 60 (2002), S. 263-273.

Scott Donaldson: The Alien Pity: A Study of Character in E.A. Robinson's Poetry. In: American Literature 37 (1966), S. 219-229. 
Donaldson 1969

Donnellan 1972

Donnellan 1974

Dummett 1973

Dunn 1973

Easthope 2003

Eberhardt 2002

Eco 1995

Eco 1999

Elias 1994

Eliot 1982

Eliot 1998

Elliott 1966/67

Emerson 1902

Emerson 1968

Emerson 1971

Emerson 1979

Emerson 1983

Ernst 1985

Ernst 1986a

Ernst 1986b

Ernst 1990

Ertl 1982
Scott Donaldson: The Book of Scattered Lives. In: Ellsworth Barnard (Hg.): Edwin Arlington Robinson. Centenary Essays. Athens 1969, S. 43-53.

Keith S. Donnellan: Proper Names and Identifying Descriptions. In: Donald Davidson/Gilbert Harman (Hg.): Semantics of Natural Language. Dordrecht 1972, S. 356-379.

Keith Donnellan: Speaking of Nothing. In: Philosophical Review 89 (1974), S. 3-31.

Michael Dummett: FREGE. Philosophy of language. London 1973.

N.E. Dunn, Riddling Leaves: Robinson's "Luke Havergal”. In: Colby Library Quarterly 10 (1973), S. 17-25.

Anthony Easthope: Poetry and Discourse. London 2003 [Reprint der Ausgabe v. 1983].

Joachim Eberhardt: „Es gibt für mich keine Zitate”. Intertextualität im dichterischen Werk Ingeborg Bachmanns. Tübingen 2002 (= Studien zur deutschen Literatur 165).

Umberto Eco: Die Grenzen der Interpretation. München 1995.

Umberto Eco: Im Wald der Fiktionen. Sechs Streifzüge durch die Literatur. Übers. v. B. Kroeber. 2. Auflage. München 1999.

Norbert Elias: Wandlungen der Wir-Ich-Balance. In: N.E.: Die Gesellschaft der Individuen. 2. Auflage. Frankfurt/M. 1994, S. 207-310.

T.S. Eliot: Old Possum's Book of Practical Cats. New York 1982.

T.S. Eliot: The Waste Land and Other Poems. Hrsg. v. Frank Kermode. New York 1998.

R.K. Elliott: Poetry and Truth. In: Analysis 27 (1966/67), S. 77-85.

Ralph Waldo Emerson: The Works. Bd. III (Poems). London 1902.

Ralph Waldo Emerson: Society and Solitude. Twelve Chapters. New York 1968 [Reprint der Ausgabe v. 1904].

Ralph Waldo Emerson: The Collected Works. Bd. 1. Hrsg. v. Alfred R. Ferguson. Cambridge 1971.

Ralph Waldo Emerson: The Collected Works of Ralph Waldo Emerson, Vol. II, Essays: First Series, Hrsg. V. Joseph Slater, Douglas E. Wilson. Cambridge 1979.

Ralph Waldo Emerson: The Collected Works of Ralph Waldo Emerson, Vol. III, Essays: Second Series. Hrsg. V. Joseph Slater, Douglas E. Wilson. Cambridge 1983.

Ulrich Ernst: Lesen als Rezeptionsakt. Textpräsentation und Textverständnis in der manieristischen Barocklyrik. In: Zeitschrift für Literaturwissenschaft und Linguistik 57/58 (1985), S. 67-94.

Ulrich Ernst: Die neuzeitliche Rezeption des mittelalterlichen Figurengedichts in Kreuzform. Präliminarien zur Geschichte eines textgraphischen Modells. In: Peter Wapnewski (Hg.): Mittelalter-Rezeption: Ein Symposion. Stuttgart 1986 (= Germanistische Symposien-Berichtsbände 6), S. 177-233.

Ulrich Ernst: The figured poem: Towards a Definition of genre. In: Visible Language 20 (1986), S. 8-27.

Ulrich Ernst: Optische Gedichte aus der Sicht der Gattungs- und Meidentheorie. In: Dieter Lamping/Dietrich Weber (Hg.): Gattungstheorie und Gattungsgeschichte. Ein Symposion. Wuppertal 1990 (= Wuppertaler Broschüren zur Allgemeinen Literaturwissenschaft 4), S. 207-258.

Wolfgang Ertl: Die Personennamen in den Romanen Fontanes. In: Fontane Blätter 34 (1982), S. 204-213. 
Evans 1982

Evans 1985

Everett 2000

Ewald v. Kleist 1971

Faderman 2000

Fairer/Gerrard 1999

Farwell 1981

Ferber 1998

Ferguson/

Salter/Stallworthy 1996

Filips 1967

Fish 1980

Fishelow 1991

Fix 2003

Fleischer 1995

Fleischer 1998

Fontane 1954

Fontane 1998

Fontane GBA

Fontane HFA

Fontane NA
Gareth Evans: The Varieties of Reference. Hrsg. v. John McDowell. Oxford, New York 1982.

Gareth Evans: Die Kausale Theorie der Namen. In: Ursula Wolf (Hg.): Eigennamen. Dokumentation einer Kontroverse. Frankfurt/M. 1985, S. 309-336.

Anthony Everett: Referentialism and Empty Names. In: Anthony Everett/ Thomas Hofweber ( $\mathrm{Hg}$.): Empty Names, Fiction, and the Puzzles of Non-Existence. Stanford 2000, S. 37-60.

Ewald Christian von Kleist: Sämtliche Werke. Hrsg. v. Jürgen Stenzel. Stuttgart 1971.

Avrom Faderman: On Myth. In: Anthony Everett/Thomas Hofweber (Hg.): Empty Names, Fiction, and the Puzzles of Non-Existence. Stanford 2000, S. 61-66.

David Fairer/Christine Gerrard (Hg.): Eighteenth-Century Poetry. An Annotated Anthology. Malden/Mass. 1999.

Byron Farwell: Mr. Kipling's Army. New York, London 1981.

Rafael Ferber: Philosophische Grundbegriffe. Eine Einführung. München 1998.

Margaret Ferguson/Mary Jo Salter/Jon Stallworthy (Hg.): The Norton Anthology of Poetry. 4. Auflage. New York, London 1996.

Katherine Filips: The Names of Poets in Georgij Ivanov's Poetry. In: Names 15 (1967), S. 70-77.

Stanley Fish: How To Recognize a Poem When You See One. In: S.F.: Is There a Text in This Class. The Authority of Interpretive Communities. Cambridge/Mass., London 1980, S. 322-337.

David Fishelow: Genre theory and family resemblance - revisited. In: Poetics 20 (1991), S. 123-138.

Ulla Fix: Grammatik des Wortes. Semantik des Textes. Freiräume und Grenzen für die Herstellung von Sinn? In: Fotis Jannidis et al. (Hg.): Regeln der Bedeutung. Zur Theorie der Bedeutung literarischer Texte. Berlin, New York 2003 (= Revisionen 1), S. 80-102.

Wolfgang Fleischer: Stilistische Funktionen der Namen in nichtliterarischen Texten. In: E. Eichler et al (Hg.): Namenforschung: Ein internationales Handbuch zur Onomastik. Hbd. 1. Berlin, New York 1995 (= Handbücher zur Sprach- und Kommunikationswissenschaft 11,1), S. 556-560.

Michael Fleischer: „Kommen Sie, Cohn.” Fontane und die „Judenfrage”. Berlin 1998.

Theodor Fontane: Briefe an Georg Friedländer. Hrsg. v. Kurt Schreinert. Heidelberg 1954.

Theodor Fontane: Gedichte. Hrsg. v. Karl Richter. Stuttgart 1998.

Theodor Fontane: Große Brandenburger Ausgabe. Hrsg. v. Gotthard Erler. Berlin ab 1997.

Theodor Fontane: Werke, Schriften und Briefe [Hanser Fontaneausgabe]. Hrsg. v. Walter Keitel, Helmuth Nürnberger. 2. Auflage. Darmstadt 1978.

Theodor Fontane: Sämtliche Werke [Nymphenburger Ausgabe]. Hrsg. v. Edgar Groß, Kurt Schreinert et al. München 1959-1975. 
Margit Frank: Das Bild des Juden in der deutschen Literatur im Wandel der Zeitgeschichte. Studien zu jüdischen Gestalten und Namen in deutschsprachigen Romanen und Erzählungen 1918-1945. Freiburg 1987 (= Hochschulproduktionen Germanistik Linguistik Literaturwissenschaft 9).

Free 1966

Free 1969

Freedman 1992

Frege 1987

Frege 1993

Frege 1994

Freud 1941

Freud 2000

Fricke 1977

Fricke 1981

Fricke 1996

Fricke 2000

Fried 1983

Friend 2000

Frye 1985

Fuß 2001

Fussell 1951/52

Fussell 1954

Gabriel 1975

Gabriel 1979

Gabriel 1982
William J. Free: E.A. Robsinson's Use of Emerson. In: American Literature 38, 1, (1966), S. 69-84.

William J. Free: The Strategy of "Flammonde". In: Ellsworth Barnard (Hg.), Edwin Arlington Robinson. Centenary Essays. Athens 1969, S. 15-30.

David Noel Freedman et al. (Hg.): The Anchor Bible Dictionary Bd. 1. New York u.a. 1992.

Gottlob Frege: Die Grundlagen der Arithmetik. Hrsg. v. Joachim Schulte. Stuttgart 1987.

Gottlob Frege: Der Gedanke. In: G.F.: Logische Untersuchungen. Hrsg. v. G. Patzig. 4. Auflage. Göttingen 1993, S. 30-54.

Gottlob Frege: Über Sinn und Bedeutung. In: Funktion, Begriff, Bedeutung. Hrsg. v. G. Patzig. 7. Auflage. Göttingen 1994, S. 40-66.

Sigmund Freud: Zur Psychopathologie des Alltagslebens. Gesammelte Werke Bd. 4. Frankfurt/M. 1941.

Sigmund Freud: Zur Psychopathologie des Alltagslebens. Über Vergessen, Versprechen, Vergreifen, Aberglaube und Irrtum. Frankfurt/M. 2000.

Harald Fricke: Die Sprache der Literaturwissenschaft. Textanalytische und philosophische Untersuchungen. München 1977.

Harald Fricke: Norm und Abweichung. Eine Philosophie der Literatur. München 1981.

Harald Fricke: Sprachphilosophie in der Literaturwissenschaft. In: Marcelo Dascal et al.: Sprachphilosophie. Ein internationales Handbuch zeitgenössischer Forschung Hbd. 2. Berlin, New York 1996 (= Handbücher zur Sprach- und Kommunikationswissenschaft 7,2), S. 1528-1538.

Harald Fricke: [Artikel] Lyrik. In: Harald Fricke (Hg.): Reallexikon der deutschen Literaturwissenschaft Bd II. Berlin, New York 2000, S. 498502.

Erich Fried: Höre Israel! 2. Auflage. Frankfurt/M. 1982.

Stacie Friend: Real People in Unreal Contexts. In: Anthony Everett/Thomas Hofweber (Hg.): Empty Names, Fiction, and the Puzzles of Non-Existence. Stanford 2000, S. 183-204.

Northrop Frye: Approaching the Lyric. In: Chaviva Hosek/Patricia Parker (Hg.): Lyric Poetry. Beyond New Criticism. Ithaca, London 1985, S. 31 37.

Peter Fuß: Das Groteske: ein Medium des kulturellen Wandels. Köln, Weimar, Wien 2001 (= Kölner Germanistische Studien: NF 1).

Robinson to Moody: Ten Unpublished Letters. In: American Literature 23 (1951/52), S. 173-187.

Edwin S. Fussell: Edwin Arlington Robinson. The Literary Background of a Traditional Poet. Berkeley, Los Angeles 1954.

Gottfried Gabriel: Fiktion und Wahrheit. Eine semantische Theorie der Literatur. Stuttgart 1975.

Gottfried Gabriel: Fiction - A semantic approach. In: Poetics 8 (1979), S. 245-255.

Gottfried Gabriel: Fiction and Truth, Reconsidered. In: Poetics 11 (1982), S. 541-551. 
Gabriel 1987

Gabriel 1997

García-Carpintero 2000

Genette 1989

Gernhardt 1990

Gernhardt 2000

Gerus-Tarnawecky 1968

Gierasch 1944

Gleim 2003

Goethe 1989

Goethe 1993

Goethe 1994

Goll 1996

Gombrich 1961

Goodman 1976

Goodman 1982

Goodman 1984

Gottschalk 2000

Greenslet 1974 [1905]

Grice 1989

Grimaud 1988

Gutschmidt 1979

Gutschmidt 1984

Habermas 1988
Gottfried Gabriel: „Sachen gibt's, die gibt's gar nicht“. Sprachanalytische Bemerkungen zur Wiederentdeckung von Meinongs Jenseits durch T. Parsons. In: Zeitschrift für Semiotik 9 (1987), S. 67-76.

Gottfried Gabriel: [Artikel] Fiktion. In: Klaus Weimar (Hg.): Reallexikon der deutschen Literaturwissenschaft. Bd. 1. Berlin, New York 1997, S. 594-598.

Manuel García-Carpintero: A Presuppositional Account of Reference Fixing. In: The Journal of Philosophy 97 (2000), S. 109-147.

Gérard Genette: Paratexte. Frankfurt/M., New York, Paris 1989.

Robert Gernhardt: Darf man Dichter verbessern? Eine Annäherung in drei Schritten. In: R.G.: Gedanken zum Gedicht. Zürich 1990, S. 37-74.

Robert Gernhardt: Simon who? Fragen zum Gedicht (9). In: Die Zeit 50 (7.12.2000), S. 74.

Iraida Gerus-Tarnawecky: Literary Onomastics. In: Names 16 (1968), S. 312-324.

Walter Gierasch: Robinson's LUKE HAVERGAL In: The Explicator 3 (1944), Nr. 8.

Johann Wilhelm Ludwig Gleim: Ausgewählte Werke. Hrsg. v. Walter Hettche. Göttingen 2003.

Johann Wolfgang von Goethe: Werke Bd. 9: Dichtung und Wahrheit. [Hamburger Ausgabe] Hrsg. v. Erich Trunz. München 1989.

Johann Wolfgang von Goethe: Werke Bd. 1: Gedichte. [Hamburger Ausgabe] Hrsg. v. Erich Trunz. München 1993.

Johann Wolfgang von Goethe: West-Östlicher Divan. In J.W.G.: Werke Bd. 2: Gedichte und Epen II. [Hamburger Ausgabe] Hrsg. v. Erich Trunz. München 1994, S. 7-270.

Ivan Goll: Lyrik in vier Bänden Bd. 3: Jean sans Terre/Johann Ohneland. Hrsg. v. Barbara Glauert-Hesse. Berlin 1996.

E. H. Gombrich: Art and Illusion. A Study in the Psychology of Pictorial Representation. Princeton 1961.

Nelson Goodman: Languages of Art. Indianapolis, Cambridge 1976.

Nelson Goodman: Fiction for Five Fingers. In: Philosophy and Literature 6 (1982), S. 162-164.

Nelson Goodman: Of Mind and Other Matters. Cambridge, London 1984.

Jürn Gottschalk: „Daddeldu Duddel Kuttelmuttel, Katteldu“ - Namen bei Joachim Ringelnatz. In: Frank Möbus et al. (Hg.): Ringelnatz! Ein Dichter malt seine Welt. Göttingen 2000, S. 73-78.

Ferris Greenslet: The Children Of The Night. In: Richard Cary ( $\mathrm{Hg}$.$) :$ Early Reception of Edwin Arlington Robinson: The First Twenty Years. Waterville, Maine 1974, S. $198 f$.

Paul Grice: Studies in the Way of Words. Cambridge/Mass., London 1989.

Michel Grimaud: Spinning Names. References in Narratives. In: Poetics 17 (1988), S. 483-496.

Karl Gutschmidt: Bemerkungen zum Gegenstand und zu den Aufgaben der poetischen (literarischen) Onomastik. In: Linguistische Studien, Reihe A, Arbeitsberichte 73/1 (1979), S. 110-115.

Karl Gutschmidt: Namenarten und Namenklassen in der schönen Literatur. In: Linguistische Studien, Reihe A, Arbeitsberichte 129/1, Beiträge zur Onomastik 1 (1984), S. 138-145.

Jürgen Habermas: Theorie des kommunikativen Handelns. Frankfurt/M. 1988. 
Hagedorn 1938

Hagenbüchle 1979

Hamburger 1957

Hamilton 1986

Hansack 1990

Harder 1983

Harig 1988

Hasubek 1998

Hebekus 2003

Hebel 1991

Heesen/Jansen/

Schilders 1997

Hegel 1973

Heine 1992

Heinemann/

Viehweger 1991

Helmstetter 1995

Henkel/Schöne 1968

Henry 1984

Herd 1776

Herget 1987

Herrnstein-Smith 1968
Hermann Hagedorn: Edwin Arlington Robinson. A Biography. New York 1938.

Roland Hagenbüchle: Sign and Process: The Concept of Language in Emerson and Dickinson. In: Emerson Studies Quarterly 25 (1979), S. 137-155.

Käte Hamburger: Die Logik der Dichtung. Stuttgart 1957.

Lynn Hamilton: Nicknames in the Novels of George Eliot. In: Literary Onomastics Studies XIII (1986), S. 65-82.

Ernst Hansack: Bedeutung, Begriff, Name. Regensburg 1990 (= Studia et exempla Linguistica et Philologica Series II: Studia minora 1).

Louise M. Harder: How Eudora Welty Speaks to Us Through her Use of Names in Delta Wedding. In: Literary Onomastics Studies X (1983), S. 133-146.

Ludwig Harig: Hundert Gedichte. Alexandrinische Sonette, Terzinen, Couplets und andere Verse in strenger Form. München, Wien 1988.

Peter Hasubek: „... wer am meisten red't, ist der reinste Mensch“. Das Gespräch in Theodor Fontanes Roman „Der Stechlin“. Berlin 1998 (= Philologische Studien und Quellen 152).

Uwe Hebekus: Klios Medien. Die Geschichtskultur des 19. Jahrhunderts in der historistischen Historie und bei Theodor Fontane. Tübingen 2003 (= Hermea. Germanistische Forschungen; N.F. 99).

Udo J. Hebel: Towards a Descriptive Poetics of Allusion. In: Heinrich F. Plett (Hg.): Intertextuality. Berlin, New York 1991 (= Research in Text Theory / Untersuchungen zur Texttheorie), S. 135-164.

Hans Heesen/Harry Jansen/Ed Schilders: Waar ligt Poot? Over de dood en de laatste rustplaats van Nederlandse en Vlaamse schrijvers. Baarn 1997.

G.W.F. Hegel: Werke in zwanzig Bänden Bd. 15: Vorlesungen über die Ästhetik III. Frankfurt/M. 1973.

Heinrich Heine: Historisch-kritische Gesamtausgabe der Werke. Bd. 3,1/2. Hrsg. v. Manfred Windfuhr. Hamburg 1992.

Wolfgang Heinemann/Dieter Viehweger: Textlinguistik. Eine Einführung. Tübingen 1991 (= Reihe Germanistische Linguistik 115).

Rudolf Helmstetter: Lyrische Verfahren. Lyrik, Gedicht und poetische Sprache. In: Miltos Pechlivanos et al. (Hg.): Einführung in die Literaturwissenschaft. Stuttgart, Weimar 1995, S. 27-41.

Arthur Henkel/Albrecht Schöne: Emblemata. Handbuch zur Sinnbildkunst des XVI. und XVII. Jahrhunderts. Stuttgart 1968.

Freeman G. Henry: Le message humaniste des Fleurs du Mal. Essai sur la création onomastico-thématique chez Baudelaire. Paris 1984.

David Herd (Hg.): Ancient and Modern Scottish Songs, Heroic Ballads etc. Bd. 1. Edinburgh 1776.

Winfried Herget: The Role of the Community in the Puritan Ordo Salutis.

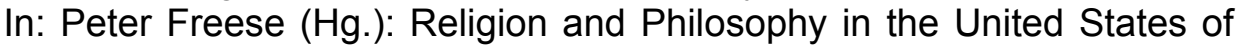
America. Proceedings of the German-American Conference at Paderborn, July 29- August 1, 1986. Essen 1987, S. 387-400.

Barbara Herrnstein-Smith: Poetic Closure. A Study of How Poems End. Chicago, London 1968. 
Walter Hettche: Vom Wanderer zum Flaneur. Formen der Großstadtdarstellung in Fontanes Prosa. In: Hanna Delf von Wolzogen/Helmuth Nürnberger ( $\mathrm{Hg}$.): Theodor Fontane am Ende des Jahrhunderts. Internationales Symposion des Theodor-Fontane-Archivs zum 100. Todestag Theodor Fontanes 13.-17. September 1998. Bd. 3: Geschichte, Vergessen, Großstadt, Moderne. Würzburg 2000, S. 149-160.

Hettche 2002

Walter Hettche: Großstadtlyrik um 1890. In: Gabriele Radecke (Hg.): „Die Decadence ist da“. Theodor Fontane und die Literatur der Jahrhundertwende. Würzburg 2002, S. 79-93.

Higgins 1986

Dick Higgins: The Corpus of British and Other English-Language Pattern Poetry. In: Visible Language XX/1 (1986), S. 28-51.

Hinck 1995

Hirsch 1969

Walter Hinck: Geschichtsdichtung. Göttingen 1995.

David H. Hirsch: "The Man Against the Sky" and the Problem of Faith. In: Ellsworth Barnard (Hg.), Edwin Arlington Robinson. Centenary Essays. Athens 1969, S. 31-42.

Holden 1992

Robert Holden: Twinkle, Twinkle, Southern Cross. The Forgotten Folklore of Australian Nursery Rhymes. Canberra 1992.

Hollis 1957

Hölty 1998

Hoops 1979

Höpel 1992

C. Carroll Hollis: Names in Leaves of Grass. In: Names 5 (1957), S. 129156.

Ludwig Christoph Heinrich Hölty: Gesammelte Werke und Briefe. Kritische Studienausgabe. Hrsg. v. Walter Hettche. Göttingen 1998.

Wiklef Hoops: Fiktionalität als pragmatische Kategorie. In: Poetica 11 (1979), S. 281-317.

Ingrid Höpel: Das mehrständige Emblem: zu Geschichte und Erscheinungsform eines seltenen Emblemtyps. In: Alison Adams/Anthony J. Harper (Hg.): The Emblem in Renaissance and Baroque Europe. Tradition and Variety. Selected Papers of the Glasgow International Emblem Conference 13-17 August, 1990. Leiden, New York, Köln 1992 (= symbola et emblemata 3), S. 104-117.

Horaz 1981

Horaz: Oden und Epoden. Lateinisch/Deutsch. Hrsg. u. übersetzt v. Bernhard Kytzler. Stuttgart 1981.

Horch 2000a Hans Otto Horch: Theodor Fontane, die Juden und der Antisemitismus. In: Christian Grawe/Helmuth Nürnberger (Hg.): Fontane Handbuch. Stuttgart 2000, S. 281-305.

Horch 2000b

Hans Otto Horch: Von Cohn zu Isidor. Jüdische Namen und antijüdische Namenspolemik bei Theodor Fontane. In: Hanna Delf von Wolzogen $(\mathrm{Hg}$.$) : Theodor Fontane. Am Ende des Jahrhunderts. Internationales$ Symposion des Theodor-Fontane-Archivs zum 100. Geburtstag Theodor Fontanes 13.-17. September 1998 in Potsdam Bd. I: Der Preuße. Die Juden. Das Nationale. Würzburg 2000, S. 169-182.

Horlacher 2003 St. Horlacher: [Artikel] Nonsense. In: Gert Ueding (Hg.): Historisches Wörterbuch der Rhetorik Bd. 6. Darmstadt 2003, Sp. 301-307.

Horn 1998

Horstmann 2001

András Horn: Theorie der literarischen Gattungen. Ein Handbuch für Studierende der Literaturwissenschaft. Würzburg 1998.

Ulrike Horstmann: Die Namen in Edmund Spensers Versepos The Faerie Queene. Immortal Name, Memorable Name, Well-becoming Name. Münster u.a. 2001 (= Studien zur Englischen Literatur 10).

Howell 1979

Robert Howell: Fictional Objects: How They Are and How They Aren't. In: Poetics 8 (1979), S. 129-177.

Hudson 1943 Hoyt H. Hudson: Robinson and Praed. In: Poetry: A Magazine of Verse 61 (1943), S. 612-620.

Hühn 1993 Peter Hühn: Lyrik und Systemtheorie. In: Henk de Berg/Matthias Prangel (Hg.): Kommunikation und Differenz. Systemtheoretische Ansätze in der Literatur- und Kunstwissenschaft. Opladen 1993, S. 114-136. 
Hühn 1995

Hühn 1998

Hühn/Schönert 2002

Husserl 1984

Husserl 1987

Hutter 2003

Ingarden 1965

Irwin 1979

Jakobson 1989

James 1979

Jandl 1992

Jean Paul 1963

Jens 2004

Joyner 1972

Kalivoda 1992

Kalverkämper 1978

Kalverkämper 1994

Kaplan 1940

Kaplan 1973

Kaplan 1989

Kavka 1975
Peter Hühn: Geschichte der englischen Lyrik Bd. 1: Vom 16. Jahrhundert bis zur Romantik. Tübingen, Basel 1995.

Peter Hühn: Watching the Speaker Speak: Self-Observation and SelfIntransparency in Lyric Poetry. In: Mark Jeffreys (Hg.): New Definitions of Lyric. New York, London 1998 (= Wellesley Studies in Critical Theory, Literary History, and Culture, 15), S. 215-244.

Peter Hühn/Jörg Schönert: Zur narratologischen Analyse von Lyrik. In: Poetica 34 (2002), S. 287-305.

Edmund Husserl: Logische Untersuchungen 2.1. Hrsg. v. Ursula Panzer. Den Haag, Boston, Lancaster 1984 (= Husserliana. Edmund Husserl, Gesammelte Werke XIX/1).

Edmund Husserl: Vorlesungen über Bedeutungslehre Sommersemester 1908. Hrsg. v. Ursula Panzer. Den Haag, Boston, Lancaster 1987 (= Husserliana. Edmund Husserl, Gesammelte Werke XXVI).

Manfred Hutter: [Artikel] Name, III. Religionsgeschichtlich. In: Hans Dieter Betz et al. (Hg.): Religion in Geschichte und Gegenwart. Handwörterbuch für Theologie und Religionswissenschaft Bd. 6. 4. Auflage. Tübingen 2003, Sp. 33.

Roman Ingarden: Das literarische Kunstwerk. 3. Auflage. Tübingen 1965.

David Irwin: John Flaxman 1755-1826. Sculptor, Illustrator, Designer. London 1979.

Roman Jakobson: Linguistik und Poetik [1960]. In: R.J.: Poetik: ausgewählte Aufsätze 1921-1971. Hrsg. v. E. Holenstein, T. Schelbert. 2. Auflage. Frankfurt/M. 1989, S. 83-121.

William James: The Will to Believe. In: W.J.: The Will to Believe and Other Essays in Popular Philosophy. Cambridge/Mass., London 1979, S. 13-33.

Ernst Jandl: Idyllen. Gedichte. Hamburg, Zürich 1992.

Jean Paul: Leben Fibels. In: J.P.: Sämtliche Werke, Abteilung I, Bd. 6: Späte erzählungen.Schriften. München 1963, S. 365-562.

Walter Jens: Ein Meister des Unterstapelns. In: Frankfurter Allgemeinen Zeitung 200 (28.08.2004), S. 38.

Nancy Joyner: Robinson's Poets. In: Colby Library Quarterly 9 (1972), S. 441-455.

G. Kalivoda: [Artikel] Auctoritas. In: Gert Ueding (Hg.): Historisches Wörterbuch der Rhetorik Bd. 1. Darmstadt 1992, Sp. 1185-1188.

Hartwig Kalverkämper: Textlinguistik der Eigennamen. Stuttgart 1978.

Hartwig Kalverkämper: Eigennamen in Texten. In: Peter Canisius et al. (Hg.): Text und Grammatik. Festschrift für Roland Harweg zum 60. Geburtstag. Bochum 1994, S. 205-238.

Estelle Kaplan: Philosophy in the Poetry of Edwin Arlington Robinson. New York 1940.

David Kaplan: Bob and Carol and Ted and Alice. In: K.J.J. Hintikka/J.M.E. Moravcsik/P. Suppes (Hg.): Approaches to Natural Language. Proceedings of the 1970 Stanford Workshop on Grammar and Semantics. Dordrecht 1973, S. 490-518.

David Kaplan: Demonstratives. In: Joseph Almog/John Perry/Howard Wettstein (Hg.): Themes from Kaplan. Oxford, New York 1989, S. 481614.

Jerome Kavka: Richard Cory's Suicide: A Psychoanalist's View. In: Colby Library Quarterly 11 (1975), S. 150-159. 
Kelletat 1986

Killy 1983

Kinder/Hilgemann 1986

Kipling 1989

Klarer 1999

Klein 1996

Kleiner 1749

Klemm 1984

Knörrich 1992

Köhler 1989

Komrij 1979

Komrij 1986

Kopelke 1990

Kornfeld 1685

Koß 2002

Kripke 1972

Kroon 1994

Kruse 1974

Kühn 1989

Kuklick 2001

Künne 1995
Alfred Kelletat (Hg.): Simon Dach und der Königsberger Dichterkreis. Stuttgart 1986.

Walther Killy: Elemente der Lyrik. München 1983.

Hermann Kinder/Werner Hilgemann: dtv-Atlas zur Weltgeschichte. Karten und chronologischer Abriß. 21. Auflage. München 1986.

Rudyard Kipling: Barrack-Room Ballads and other Verses. London 1989.

Mario Klarer: Einführung in die neuere Literaturwissenschaft. Darmstadt 1999.

J. Klein: [Artikel] Exemplum. In: Gert Ueding (Hg.): Historisches Wörterbuch der Rhetorik Bd. 3. Darmstadt 1996, Sp. 60-70.

Gottfried Kleiner: Gottfried Kleiners Garten-Lust im Winter, angestellt durch kurtze und Christliche Betrachtung unterschiedner Gartensprüche heiliger Schrift: welchen beygefüget sind allerhand zufällige Gedanken bey Freud und Leid entworffen, und auf Verlangen Christlicher Freunde dem Druck überlassen. Breslau, Leipzig 1949.

Imma Klemm: Fiktionale Rede als Problem der sprachanalytischen Philosophie. Königstein/ Ts. 1984 (= Hochschulschriften Literaturwissenschaft 65).

Otto Knörrich: Einleitung. In: O.K.: Lexikon lyrischer Formen. Stuttgart 1992, S. XII-L.

Peter Köhler: Nonsens. Theorie und Geschichte einer literarischen Gattung. Heidelberg 1989 (= Beiträge zur neueren Literaturgeschichte III, 89).

Gerrit Komrij: De Nederlandse Poezie van de 19de en 20ste eeuw in 1000 en enige Gedichten. Amsterdam 1979.

Gerrit Komrij: De Nederlandse Poezie van de zeventiende en achttiende eeuw in 1000 en enige gedichten. Amsterdam 1986.

Bettina Kopelke: Die Personennamen in den Novellen Maupassants. Frankfurt/M. u.a. 1990 (= Bonner Romanistische Arbeiten 34).

Theodor Kornfeld: Theodorii Kornfeldi Selbstlehrende Alt-Neue Poesie oder Vers-Kunst der edlen teutschen Helden-Sprache; darinnen grundeigendlich aller gebräuchlichen Sylben, Reymen/Versen/Gedichten u. Strophen/Beschaffenheit nebenst guter Invention der Gedichte deutlich vorgestellt werden. Bremen 1685.

Gerhard Koß: Namenforschung. Eine Einführung in die Onomastik. 3. Auflage. Tübingen 2002 (= Germanistische Arbeitshefte 34).

Saul A. Kripke: Naming and Necessity. In: Donald Davidson/Gilbert Harman (Hg.): Semantics of Natural Language. Dordrecht 1972, S. 253355.

Frederik Kroon: Make-Believe and Ficional Reference. In: The Journal of Aesthetics and Art Criticism 52 (1994), S. 207-214.

Horst Kruse: Edwin Arlington Robinson. In: Klaus Lubbers (Hg.): Die Amerikansiche Lyrik. Von der Kolonialzeit bis zur Gegenwart. Düsseldorf 1974, S. 176-186.

Ingrid Kühn: Illokutionsstrukturen im poetischen Text. In: Linguistische Studien 191, Reihe A, Arbeitsberichte. Berlin 1989, S. 203-273.

Bruce Kuklick: A History of Philosophy in America 1720-2000. Oxford 2001.

Wolfgang Künne: Fiktion ohne fiktive Gegenstände: Prolegomenon zu einer Fregeanischen Theorie der Fiktion. In: Johannes L. Brandl (Hg.): Metaphysik. Neue Zugänge zu alten Fragen. Sankt Augustin 1995 (= Conceptus-Studien 11), S. 121-140. 
Kunze 1998

Kuzminski 1979

Lamarque/Olsen 1994

Lambert 1990

Lamping 1983

Lamping 1993

Lamping 2000

Langenbach 1994

Laur 1996

Lausberg 1963

Lawn 2001

Lear 2001

Leibfried 1970

Leibniz 1961

Lerner/

Zimmermann 1991

Lessico Universale 1973

Lessing 1970

Levenson 1969

Levin 1976

Lewis 1978

Lichtenberg 1967

Lichtenberg 1968
Konrad Kunze: dtv-Atlas Namenkunde. Vor- und Familiennamen im Deutschen Sprachgebiet. Stuttgart 1998.

Adrian Kuzminski: Names, Descriptions and Pictures. In: The Review of Metaphysics 32 (1979), S. 453-470.

Peter Lamarque, Stein H. Olsen: Truth, Fiction, and Literature. Oxford 1994.

Anne H. Lambert: Eliot's Naming of Cats. In: Names 38 (1990), S. 3941.

Dieter Laming: Der Name in der Erzählung. Zur Poetik des Personennamens. Bonn 1983 (= Wuppertaler Schriftenreihe Literatur 21).

Dieter Lamping: Das lyrische Gedicht: Definitionen zu Theorie und Geschichte der Gattung. 2. Auflage. Göttingen 1993.

Dieter Lamping: Moderne Lyrik als Herausforderung der Lyriktheorie. In: Ernst Rohmer et al.: Texte. Bilder. Kontexte. Interdisziplinäre Beiträge zu Literatur, Kunst und Ästhetik der Neuzeit. Heidelberg 2000, S. 229-242.

James Langenbach: "Mature Poets steal": Eliot's allusive Practice. In: H. David Moody (Hg.): The Cambridge Companion to T.S. Eliot. Cambridge 1994, S. 176-188.

Wolfgang Laur: Der Gebrauch von Ortsnamen in der Schönen Literatur. In: F. Debus/W. Seibicke: Reader zur Namenkunde III,2: Toponymie. Hildesheim, Zürich, New York 1996 (= Germanistische Linguistik 131133), S. 157-164.

Heinrich Lausberg: Elemente der literarischen Rhetorik. 2. Auflage. München 1963.

Christopher Lawn: Gadamer on Poetic and Everyday Language. In: Philosophy and Literature 25,1 (2001), S. 113-125.

Edward Lear: The Complete Verse and Other Nonsense. Hrsg. v. Vivien Noakes. London u.a. 2001.

Erwin Leibfried: Kritische Wissenschaft vom Text. Manipulation. Reflexion. Transparente Poetologie. Stuttgart 1970.

Gottfried Wilhelm Leibniz: Philosophische Schriften Bd. III: Neue Abhandlungen über den menschlichen Verstand. Buch III-IV. Hrsg. und übersetzt v. Wolf von Engelhardt, Hans Heinz Holz. Darmstadt 1961.

Jean-Yves Lerner/Thomas E. Zimmermann: Eigennamen. In: A. v. Stechov, Dieter Wunderlich (Hg.): Semantik. Ein internationales Handbuch der zeitgenössischen Forschung. Berlin, New York 1991 (= Handbücher zur Sprach- und Kommunikationswissenschaft 6), S. 349-370.

[Artikel] Lombróso, Cesare. In: Lessico universale Italiano di lingua, lettere, arti, scienze e tecnica Bd. XII. Hrsg. v. Istituto della Enciclopedia Italiana. Rom 1973, S. 310.

Gotthold E. Lessing: Werke I. Hrsg. v. Julius Petersen, Waldemar von Olshausen. Hildesheim, New York 1970.

J.C. Levenson: Robinson's Modernity. In: Ellsworth Barnard (Hg.): Edwin Arlington Robinson. Centenary Essays. Athens 1969, S. 157-174.

Samuel R. Levin: Concerning what kind of speech act a poem is. In: Teun A. v. Dijk (Hg.): Pragmatics of Language and Literature. Amsterdam, Oxford, New York 1976, S. 141-157.

David Lewis: Truth in Fiction. In: American Philosophical Quarterly 15 (1978), S. 37-46.

Georg Christoph Lichtenberg: Schriften und Briefe IV: Briefe. Hrsg. v. Wolfgang Promies. München 1968.

Georg Christoph Lichtenberg: Schriften und Briefe I: Sudelbücher I. Hrsg. v. Walther Promies. München 1968. 
Liede 1992

Liliencron 1912

Link 1981

Loar 1975

Loar 1980

Locke 1997

Logau 1967

Loges 2000

Lohse 2001

Lonsdale 1987

Lowsky 2000

Luserke 1999

Lyons 1977

Maché/Meid 1980

Mainberger 2003

Malone 1957

Man 1985

Martin 1982

Martinich 1984

Martinich 2001

Masters 1992

McCrady 1955

McFarland 1974
Alfred Liede: Dichtung als Spiel. Studien zur Unsinnspoesie an den Grenzen der Sprache. 2. Auflage. Hrsg. v. Walter Pape. Berlin, New York 1992.

Detlev von Liliencron: Die Dithmarschen, in: D.L.: Gesammelte Werke 7: Novellen. Berlin 1912, S. 158-176.

Jürgen Link: Elemente der Lyrik. In: Helmut Brackert/Jörn Stückrath (Hg.): Literaturwissenschaft. Ein Grundkurs. Reinbeck/H. 1981, S. 86101.

Brian Loar: The Semantics of Singular Terms. In: Philosophical Studies 30 (1975), S. 353-377.

Brian Loar: Names and Descriptions: A Reply to Michael Devitt. In: Philosophical Studies 38 (1980), S. 85-89.

John Locke: The Works of John Locke 1: An Essay concerning Human Understanding, to the End of Book III. Chap. VI. London 1997 [Reprint der Ausgabe von 1794].

Friedrich von Logau: Sinngedichte. Hrsg. v. Uwe Berger. Berlin 1967.

Max L. Loges: Robinson's MR. FLOOD'S PARTY. In: The Explicator 58, 2 (2000). S. 92-94.

Rolf Lohse: „Pour lire sous la douche“. Das Komische in den Werken des Humoristen Pierre Henri ami. Bonn 2001 (= Abhandlungen zur Sprache und Literatur 135).

Roger Lonsdale (Hg.): The New Oxford Book of Eighteenth-Century Poetry. Oxford 1987.

Martin Lowsky: „Der Bahnhof ist der Ararat“. Abstraktion, Modernität und mathematischer Geist in Theodor Fontanes Erzählung Die Poggenpuhls. In: Hanna Delf von Wolzogen $\left(\mathrm{Hg}_{\text {. }}\right)$ : Theodor Fontane. Am Ende des Jahrhunderts. Internationales Symposion des Theodor-Fontane-Archivs zum 100. Geburtstag Theodor Fontanes 13.-17. September 1998 in Potsdam. Bd. III: Geschichte. Vergessen. Großstadt. Moderne. Würzburg 2000, S. 137-148

Matthias Luserke: Der junge Goethe. Ich weis nicht warum ich Narr soviel schreibe. Göttingen 1999.

John Lyons: Semantics 1. Cambridge u.a. 1977.

Ulrich Maché/Volker Meid (Hg.): Gedichte des Barock. Stuttgart 1980.

Sabine Mainberger: Die Kunst des Aufzählens. Elemente zu einer Poetik des Enumerativen. Berlin, New York 2003 (= Quellen und Forschungen zur Literatur- und Kulturgeschichte 22).

Kemp Malone: Meaningful Fictive Names in English Literature. In: Names 5 (1957), S. 1-14.

Paul de Man: Lyrical Voice in Contemporary Theory: Riffaterre and Jauss. In: Chaviva Hosek, Patricia Parker (Hg.): Lyric Poetry. Beyond New Criticism. Ithaca, London 1985, S. 55-72.

Graham D. Martin: A New Look at Fictional Reference. In: Philosophy 57 (1982), S. 223-236.

A.P. Martinich: Communication and Reference. Berlin, New York 1984, S. $24 \mathrm{f}$.

A.P. Martinich: A Theory of Fiction. In: Philosophy and Literature 25,1 (2001), S. 96-112.

Edgar Lee Masters: Spoon River. An Annotated Edition. Hrsg. v. John E. Hallwas. Urbana, Chicago 1992.

Archie R. McCrady: The following rhyme... In: Names 3 (1955), S. 171.

Ronald E. McFarland: Robinson's “Luke Havergal”. In: Colby Library Quarterly 10 (1974), S. 365-372. 
McHale 1992

McKinsey 1995

Mecklenburg 2001

Meyer 1963

Meyer 1975

Meyer 1982

Mill 1900

Milton 1931

Montalbán 1996

Mook 1968

Moore 1955

Moran 1967

Moraru 2000

Morgenstern 1990

Morris 1965

Moritz 1980

Morris 1999

Mother Goose 1994

Mukařovsky 1976

Müller 1991a

Müller 1991b

Müller 1998
Brian McHale: Making (non)sense of postmodernist poetry. In: Michael Toolan ( $\mathrm{Hg}$.): Language, Text and Context. Essays in stylistics. London, New York 1992, S. 6-38.

Michael McKinsey: [Artikel:] indexical. In: Robert Audi (Hg.): The Cambridge Dictionary of Philosophy. Cambridge 1995, S. 366.

Norbert Mecklenburg: Als ich 75 wurde / An meinem 75ten. In: Helmut Scheuer (Hg.): Interpretationen. Gedichte von Theodor Fontane. Stuttgart 2001, S. 230-245.

Conrad Ferdinand Meyer: Sämtliche Werke 1. Historisch-kritische Ausgabe. Hrsg. v. Hans Zeller, Alfred Zäch. Berlin 1963.

Conrad Ferdinand Meyer: Sämtliche Werke 4. Historisch-kritische Ausgabe. Hrsg. v. Hans Zeller, Alfred Zäch. Berlin 1975.

Horst Meyer: Theodor Kornfeld (1636-1698) - ein Osnabrücker Barockdichter in Zesens „Deutschgesinnter Genossenschaft“. In: Osnabrücker Mitteilungen 88 (1982), S. 130-153.

John Stuart Mill: A System of Logic. Ratiocinative and Inductive: Being a Connected View of the Principles of Evidence and the Methods of Scientific Investigation. New York, London 1900.

John Milton: The Works of John Milton 1,1. New York 1931.

Manuel Vázquez Montalbán: Memoria y deseo. Obra poética (19631990). Barcelona 1996.

Maurice A. Mook: Décima Onomástica. In: Names 16 (1968), S. 294297.

M.V. Moore: Southern Rivers. In: Names 3 (1955), S. 38-168.

Richard Moran: Meaning and Value in "Luke Havergal“. In: Colby Library Quarterly VII, 9, S. 385-392.

Christian Moraru: "We Embraced Each Other by Our Names": Lévinas, Derrida, and the Ethics of Naming. In: Names 48 (2000), S. 49-58.

Christian Morgenstern: Werke und Briefe 3: Humoristische Lyrik. Stuttgart 1990.

Charles R. Morris: Robinson's RICHARD CORY, in: The Explicator XXIII, 7 (1965), Nr. 52.

Karl Philipp Moritz: Neues ABC-Buch. Faksimile der Erstausgabe 1794. Frankfurt/M. 1980.

Saundra Morris: "Metre-Making" Arguments: Emerson's Poems. In: Joel Porte/S.M. (Hg.): The Cambridge Companion to Ralph Waldo Emerson. Cambridge 1999, S. 218-242.

Mother Goose. Illustrated by Arthur Rackham. Herdfortshire 1994.

Jan Mukařovsky: Poetic Reference. In: Ladislav Matejka, Irwin R. Titunik (Hrg.): Semiotics of Art: Prague School Contributions. Cambridge, London 1976, S. 155-163.

Wolfgang G. Müller: Namen als intertextuelle Elemente. In: Poetica 23 (1991), S. 139-165.

Wolfgang G. Müller: Interfigurality. A Study on the Interdependence of Literary Figures. In: Heinrich F. Plett (Hg.): Intertextuality. Berlin, New York 1991 (= Untersuchungen zur Texttheorie), S. 101-134.

Wolfgang G. Müller: Das Problem der Subjektivität der Lyrik und die Dichtung der Dinge und Orte. In: Ansgar Nünning (Hg.): Literaturwissenschaftliche Theorien, Modelle und Methoden. Eine Einführung. 3. Auflage. Trier 1998, S. 93-105. 
Müller-Zettelmann 2000

Napoli 1997

Neff 1948

Nelson 2002

Neruda 1957

New 1997

New 1999

Nicolaisen 1978

Nicolaisen 1979

Nicolaisen 1995

Niefanger 1993

Nivison 1960

Nürnberger 1997

Nürnberger 2000

Nute 1995

Olsen 1987

Ord 1985

Orilia 2000

Otto 1986

Parlett 1945
Eva Müller-Zettelmann: Lyrik und Metalyrik. Theorie einer Gattung und ihrer Selbstbespiegelung anhand von Beispielen aus der englisch- und deutschsprachigen Dichtkunst. Heidelberg 2000 (= Beiträge zur neueren Literaturgeschichte 171).

Ernesto Napoli: Names, Indexicals, and Identity Statements. In: Wolfgang Künne et al. (Hg.): Direct Reference, Indexicality, and Propositional Attitudes. Stanford 1997 (= CSLI Lecture Notes 70), S. 185-211.

Emery Neff: Edwin Arlington Robinson. [Ohne Ort] 1948 (= The American Men of Letters Series).

Michael Nelson: Descriptivism Defended. In: Noûs 36:3 (2002), S. 408436.

Pablo Neruda: Obras Completas 1. Buenos Aires 1957.

Christopher New: A Note on Truth in Fiction. In: The Journal of Aesthetics and Art Criticism 55 (1997), S. 421-423.

Christopher New: Philosophy of Literature. An Introduction. London/New York 1999.

Peter Nicolaisen: "Richard Cory": E.A. Robinsons Gedicht im Vergleich mit dem Lied Paul Simons. In: Klaus Detering/Rolf Högel (Hg.), Englisch in der Sekundarstufe I. Festschrift für Käte Lorenzen zu ihrem 60 . Geburtstag. Hannover u.a. 1978, S. 147-156.

W. F. H. Nicolaisen: The Toponymy of Literary Landscapes. In: Literary Onomastics Studies VI (1979), S. 75-104.

Wilhelm F.H. Nicolaisen: Names in English Literature. In: E. Eichler et al $(\mathrm{Hg}$.$) : Namenforschung: Ein internationales Handbuch zur Onomastik.$ Hbd. 1. Berlin, New York 1995 (= Handbücher zur Sprach- und Kommunikationswissenschaft 11,1), S. 560-568.

Dirk Niefanger: Produktiver Historismus: Raum und Landschaft in der Wiener Moderne. Tübingen 1993 (= Studien zur deutschen Literatur 128).

David S. Nivison: Does it Matter How Annandale Went Out? In: Colby Library Quarterly 5 (1960), S. 170-185.

Helmuth Nürnberger: Fontanes Welt. Berlin 1997.

Helmuth Nürnberger: Epigrammatik und Spruchpoesie. Grillparzer und Fontane blicken auf ihr Jahrhundert. In: Hanna Delf von Wolzogen, Helmuth Nürnberger (Hg.): Theodor Fontane am Ende des Jahrhunderts. Internationales Symposion des Theodor-Fontane-Archivs zum 100. Todestag Theodor Fontanes 13.-17. September 1998. Bd. III: Geschichte, Vergessen, Großstadt, Moderne. Würzburg 2000, S. 87-103.

Donald Nute: [Artikel] intension. In: Robert Audi ( $\mathrm{Hg}$.): The Cambridge Dictionary of Philosophy. Cambridge u.a. 1995, S. 379.

Stein H. Olsen: The End of Literary Theory. Cambridge u.a. 1987.

Priscilla A. Ord: "There was an Old Derry down Derry, who loved to make Little Folks Merry": A Closer Look at the Limericks of Edward Lear. In: Literary Onomastics Studies XII (1985), S. 93-118.

Francesco Orilia: The Property-theoretical, Performative-nominalistic Theory of Proper Names. In: Dialectica 54 (2000), S. 155-176.

Karl F. Otto Jr.: Georg Weber's Lebens-Früchte (1649). In: Visible Language XXX/1 (1986), S. 136-154.

Mathilde M. Parlett: Robinson's LUKE HAVERGAL, in: The Explicator, III, 8 (1945), Nr. 57. 
Parr 2002

Parsons 1980

Parsons 1982

Parsons 1987

Pavel 1979

Pavel 1986

Paz 2000

Pelczar 2001

Pelczar/Rainsbury 1998

Perels 1979

Perk 1971

Perloff 1998

Perrine 1962

Perry 1997

Peters 1982

Petersen 1996

Pettersson 2000

Pickerodt 2001

Pierce 2003

Pinthus 1997

Platon 1993

Plett 1991

Poetisches dabra 1992
Rolf Parr: Kongobecken, Lombock und der Chinese im Hause Briest. Das ,Wissen um die Kolonien' und das ,Wissen aus den Kolonien' bei Theodor Fontane. In: Konrad Ehlich ( $\mathrm{Hg}$.): Fontane und die Fremde, Fontane und Europa. Würzburg 2002, S. 212-228.

Terence Parsons: Nonexistent Objects. New Haven, London 1980.

Terence Parsons: Nominalistic Theories of Fictional Objects. In: Poetics 11 (1982), S. 311-329.

Talcott Parsons: Frege vs. Meinong. In: Zeitschrift für Semiotik 9 (1987), S. 51-66.

Thomas G. Pavel: Fiction and the Causal Theory of Names. In: Poetics 8 (1979), S. 179-191.

Thomas G. Pavel: Fictional Worlds. Cambridge u.a. 1986.

Octavio Paz: Das fünfarmige Delta. Gedichte Spanisch und Deutsch. Übetragen von Fritz Vogelsang, Rudolf Wittkopf. Frankfurt/M. 2000.

M. W. Pelczar: Names as Tokens and Names as Tools. In: Synthese 128 (2001), S. 133-155.

M. W. Peczar/J. Rainsbury: The Indexical Character of Names. In: Synthese 114 (1998), S. 293-317.

Christoph Perels: Fremdes Wort und fremde Sprache. Ein Beitrag zur Stilgeschichte der deutschen Lyrik von Heinrich Heine bis Gottfried Benn. [Diss. Masch.] Braunschweig 1979.

Jaques Perk: Gedichten. Hrsg. v. G. Stuiveling. 2. Auflage. Culemborg 1971.

Marjorie Perloff: A Response. In: Mark Jeffreys (Hg.): New Definitions of Lyric. New York, London 1998 (= Wellesley Studies in Critical Theory, Literary History, and Culture, 15), S. 245-255.

Laurence Perrine: A Reading of "Miniver Cheevy". In: Colby Library Quarterly 6 (1962), S. 65-74.

John Perry: Reflexivity, Indexicality and Names. In: Wolfgang Kunne, Martin Anduschus, Albert Newen (Hg.): Direct Reference, Indexicality and Propositional Attitudes. Stanford 1997, S. 3-19.

Günter Peters: Der zerrissene Engel: Genieästhetik und literarische Selbstdarstellung in 18. Jahrhundert. Stuttgart 1982 (= Studien zur allgemeinen und vergleichenden Literaturwissenschaft 24).

Jürgen H. Petersen: Fiktionalität und Ästhetik. Eine Philosophie der Dichtung. Berlin 1996.

Anders Pettersson: Verbal Art. A Philosophy of Literature and Literary Experience. Montreal 2002.

Gerhart Pickerodt (Hg.): Deutsche Lyrik von den Anfängen bis zur Gegenwart 6: 1770-1800. 2. Auflage. München 2001.

Robert B. Pierce: Defining "Poetry". In: Philosophy and Literature 27 (2003), S. 151-163.

Kurt Pinthus (Hg.): Menschheitsdämmerung. Ein Dokument des Expressionismus. Reinbeck/H. 1997 (= Rowohlts Klassiker der Literatur und der Geschichte. Deutsche Literatur 4).

Platon: Kratylos. In: Sämtliche Werke 2. Hrsg. v. W.F. Otto, E. Grassi. G. Palmböck. Hamburg 1993, S. 123-181.

Bettina Plett: Tintensklaven mit Kronenorden. Diagnose, Travestie und Kritik in Fontanes „Dichtergedichten“. In: Fontane Blätter 52 (1991), S. 15-28.

Abraca- Poetisches Abracadabra. Neuestes ABC- und Lesebüchlein. Hrsg. v. Joseph Kiermeier-Debre, Fritz Franz Vogel. München 1992. 
Politisches Journal Brutus und die Franzosen. Anonym erschienen in: Politisches Journal 1793 nebst Anzeige von gelehrten und andern Sachen o.O. 1793, erster Band, drittes Stück, S. 239-242.

Prior 1733

Matthew Prior: Poems on Several Occasions 3. 3. Auflage. London 1733.

Putnam 1975

Hilary Putnam: The meaning of meaning. In: Mind, Language and Reality. Philosophical Papers 2. Cambridge u.a. 1975, S. 215-271.

Quine 1980a

Willard V. O. Quine: On what there is. In: W.V.O.Q.: From a Logical Point of View. 2. Auflage. Cambridge, London 1980, S. 1-19.

Quine 1980b

Willard V. O. Quine: Wort und Gegenstand (Word and Object). Stuttgart 1980.

Raven 1944

A. A. Raven: Robinson's LUKE HAVERGAL, in: The Explicator, III, 2 (1944), Nr. 24.

Read 1980

Allen Walker Read: Walt Whitman's Attraction to Indian Place Names. In: Literary Onomastics Studies VII (1980), S. 189-203.

Read 1982

Allen Walker Read: The Incantatory Use of Place Names in American Poetry. In: Literary Onomastics Studies IX (1982), S. 21-52.

Recanati 1997

Francois Recanati: Direct Reference. From Language to Thought. Oxford, Malden 1997.

Reich-Ranitzky 1999 Marcel Reich-Ranitzky: Adam, Isack, Israel. In: M.R.-R. (Hg.): Frankfurter Anthologie 22. Frankfurt/M. 1999, S. 95-99.

Reuter 1995

Hans-Heinrich Reuter: Fontane 2. Hrsg. v. Peter Görlich. Berlin u.a. 1995.

Reyes 1993

Rogelio Reyes (Hg.): Poesía española del siglo XVIII. 2. Auflage. Madrid 1993.

Richards 1971

Bertrand F. Richards: "No, there is not a dawn...". In: Colby Library Quarterly 9 (1971), S. 68-71.

Richardson 1999 Robert D. Richardson, Jr.: Emerson and Nature. In: Joel Porte/Saundra Morris (Hg.): The Cambridge Companion to Ralph Waldo Emerson. Cambridge 1999, S. 97-105.

Richter 1966

Karl Richter: Resignation. Eine Studie zum Werk Theodor Fontanes. Stuttgart u.a. 1966.

Richter 1980

Karl Richter: Die späte Lyrik Theodor Fontanes. In: Hugo Aust (Hg.): Fontane aus heutiger Sicht. München 1980, S. 118-142.

Richter 1986

Karl Richter: Arm oder reich. Zur späten Lyrik Fontanes. In: Günter Häntzschel (Hg.): Gedichte und Interpretationen 4: Vom Biedermeier zum Bürgerlichen Realismus. Stuttgart 1986, S. 435-446.

Richter 2000

Karl Richter: Das Gedichtwerk. In: Christian Grawe/Helmuth Nürnberger (Hg.): Fontane Handbuch. Stuttgart 2000, S. 706-747.

Ricœur 1989-1991

Paul Ricœur: Zeit und Erzählung. Bd. I, II, III. München 1989-1991.

Ringelnatz 1982

Joachim Ringelnatz: Gesamtwerk in sieben Bänden 4: Erzählungen. Hrsg. v. Walter Pape. Berlin 1982.

Ringelnatz $1984 \quad$ Joachim Ringelnatz: Gesamtwerk in sieben Bänden. Bde. 1, 2 (Gedichte). Hrsg. v. Walter Pape. Berlin 1984.

Robinson $1947 \quad$ Edwin Arlington Robinson: Untriangulated Stars. Letters of Edwin Arlington Robinson to Harry de Forest Smith 1890-1905. Hrsg. v. Denham Sutcliffe. Cambridge 1947.

Robinson $1954 \quad$ Edwin Arlington Robinson: Collected Poems of Edwin Arlington Robinson. New York 1954.

Robinson $1968 \quad$ Edwin Arlington Robinson's Letters to Edith Brower. Hrsg. v. Richard Cary. Cambridge/Mass. 1968. 
Robinson 1975

Robinson 1979

Robinson 1999

Rodiek 1993

Rolf 2000

Rudnyckyj 1959

Rühling 1996

Russell 1980

Ryle 1933

Ryle 1990

Sachs 1961

Salmon 1998

Sandig 1995

Satterfield 1981

Sauerbeck 1996

Sauerbeck 2000

Schächter 1978

Scheerbart 1994

Scherpe 2000

Scheuer 2001

Schiffer 2000

Schillemeit 1982
Edwin Arlington Robinson: Uncollected Poems and Prose of Edwin Arlington Robinson. Hrsg. v. Richard Cary. Waterville, Maine 1975.

Edwin Arlington Robinson: Selected Letters of Edwin Arlington Robinson. Hrsg. v. Ridgely Torrence. New York 1940 [Reprint 1979].

Edwin Arlington Robinson: The Poetry of E. A. Robinson. Hrsg. v. Robert Mezey. New York 1999.

Christoph Rodiek: Prolegomena zu einer Poetik des Kontrafaktischen. In: Poetica 25 (1993), S. 262-281.

Eckard Rolf: Textuelle Grundfunktionen. In: Klaus Brinker et al. (Hg.): Text- und Gesprächslinguistik. Hbd. 1. Berlin, New York 2000 (= Handbücher zur Sprach- und Kommunikationswissenschaft 16,1), S. 422-435.

J. B. Rudnyckyj: Functions of Proper Names in Literary Work. In: Paul Böckmann (Hg.): Stil- und Formprobleme in der Literatur. Vorträge des VII. Kongresses der Internationalen Vereinigung für moderne Sprachen und Literaturen in Heidelberg 1959, S. 378-383.

Lutz Rühling: Fiktionalität und Poetizität. In: Heinz Ludwig Arnold/Heinrich Detering ( $\mathrm{Hg}$.): Grundzüge der Literaturwissenschaft. München 1996, S. 25-51.

Bertrand Russell: The Problems of Philosophy. Oxford, New York 1980.

Gilbert Ryle: Imaginary Objects. In: Proceedings of the Aristotalian Society 12 (1933), S. 18-43.

Gilbert Ryle: The Concept of Mind. 3. Auflage. London 1990.

Nelly Sachs: Fahrt ins Staublose: Die Gedichte der Nelly Sachs. Frankfurt/M. 1961.

Nathan Salmon: Nonexistence. In: Nous 32 (1998), S. 277-319.

Barbara Sandig: Namen, Stile, Textsorten. In: E. Eichler et al (Hg.): Namenforschung: Ein internationales Handbuch zur Onomastik. Hbd. 1. Berlin, New York 1995 (= Handbücher zur Sprach- und Kommunikationswissenschaft 11,1), S. 539-551.

Leon Satterfield, Robinson's LEONORA. In: The Explicator 39, 3 (1981), S. 7-9.

Karl Otto Sauerbeck: Beziehungen zwischen Eigennamen in der Literatur. In: Beiträge zur Namenforschung N.F. 31 (1996), S. 407-424.

Karl Otto Sauerbeck: Die Funktion von Eigennamen in der Dichtung. In: Beiträge zur Namenforschung N.F. 35 (2000), S. 15-39.

Josef Schächter: Prolegomena zu einer kritischen Grammatik. 2. Auflage. Stuttgart 1978.

Paul Scheerbart: Gesammelte Werke 9. Hrsg. v. Uli Kohnle. Bellheim 1994.

Klaus R. Scherpe: Ort oder Raum? Fontanes literarische Topographie. In: Hanna Delf von Wolzogen (Hg.): Theodor Fontane. Am Ende des Jahrhunderts. Internationales Symposion des Theodor-Fontane-Archivs zum 100. Geburtstag Theodor Fontanes 13.-17. September 1998 in Potsdam. Bd. III: Geschichte, Vergessen, Großstadt, Moderne. Würzburg 2000, S. 161-169.

Helmut Scheuer: Der alte Zieten. In: H. S. (Hg.): Interpretationen. Gedichte von Theodor Fontane. Stuttgart 2001, S. 7-12.

Stephen Schiffer: Pleonastic Fregeanism and Empty Names. In: Anthony Everett/Thomas Hofweber ( $\mathrm{Hg}$.): Empty Names, Fiction, and the Puzzles of Non-Existence. Stanford 2000, S. 3-16.

Jost Schillemeit: Namen, Poesie und Geschichte. Gedanken zu Hendrik Birus' Buch über ,Poetische Namengebung'. In: GermanistischRomanistische Monatsschrift N.F. 32 (1982), S. 85-96. 
Schlaffer 1995

Schmidt 1968

Schmoldt 1990

Scholz 1984

Schönert 1999

Schröder 1994

Schumann 1942

Schwarz 2000

Schwitalla 1995

Schwitters 1998

Scofield 1988

Searle 1958

Searle 1975

Searle 1994

Seibicke 1982

Semino 1995

Shakespeare 1974

Shakespeare 1975

Shawcross 1978

Shawcross 1983

Shelley 1977
Heinz Schlaffer: Die Aneignung von Gedichten. Grammatisches, rhetorisches und pragmatisches Ich in der Lyrik. In: Poetica 27 (1995), S. 3857.

Siegfried J. Schmidt: Alltagssprache und Gedichtsprache. Versuch einer Bestimmung von Differenzqualitäten. In: Poetica 2 (1968), S. 285-303.

Hans Schmoldt: Kleines Lexikon der biblischen Eigennamen. Stuttgart 1990.

Oliver R. Scholz: Fiktionale Welten, mögliche Welten und Wege der Referenz. In: Peter Finkt/Siegfried J. Schmidt (Hg.): Analytische Literaturwissenschaft. Braunschweig, Wiesbaden 1984 (= Wissenschaftstheorie, Wissenschaft und Philosophie 22), S. 70-89.

Jörg Schönert: Empirischer Autor, Impliziter Autor und Lyrisches Ich. In: Fotis Jannidis et al. (Hg.): Rückkehr des Autors. Zur Erneuerung eines umstrittenen Begriffs. Tübingen 1999, S. 289-284.

Jürgen Schröder: On the Reference of Proper Names. In: Conceptus 27 (1994), S. 219-237.

Detlev W. Schumann: Enumerative Style and Its Significance in Whitman, Rilke, Werfel. In: Modern Language Quarterly 3 (1942), S. 171204.

Bettina Schwarz: Die Imagebildung - ein kreativer Prozeß zur Genese eines „Namens”. In: Kodikas/Code 23 (2000), S. 35-54.

Johannes Schwitalla: Namen in Gesprächen. In: E. Eichler et al (Hg.): Namenforschung: Ein internationales Handbuch zur Onomastik. Hbd. 1. Berlin, New York. 1995 (= Handbücher zur Sprach- und Kommunikationswissenschaft 11,1), S. 498-504.

Kurt Schwitters: Das literarische Werk 1: Lyrik. Hrsg. v. Friedhelm Lach. Köln 1998.

Martin Scofield: T.S. Eliot. The poems. Cambridge u.a. 1988 (= British and Irish Authors. Introductory Studies).

John R. Searle: Proper Names. In: Mind 67 (1958), S.166-173.

John R. Searle: The Logical Status of Fictional Discourse. In: New Literary History 6 (1975), S. 319-332.

John R. Searle: Sprechakte. Ein sprachphilosophischer Essay. 6. Auflage. Stuttgart 1994.

Wilfried Seibicke: Die Personennamen im Deutschen. Berlin, New York 1982

Elena Semino: Deixis and the Dynamics of Poetic Voice. In: Keith Green $(\mathrm{Hg}$.$) : New Essays in Deixis. Discourse, Narrative, Literature. Amster-$ dam, Atlanta 1995, S. 143-160.

William Shakespeare: The Riverside Shakespeare. Hrsg. v. G. Blakemore Evans. Boston u.a. 1974.

William Shakespeare: Sämtliche Werke in vier Bänden. [Nach der Übersetzung v. August Wilhelm Schlegel, Dorothea Tieck, Ludwig Tieck, Wolfgang Baudissin u.a.] Hrsg. v. Anselm Schlösser. Berlin 1975.

John T. Shawcross: An Inquiry into the Metric of Names: Sound and Rhythm of Names in Hart Crane's White Buildings. In: Literary Onomastics Studies V (1978), S. 14-33.

John T. Shawcross: A Consideration of Title-Names in the Poetry of Donne and Yeats. In: Names 31 (1983), S. 159-166.

Percy Bisshe Shelley: Shelley's Poetry and Prose. Hrsg. v. Donald H. Reiman, Sharon B. Powers. New York, London 1977. 
Shucard 1998

Slethaug 1971

Smith 1965

Smith 1996

Soames 2002

Sorgenfrei 1970

Spinner 1975

Šrámek 1995

Staiger 1961

Stanford 1983

Stanley 1997

Stenzel 1991

Stevick 1969

Stierle 1979a

Stierle 1979b

Stocker 2002

Storch $2000 a$

Storch 2000b

Strachan/Terry 2000 John Strachan/Richard Terry: Poetry. Edinburgh 2000.
Alan Shucard: Edwin Arlington Robinson (1869-1935). In: Eric L. Haralson (Hg.): Encyclopedia of American Poetry. The Nineteenth Century. Chicago, London 1998, S. 365-369.

G.E. Slethaug: The King in Robinson's "Old King Cole". In: The English Record 21 (1971), S. 45f.

Chard Powers Smith: Where the Light Falls. A Portrait of Edwin Arlington Robinson. New York, London 1965.

David W. Smith: Phenomenological approaches. In: Marcelo Dascal et al. (Hg.): Sprachphilosophie. Hbd. 1. Berlin, New York 1996 (= Handbücher der Sprach- und Kommunikationswissenschaft 7.1), S. 649-663.

Scott Soames: Beyond Rigidity. The unfinished Semantic Agenda of Naming and Necessity. Oxford 2002.

Günter Sorgenfrei: Personennamen in Titeln literarischer Werke. In: Sprachpflege (1970), S. 52-56.

Kaspar H. Spinner: Zur Struktur des lyrischen Ich. Frankfurt/M. 1975.

Rudolf Šrámek: Eigennamen im Rahmen einer Kommunikations- und Handlungstheorie. In: Ernst Eichler et al. (Hg.): Namenforschung. Ein internationales Handbuch zur Onomastik. Hbd. 1. Berlin, New York 1995 (= Handbücher zur Sprach- und Kommunikationswissenschaft 11.1), S. 380-383.

Emil Staiger: Grundbegriffe der Poetik. 5. Auflage. Zürich 1961.

Donald E. Stanford: Revolution and Convention in Modern Poetry. Studies in Ezra Pound, T.S. Eliot, Wallace Stevens, Edwin Arlington Robinson, and Yvor Winters. Newark, London, Toronto 1983.

Jason Stanley: Names and rigid designation. In: Bob Hale/Crispin Wright (Hg.): A Companion to Philosophy of Language. Oxford, Malden 1997 (= Blackwell Companions to Philosophy 10), S. 555-585.

Jürgen Stenzel: Silbersteins war'n nicht dabei! In: Frankfurter Allgemeine Zeitung 119 (25.05.1991 = Frankfurter Anthologie).

Robert D. Stevick: Formulation of E. A. Robinson's Principles of Poetry. In: Colby Library Quarterly 8 (1969), S. 295-308 [wieder abgedruckt in: Richard Cary ( $\mathrm{Hg}_{\text {.): }}$ : Appreciation of Edwin Arlington Robinson. Waterville (Maine) 1969, S. 289-300].

Karlheinz Stierle: Die Identität des Gedichts - Hölderlin als Paradigma. In: K. Stierle/Odo Marquard (Hg.): Identität. München 1979 (= Poetik und Hermeneutik 8), S. 505-552.

Karlheinz Stierle: Notwendige Abgrenzungen. In: K. Stierle/Odo Marquard (Hg.): Identität. München 1979 (= Poetik und Hermeneutik 8), S. 743-746.

Peter Stocker: Intertextuelle Namen. In: Dieter Kremer: Onomastik. Akten des 18. Internationalen Kongresses für Namenforschung Trier, 12. 17. April 1993. Bd. 6. Tübingen 2002, S. 301-307.

Dietmar Storch: Theodor Fontane - Zeuge seines Jahrhunderts. In: Christian Grawe/Helmuth Nürnberger (Hg.): Fontane Handbuch. Stuttgart 2000, S. 103-191.

Dietmar Storch: „...unterm chinesischen Drachen...Da schlägt man sich jetzt herum". Fontane, der ferne Osten und die Anfänge der deutschen Weltpolitik. In: Hanna Delf von Wolzogen (Hg.): Theodor Fontane. Am Ende des Jahrhunderts. Internationales Symposion des TheodorFontane-Archivs zum 100. Geburtstag Theodor Fontanes 13.-17. September 1998 in Potsdam. Bd. I: Der Preuße. Die Juden. Das Nationale. Würzburg 2000, S. 113-118. 
Strawson 1968

Strawson 1993

Stüssel 2000

Sullivan 1986

Sutrop 2002

Swinburne 1925

Tate 1995

Taylor 2000

Thakur 1977

The Holy Bible 1902

The New Encyclopaedia Britannica 2002

Theokrit 1970

Thies 1978

Thies 1998

Thomasson 2003

Thoor 1956

Thurmair 2002

Toorn 1999

Trapero 1995
Peter F. Strawson: On Referring. In: G.H.R. Parkinson (Hg.): The Theory of Meaning. Oxford 1968, S. 61-85.

Peter F. Strawson: Individuals. An Essay in Descriptive Metaphysics. 7. Auflage. London, New York 1993.

Kerstin Stüssel: „Autodidakten übertreiben immer“. Autodidaktsiches Wissen und Autodidaktenhabitus im Werk Theodor Fontanes. In: Hanna Delf von Wolzogen, Helmuth Nürnberger (Hg.): Theodor Fontane am Ende des Jahrhunderts. Internationales Symposion des TheodorFontane-Archivs zum 100. Todestag Theodor Fontanes 13.-17. September 1998. Bd. III: Geschichte, Vergessen, Großstadt, Moderne. Würzburg 2000. S. 119-135.

Winifred H. Sullivan: The Double-Edged Irony of E. A. Robinson's "Miniver Cheevy". In: Colby Library Quarterly 22 (1986), S. 185-191.

Margit Sutrop: Imagination and the Act of Fiction-Making. In: Australasian Journal of Philosophy 80,3 (2002), S. 332-344.

Algernon Charles Swinburne: The Complete Works. Poetical Works 2. Hrsg. v. Sir Edmund Gosse/Thomas James Wise. London, New York 1925.

Alison Tate: Deictic Marcers and the Disruption of Voice in Modernist Poetry. In: Keith Green (Hg.): New Essays in Deixis. Discourse, Narrative, Literature. Amsterdam, Atlanta 1995, S. 131-142.

Kenneth A. Taylor: Emptiness without Compromise. In: Anthony Everett/Thomas Hofweber (Hg.): Empty Names, Fiction, and the Puzzles of Non-Existence. Stanford 2000, S. 17-36.

G.P. Thakur: Tilbury Town as Region: A Study of the Poetry of E.A. Robinson. In: Indian Journal of American Studies 7 (1977), S. 54-67.

The Holy Bible: Oxford Self Pronouncing Bible. Oxford 1902.

[Artikel] Robert Burns. In: The New Encyclopaedia Britannica. 15. Auflage. Chicago u.a. 2002, S. 662-664.

Theokrit: Die echten Gedichte. Deutsch von Emil Staiger. Zürich, Stuttgart 1970.

Henning Thies: Namen im Kontext von Dramen. Studien zur Funktion von Personennamen im englischen, amerikanischen und deutschen Drama. Frankfurt/M., Bern, Las Vegas 1978 (= Sprache und Literatur. Regensburger Arbeiten zur Anglistik und Amerikanistik 13).

Henning Thies: [Artikel] Onomastik, literarische. In: A. Nünnung (Hg.): Metzler Lexikon Literatur- und Kulturtheorie. Ansätze - Personen Grundbegriffe. Stuttgart, Weimar 1998, S. 406-407.

Amie L. Thomasson: Fictional Characters and Literary Practices. In:

British Journal of Aesthetics 43 (2003), S. 138-157.

Jesse Thoor: Die Sonette und Lieder. Hrsg. v. Alfred Marnau. Heidelberg, Darmstadt 1956 (= Veröffentlichungen der Deutschen Akademie für Sprache und Dichtung Darmstadt 7).

Maria Thurmair: Der Harald Juhnke der Sprachwissenschaft. Metaphorische Eigennamenverwendungen. In: Deutsche Sprache 30 (2002), S. 127.

Karel van Toorn et al. $(\mathrm{Hg}$.): Dictionary of Deities and Demons in the Bible. Leiden, Boston, Köln 1999.

Maximiniano Trapero: Para una teoría lingüistica de la toponimia (Estudios de Toponimia Canaria). Las Palmas de Gran Canaria 1995 (= Colección Monografías, Serie Lingüística y Filología 3). 

gie, auch unter Berücksichtigung fiktionaler Texte. Bochum 1989 (= Bochumer Beiträge zur Semiotik 22).

Tucker 1985

Herbert F. Tucker: Dramatic Monologue and the overhearing of Lyric. In: Chaviva Hosek, Patricia Parker (Hg.): Lyric Poetry. Beyond New Criticism. Ithaca, London 1985, S. 226-246.

Tugendhat 1990

Ernst Tugendhat: Vorlesungen zur Einführung in die sprachanalytische Philosophie. 5. Auflage. Frankfurt/M. 1990.

Turner 1970

Steven Turner: Robinson's RICHARD CORY. In: The Explicator XXVIII, 9 (1970), Nr. 73.

Utley 1968

Vallejo 1996

van Inwagen 1977

Francis Lee Utley: From the Dinnsenchas to Proust: The Folklore of Placenames in Literature. In: Names 16 (1968), S. 273-293.

César Vallejo: Poesía Completa. Hrsg. v. Antonio Merino. Madrid 1996.

Peter van Inwagen: Creatures of Fiction. In: American Philosophical Quarterly 14 (1977), S. 299-308.

Vergil 1989

Vergil: Aeneis. Hrsg. u. übersetzt v. Wilhelm Plankl. Stuttgart 1989.

Vergil 2001

Verwey 1899

Vergil: Bucolica. Hirtengedichte. Lateinisch/Deutsch. Hrsg. u. übersetzt v. Michael von Albrecht. Stuttgart 2001.

Albert Verwey: Het brandende Braambosch. Amsterdam 1899.

Viljoen 2002

Louise Viljoen: The functioning of the proper name in the poetry of Breyten Breytenbach. In: Dieter Kremer: Onomastik. Akten des 18. Internationalen Kongresses für Namenforschung Trier, 12.-17. April 1993. Bd. 6. Tübingen 2002, S. 309-317.

Villon 1988

François Villon: Das kleine und das große Testament. Französisch/Deutsch. Hrsg. v. Frank-Rutger Hausmann. Stuttgart 1988.

Voss 1996 Johann Heinrich Voss: Ausgewählte Werke. Hrsg. v. Adrian Hummel. Göttingen 1996.

Voss 1996

Johann Heinrich Voss: Ausgewählte Werke. Hrsg. v. Adrian Hummel. Göttingen 1996.

W. R. Robinson William Ronald Robinson: Edwin Arlington Robinson. A Poetry of the 1967 Act. Cleveland 1967.

Wagenknecht 1965 Christian Wagenknecht: Das Wortspiel bei Karl Kraus. 2. Auflage. Göttingen 1975 (= Palaestra 242).

Wagenknecht 1992 Christian Wagenknecht: Lichtenbergs Gedichte. Metrische Miszellen. In: Text und Kritik 114: Georg Christoph Lichtenberg (1992), S. 57-63.

Wagenknecht 2001 Christian Wagenknecht: Deutsche Lyrik von den Anfängen bis zur Gegenwart 4: 1600-1700. 2. Auflage. München 2001.

Waggoner 1968 Hyatt H. Waggoner, American Poets. From the Puritans to the Present. Baton Rouge, London 1968.

Wagner 1905

Richard Wagner: Gedichte von Richard Wagner. Hrsg. v. C. Fr. Glasenapp. Berlin 1905.

Wagner 1995

Walcott 1986

Walcott 1992

Steven J. Wagner: [Artikel:] proposition. In: Robert Audi (Hg.): The Cambridge Dictionary of Philosophy. Cambridge 1995, S. 658f.

Derek Walcott: Collected Poems 1948-1984. New York 1986.

Derek Walcott: The Antilles. Fragments of Epic Memory. The Nobel Lecture. New York 1992.

Walton 1990

Kendall L. Walton: Mimesis as Make-Believe. On the Foundations of the Representational Arts. Cambridge/Mass., London 1990.

Walton 2000

Kendall Walton: Existence as Metaphor? In: Anthony Everett/Thomas Hofweber (Hg.): Empty Names, Fiction, and the Puzzles of NonExistence. Stanford 2000, S. 69-94. 
Warner 1999

Warning 1997

Webern 1649

Weeks 1969a

Weeks 1969b

Weil 1993

Weimar 2003

Welton 1983

Wennerberg 1998

Wettstein 1995

Whiteside 1987

Widdowson 1984

Wiegand 1997

Wienold 1994

Wilde 2000

Williams 1978

Wilson 1983
Martin Warner: Literature, Truth and Logic. In: Philosophy 74 (1999), S. 29-54.

Rainer Warning: Interpretation, Analyse, Lektüre: Methodologische Erwägungen zum Umgang mit lyrischen Texten. In: R.W.: Lektüren romanischer Lyrik: von den Troubadors zum Surrealismus. Freiburg/Br. 1997 (= Litterae 51), S. 9-44.

Robert G. Warnock/Roland Folter: The German Pattern Poem. A Study in Mannerism of the Seventeenth Century. In: Albert R. Schmitt: Festschrift für Detlev W. Schumann zum 70. Geburtstag. München 1970, S. 40-73.

Georg Webern: Sieben Theile Wohlriechender Lebens-Früchte eines recht gott-ergebenen Herzen, deren Saft und Wachsthum, auß inrem ewigen Lebens-Baume Jesu Christo gesogen und entsprossen ist. Danzig, Königsberg 1649.

Lewis E. Weeks, Jr.: Maine in the Poetry of Edwin Arlington Robinson. In: Colby Library Quarterly 8 (1969), S. 317-334.

Lewis E. Weeks, Jr.: E. A. Robinson's Poetics. In: Richard Cary (Hg.): Appreciation of Edwin Arlington Robinson. Waterville (Maine) 1969, S. 225-242.

Eric A, Weil: Robinson's THE TREE IN PAMELA'S GARDEN. In: The Explicator 51, 4 (1993), S. 230-232.

Klaus Weimar: Literarische Bedeutung? In: Fotis Jannidis et al. (Hg.): Regeln der Bedeutung. Zur Theorie der Bedeutung literarischer Texte. Berlin, New York 2003 (= Revisionen 1), S. 228-245.

Don Welton: The Origins of Meaning. A Critical Study of the Thresholds of Husserlian Phenomenology. Den Haag 1983 (= Phaenomenologica 88).

Hjalmar Wennerberg: Der Begriff der Familienähnlichkeit in Wittgensteins Spätphilosophie. In: Eike v. Savigny (Hg.): Ludwig Wittgenstein: Philosophische Untersuchungen Berlin 1998 (= Klassiker Auslegen 13), S. 41-70.

Howard Wettstein: [Artikel] Causal theory of proper names. In: Robert Audi (Hg.): The Cambridge Dictionary of Philosophy. Cambridge 1995, S. 109-110.

Anna Whiteside: Theories of Reference. In: A.W./Michael Issacharoff (Hg.): On Referring in Literature. Bloomington, Indianapolis 1987, S. 175-208.

H.G. Widdowson: Explorations in Applied Linguistics 2. Oxford 1984.

Hermann Wiegand: [Artikel] Epitaph. In: Klaus Weimar (Hg.): Reallexikon der deutschen Literaturwissenschaft 1. Berlin, New York 1997, S. $475 f$.

Götz Wienold: Über den Umgang mit der Bedeutung von Literatur anhand von Gedichten von Goethe und Celan. In: Walter A. Koch ( $\mathrm{Hg}$.): Die Welt der Lyrik. Bochum 1994 (= Bochumer Beiträge zur Semiotik 39), S. 219-249.

Oscar Wilde: The Complete Works of Oscar Wilde 1. Hrsg. v. Bobby Fong, Karl Beckson. Oxford, New York 2000.

Bernard Williams: Kontinuität des Leibes und Identität der Person. In: B.W.: Probleme des Selbst. Übersetzt v. Joachim Schulte. Stuttgart 1978, S. 37-46.

A.N. Wilson: The Life of John Milton. Oxford, New York 1983. 
Wimmer 1993

Wimmer 1995

Wimsatt 1967

Wittgenstein 1984

Wittgenstein 1992

Wittstruck 1987

Wolf 1985

Wolf 1998

Wollheim 1980

Wolterstorff 1979

Woods 1982

Wruck 1999

Wülfing/Bruns/Parr 1991

Yagisawa 1995

Zalta 1987

Zalta 2000

Zietlow 1967

Zink 1985

Zipfel 2001

Zymner 2003
Rainer Wimmer: Zur Stellung des Eigennamens im Wortschatz. In: Hans Jürgen Heringer/Georg Stötzel (Hg.): Sprachgeschichte und Sprachkritik. Festschrift für Peter von Polenz zum 65. Geburtstag. Berlin, New York 1993, S. 46-51.

Rainer Wimmer: Eigennamen im Rahmen einer allgemeinen Sprachund Zeichentheorie. In: Ernst Eichler et al. (Hg.): Namenforschung. Ein internationales Handbuch zur Onomastik. Hbd. 1. Berlin, New York 1995 (= Handbücher zur Sprach- und Kommunikationswissenschaft 11.1), S. 372-379.

W. K. Wimsatt, Jr.: The Verbal Icon. Studies in the meaning of poetry. Lexington 1967.

Ludwig Wittgenstein: Philosophische Untersuchungen. In: L.W.: Werkausgabe Band 1. Frankfurt/M. 1984, S. 225-580.

Ludwig Wittgenstein: Über Gewißheit. Hrsg. v. G.E.M. Anscombe, G.H. von Wright. Frankfurt/M. 1992.

Wilfried Wittstruck: Der dichterische Namengebrauch in der deutschen Lyrik des Spätmittelalters. München 1987 (= Münsterliche Mittelalterschriften 61).

Ursula Wolf: Einleitung. In: U.W. (Hg.): Eigennamen. Dokumentation einer Kontroverse. Frankfurt/M. 1985, S. 9-41.

Werner Wolf: Aesthetic Illusion in Lyric Poetry? In: Poetica 30 (1998), S. 251-289.

Richard Wollheim: Art and its objects. 2. Auflage. Cambridge 1980.

Nicholas Wolterstorff: Characters and their Names. In: Poetics 8 (1979), S. 101-127.

John Woods: Animadversions and Open Questions, Reference, Inference and Truth in Fiction. In: Poetics 11 (1982), S. 553-562.

Peter Wruck: Bildungsmisere? Die atypische literarische Sozialisation des Schriftstellers Fontane in ihren Bildungsgeschichtlichen Zusammenhängen. In: Roland Berbig (Hg.): Theodorus victor: Theodor Fontane, der Schriftsteller des 19. am Ende des 20. Jahrhunderts; eine Sammlung von Beiträgen. Frankfurt u.a. 1999, S. 15-29.

Wulf Wülfing/Karin Bruns/Rolf Parr: Historische Mythologie der Deutschen 1798-1918. München 1991.

Takashi Yagisawa: Reference Ex Machina. In: J. Hill, P. Kotatko (Hg.): Karlovy Vary. Studies in Reference and Meaning. Prag 1995, S. 215242.

Edward N. Zalta: Erzählung als Taufe des Helden. In: Zeitschrift für Semiotik 9 (1987), S. 85-96.

Edward N. Zalta: Pretense Theory and Abstract Object Theory. In: Anthony Everett/Thomas Hofweber ( $\mathrm{Hg}$.): Empty Names, Fiction, and the Puzzles of Non-Existence. Stanford 2000, S. 117-148.

Paul Zietlow, The Meaning of Tilbury Town: Robinson as a Regional Poet. In: The New England Quarterly 40 (1967), S. 188-211.

Sidney Zink: Die Bedeutung von Eigennamen. In: Ursula Wolf (Hg.): Eigennamen. Dokumentation einer Kontroverse. Frankfurt/M. 1985, S. 151-178.

Frank Zipfel: Fiktion, Fiktivität, Fiktionalität. Analysen zur Fiktion in der Literatur und zum Fiktionalitätsbegriff in der Literaturwissenschaft. Berlin 2001 (= Allgemeine Literaturwissenschaft - Wuppertaler Schriften 2).

Rüdiger Zymner: Uneigentliche Bedeutung. In: Fotis Jannidis et al. (Hg.): Regeln der Bedeutung. Zur Theorie der Bedeutung literarischer Texte. Berlin, New York 2003 (= Revisionen 1), S. 128-168. 


\section{Gliederung}

1 VORBEMERKUNG

2 HOW TO INTERPRET NAMES WHEN YOU SEE THEM - EINLEITUNG

3 THEORETISCHE ÜBERLEGUNGEN

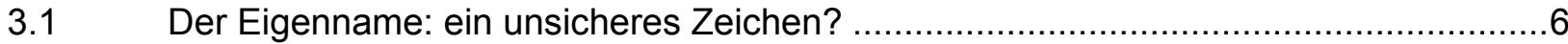

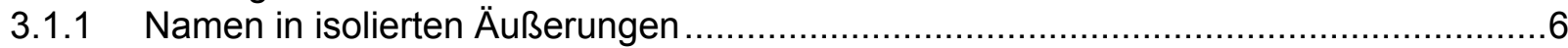

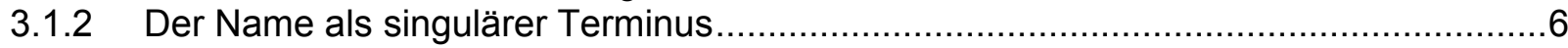

3.1.3 Die erste Unsicherheit des Namens: die definite description des Namenträgers..........8

3.1.4 Die zweite Unsicherheit des Namens: Namen als Teil einer kommunikativen Situation 15

3.1.5 Die dritte Unsicherheit des Namens: das Eigennamenzeichen ..............................24

3.1.6 Die vierte Unsicherheit des Namens: der Kommunikationswert...........................26

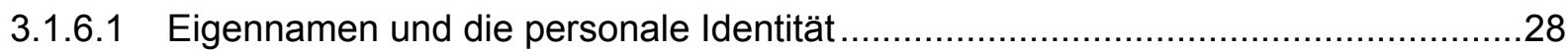

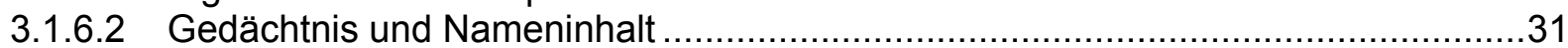

3.2 Unsichere literarische Eigennamen: Wahrheit und Fiktion....................................36

3.2.1 Fiktion und Realität - die Rolle wahrer Sätze in fiktionalen Texten ..........................36

3.2.2 Wer einmal lügt, dem glaubt man nicht? ..........................................................

3.2.3 Namenreferenz, Fiktion, Wahrheit und Gedichtinterpretation ................................53

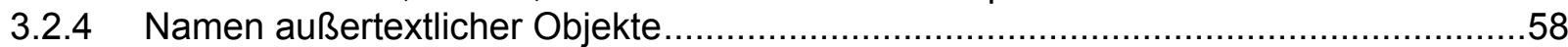

3.2.4.1 Formen des referentiellen Bezugs auf den Kontext eines literarischen Werkes .....58

3.2.4.2 Außertextliche Objekte und die Textwelt: Positionen ........................................61

3.2.4.3 Formen der Namenreferenz über die Textwelt hinaus: eine moderate

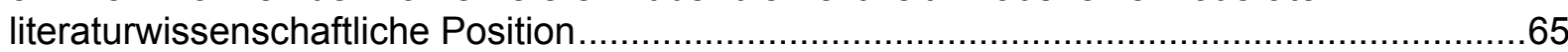

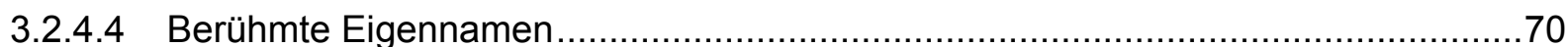

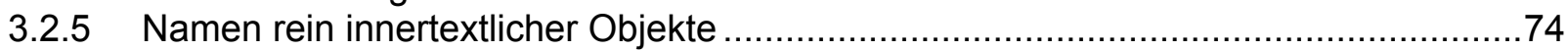

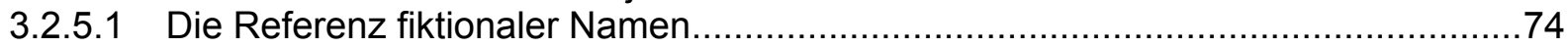

3.2.5.2 Kohärenz und Inhalt fiktionaler Eigennamen.................................................

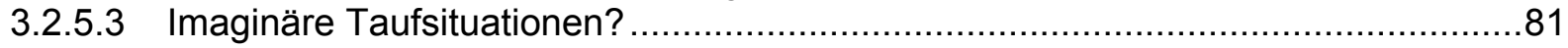

3.2.5.4 Die Evokation fiktiver Namenträger durch Eigennamen - eine moderate Position .82

3.3 Zusammenfassung: Eigennamen als unsichere Zeichen in literarischen Texten........85

4 SYSTEMATISCHE ÜBERLEGUNGEN

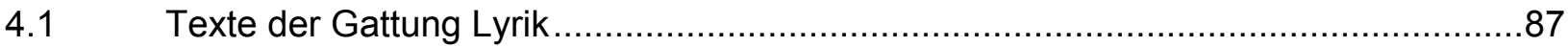

4.1.1 Eigennamen und der ,entstofflichte Charakter' des Gedichts ...............................87

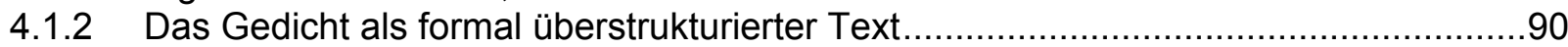

4.1.3 Das Gedicht als fiktionaler oder nichtfiktionaler Text .....................................95

4.1.4 Das Gedicht als isolierter Gesprächsbeitrag .................................................. 100

4.1.5 Zusammenfassung: eine Arbeitsdefinition .................................................... 102

4.2 Funktionen von Eigennamen in überstrukturierten Texten - Einleitung ...................103

4.2.1 Namen, Namenträger und Text: Typologien zur Namenfunktion ............................103

4.2.2 Name, Text und Namenbenutzer: eine Typologie .............................................108

$4.3 \quad$ Textbezogene Funktionen ..............................................................................111

4.3.1 Textstrukturierende Funktionen - der semantische Hintergrund des Namens und der

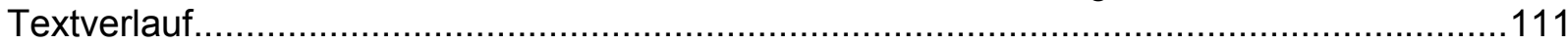

4.3.1.1 Namen und Textstrukturierung ..................................................................111

4.3.1.2 Eigennamen und story line - Eigennamen und Textumriß .............................115

4.3.1.2.1 Charakterisierung und Handlungsverlauf .......................................... 115 


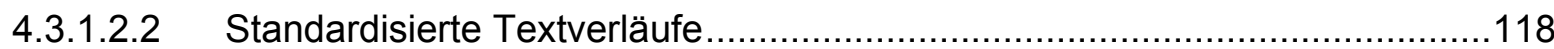

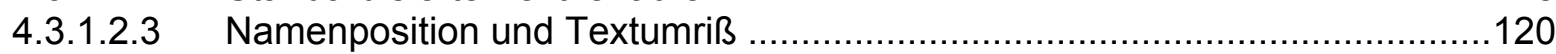

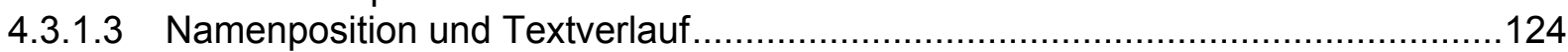

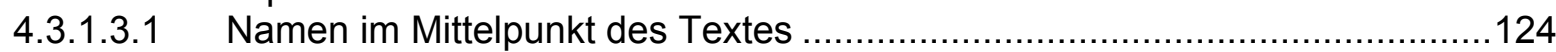

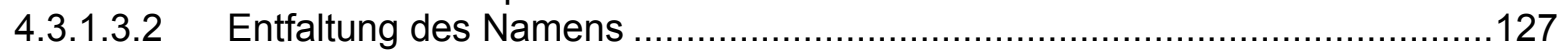

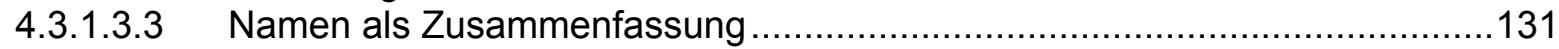

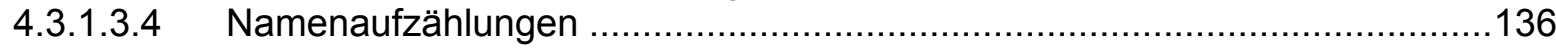

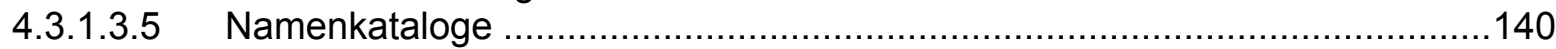

4.3.1.3.6 Kulturelle Namenfelder ..................................................................... 144

4.3.1.3.7 Zusammenfassung: Die Semantik des Eigennamens und der Textverlauf...146

4.3.2 Anbindung, Transposition, Ausrichtung - die Referenz des Eigennamens ..............147

4.3.2.1 Die Anbindung an Kontextwelten .................................................................147

4.3.2.1.1 Eigennamen und die ,pragmatische Einbindung' des Gedichts...................147

4.3.2.1.2 Die Anbindung an Kontexte ....................................................................148

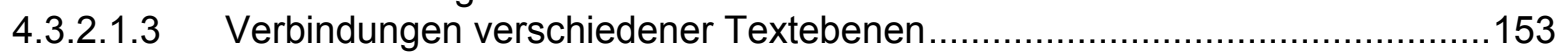

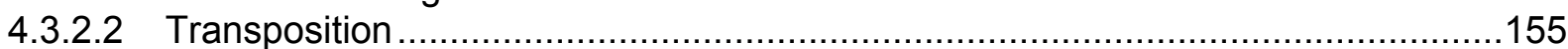

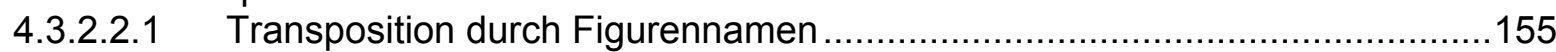

4.3.2.2.2 Transposition durch diskursive Namennennungen ..................................160

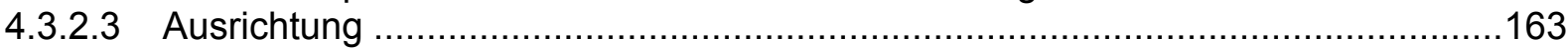

4.3.2.3.1 Die Anrede beim Namen und das make-believe .......................................163

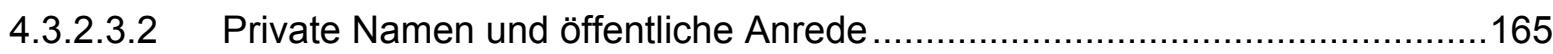

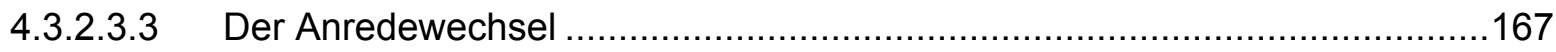

4.3.2.4 Zusammenfassung: Die Eigennamenreferenz und der Kontextbezug des Gedichts 171

4.3.3 Ästhetische Funktion: artistische und komische Formerfüllung durch das

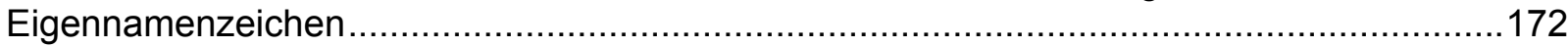

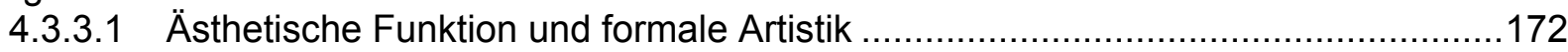

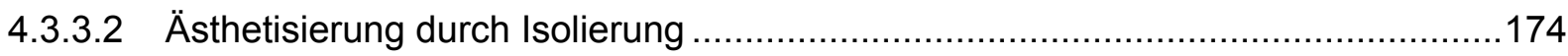

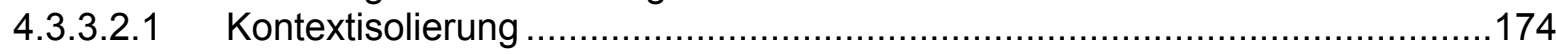

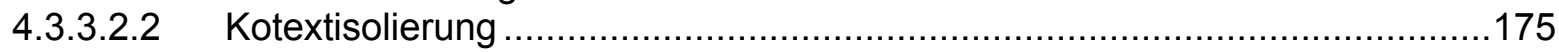

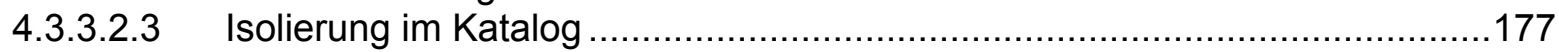

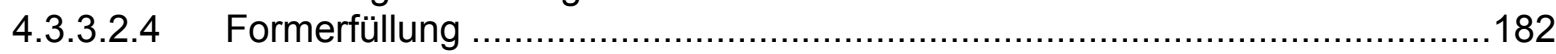

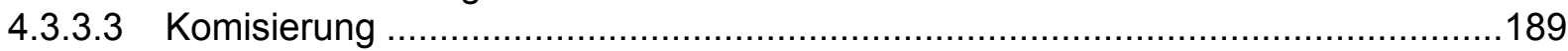

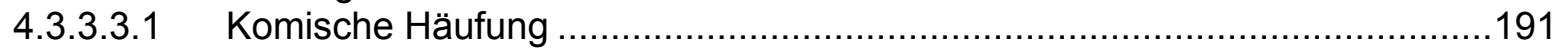

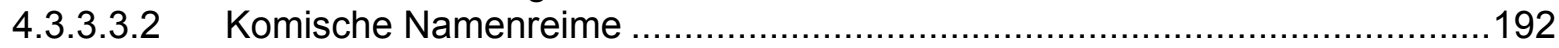

4.3.3.3.3 Durch Änderung des Namenzeichens erfüllte Formen ...............................197

4.3.3.3.4 Komische Namenzeichen ......................................................................199

4.3.3.4 Zusammenfassung: Das Eigennamenzeichen und die ästhetische Gestaltung des Gedichts 201

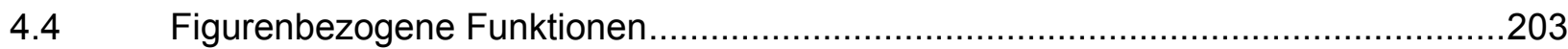

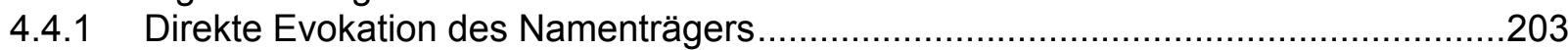

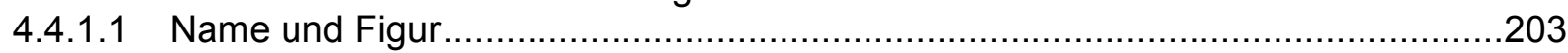

4.4.1.2 Edgar Lee Masters fiktive Namenträger .....................................................204

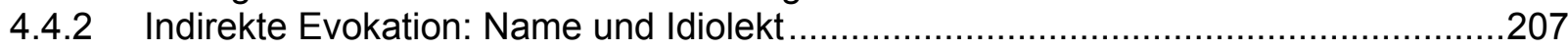

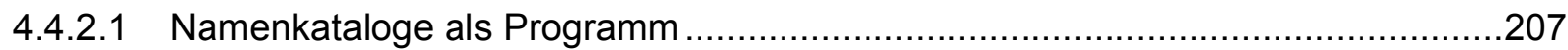

4.4.2.2 Die Charakterisierung fiktiver Sprecher durch die Namenverwendung ................210

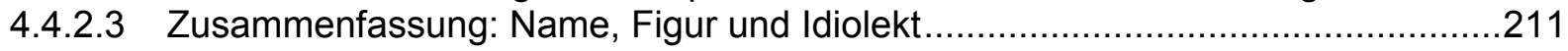

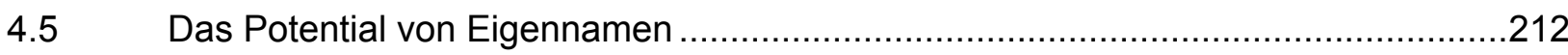

5 EIGENNAMENGEBRAUCH ALS STILZUG BEI THEODOR FONTANE UND EDWIN

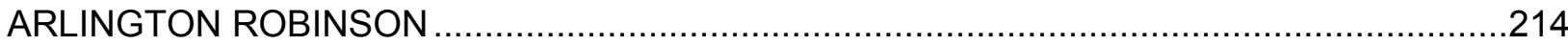

5.1 Plauderei mit Namen - der Gebrauch realer und realistischer Namen zur indirekten

Evokation des Sprechers in Theodor Fontanes Gedichten................................................214

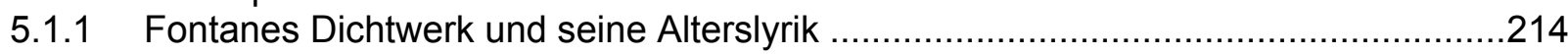

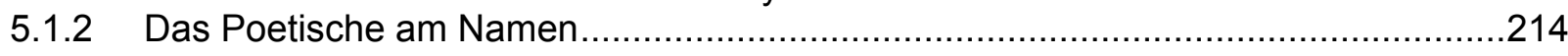


5.1.2.1 „Epigramm“ und „Gedicht“ - redende Namen bei Fontane ................................214

5.1.2.2 „Kein bloßer Ballast“ - die Aufzählung von Namen .............................................219

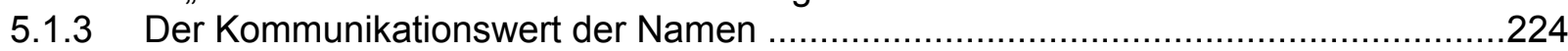

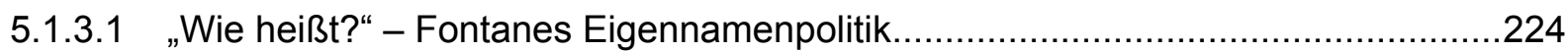

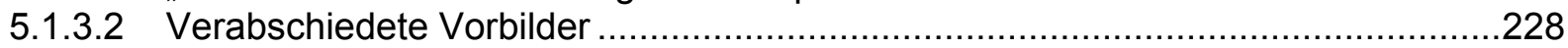

5.1.4 Der Kampf um den Kommunikationswert der Namen ..........................................230

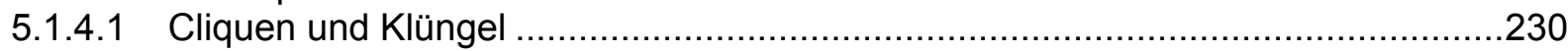

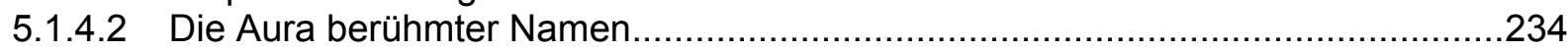

5.1.4.3 Der heroische Einzelne und der Aufstand der Massen ................................237

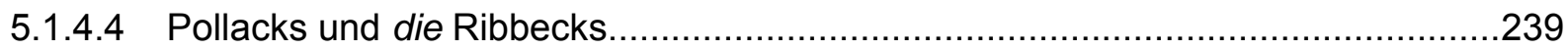

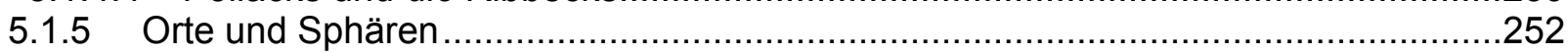

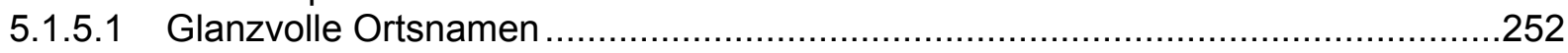

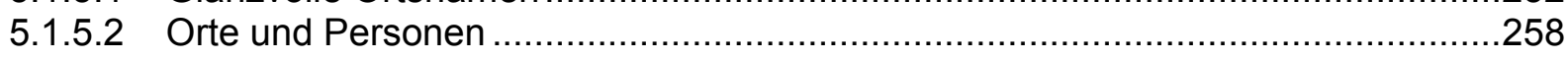

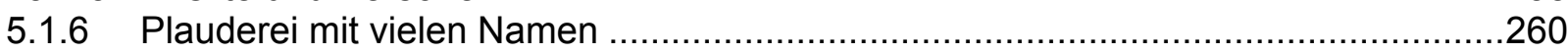

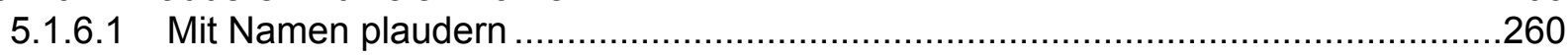

5.1.6.2 „Brockhaus“ statt „Doktorthema“: normatives Eigennamenwissen.......................262

5.1.6.3 Eigennamenskepsis und Resignation .......................................................267

5.2 „A toy made out of letters?“ - Schwierige direkte Evokationen mit Eigennamen bei

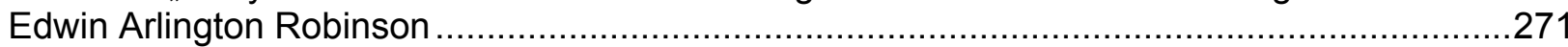

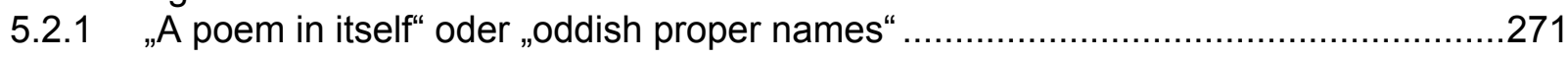

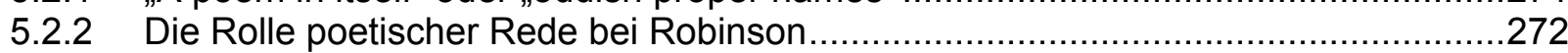

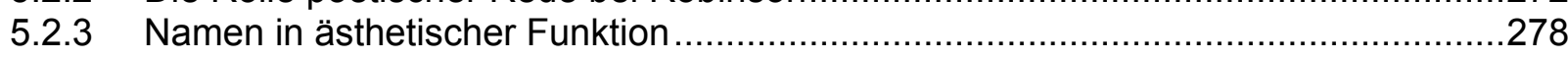

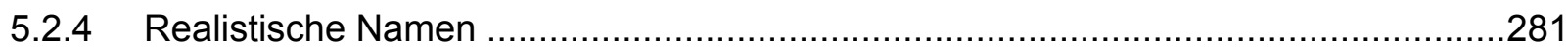

5.2.4.1 Tilbury Town als gemeinsamer wirklichkeitsnaher Hintergrund ............................281

5.2.4.2 Wirklichkeitsnähe durch die Gestalt der Namen............................................284

5.2.4.3 Die suggestive Wirkung realistischer Namen ................................................289

5.2.5 Das problematische Verhältnis der Namen zur Wirklichkeit.....................................293

5.2.5.1 Namen als Problem der Handlung in Robinsons Verserzählungen .....................293

5.2.5.1.1 Der Kommunikationswert des Namens .....................................................293

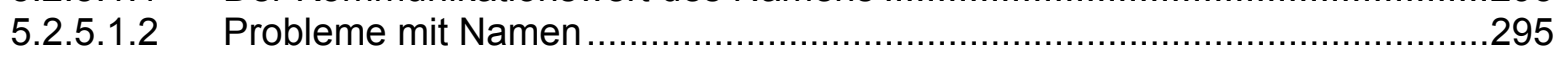

5.2.5.1.3 Erfolglose Evokationsversuche mit Namen ............................................298

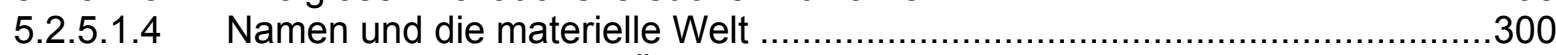

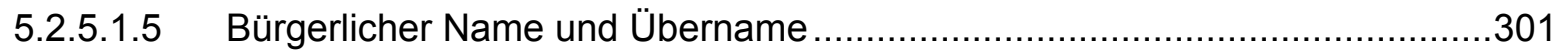

5.2.5.2 Intentionale Namenbedeutungen und die Wahrheit ...........................................303

5.2.5.2.1 Eigenname und memoria: Stafford's Cabin ..........................................304

5.2.5.2.2 Versuchsweise Namenvergabe: Theophilus und The Wandering Jew (1920) 306

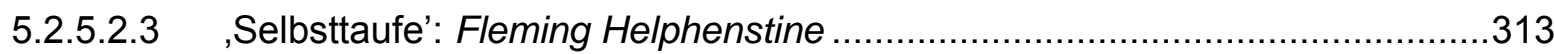

5.2.5.3 Das Vorurteil der Anderen und die Auslegung des Namens ..............................316

5.2.5.3.1 Schein und Sein: Richard Cory, The Tree in Pamela's Garden , Mr. Flood's

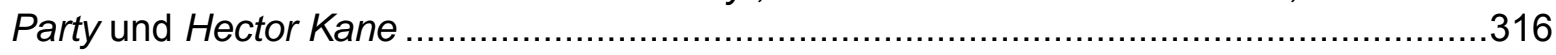

5.2.5.3.2 Die Gleichgültigkeit der Gesellschaft: Job the Rejected .............................322

5.2.5.3.3 Die Ratlosigkeit der Gesellschaft: Flammonde .........................................324

5.2.5.4 Immigrant objects oder native objects? Die Namenreferenz ..............................326

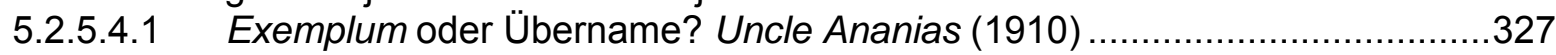

5.2.5.4.2 Exemplum oder konventioneller Name? Amaryllis .....................................328

5.2.5.4.3 Die Fortgestaltung eines außertextlichen Objekts: Old King Cole .................330

5.2.5.4.4 Vermischte Vorbilder: John Evereldown und Aaron Stark .............................333

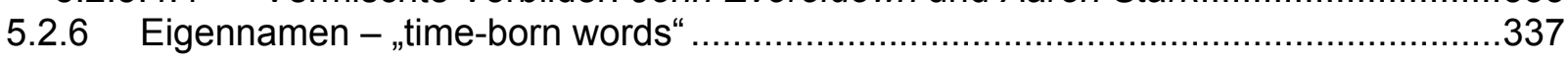

5.3 Die kommunikative Unsicherheit von Namen bei Fontane und Robinson.................342

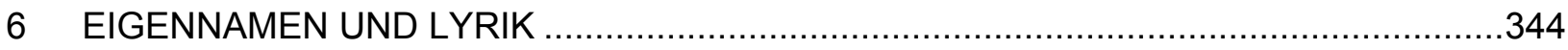

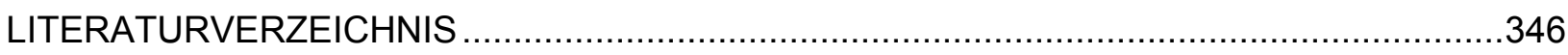


